Maria Deppermann

\title{
Andrej Belyjs ästhetische \\ Theorie des schöpferischen Bewusstseins
}

\section{Symbolisierung und Krise der Kultur um die Jahrhundertwende}

Verlag Otto Sagner München · Berlin - Washington D.C.

Digitalisiert im Rahmen der Kooperation mit dem DFG-Projekt „Digi20“

der Bayerischen Staatsbibliothek, München. OCR-Bearbeitung und Erstellung des eBooks durch den Verlag Otto Sagner:

http://verlag.kubon-sagner.de

() bei Verlag Otto Sagner. Eine Verwertung oder Weitergabe der Texte und Abbildungen, insbesondere durch Vervielfältigung, ist ohne vorherige schriftliche Genehmigung des Verlages unzulässig. 


\title{
SLAVISTISCHE BEITRÄGE
}

\author{
BEGRÜNDET VON \\ ALOIS SCHMAUS \\ HERAUSGEGEBEN VON \\ JOHANNES HOLTHUSEN - HEINRICH KUNSTMANN \\ PETER REHDER $\cdot$ JOSEF SCHRENK \\ REDAKTION \\ PETER REHDER
}

Band 150

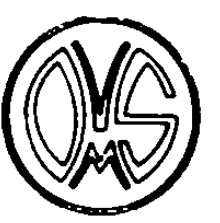

VERLAG OTTO SAGNER

MÜNCHEN 


\section{MARIA DEPPERMANN}

\section{ANDREJ BELYJS ÄSTHETISCHE THEORIE DES SCHÖPFERISCHEN BEWUSSTSEINS}

Symbolisierung und Krise der Kultur um die Jahrhundertwende

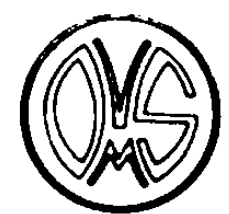

\section{VERLAG OTTO SAGNER · MÜNCHEN 1982}



München

\section{ISBN 3-87690.215-0 \\ (c) Verlag Otto Sagner, München 1982 \\ Abteilung der Firma Kubon \& Sagner, München \\ Druck: UNI-Druck. München}




\section{Vorwort}

Meine Beschäftigung mit Andrej Belyj geht auf eine Anregung von Swetlana Geier, Ubersetzerin und Lektorin an der Freiburger Universität, zurück. Fördernd auf die Arbeit hat Herr Prof. Wilhelm Lettenbauer eingewirkt. Als Herausgeber der Solov'ev-Ausgabe betraute er mich mit der Ubersetzung von Solov'evs "Vorlesungen über das Gottmenschentum". Dadurch habe ich mich in den geistigen und philosophischen Hintergrund des russischen Symbolismus eingearbeitet, der mir weiter erschlossen wurde in wertvollen Gesprächen mit Prof. D. E. Maksimov, Leningrad.

Zunehmendes Aufmerksamwerden auf ästhetische und poetologische Probleme verdanke ich den of $t$ kontroversen Gesprächen mit Prof. Wolf Schmid, Hamburg.

Wichtige Impulse dazu, interdisziplinär zu arbeiten: komparatistische Gesichtspunkte einzubeziehen und ästhetische mit literaturpsychologischen Fragestellungen zu verbinden, - stammen aus den Seminaren und Forschungen von Prof. Wolfram Mauser. Ansporn erfuhr ich von Prof. Gottfried Schramm und seinem russischen Gesprächskreis.

Ihre jetzige Richtung erhielt die Arbeit in zahlreichen Gesprächen mit Prof. RolfDieter Kluge. Ihm gilt mein besonderer Dank für sein anhaltendes großes Interesse, für seine wertvollen und kritischen Hinweise, nicht zuletzt aber dafür, daß er durch Diskussionen und Vorlagen in seinem Doktoranden-Kolloquium Gelegenheit gegeben hat, eigene Thesen vorzustellen, der Kritik auszusetzen und Einblick in den Werdegang anderer Arbeiten zu bekommen.

Für großzügige Hilfe beim Korrigieren des Manuskripts danke ich Christa Marx und Hildegard Roth.

Danken möchte ich auch Klaus Deppermann für seine unermüdliche Gesprächsbereitschaft, meinen Kindern und Freunden, die mich ertragen, angeregt und ermutigt haben, besonders Ulla Renner, Helga Stelzer, Heath King und Ludwig Wenzler: bei ihnen fand ich immer Rat, aber auch kritische Infragestellung.

Schließlich gilt mein Dank für die Aufnahme der Arbeit in die Reihe "Slavistische Beiträge" dem Verlag Otto Sagner in München und den Herausgebern der Reihe, Herrn Prof. Johannes Holthusen und Herrn Dr. Peter Rehder, der mich als Redakteur beim Herstellen der Druckvorlage mit Rat und Mithilfe unterstützte.

Die vorliegende Arbeit wurde vom Gemeinsamen Ausschuß der Philosophischen Fakultäten der Albert-Ludwigs-Universität Freiburg als Dissertation angenommen.

Freiburg i. Breisgau, Februar 1982

Maria Deppermann 
Einleitung:

Positionen der Forschung zu Belyjs Ästhetischer Theorie

I. Erste kritische Stellungnahmen von V. Brjusov und F. Stepun im Jahre 1910

II. Die formästhetische Richtung

Zusammenfassung

III. Die geistesgeschichtliche Richtung

Zusammenfassung

IV. Resultate und offene Probleme

V. Fragestellung und Vorgehen der folgenden Untersuchungen

1. Kapitel: Der poeta doctus als Dichtertypus der modernen Kulturkrise

I. Der poeta doctus in der Moderne

1. Modellfall der reflektierten Kreativität

2. Spannweite und existentielle Belastungsprobe am Beispiel Belyjs

11. Krisentendenzen der Kulturkrise um 1900

1. Krise des Bewußtseins.

Rilke, Musil, Belyj und der "Probemensch" der Kulturkrise

2. Krise der Sprache.

a) Sprachskepsis:

Hofmannsthal und Tjutcev

b) Spracherneuerung:

Schöpferische Deformation - "symbolischer" und "poetischer" Konstruktivismus.

3. Krise der bürgerlichen Lebensformen.

Zum Selbstverständnis des modernen Dichters - Belyj als poeta doctus und poète maudit.

Zusammenfassung und Exkurs:

Weichenstellung für den Bewußtseinsroman im russischen Symbolismus 
2. Kapitel: Die Erscheinung des poeta doctus in Rußland -

Belyj im Kontext der "Intelligencija"

1. Zum Wandel im Selbstverständnis der russischen "Intelligencija" der Jahrhundertwende:

Der "Weg Rußlands" und der "Weg der Seele" 59

II. Die beiden Fronten der "Künstler" und der "Philosophen" 66

3. Kapitel: Denkvoraussetzungen Belyjs $\quad 70$

I. Krisenbewußtsein und Selbstwertproblematik 71

II. Ästhetische Praxis $\quad 80$

III. Naturwissenschaftliches Methoden- und Theoriebewußtsein 80

IV. Positivismus und Idealismus: äußere und innere Erfahrung 84

4. Kapitel: Denkformen und Diskursebenen 86

ZWEITER TER: TELOS, TECHNIK, SELBSTERFAHRUNG

BELYJS ENTWURF EINER INDUKTIVEN ÄSTHETIK

\section{Einleitung:}

Ästhetik der Kreativität

1. Kapitel: Dimensionen der Wirklichkeit

I. Existentielle Verankerung 94

II. Objektive und subjektive Auffassung von der Wirklichkeit 96

III. Objektive Bedingungen der Kunst-

Kunst als Prozeß technischer Bearbeitung der Wirklichkeit 99

IV. Subjektive Bedingungen der Kunst-

Zur Konstitution des Gegenstandes der Kunst durch das künstlerische Bewußtsein:

1. Die künstler ische Wahrnehmungsweise 109

2. Die ideelle Konstruktion der Wirklichkeit 113

3. Die künst lerische Erlebnisstruktur

a) Das Erleben als psychischer Ganzheitsvorgang aus den drei Komponenten: Verstand, Gefühl und Wille

b) Fehlformen vereinseitigter Kunst und Ästhetik gegenüber der "wahren" Kunst aus der Totalität des Erlebens 
I. Symbol der ersten Phase:

Deixis und Appell

II. Symbol der zweiten Phase:

Modell der Erfahrung

III. Triadische Konzeption der Symbolisierung

1. Die Innen-Außen-Relation

2. Der unendliche Bezug

IV. Symbol der dritten Phase:

Wert- und Sprachschöpfung

Zusammenfassung

3. Kapitel: Zur Legitimierung der künstlerischen Symbolisierung

I. Theoretische Legitimation: symbolisches Denken in

Wissenschaften und Mathematik

II. Existentielle Legitimation: Ibsen und Nietzsche als

Prototypen des Symbolisten in der Moderne

4. Kapitel: Verwandlung der Persönlichkeit.

Von der "Theurgie" zur "Revolution des Geistes"

1. Verwandlung als Ziel der Kunst in Abhängigkeit von der Form

II. Der hohe Anspruch an den Leser

III. Stufen des "preobraženie"

Schluß: $\quad$ Modell des kreativen Prozesses

I. Drei Stadien der schöpferischen Bearbeitung der Wirklichkeit

II. Zur Autonomie der Kunst.

Einige Folgerungen aus Belyjs Modell

des kreativen Prozesses. 
ER STER TEIL

ANDREJ BELYJ ALS DICHTER-THEORETIKER

KRISENBE WUSSTSEIN UND DENK VORAUSSETZUNGEN 


\section{E I N L E I T U N G}

Belyjs herausragende Bedeutung unter den russischen Symbolisten als Innovator der Prosasprache und Begründer des modernen russischen Romans ist von der Symbolismusforschung erkannt und in manchen wichtigen Zügen erforscht worden. Obwohl sein Rang als Theoretiker und experimenteller Praktiker des russischen Symbolismus immer wieder hervorgehoben wird, ist seinen Schriften zur Ästhetik bisher keine systematische Untersuchung gewidmet worden. Die Gründe dafür liegen zunächst in Belyj selbst: Er hat keine geschlossene übersichtliche Theorie hinterlassen, sein umfangreiches theoretisches Werk von ca. 3000 Seiten ist teils in editorisch unzulänglichen Sammelbänden gebündelt, teils in schwer zugänglichen Zeitschriften oder nicht wieder aufgelegten alten Ausgaben verstreut. Manches davon ist ad hoc aus polemischem Anlaß geschrieben, anderes aus dem Bedürfnis nach Legitimation gegenüber einer großen, ebenso provozierenden wie verpflichtenden Tradition, das meiste aber aus dem Ringen um neue theoretische Positionen der Ästhetik für eine Kunstbewegung, die sich um 1900 in stürmischer und krisenhafter Entwicklung befand. Wie der Kunst jener Zeit des Umbruchs in die Moderne, haf ten auch Belyjs Denken Widersprüche und Dissonanzen an, die die Konstanten der Denkbewegung nicht leicht erkennen lassen.

Verwirrend wirkt überdies die Komplexität seines geistigen Profils. Einerseits ausgebildeter Naturwissenschaftler mit Sinn für Experiment und Methode, andererseits Philosoph mit dem Drang zu grundlegenden Wert- und Wahrheitsfragen, darüber hinaus profunder Kenner der zeitgenössischen Debatten über Materialismus, Religion, Psychologie, Energetik, Okkultismus und außerdem vom vitalen Interesse des Künstlers an der neuen poetischen Formensprache besessen - bietet Belyj das Bild des Dichter-Theoretikers, des poeta doctus, in ungewöhnlicher Differenzierung und Universalität. So schwankte man, ob er als "kolossal'nejšij um" (von kolossalem geistigem Format) oder nicht doch als "bezumec" (Wahnwitziger) anzusehen sei (cf. Maksimov, 1975, 232).

Daß ein so angelegter Geist Berührungsscheu um sich verbreitet, kann nicht wunder nehmen. Das selbstgewählte Identitätsmuster des "čudak" (cf. "Zapiski čudaka") ließen sich denn auch viele Interpreten von Belyj selbst suggerieren. Und die vorherrschende Meinung blieb es, ihn als Exzentriker, zwar genial aphoristisch, aber letztlich unsystematisch, einzustufen.

Die Berührungsscheu vor dem Theoretiker wurde beim Entstehen dieser Arbeit unwillkürlich durch eine Spurabweichung unterlaufen. Denn der Zugang zu Belyj war zunächst über sein Roman-Poem "Kotik Letaev" (1916/17) gefunden worden. Bei der geplanten Analyse dieses Werkes - die inzwischen in den Hintergrund gerückt ist - erhob sich bald die einfache Frage: "Was versteht Belyj eigentlich unter "Symbol"?" Da lag es nahe, bei ihm selbst nachzulesen. Und dabei bildete sich (zuerst als Notwehr) der feste Entschluß, sich nicht beirren zu lassen von den Widersprüchen an der Oberfläche, sondern 
wissenschaftliche, aber evident und unabweisbar empfundene Ersnker und Dichter von Rang vor sich zu haben, lieferte die Berech;ich konsistenten, wenngleich von ungewöhnlicher Dynamik besetzyjs zu fahnden, die den Sinn und die Form dieses Denkens begründet

?n vermeintlichen Dualismus als "Palimpsest" $z u$ verstehen und auf in transparent zu machen. So formierte sich die Absicht, das Bild rillanten, aber wohl doch konfusen Denkers kritisch zu sichten und zren. Auf der Suche nach den Intentionen seines Denkens ging es :der darum, sich - im genauen Hinhören auf Belyj - nicht durch ihn lassen, sondern im anscheinend Unsystematischen die Perspektivik oten. Als fester Kern seiner Ästhetik wird Belyjs Uberzeugung von aft des schöpferischen Bewußtseins angesehen. Von diesem Haupt"Methode der Symbolisierung" in ihrer Genese während des ersten hrhunderts betrachtet. Denn "kreative Energie" ist für Belyj nicht 3 des Künstlers, sondern wird prinzipiell auch beim Rezipienten wirken in der Kunst als kreativem Prozeß zusammen. Belyjs Kunstmehr primär eine Theorie der schönen Künste, sondern weitet sich tivität.

lifferenziertes geistiges Profil auch nur annähernd zu erfassen, $\mathrm{er}$ ndig, ihn aus dem problemgeschichtlichen Kontext seiner Epoche zu ie auch andere russische Symbolisten und europäische Dichter und :alter des Umbruchs mit krisenhaften Tendenzen empfand und in :ierte. Da der geistige Prozeß jener Epoche noch nicht abgeschlcswirkt, hat gerade eine geistige Erscheinung wie Belyj nicht allein eresse, sondern eine noch heute spürbare Aktualität als Dichter und le von Symbolismus und Avantgarde in Rußland. 
POSITIONEN DER FORSCHUNG ZU BELYJS ASTHETISCHER THE

1. Erste kritische Stellungnahmen von V. Brjusov und F. Stepun inlisten als Innovator der $t$ von der Symbolismus-

Forscher der verschiedensten Richtungen sind sich darüber eirrden. Obwohl sein Rang render Theoretiker unter den russischen Symbolisten gelten kann. ıbolismus immer wieder theoretischen Werkes fällt aber, je nach Vorverständnis und methe systematische Untersehr verschieden aus. Die vorläufige Summe seiner Kunsttheorieelyj selbst: Er hat keine 1910 in dem Sammelband "Symbolismus" zusammen. Der Moskauches theoretisches Werk hatte ihm den Auftrag dazu erteilt, um mit Belyjs Buch als Progrlbänden gebündelt, teils lagstätigkeit zu eröffnen. ${ }^{1)}$ Der Doppelcharakter seiner ästhetischèen alten Ausgaben versche Kunstphilosophie, die Kunst als symbolische Erkenntnis uncieben, anderes aus dem schöpfung eines kreativen Bewußtseins versteht, und neopositivrovozierenden wie verschaft, die darauf dringt, spezifische Formen der Kunst endlich mi theoretische Positionen erforschen - diese weitausgreifende Ästhetik wurde bis heute ganz lischer und krisenhafter sowohl als Widerspruch wie auch als Syntheseversuch. Einem eire Moderne, haften auch außerdem die hypothetische und aphoristische Denkweise Belyjs inten der Denkbewegung von Lyrismen durchsetzten, teils abstrakten, teils polemischen Stil

die ihn nicht zum Ausbau eines übersichtlichen und geschlossenen Srofils. Einerseits ausgeselbst war sich der Ungleichmäßigkeit, der vielen Widersprücheode, andererseits Philoseiner of heterogenen Aussagen voll bewußt und wagte den "Kololen, darüber hinaus provon mehr als sechshundert Seiten nur mit großen Vorbehalten zu, Religion, Psychologie, Zukunft für diesen "Haufen von schreiend widersprüchlichen Artike Künstlers an der neuen und 1910 in acht Jahren voll scharfer Polemik entstanden waren, sachter-Theoretikers, des ihn als "Denkmal der Epoche" - all seinen Deformationen und dertät. So schwankte man, schrieben werden mußte, zum Trotz - gegen den Strich herkömmlit) oder nicht doch als sen würden. ${ }^{4)}$ Der umfängliche Kommentar, der noch während der I).

hafter Eile verfaßt wurde, sollte allzu Widerstrebendes wenigsteritet, kann nicht wunder mern und zum Verstehen der Grundlinien verhelfen. ${ }^{\text {5) }}$ Ein Register Zapiski čudaka") ließen weder Belyj noch später im Reprint (1969) jemand angefertigt, was Ind die vorherrschende dicken Buch sehr erschwert.

aber letztlich unsyste-

Die ersten Reaktionen auf Belyjs programmatischen Sammelt

jahr 1910 lassen bereits Prototypen zweier verschiedener Beurteikehen dieser Arbeit unD. E. Maksimov führt in seiner über Blok hinausreichenden, wegwogang zu Belyj war zuzur Rolle der Literaturkritik im russischen Symbolismus erste kriten worden. Bei der gezu Belyjs Kunst theorie von V. Brjusov, F. Stepun und Boris Grifcov.nnd gerückt ist - erhob schlossener Vorkämpfer für die Autonomie der Kunst, löst einseitiar "Symbol"?" Da lag es Probleme heraus und erklärt sich für inkompetent, die kunstphilcals Notwehr) der feste Belyjs zu beurteilen. ") Mit der Beschränkung auf die "Poetik" wirder Oberfläche, sondern 
Rezeption Belyjs bei den Formalisten vorgezeichnet, die ihn als ihren Vorläufer ansahen. B. Grifcov $^{8)}$ und F. Stepun ${ }^{9)}$ dagegen beurteilen Belyj vom Standpunkt der Kulturphilosophie. Beide sehen in seinem Denken, das den Bereich des ästhetischen Urteils überschreitet, ein Symptom der modernen Bewußtseinskrise. Während Grifcov vor dem Erwartungshorizont des Systemdenkens die Unfertigkeit und Widersprüchlichkeit einer nicht bewältigten Materialfülle kritisiert (den "Kampf $z$ wischen intuitiven und analytischen Kräften, die sich gegenseitig lahmlegen"), vermag Stepun gerade aufgrund der thematischen und stilistischen Doppelnatur dieser Kunsttheorie, im Ineinander von diskursivem Denken und poetischer Bildhaftigkeit ${ }^{10)}$ Anzeichen einer organischen Synthese aus kulturphilosophischem Erneuerungsdenken und Formästhetik zu entdecken. Er bezeichnet Belyj als "Propheten" im "Arbeitskittel des Laboranten", der auf moderne Weise Alchimie betreibe, den "Geist des Mittelalters" in die Erde einer säkularisierten Welt "einpflanzen" wolle.

Nach Maksimov hat Belyjs Kunst theorie zu ihrer Zeit, aber auch bis heute kaum adäquate Resonanz gefunden. "1) Ihm ist zuzustimmen, daß bisher eine detaillierte oder analytische Darlegung von Belyjs Ästhetik in ihrem ganzen Umfange fehlt, der sich auf fast dreitausend Seiten ${ }^{12)}$ beläuft. Doch gibt es immerhin in den beiden Hauptrichtungen fruchtbare Ansätze dazu. Ein Uberblick über die formästhetische und die philosophische Richtung der Belyj-Forschung mag das verdeutlichen.

\section{Die formästhetische Richtung}

Den breitesten Raum in der Belyj-Forschung nimmt bisher die formästhetische Rezeption seiner Kunst theorie ein. War Belyjs Kunst theorie zu ihrer Zeit für die journalistische Kritik, selbst für viele Symbolisten unverständlich, für die akademische Ästhetik unseriös, so wurde sie von der entstehenden formalistischen Schule als Anregung, Bestätigung und ernstzunehmender Gegenstand der Kritik angesehen. ${ }^{13)}$ Auf der Linie Brjusovs wurden von den formalistischen Verstheoretikern Tomaševskij, Žirmunskij und R. Jakobson Belyjs Untersuchungen zur Metrum-Rhythmus-Dichotomie aufgegriffen, zwar scharf kritisiert, aber weiter ausgearbeitet; sein stilkritisches Verfahren, die "Poetik" Gogol's zu analysieren, gilt bis heute als formalistische Pionierleistung in der Prosaforschung. v. Śklovskij und B. Ėjchenbaum schätzten Belyj weniger als Theoretiker, sondern vor allem als innovatorischen Stilisten: als modernen Vertreter der "ornamentalen" Prosa bzw. des "skaz". Mit Krise und Zusammenbruch des russischen Formalismus bricht die von Brjusov initiierte Rezeptionslinie der Poetik Belyjs um 1930 ab.

Erst in den fünfziger Jahren wird sie in Amerika wieder fortgesetzt. Durch seine Nähe zum "New Criticism" war der russische Formalismus für die amerikanische Literaturwissenschaft interessant geworden ${ }^{14)}$. Breiteren Kreisen bekannt machte ihn aber erst v. Erlich, Schüler von Roman Jakobson, mit seinem bahnbrechenden Buch "Russian Formalism. History - Doctrine." (1955). Neben Brjusov wird nun auch Andrej Belyj als Vorläufer - von V. Markov sogar als der "eigentliche Begründer" - des Formalismus verstan- 
den. ${ }^{15)}$ Erlich zeigt, daß Brjusov und vor allem Belyj als "Veteranen der Versforschung" bei den Formalisten in hohem Ansehen standen. Als die wichtigsten Beiträge Belyjs zur modernen Poetik sieht Erlich neben den Untersuchungen über Verstheorie, seine Technik der Klangwiedergabe (zvukopis'), seine formale Neubewertung der Prosa Gogol's und seine Sprachtheorie des autonomen poetischen Wortes an, mit der er schon auf das "eigenständige Wort" (samovitoe slovo) Chlebnikovs hinarbeite (40 - 44). Denn der "Wendepunkt in der Entwicklung des russischen kritischen Denkens" (dt. 1973, 35) liege nicht erst im Formalismus, sondern bereits im ersten Jahrzehnt des zwanzigsten Jahrhunderts, im Symbolismus, wo Probleme des literarischen Handwerks in den Mittelpunkt rückten. Das trifft so pointiert allerdings nur für einige der frühen Symbolisten zu, besonders für Brjusov und Bal'mont, die sich vor allem westliche Stilformen aneignen und sie in Rußland einbürgern. In Belyjs stilistischen Innovationen und verstheoretischen Forschungen steht dagegen das Formale nicht einseitig im Mittelpunkt, sondern ist unlösbar mit Inhalten verbunden, die nur so, nur in einer spezifischen und einmaligen Form ausgedrückt werden können. Das Prinzip der Untrennbarkeit von Form und Inhalt ist für Belyj unterscheidendes Kennzeichen der Kunst, der "Kanon der Ästhetik":

"Wenn wir von der Form der Kunst sprechen, verstehen wir darunter nicht etwas, was vom Inhalt verschieden ist. Die unteilbare Einheit von Form und Inhalt ist der Kanon der Ästhetik, wenn die Ästhetik danach strebt, aus der Bevormundung eines Schuldogmatismus zu entkommen." (Princip 175)

Wie Brjusov und die Formalisten hält Erlich nur die "Poetik" Belyjs für relevant, seine Ästhetik hingegen für verzeihliche "Esoterik", deren "Dogmatismus" durch das formale Problembewußtsein abgemildert sei ("Pendeln zwischen Metaphysik und Prosodie", 94). Damit ist aber Belyjs Eigenart verfehlt; gerade die komplizierten Beziehungen zwischen Poetik und Kunstphilosophie kennzeichnen sein ästhetisches Denken. Die Analyse dieser Beziehungen ist noch Desiderat der Forschung.

Erlich sieht in Belyj eine moderne Erscheinungsform des Dichter-Gelehrten, der den "Theoretiker des Symbolismus" und den "Praktiker des literarischen Handwerks" noch in der Personalunion des poeta doctus vereinigt. Als solchen stellt er ihn dem Prototyp des futuristischen Dichters gegenüber, dem Dichter-Rebellen, der Fragen der Poetik professionellen Kritikern überläßt, aber mit ihnen in einen Dialog eintritt (56). Die These vom poeta doctus hat weitere Implikationen, die für Belyj noch erforscht werden müssen. In der formalistischen Tradition stehen die Untersuchungen von J. Holthusen (1956), J. Striedter (1966), K. Pomorska (1968), M. Stojnič-Caričič (1971) und E. M. Thompson (1971).

In Deutschland wurde das Interesse am russischen Formalismus in der Phase der "Werkinterpretation" wach. J. Holthusen leitet in seinen "Studien zur Ästhetik und Poetik des russischen Symbolismus" (1957), erschienen zwei Jahre nach Erlichs Formalismusbuch, die literaturwissenschaftliche Rezeption und Analyse des russischen Symbolismus 
in Deutschland ein. Ausgehend von der "hybriden Natur" des Symbolismus (25) beschränkt er sich nicht mehr auf die "Poetik" Belyjs, sondern stellt sie seiner "Ästhetik" gegenüber. Ihr Verhältnis begreift er unter dem binären Denkmuster der Oppostion in zwei Reihen: Die Reihe der Ästhetik umfaßt die weltanschauliche Sphäre religiöser und ästhetischer Sehnsucht nach Welterneuerung (30), die in sich wiederum "hybrid" sei. Symbolismus wird verstanden als Wiederbelebung der religiös-symbolischen Weltsicht, die vom symbolistischen Dichter in mystischer Ekstase erreicht werden könne: durch Intensivierung des Gefühls ("dionysische Epiphanie") oder durch intuitive Erkenntnis, die den Weg zu "anderen Welten" öffnet (35). Dem Dichter werden dabei ähnlich tiefe Einsichten zuteil wie dem Propheten, dessen Rolle ihm deshalb auch zeitweise zuerteilt wird. Nach "kathartischer Beruhigung" soll er sich in die strenge Zucht der Form nehmen, um eine Kunst zu schaffen, die imstande wäre, die "Natur unserer Persönlichkeit umzuschaffen" (27). Aufgrund dieses weltanschaulichen "inneren Kanons" wird der Kunst "religiöser Sinn" zugesprochen. Diesem "inneren Kanon" steht der "äußere Kanon" der poetischen Sprache gegenüber (32), der sich in einem Umbruch der Formen befindet. An der "semantischen Belebung des Wortes" sind die russischen Künstler der Moderne - sensibilisiert durch die Wortkunst des französischen Symbolismus - in bisher nicht gekanntem Maße experimentell interessiert (21), zugleich aber auch am inneren Rhythmus und einer neuartigen Darstellung ihrer minutiös beobachteten Erlebniswelt, die gegenüber der Außenwelt oft alleinige Geltung beansprucht (27). Die Poetik der Symbolisten, in der höchst subjektivierte Erlebnisbilder gleichwohl zu überpersönlichen Symbolen erhöht werden sollen, und in der sich eine musikalisch rhythmisierte und magisch suggestive Sprache zu verselbständigen beginnt (28 f.), sieht Holthusen in einem Gegensatzverhälthis zur religiös akzentuierten Ästhetik. Die Ausprägung dieses Grundwiderspruchs zwischen formalistischem "modus operandi" (Poe) und religiös gebundenem "Sinn der Kunst" (Belyj) findet er bei Belyj ebenso wie bei Ivanov und Blok. Brjusov räumt er eine Sonderstellung ein ( $35 \mathrm{f}$., 41 f.).

A. Belyj habe versucht, in einem "hybriden Lehrgebäude" (25) den Symbolismus theoretisch zu begründen. Dabei widerstreiten einander zwei Tendenzen: die erkenntnistheoretische Suche nach einer philosophischen Grundlage für die Kunst des Symbolismus und der Versuch, eine formalistische Poetik zu entfalten. In alexandrinischer Manier habe er die verschiedensten Positionen der westlichen und östlichen Philosophie ausgenutzt, die er eklektisch zusammenfüge, um Kunst als "symbolische Erkenntnis" gegenüber dem erkenntnistheoretischen Skeptizismus Kants zu begründen. Zum transzendenten Grenzwert der "symbolischen Erkenntnis" erkläre er - verfangen in der Begrifflichkeit des Neukantianismus - das "Symbol" an sich ("Emblematika smysla"). Den religiösen Sinn der Kunst sehe er im Aufruf zum "verklärten Leben".

Im antagonistischen Widerspruch zu den Forderungen dieser religiös begründeten Ästhetik stehen für Holthusen die Ansprüche einer modernistischen Poetik. Belyj sei als 
Theoretiker des Symbolismus in der Widersprüchlichkeit eines "hybriden" Systems von philosophischen und verstechnischen Traktaten in "begrifflicher Unentschiedenheit" (25) steckengeblieben. Vor allem aber bleibe der Anspruch auf religiösen Sinn der Kunst bei ihm ungedeckt, weil er sich jedem moralischen Engagement - wie es selbst Blok gefordert habe - entziehe; denn der Aufruf zu "verklärtem Leben" bleibe, statt kathartisch zu wirken, esoterisch; gebunden an die perfekte Form verwirkliche er sich viel eher in der Sprachmagie des "fetischisierten" Wortes, in der "musikalischen Kraft des Lautes" (28).

Widersprüche sieht Holthusen auch in der Auffassung Belyjs vom Symbol. In ungelöster Antinomie zu dem transzendenten Grenzwert des "Symbols an sich" werde das bloß künstlerische Symbol einmal als "Hülle der Idee" verstanden, als "Ideenbild", das auf Transzendentes hinweise ("Fenster in die Ewigkeit"), andererseits aber als verbal-poetisches "Schema" der künstlerischen Erfahrung, das nur sich selbst bedeute und in der Immanenz verbleibe. Die beiden Reihen: Ästhetik, die entweder archaisierend auf die Wiederbelebung eines geschlossenen Weltbildes im "Mythos" ziele (Ivanov) oder esoterisch nach "symbolischer Erkenntnis" strebe (Belyj) und gegen den rationalen "Logos" ankämpfe; Poetik, die modemistische Forderungen an den Künstler stellt - definiert Holthusen als eigengesetzliche Bereiche, die miteinander konkurrierend in Widerspruch stehen. Er sieht also den Grundwiderspruch des russischen Symbolismus in doppelter Weise: Einmal in der ungelösten Opposition von Weltanschauung und künstlerischem Handwerk, von "Mythos" und poetischem "Logos" einer zur Selbstwertigkeit tendierenden Sprache; andererseits in der Opposition von irrationalen und rationalen Zügen innerhalb der Weltanschauung selbst, von "Mythos" und rationalem "Logos" der begrifflichen Sprache des modernen Szientismus (Mythos-Logos-Opposition als Erbe der deutschen Philosophie, 34/35).

Die suggestive Griffigkeit der Gegensatzformel von "Mythos und Logos" verfehlte ihre Wirkung nicht und wurde zu einem "Lehrsatz" der Holthusen-Schule. ${ }^{16)}$ Holthusen weist mit seiner Pionierarbeit auf die Polarität von Ästhetik und Poetik im russischen Symbolismus hin, die er jedoch nicht als Spannungsverhältnis von zwei innerlich zusammengehörigen Polen eines umf assenderen Kulturzusammenhanges versteht, die beide die künstlerische Symbolisierung steuern, sondern als konkurrierende Eigengesetzlichkeiten. ${ }^{17)}$ Belyjs ästhetische Theorie mißt er am Maßstab eines Denkens in binären Oppositionen, einem Axiom des frühen russischen Formalismus. Dieses Grundmodell aus dem linguistischen Sprachdenken, mit dem kleinste distinktive Einheiten ermittelt und voneinander abgetrennt werden konnten, wurde damals in die Kunsttheorie übernommen. In einer implizit formalistischen Optik - Dichotomie von Weltanschauung und Poetik - beurteilt er Belyjs ästhetisches Denken als repräsentativ für den russischen Symbolismus. Der imere Zusammenhang der widersprüchlichen Positionen, die Entwicklung des Symbolbegriffs und die hypothetische Denkstruktur Belyjs konnte mit dem deskriptiven binären Modell nicht erfaßt werden. 
D. Tschižewskij (Begründer der Reihe "Slavische Propyläen", in der Belyjs theoretische Schriften im Reprint erschienen) sieht Belyjs schulbildende Bedeutung überhaupt nicht in seiner Theorie, sondern in seiner Originalität als moderner Romancier, und zwar (im Gegensatz zur Dichotomie Šklovskijs) sowohl in den ideologischen Positionen wie auch in den stilistischen Qualitäten seiner Prosa. ${ }^{18)}$ Uber Belyjs Ästhetik fällt er nächst Trockij ${ }^{19)}$, wenngleich von ganz anderer Seite - das negativste Urteil: Seine philosophischen Abhandlungen seien "schwach", seine "Traktate über Fragen der Poetik" ïberholt. $^{20)}$

Dagegen ist J.Striedter: Transparenz und Verfremdung. Zur Theorie des poetischen Bildes in der russischen Moderne (1966), überzeugt, Belyj habe "in der ästhetischen Theorie ebenso Bedeutendes geleistet wie in der poetischen Praxis" (264). Seine Gründe:

1) Belyjs Theorie des postrealistischen Symbols bildet eine Gelenkstelle in der Entwicklung des poetischen Bildes in der "russischen Moderne", wobei er "Moderne" als übergreifenden Epochenbegriff versteht, der - neben anderen literarischen Strömungen auch den Symbolismus umfaßt. So kann er antithetisch zwei Bildtheorien gegenüberstellen, die auf einem gegensätzlichen weltanschaulichen Hintergrund entstanden: die des religiös ambitionierten Flügels der russischen Symbolisten und die der antimetaphysischen Formalisten. Dabei setzt er den religiösen Flügel des Symbolismus mit dem "frühen" Symbolismus gleich, was historisch nicht zutrifft. Bereits unter den Vorläufern des Symbolismus in den neunziger Jahren gab es mit Merežkovskij eine religiöse, mit Annenskij und Bal'mont eine vorwiegend formal orientierte Richtung. Die eigentlichen "frühen" (oder älteren) Symbolisten, Brjusov und seine Schule, lehnten aber gerade einen philosophischen oder metaphysischen Anspruch an die Literatur ab, den eben dann die "späteren" (oder jüngeren) Symbolisten (Ivanov, Belyj, Blok) wieder stellten.

2) Ist zentral für den religiös ambitionierten Symbolismus die "Transparenz" (prozračnost') des poetischen Bildes für Ideelles (Merě̌kovskij: "Amphora"; Belyj: "Fenster in die Ewigkeit"), so sieht der antimetaphysische Formalismus, mit Śklovskijs "Verfremdung" automatisierter Bilder, die Hauptleistung der poetischen Metapher darin, daß sie zum "Neuen Sehen" (Šklovskij: 1929, 13) der konkreten Dinge selbst führt. Im Futurismus schließlich verselbständigt sich die widerständige Sprachsubstanz derart ("tugoj jazyk"), daß es bis zum Abschied der poetischen Wahrnehmung von der abbildenden Bildlichkeit überhaupt kommt. Striedter sieht bereits im "Symbol", als einem transparent gemachten Bild, die Antinomie zwischen dem Hinweischarakter des Symbols (nach Ivanov: Zeichen für die "realiora") und dem poetischen Eigenwert der Metapher als "subjektivem Stimulans", worin das Erbe der französischen Symbolisten weiterwirkt (266). Als Vertreter dieser Antinomie stellt er Brjusov und Ivanov gegenüber: Besteht Brjusov - besorgt um die Autonomie der Kunst - auf der poetischen Selbständigkeit des Bildes (auf Kosten seiner Transzendenz), so gibt Ivanov - als Anwalt der Transzendenz - den Primat der Transparenz (auf Kosten der eigenständigen Poetizität). Auch diese Antithese ist un- 
historisch gesehen, denn sie läßt unberücksichtigt, daß es sich hier zunächst um eine Entwicklung handelte: Ivanov gibt Antwort auf Brjusovs theoretische Forderungen. Die offene Auseinandersetzung zwischen beiden Flügeln fand erst statt um 1909/10 im Symbolistenstreit. 21) Daß es bereits eine Vorform davon um 1900 zwischen den "Philosophen" und den "Künstlern" im Kreis um die "Welt der Kunst" gab, blieb bisher in der Symbolismusforschung im Hintergrund.

3) Striedter sieht in Belyj eine Vermittlungsinstanz; er strebt zum "Ausgleich der Extreme" (268), denn er begründet das Symbol nicht mehr allein vom weltanschaulichen oder rein poetischen Standpunkt her, sondern er führt einen psychologischen Begründungsrahmen ein, in dem das Symbol primär als ein "Modell zu Erlebnissen" (275) konstruiert wird. Das kann in verschiedenen Symbol-Typen geschehen, die Belyj in partieller Ubereinstimmung mit Ivanovs Unterscheidung zwischen einem "realistischen" und einem "idealistischen" Symbolismus entwickelt. Während Striedter zuvor vom historischen Ablauf zugunsten einer übersichtlichen Antithese abstrahierte, berücksichtigt er hier, daß Belyj verschiedene Phasen durchläuft: vom hinweisenden Symbol-Zeichen über die Theurgie-Lehre bis hin zur Wortmagie als sprachschöpferischer Grenzsphäre, in der Poesie und Mythos aneinandergrenzen (273).

Wichtig an Striedters Analyse scheint mir zweierlei: 1) zeigt er die innere Verbindung zwischen "psychologischem System" (275) und Symbolkonstruktion, die er auch in Belyjs theoretischen Untersuchungen über Formprozesse in der Lyrik wiedererkennt (277); 2) verweist er auf Stufen der Entwicklung in Belyjs Symbolkonzeption, die allerdings erst noch genauer herausgearbeitet werden müßten. In beiden Thesen Striedters liegen Ausgangspunkte für weitere Forschungen. Striedter - wie auch die anschließende Diskussion 22) - machten deutlich, daß Belyjs Bildtheorie des modernen Symbols als Modell der inneren Erfahrung sowohl einen Wendepunkt in der russischen Poetologie darstellt, als auch einen Beitrag gibt zur Bildtheorie der europäischen Avantgarde, die über die Bildauffassung der französischen Symbolisten hinausgeht und auf Futurismus und Expressionismus vorausdeutet.

Ewa M. Thompson: Russian Formalism and Anglo-American New Criticism (1971), legt nach Erlichs Bestandsaufnahme von Geschichte und Doktrin des russischen Formalismus eine Analyse des philosophischen Hintergrundes der Grundbegriffe in der russischen und anglo-amerikanischen formalen Schule vor. Wie Coleridge für den New Criticism räumt sie Belyj für den russischen Formalismus eine Schlüsselstellung ein (55). Sie weist an Zeugnissen von Šklovskij, E்jchenbaum, Tomaševskij (27 - 30), vor allem aber von Žirmunskij (75 f.) nach, daß Belyj als führender Theoretiker des russischen Symbolismus nicht nur poetologische, sondern auch entscheidende philosophische Bedeutung für die idealistische Tendenz im russischen Formalismus (75 f.) gehabt habe, die sie neben der neopositivistischen sehr hoch veranschlagt. Sie zeigt, daß Belyj mit seiner Auffassung von der Kunst als "symbolischer Erkenntnis" Aussagen Kants in der "Kritik der reinen 
Vernunf $t$ " zur Einbildungskraft und zu den "ästhetischen Ideen" weiterentwickelt, und daß er durch sein Studium des Neukantianismus spätere Einsichten Ernst Cassirers auf dessen "Philosophie der symbolischen Formen" vorwegnimmt (12). Sie reiht Belyj in die große Linie der Kant-Rezeption ein, die im neunzehnten Jahrhundert bereits zwei Wege eingeschlagen habe: zum Intellektualismus Hegels und zum Intuitivismus Schopenhauers (56). Die Widersprüche in Belyjs Theorie: Rationale Deskription literarischer Formkomplexe und Rückgriff auf "ästhetische Ideen", die vom Subjekt nicht rational, sondern intuitiv erkannt werden, aus denen er die Begründung der Kunst als "symbolischer Erkenntnis" herleitet, die über die Erfahrung hinausführt (und deshalb von Belyj als "religiös" bezeichnet wird) - diese vermeintlichen Widersprüche rückt $E$. Thompson damit in ein neues Licht. Denn in der Auseinandersetzung mit Kant sei Belyj zu einem Verständnis der Kunst als "vollkommener Erkenntnis" (62) gekommen, die aber nicht mehr kontemplativ und "reflexiv", sondern "schöpferisch" vor sich geht.

"In seinem Essay "Emblematik des Sinns" sagt Belyj, wenn die Wirklichkeit unerkennbar ist in ihrem Wesen (und nach Kant ist sie das), dann ist Erkenntnis nicht ein Prozeß der Widerspiegelung, sondern schöpferische Rekonstruktion der Daten der Wahrnehmung." (63)

Wieso und in welcher Weise Belyj über Kant hinausgeht, müßte noch weiter geklärt werden, vor allem der zentrale Begriff des "Schöpferischen".

Nach E. Thompson bleibt Belyj jedoch insofern inkonsequent, als er symbolische Erkenntnis nicht autonom setzen kann, sondern ihr "noch" religiösen Sinn beimißt (was Cassirer nicht mehr tut).

"Belyj konnte nicht einen Typus des Symbolismus zulassen, der weder religiös noch wissenschaftlich wäre." (65)

Hier muß man fragen, wieso in Cassirers Auffassung von der Symbolisierung eine Art Norm zu sehen ist. Wer davon abweicht, muß deshalb nicht inkonsequent sein. Es kann durchaus eine Auffassung von Symboiisierung geben, die sich nicht in einer "Formenlehre des Geistes" (Cassirer) erschöpft. Hier müßte Belyj von seinen eigenen - von Cassirer abweichenden Voraussetzungen - verstanden und von diesem abgegrenzt werden. Darüber und über die Bedeutung der Wertphilosophie in diesem Zusammenhang fehlen noch Untersuchungen.

Davon abgesehen verkörpert Belyj nach Thompson den modernen Versuch, Philosophie und Poetik in der erkenntnistheoretischen Bestimmung von Kunst als "symbolischer Erkenntnis" zueinander auf fruchtbare Weise neu in Beziehung zu setzen. ${ }^{23)}$ Sie zeigt, daß die Grundlage dieses Verständnisses von Kunst weder abstrakt noch irrational ist, sondern in der Einsicht besteht, daß "die relevante Erfahrung der Seele" (Belyj) in der Kunst in die "Architektonik der Fabel" (Belyj) transformiert werde, und daß Kunst aus diesem Grunde eine eigene, durch nichts zu ersetzende Formader schöpferischeng Enkenntnis ist. 
Wie in der literaturwissenschaftlichen Praxis die deskriptive Analyse der Struktur des literarischen Kunstwerkes mit einem Erfassen seiner "metaphysischen Qualtitäten" vereint werden kann, zeigt sie an Ingardens Schichtenmodell, das sie durch einige Ergebnisse der formalistischen Forschung ergänzt $(111 \mathrm{f}$.). Von hier aus sieht sie auch einen Weg, die literarische Wertung, die im russischen Formalismus wenig fundiert blieb, neu zu definieren. Beispiele dafür führt sie aus dem New Criticism (Ransom, Tate, Brooks) an (141).

Nach V. Erlichs literarhistorischer und E. Thompsons komparatistischer Darstellung legte der Wiener Slavist Aage A. Hansen-Löve: Der russische Formalismus. Methodologische Rekonstruktion seiner Entwicklung aus dem Prinzip der Verfremdung. Wien 1978 eine darüber hinausgreifende systematische Untersuchung des russischen Formalismus vor. Wie aus dem Untertitel hervorgeht, sieht er im Verfremdungsakt dessen methodisches Grundprinzip, was an sich keine neue Erkenntnis ist. Neu ist, daß ein anscheinend genügend bekanntes Theorem in ein methodisches Werkzeug verwandelt wird, um den Formalismus systemimmanent in seiner Entwicklung zu analysieren und seine Grenzen zu definieren, wobei neue Aspekte zum Vorschein kommen. Hansen-Löve leitet die Entwicklung des V-Prinzips vom sokratischen (umwertenden) "Neu-Sehen" und von dem konstruktiven Verfahren des aristotelischen Metaphorisierens, der "Umbenennung" ab; über den Ironiebegriff Schlegels und Kierkegaards verfolgt er sie weiter bis zum entautomatisierenden "Neuen Sehen" Šklovskijs, dem die konstruktiven Verfahren der semantischen Verdichtung und Verschiebung (sdvig), S. 27, entsprechen, und weiter bis zum "karnevalistischen Prinzip" in Bachtins Kultursemiotik. "Verfremdung" erweist sich dabei als ein Antriebsverfahren der Kreativität, das Philosophie und Kunst gleichermaßen umfaßt: als "noetisches Prinzip" (uznavanie) und "poetisches Verfahren" (inoskazanie), S. 19 f.

"Nicht nur am Anfang des Philosophierens, sondern auch der ästhetischen Weltbetrachtung steht die Neugierde, die zunächst spielerische Verschiebung des gewohnten Gesichtspunktes, die Einnahme eines fiktiven, utopischen, theoretischen Standpunktes, von dem aus die Dinge und ihre Zusammenhänge fremd erscheinen, neu und spannend (...)." (21)

Aus dem V-Prinzip ist - wie H.-L. zeigt - eine "Ásthetik der Abweichung" begründet worden; sie setzt jedoch als "Apperzeptions-Fond" immer die Norm, also ein ästhetisch und kulturell festgefügtes Bezugssystem (42) voraus, einen "intakten Allusionshintergrund" (483). Den russischen Formalismus - und das ist ein Novum in der Forschung betrachtet H.-L. nicht als in sich geschlossene Formation, sondern in seinen verschiedenen Entwicklungsstufen. Er unterscheidet: 1) ein polemisch-reduktionistisches Frühstadium; 2) eine Phase konstruktiver Verfahren; 3) ein Spätstadium der Öffnung gegenüber weltanschaulichen und psychologischen Fragen.

Im ersten Stadium wurde der Kampf um die Ästhetizität der Kunst (èstetǐ̌nost', literaturnost') mit ebenso aufreizender wie methodisch klärender (176) Einseitigkeit ge- 
führt. Dabei wurden nicht nur alle weltanschaulichen und psychologischen Implikationen der Kunst negiert (185 ff.), sondern die V-Methode, gewonnen an den avantgardistischen zaum'-Texten der Futuristen, zur einzig gültigen ästhetischen Methode überhaupt verabsolutiert. Nicht einzelne Kunstwerke wurden analysiert, sondern nur ins Konzept passende Strukturzüge oder Werke, was - statt zur empirischen Objektivität - zur methodischen "Tautologie" (177) führte.

Wurde zunächst also die Kunst v. a. unter dem Gesichtspunkt der "Abweichung" als "Summe" von bestimmten Verfahren und als Weg zur Sensibilisierung der erstarrten Wahrnehmung betrachtet, so steht im zweiten Stadium die "Anordnung" einzelner Strukturzüge innerhalb des Kunstwerkes zur Debatte; das "konstruktive Prinzip" (232) der Uber - und Unterordnung von "Funktionen" in hierarchischer Spannung zueinander. Nach dem Ubergang vom Formalismus zum "Funktionalismus" wird das Kunstwerk nicht mehr als Summe von Verfahren, sondern als "System von Systemen" (235) verstanden. ${ }^{24)}$

In der dritten Phase tritt neben der Frage der historischen Evolution (Literaturgeschichte wird ebenfalls verstanden als "System von Systemen") ein literatursoziologisches Konzept hervor (vor allem in Bezug auf den literarischen "byt"). Der antiideologische und apsychologische Reduktionismus wird durch den kommunikationstheoretischen Entwurf von L. S. Vygotskij und M. Bachtin (Vološinov) überwunden.

Hansen-Löve erklärt die Entwicklung des russischen Formalismus aus den ästhetischen Grundlagen der Moderne. Außer dem Einfluß der bildenden Kunst der Zehner Jahre (v. a. Impressionismus, Kubismus) und der kubo-futuristischen zaum'-Poesie schätzt er die Bedeutung der symbolistischen Poetik für den Formalismus höher ein, als das bislang geschah, v. a. weil er sich von der herabmindernden Optik des OPOJAZ weitgehend freimacht $(43,304)$. Neben Potebnja und Veselovskij ist es Belyj, den er in vierfacher Hinsicht als bahnbrechend für den Formalismus ansieht: 1) seine Pionierarbeit in der Verstheorie (304 f.); 2) den Beitrag zur semantischen Autonomie der poetischen Sprache in seiner Bildtheorie $(45 \mathrm{f}$.). Darauf hatte die bisherige Forschung (Erlich, Holthusen, Strieoter u. a.) schon hingewiesen. Neu sind die folgenden beiden Urteile: 3) Belyjs Sicht der Kunstproduktion als priēm-material-Verhältnis, d. h. als Vorgang kunsttechnischer Bearbeitung (pererabotka) der Wirklichkeit $(55,192)$, löst den starren Inhalt-FormDualismus auf und präfiguriert die Hauptthese Šklovskijs: "Iskusstvo kak priëm". 4) Die wahrnehmungsästhetische Ausrichtung in der Poetik des Symbolismus, besonders Belyjs, erfordert eine Neubewertung der Leserposition: Notwendig wird der "Mitvollzug des Kunstwerkes" durch den Leser als kreativer Prozeß. Hier müßte Belyj genauer analysiert werden. Ihn nur in den Grenzen der frühsymbolistischen Suggestionsästhetik (die H.-L. u. a. vom Einfluß Bergsons herleitet, 54) zu sehen, ist zu wenig, seine wirkungsästhetische Orientierung des "preobraženie ličnosti" geht darüber hinaus (cf. dazu auch 62, 168 - 72 zu "Kotik Letaev" Belyjs). 
Kritik an H.-L.s Sicht der symbolistischen Poetik und der kunsttheoretischen Position Belyjs ist in zweierlei Hinsicht anzumelden: 1) Es fehlt - im Gegensatz zu E. Thompson - an Verständnis für die weltanschaulichen Grundlagen der symbolistischen Ästhetik; der formalistische "Binarismus" (179) wirkt sich in der Beurteilung weiter aus (47, 52, 55, 57), obwohl doch seine reduktionistische Tendenz innerhalb der Entwicklung des frühen zum späteren Formalismus kritisch als Manko erkannt wird. 2) Belyj wird auf das "System der Kunstformen", Hierarchie der Künste mit der Musik an der Spitze, festgelegt (59 f.), das er 1902 (!), in "Formen der Kunst", aber nicht mehr 1910 vertreten hat; seine "v. a. an Schopenhauer geschulte Kunstphilosophie" (60) gilt ebenfalls 1910 längst nicht mehr; die inzwischen erfolgte Auseinandersetzung mit Schopenhauer fehlt bei H.-L., ist aber auch der Belyjforschung bis in die jüngste Zeit entgangen. Trotz dieser Einschränkungen hat H.-L. die zunehmend differenzierter werdende Beurteilung der ästhetischen Bedeutung Belyjs innerhalb der formalistischen Forschung entscheidend weitergebracht.

\section{Zusammenfassung}

Im Uberblick kann man sagen, daß sich in der formästhetischen Beurteilung Belyjs als Kunst theoretiker verschiedene Stadien abzeichnen.

Im Formalismus ist vorherrschend die Reduktion seines doppelten Ansatzes von Ásthetik und Poetik auf die rein literaturwissenschaftlichen Arbeiten zur Vers- und Prosaforschung sowie zur Sprachtheorie. Tschižewskijs generelle Negation der theoretischen Bedeutung Belyjs hat sich als nicht haltbar erwiesen. Holthusens Erkenntnis von der Polarität zwischen Ásthetik und Poetik weist auf die Spannweite von Belyjs ästhetischer Theorie hin. Da er jedoch das binäre Denkmodell der frühen Formalisten als Axiom übernimmt, daß die beiden "Reihen" Weltanschauung und Sprache unverbundene Eigengesetzlichkeiten darstellen, kann er das Verhältnis von Ästhetik und Poetik nur als Opposition begreifen und die "hybride Natur" von Belyjs ästhetischer Theorie feststellen.

Striedter sieht den Symbolismus nicht mehr als isolierte Kunstrichtung, sondern ordnet ihn ein unter die verschiedenen Strömungen der europäischen "Moderne". Belyjs Bildtheorie versteht er als Kristallisationspunkt der Grundspannung von Ästhetik und Poetik. Weltanschaulicher Symbolismus (Symbol als Ideen-Zeichen bei Ivanov) und artistischer Symbolismus (Symbol als synästhetisches, polysemantisches Wort-Zeichen bei Brjusov) gehen in Belyjs komplexer Bildtheorie des postrealistischen Symbols, das zugleich erlebt und poetisiert ist, ein spezifisch modernes Amalgam ein: "Modell zu Erlebnissen". Striedter zeigt indirekt, daß die Spannung von Mythos und poetischem Logos nicht nur formalistisch als Opposition oder Konkurrenz zweier Systemreihen verstanden werden kann, sondern daß bei Belyj durch die Poetisierung des "psychologischen Systems" eine neue Nähe von Mythos und Poesie entstehe, wie sie auch sonst in der Moderne zu erkennen sei - z. B. bei Majakovskij. 
E. M. Thompson weist als erste die nicht nur poetologische sondern auch philosophische Bedeutung von Belyjs Kunstphilosophie für die idealistische Tendenz innerhalb des Formalismus nach, die dieser - trotz vieler Dementi - durchaus neben seinem neopositivistischen Credo gehabt habe. Für die Widersprüche innerhalb seines ästhetischen Denkens sieht sie eine verbindende Basis in der Erkenntnistheorie Kants, die die beiden Möglichkeiten rationaler und "symbolischer" Erkenntnis in sich schließe. Belyjs Weiterentwicklung von Ansätzen zur erkenntnistheoretischen Begründung der Kunst als "symbolischer Erkenntnis" steht nach Thompson nicht im Widerspruch zu seinen Versuchen, ein Kunstwerk rational so präzis wie möglich zu analysieren. Hierin deute Belyj auf Cassirer und Ingarden voraus. In Belyjs doppeltem Bestreben nach erkenntnistheoretischer Begründung der Kunst und nach deskriptiver Strukturbeschreibung sieht Thompson keinen Widerspruch, sondern eine innere Stringenz, in der Ästhetik und Poetik von einem sowohl idealistischen als auch positivistischen Standpunkt aus aufeinander bezogen werden.

Hansen-Löve bleibt gegenüber Striedter und E. Thompson stärker dem binären formalistischen Kontrastdenken verhaftet und präzisiert deshalb v. a. den Beitrag Belyjs zur Vers-, Sprach- und Bildtheorie, der den Formalismus vorbereitete. Neu ist seine Erkenntnis, daß die "kopernikanische Wende" (Belyj) von der traditionellen Ästhetik, die im Form-Inhalt-Dualismus verharrte, zur Ästhetik als Kunstwissenschaft bereits im Symbolismus durch Belyj vollzogen wurde. Wie die priëm-material-Relation Belyjs sich von der späteren reduktionistischen Formel Sklovskijs (Iskusstvo kak priëm) unterscheidet, bleibt noch zu klären. Neu ist zweitens H. -L.s These von der Neubewertung der Leser-Position im Symbolismus als Prozeß kreativen "Mitvollzugs". Daß Dichtung der Moderne ein unabgeschlossener produktiver Akt ist, der den Leser zum Weiterproduzieren herausfordert, - ist allerdings schon in der Poetik des französischen Symbolismus (Mallarmés vor allem) angelegt (cf. z. B. H. Friedrich, Struktur, 92). Was die Umwertung der Leserposition angeht, so kann durch "close reading" von Belyjs ästhetischen Schriften ebenfalls noch Genaueres herausgefunden werden, vorausgesetzt man überwindet den Engpaß des formalistischen "Binarismus", was mir in den erkenntnistheoretischen und komparatistischen Analysen E. Thompsons gelungen erscheint.

Man kann also sagen, daß die formalistische Richtung um die eine wesentliche Konstante kreist: um die Auseinandersetzung mit dem Doppelcharakter von Belyjs Theorie, mit der Grundspannung von Ästhetik und Poetik. Die Ansichten divergieren hier in alle Grade der Wertskala. Dennoch sind innerhalb der formästhetischen Richtung der Belyjforschung zwei ganz verschiedene Stadien erkennbar: 1) Ein doktrinär-formalistisches mit antipsychologischem und antiphilosophischem Affekt; 2) ein "aufgeklärt"-formalistisches, in dem die polemische Abwehr überwunden ist und in dem jetzt auch psychologische und philosophische Implikate einbezogen werden, weil man aus formalistischem Isolationismus herausstrebt. Dementsprechend wurde Belyjs Theorie von den Formalisten der "strengeren" Observanz entweder ganz negiert, auf ihre poetologische Hälfte 
ermäßigt oder aber für hybrid erklärt und als Opposition zweier konkurrierender Reihen behandelt; von den neueren Formalisten dagegen wurde die literaturpsychologische (Striedter) und kunstphilosophische (Thompson) Bedeutung Belyjs thematisiert bzw. erforscht.

In der Entwicklung der formalistischen Forschung zu Belyj spiegelt sich - wie auch in der geistesgeschichtlichen Richtung - zugleich ein Stück Forschungsgeschichte. Die einzelnen Positionen, die jeweils besondere Aspekte in den Vordergrund rücken, müßten wenn man sie wirklich gerecht beurteilen will - vor dem Hintergrund des jeweils erreichten allgemeinen Forschungsstandes gesehen werden, der ihnen einerseits den Rahmen vorgegeben hat, den sie aber umgekehrt auch vorangetrieben haben. Eine kritische Auseinandersetzung läuft leicht Gefahr, diesen dialektischen Prozeß außer acht zu lassen und in einen abrechnenden Ton zu verfallen, selbst wenn das nicht beabsichtigt ist. Denn im Grunde genommen wird ja durch kritische Sichtung der Forschungsgeschichte gerade der Blick für die Vorläufigkeit des eigenen Urteils geschärft, das aber trotz der Einsicht in diese Bedingtheit versuchen muß, sich so präzis wie möglich zu artikulieren. Vielleicht kann man hier an Lessing erinnern: "Wenn es ein wenig beißend gesagt sein sollte - wozu hilft das Salz, wenn man nicht damit salzen soll?"

\section{Die geistesgeschichtliche Richtung}

Wurde die Grundlinie der formästhetischen Betrachtungsweise Belyjs durch V. Brjusov vorgezeichnet, so war innerhalb der geistesgeschichtlich-philosophischen Richtung der Kulturphilosoph Fedor Stepun bis in die sechziger Jahre außerhalb Rußlands wegweisend. In seinem Nekrolog auf Belyj: Pamjati Andreja Belogo (1934), versteht er dessen Person, Denken und künstlerisches Werk als Ausdruck der modernen Kulturkrise; und das in doppelter Hinsicht: als Indikator - aber auch als Gegenreaktion. Als zeitweiliger Weggenosse (1909 - 1910 Zusammenarbeit im Verlag Musagetes) ${ }^{25)}$ sieht er mit Belyjs "unzeitigem" Tode die "letzte große Figur der Moskau-Petersburger Vorkriegsliteratur in Sowjetrußland" dahinscheiden, an deren renaissancehaftem Aufschwung er aktiv teilgenommen, für deren innere und äußere Bedrohtheit er jedoch mit seismographischem Spürsinn in eigener Person und mit einem nicht zum Abschluß gebrachten Werk gezeugt habe (162 - 65). Daß Belyj zum "Seismographen der Krise" werden konnte, sieht Stepun begründet in der eigentümlichen Seinsweise seiner Person und in ihrem geistigen Habitus. Die Gestalt Belyjs ist für ihn bestimmt durch ein ontologisches Defizit, durch ihren Mangel an einfachem menschlichen Sein, der seine Existenz phantomhaft machte und ihn als "Unperson" erscheinen ließ, als ein Wesen, das "seine Wurzeln gegen Flügel eingetauscht" habe (170 f.). Stepun verneint entschieden, daß Belyj deshalb ein Poseur gewesen sei, im Gegenteil: In schutzloser "Nacktheit" und medialer "ozeanischer" Offenheit habe er sich den extremsten Zügen seiner Zeit ohne Abschirmung ausgesetzt ("Veitstanz einer hilflos nackten Seele"; 1964, 279). Dem ontologischen Mangel komplementär sieht Stepun 
die enorme geistige Intensität Belyjs. Die Weite seines überdimensionalen Bewußtseins, die Tiefe und Schärfe seines künstlerischen Blicks, die polemische Fechterleidenschaft und der lebenslange Kampf "gegen sich selbst um sich selbst" (166) erzeugten eine Dynamik, die ihn zu einem "unerhörten geistigen Ereignis" (170) machte. Doch Belyjs geistiger Aktionsradius sei auf die Grenzen seines eigenen Bewußtseinspanoramas beschränkt, in dem seine Freunde und Feinde ungeachtet ihrer eigenen Realität figurierten, dessen Immanenz jeden Ubergang zu realistischen und transzendenten Bereichen unmöglich gemacht und seinem Geist den Charakter einer alles widerspiegelnden Monade verliehen habe. Die besondere Art dieser Widerspiegelung sei begründet im "Belyjschen Blick" (172), in seiner minutiösen Wahrnehmung, die überwach gespannt war bis zur genialen Karikatur, aber auch Züge unirdischer Güte und Zartheit enthielt. Das Monadenhafte an Belyj sieht Stepun begründet in seiner "Wurzellosigkeit". Ohne historisch in einer gewachsenen Wirklichkeit heimisch geworden zu sein, verkörpere er den Typ des radikalen Aufklärers und egalitären Rebellen - trotz aller mystischen Sehnsüchte.

Aus dieser psychisch-geistigen Grundausrüstung Belyjs, aus seinem phantomhaften Sein und seiner zerebralen Grenzenlosigkeit, erklärt Stepun auch die Widersprüche Belyjs. In seiner ästhetischen Theorie schwanke er zwischen dem enzyklopädischen Alexandriner auf dem Gipfel der alten Kultur, der in einem neukantianischen Panmethodologismus (H. Cohen) durch Neukombination des Alten eine Synthese erstrebe, und dem zuwiderlaufenden Konzept Solov'evs von der "Theurgie" als Neuschöpfung des Lebens. Stepun vermerkt den scharfen Gegensatz von theoretischer Forderung eines ästhetischen Sollens und der inkongruenten dichterischen Praxis. In seiner Romanprosa dominiere anstelle von Synthese oder Lebenserneuerung, aufgrund seiner Wurzellosigkeit, im Eruptionsmotiv der Krise die Prophetie des Chaos und der Revolution ("geschichtsphilosophische Alpträume"). Ohne Nihilist geworden zu sein, verkörpere Belyj das Nichtsein der Epoche. Sein Versuch, zu neuer "gottebenbildlicher" Personalität zu gelangen, bliebe erhalten, aber unvollendet.

Dreißig Jahre später revidiert Stepun: A. Belyj (1964), seine Ansicht über Belyjs Lehre vom Symbolismus. Statt des ultrarationalen Panmethodologismus der Marburger Schule in ungelöster Opposition zur "Theurgie" Solov'evs sieht er jetzt die andere Seite des neukantianischen Einflusses auf Belyj, die Wertphilosophie der Badischen Schule (H. Rickert), als zentral an. "Ästhetische Theorie und Lebensforderung" (290) sind für Stepun jetzt unter dem gemeinsamen Gesichtspunkt des "Schaffens von neuen Werten" als "religiöse Wertverpflichtung" (294) nicht mehr unverbundene Widersprüche, sondern vermittelt in einem neuen kreativen Religionsbegriff, der Belyj zur Forderung nach einer Kunst in neuen Formen geführt habe. Hiermit führe Belyj die Tradition der russischen Ästhetik des neunzehnten Jahrhunderts fort, vor allem die Solov'evs. Dennoch hält Stepun seine Ansicht aufrecht, daß der theoretische Anspruch von Belyjs Symbolismus die künstlerische Wirklichkeit seines Spätwerkes nicht zu steuern vermochte, in der die 
"Lüge des bürgerlichen Lebens" (344), die Herrschaft von Gewalt und Trieb dominiert (Moskau-Zyklus). Stepun versteht Belyj als kompromißlosen Denker und Künstler der modernen Kulturkrise; seine ästhetische Theorie beurteilt er aus dem inneren Zusammenhang von Ethik und Ästhetik als Theorie der kreativen Erfahrung. Stepun erkennt, daß Belyj die "religiöse" Dimension der künstlerischen Erfahrung in der Moderne wiederentdeckt bzw. bewahrt hat. Er zeigt aber auch die Diskrepanz zwischen theoretischer Forderung und poetischer Praxis bei Belyj.

Die Bedeutung der Wertphilosophie der südwestdeutschen Schule des Neukantianismus für den Umbau der Lehre vom Symbolismus hatte bereits kurz nach dem Kriege Jutta Pflanzl: Weltbild und Kunstschau des Russischen Symbolismus in der theoretischen Gestaltung durch A. Belyj (1946) herausgearbeitet (bes. 57 - 59 und 74 - 77). Ihr Erkenntnisziel ist, den "Denker" Belyj ${ }^{26)}$ und seine "Wege zum geschlossenen Weltbild" (93) im Zusammenhang mit der deutschen Philosophie, vor allem mit Schopenhauer und Rickert, zu zeigen. Vom Standpunkt der Kulturphilosophie der dreißiger Jahre (A. Gehlen, J. Ritter) vertritt sie die Hauptthese, Belyj als Theoretiker des russischen Symbolismus strebe nach Vereinigung von Kunst und Wissenschaft in dem "Versuch, ein einheitliches Kulturbild, das alle damaligen Kulturprobleme lösen sollte, auf der Grundlage der Rickertschen Wertlehre aufzubauen" (12). Vor dem Hintergrund des weltanschaulichen Umbruchs der Jahrhundertwende - vom pragmatisch-fortschrittsgläubigen Positivismus der "Väter" (dessen wissenschaftstheoretisches Ethos der genauen Beobachtung sich auf die Kunst des Impressionismus auswirkte, hier aber schon weitgehend "ichbezogen" wurde) zum Subjektivismus der "Söhne" (in dem sich die positivistische Geisteshaltung der Beobachtung und Erfahrung (4) vorwiegend auf den Reflex der Außenwelt im Innenleben richtete) - unterscheidet J. Pflanzl zwei Entwicklungsphasen des modernen Subjektivismus in Belyjs theoretischem Werk: 1902 - 1904 wird unter dem Einfluß der Kunstmetaphysik Schopenhauers Kunst als intuitive symbolische Erkenntnis definiert, 1906 - 1910 unter dem Einfluß der neukantianischen Wertphilosophie Rickerts als lebensorientierte Wertschöpfung. Kronzeugen sind Ellis ("Anschauung des Wesens der Dinge") ${ }^{27)}$ und Ivanov-Razumnik ("Religion des Lebens") ${ }^{28)}$, deren Urteile sie als Entwicklungsstadien kontaminiert. Im ersten Stadium wird die Kunst erkenntnistheoretisch auf dem Vorstellungsidealismus Schopenhauers begründet: als symbolische Erkenntnis (38). Der Erkenntnisprozeß - einst Domäne des theoretischen Denkens - wird mit Schopenhauer als intuitiv zu erlangende Wesensschau der Ideen begriffen, die in Vollendung nur vom Künstler erreicht werde, dem sie Einblick in das Wesen der Welt - die reine Bewegung - verschaffe. Die künstlerische Gestaltung der Ideenschau zu Symbolen, als sinnlich anschaubaren Bildern der Ideen, wird als religiöse Aufgabe verstanden (23). Belyjs formales Interesse an den Einzelkünsten richtet sich deshalb auf den Grad ihrer Eignung für die als "symbolische Erkenntnis" definierte Kunst (Hierarchie mit Musik an der Spitze, 20 - 23). Das philosophische Interesse (an der erkenntnistheoretischen Be- 
gründung der Kunst als eines autonomen Bereiches) und das formalästhetische Interesse (an den formalen Bedingungen der Kunstformen wie Raum-Zeit/Material und Techniken) sind miteinander organisch verbunden. Der Kunst wird gegenüber allen anderen Kulturgebieten eine Sonderstellung eingeräumt. Die Kunstphilosophie trägt, da sie neu begründet werden muß, notwendig aphoristischen Charakter.

Im zweiten Stadium wird die erkenntnistheoretische Begründung der Kunst verändert. Belyj erhebt jetzt die Forderung nach einer neuen eigenen Ästhetik mit Methoden, die nicht mehr an die normativen Ansprüche eines philosophischen Leitmodells gebunden sein dürfen, sondern induktiv aus den "Tatsachen des künstletischen Schaffens selbst" gewonnen werden sollen. Nur so kann später eine Logik der Künste begründet werden. Kunst wird nicht mehr allein als "symbolische Erkenntnis" verstanden, sondern - aufgrund der eigenen Erfahrung als Dichter - als eine Form des Schaffens. Dazu greift er wieder auf philosophische Legitimation zurück: auf den Neukantianismus Rickerts mit der Lehre vom Primat des schöpferischen Bewußtseins, vom Vorrang der inneren über die äußere Erfahrung, von der Verpflichtung allen Schaffens auf "Werte", die in einem System der Wertgebiete hierarchisch gestuft sind. Auf dieser philosophischen Basis rücken jetzt das "Erleben" (pereživanie) ( $50 \mathrm{ff}$.) des schöpferisch erkennenden Bewußtseins und der Vorgang der künstlerischen Symbolisierung (53) ins Zentrum von Belyjs Interesse, und zwar als die beiden ersten Stadien des künstlerischen Prozesses. Diesen Prozeß sieht Belyj als wertgeleitet und als wirkungsorientiert an: "Kunst bildet Lebensformen in Werte um, die zur Bewußtseinsänderung führen" (59). Dieses Ziel ist jedoch abhängig von der meisterhaft beherrschten Form. Auch in der zweiten Phase besteht ein innerer Zusammenhang von Kunstphilosophie und Formästhetik bei Belyj, denn Weltanschauung und Kunst theorie entstammen für ihn der gleichen Wurzel: dem Symbol. Es ist sowohl ein philosophischer wie auch ein formalistischer Begriff. In der Philosophie gibt es symbolische Begriffe, die die einzelnen Wertgebiete bezeichnen, in der Kunst symbolische Bilder, die in der Moderne nicht mehr in einem festen Kanon verankert sind, sondern allen Bereichen der Wirklichkeit entnommen werden können, aber symbolische Bedeutung annehmen, wenn hinter dem Schaffen des Künstlers - das aus dem ganzheitlichen Erleben hervorgeht - als einziges "Dogma" ein "fragloses Ja" zum Wert, und das heißt zum Leben, steht (91). Insofern ist $\ddot{A}$ sthetik nicht auf sich begrenzt, sondern steht bei Belyj im Rahmen der Erneuerung der Kultur.

J. Pflanzl gelingt es, die innere Entwicklung und die Zusammengehörigkeit von Kunstphilosophie und Formästhetik bei Belyj nachzuweisen. Dabei neigt sie allerdings zur Harmonisierung und entgeht nicht den Gefahren, die mit dieser Tendenz verbunden sind (94 f.). Ihre methodische Trennung von Denker und Dichter hat den Vorteil, daß die Theorie unabhängig davon betrachtet werden kann, wieweit Belyj selbst imstande war, sie künstlerisch zu verwirklichen ${ }^{29)}$. Die Beschränkung auf den Einfluß der beiden deutschen Philosophen hat zur Folge, daß die erste Phase einseitig als Schopenhaver-Phase ${ }^{30)}$ er- 
scheint, und Belyj als Kunstphilosoph des Ästhetizismus. Hier müßte der starke und konkurrierende Einfluß Solov'evs berücksichtigt werden, vor allem in Belyjs früher Programmschrift "O teurgii", in der bereits die spätere Wendung zur ethisch verpflichteten Wirkungsästhetik (unter Einfluß von Rickert) vorbereitet wird. Außerdem fehlt der prägende Einfluß von F. Nietzsche. In der zweiten Phase wird die Orientierung des Symbolismus an der Kulturphilosophie Rickerts einseitig betont. Was aber u. a. durch den Bewußtseinsidealismus bei Belyj ebenso stark entsteht, ist die Forderung nach Selbsterkenntnis bzw. Erschaffung des eigenen Ichs als Voraussetzung für eine Kunst, die an der Erneverung der Kultur mitwirken soll. ${ }^{31)}$

Oleg A. Maslenikov: The Frenzied Poets. Andrej Belyj and the Russian Symbolists (1952), legte die erste Monografie zu Belyj vor. Er geht von biografischen Daten aus und versteht Belyjs Werk als "Reflex seiner inneren Erfahrungen" (VIII) sowie als Ausdruck einer "symbolistischen Mentalität". Er stellt ihn deshalb in den Rahmen der Künstlerkreise des russischen Symbolismus und untersucht seine Beziehung zum Solov'ev-Kreis, zu Brjusov, den Merežkovskijs, zu Blok und Ivanov. Belyj wird als Zentralfigur des russischen Symbolismus, als sein "Prophet" angesehen, dessen individuelle Krise eine auslösende Rolle in der Krise der symbolistischen Bewegung gespielt habe (222). Maslenikov beurteilt ihn innerhalb seiner Gesamtsicht des russischen Symbolismus, dessen Eigencharakter er in seiner dreifachen Bedeutung sieht: als philosophische Weltanschauung, die auf intuitivem Wege nach Erkenntnis des Absoluten strebte, als künstlerische Methode und als neves, elitäres Selbstverständnis des Dichters als Vorläufer eines neven Künstler-Menschen ("a poet was to demonstrate how man should live", 220). An Belyj als seinem symptomatischsten Repräsentanten und führenden Theoretiker zeige sich, daß der Symbolismus in philosophischer Hinsicht gescheitert sei, und zwar am ungelösten Dualismus von erstrebtem, aber nicht erreichtem mystischen Glauben und einem Wissensdrang, der gelenkt werde von skeptisch-rationalem Beweisstreben (218). Den Zeitpunkt der Krise Belyjs - ausgelöst durch persönliche Hysterie und Verzweiflung - sieht er um 1906, also gerade zu Beginn seiner zweiten Theoriephase, die jedoch für Maslenikov der Desillusionierung aller ursprünglichen Hoffnungen des Symbolismus gleichkommt $(80,221)$.

Gescheitert hält er den Symbolismus zweitens in bezug auf die geforderte Lebensweise des Künstler-Menschen, wegen des Scheiterns am eigenen Leben (221). Gelungen dagegen hält er ihn als künstlerische Methode, als einen der "Höhepunkte der russischen Kulturgeschichte": In der Lyrik werde eine neve Ära eröffnet, überhaupt ein neuer Kunststil geschaffen, neue Leserkreise durch die propagierende Aktivität der Symbolisten für den Modernismus gewonnen (222). Maslenikov zeigt - wie vorher J. Pflanzl, die aber nicht erwähnt wird - zwei Phasen des russischen Symbolismus bei Belyj: von der eschatologischen Naherwartung zur kulturellen Arbeit an einem Fernziel im tätigen Schaffen (80). Er zieht jedoch den entgegengesetzten Schluß daraus. Seine These vom "Scheitern des Symbolismus" (1906) läßt sich nur daraus erklären, daß er den Versuch 
Belyjs, den Symbolismus aus der Wertphilosophie und einer Theorie des kreativen Bewußtseins neu zu legitimieren, offenbar nicht ernst nehmen kann: "Die typische Philosophie von 'Kindern einer lost generation"' (222). Seine Ansicht vom elitären Selbstverständnis des symbolistischen Dichters ist zu einseitig (wurde aber seit Chodasevič unkritisch wiederholt ${ }^{32)}$, cf. "Nekropol"', 43). Belyjs wirkungsorientierte Kunstauffassung mit dem Ziel der Bewußtseinsveränderung steht dazu im Widerspruch.

Positiv an Maslenikovs Darstellung ist sein Hinweis auf die dreifache Zielrichtung des russischen Symbolismus (Weltanschauung, Kunststil, Lebensform), der Aufweis der beiden Phasen eines eschatologischen und eines evolutionären, kulturorientierten Stadiums. Nicht überzeugen kann seine Begründung des "Scheiterns".

K. V. Močul'skij: Andrej Belyj (1955), gibt ein Lebensbild Belyjs ${ }^{33)}$, in dem die Interpretation seines dichterischen und theoretischen Werkes breiten Raum einnimmt. Mołul'skij sieht die kulturgeschichtliche Bedeutung des russischen Symbolismus darin, daß er die Traditionen der großen russischen Literatur und der ethisch orientierten Ásthetik des neunzehnten Jahrhunderts fortsetzt (175) und durch Verarbeitung der westeuropäischen Dekadenz auf originelle Weise erneuert; er spricht von einer "Russischen Renaissance" der Jahrhundertwende (109). Belyj sieht er als bedeutendsten Prosaiker und als den Chefideologen des russischen Symbolismus an (besonders $1907-1909$ in der Kolumne "Na perevale" in der Zeitschrift "Vesy"); seinen frühen, noch naiv-enthusiastischen Artikel "Von der Theurgie" (1903) hält er für das Manifest der symbolistischen Bewegung, in dem die Ästhetik Solov'evs aus den achtziger Jahren weitergeführt werde (53). Močul'skij zeigt, daß für Belyj der Gedanke der "Verwandlung" des Lebens auf dem Wege einer religiös inspirierten Kunst von Anfang an leitend gewesen ist; ${ }^{34)}$ er weist diesen Grundzug auch in den späteren, von der neukantianischen Wertphilosophie beeinflußten Artikeln der zweiten Phase "Sinn der Kunst" (1907) und "Kunst der Zukunft" (1907) nach (118, 14l ff.). Er zeigt vor allem, daß Belyj die innere Voraussetzung für diese Kunstauffassung immer mehr in der Hinwendung zum Thema des eigenen Selbst gesehen hat (99). In der Ästhetik des russischen Symbolismus sieht er - ebenso wie in Dichtung und Prosa - die Fortführung der ethisch-ästhetischen Tradition des neunzehnten Jahrhunderts, wie sie von Gogol', Dostojevskij, Tolstoj und Solov'ev vertreten worden sei (99). Den Untergang des russischen Symbolismus sieht er in der inneren Zerstrittenheit der Bewegung, an der Belyj wesentlich durch die persönlich bedingte Schärfe seiner Polemik "schuld" gewesen sei. Močul'skijs Monografie blieb unvollendet und wurde erst posthum aus seinen Manuskripten veröffentlicht.

Renato Poggioli: The Poets of Russia (1960) beurteilt den russischen Symbolismus im Kontext des europäischen Nihilismus der Moderne. Er vertritt vier Haupt thesen:

1) Soziologische Voraussetzung ist der unversöhnliche Gegensatz von Autokratie (Modernisierung, Korruption, 47 - 49) und Radikalität einer antikonservativen, staatsfeindlichen Intelligenz, die vorn Nemesis-Denken beherrscht wurde und den Prototyp des "dekadenten Aktivisten" favorisierted (52 Masia Peppermann - 9783954792740 
In der radikal antibürgerlichen Haltung der russischen Intelligenz ist ihre Anfälligkeit für die Geisteshaltung der westeuropäischen Dekadenz und ihres "moralischen Nihilismus" (53) begründet. Dabei kann er nicht umhin, einige Zugeständnisse zu machen: Immerhin bescheinigt er der russischen Intelligenz, daß sie "von tief religiöser und moralischer Gesinnung" (54) trotz ihrer Radikalität gewesen sei, daß sie einen "ästhetischen und kulturellen Erziehungsprozeß der russischen Offentlichkeit" (61) herbeigeführt habe, sowie "neue Strömungen des Denkens" bei Merežkovskij, Berdjaev, Sestov und Rozanov zu verzeichnen seien (71 - 78). Das alles aber eher der Vollständigkeit halber, denn ins Gewicht gegenüber der nihilistischen Grundtendenz fällt das für ihn nicht. Hier klaffen Widersprüche.

Die russische Dekadenz in einem ambivalenten Krisenzeitalter zwischen "kultureller Agonie" und Hoffnung auf Wiedergeburt bleibt gebannt in der Ablehnung des Alten und der Furcht vor dem Neuen (80 - 83). Sie ist gekennzeichnet durch ihren eskapistischen Ästhetizismus, der auf einem amoralisch-hedonistischen Nihilismus beruhe, durch extremen Individualismus (Kult des Ich und der schöpferischen Persönlichkeit) und senilen solipsistischen Erotizismus (84 - 86). Als Leistung der russischen Variante der europäischen nihilistischen Dekadenz erkennt er einzig die "Leistung der Form" an: "Nicht eine Ablehnung der Kultur, sondern eine Kultur der Negation, eine Blume des Bösen wie auch des Kranken" (88).

4) Der russische Symbolismus ist eine Mischung aus Dekadenz (Merežkovskij, Gippius, Brjusov, Sologub, Bal'mont) und einem "modischen" religiösen Suchen (bei Belyj, Blok, Ivanov, 119), gestützt auf Solov'evs unzeitgemäße theokratische und spirituelle Utopie der Inkarnation ("Vergeistigung der Materie - Materialisation des Geistes", 122). Solov'evs Syntheseideal einer Verbindung antagonistischer Prinzipien und die Skepsis seiner romantischen Ironie habe zugleich den religiösen Kult wie auch die Poetik der Symbolisten begründet. Für Poggioli sind die Symbolisten zeitweilige und gescheiterte Anhänger eines Kults, moderner Orden oder Sekte; als Literaten jedoch seien sie nur graduell verschieden von den antimetaphysischen französischen Symbolisten (130). Den Beweis dafür sieht er in der gemeinsamen Präferenz der Musik (ohne die unterschiedliche Auffassung beider von der Musik zu diskutieren), in der gemeinsamen Distanz ihres modernen, auf Musikalität und Stimmung beruhenden Symbolismus zum nicht mehr erreichbaren "ewigen" Symbolismus des Mittelalters, der seine Verbindlichkeit aus einem geschlossenen Weltbild bezogen habe (133). Symbolismus und Dekadenz sieht er als "verschiedene Seiten ein und derselben Medaille, oder parallele Varianten derselben historischen Situation". Für ihn gibt es da eine sehr einfache Regel: "Daß es Dekadente gab, die keine Symbolisten waren, daß es aber keinen Symbolisten gab, der nicht zugleich ein Dekadenter gewesen wäre" (14). 35) Poggioli spricht von der "Nemesis" des russischen Symbolismus, die nicht nur in soziologischer Hinsicht gilt. Die beiden Sackgassen, in die der 
Versuch einer nur pseudoreligiösen Begründung seiner Meinung nach führt, sind Intellektualismus oder Irrationalismus. Denn die Symbole des modernen Dichters seien entgegen ihrem Anspruch, Bildzeichen der realiora zu sein - nur noch "verbale Ikonen", die auf die "chaotische" Psyche des Dichters zurückverweisen (Symptome im Sinne Freuds statt Symbole, weil "spontaner und automatischer Ausdruck des Unbewußten", 145). Anstatt Ausdruck des "Mysteriums" seien sie Zeichen der "Sphinx" (145). Die innere Dialektik des Symbolismus sieht er in der ungelösten Spannung von elevatio und desperatio, wo Dichtung nur noch als "Muse der Flucht" (146) möglich sei. "Und so endete der Symbolismus in einem Symbolismus der Negation, in einer Allegorie des Scheiterns, in einem Gesang des Nichts (147)." Da der Moderne nach Poggioli der Sinn für das Heilige verloren gegangen sei, private Glaubensbekenntnisse und Mythen nur willkürlicher Ersatz für echte mystische Erfahrung seien, verfalle sie der "Nemesis"des Nihilismus, erreiche nur noch ein "kunstvolles Spinngewebe einer glanzvollen Form" (157).

Gemäß dieser Gesamtsicht des russischen Symbolismus sieht er die theoretische Bedeutung Belyjs vor allem in den Abhandlungen zur russischen Verstechnik (Vorläufer des Formalismus). Wegen seiner religiösen, literarischen und psychologischen Erfahrungsbreite hält er Belyj für die repräsentativste Figur des russischen Symbolismus ("crank, daydreamer, seeker of God"). Vor allem aber hält er ihn für den Indikator der Krise des Zeitalters im allgemeinen und des Symbolismus im besonderen:

"Belyj diente unbewußt, besser als sonst jemand, der verborgenen historischen Aufgabe dieser Bewegung, die darin bestand, die kulturelle Krise der Epoche gleichzeitig zu verdecken und auf zudecken (161)."

Poggioli denkt in den starren Oppositionen von Autokratie und Radikalismus, dogmatischer Religion (135 f.) und Nihilismus ${ }^{36}$ ), Eskapismus und Formbrillanz - und kann deshalb der Eigenart des russischen Symbolismus nicht gerecht werden. Weder berücksichtigt er den sozialen Wandel innerhalb des Selbstverständnisses der russischen Intelligenz ("gap between 1880 und 1905")" land und in der Moderne überhaupt, die nicht mehr an der Rückkehr zu den "etablierten Dogmen" und einem geschlossenen Weltbild gemessen werden kann, sondern die auf der religiösen Erfahrung des entwickelten modernen Individuums in der Geisteshaltung des Subjektivismus beruht ${ }^{38)}$. Sie führte seit Mitte der neunziger Jahre zur religiösen Bewegung unter den Intellektuellen (religioznoe iskanie). J. Scherrer schreibt über das "Neue religiöse Bewußtsein" (aber erst dreizehn Jahre nach Poggioli):

"Die damals vollzogene religiöse Wende verschiedener wenn auch kleiner Fraktionen der russischen Intelligenz war als ein Grupggnphänomen in der Geschichte der Intelligenz etwas völlig Neues (13)". 
Samuel D. Cioran: The Apocalyptic Symbolism of Andrej Belyj (1973), gibt nach den vorwiegend biografischen Monografien von Maslenikov (1952) und Močul'skij (1955) eine religionspsychologische Gesamtinterpretation von Belyjs Werk bis zum Anfang der zwanziger Jahre. Im Thema der Apokalypse sieht er den Schlüssel zu Belyjs dichterischem und theoretischen Werk, aber auch den Weg, ihn in seine Epoche einzuordnen (6). Das vorrevolutionäre Rußland versteht er als "crisis-ridden age" (5) auf der Suche nach Erneuerung der individuellen und gesellschaftlichen Lebensformen. Als Dominante des kulturellen Bewußtseins der Jahrhundertwende sieht er eine "eschatologische Mentalität"40) (5) an, die vom Bedürfnis nach religiöser Symbolisierung "besessen" (5) das extrem mystische, archetypische Symbolsystem der biblischen Apokalypse zu ihrem "standard text of reference" (9) macht, und zwar sowohl in geschichtsphilosophischer als auch in individueller Hinsicht. Cioran zeigt, daß das spätjüdische apokalyptische Weltmodell drei spezifische Züge trägt:

1) den durchgängigen geschichtsphilosophischen und kosmischen Dualismus von Ordnung und Chaos, dem die Gegensatzpaare von Himmel und Abgrund, Christ und Antichrist, Sonnenweib und Hure (Tier), das Neue Jerusalem und das verkommene Babylon entsprechen;

2) die Utopie der zweiten Ankunft Christi, des neuen Menschen, eines neuen Himmels und einer neuen Erde;

3) das "apokalyptische Dogma von Schöpfung durch Zerstörung" (46), in dem der Untergang als notwendige "Katharsis" verstanden wird, der die Endharmonie herbeiführe. Doch die Apokalypse sei nicht als Untergangsdrohung zu verstehen, sondern als Ermutigung des Christen zum Durchhalten, denn die Weltgeschichte werde als dreistufiger Prozeß von Schöpfung - Zerstörung - Wiedergeburt dargestellt (26). In dieser Interpretation sei sowohl Raum für pessimistische und optimistische Auffassungen, für die Strukturen des Dualismus in der individuellen und geschichtlichen Realität, aber auch für die synthetische Zukunftsvision einer Vollendung der Welt und des Menschen in der wiederhergestellten All-Einheit - jedoch um den Preis des Unterganges. Die monumentale Bildmacht und emotionale Suggestivkraft dieses mehrsinnigen symbolischen Weltmodells der Zeitenwende habe auf die vorrevolutionäre Intelligenz in Rußland eine unwiderstehliche Faszination ausgeübt. Cioran leitet sie aus dem geistig-emotionalen Maximalismus ihrer kompromißlosen "eschatologischen Mentalität" eines "Entweder-Oder", "Jetzt oder Nie" ab, die zur Dramatisierung geneigt, in einem ahistorischen Katastrophendenken einen elementaren Umschwung in eine bessere Zukunft erwartet habe, den irrationalen "Sprung über die Geschichte".

Vor dem Hintergrund einer generell eschatologisch-apokalyptisch begriffenen Epoche betrachtet er Belyjs Werk als "apokalyptischen Symbolismus". Das kollektiv vorgeprägte Symbolsystem der Apokalypse sei von ihm ganz bewußt zum Ausdruck seiner

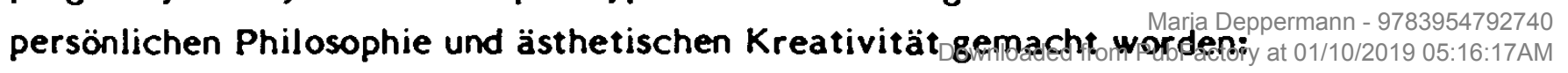


"In der Tat, die dramatische Grundspannung in seinen Werken entsteht aus seinem erfolglosen Versuch, diese Opposition (Dualismus vs. Zukunftsvision des kosmischen Menschen) zu versöhnen (5)."

Dieses archetypische Symbolgefüge sei - besonders von Belyj und Blok - nicht nur als geschichtsphilosophisches Erklärungsmodell begriffen worden, sondern auch als "individuelle oder persönliche Apokalypse":

"Dieses persönliche Gefühl, am Schnittpunkt von zwei Zeitaltern gg̨łf zigt zu sein, gab ihrem Werk eine unleugbar eschatologische Wendung (5)."

Auch auf Belyjs Kunst theorie wendet er das Konzept der Apokalypse an: Seine ästhetische Theorie sei gegründet in dem apokalyptischen Dogma der "Schöpfung durch Zerstörung", das er u. a. dem "kreativen Anarchismus Nietzsches" entnommen habe.

"Der Symbolismus war nicht nur eine ästhetische Doktrin, sondern wurde auch als Mittel benutzt, das Alte geistig umzustürzen und das Neue anzukündigen (47)."

Dominiere in der ersten Phase noch die platonische, harmonisierende Auffassung vom Symbol als "Ideen-Bild", so zeige sich in der zweiten Phase eine extrem emotionale und pathologische Note ("Opfer seiner Emotionen", S. 52), die das chaotische Substrat des äußerlich harmonischen Symbolverständnisses verrate. Das Symbol werde zum Bild der "Krisenerfahrung" (Ciorans Ubersetzung des "pereživanie"!), enthalte den Dualismus von Licht und Dunkel, Leben und Tod in sich und - nur vom theoretischen Postulat nach "homogener Einheit" zusammengehalten - werde es zur "Bombe, die in den Händen des Künstlers explodieren kann. Es gibt kein besseres Beispiel (sicher aber noch einige andere) für das Explosive des Symbols als in 'Petersburg', wo es beschrieben wird als Zeitbombe in der Sardinenbüchse (50)". Den Kulminationspunkt seiner Symboltheorie sieht Cioran in dem Essay "Emblematik des Sinns". Hier werde das Prinzip der All-Einheit, unterstützt durch theosophische Spekulation, als Wert- und Sinngebung der Grundwidersprüche des Daseins, Chaos und Ordnung, lediglich "graphisch" entworfen. Auch theoretisch also ist, nach Cioran, Belyjs Symbolismus "apokalyptisch":

"Belyjs Formulierung des Symbolismus ist apokalyptisch, denn sie beruht auf jenen übernatürlichen Mächten, die die Welt neu erschaffen werden in der Zweiten Ankunft Christi (67)."

Cioran weist - wie schon Stepun - auf die Diskrepanz hin zwischen ästhetischer Theorie mit ihrem Synthese-Ideal und künstlerischer Praxis mit Dominanz des "apokalyptischen Dualismus". 42) Das Urteil Ciorans über Belyj und den russischen Symbolismus ist vorherbestimmt vom Rahmen seines Denkansatzes: Als apokalyptische Losung des russischen Symbolismus sieht er daher die Worte über die Situation um 1900 an: "Zum Beginn 
streben wir hin durch das Ende hindurch (22)."42a) Doch dieser Durchbruch zur "geistigen Revolution einer siegreichen Auferstehung (195)" sei den Symbolisten nicht gelungen; weder Blok (endete nach $C$. in der Tragödie der Zerstörung, S. 22) noch Belyj:

"Aber obgleich sein Werk die Vision der All-Einheit wiederzuerlangen suchte, kam es in Wirklichkeit niemals über die Beschreibung zerstörerischer Gegensätze hinaus (6)."

Den Fehlschlag des russischen Symbolismus beurteilt Cioran vom religionspsychologischen Standpunkt aus als Scheitern an inneren - nicht an äußeren - Gründen: Ihren Worten folgten keine Taten (24), sie schufen kein neues Sein. Dennoch gesteht er ihm als Versuch - in der Tradition der "amerikanischen" Schule - Größe zu: (24)."

"Der Großartigkeit des Versuchs entsprach die Großartigkeit des Scheiterns

Bei dieser Beurteilung bleibt der Symbolismus als literarische Bewegung innerhalb der europäischen Moderne unberücksichtigt; Belyj wird auf seine Beziehung zur Apokalypse - die in der Tat unübersehbar ist - festgelegt. Allein an diesem Maßstab messend, kann man aber seiner theoretischen und künstlerischen Leistung in ihrer Eigenständigkeit nicht gerecht werden.

Cioran hat einen schon vorher öfter erwähnten Grundzug symbolistischen Denkens aufgedeckt, den apokalyptischen, aber seine unzulässigen Generalisierungen mindern den Erkenntniswert seines Zentralbegriffs. ${ }^{43)}$ Liest man ihn jedoch entgegen seinen monopolisierenden Absichten, dann bringt er eine Menge neuen Materials, einschließlich der detaillierten Bibliografie sonst schwer zugänglicher Veröffentlichungen Belyjs in Zeitschriften. Auch seine Kronzeugen Jung und Eliade sind sicher geeignet, Belyj besser zu verstehen; was er zu Wundt, zur Theosophie und zur Psychologie bei Belyj zu sagen hat, ist wertvoll - vor allem dann, wenn man seine Schlüsse nicht übernimmt. Denn Belyj als genialen, aber schwer verhaltensgestörten Verwalter apokalyptischer Archetypen in künstlerischer Abwandlung zu verstehen, das ist sicher eine Zumutung. Zum Glück widersprechen die sorgfältig ausgewählten Belegstellen oft genug dem, was Cioran damit beweisen will.

\section{Zusammenfassung}

Zusammenfassend kann man sagen, daß sich innerhalb der geistesgeschichtlichen Beurteilung der ästhetischen Theorie Belyjs noch stärkere Divergenzen abzeichnen als in der formästhetischen - aber auch vier deutliche Konstanten.

1) Die jeweilige Einschätzung der Kunsttheorie Belyjs hängt ab von der Gesamtsicht des russischen Symbolismus. 
2) Die genetische Fragestellung berücksichtigt die Entwicklung im ästhetischen Denken Belyjs, das nicht allein am Maßstab des Systemdenkens gemessen wird.

3) Die Person Belyjs und die psychologischen Bedingungen seines Denkens werden berücksichtigt.

4) Die Theorie Belyjs wird mit seiner Dichtung verglichen.

Zu 1) Gesamtsicht des russischen Symbolismus:

Während Belyj übereinstimmend als Zentralfigur und führender theoretischer Repräsentant des russischen Symbolismus angesehen wird, scheiden sich an der Beurteilung dieser Bewegung jedoch die Geister: Es kommt zu Urteilen, die sich diametral gegenüberstehen. Der These von der "Russischen Renaissance" - vertreten von Močul'skij und Stepun - steht das Urteil Poggiolis von der "Kultur der Negation", die geistig gescheitert aber formal brillant formuliert sei, gegenüber. Eine Mittelstellung nimmt die psychologisch akzentuierte, aber leider auch reduzierte Auffassung vom Symbolismus als "symbolistischer Mentalität" ein, vertreten in der Nachfolge Chodasevičs von Maslenikov und Cioran. Die beiden russischen Kulturphilosophen Stepun und Močul'skij betrachten Belyj als Denker der modernen Kulturkrise, als "Seismograph" und Versuch einer Gegenreaktion. Als solchen Versuch beurteilen sie Belyjs Kunsttheorie, deren Doppelcharakter sie als Gesamtheit zu verstehen vermögen, als inneren Zusammenhang zwischen Ästhetik und Poetik, den sie als moderne Weiterführung der ethisch-ästhetischen Tradition des neunzehnten Jahrhunderts positiv beurteilen. Denn als Ziel der geistig-künstlerischen Befreiungsbewegung der Jahrhundertwende sehen die beiden Russen - in Anlehnung an Solov'ev und Berdjaev - die Schaffung einer neven Kultur an, die auf der Freiheit einer religiös gebundenen aber selbständig schöpferischen Personalität basieren sollte. ${ }^{44)}$ An diesem Ziel gemessen, wird Belyjs Ästhetik von ihnen als originärer Beitrag zur Erneuerung der Kultur in den folgenden vier Hinsichten anerkannt:

a) In der ästhetischen Erfahrung der Moderne bleibt bei Belyj trotz der Bedrohtheit vom "Nicht-Sein" der Epoche die "religiöse" Dimension bewahrt bzw. wird neu gewonnen - ohne daß damit die Autonomie der Kunst aufgegeben würde.

b) Der Einbruch des Nihilismus wird theoretisch keineswegs sanktioniert, sondern mit dem Versuch einer "Umwertung des ästhetisch-philosophischen Erbes" ${ }^{45)}$ unter der Setzung einer absoluten Wertverpflichtung bekämpft - bei vollem Respekt vor der Autonomie der Kunst.

c) Im engen und zwingenden Zusammenhang damit erhält Belyjs Kunstauffassung eine wirkungsästhetische Ausrichtung, die Rolle des Rezipienten wird aufgewertet; es wird riskiert, die avantgardistische Form als movens der Bewußtseinsveränderung zu erproben, im Glauben daran, daß die Wirklichkeit veränderbar sei über die "Verwandlung der Persönlichkeit".

d) Belyj erhebt die ästhetische Forderung an eine zukünftige Kunst, das Thema des Selbst mit radikalem künstlerischem Ernst in Angriff zu nehmen, trotz der Gefähr- 
dung, die die ungeschützte Aussetzung gegenüber dem eigenen Selbst in der Situation der Krise für den Künstler und für den ästhetischen Kanon mit sich bringt.

Diametral dazu steht die These Poggiolis. Während Stepun und Močul'skij den russischen Symbolismus als geistig-künstlerische Befreiungsbewegung aus der russischen Tradition deuten, die auch in den Stilformen der europäischen Moderne in Rußland fortgeführt worden sei, deutet Poggioli den russischen Symbolismus in den Beurteilungskategorien von Nihilismus, Dekadenz und Formbrillanz, wie sie in den fünfziger Jahren auf die westliche Moderne - die jedoch unter sehr anderen Voraussetzungen entstand - angewendet wurden, z. B. in H. Friedrichs "Struktur der modernen Lyrik" oder in Forschungen zum Werk Ernst Jüngers. Poggioli kann von einem sozio-psychologisch und geistes-geschichtlich begründeten Nemesis-Denken (Gewalt vs. Aufruhr; Pseudoreligion vs. Nihilismus) im russischen Symbolismus nur eine "Kultur der Negation" erblicken, eine russische Variante der europäischen nihilistischen Dekadenz. Denn Poggioli hält einen modernen Symbolismus überhaupt für ausgeschlossen, da der Moderne die religiöse Dimension ohnehin abhanden gekommen sei. Wo nur noch die Erfahrung des Nichts gemacht werden kann, führen pseudoreligiöse Bekenntnisse aber in die beiden Sackgassen des Irrationalismus oder des intellektualismus. Im Symbolismus als einer religiös-philosophisch ambitionierten Kunstrichtung kann er nur die "Allegorie des Scheiterns" sehen. Einzige Leistung der Kunst im Krisenzeitalter des Nihilismus ist nur noch ihre brillante Form. Belyj schätzt er daher hoch ein als Avantgardisten der Prosa ${ }^{46)}$ und als Theoretiker der Form. Sein kunstphilosophisches Denken fällt nicht ins Gewicht. Seine Symbollehre erscheint ihm inkonsistent, denn sie oszilliert zwischen einer intellektualistischen ("Ideen-Bilder") und einer irrationalistischen Version ("verbale Ikonen"), die statt auf Transzendentes auf die chaotische Psyche ihres vom Nihilismus zerrissenen Schöpfers verweisen. Ist Poggiolis Nihilismus-Dekadenz-These einerseits Gemeingut der Nachkriegsforschung zur westlichen Moderne, so ist sie andererseits die Extremfassung einer Dominante in der Kritik der englischschreibenden Slavisten in Amerika, die auf Chodasevičs Psychogramm des russischen Symbolismus zurückgeht: der psychologisch reduzierten Auffassung vom russischen Symbolismus als epochentypischer "Mentalität", die sich durch elitären Anspruch, Exzentrik und Ambivalenz auszeichnet. Die Weichen stellt hier V.F. Chodasevič. Aus dem Gesichtswinkel des neoklassizistischen Akmeismus beurteilt er den Symbolismus als konfliktbelastete, sozialpsychologische Erregungspsychose ("oderžimost"' um jeden Preis) mit ungewöhnlichem künstlerischem Formniveau. ${ }^{47)}$ Die genuin geistige und religös-philosophische Dimension des russischen Symbolismus bleibt quantité négligable (Poggioli) oder religiöse Obsession (Cioran). Dieser reduktionistischen Sicht sind - je anders akzentuiert - Maslenikov, Poggioli und Cioran verpflichtet. Maslenikov hält trotz des "notwendigen Scheiterns" der überspannten "symbolistischen Mentalität" ("frenzied poets") den Symbolismus für einen bedeutenden und gelungenen Kunststil der Moderne. Belyjs Bedeutung - abgesehen von seiner repräsentativen Teilhabe als "Pro- 
phet" an der "symbolistischen Mentalität" - reduziert er auf seine formalästhetische Leistung als Stilist und Formalist.

Die amerikanische These von "Fehlschlag und Erfolg" (failure and success), seit Maslenikov etabliert, von Poggioli mit seinem verkürzenden Dekadenz-Nihilismus-Konzept extrem modifiziert, wird extravagant religionspsychologisch zugespitzt von Cioran. Die mehrschichtige symbolistische "Mentalität" wird als "eschatologisch-apokalyptische" auf einen ihrer Grundzüge und auf die Denk- und Ausdruckskonventionen eines archetypischen Symbolsystems festgeschrieben. In der geistesgeschichtlichen Gesamtbeurteilung des russischen Symbolismus in der Belyjforschung stehen sich also die beiden Extreme "Russische Renaissance" vs. "Kultur der Negation" gegenüber; dazwischen die psychologische These von "Fehlschlag und Erfolg". Hier liegen offene literarhistor ische Probleme, die über die Belyjforschung hinausweisen.

\section{Zu 2) Gesichtspunkt der Entwicklung}

$\mathrm{Zu}$ den Verdiensten der geistesgeschichtlichen Richtung gehört die genetische Fragestellung, die aus den Antinomien der binaristischen Betrachtungsweise herausführt, da sie die Entwicklung im ästhetischen Denken Belyjs untersucht. Allgemeingut ist die Unterscheidung in zwei Phasen geworden: von $1902-1904$ und von 1906-1910. Auch hier scheiden sich die Geister. Innerhalb der Kulturphilosophie wird entweder die russische Tradition betont oder der deutsche Einfluß. Stepun und Močul'skij betonen in der ersten Phase den Einfluß der Theurgielehre Solov'evs, die zwar in ungelöster Spannung zum erkenntnistheoretischen Skeptizismus Kants verblieben sei, aber die Wirkung der Wertphilosophie Rickerts vorbereitet habe. Dagegen sieht J. Pflanzl - ohne Berücksichtigung der russischen Tradition - einen Bruch zwischen der einseitig von Schopenhaver bestimmten Frühphase des Ästhetizismus (was revisionsbedürftig ist, es fehlt Belyjs Schopenhauer-Auseinandersetzung, es fehlt der bedeutende Einfluß Nietzsches) und der wiederum einseitig von Rickert bestimmten zweiten Phase, die den Wiederanschluß der Kunst an das Kulturganze bringe (hier fehlt die besondere Auffassung Belyjs von der Notwendigkeit eines entwickelten Individualismus als Voraussetzung für die Erneuerung der Kultur). Einig sind sich die Kulturphilosophen in der Beurteilung der zweiten Phase über den inneren Zusammenhang zwischen der philosophischen Neubegründung des Symbolismus aus der Wertphilosophie mit der parallel sich anbahnenden eigenständigen Ästhetik ("Kulturarbeit" auf der Basis des schöpferischen Bewußtseins). Auch die amerikanische Kritik trifft die Unterscheidung in beide Phasen, differiert aber in ihrer Beurteilung: Poggioli und Cioran erkennen eine platonisch-ideelle und eine emotional-chaotische Tendenz nacheinander in ihnen, die nicht zum Ausgleich gekommen seien. Maslenikov sieht dagegen eine Frühphase "eschatologischer Naherwartung" abgelöst von einer Spätphase der Resignation auf das "Fernziel der Kulturarbeit", zu der als Beitrag nur ein neuer "Kunststil" geleistet wurde. ${ }^{48)}$ Alle drei beurteilen aufgrund dieser Widersprüche Belyjs Theorie als "hybrid", kaschiert nihilistisch oder "apokalyptisch" und geben den Primat seiner formalästhe tischen Bedeutunga from PubFactory at 01/10/2019 05:16:17AM 


\section{Zu 3) Person Belyjs und psychologische Bedingungen seines Denkens.}

Sehen die "Russen" trotz seiner psychischen Gefährdung und seines ontologischen Seinsmangels in Belyj ein "unerhörtes geistiges Ereignis", ohne das die Epoche um einen Bewußtheits- und Ausdrucksgrad ärmer gewesen wäre, so reduzieren die "Amerikaner" sein Denken auf die verzichtbare Pseudophilosophie eines unsteten Suchers, nihilismusbedrohten Sonderlings und "Apokalyptikers". In der Optik Chodasevičs und Erlichs sehen sie in Belyj den Extremfall der "symbolistischen Dimension", der aber mit erstaunlicher Formbravour die russische Literatur ins zwanzigste 3ahrhundert hineinstie $\beta$ und als Theoretiker dem Formalismus Bahn brach.

\section{Zu 4) Theorie und Dichtung}

Wo die "Russen" eine Diskrepanz von ästhetischem "Sollen" und nicht adäquater dichterischer Realisierung - vor allem thematisch - vermerken, sehen die "Amerikaner" in Belyjs Dichtung - obwohl sich in ihr nur die chaotische Psyche des Dichters spiegele durch stilistisches Niveau seine formalästhetischen Positionen als Theoretiker bestätigt. Mit ihrem psychologischen Ansatz kommen die "Amerikaner" zu ähnlich verkürzenden Schlüssen über Belyj wie die Formalisten der "strengen" Observanz. Beiden unverständlich ist die geistige Dimension im ästhetischen Denken Belyjs.

\section{Resultate und of fene Probleme}

Resümiert man die Konstanten und Divergenzen der Forschung zu Belyjs ästhetischer Theorie, so ergibt sich folgendes Bild:

An ihrem Doppelcharakter, dem die Grundspannung von Ästhetik und Poetik zugrunde liegt, die in der Situation der modernen Kultur-und Sprachkrise von Belyj existentiell erlebt, neu durchdacht und neu formuliert wird, kann inzwischen nicht mehr vorbeigesehen werden. Aus einer Synopse der formalistischen und geistesgeschichtlichen Forschungspositionen wird deutlich, daß es auf beiden Seiten Versuche gibt, den inneren Zusammenhängen von Kunstphilosophie und Kunstwissenschaft auf die Spur zu kommen, wobei man schon früh begonnen hat, auch die psychologischen und ontologischen Bedingungen seines Denkens zu beachten. Es zeigt sich aber auch, daß die vorgefaßte Gesamtsicht des jeweiligen Kritikers vom russischen Symbolismus ausschlaggebend für das Urteil über Belyjs Theorie ist. Insofern gehen einige der divergierenden Punkte der Belyjforschung über ihren Rahmen hinaus und erweisen sich als ungelöste Fragen der Forschung zum russischen Symbolismus als Epoche.

Innerhalb der Belyjforschung fällt auf, daß Kontroversen zwischen den beiden Hauptrichtungen nicht ausgetragen werden; die formästhetische und die geistesgeschichtliche Richtung laufen unverbunden nebeneinander her und nehmen in der Regel die Ergebnisse der jeweils anderen Richtung nicht zur Kenntnis. (Eine Ausnahme bildet die Ansicht der Formalisten von der einseitigen Bedeutung Belyjs als Stilist und Poetiker, die von Poggio- 
li und Maslenikov z. B. mit dem Urteil über das Scheitern des Symbolismus zur "Failureand-success"-These kontaminiert wird.)

$\mathrm{Zu}$ den offenen Problemen der Forschung zu Belyj und zum russischen Symbolismus, die überprüft werden müßten, gehören:

1) Die Dekadenz- und Nihilismus-These im Gegensatz zur "Russischen Renaissance".

2) Das Verhältnis der russischen philosophisch-ästhetischen Tradition (Kunstlehre Solov'evs) zur konkurrierenden bzw. komplementären Einwirkung der deutschen Philosophie (Belyjs Auseinandersetzung mit Schopenhauer und Nietzsche; mit Kant und dem Neukantianismus).

3) Die psychologische These vom russischen Symbolismus als "symbolistischer Mentalität" (Gruppenpsychose vs. künstlerische Bewegung mit weltanschaulichen und stilistischen Neuentwürfen; das anthropologische Problem des "Künstler-Menschen" in der Kulturkrise der Moderne).

4) Das Verhälthis von außerkünstlerischen Ideen und Werten (Weltanschauung) zur poetischen Sprache, die in der Sprachkrise der Moderne ihrer selbst bewußt geworden ist. (Relevanz der Opposition von "Mythos" und "Logos"; Problem der "Umwertung" und seine Auswirkungen auf die Aussageformen der modernen Dichtung und Dich tungstheorie.)

5) Neue Denk- und Sprachformen in der Dichtungstheorie des russischen Symbolismus, insbesondere in der ästhetischen Theorie Belyjs (Unterscheidung verschiedener Diskursebenen, Funktion des Kommentars zu "Symbolismus").

6) Symbolistische Dichtung im Verhältnis zu anderen Kunstformen (Musik und Malerei) der Moderne.

7) Der Bezug zwischen Autor und Leser im russischen Symbolismus. Die wirkungsästhetische Dimension in der Kunsttheorie Belyjs.

8) Die Entwicklung der Symbolauffassung im russischen Symbolismus innerhalb des ersten Jahrzehnts. Die Wirklichkeitsauffassung Belyjs und die Herausbildung verschiedener Symboltypen als Möglichkeiten einer postrealistischen "Methode der Symbolisierung". Thre Bedeutung im Kontext des Modernismus bzw. der Avantgarde.

\section{Fragestellung und Vorgehen der folgenden Untersuchungen}

Aus dem Katalog offener Fragen sollen einige Probleme ausgegliedert und im folgenden näher untersucht werden. Den Ausgangspunkt bildet die Beobachtung, daß Belyj als Dichter-Theoretiker, der gegen alte Ordnungen rebelliert, in besonderer Weise den Prototyp des poeta doctus verkörpert. Man kann diesen Dichtertypus als eine Erscheinung der Kulturkrise der Moderne deuten. Deshalb wird im Ersten Teil der Versuch gemacht, den Hintergrund der Kulturkrise um 1900 anhand von drei hervorgehobenen Krisentenden- 
zen deutlich zu machen, die nicht auf Rußland beschränkt sind: 1) Krise des Bewußtseins; 2) Krise der Sprache; 3) Krise der bürgerlichen Lebensformen.

Auf diese Weise soll Belyj (geboren 1880) nicht nur isoliert oder allein im russischen Kontext betrachtet, sondern in den Zusammenhang der vor hundert Jahren geborenen Dichtergeneration von 1880 eingeordnet werden, wobei sich einige Parallelen zu Rilke (geboren 1875) und Musil (geboren 1880) ziehen lassen. Wird also zunächst versucht, Belyj im übernationalen Maßstab unter komparatistischen Gesichtspunkten zu verstehen, so besteht der nächste Schritt der Annäherung darin, Belyj im Zusammenhang mit dem Wandel im Selbstverständnis der russischen Intelligenz der Jahrhundertwende zu verstehen, die von zwei großen Fragekomplexen bewegt wurde: 1) Wohin geht der Weg Rußlands, wohin der Weg der modernen Seele? 2) Welche Rolle spielt die Kunst in der Moderne? Ist sie ein neuer "Stil" oder ein neues "Weltverhältnis", das künstlerische und philosophische Fragen einschließt? In den Kontroversen zu beiden Leitfragen, die im Kreis um die "Welt der Kunst" bereits zu Beginn der symbolistischen Bewegung geführt wurden, zeichnet sich eine Weichenstellung für die Positionen im sogenannten Symbolistenstreit um 1910 ab. Beide Fragen führen u. a. zur Neudefinition des Leserbezuges und der Wirkungsweise von Dichtung im russischen Symbolismus. Im weiteren Verlauf des Ersten Teils geht es dann um Belyj selbst: seine eigenen, spezifischen Denkvoraussetzungen (Krisenbewußtsein, Nähe seines Denkens zur dichter ischen Praxis, Methodenbewußtsein als Naturwissenschaftler) und die besonderen Denk- und Sprachformen, die für Belyj als Kunst theoretiker typisch sind.

Im zweiten Teil sollen der besondere Charakter und einige Grundbegriffe der Kunsttheorie Belyjs herausgearbeitet werden. Zum Ausgangspunkt wird dabei die Auffassung Belyjs von der Wirklichkeit genommen, die in der modernen Kunst auf neue Weise dargestellt wird. Denn sie ist konstitutiv für die "Methode der Symbolisierung". Belyj hat als Angehöriger einer Generation, die sich sowohl mit dem Positivismus als auch mit dem Idealismus kritisch auseinandersetzte, eine mehrschichtige Auffassung von der Wirklichkeit. Verschärfend kommt im Falle Belyjs ein biografisches Moment hinzu: die prägende psychische Erfahrung von der Wirklichkeit als "Mangel". Die Unterscheidung verschiedener Schichten innerhalb der Wirklichkeit bei Belyj entsteht dadurch, daß er sie in verschiedenen Hinsichten betrachtet: Er wechselt zwischen verschiedenen "hypothetisch" eingenommenen Standpunkten, die jeweils andere Seiten der Wirklichkeit aufschließen. Vom erkenntnistheoretischen Standpunkt erscheint die Wirklichkeit als Bewußtseinszusammenhang, vom naturalistischen als energetischer Materialzusammenhang, von der inneren Erfahrung als erlebte Wirklichkeit, schließlich von einem wertorientierten Standpunkt aus als eine Wirklichkeit die nicht vorgegeben, sondern der Darstellung in der Kunst aufgegeben ist.

Entsprechend dem Wirklichkeitsbegriff entfaltet er seine Theorie von der Symbolisierung. Sie ist als Gegenbewegung zum Realismus des späten neunzehnten Jahrhunderts, 
genauer gesagt zum Naturalismus, zu verstehen. Kunst wird nicht mehr als Abbildung oder Widerspiegelung der Wirklichkeit aufgefaßt, sondern als Darstellung, der eine schöpferische Aneignung, Prismatisierung und Umarbeitung vorangeht. Die symbolische Konzeption der Darstellung ist nicht von Anfang an feststehend, sondern entwickelt sich im Laufe des ersten Jahrzehnts in Abhängigkeit von der Entfaltung der Wirklichkeitsauffassung. Belyj konzipiert verschiedene Symbol-Typen. Ein Dreischritt läßt sich erkennen: vom Symbol als "Modell zu Erfahrungen" bis zum Symbol als Erlebnismodell unter dem Gesichtspunkt der "Wertschöpfung".

Ein besonderes Problem Belyjs als Dichter-Theoretiker in der Umbruchsituation der modernen Kulturkrise ist sein Bedürfnis nach Rechtfertigung. Belyj verfolgt verschiedene Strategien der Legitimation: Sein Streben nach theoretischer Legitimation verwies ihn auf Zusammenhänge der künstlerischen Symbolisierung mit der Symbol- und Zeichentheorie in den modernen Wissenschaften und der Mathematik; die Suche nach existentieller Legitimation bei Vorbildern und Kronzeugen der Symbolisierung in der Kunst und Philosophie der Moderne ließen ihn die besondere Bedeutung von Ibsen und Nietzsche für den russischen Symbolismus erkennen.

Belyj kommt im Laufe seines kunst theoretischen Denkens zunehmend dazu, moderne Kunst nicht mehr im Rahmen der "Schönen Künste", sondern als Prototyp von Kreativität überhaupt zu verstehen. Das Thema des schöpferischen Bewußtseins steht deshalb nicht zufällig im Zentrum seines theoretischen Denkens. Belyj ist von Anfang an - unbeschadet seines positivistischen Ethos der methodischen Exaktheit - ein entschiedener Vertreter des Bewußtseinsidealismus und erhebt von Anfang an die "Energie" des schöpferischen Bewußtseins in den Rang einer höchsten ästhetischen Instanz (bereits in "Formy" (1902), S. 150, bis zu Embl. (1910), S. 70, Komm. 457 - 59). Das ist eine zwar variierte, aber nie fehlende Konstante seines ästhetischen Denkens.

Vor der Kreativitätsforderung an den Künstler ist auch die wirkungsästhetische Dimension seiner Kunst theorie bestimmt. Die Dominante seiner Einstellung zum Leser, dem aufgrund des Bewußtseinsidealismus ebenfalls potentielle Kreativität zuerkannt wird, besteht in der Forderung nach "Verwandlung der Persönlichkeit", die sich steigert bis zur Uberzeugung, daß die Kunst beitragen müsse zu einer "Revolution des Geistes", die er der sozialen Revolution gegenüber für vorrangig hielt. Die wirkungsästhetische Dimension wird gegen Ende der Arbeit untersucht. Ihren Abschluß bildet der Versuch, aus Belyjs ästhetischen Schriften des ersten Jahrzehnts ein "Modell des kreativen Prozesses" in drei Phasen herauszufiltern, in dem seine wichtigsten Aussagen zu den drei Hauptgebieten der Ästhetik: zur "Produktions-", zur Werk- und zur Wirkungsästhetik zusammengefügt werden. In einer "wachsenden" Grafik soll verdeutlicht werden, was vorher im Text dargelegt wurde; das kann sicher ohne eine gewisse Vereinfachung nicht getan werden, die aber um der Ubersichtlichkeit willen in Kauf genommen wird. 
Vielleicht kann durch die hier vorgelegten Studien zu Belyjs ästhetischer Theorie das geläufige Urteil über Belyj, in dem er meist als undurchsichtiger und konfuser Denker erscheint, dahingehend modifiziert werden, daß sich in seinem komplizierten und oft sprunghaften Denken ein roter Faden erkennen läßt. Doch nicht nur das. Mit den folgenden Untersuchungen soll versucht werden, darüber noch einen Schritt hinauszugehen. Denn im Verlauf der Auseinandersetzung mit Belyjs Denken war bei allen Ab- und Umwegen eine Zielvorstellung leitend: Daß nämlich Belyj zu jenen Vertretern eines experimentierenden, prozeßhaf ten und offenen Denkens zu rechnen ist - zu erinnern wäre hier etwa an Shaftesbury oder Herder, an Nietzsche oder Lev Sestov - die am Maßstab des Systemdenkens mit stringenter Argumentation in geschlossenen, architsktonischen Denkgebäuden nicht zu messen sind. Das vor allem deshalb nicht, weil es sich bei Belyj um einen Denkprozeß handelt, der in ständiger Bewegung und sehr wechselnden Tempi vor sich geht. Zu dieser Dynamik gehören hypothetische, sich selbst erprobende Denkkonzepte ebenso wie polemische Ubersteigerung; metaphorische Verdichtung aus besonders intensivem Engagement heraus ebenso wie der distanzierte wissenschaftliche Diskurs des exakten Analytikers, der sich der grafischen Darstellung in Diagrammen oder mathematischer Formeln und Zeichen bedient. Will man eine Anleihe bei der linguistischen oder psychoanalytischen Terminologie machen, so kann man es auch so sagen: Belyjs Denken bietet dem Leser eine Oberflächenstruktur, deren verwirrende Vielgliedrigkeit und anscheinende Widersprüchlichkeit nicht leicht vermuten läßt, daß unter ihr eine Tiefenstruktur existiert, die in sich geordnet und schlüssig ist, die bestimmte Konstanten und Variablen enthält. Die innere Ordnung und Stimmigkeit im Denken Belyjs ans Licht zu heben, darum soll es in den folgenden Uberlegungen gehen. Sie verstehen sich nicht zuletzt als einen Beitrag dazu, die innere Konsistenz in der eigenwilligen Denkbewegung eines organischen Denkers herauszufiltern. 


\section{KA P I T E L}

\section{DER POETA DOCTUS ALS DICHTERTYPUS DER MODERNEN KULTURKRISE}

\section{DER POETA DOCTUS IN DER MODERNE}

\section{Modellfall der reflektier ten Kreativität}

Der Dichtertypus des poeta doctus bildet mit seinem Gegenpart, dem naturtalentierten Originalgenie oder dem quasigeheiligten vates, ein traditionelles Gegensatzpaar der europäischen Dichtungsgeschichte. Begabt mit einem höher gesteigerten Reflexionsgrad und einem breiter gespannten Wissenshorizont sind ihm auch die Probleme des künstlerischen Schaffens in der Regel schärfer bewußt als seinem naiveren Dichter-Bruder. " Auf Höhepunkten literarischer Bewegungen kam es traditionell zu spannungsreichen, doch fruchtbaren Konstellationen solcher polaren Paare, die zeitweise auch miteinander befreundet sein konnten. Im deutschen Mittelalter figurierten derart Gottfried und Wolfram, im elisabethanischen England Milton - "the poets' poet" - und Shakespeare, in der deutschen Klassik Schiller und Goethe, im russischen Symbolismus Belyj und Blok, die in einer lebenslangen Haßliebe (družba-vražda) aufeinander bezogen blieben. ${ }^{2)}$

Um die Jahrhundertwende begegnet der Typus des Dichter-Theoretikers in bisher ungewohnter Häufigkeit. Der Zusammenhang von Dichtung und Kunstphilosophie in der Personalunion des poeta doctus, ein Grundzug der Literaturgeschichte seit Lessing, Schiller und der Frühromantik, tritt in der Moderne verstärkt hervor. Ist im klassischen Idealismus Schillers die ästhetische Reflexion noch gerichtet auf die Aura maßvoll umgrenzter, in sich vollendeter Schönheit, in der die Totalität des humanum erblickt wird in den Worten des späten Mörike: "Was aber schön ist, selig scheint es in ihm selbst"; wird dann in der Frühromantik, vor allem bei Schlegel und Novalis, von der schöpferischen Einbildungskraft die "progressive Universalpoesie" entworfen, in der die Ganzheit des Menschen dynamisch begriffen wird, als "innere Unendlichkeit", und in Analogie gesetzt zu einem Universum, das in ständigem Werden begriffen ist; kann sich also im umgreifenden Horizont des Idealismus der Künstler noch die Aufgabe stellen, "das offene Geheimnis des Universums zu lesen" (Carlyle) ${ }^{3)}$, so sind es an der Wende zum zwanzigsten Jahrhundert die akut verschärften Widersprüche der Moderne, der Zerfall von Ganzheit und Totalität, die die ästhetische Reflexion des poeta doctus in Garg setzen. Im Gegensatz zum klassisch-romantischen Künstler findet er sich vor in einer radikalen "Dissoziation der Interessen", in der ihm die Bestimmung seiner eigenen Position abverlangt wird, ohne daß er sie noch von einem verpflichtenden Deutungshorizont ver ableiten oder rechtfertigen könnte. ${ }^{4)}$ 
Auch Andrej Belyj gehört zu jenem Typus des reflektierenden Dichters der europäischen Avantgarde ${ }^{\text {) }}$ - wie ihn im frühen zwanzigsten Jahrhundert etwa in Österreich Robert Musil und Hugo von Hofmannsthal, in Deutschland Gottfried Benn und Thomas Mann, in England die Präraffaeliten und nach ihnen T.S. Eliot und Virginia Woolf, in Frankreich André Gide und Paul Valéry vertreten - der in zwei Richtungen produktiv ist: in seinem dichterischen Werk, aber auch in kritischen Essays über die geistige Situation der Zeit, vor allem über Ästhetik und Poetik - über Sinn und Formen der Kunst.

Einigen Aufschluß über die Erscheinung des poeta doctus in der Moderne gibt Walter Jens - kompetent, weil selbst eine Variante des beschriebenen Typus - in seinem literaturkritischen Querschnitt durch die Generation von 1880 "Statt einer Literaturgeschichte":

\begin{abstract}
"Der poeta doctus, Essayist und Dichter in einer Person, Erbe der Aufklärung, Nachfolger Lichtenbergs und Nietzsches, ein Freund der taciteischen Prägnanz, ist Analytiker und Forscher, sachkundiger Interpret und, wie $M$. Teste, Beherrscher eines Labors von unermeßlicher Größe. Als ein Mann, der, nach Gide, den 'Dichter' durch den 'Künstler' ersetzt hat, liebt er das Experiment, sucht - die Juristen Kandinskij und Kafka! - überall Ordnungsprinzipien und 'gestaltet nur das Typische' (Brecht), als Fachmann und Spezialist (...) verehrt er wissenschaftliche Strenge, preist die Exaktheit des Handwerks, bewundert die Präzision des Artisten, haßt Zauberei und das Vage der Psychologie - 'scharf denken kann man immer' (Musil) - und sucht, gleich Valéry, in allem jenes Kalkül, das sich in der Struktur der griechischen Tragödie, aber auch in der stichomythischen Selbstbeschränkung des Hemingwayschen Dialogs, in den 'Programmpunkten' Pindars, aber auch in der Gliederung einer Bennschen Periode spiegelt. Zugleich jedoch verliert gerade der poeta doctus die romantische These einer wechselseitigen Durchdringung von Phantasie und Denkk f $^{\mathrm{f} t}$, Wissenschaft und Märchen, Wachsamkeit und Träumerei nie aus den Augen."
\end{abstract}

Der poeta doctus erscheint hier nicht nur als ein besonders gebildeter oder technisch versierter Dichtertypus, sondern als der nicht spezialisierte Modellfall der reflektierten Kreativität, der zwei Grundbedingungen des Schöpferischen erfüllt: Er ist sowohl fähig zur rationalen Anspannung aller Kräfte des Wissens, Machens und Ordnens, aber auch offen für die Entspanntheit und Hingabe an Irrationales: an Traumhaftes, Nichtmachbares, Wunderbares; aus der Existenzform des homo faber vermag er in die des homo ludens hinüberzugleiten. In diesem Sinne ist wohl Gides Wort, der "Dichter" werde vom "Künstler" ersetzt, zu verstehen. Insofern als bei ihm die Wände zwischen Bewußtheit und den dunklen Räumen der Seele durchlässig sind, kann er als Einlösung der "romantischen These einer wechselseitigen Durchdringung" beider Pole gelten.

Richtet man nun den Blick auf Rußland, so trifft er um die Jahrhundertwende auf ein Panorama sehr verschiedener Dichtertypen: Könnte man in Aleksandr Blok den tragischen "ordre du coeur" des modernen Künstler-Menschen sehen, in Valerij Brjusov den Organisator und poetischen Baumeister der Form, in VjaCeslav Ivanov den spiritus rector jenes Silbernen Zeitalters der russischen Dichtung, so verkörpert Andrej Belyj in besonderer Weise den Typus des modernen Dichter-Theoretikers, den poeta doctus des $_{2}$ russi- 
schen Symbolismus. Seit seinem literarischen Debüt als Dichter experimenteller Wortsymphonien und dem ersten Entwurf zu einer Ästhetik in "Formen der Kunst" (beide 1902), seit seinem ersten kulturkritischen Angriff in dem "Offenen Brief an die Konservativen und Liberalen" und dem symbolistischen Manifest "Von der Theurgie" (beide 1903) - seit Begim also seines öffentlichen Hervortretens als Literat unter dem Pseudonym Andrej Belyj, hat er in zahlreichen Aufsätzen Beiträge zu einer "Ästhetik neuen Typus" veröffentlicht, die er in den Sammelbänden "Symbolismus" und "Grüne Wiese" (beide 1910), "Arabesken" (1911) zusammenfaßte, von denen der erste den Charakter einer Programmschrift des russischen Symbolismus trägt. Ergänzend ist hier anzumerken, daß Ivanov sicher in einem traditionellen Sinne gleichfalls als poeta doctus bezeichnet werden muß. "Vjačeslav-Mudryj" - wie er im Bǎ̌nja-Kreis nur hieß - ist als klassischer Philologe, Philosoph, Kunsttheoretiker und Ubersetzer vielleicht die größere Potenz, sicher aber der gründlichere und systematischere Denker. Worin ihm Belyj überlegen ist, sind Originalität und Spontaneität des Denkens. ${ }^{7)}$ F. Stepun, Zeitgenosse und scharfsichtiger Kritiker Belyjs, beschreibt anläßlich des Erscheinens von "Simvolizm" im Jahre 1910 seine Eigenart als poeta doctus folgendermaßen:

"Eigentümlich verdoppelt sich beim Lesen die Gestalt des Dichter-Denkers. Gewissermaßen ein Prophet, der seigen Priestermantel abwirft und in den Arbeitskittel des Laboranten schlüpft."

Stepun bringt hier etwas spezifisch Modernes an Belyjs Variante des poeta doctus zur Sprache: nämlich seine Teilhabe an den "beiden Kulturen" der Neuzeit, an der szientistisch-experimentellen und an der traditionell-geisteswissenschaftlichen. ${ }^{9)}$ Belyj ist auf der einen Seite der liberal-rationalistische, szientistische Zögling des fortschrittsgläubigen und positivistischen neunzehnten Jahrhunderts, auf der anderen Seite Mystiker und geschichtsphilosophischer Prophet des "zusammenbrechenden Humanismus" (Blok) und der kommenden Revolution, in der das Gebäude der alten Kultur einstürzt. Ist die Doppelheit von Vision und Experiment, die Stepun als Kern der Belyjschen Eigenart herausschält, nun einerseits ein spezifisch moderner Zug des poeta doctus, was auch W. Jens zeigt, so erinnert sie gleichzeitig an die Koexistenz von Forscher und Seher, wie sie der mittelalterliche Alchimist vor der Trennung von Wissenschaft und Metaphysik in sich vereinigte. Stepun schreibt weiter über Belyjs Denk - und Sprachform:

"Ist er nicht ein Alchimist? Und tatsächlich, das ganze Gebäude des zu untersuchenden Buches "Simvolizm" ist gleichsam umweht vom Geist des Mittelalters, aber aufgeführt auf einem grundverschiedenen Fundament. Das Fundament, um das es hier geht, ist tief eingesenkt in die Erde. Und es wäre schade, es zu sprengen. Wie von Blumen, die alles umwinden, ist es überwachsen und geschmückt von erstaunlichen Bildern und Vergleichen des Dichters; wie von Morgenfau, wehmütig-neblig, ist es benetzt von einem unvergleichlichen Lyrismus." 


\title{
2. Spannweite und existentielle Belastungsprobe am Beispiel Belyjs
}

Die Situation des modernen poeta doctus kann nicht nur idealtypisch als "Alchimie" oder als Einlösung der "romantischen These einer wechselseitigen Durchdringung" verstanden werden; man muß sich auch fragen, was diese Spannweite existentiell für den Dichter bedeutet: woher er sie aufbringen, wie er sie aushalten und rechtfertigen kann. Für Belyj hatte sie in der Realität nicht das idealtypische Gepräge einer überlegenen Synthese, sondern war mit dem vollen Druck des Außenseiters belastet, der sich auf eine solche "Schere" einläßt und sich dafür vor seiner Zeit rechtfertigen muß."

Diese existentielle Belastungsprobe wird von W. Jens nicht einbezogen. Wer sich aber in der Moderne auf die Vermittlung von szientistischem Experiment und Vision einläßt, gerät leicht unter Pathologieverdacht und kann schnell an die Grenze des Wahnsinns kommen. Belyj erfuhr an sich selbst sehr scharf die Anspannung und Gefahr solcher Pläne, die von der institutionalisierten Universitätswissenschaft seiner Zeit als Fantasterei, von der bildungsbürgerlichen Gesellschaft als dekadente Provokation angesehen wurde:

\begin{abstract}
"Meine Lage schien auswegslos, wenn man sie von außen betrachtete; mit der rechten Hand schrieb ich die 'Symphonie' [gemeint ist die dritte, 'Die Rückkehr' (Vozvrat)], wo der Laborant Chandrikov den Verstand verliert wegen des Lebens im Labor; mit der linken aber - wog ich auf der Waage das Granulat ab, das zu analysieren war, wobei ich mich in eben dem Laboratorium befand, das ich als Irrenhaus beschrieb." (Nrds 403)
\end{abstract}

Stepuns Urteil, daß Belyj als Dichter der Kulturkrise ein "wurzelloser" Intellektueller gewesen sei und letztlich nur imstande, aus Mangel an einfachem menschlichem Sein, das "Nichtsein" der Epoche wie eine in sich abgeschlossene Monade widerzuspiegeln, muß vor dem realen Hintergrund der Zeitsituation und in Anbetracht des Legitimationsdruckes neu überdacht werden. In welchem "historisch gewordenen Sein" Rußlands sollte ein Künstler von der Wahrnehmungsschärfe und dem Krisenbewußtsein Belyjs verwurzelt sein? ${ }^{12)}$

Eine tiefere Einsicht in das Wesen des nachnietzscheschen Typus des Krisenmenschen, der sein Sein als Ausnahmezustand erfährt, hat Karl Jaspers. Was er über die beiden Prototypen des modernen Krisendenkers, Kierkegaard und Nietzsche sagt, daß nämlich ihr Selbstbewußtsein bestimmt sei vom psychologischen Wissen um ihr "menschliches Mißratensein", hat auch Geltung für Belyj:

"Das Erstaunliche ist ihnen dann wieder, daß gerade die Weise ihres Mißratenseins selbst die Bedingung ihrer eigentümlichen Größe ist. Denn diese ist ihnen nicht Größe schlechyhin, sondern eine einmalige, der Situation des Zeitalters eigen zugehörige."

Wenn hier von Größe die Rede ist, dann muß man sie wohl vor allem darauf beziehen, daß ein beachtliches $M a ß$ an Durchhaltevermögen und eigenem, wenngleich sehr 
von der Norm abweichendem Alternativ-"Sein" für die unlegitimierte Existenzform des "Modernen" - im Sinne des Unzeitgemäßen - notwendig war.

\section{KRISENTENDENZEN DER KULTURKRISE UM 1990}

\section{Krise des BewuBtseins.}

Rilke, Musil, Belyj und der "Probemensch" der Kulturkrise

Die Erscheinung des poeta doctus in Rußland ist sicher wesentlich von der nationalen Kunst- und Gesellschaftsszene der Moskau-Petersburger Vorkriegskultur her zu verstehen. Dennoch steht sie - wie sich inzwischen gezeigt hat - in engem Zusammenhang mit dem europäischen Kontext der modernen Kulturkrise. Deshalb soll hier nicht direkt auf Belyj zugesteuert werden, sondern eine Annäherung in konzentrischen Kreisen versucht werden. Das ermöglicht zum einen, ihn in den europäischen Kontext einzuordnen, in dem er heute selbst einem gebildeten Lesepublikum noch weitgehend ein Unbekannter geblieben ist; das ermöglicht aber auch, Kategorien zu einer kritischen Beurteilung zu gewinnen, was durch den Vergleich mit Zeitgenossen vorbereitet werden könnte.

Wenn hier von Krise der Kultur um 1900 gesprochen wird, so geschieht das durchaus im Bewußtsein dessen, daß damit ein Begriff ins Spiel gebracht und ein Problemfeld betreten wird, die den Rahmen dieser Arbeit übergreifen. Eine systematische Untersuchung, etwa vergleichbar Paul Hazards "Krise des europäischen Geistes", an der man sich orientieren könnte, gibt es zu Krisenphänomenen der Jahrhundertwende bislang nicht. Es kann auch im folgenden nicht darum gehen, den Begriff der Kulturkrise in einem strukturellen Sinne zu verwenden, wie das etwa von R. Koselleck in seiner Schrift "Kritik und Krise" für das Zeitalter der Aufklärung versucht wurde oder in J. Burckhardts "Weltgeschichtliche Betrachtungen" für das ausgehende 19. Jahrhundert. Es kann auch nicht auf die sehr schwierige Abgrenzung von "Krise" und Veränderung oder historischem Wandel eingegangen werden, wenngleich das nicht nur notwendig, sondern auch sehr lohnend wäre. Es läßt sich aber trotz aller Einschränkungen, die gemacht werden müssen, nicht übersehen, daß um die Jahrhundertwende sich bei den verschiedenen Denkern und Dichtern ein $\underline{K}$ risenbewußtsein mehr oder weniger deutlich artikuliert, dem im folgenden Rechnung getragen werden soll. Daß daneben auch andere Züge der geistigen Situation berücksichtigt werden müßten, die einer einseitig am Krisenbegriff orientierten Beurteilung entgegenstehen, ist nicht zu bestreiten.

Vor allem in Rußland zeichnet sich die geistige Situation durch eine besondere Zuspitzung von Krisenerfahrung und Krisenbewußtsein aus. Daß das in Rußland so ist, hat verschiedene Ursachen (cf. dazu S. 57 ff.). Hier seien nur zwei erwähnt: einmal die antagonistische Gesellschaftsstruktur, zum anderen die von ihr mitbedingte umfassendere Rolle der Literatur als eines Forums, auf dem nicht nur künstlerische, sondern auch 
politische, moralphilosophische und gesellschaftskritische Funktionen wahrzunehmen waren. Hinzu kommt, daß sich die Literatur noch immer des Druckes der Zensur zu erwehren hatte, was ihr nicht immer gelang.

Wenngleich von der geistigen Situation Rußlands, die vom Bewußtsein der Krise geprägt ist, nicht ohne weiteres auf Westeuropa zu schließen ist, so lassen sich doch auch im Westen Krisenphänomene und Krisenbewußtsein feststellen, wenn auch in sehr anderer Gewichtung. Wenn also im weiteren von Krise der Kultur die Rede ist, so ist das nicht im Sinne einer feststehenden Definition gemeint, sondern eher als ein Suchbegriff oder als heuristischer Leitterminus, der es erlaubt, Krisentendenzen hervorzuheben, die noch genaver analysiert werden müßten, als das hier geschehen kann. Sie sollen aber zunächst einmal benannt und im Umriß dargestellt werden, ohne daß damit der Anspruch erhoben würde, Repräsentatives in einem generellen Sinne zu den genannten und miteinander in Beziehung gesetzten Denkern und Künstlern zu sagen. Es kann sich nur um Beobachtungen handeln, die jeweils nur einen Ausschnitt erfassen. Will man also mit diesen Einschränkungen den Begriff der Kulturkrise beibehalten, so kann man sagen, daß sie einen breiten Fächer von Krisenphänomenen umfaßt. Hier soll nur auf einige ins Auge fallende Krisentendenzen eingegangen werden, vor allem auf die Krise des Bewußtseins, die mit ihr verbundene Krise der Sprache und Krise der bürgerlichen Lebensformen.

In einem Zeitalter der unaufhaltsamen Explosion wirtschaftlicher und machtpolitischer Prozesse, denen die traditionalistischen, staatlichen Führungseliten mit zwiespältigen Wünschen begegneten: nach Teilhabe am neuen Reichtum oder dem Griff nach der Weltmacht und - damit unvereinbar - nach Konservierung ihrer starren Hausmachtsysteme; ${ }^{14)}$ in einer Zeit des Sozialdarwinismus, dessen rücksichtslose common-senseMaximen von Selbstbehauptung und Glücksstreben zu den tradierten Werten des europäischen, christlich geprägten Geistes in immer größere Diskrepanzen gerieten, denen die bürgerliche Moral ebenfalls zwiespältig begegnete: mit dem praktizierten Recht des Stärkeren, der Gehorsamsforderung an den Schwächeren und - damit unvereinbar - mit dem Appell an die innere Stimme des Gewissens; ${ }^{15)}$ in einer Blüte der zu Macht und Fortschritt unbedingt erforderlichen Technik und Wissenschaften, die das Ethos der rationalen Kontrolle und Denkökonomie verabsolutieren wollten; ${ }^{16)}$ in einem Umbruch der künstlerischen Formen, die die Aura klassischer Vollendung abstreifen und der Gesellschaft entweder die glänzende Fassade der Salonkunst und der "großen Oper" liefern oder aber sich und ihr die unwiderbringlichen Opfer der Rationalisierung vorhalten $^{17)}$ - innerhalb dieses dynamischen Krisenzeitalters der verschärften äußeren Widersprüche, deren innere Antagonismen man mit Kompromissen zu steuern suchte, kam es von verschiedenen Seiten zu kulturkritischen Äußerungen, die ihr Zeitalter in Frage stellten; erinnert sei hier noch einmal an J. Burckhardt, an Wagners Kulturkritik in seinen theoretischen Schriften (cf. unten S. 73), an Ibsens kritische Dramatik, um nur einiges herauszugreifen. Besondere Bedeutung kommt in diesem Zusammenhang Friedrich 
Nietzsche zu, der als Philosoph des Lebens und des Menschen die Tatsache einer veränderten modernen Welt als radikale Herausforderung annahm und den riskanten Versuch einer "Umwertung aller Werte" zum geistigen Programm der Epoche erklärte; schon im Frühwerk, am schärfsten formuliert aber in der Sprache des späten Nietzsche, in "Ecce homo":

"Umwertung aller Werte: Das ist meine Formel für einen Akt höchster Selbsthostimmung der Menschheit, der in mir Fleisch und Genie geworden ist..."

Diese Aufgabe, in der Nietzsche das Revisionsbedürfnis der Kulturkritik des neunzehnten Jahrhunderts auf die philosophische Formel gebracht hatte, wurde nicht von ihm allein gesehen, sondern auch unter den Künstlern der Jahrhundertwende setzte, teilweise unter seinem Einfluß, aber auch unabhängig von ihm - es geht hier um analoge, nicht etwa kausale Zusammenhänge - eine Neubesinnung auf ihr Selbstverständnis und auf die Rolle der Kunst für eine Erneuerung der Gesamtkultur ein.

Die Generation der um 1880 Geborenen, der auch Belyj angehört, sah - soweit sie nicht verschreckt zu alten Glaubenssätzen zurückkehrte - drei Auswege offen: den Aufbruch in neue künstliche Paradiese, den linken Marsch in die materialistische Sozialethik des Sozialismus und Marxismus oder aber die schöpferische Transformierung der überkommenen idealistischen und religiösen Werte in einem gewagten, langwierigen und offenen Prozeß der Selbst - und Welterfahrung, die zu einer neuen "Auslegung" der Welt und des eigenen Ich führte. ${ }^{19)}$ Unter denjenigen, die sich der Mühe des dritten Weges unterzogen, gab es nicht wenige, die bald erkannten, daß die geistige Verfassung des modernen Bewußtseins in keiner geringeren Krise steckte als die Gesamtkultur. Wiederum war es Nietzsche, der schon in seinem Frühwerk "Die Geburt der Tragödie" (1872) so etwas wie den Urtext der Bewußtseinskrise sprach. ${ }^{20)}$ Als Wurzel der Kulturkrise legte er die dominierende Fehlhaltung des modernen ultrarationalen und einseitig zweckorientierten Bewußtseins frei, das Dilemma eines Rationalismus, der alle Energien auf Logik, Kritik und Organisation verwendet, vor dem Leben selbst aber zurückscheut:

"Das ist ja das Merkmal jenes 'Bruches', von dem jedermann als von dem Urleiden der modernen Kultur $z u$ reden pflegt, daß der theoretische Mensch vor seinen Konsequenzen erschrickt und unbefriedigt es nicht mehr wagt, sich dem furchtbaren Eisstrome des Daseins anzuvertrauen: Ängstlich läuft er am Ufer auf und ab. Er will nichts mehr ganz haben, ganz auch mit aller der natürlichen Grausamkeit der Dinge. Soweit hat ihn das optimistische Betrachten verzärtelt. Dazu fühlt er, wie eine Kultur, die auf dem Prinzip der Wissenschaft aufgebaut ist, zugrunde gehen muß, wenn sie anfängt, unlogisch zu werden, d. h. vor ihren Konsequenzen zurückzufliehen. Unsere Kunst offenbart diese allgemeine Not: umsonst, daß man sich an alle großen produktiven Perioden und Namen imitatorisch anlehnt, umsonst, daß man die ganze "Weltliteratur" zum Troste des modernen Menschen um ihn versammelt und ihn mitten unter die Kunststile und Künstler aller Zeiten hinstellt, damit er ihnen, wie Adam den Tieren, einen Namen gebe: er bleibt doch der ewig Hungernde, der "Kritiker" ohne Lust und 
Kraft, der alexandrinische Mensch, der im Grunde Bibliqt\}ekar und Korrektor ist und an Bücherstaub und Druckfehlern elend erblindet.

Die fortschreitende Verhirnung des "theoretischen" Menschen, dessen logische Effizienz und utilitaristische Glückserwartung den Fortschritt der modernen Zivilisation erst möglich gemacht hatten, wurde von ihm als gefahrvolle Reduktion der menschlichen Möglichkeiten decouvriert, die ihn veranlaßte, das Ende des "sokratischen Optimismus" zu fordern und zu seiner Uberwindung die Anstrengung einer modernen Anthropologie und neuen "Weltauslegung" zu unternehmen. 22 )

Es gibt in der nachnietzscheschen Generation mehrere große Versuche, dichterisch auf Phänomene der Kulturkrise zu reagieren. Man kann sagen, daß auf der Suche nach Lösungswegen ein neuer anthropologischer Typus des modernen Romanhelden entstand: der "Probemensch" der Kulturkrise. 23)

Wie ein solcher Mensch aussieht, der sich der Mühe des dritten Weges tatsächlich unterziehen will, zeigt z. B. R. M. Rilke, der ebenso wie Belyj der nachnietzscheschen Generation von 1880 angehört, am Paradigma des heimatlosen Künstlers, an Malte Laurids Brigge. ${ }^{24)}$ Mitten in Paris, der anonymen "Hauptstadt des neunzehnten Jahrhunderts" (Benjamin) sieht er sich gezwungen, "sehen zu lernen". Was dabei in Blickfeld und Hörweite eindringt, sind Phänomene der Großstadtzivilisation: "Elektrische Bahnen rasen läutend durch meine Stube. Automobile gehen über mich hin." Die Aggressivität des Verkehrs erlebt er ebenso bedrohlich wie die Pathologie des Großstadtelends. Die Innenseite eines halbabgerissenen Hauses, der Ausschlag auf der Haut eines Kindes liegen bloß vor seinen Augen, der Veitstanz eines Epileptikers und die Elektroschocks in der Salpetrière verfolgen ihn. Seine Angst zwingt ihn in die Kommunikation des genauen Hinsehens und in die Offenheit der Reflexion. Mit allen Anzeichen des Entsetzens wird ihm klar, daß er mit seiner Existenz auf dem kritischen Nullpunkt der Moderne steht und ihm eine Veränderung von bisher nicht gekannten Ausmaßen bevorsteht:

"Ich sitze hier und bin nichts. Und dennoch, dieses Nichts fängt an zu denken und denkt fünf Treppen hoch, an einem grauen Pariser Nachmittag diesen Gedanken:

'Ist es möglich, denkt es, daß man noch nichts Wirkliches und Wichtiges gesehen hat? Ist es möglich, daß man Jahrtausende Zeit gehabt hat, zu schauen, nachzudenken und aufzuzeichnen, und daß man die Jahrtausende hat vergehen lassen wie eine Schulpause, in der man sein Butterbrot ißt und einen Apfel?

Ja, es ist möglich.

Ist es möglich, daß man trotz Erfindungen und Fortschritt, trotz Kultur, Religion und Weltweisheit an der Oberfläche des Lebens geblieben ist?"

In einem siebenstufigen Fragerhythmus stellt Malte die alte Auslegung der Kultur infrage, um zu dem Schluß zu kommen, daß es trotz seiner anonymen Bedeutungslosigkeit für ihn angesichts dessen hier kein Ausweichen gibt, daß er es ist, der sich der Krise, die er erkannt hat, stellen muß: 
"Wenn aber dieses alles möglich ist, auch nur einen Schein von Möglichkeit hat - dann muß ja, um alles in der Welt, etwas geschehen. Der Nächstbeste, der, welcher diesen beunruhigenden Gedanken gehabt hat, muß anfangen, etwas von dem Versäumten zu tun (...) : Ja er wird schreiben müssen, das wird das Ende sein."

Wohin ihn dieses Schreiben führen wird, bleibt lange unklar, bis es ihm aufgeht:

"Die Zeit der anderen Auslegung wird anbrechen, und es wird kein Wort auf dem anderen bleiben, und jeder Sinn wird wie Wolken sich auflösen und wie Wasser niedergehen(...) Aber diesmal werde ich geschrieben werden. Ich bin der Eindruck, der sich verwandeln wird."

Daß die "andere Auslegung" keine Leistung des "theoretischen Menschen" mehr sein kann und darf, sondern nur in einem Prozeß des "Sehen-Lernens" und der verwandelten Selbsterfahrung geschehen kann - "Aber diesmal werde ich geschrieben werden" - das, so scheint es, will Rilke an der Erschütterung, die mit Malte vor sich geht, am Paradigma des Künstlers zeigen. Daß er dies im Geiste der Nietzscheschen Forderung nach einer neuen "Weltauslegung" getan hat, ist offensichtlich, ob unter seinem direkten Einfluß, das sei dahingestellt. Dessen ungeachtet haben wir in Rilkes "Aufzeichnungen des Malte Laurids Brigge" ein Dokument der modernen Bewußtseinskrise vor uns.

Mit der gleichen Schubkraft, aber in umgekehrter Richtung, wuchsen sich in der Kulturkrise der Jahrhundertwende zwei gegenläufige Bewegungen aus: Der antirationalistische Protest gegen die geistige Dürre des positivistischen Wissenschaftsdogmatismus und Agnostizismus, die Revolte gegen die Lebenslüge der bürgerlichen Gesellschaft, die mit unglaubwürdig gewordenen Idealen weiter verbrämt wurde, kurz der Angriff auf den "ganzen Lügenapparat des alten Ideals" (Nietzsche) wuchs unter der Künstlerelite der Jahrhundertwende in gleichem Maße, wie das unaufhaltsame Bedürfnis nach einer neuen Denkungsart, in der Intellekt und schöpferische Intuition, Erkenntnis und Empfindung, sich nicht mehr als feindliche Brüder verachteten und lahmlegten.

Die Trennung von Intellekt und Gefühl wurde über die Grenzen der sehr verschiedenen Einzelnationen und -gesellschaften hinweg als Krankheitssymptom der modernen Kultur empfunden. Nietzsches Klage über die Kümmerform des "theoretischen Menschen" und seine Gegen-Vision des Künstler-Philosophen der Zukunft, des "musiktreibenden Sokrates", 25) fand gesamteuropäisches Echo: erst viel später, aber vielleicht am prägnantesten formuliert bei T.S. Eliot. Ebenso wie Nietzsche beklagte der die "dissociation of sensibility" und sann auf Uberwindung, indem er - unter Berufung auf die "Metaphysical Poets" des 17. Jahrhunderts - zur Versinnlichung des Gedankens aufrief, der umgekehrt eine Präzisierung des Emotionalen zu entsprechen habe: "the thought felt". 26) Aleksandr Blok erhoffte in Rußland die Erneuerung der Kultur aus dem "Geist der Musik" - einer Eliots Ideal ähnlichen Vorstellung von der Ganzheit des "Organischen" als Gegenwehr zur rational reduzierten Weltsicht des "Mechanischen". 27) Anwalt einer 
Synthese aus "Genauigkeit" und "Seele" in der Generation von 1880 war im gesamteuropäischen Rahmen vor allem Robert Musil. Im Medium der permanenten Reflexion des poeta doctus suchte er die beiden "Bäume des Lebens", den der sachlichen Härte des Begrifflichen und den der "sanften Schattenseite des Gefühls", eines ursprünglich kindhaf ten Verhältnisses zur Welt, zu entwirren und wieder zu vereinigen.

Ganz anders als Rilkes heimatloser Ausländer Brigge in der Isolation seiner Pariser Mansarde, aber mit der gleichen Dringlichkeit, erhebt Musils "Mann ohne Eigenschaften" im Zentrum der alten Habsburger Hausmacht, vor dem Hintergrund der Staats- und Gesellschaftskrise der Mittelmächte die Forderung nach einer "geistigen Generalinventur". Als im internen Kreis eines führenden Wiener Politik-Salons die ideenverbrämte, aber von Militär - und business-Interessen durchsetzte "Parallelaktion" zum Doppeljubiläum des österreichischen und des deutschen Kaisers ins Stocken gerät - das mit bitterer Ironie auf den Untergang beider Monarchien, auf das Jahr 1918 datiert ist - läßt Musil seinen Protagonisten Ulrich in einem Moment von unerwarteter Klarsicht und Entschlossenheit vorpreschen in die Konfrontation und offiziell vor den Spitzen der Wiener Gesellschaft ein "Erdensekretariat für Genauigkeit und Seele" fordern:

"Da unternahm Ulrich einen unsinnigen Versuch. 'Erlaucht', sagte er, 'es gibt nur eine einzige Aufgabe für die Parallelaktion: Den Anfang einer geistigen Generalinventur zu bilden! Wir müssen ungefähr das tun, was notwendig wäre, wenn ins Jahr 1918 der Jüngste Tag fiele, der alte Geist abgeschlossen werden und ein höherer beginnen sollte. Gründen Sie im Namen Seiner Majestät ein Erdensekretariat der Genauigkeit und Seele; alle anderen Aufgaben sind vorher unlösbar oder nur Scheinaufgaben!"

Diese Forderung nach einer geistigen Positionsbestimmung, die Musil seinen "Mann ohne Eigenschaften" ebenso engagiert wie skeptisch erheben läßt, als aus dem ratlos gewordenen Zentrum der Macht die Frage aufkommt: "Also was soll geschehen? Wir müssen doch wenigstens vorläufig irgend etwas Entscheidendes tun, um den Gefahren für unsere Aktion vorzubeugen!"' - repräsentiert im präzisen Ausdruck eine Grundsehnsucht der Epoche. 29) Denn mit "Genauigkeit und Seele" sind die beiden Pole des modernen Bewußtseins genannt, die ihre Bezogenheit aufeinander verloren haben: die auseinandergefallenen Bereiche von Tatsachen und logischer Präzision des Gedankens auf der einen Seite und des emotionalen, aber auch des metaphysischen Bedürfnisses auf der anderen Seite.

Haben wir in Rilkes Malte als Träger des kulturkritischen Angriffes auf den status quo der Vorkriegskultur im einsam reflektierenden Künstler den von Ängsten und Krankheit geschüttelten Typus der reinen Innerlichkeit vor uns, der aber dennoch die Kraft der Schwachen aufbringt, die Widersprüche der Moderne phänomenologisch genau zu registrieren und ihnen standzuhalten, so verkörpert Musils "Mann" Ulrich, mit dem zwar keine der gängigen Eigenschaften fest zu verbinden ist, den körperlich durchtrainierten und geistig reflektierten Typus der kämpferischen, leidenschaftlichereregbarteng Existenz 
der vita activa, den Weltmann, den Musil ironischerweise als "Ehrensekretär" der Parallelaktion der k. u. k.-Führungsspitze an die Seite stellt. Dem Typus der reinen Innerlichkeit bei Rilke entspricht die literarische Form der "Aufzeichnungen", deren Tradition ihm aus der russischen Literatur bekannt war. Dem Typus des reflektierenden Weltmannes bei Musil, der sich nur vorübergehend "Urlaub vom Leben" nehmen wollte, entspricht die Gattung des essayistischen Staatsromans. ${ }^{30)}$ Erscheint der Angriff auf die alte Auslegung der Kultur bei Rilke im privaten Maßstab der Aufzeichnungen eines heimatlosen "Nichts" in der Anonymität der Großstadt Paris, wird er bei Musil im nationalen Maßstab "Kakaniens" geführt, der untergehenden Habsburger Macht - einst Statthalter des Heiligen Römischen Reiches deutscher Nation - mit dem Zentrum Wien.

Bei Andrej Belyj, den man in die Reihe der Zeugen einfügen kann, wird die Kulturkrise der Moderne zum Weltmaßstab des Ost-West-Konfliktes ausgeweitet und ihre zwiefältige Wurzel, die Dissoziation von Herz und Hirn, auf zwei Romane verteilt, auf den Roman des dionysischen Ostens "Die Silberne Taube" (1909) und auf den Staats- und Stadtroman des apollinisch-rationalen Westens "Petersburg" (1913). Die auseinandergefallenen Sphären der menschlichen Ganzheit, Intellekt und Gefühl, werden hier in ihre Extreme gesteigert. Der Bereich des Intellekts umfaßt die geometrische Starrheit und Kälte des mathematisch - juristischen Prinzips wie auch die Trägheit des Unveränderlichen - "kvadratnost"' nennt Blok das; ${ }^{31)}$ der Bereich des Gefühls umgreift sowohl Sinnlichkeit als auch religiöse Sehnsucht, pervertiert zum erotisch-pseudomystischen "Chlystentum". Diese besondere Mischung aus Ekstase und Askese hatte sich in der russischen Volkssekte der "Chlysten" (Geißler) oder "Gottesleute" als religiöse Subkultur herausgebildet und war um die Jahrhundertwende in ganz Rußland in Gebieten mit bäuerlicher Bevölkerung verbreitet. ${ }^{32)}$

Der "theoretische Mensch" auf der Suche nach dem Leben soll te bei Belyj in seiner Romantrilogie "Osten und Westen" an die Grenzen beider Extreme geführt und in der Synthese eines neuen ganzheitlichen Menschen, dem nachnietzscheschen Ich, überwunden werden: in einer "Trılogie der Menschwerdung", von der auch Blok in bezug auf sein dichterisches Programm gesprochen hat. ${ }^{33)}$ Gelungen ist Belyj dieser große Wurf nicht so, wie er wollte, sondern nur so, wie er es als Dichter der modernen Krise konnte. Dennoch kann man sagen, daß die beiden ersten großen Romane zur Synthese gebracht werden in seinem Roman-Poem "Kotik Letaev" (1917). Denn am Archetyp des Kindes stellt er die Genese des schöpferischen Bewußtseins den beiden Extremformen des dionysischen Rausches und der apollinischen Zerebralisation gegenüber und gibt zumindest den Entwurf einer neuen Ganzheit des Künstler-Menschen. Dieses neue anthropologische Synthese-Ideal des ganzheitlichen oder des "Künstler-Menschen" kann nicht ohne den Einfluß Wagners verstanden werden, wovon im folgenden noch die Rede sein wird (cf. unten S.73.).

Belyj fantasiert den Helden der Trilogie, seinen "Probemenschen", in drei Versionen: 
zweimal als desorientierten Studenten - als den Altphilologen und Sektierer wider Willen, Dar'jal'skij, und als den Neukantianer und Terroristen wider Willen, Ableuchov, - schließlich regredierend auf den Prototyp des Künstlers im Kinde Kotik Letaev. Im ersten Roman "Die Silberne Taube" ringt der Student Dar'jal'skij - im russischen Dorf "das Land der Griechen mit der Seele suchend" - um eine "künftige Lebensform", 34) in der ihm alles erlaubt sein soll und er sich keiner Autorität mehr beugen muß. Der angehende "Ubermensch" verfällt dem Lebensrausch einer pseudomystischen, aber orgiastisch-gewalttätigen russischen Bauernsekte und wird - da er sich wieder herauslösen will - als Verräter erdrosselt und von den Stiefelabsätzen der Gewalt zertrampelt. Das Dionysische Nietzschescher Provenienz wird in die vorrevolutionäre Gärung des russischen Volkes übertragen, dabei mit desillusionierender Kritik entmythologisiert, denn das russische Volk ist für Belyj keine ästhetische Kategorie. ${ }^{35)}$ Die Geburt der Tragödie - wie sie Nietzsche aus dem Geist der Musik erhofft hatte - findet bei Belyj nicht statt; sondern sein Protagonist Dar'jal'skij wird brutal umgebracht. Ohne Steuer und Ruder einer eigenen Identität und Wertsetzung gerät er in den Sog der Gewalt und geht unter. Die Antike ist nicht mehr einholbar - was sie im Grunde genommen, trotz der Idealisierung im Frühwerk, für den späten Nietzsche auch nicht mehr war: "Das griechische Altertum ist als Ganzes noch nicht taxiert (...)."36)

Die Gegenmöglichkeit des "theoretischen Menschen" entwirft Belyj im zweiten Roman "Petersburg". Der zerebralisierte Kantianer Nikolaj Apollonovič Ableuchov gerät zwischen die beiden Fronten der "Staatsplanimetrie" - verkörpert von seinem Vater, einem ultrarationalen Juristen und Reformpolitiker - und der revolutionären "Provokation" - verkörpert von dem molluskenhaften Provokateur Lippanર́enko, dem schmierigen Geschäftemacher und Drahtzieher einer Terroristengruppe. ${ }^{37)}$ Der Student Nikolaj wieder zerfallen in Ratio und Trieb, aber jetzt auf der Suche nach einer eigenen Identität und Wertwelt - verfängt sich im Agentennetz des Terrorismus und läßt sich eine Zeitbombe aufdrängen, mit der er seinen Vater umbringen soll. Die Bombe explodiert schließlich, ohne daß er es mehr verhindern kann, aber Vater und Sohn, die in der Zwischenzeit an die Grenzen ihrer Hybris geraten sind, überleben. Auf tierisch-widerwärtige Weise dem Untergang verfällt ein anderes Vater-Sohn-Paar: Der Terrorist Dudkin bringt, selbst dem Wahnsinn verfallend, mit einer Schere seinen Zwingsherrn, den ekelhaften Provokateur Lippančenko, um. Das "dionysische Prinzip" legt sich - wie in der "Silbernen Taube" - durch Gewalt lahm; das apollinische Prinzip dagegen erscheint transformierbar; über Selbsterkenntnis und durch die Begegnung mit einer visionär-verflüchtigten Christusfigur wird schließlich der Held zur Mystik und zur Möglichkeit des einfachen bäuerlichen Lebens eines Gutsherrn à la Tolstoj geführt.

Entsprach den Reflexionen des auf sich gestell ten Einzelnen in Rilkes "Malte" die literarische Form der privaten Aufzeichnungen, dem Versuch des reflektierten Weltmannes bei Musil der essayistische Staatsroman, so verbindet Belyj die literarische Kon- 
vention des Staats- und Stadtromans mit der des barocken Abenteuer-Romans, der von einem Rahmen aus Prolog und Epilog umfaßt wird. Der Prolog hat den Charakter eines petrinischen Ukas, in dem die Existenz Petersburgs allen Legenden zum Trotz als Hauptstadt des russischen Imperiums und Ausgangspunkt der dichterischen Rede dekretiert wird:

\begin{abstract}
"Wie dem auch sei - Petersburg ist keine bloße Einbildung, denn man kann es auf der Landkarte finden (...) diesem und keinem anderen Punkt entspringt der reißende Strom von Worten, die dieses Buch bilden, von diesem unsichtbaren Punkt gehen Rundschreiben nach allen Richtungen."
\end{abstract}

Dem Beglaubigungstopos für Petersburg und seinen Dichter steht die "Summe" des Epilogs gegenüber. Der Held ist inzwischen fernab von Petersburg und dem Europa der Zivilisation am Rande der arabischen Wüste gelandet und sitzt - wie Ödipus - vor der Sphinx:

"Nikolaj Apollonovič hatte sich in die ägyptische Kultur vergraben; er sah voraus, daß das Schicksal des alten Ägypten sich im zwanzigsten Jahrhundert wiederholen würde: die Kultur war ein vermoderter Kopf, alles in ihr war tot; nichts würde bleiben: eine Explosion würde alles hinwegfegen (...). Er lehnte sich nachdenklich an die Seite der toten Pyrapgide; er selbst war eine Pyramide, der Gipfel einer Kultur, die zerfallen würde."38)

Doch er geht nach Rußland zurück. Wie Voltaires Candide wird er Landwirt und bebaut seinen eigenen Garten. Doch beginnt er - darin Tolstojs Levin folgend - für seine Seele zu sorgen, die er aus dem erlittenen Fiasko herausretten konnte. Doch seine Augen haben gelitten: Er hatte wohl zuviel gesehen. "Der König Ödipus hat ein Auge zuviel vielleicht" - sagt Hölderlin. Neben der Landarbeit liest er dennoch den mystischen Philosophen Skovoroda.

In den beschriebenen drei dichterischen Reaktionen auf die Kulturkrise bei Belyj, Rilke und Musil werden im Bereich der österreichischen und der russischen Literatur drei Arten des "Probemenschen" entworfen: Der Künstler Malte, ein Nichts, das anfängt zu sehen und zu denken; der Mann Ulrich, reflektierender Weltmann im Ausnahmezustand und Monitor der untergehenden alteuropäischen Herrschaft; Belyjs geschundener Dionysos Dar'jal'skij und sein geblendeter Ödipus Ableuchov. In ihnen kann man ein literarisches Tryptichon der Kulturkrise erkennen, in dem Belyjs "theoretischer Mensch" in seiner janusköpfigen Doppelgestalt im Mittelfeld steht, flankiert von seinem Vorgänger Malte und von seinem Nachfolger Ulrich.

Es zeigt sich, daß Nietzsches Zeitdiagnose des Nihilismus sowie seine Kritik der fragwürdig gewordenen humanistischen Kultur von hohem Symptomwert ist, und daß ihr ein analoges $\mathrm{Krisenbewußtsein} \mathrm{bei} \mathrm{den} \mathrm{oben} \mathrm{zueinander} \mathrm{in} \mathrm{Beziehung} \mathrm{gesetzten} \mathrm{Dichtern}$ der Krise korrespondiert. Soweit sie von Nietzsche beeinflußt sind - was für alle drei in sehr unterschiedlichem Maße gilt - begegnen sie seiner Diagnose jeweils kritisch und in 
schöpfer ischer Auseinandersetzung. Für Rilke wird die Erfahrung des Nichts zum Anlaß, um überhaupt erst Wirkliches "sehen zu lernen" und im Aufzeichnen daraus "Dinge zu machen aus Angst". Musil stellt Nietzsche einen neuen Geistbegriff gegenüber, in dem der Geist keineswegs Widersacher der Seele oder des Lebens sein muß, sondern dem die Versöhnung von Geist und Leben aufgegeben ist. Belyj konfrontiert den "theoretischen Menschen" und seinen Wertverlust mit den beiden "mongolischen" Extremgewalten des dionysischen Rausches und der appollinischen Starre einer vom Allmachtswahn erfaßten Zahlenwelt; während er aber im Chaos der Gewalt rettungslos untergeht, enthält die apollinische Alternative offensichtlich die Möglichkeit zur Regeneration durch die Rückbindung der Reflexion an die einfachen christlichen und menschlichen Werte der verzeihenden Liebe, der täglichen Arbeit und der mystischen Versenkung. 39)

Belyj und Musil rühren mit der Beschreibung der "dissociation of sensibility" an eine Kernfrage der modernen Bewußtseinskrise, die sich u. a. aus der inneren Dialektik des Positivismus ergab. Die Reduktion der Wahrheit auf den Tatsachenrealismus der logischen Domäne - die auf den beiden Säulen der Evolution und des Determinismus ruhte war erkauft worden um den Preis der Verdrängung des Gefühls und der Metaphysik, seit sie von Auguste Comte, dem Wortführer des älteren Positivismus, zum "Scheinproblem" erklärt worden war. ${ }^{40)}$ Dieser inneren Dialektik konnte man auf zweierlei Weise begegnen; entweder unterzog man sich der Mühe der Auseinandersetzung mit dem verdrängten Bereich des Emotionalen und Metaphysischen, oder aber man suchte den Ausweg im Unterlaufen oder Uberspringen dieser Problemspannung, das auf den verhängnisvollen Weg in den Irrationalismus führte. Für die Auseinandersetzung war aber gerade im Positivismus eine wesentliche Grundlage enthalten, nämlich die Erkenntnishaltung der genauen Beobachtung und der eigenen Erfahrung, und $z$ war sowohl der äußeren als auch der inneren, die zum genauen Hinsehen auf die Phänomene veranlaßte. Zu denjenigen, die die Grundspannung ihres Zeitalters nicht vorschnell lösen, sondern die "Dissoziation der Interessen" in aller Offenheit aushalten wollten, weil sie darin den einzigen Lösungsweg für die Krise der Moderne sahen, gehören unter den Dichtern sowohl Rilke als auch Musil und Belyj. Der innere Grund dafür, daß ihre Romanwerke fragmentarischen Charakter behielten, liegt nicht zuletzt im Aushalten dieser Grundspannung von "Genauigkeit und Seele".

Abschließend sei noch darauf hingewiesen, daß mit der Gegenüberstellung der drei Dichter Rilke, Musil und Belyj nicht angestrebt wird, ihnen repräsentative Geltung für ihr Zeitalter oder für die österreichische oder russische Literatur in einem generellen Sinne zuzuschreiben. Es geht vielmehr um den Vergleichswert der Autoren untereinander, die einem gemeinsamen Generationszusammenhang entstammen, im Hinblick auf ihre Auseinandersetzung mit Krisenphänomenen der Jahrhundertwende. 


\section{Krise der Sprache}

a) Spachskepsis:

Hofmannsthal und Tjutčev

Der geistige Umbruch der Kultur- und Bewußtseinskrise ${ }^{41)}$ wirkte sich aber für die Dichter nicht nur thematisch aus, sondern auch im unmittelbaren Betroffensein von der Krise der Sprache, das ihre Reflexion und Kreativität in Gang setzte. ${ }^{42}$ ) Diejenige Sprache, in der noch gestern mit rhetorischem Glanz die Scheinharmonien der alten Werte verkündet wurden, begann nicht nur Hofmannthals Lord Chandos wie "modrige Pilze" im Munde zu zerfallen. ${ }^{43)}$ Tjutčevs Vers "Der ausgesprochene Gedanke ist Lüge" (Mysi' izrečennaja est' lož') - niedergeschrieben im Jahre 1830, wenngleich in anderem Zusammenhang und dann lange vergessen ${ }^{44}$ ) - begann in Rußland etwa zur gleichen Zeit, seitdem nämlich V. Brjusov diesen Vers als Motto seinen "Chefs d'oeuvre" im Jahre 1895 vorangestellt hatte, unter den Symbolisten zu kursieren und bekam den Signalwert eines Codewortes für das Mißtrauen in die Konvention der Sprache. ${ }^{45)}$

Die Sprachskepsis bezog sich auf zwei Grundfunktionen der Sprache; einmal darauf, die Dinge richtig zu benennen, zum anderen darauf, einander etwas mitzuteilen. An beidem wurde gezweifelt. Ist im ersten Falle die ins Wanken geratene Bewertung der Dinge spürbar - dem Zerfallen der Wertschätzungen entspricht ein Zerfall der Dinge und der Sprache -, so ist im zweiten Falle die Trennung des sozialen Diskurses von der poetischen Sprache als Ursache für eine fragwürdig gewordene Kommunikation zu erkennen. ${ }^{46)}$

Hofmannsthal scheint eher den ersten Fall zu verkörpern; zwischen Abstraktion und Einfühlung ist er gespalten und kann die Dinge nicht mehr eindeutig benennen. Tjutčev meint offenbar vor allem das Sprachversagen in der poetischen Kommunikation. Für beide ist der Zweifel an der Sprache verschieden; was dem einen vor allem eine Benennungskrise war, war dem anderen eine Kommunikationskrise. Doch diese Unterscheidung müßte noch weiter überdacht werden. ${ }^{47)}$ Die Konsequenz, die beide Dichter zogen, war die gleiche: Beide verordnen sich die Abstinenz des poetischen Schweigens. Hofmannsthal spricht vom "Anstand des Schweigens", den man aufbringen müsse, bis eine neue Sprache gefunden sei; Tjuť̌evs berühmtestes Gedicht wurde "Silentium". Sein Werk blieb schmal, aber von hoher Qualität. ${ }^{48)}$

An der Situation der Sprachkrise in der Moderne zeigt sich ein Paradox des Dichters - das nicht neu ist, aber schärfer zugespitzt. Der Dichter in der Moderne ist nicht immer derjenige, dem das Sprechen besonders leicht fällt und gut gelingt, sondern dem es schwerer fällt als der Durchschnittsrede, zum Wort zu kommen. ${ }^{49)}$ Belyjs Formierung als Schriftsteller um die Jahrhundertwende fällt mitten hinein in diese allgemeine Situation der sich entziehenden Sprache. Die eigene Erfahrung der Sprachohnmacht, die er als Kind und Heranwachsender machen mußte, sensibilisierte ihn für das "lebendige Wort" und ließ ihn zum Dichter werden. Das rational-liberale Milieu der Kulturkrise, das ihn zum Verstummen gebracht hatte, beschreibt er folgendermaßen:from PubFactory at 01/10/2019 05:16:17AM 


\begin{abstract}
"Man kann von der arithmetischen Durchschnittswohnung, vom arithmetischen Durchschnittswort, vom arithmetischen Durchschnittsgemüt sprechen, (...) das arithmetische Durchschnittswort - stumpf ist es, pauschal, knochentrocken: du betrachtest dich einundzwanzig Jahre umstellt von diesem Wort; und du siehst: nicht ein einziges von Herzen kommendes Wort (alle von Heczen kommenden Worte waren an anderer Stelle zu hören, und später (Nrds 481);"
\end{abstract}

Von der Erfahrung des Sprachversagens her kann man auch die gesteigerte Aufmerksamkeit verstehen, die der Musik zufiel. Wo verbale Kommunikation als gestört oder unzulänglich erfahren wird, gewinnt die nonverbale, nicht rationale und überpersönliche Sprache der Musik an Wert. Daß sie in der ästhetischen Hierarchie der Künste seit der Romantik an die Spitze gerückt wurde, kann u. a. von der Kommunikationssituation her verstanden werden.

Die Aufwertung des Schweigens und der Musik sind zwei nonverbale Reaktionen auf die Sprachkrise, die ihrerseits Rückwirkungen auf die Sprache und die Veränderung der Gattungen hatten, wie z. B. der Stil des Nicht-zu-Ende-Redens (nedoskazannost') und der Pause in Čechovs Prosa und Dramatik; ${ }^{51)}$ die Musikalisierung der Lyrik seit der Romantik, die bei Mallarmé und Fet kulminiert und bei Aleksandr Blok einen späten Höhepunkt erreicht, der das russische Versgefüge grundlegend verändert; ${ }^{52)}$ die Rhythmisierung der Prosa, die zum "Gedicht in Prosa" führte, wie z. B. bei Baudelaire, von dem Turgenev das neve Genre übernahm, bis schließlich zum "symphonischen Stil" in der Prosa Belyjs. 53 )

Die Situation der Sprachskepsis trägt aber ein bezeichnendes Paradoxon in sich: Im Formulieren dieser Sprachnot zeigt sich, daß die Sprache trotzdem die Fähigkeit besitzt, ihr eigenes Verfehlen zum Ausdruck zu bringen. Sowohl Tjutčev als auch Hofmannsthal und Musil bringen ausgefeilte sprachliche Kunstwerke hervor, gerade indem sie ihr Sprachversagen zur Sprache bringen. Diese Fähigkeit, sich zu sich selbst zu verhalten, teilt die Sprache mit der Vernunft: Ebenso wie Kant durch die "Kritik der reinen Vernunft" eine "Revolution der Denkart" auslöste, indem er von innen, aus dem Wesen der Vernunft ihre Grenzen und Antinomien bestimmte, so löst auch die moderne dichterische Kritik der "reinen" Sprache eine Revolution der poetischen Rede aus, indem sie ebenso von innen, aus dem Wesen der Sprache, ihre Grenzen, ihre Antinomien und Auswege daraus zu bestimmen suchte.

\title{
b) Spracherneuerung:
}

Schöpferische Deformation - "symbolischer" und "poetischer" Konstruktivismus

Es blieb nun nicht bei der Zeitklage der Sprachskepsis über eine untauglich gewordene Sprache, sondern es wurden neue Sprachformen erprobt. Es kam zu einer semantischen Belebung des Wortes. ${ }^{54)}$ In der Konzentration auf das dichterische Wort stehen sich um 
die Jahrhundertwende Sprachversagen und "Kultus des poetischen Wortes" dialektisch aufeinander bezogen als Extreme gegenüber. ${ }^{55}$ Die neue Sensibilisierung in bezug auf die Sprache hatte nicht nur stilistische Konsequenzen. Da der reflektierende Dichter der Moderne nicht mehr das selbstverständliche Verhältnis zur Sprache aufbringen konnte wie die Realisten - es sei denn, er blieb davon unberührt, wie das auch in unserem Jahrhundert noch Schriftstellern gelang - stand er der Sprachform seiner eigenen Dichtung als bewußter Analytiker gegenüber. In Rußland trug er darüber hinaus nicht selten als "Dichter-Philologe" wesentlich bei zur Theorie der Sprache und Literatur. 58 )

In der Reaktion auf die moderne Sprachkrise kann man verschiedene Stadien und Richtungen der semantischen Belebung der dichterischen Rede unterscheiden:

1) Im Protest gegen die alte "Auslegung" der Welt in der hergebrachten Sprache wurde in der postrealistischen Avantgarde die Auflösung und schöpferische Deformation der alten, automatisierten Konventionen der Sprache im vollen Bewußtsein der Provokation betrieben. Es kam zur Verrätselung der Welt durch die in Bewegung geratene Sprache. Mit ihr wurde zunächst eine suggestive Wirkung auf den Leser angestrebt; er sollte aus seinen Konventionen aufgeschreckt, aber auch in Bann geschlagen werden. ${ }^{57)}$ Vor der ausdrücklich formulierten Sprachkrise um 1900 hatten bereits die französischen Symbolisten poetische Verfahren entwickelt, auf die nun in der Situation der Sprachkrise mehr oder weniger bewußt zurückgegriffen werden konnte.

2) Neben diesen Tendenzen zur Auflösung der alten Sprache - aber auch bereits in ihnen - zeichnet sich ein Bauwille zur neuen Sprache ab. Will man für diesen "Bauwillen" den bereits anderweitig definierten Begriff des "Konstruktivismus" in Anspruch nehmen, ${ }^{58)}$ so kann man sagen, daß er sich sowohl in der "Symbolkonstruktion" der jüngeren Symbolisten wie auch im "poetischen" Konstruktivismus der Futuristen äußerte. Hierbei handelt es sich um zwei verschiedene Auffassungen von "Konstruktivismus". Während es dem poetischen Konstruktivismus vor allem darum ging, "wie man Verse macht" (Majakovskij), also um das poetische Handwerk, so geht es in der Symbolkonstruktion neben diesem Aspekt, der nicht gering zu veranschlagen ist, sondern auch hier bereits eigene Bedeutung erlangt hat, vor allem um die "Poetisierung des psychologischen Systems" (Striedter), also um einen postrealistischen Zusammenhang von Idee, Erlebnis und Dichtung: um das "Konstruieren von Modellen zu Erfahrungsprozessen" (Belyj). ${ }^{\text {59) }}$

3) In diesem Prozeß der Uberwindung der Sprachkrise zog nun das Medium der Sprache selbst immer mehr Aufmerksamkeit auf sich. Analoges geht in den anderen Künsten vor. In der Malerei ist es vor allem die Farbe - bei den Fauves - aber auch die Linie - Hauptstilmittel des Jugendstils, die sich ornamental verselbständigt. Man kann von einer Ästhetisierung der Kunstmittel sprechen. Die "selbstwertige" Sprache, die von den Futuristen und Dadaisten erst später entdeckt wurde, machte sich 
bereits den Dichtern der Jahrhundertwende als neuer Faktor, mit dem sie in ihrem Schaffen zu rechnen hatten, gegenüber ihrer Vorgängergeneration bemerkbar. Den Vorgang einer sich verselbständigenden Sprache bezeugt auch Musil in seinen Tagebüchern:

"Das Wort wird souverän und springt aus dem Satz hinaus, der Satz greift über und verdunkelt den Sinn der Seite, die Seitf gewinnt Leben auf Unkosten des Ganzen - das Ganze ist kein Ganzes mehr."

Die verschiedenartigen Reaktionen auf die Krise der Sprache über die Stadien der schöpferischen Deformation, des "symbolischen" und "poetischen" Konstruktivismus, der sinnüberschreitenden Sprache des "zaum"', führte zu einer poetologischen Revolution, die maßgeblich von der nachnietzscheschen Generation von 1880 durchgekämpft wurde. Den beiden Stadien der schöpferischen Deformation und des dichterischen Konstruktivismus lassen sich je verschiedene Stilfiguren der Sprachkrise zuordnen. Für das erste ist kennzeichnend die Sprachfigur der Katachrese bzw. des Oxymorons. Als Sprachfigur des Paradoxons und damit verbunden der Deformation hat sie seit dem Barock eine große Tradition. Sie kann als der anti-klassische priëm par excellence gelten und hat von daher eine innere Affinität zu Widersprüchen. Beispiele für die russische und die deutsche Literatur der Jahrhundertwende finden sich bei V. Gofman und W. Jens. ${ }^{61)}$ V. Gofman sieht das Programm der schöpferischen Deformation der Sprache in den Versen des frühen Symbolisten K. Bal'mont ausgesprochen:

"Protjažnost'ju zakljatij perepevnych, Sostavlennych iz povsednevnych slov, No lił̌' ne v soŽetanijach ežednevnych..."

"Durch die Gedehntheit wiederholter Beschwörungen, Zusammengefügt aus All tagsworten, Aber eben in nicht alltäglichen Verbindungen." ${ }^{62)}$

Die verschiedenen Variationen der Katachrese haben gemeinsam, daß sich in ihr die Wortbedeutungen von ihrer allgemein akzeptierten Verwendung lösen und miteinander zusammenstoßen. Daher sind sie besonders geeignet, eine automatisierte Sprachstruktur in Bewegung zu bringen. Frühe Beispiele finden sich bereits in der ironischen Lyrik V. Solov'evs, der z. B. von der "feuerspeienden Eisscholle" (l'dina ognedyšaščaja) oder den "Leoparden der Rache" (leopardy mščenija) spricht. Sprachlich kühner schreibt dann Brjusov; z. B. in seinem Gedicht "Schaffen" (Tvorčestvo) über die Verwandlung der Dinge - hier seiner Zimmerpalme - im schöpferischen Moment:

"Fioletovye ruki

$\mathrm{Na}$ emalevoj stene

Polusonno Zertjat zvuki

v zvonko-zvurnoj tiß̌ne ..." 
Violette Hände zeichnen

Auf der emaillierten $W$ and

Halb in Schlaf versunken Kläğge

Klingend in der Stille Klang

Als typische Stilfigur des "symbolischen" Konstruktivismus kann man die "entfaltete" Metapher bezeichnen bzw. das "serielle" Symbol. Beispiele dafür finden sich in Bloks "Snežnaja Maska" (Schneemaske) und Belyjs "Kubok Metel ej" (Pokal der Schneegestöber). Für die Poetisierung psychischer Prozesse, vor allem des Liebeserlebnisses, ist der Prozeßcharakter dieser Stilfigur geeignet. ${ }^{64)}$

Als Sprachfiguren des "poetischen" Konstruktivismus kann man vor allem die beiden Bildverfahren der Metonymie und der Metapher anführen. Beide sind natürlich - wie auch die vorhergenannten - nicht neu, werden aber in innovatorischer Absicht ausgebaut. Die Metonymie ist die Sprachfigur der Berührung; aneinandergrenzende Gegenstandsbereiche werden bildlich fusioniert. Die Synekdoche, in der das pars-pro-toto-Prinzip tropologisch genutzt wird, stellt einen Sonderfall metonymischen Sprechens dar. Die Metapher unterscheidet sich von der Metonymie dadurch, daß sie die Figur der Ähnlichkeit ist. ${ }^{65}$ ) Während die Metonymie Aneinandergrenzendes verkoppelt - z. B. Lebensgeräusche im stillen Wald mit dem Ticken in einer Uhrmacherwerkstatt und weiter: das Zifferblatt mit einem Himmelssegment, vom Waldboden aus gesehen - wie in Pasternaks Waldgedicht "V lesu" -, funktioniert die Metapher, indem sie Ähnliches an die Stelle des gemeinten Gegenstandes setzt; statt zu verkoppeln leistet sie Ersatz: die Metapher des Brandes für ein leidenschaftlich "entbranntes" Herz - wie z. B. in Majakovskijs Poem "Obloko v štanach" (Wolke in Hosen). ${ }^{66)}$ Beide hergebrachten tropologischen Verfahren werden im poetischen Konstruktivismus radikalisiert; als Grenzwert der Sprachfigur gilt nicht mehr, daß sie abbildendes Äquivalent der Wirklichkeit zu sein habe, sondern dem mimetischen Bild wird der Abschied gegeben in einer neuartigen Wahrnehmungsweise, die sich aus dem Arsenal des Gegenständlichen ebenso bedient wie aus den Klang- und Zeichenpotenzen der Sprache. Der Weg für eine nicht mehr traditionell mimetische Tropologie ist freigemacht. ${ }^{67)}$ Die Synekdoche, die das organische Bild zur Collage umfunktioniert, verwendet avantgardistisch - worin sie an die Malerei des frühen zwanzigsten Jahrhunderts erinnert - z. B. Belyj in "Petersburg":

" (...) auf der eisernen Brücke (...) folgten ihr ein steifer Hut, ein Spazierstock, ein Mantel, Ohren und ein Schnurrbärtchen in den heftigen Stößen des Newawindes."68)

Unter den Futuristen arbeitet metonymisch vor allem der junge Pasternak, Majakovskij mit der hyperbolisch "realisierten Metapher".

Neben der Revolutionierung der Bildfügung ist es die "sperrige Sprache" (tugoj jazyk), die den abbildenden Charakter der Sprache abschwächt und den Widerstand des Materials zum poetischen Maßstab erhebt. Gegenüber der Musikalität symbolistischer 
Lyrik wird jetzt z. B. die aufrauhende Wirkung harter Konsonantengruppen oder das Stakkato einsilbiger Worte gesetzt. ${ }^{69)}$

In diesem gesamteuropäischen Prozeß einer poetologischen Revolution der postrealistischen Avantgarde als Antwort auf die moderne Sprachkrise hat Belyj den russischen Beitrag wesentlich mitbestimmt. Wie Blok in der Lyrik - und wohl auch im Drama - hat Belyj in der Prosa schulbildende Bedeutung gewonnen. Seine Formierung zum Schriftsteller fand statt um die Jahrhundertwende und wurde ihm durch das neue, unzeitgemäße, aber lebendige Sprechen der europäischen und russischen Symbolisten ermöglicht, in deren Chor er seine Stimme bald unverwechselbar ertönen ließ, und zwar bereits von Anfang an als gerade volljährig gewordener Autor seiner "Symphonien" in Prosa, deren stilistischen Rang Boris Pasternak folgendermaßen bemißt:

"Als hervorragender Lyriker, und mehr noch als Autor der 'Symphonien' in Prosa und der Romane 'Die Silberne Taube' und 'Petersburg', hat er vor der Revolution den literarischen Geschmack der Epoche zyerändert und die sowjetische Prosa in ihren Anfängen entscheidend geprägt."

Das Paradox seiner zweiten Geburt in die Sprache unter dem Pseudonym "Andrej Belyj" beschreibt er selber nicht ohne Selbstironie gegen Ende seines Lebens im zweiten Band seiner symbolistischen Memoiren "Zwischen zwei Revolutionen". Aus dem stummen Kind wurde eine Erscheinung des öf fentlichen Lebens, und zwar eine prekäre:

"Seine Worte erwarb Borjenka bei den Symbolisten, als inm bereits das sechzehnte, siebzehnte Lebensjahr schlug (zusammen mit seinem sprießenden Bart); in diesen Worten schrieb er heimlich dieses und jenes; zusammen mit der Uniform des Studenten legte er, wie einen Panzer, 'seine' Sprache an, die ihm zum Schutz diente, die Termini Kants, Schopenhauers, Hegels, Solov'evs; in der Sprache der Termini fuhr er, wie auf einem Fahrrad, durchs Leben; doch seine eigene Gangart - die hatte er damals gar nicht, als ihn seine Zungenspitze, die er in den 'Symphonien' herausgestreckt hatte, zu 'Andrej Belyj' machte, der ununterbrochen Vorträge hielt im Kreise seiner Freunde, die ihn für einen Theoretiker hielten; der 'Schwätzer' fuhr flott auf dem 'Fahrrad' der Termini; wenn er aber davon abstieg, so wurde er sprachlos und eingeschüchtert, so wie er es in der Kindheit gewesen war; hervorragend konnte er daher alle Nuancen der Terminologie unterscheiden ('transzendent', nicht 'transzendental'); beim einfachen Sprechen aber kam er ins Schleudern, weil er Angst hat te vor dem Ausruf: 'Borjenka, du redest Unsinn!'" (Mdr. 8)

Uber Belyjs theoretische Position zur Sprachskepsis und Spracherneverung wird im Zusammenhang seiner Symbolkonzeption noch zu reden sein (cf. unten S. $145 \mathrm{ff}$.). 


\section{Krise der bürgerlichen Lebensformen.}

\section{Zum Selbstverständnis des modernen Dichters - Belyj als poeta doctus} und poète maudit

Der kulturkritische Protest, der in der Elite der europäischen Künstlergeneration von 1880 heranwuchs, richtete sich nun nicht nur gegen einen hypertrophierten Rationalismus und Zweckoptimismus des Denkens, nicht nur gegen die Automatisierung der Sprache, sondern - damit verbunden - wuchs das Unbehagen an der utilitaristisch verflachten und moralisch defizienten bzw. verlogenen Lebensweise des arrivierten Bürgertums. Die soziologische, aber auch die daseinsunmittelbare Komponente der modernen Kulturkrise wurde manifest an der Krise der bürgerlichen Lebensformen, die z. B. in allen bedeutenden Romanen der Jahrhundertwende die Sujetlinien bestimmte und sich bereits im realistischen Roman abgezeichnet hatte. Sie wirkte sich aber nicht nur im Werk, sondern auch unmittelbar im Selbstverständnis des modernen Dichters aus, der in den meisten Fällen dem Sozialmilieu des aufsteigenden oder arrivierten Besitz-oder Bildungsbürgertums entstammte. Als Außenseiter der Gesellschaft verstand er sich entweder zur anscheinend konservativen Anpassung des dezenten vornehmen Herrn - wie Musil oder Thomas Mann, Eliot und Hofmannsthal - oder aber er schlug den entgegengesetzten Weg der offenen Feindschaft zur Gesellschaft ein im épater le bourgeois und verbarg sich hinter der Maske des Dandy - wie Oscar Wilde, oder er nahm als poète maudit die Rolle des Rebellen ein - wie Verlaine und Majakovskij.

Der tiefgreifende Wandel im Selbstverständnis des modernen Künstlers muß vor dem Hintergrund der antagonistischen Beziehungen von Kunst und Gesellschaft im neunzehnten Jahrhundert gesehen werden. ${ }^{71)}$ Der Künstler als Anwalt der Ganzheit des Lebens und der gefährdeten Fantasie sah sich einer Gesellschaft gegenüber, die von Partialinteressen und Konventionen beherrscht war. Zwischen den gesellschaftlichen Normen und dem imıner solipsistischer werdenden Künstler brach eine tiefe Kluft auf. Die ästhetische Wahrnehmung verschärfte sich in diesem Prozeß in dem Maße, wie sie nicht mehr normativ gebunden war, also die Wirklichkeit nicht länger allein unter vorgefaßten Harmonieidealen des Schönen betrachtete, sondern gerade die Differenzen zu ihnen in einer durch die Industrialisierung verhäßlichten, anonymen Zivilisationswelt wahrzunehmen begann. ${ }^{72)}$ Dabei erlitt das ästhetische Bewußtsein - das sich im Protest gegen die "Entzauberung der Welt" (Max Weber) autonom gesetzt hatte - einen traumatischen "Chok". Prototypisch dafür ist Baudelaire, was von Walter Benjamin exemplarisch herausgearbeitet wurde. Erfuhr jener einerseits die Wirklichkeit als "cauchemar plein de choses inconnues", so setzte er ihr dennoch in einer modernen Form des Heroismus den Akt der künstlerischen Gestaltung als "Duell" entgegen:

"L'éfyde du beau est un duel où l'artiste crie de frayeur avant d'être vaincu." 
Seine Waffe in diesem Duell ist die produktive Einbildungskraft. In dieser Auffassung gewinnt die Kunst seit der Romantik zunehmend den Charakter einer Herausforderung der offiziellen Normen, und der Künstler als "Dandy" das Selbstiverständnis eines charismatischen Außenseiters der Gesellschaft. Er rückt in die Nähe des Verbrechers und Rebellen, was bereits im romantischen Künstlermythos poetologisch vorgeprägt war. Diese Entwicklung des künstlerischen Selbstverständnisses im Ästhetizismus wurde prägend für die nachfolgenden Protestgesten der verschiedenen "Avantgarden". 74)

Um sich von dem damit verbundenen, enormen Legitimationsdruck zu entlasten, kam es sowohl bei den angepaßten wie auch bei den unangepaßten Außenseitern der Gesellschaft zu den für die Jahrhundertwende typischen Kreisbildungen. Dichtergruppen wie das "Junge Wien" "5), der "George-Kreis", 76) der "Bloomsbury set" in London, 77) die Moskauer Symbolisten-Gruppe "Argonauten", 78) der Petersburger Bǎ̌nja-Kreis (Turmgesellschaft) um Vjačeslav Ivanov, die zahlreichen Künstler - und Religionsphilosophischen Vereinigungen in Moskau und Petersburg; ${ }^{79)}$ Künstlerkolonien wie Worpswede und Meudon, Abramcevo und Peredelkino ${ }^{80}$; Kongregationen der Suche nach alternativen Lebensformen, wie der "Monte Verità" bei Ascona ${ }^{81)}$ oder Rudolf Steiners anthroposophische Provinz um das Goetheanum im Schweizer Dornach - solche Selbstvergewisserung der modernen Avantgarde in Gruppen ist ein kunstsoziologisches Symptom des kulturellen Umbruchs der Moderne. ${ }^{82)}$

Belyjs Formierung als Schrif tsteller ist von diesen Prozessen wesentlich mitgeprägt. Die drei Komponenten der Kulturkrise: die Krise des Bewußtseins, der Sprache und der bürgerlichen Lebensformen haben auf seinen Selbstwerdungsprozeß als Künstler eingewirkt. Die Erkenntnis von der Trennung zwischen Intellekt und Gefühl, die sich im Zerfall der Gesamtkultur in "zwei Kulturen" anbahnte, in die naturwissenschaftliche und die schöngeistige, hatte in ihm grundsätzliche Vorbehalte gegen die, ihm von seinem Vater bestimmte, ausschließliche Existenz als exakter Wissenschaftler ausgelöst und den Drang zur Kunst als einer ganzheitlichen Tätigkeit geweckt. Das Wort des frühen Nietzsche von "der Kunst als der höchsten Aufgabe und der eigentlich metaphysischen Tätigkeit" ${ }^{83)}$ hat so verstanden auch für Belyj Geltung. Wie Musil war er zu der Uberzeugung gekommen, daß die Kunst für ihn eine absolute Notwendigkeit war: "Weil es Dinge gibt, die sich nicht wissenschaftlich erledigen lassen..."84) Trotzdem blieb das in seiner positivistischen Erziehung angelegte Bedürfnis nach wissenschaftlicher Exaktheit und Methode prägend für seine Künstlerexistenz, die von daher das Signum des poeta doctus, als eines Teilhabers an den "beiden Kulturen" behielt - als Dichter-Theoretiker.

Die Krise der Sprache und die aus ihr hervorgehende poetologische Revolution der dichterischen Rede um die Jahrhundertwende bewirkte und ermöglichte ihm seine zweite Geburt in die Sprache als "Andrej Belyj", d. h. Andreas, der Weiße. An der Tatsache, daß er dieses Pseudonym annahm, läßt sich zweierlei ablesen: 1. Er empfand seine eigene 
Künstlerexistenz als ein Scandalon, als Verstoß gegen die Erwartungen der "Väter", sich selbst als Abtrünnigen und Provokateur, soweit er sich mit den Augen der Väter sah - und von dieser Optik hat er sich wahrscheinlich nie ganz freimachen können. 2. Gegenüber dieser Fremdsicht beteuert er gleichzeitig seine Unschuld, sein Recht als "Candide" auf ein ihm eigenes gemäßes Leben. Belyjs Selbstverständnis als Dichter blieb äußerst prekär. Mangels eines festen Selbstwertgefühls war er - mythologisch gesprochen - Kain und Abel in einer Person (cf. unten S. 160). Sah er sich auf der einen Seite als "čelovek iz podpol'ja" (Kellerlochmensch), der sich mit der Chemie der Bombe beschäftigt und ein potentieller Herostrat der Kultur ist, so sah er sich auf der anderen Seite als den Reinen und Erwählten, als das göttliche Kind, eine Lichtgestalt, die den Keim der Zukunft in sich trägt und nie verraten wird. ${ }^{85)}$ Die Selbstwertproblematik, die sich aus der unbewältigten Kollision dieser beiden Optiken ergab, ist kennzeichnend für die existentielle Grundlage seiner Erscheinung als poeta doctus, die von der Neigung zum Extremen gekennzeichnet ist. Das Entscheidende daran ist aber, daß die Polaritäten nicht abwechselnd auf ihn einwirkten, sondern gleichzeitig. Als Belyjs existentielles Grundmuster kann man die "Vereinbarung des Unvereinbaren" bezeichnen - und zwar gilt das sowohl geistig als auch emotional. ${ }^{86)}$ Als Metaphern der Existenzproblematik - die aber auch als Niederschlag von Problemen der modernen Kultur verstanden werden müssen und von daher überindividuelle Bedeutung haben - schuf er die Denk- und Existenzmetaphern der "Schere" und der "Bombe". Sie erscheinen in verschiedenster Ausprägung als "entfaltete" Metaphern für Konfliktkonstanten an zentralen Stellen in seinem Werk. Die "Schere" ist der metaphorische Prototyp des Differenzerlebnisses, die "Bombe" archetypischer Ausdruck der "Rebellion" sowie eines Gefühls der herannahenden Katastrophe. Obwohl das Schwergewicht bei Belyj auf der kritisch-negativen Seismographik liegt, gibt es dennoch ein grundsätzliches "Dogma" der Positivität in seiner Weltanschauung, nämlich ein grundsätzliches "Ja" zum Leben, trotz seiner ebenso grundsätzlichen "katastrofiěnost"'. Das muß unbedingt zusammengesehen werden, wenn man Belyj verstehen will. Deshalb stehen den beiden Krisenmetaphern der "Schere" und der "Bombe" zwei Entwurfsmetaphern der Ganzheit gegenüber: Der "Kelch" - mit Anklängen an die mittelalterliche Parzifalsage und den Gral - sowie die "Spirale" - als Denkbild des trotz Rückschlägen unbeirrbaren Weges in die Höhe. Beides sind symbolische Entwürfe einer Versöhnung von Geist und Leben, die allerdings über Fragmentarisches nicht hinausreichen, Belyjs Rang als Dichter der Kulturkrise aber entscheidend mitbestimmen. ${ }^{87)}$

Daß es ihm in Anbetracht der Schärfe seiner Selbstwertproblematik gelang, den Legitimationsdruck auszuhalten, unter den er sich im Prozeß seiner Formierung als avantgardistischer Künstler gestellt sah, das ist wesentlich auf die Stützung durch "relevante Andere" und durch "Peers" in der Kreisbildung modernistischer Gruppen zurückzuführen. "Relevante Andere" in der Generation der "Väter" fand er überzeugend im Kreis der Solov'evs; "Peers" in der Ordens- und Bruderschaftsmentalität seiner Generation, die sich als "Gezeichnete" empfanden. ${ }^{88)}$ 
Belyj stellt innerhalb der modernen Erscheinungsformen des poeta doctus insofern einen besonderen Fall dar, als er zugleich auch poète maudit ist. Das Moment der Rebellion rückt ihn vom Selbstverständnis her in die Nähe der Futuristen. ${ }^{89)}$

Das ausgeprägte Bedürfnis nach Legitimierung durch theoretische Rechtfertigung seiner Kunst trug darüber hinaus wesentlich dazu bei, daß Belyj zum führenden Theoretiker des russischen Symbolismus wurde (cf. unten S. 150 ff).

\section{Zusammenfassung und Exkurs}

Weichenstellung für den Bewußtseinsroman im russischen Symbolismus

Will man die dichterische Reaktion der nachnietzscheschen Generation von 1880 auf die moderne Kulturkrise zusammenfassen, so kann man das in drei miteinander zusammenhängenden Hinsichten tun: Es gab eine thematische Reaktion, in der als neuer literarischer "Held" der "Probemensch" der Kulturkrise auftauchte, dessen fiktionale Erscheinung je verschieden aus dem existentiellen Dilemma seines Autors mitgespeist war; sprachlich wurde im Ankämpfen gegen die Krise der Sprache eine poetologische Revolution ausgelöst, die über das Stadium der schöpferischen Deformation der Sprachnormen zum "symbolischen" und "poetischen" Konstruktivismus führte, mit dem im 20. Jahrhundert eine neue Literatursprache geschaffen wurde. Existentiell entstand ein neuer Dichtertypus, der sich durch überdurchschnittliche Reflektiertheit auszeichnete und dessen Selbstverständnis zwischen den existentiellen Grenzfiguren der "elevatio" und "desperatio" hin- und hergerissen wurde. ${ }^{90)}$

Betrachtet man vor diesem Hintergrund Belyj als poeta doctus in Hinblick darauf, inwieweit er Anteil hat an der allgemeinen Situation der europäischen Kulturkrise, so ist seine Individualität in höherem Maße prototypisch, als das auf den ersten Blick scheinen mag. Wenngleich Sartres Demontage des Individuums nicht zugestimmt werden kann, so soll zur Verdeutlichung dennoch seine Ansicht über den Anteil des Individuellen am Allgemeinen zitiert werden, weil sie den Teil - zumindest - einer Wahrheit enthält. Im Vorwort zu "Idiot der Familie. Gustav Flaubert" schreibt er:

"Ein Mensch ist nämlich niemals ein Individuum; man sollte ihn besser ein einzelnes Allgemeines nennen: von seiner Epoche totalisiert und eben dadurch allgemein geworden, retotalisiert er sie, indem er sich in ihr als Einzelheit hervorbringt. Da er durch die einzelne Allgemeinheit der menschlichen $\mathrm{Ge}$ schichte allgemein und durch die allgemeinmachende Einzelheit seiner Entyürfe einzeln ist, muß er zugleich von den beiden Enden her untersuctit werden."

Die dichterische Reaktion der "Avantgarde"-Künstler auf die verschiedenen Krisentendenzen der Moderne läßt einen gemeinsamen Nenner erkennen: Den europäischen Dichtern der Kulturkrise war offenbar bei allen Unterschieden der Rekurs auf die Kräfte des schöpferischen Bewußtseins gemeinsam, aus denen - wenn überhaupt - die Erneue- 
rung der Kultur erwartet wurde. In diesen Zusammenhang kann die reflektierende Besinnung der Künstler auf die Verfassung des eigenen Selbst in der Moderne gestellt werden, die zur Entwicklung des europäischen Bewußtseinsromans führte: Sei es, daß man sich im Protest gegen den Verfall der Werte, der Denk- und Lebensformen der Kraft des produktiven Erimerungsvermögens bewußt wurde, wie Proust, oder der utopischen Sehnsucht nach dem Ganzen in der "Anarchie der Atome", wie Musil, oder der "Epiphanie des Augenblicks", in der der verlorene Zusammenhang neu antizipiert werden kann, wie bei Joyce.

Die großen Dichter der modernen Kulturkrise - und zu ihnen rechnen wir Belyj - sind nicht nur deren Seismographen gewesen, die den "Ausschlag" bis über die Schmerzgrenze hinaus aushielten, sondern sie machen in je verschiedenem Grade und in sehr unterschiedlichen Richtungen, aber gleichermaßen hartnäckig in der geistigen Anstrengung und avantgardistisch in der Form, den Versuch zur Gegenreaktion im Medium der dichterischen Erkenntnis des schöpferischen Bewußtseins. Die Anfänge des Bewußtseinsromans in Rußland entstehen im Symbolismus in der Prosa Belyjs. Die Linie läßt sich von den "Symphonien" in Prosa (1902 - 1908) bis zum Abschluß der Romantrilogie mit "Kotik Letaev" (1915/16) verfolgen. Sie markiert deutlich das avantgardistische Potential des russischen Symbolismus. Die neuere Diskussion zur "Avantgarde" als Stilformation wird sich damit noch weiter. auseinandersetzen müssen. 


\section{K A P I T E L}

\section{DIE ERSCHENUNG DES POETA DOCTUS IN RUSSLAND - BELYJ IM KONTEXT DER "INTELLIGENCLJA"}

\section{Zum Wandel im Selbstverständnis der russischen "Intelligencija" der Jahrhundert- wende: Der "Weg Ruslands" und der "Weg der Seele"}

Wurde im Vorangehenden der Versuch gemacht, den Dichtertypus des poeta doctus als Prototyp der modernen Kulturkrise im Rahmen der dichterischen Reaktion der nachnietzscheschen Generation von 1880 auf die drei herausgehobenen Krisentendenzen der Krise des Bewußtseins, der Sprache und der bürgerlichen Lebensformen zu beschreiben und als den gemeinsamen Nenner der dichterischen "Antworten" den Rekurs auf die Kräfte des schöpferischen Bewußtseins zu definieren; wurde gleichzeitig damit versucht, den Anteil Belyjs an diesem Prozeß anzudeuten, so soll jetzt auf einige der besonderen Bedingungen eingegangen werden, von denen die Erscheinung des poeta doctus in Rußland mitbestimmt ist. Sie ergeben sich vor allem aus dem Selbstverständnis der russischen "Intelligencija", die seit den sechziger Jahren zum festen Begriff für eine geistig und politisch engagierte Schicht in Rußland wurde. Mit der "bürgerlichen Intelligenz" des Westens kann sie nur bedingt verglichen werden. ${ }^{1)}$

Der Dichter in Rußland stand aufgrund seiner Zugehörigkeit zur Intelligenz viel mehr als gemeinhin in Westeuropa in der ideologischen Auseinandersetzung innerhalb der geselischaftlichen Prozesse und hatte im neunzehnten Jahrhundert in Ermangelung parlamentarischer Institutionen eine Ersatzfunktion als "Prophet und Richter" wahrzunehmen, in der er mit westlichen Dichtern dieser Zeit nicht zu vergleichen ist. ${ }^{2)}$ Die "soziale Funktion der Literatur" - aber auch ihre religiöse und philosophische - trat aufgrund dieser Lage gegenüber der "ästhetischen" stärker hervor, weil die Literatur sich außerästhetischen Forderungen dringlicher verpflichtet fühlte, als die Literatur in westlichen Ländern, deren Sozialstruktur weniger antagonistisch und deren kulturelle Aktivitäten weiter ausdifferenziert waren. 3 )

Ein Indiz dafür ist der "gesteigerte Ideologismus" in der künstlerischen Intelligenz der neunziger Jahre. Nach der Stagnation der russischen Intelligenz unter Alexander III. kam es in den frühen neunziger Jahren zu einem neuen Aufschwung, in dem sich sowohl eine politisch-soziale Befreiungsbewegung - getragen von der Zemstvo-Bewegung, dem demokratischen Liberalismus, vor allem aber vom entstehenden Marxismus - als auch eine geistig-kulturelle Befreiungsbewegung herausbildete, die sich als "geistige Renaissance" verstand. ") Eines der Zentral themen dieser Dauerdebatte innerhalb der russischen Intelligencija, die bis zur Revolution 1917 anhielt, ist die Frage nach "Niedergang oder

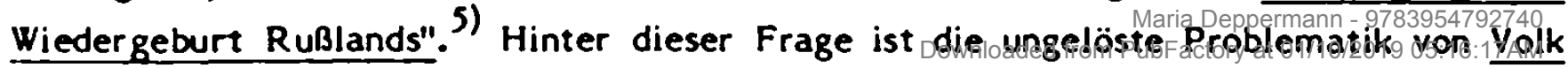


und Intelligenz zu erkennen, die u. a. als Folge der unbewältigten Reformen unter Alexander II. sowie aus dem Fiasko des narodničestvo zu erklären ist. ${ }^{6)}$ Verbunden mit der sozialen Frage ist aber auch die Forderung nach Selbstbesinnung auf den religiös-moralischen Zustand des modernen Intellektuellen, der seine Verantwortung vor dem Volk nur dann erfüllen kann, wenn er die Gefahren der Dekadenz und Selbstbezogenheit überwindet. Eine der schärfsten Diagnosen der bedrohlichen Entfremdung zwischen Volk und Intelligenz stell te $\underline{A}$. Blok in seinem Vortrag vor der Religiös-Philosophischen Gesellschaft in Petersburg im Jahre 1908 "Volk und Intelligenz", 7) der hef tige Gegenangriffe auslöste wegen der Unerbittlichkeit, mit der Blok die nicht bewältigten Aufgaben der Intelligenz bloßlegte. Das Thema vom Weg Rußlands hatte die Intelligenz schon in der zweiten Hälfe des neunzehnten Jahrhunderts immer mehr beschäftigt. Es fand literarischen Niederschlag beim späten Gogol', auf den sich Blok bezieht ${ }^{8)}$, in den großen Romanen Dostojevskijs, in denen aktuelle und politische gesellschaftskritische Problematik mit philosophischen Ideen verbunden wird - vor allem in "Besy" und "Brat'ja Karamazovy"9) wie auch in seiner und Tolstojs Publizistik. Darüber hinaus prägte es die soziale Thematik der realistischen Literatur des narodničestvo. ${ }^{10)}$ Die Pứkin-Rede Dostojevskijs im Jahre 1880 wurde von vielen Zeitgenossen als Beginn einer neuen Phase moralphilosophischer Besinnung auf die Zukunft Rußlands angesehen. (1)

Das Schicksal Rußlands beschäftigte die Intelligenz aber nicht nur literarisch, sondern seit den Aufrufen der beiden großen Emigranten Alexander Herzen (1861) und Michail Bakunin (1869), "ins Volk zu gehen" (choždenie v narod"), bildete sich vor allem unter der gebildeten Jugend ein starkes soziales und politisches Engagement heraus, das zum Entstehen eines politischen Aktivismus führte, der sich zuerst in der NarodnikiBewegung formierte. ${ }^{12)}$ Die Narodniki verstanden sich als geistig-revolutionäre Elite. Uberzeugt davon, daß nur eine Revolution des Volkes die Verhältnisse in Rußland ändern könne, setzten sie auf den russischen Bauern. In Anbetracht der Tatsache, daß vier Fünftel der Bevölkerung auf dem Lande lebten, sahen sie in einem "utopischen Bauernsozialismus spezifisch russischer Prägung" ${ }^{13)}$ den Sonderweg Rußlands, an den übrigens auch Marx eine zeitlang geglaubt hatte. ${ }^{14)}$ Ideologische Grundlage war die Idealisierung der Dorfgemeinde und der Glaube daran, daß man dem Volk "die ganze Wahrheit erzählen müsse", um sein Bewußtsein zu revolutionieren. Doch die spontane Aktion der Narodniki, die mit einem idealistischen Massenaufbruch im "verrückten Sommer" des Jahres 1873 begann, endete in einem Fiasko. Die Bauernaufklärung schlug fehl, die Polizei schlug zu mit scharfen Gegenmaßnahmen.

Jetzt polarisierten sich die beiden Flügel der Narodniki. Waren ohnehin schon zwei ideologische Konzepte statt eines einheitlichen Programms des NarodniCestvo vorhanden: die anarchistischen Thesen Bakunins zur sofortigen Revolutionierung " tari" (Aufrührer) anhingen, und die evolutionäre Konzeption Lavrovs und Michajlovskijs, ${ }^{16)}$ denen die "podgotoviteli" (Vorbereiter) folgten - so sah sich die Mehrheit der 
Volkstümler jetzt nach dem doppelten Fehlschlag auf den Weg des individuellen Terrors gedrängt. Sie organisierte sich 1876 in der revolutionären Organisation "Zemlja i volja" (Land und Freiheit). 1877/78 wurden in Massenprozessen Märtyrer der Bewegung geschaffen; eine Welle von Attentaten folgte, denen schließlich im Jahre 1881 der als "ZarBefreier" angetretene Alexander II. zum Opfer fiel.

Doch bereits 1879 hatten sich an der Frage des Terrors innerhalb der Narodniki die Geister geschieden: Unter G. V. Plechanov und P. B. Aksel'rod spaltete sich eine gemäßigte Minderheit ab, "Černyj peredel" (Geheime Umverteilung), die den Terror ablehnte und sich auf Agitation und Aufklärung beschränken wollte. Die Mehrheitsgruppe radikalisierte sich weiter zur "Narodnaja volja" (Volkswille) und sah den Ausweg nur noch im Zarenmord. Doch das radikale Narodničestvo erreichte trotz der Ermordung des Zaren keine revolutionären Erfolge, sondern seine Aktionen brachen zusammen. Es kam zu einer Krise des narodničestvo in den achtziger Jahren, die sich vor allem aus dem Zweifel an der revolutionären Basis ergab. Welches "Volk" konnte Träger der Revolution werden?

G.V.Plechanov und seine Gruppe wandten sich nicht nur von der Ideologie des Terrors $a b$, sondern auch von der des Bauernsozialismus. Die kommende revolutionäre Kraft - auch im noch agrarischen Rußland - erkannten sie in der Industriearbeiterschaft. 1883 gründete Plechanov in Genf die erste marxistische russische Organisation "Osvoboždenie truda" (Befreiung der Arbeit). Die Marxisten sahen den Weg Rußlands in straffer Organisation einer klassenbewußten Arbeiterschaft, mit der der äußere Umsturz geplant werden konnte.

Petr Lavrov und N.K. Michajlovskij vertraten gegen den materialistischen und deterministischen Marxismus, in dem ihnen die Dimension der Freiheit und der Persönlichkeit fehlte, die "subjektive Methode" einer allmählichen Bewußtseinsveränderung des Einzelnen. Die Narodniki versuchten es jetzt mit der Legalität; sie machten sich an die pragmatische Kleinarbeit der "malye dela" (kleine Werke) und gründeten Arbeits- und Lebensgemeinschaften (artel'), die Vorbildcharakter haben sollten.

Immer noch illegal - mit Zentren im Ausland - bildeten sich um 1900 die ersten drei Parteien heraus. Der radikale Flügel der Opposition wurde einerseits repräsentiert von den "Marxistischen Sozialdemokraten" (RSDRP ab 1898) mit einer materialistischen, wissenschaftsorientierten Welt anschaung und rigider Parteidisziplin, auf der anderen Seite von den anarchistischen und agrar-populistischen Sozialrevolutionären (SR ab 1900), mit einer individualistischen und idealistischen Weltanschauung ohne festen Klassenbegriff und straffe Organisation; schließlich der liberale Flügel (ab 1902) von den künftigen konstitutionellen Demokraten (Kadetten), die einen Weg der Reformen erstrebten. ${ }^{17)}$

$Z$ wischen Marxisten und Sozialrevolutionären bestand eine tiefe weltanschauliche Kluft. Die strittigen Werte waren Freiheit und Persönlichkeit. Die Intelligenz der "geistigen Renaissance" wurde vom geistigen Maximalismus der Sozialrevolutionäre ("Esery") stärker angezogen; mit ihnen teilten sie den Glauben an eine "Revolution des Geistes" 
über die Veränderung des Bewußtseins des Einzelnen, der sie den Primat vor dem äußeren Umsturz gaben.

Neben dem traditionellen Thema vom "Weg Rußlands" tauchte ein für die Intelligenz bisher untypisches Thema auf, nämlich das vom "Weg der Seele". Es ist eng verbunden mit der Erscheinung eines "Neuen religiösen Bewußtseins" innerhalb der russischen Intelligenz - ein Novum in ihrer bisherigen Geschichte.

"Die damals vollzogene religiöse Wende verschiedener wenn auch kleiner Fraktionen der russischen Intelligenz war affs) Gruppenphänomen in der $\mathrm{Ge}-$ schichte der Intelligenz etwas völliges Neues."

Wie hatte es in der russischen Intelligenz, die zwar aufgeklärt, aber religiös weitgehend indifferent und nicht konfessionell gebunden war, zu einem solchen Wandel kommen können?

Hierfür gibt es komplexe Gründe, von denen nur einige aufgeführt werden können. Zunächst kann man sagen, daß einer religiösen Orientierung von Gruppen der Intelligenz in Rußland vor allem die Allianz der Orthodoxie mit dem autokratischen Staat im Wege stand, aber auch deren Tendenz zur Beschränkung auf Kult und Liturgie. ${ }^{19)}$ Die drei großen religiösen Beziehungsfiguren Rußlands: Tolstoj, Dostojevskij und Solov'ev waren von der Orthodoxie entweder exkommuniziert oder verfolgt worden. Doch gerade an ihnen war eine Möglichkeit von Religiosität manifest geworden, in der die individuelle Erfahrung des Einzelnen als neue Grundlage der Religion aufgeschlossen und aufgewertet wurde. Obwohl die drei religiösen Denker nicht unmittelbar eine Auswirkung auf ihre Zeitgenossen ausübten, hatten sie doch eine entscheidende Fernwirkung auf die nächste Generation, ${ }^{20)}$ nämlich zu dem Zeitpunkt, als das Selbstverständnis eines Teiles der Intelligenz in eine Krise geriet.

Innerhalb der religiös enttäuschten oder indifferenten Intelligenz polarisierten sich der materialistische und der idealistische Flügel immer mehr. Doch auf beiden Seiten wuchs das geistige Ungenügen. Der rationalistische und deterministische Materialismus hatte für die Probleme der menschlichen Freiheit und Persönlichkeit keine philosophische Grundlage. Der Positivismus konnte die Welt zwar immer genauer erklären, doch die Ergebnisse der Wissenschaften konnten keine Antwort auf die Sinnfrage geben. Gegen die Philosophie des Hegelianismus war seit Belinskijs und Herzens Kritik um 1840 in der russischen Intelligenz von verschiedenen Seiten her der Einwand erhoben worden, daß hier das Individuum auf ein Instrument der Selbstverwirklichung des absoluten Geistes reduziert würde. Hegels Intellektualismus schien diesen Kritikern keinen Raum zu lassen für die Autonomie, Freiheit und Kreativität das Individuums. ${ }^{21)}$

Das Bedürfnis nach einer Philosophie der Persönlichkeit löste in der Intelligenz der Jahrhundertwende die Suche nach neuen inneren Grundlagen jenseits des materialistischen und idealistischen Rationalismus aus. Dieses Bedürfnis hat offenbar seine Wurzel 
nicht nur im Vernunftprotest allein, sondern kann auch anders gedeutet werden, nämlich als eine Gegenbewegung zum Kollektivdenken der orthodoxen sobornost'. Man kann in dem Suchen nach einer neuen anthropologischen und religiösen Basis die Auswirkung einer der enttäuschendsten Erfahrungen der narodničestvo-Intelligenz sehen. Waren sie doch in ihrem Aufklärungsstreben vor allem an der religiösen und dogmatischen Kollektivnatur des Bauernvolkes gescheitert, das der Aufklärung gar nicht zugänglich war. ${ }^{22}$ ) Ein Teil der Narodniki hatte sich resigniert auf den Pragmatismus der malye dela (kleinen Werke) beschränkt. Wollte man aber darüber hinaus zur Persönlichkeitsbildung und Bewußtseinsentfaltung im Volk kommen, dann war dazu eine Philosophie der ganzen Persönlichkeit nötig, die überzeugende Kraft ausstrahlen konnte. Das war von den Theoretikern des narodničestvo, von Lavrov und Michajlovskij, auch erkannt worden, die schon an einer philosophischen Grundlage für ihre "subjektive Methode" gearbeitet hatten.

Nun ist mit dem Bedürfnis nach einer Philosophie der Persönlichkeit das vielschichtige und damals besonders umstrittene Problem des Individualismus berührt. Man kann in der Hinwendung zum Individuum außer den genannten Komponenten auch eine eskapistische Tendenz erblicken. Statt sich weiter mit der mühsam gewordenen sozialen Frage zu beschäftigen, wich man aus in die Kultivierung des eigenen Selbst und in religiöses Suchen. Daß es im fin de siècle einen Modetrend gab, der zu Mystik, Okkultismus und religiöser Pseudoromantik neigte, ist unbestreitbar, ebenso dessen resignative und eskapistische Seiten. Hier die Spreu vom Weizen zu sondern, ist nicht einfach. Es ist aber die Frage, ob man die Entstehung eines "Neuen religiösen Bewußtseins" allein mit Eskapismus erklären kann. Der Aufschwung, den die russische Religionsphilosophie seit VI. Solov'ev in Rußland genommen hat, ist mit der Eskapismus-These schwerlich zu erfassen. Auch die Gründung und Wirkung der Religiös-Philosophischen Gesellschaften in Moskau und Petersburg ist - wie die eingehenden Untersuchungen von Jutta Scherrer gezeigt haben - nicht ohne einen Wandel im Selbstverständnis eines Teils der russischen Intelligenz zu erklären.

Neben den ideellen Voraussetzungen dieses Wandels gibt es soziologische. Wenngleich die Reformen unter Alexander II. über einige liberale Ansätze nicht hinausgekommen waren - das Reformprojekt des Innenministers Loris-Melikov wurde nach dem Attentat auf Alexander II. von seinem Nachfolger abgelehnt - so hatten sie doch eine soziale Statusveränderung innerhalb der Intelligenz zur Folge. Rußland war zum ersten Mal in einem Prozeß der Modernisierung begriffen, der in den russischen Gründerjahren um 1890 sprunghaft anwuchs. Wollte der Staat die ökonomischen und administrativen Veränderungen, die aus den Reformen resultierten, bewältigen, war er auf eine geschulte und effiziente Fachintelligenz angewiesen. War die alte Intelligenz der vierziger und sechziger Jahre, trotz ihrer Gegensätze zueinander, einig in ihrer staatsfeindlichen Einstellung, so spaltete sich die Intelligenz der achtziger Jahre auf. Denn hier wurde von einem beträchtlichen Teil zum ersten Mal der Versuch gemacht, sich in den Staat zu integrieren. 
An die Stelle der alten philosophisch-politisch-künstlerischen Intelligenz in Opposition zum Staat, trat ein neuer Typ des "Intelligent" auf, der spezialisierte, wissenschaftlich ausgebildete homo novus, der als Arzt, Wissenschaftler, Ingenieur, Ökonom oder Jurist im Staat, der einen wirtschaftlichen Boom erlebte, Fuß faßte und, meist liberal konservativ eingestellt, keine Opposition mehr betrieb. Vom Glauben an Wissenschaft und Fortschritt erfaßt, erhoffte diese neue Schicht eine allmähliche Reformierung des Staatsund Wirtschaftswesens und stellte, zufrieden mit ihrem sozialen Status, die Legitimation des Staates nicht infrage. ${ }^{23)}$

Von denjenigen aber, die sich weiterhin den kritischen Denktraditionen der Intelligenz alten Stils verpflichtet fühlten, wurde hierin optimistische Blindheit und Gleichgültigkeit gesehen, die sie zum Protest trieb, der wesentlich davon bestimmt war, daß sie ein deutliches Gefühl dafür entwickelten, in einer Situation der Krise zu leben. ${ }^{24)}$ Verschärft wurde dieses Krisenbewußtsein durch den Einfluß des europäischen Kulturpessimismus, löste aber zugleich auch die Gegenreaktion aus, sich für die Erneuerung Rußlands auf dem inneren Wege über die Schaffung einer neven Kultur auf religiöser Grundlage einzusetzen. Jutta Scherrer schreibt in ihrer Analyse des "Neuen religiösen Bewußtseins":

"Die Vorstellung von dem Ende der Kultur ist in unmittelbarem Zusammenhang mit der Krisenstimmung zu sehen, die von der Jahrhundertwende bis zum Ausbruch der Revolution 1917 nicht nur von dem engeren Lager der symbolistischen Lyriker wie Blok, Belyj, Vjačeslav Ivanov, Z. Gippius U. a. empfunden wurde, sondern ebenfalls auch von Schriftstellern, die den literarischen Strömungen des Symbolismus verbunden waren wie Rozanov, Berdjaev, Ternavcev, Bulgakov, Mejer. Diese stimmten zwar keineswegs uneingeschränkt Merezkovskijs Herausstellung Tolstojs und Dostojevskijs als dem überzeugenden Symbol dieser Krisenstimmung zu. Doch kennzeichnete diese primär von Nietzsche und dem westeuropäischen Kulturpessimismus beeinflußten Kreise das Bewußtsein, sich unmittelbar vor einer Kulturkatastrophe, vor dem 'Untergang des Humanismus' zu befindf5?, 'am Rande der Geschichte', in der 'Apokalypse unserer Zeit' zu stehen."

Eine besondere Ausformung fand das Krisenbewußtsein in der eschatologischen Ideologie VI. Solov'evs, die sich sowohl in seinen Gedichten ("Panmongolismus") ausdrückte, wie auch in den "Drei Gesprächen über den Krieg, den Fortschritt und das Ende der Weltgeschichte, mit einer kurzen Erzählung vom Antichrist" - erschienen im Mai 1900, drei Monate vor seinem Tode. Verbunden mit den Entwicklungen im Fernen Osten (China als "Gelbe Gefahr") übten die prophetischen Worte Solov'evs vom drohenden Einbruch des Bösen in der Geschichte - die sich im stalinistischen und faschistischen Terror nur allzu grausam bewahrheiten sollten - auf das Krisenbewußtsein der jungen Generation von 1900 eine prägende Wirkung aus. ${ }^{26)}$ Wenngleich die Drohung der Apokalypse schnell den Charakter eines Schlagwortes für eine dumpf gefühl te Katastrophenstimmung annahm, so war sie doch im Kern als Appell zum Widerstand gegen die Macht des Bösen in der Geschichte gemeint, die Solov'ev in der Fähigkeit des Menschen zur freien Entscheidung 
gegründet sah. 27)

Das Krisenbewußtsein in Rußland - und das gilt nicht nur für Solov'ev - zeichnet sich dadurch aus, daß man sich zwar der Bedrohtheit der Situation bewußt war, aber dennoch das Gefühl hatte, ihr nicht hilflos ausgeliefert zu sein. Denn gleichzeitig bildete sich auch die Uberzeugung, ihr durch eine "geistige Renaissance" begegnen zu können. Innerhalb des "Neuen religiösen Bewußtseins" entwickelten sich verschiedene Varianten: der evangelische Anarchismus der Tolstojaner, die religionsphilosophische Richtung der Solovjaner, die "Gottsucher" und die "Gotterbauer". Die religiöse Frage erfaßte in dieser Zeit auch Materialisten, die nach einer Religion ohne Gott suchten und sich als Anhänger des "Gotterbauertums" zusammenfanden. Zu ihnen gehörten A. V. Lunačarskij, S. Vol'skij, A. A. Bogdanov, V. A. Bazarov und der Schriftsteller Maxim Gor'kij. ${ }^{28)}$ Ihnen gegenüber standen die vom Idealismus herkommenden "Gottsucher", deren Führer D. S. Merežkovskij wurde. Zu ihnen gehörten außerdem seine Frau Z. Hippius, N. M. Minskij, V. Rozanov und zeitweise auch der Philosoph Lev Šstov. ${ }^{29)}$ Den "Gottsuchern" näher standen die Solovjaner, die mit der Gründung der Moskauer Religiös-Philosophischen VladimirSolov'ev-Gesellschaft und den Petersburger Religiös-Philosophischen Vereinigungen eine Bewegung schufen, die nicht nur religiöse, sondern vielfältige geistige und künstlerische Interessen verfolgten. ${ }^{30)}$ Für den Symbolismus hatten die "Gottsucher" und die Solovjaner wichtige Bedeutung. Von ihnen wurde eine Entwicklung eingeleitet, in der sich der Symbolismus zur religiös bestimmten Weltanschauung ausformte. Als ihren vielleicht bedeutendsten Ertrag wird man V. Ivanovs Versuch ansehen können, in seiner Idee vom "leidenden Gott" eine Synthese aus Dionysos und Christus zu finden. Ivanov schwebte nichts Geringeres vor, als zu einer Versöhnung der gegensätzlichen Positionen von Nietzsche und Solov'ev zu kommen.

Man kann also sagen, daß sowohl die Zuspitzung des "Ideologismus" in den neunziger Jahren wie auch das Aufkommen des "Neuen religiösen Bewußtseins" eine unterscheidende weltanschauliche Basis für den russischen Symbolismus gewesen ist, die ihn vom französischen grundsätzlich abhebt, der einer ganz anderen philosophischen und sozialen Tradition entstammte, nämlich der Trennung von Künstler und Gesellschaft. Außerdem fehlen ihm vergleichbare zeitgenössische religiöse Beziehungsfiguren. Er ist dagegen gekennzeichnet vom Protest gegen den christlichen "Erbzwang" und von der Erfahrung der "leeren Transzendenz", 31) eine geistige Ausgangslage, wie sie Nietzsche in der "Fröhlichen Wissenschaft" in seiner klassisch gewordenen Formulierung bestätig te:

"Das größte neuere Ereignis - daß 'Gott tot ist', daß der Glaube an den christlichen Gott unglaubwürdig ${ }_{3}$ geworden ist - beginnt bereits seine ersten Schatten über Europa zu werden.

Dieser ideologische Hintergrund des russischen Symbolismus, der hier nur in einigen Umrissen gezeichnet werden konnte, ist charakterisiert durch die beiden wesentlichen 
Fragen der intellektuellen Debatte der Jahrhundertwende: nach dem "Weg Rußlands" und nach dem "Weg der Seele", die sich verbinden im Suchen nach einer neuen, religiös begründeten Kultur. Bei einer Gesamtbeurteilung des russisctien Symbolismus kann er nicht außer acht bleiben. Das gilt für alle großen Symbolisten, mit Ausnahme von Valerij Brjusov, der in dieser Hinsicht von Anfang an eine Sonderstellung einnimmt.

\section{Die beiden Fronten der "Künstler" und der "Philosophen"}

Der reflektierende Dichter der russischen Jahrhundertwende stand aber nicht nur in der ideologischen Auseinandersetzung um eine neve Weltanschauung und um die Rolle der Kunst in ihr, sondern er mußte sich auch mit der Beziehung zum Publikum auf eine neue Weise befassen; vor allem dann, wenn er sich als Teilnehmer an einem allgemeinen Prozeß der Erneuerung der Kultur verstand, der mit Kunst auf die Veränderung des Bewußtseins einwirken will. Mit der "Demokratisierung des Kunstlebens" in Rußland seit dem Aufschwung der neunziger Jahre, verursacht durch die sprunghafte Modernisierung, die das Aufblühen von Zeitschriften, Verlagen, Theater und anderen kulturellen Einrichtungen mit sich brachte, war der Zugang viel breiterer Leser- und Betrachterschichten zur Kunst möglich geworden. ${ }^{33)}$ Ihnen gegenüber mußte sich der moderne Künstler über den Wandel in den Formen der ästhetischen Kommunikation klar werden. Wollte er an der Erneuerung der Kultur mitwirken, so stand er vor einem grundsätzlichen Kommunikationsproblem: Soll te er sich auf die Forderung nach "Allgemeinverständlichkeit" breiterer Leserschichten einlassen oder sollte er auf den Maßstäben seiner eigenen schöpferischen Individualität und den neuen ästhetischen Standards bestehen?

Von denjenigen, die sich in der Vorgängergeneration um eine Erneuerung der Kunst bemüht hatten, vor allem um die Uberwindung der Kluft zum Volk - von der bildenden Kunst der peredvižniki-Maler wie auch von der Literatur des narodničestvo - war diese Frage immer mehr zu größerer Volkstümlichkeit hin entschieden worden. Tolstoj forderte schließlich in seinem Traktat "Was ist Kunst" (1898) eine offen didaktische Kunst der Volkserziehung, die eine ästhetische Maßstabverschiebung zugunsten des Adressatenkreises implizierte. Darin folgte ihm Gor'kij - wenngleich nur eine zeitlang. ${ }^{39)}$ Gegen das Vorherrschen der sozialen Funktion der Kunst über ihre ästhetische wandte sich aber die Kunstauffassung der Symbolisten und des "Stil' modern", wie er im Kreis um die "Welt der Kunst" vertreten wurde: Merežkovskij in seinem Manifest von 1893 "Uber die Ursachen des Niedergangs und über neue Strömungen in der zeitgenössischen russischen Literatur"; Benois mit der Kunstpolitik seiner neuen Zeitschrift, "ein großangelegtes Programm, doch ohne die Spur eines Kompromisses". Hauptpunkt seines "Programms" war das Recht der Kunst auf Schönheit, und die führende Rolle wurde der schöpferischen Individualität zuerteil t. ${ }^{35)}$ 
Um ihre neuen Standpunkte zu erläutern, nahmen die symbolistischen Dichter selbst häufig die Funktionen der Literaturkritik und Ästhetik wahr. Vor allem auch, weil die installierte Kunstkritik sich an vergangenen Kunstwerken orientierte und sich auf die neue Kunst nicht einlassen wollte. ${ }^{36)}$ Nun wichen diese Standpunkte aber beträchtlich voneinander $a b$, auch in den Reihen der Vertreter der "Neuen Kunst". Denn obwohl man sich darin einig war, daß die Maßstäbe der ästhetischen Kommunikation von den Künstlern selbst gesetzt werden müßten, so gab es doch zwei grundverschiedene Ansichten darüber, was die Kunst sein und auf welchem Wege sie wirken sollte. Denn die Kunst der russischen Moderne verstand sich nicht als reine Ausdruckskunst, sondern suchte die Wirkung auf den Betrachter bzw. Leser; jedoch auf eine weitaus anspruchsvollere Art, als das bisher in der realistischen Kunst für möglich gehalten wurde, und auch in anderer Weise als in der Suggestionsästhetik, die von den französischen Symbolisten und ihrer l'art pour l'art-Konzeption vertreten wurde. Die Symbolisten in Rußland standen nicht auf dem parnassistischen Standpunkt einer "monologischen" Kunst, sondern auf dem einer "Kunst vor Zeugen" 37) - allerdings ohne Zugeständnisse, was zur Wirkungsabsicht in einem gespannten Verhältnis steht: Denn entweder wird der Rezipient aktiviert oder er geht verloren (vgl. dazu 2. Teil, Kap. 4).

Ein Symptom des Ringens der künstlerischen Intelligenz um ein neues Kunst - und Wirkungsverständnis sind die heftigen Polemiken, die seit den neunziger Jahren bis zum Ende des ersten Jahrzehnts des zwanzigsten Jahrhunderts die Zeitschriften füllten. Eine Grundkonstellation bildete sich bereits am Anfang heraus: die beiden Fronten der "Künst ler" und der "Philosophen".

Die "Künstler" sammelten sich um die Petersburger Zeitschrift "Welt der Kunst", deren Organisator Djagilev, deren geistiger Kopf Alexander Benois war. ${ }^{38)}$ Sie vertraten den Standpunkt der "reinen Kunst". Uber diesen Begriff ist es oft zu Mißverständnissen gekommen. Was hiermit gemeint ist, darf nicht mit einem l'art pour l'art-Programm jenseits der Gesellschaft verwechselt werden, wie es von ästhetischen Parnassiens in einer ganz anderen gesellschaftlichen Umwelt im Frankreich des Zweiten Kaiserreiches vertreten wurde. Den russischen Vertretern der "reinen Kunst" geht es um eine Kunst, die ihre Unabhängigkeit in zweierlei Richtungen erkämpfen will, von denen sie bislang in Anspruch genommen wurde: vom Utilitarismus - wie inn der soziale Auftrag mit sich brachte - und von philosophisch-moralischer "Bevormundung" durch eine normative Asthetik des zeitlos Wahren, Guten und daher auch Schönen. Vorreiter in diesem Unabhängigkeitskampf waren hier die bildenden Künstler, die sich gegen die direkt sozialengagierten "Wanderer" ebenso wie gegen die akademische Salonkunst abheben (da beide die Kunst durch Uberlagerung von kunstfremden Interessen ins formale Abseits geführt hatten) und den Anschluß an die Kunst Westeuropas wiederfinden wollten. Für die Literatur hatte das auch Geltung. Zu den ersten Literaten, die sich den bildenden Künstlern anschlossen, gehörten Brjusov und Merežkovskij, denn in der Ablehnung des Utilitarismus 
waren sie sich einig. Ihr Ziel war aber nicht die Kunst als reiner Selbstwert, sondern ebenso wie ihre Gegner, die "Philosophen", wollten sie ja zur Wiedergeburt der russischen Kultur und Gesellschaft beitragen, aber eben nicht auf eine Weltanschauung verpflichtet werden und nicht unter Verzicht auf ihre ästhetische Autonomie. Sie verstanden ihren Beitrag als "humanitäre Utopie" durch Hinführung des Menschen zum Schönen: Aus einem reinen "Sensualismus" wurde von ihnen eine Umgestaltung der Lebensformen erhofft. Ihre Tradition einer Erlösung der Menschheit durch das "Schöne" bezogen sie aus der englischen Kunstphilosophie Carlyles und Ruskins, aus der bildnerischen Praxis der Präraffaeliten, ein Vorbild besonderer Art war Morris. ${ }^{39)}$ Auf den Einfluß dieser kulturkritischen Strömung Englands weist Sternin mit vielfältigen Belegen aus dem empirisch erforschten Kunstleben Rußlands der Jahrhundertwende hin; er kann sich dabei u. a. auch auf Belyjs Memoiren und auf sein nostalgisches Poem "Erstes Rendezvous" (Pervoe svidanie) berufen, wo Belyj die Bedeutung der neuartigen Kunst der Präraffaeliten hervorhebt, die nach Sternin zu den "Ahnen des russischen Symbolismus" zu rechnen sind. ${ }^{40)}$ Auf diese noch kaum erforschten Beziehungen wird von Sternin zum ersten Mal aufmerksam gemacht.

Den "Künstlern" skeptisch gegenüber standen die "Philosophen", angeführt von Benois' Widerpart D. Merežkovskij. Vorreiter waren hier die Literaten mit ihren traditionell ideologischen Gattungen von Traktat, Manifest und philosophisch grundierter Lyrik. ${ }^{41)}$ Sie vertraten den Standpunkt einer religiös-philosophischen Erneverung der Kunst in der Nachfolge der "positiven" Ästhetik V1. Solov'evs. Sie wehrten sich aber ebenso wie die "Künstler" gegen die Tagesforderungen eines direkt gesellschaftsbezogenen Utilitarismus. Gemeinsam war beiden auch das "Interesse für das historische Schicksal der russischen Kultur". 4la) Der "reinen Kunst" jedoch standen sie kritisch gegenüber und verurteilten sie oft kurzsichtig als "Dekadenz". Dem ästhetischen Sensualismus standen sie - in der Tradition Platons - kritisch gegenüber und befürchteten, daß er zur Quelle eines ästhetischen Anarchismus werden könne. Sie erstrebten dagegen die innere Wandlung des Künstlers durch religiöse Erfahrung vor allem Schaffen, so daß er eine Kunst schaffen könne, die wiederum zur Wandlung des moralisch-sittlichen Bewußtseins im Leser führen solle. Hierin sahen sie den Beitrag der Kunst zur "Wiedergeburt" Rußlands. Zunächst waren die "Künstler" und die "Philosophen" gemeinsam in der "Welt der Kunst" vereint. Sie führten dort aber eine dauernde innere Polemik, in der D. V. Filosofov vergeblich zu vermitteln suchte. Schließlich zogen die "Philosophen" aus und gründeten im Jahre 1902 ihre eigene Zeitschrift "Neuer Weg", die erste ausschließliche und zwei Jahre lang auch einzige Zeitschrift des weltanschaulichen Symbolismus. Die "Künstler" unter den Literaten gruppierten sich ab 1904 um Brjusov und seine neue Zeitschrift "Waage" (Vesy), nachdem die "Welt der Kunst" eingegangen war.

Die Fortsetzung des Meinungsstreites über eine "autonome" oder eine "positive" Kunst erstreckte sich in scharfen Polemiken, an denen Belyj wesentlichen Anteil hatte und in denen er die Erfahrungsbasis für seine ästhetische Theria Peppermann 9783954792740 ganze 
erste Dekade des neuen Jahrhunderts und kulminierte schließlich im "Symbolistenstreit" von 1910 in der Zeitschrift "Apollon", in der die "Künstler" von Brjusov, die "Philosophen" - je verschieden - von Blok, Belyj und Ivanov vertreten wurden. ${ }^{42)}$ Diesem Streit liegt die manifest gewordene Antinomie von Ethik und Ästhetik, von Sinnlichkeit und Geistigkeit zugrunde, die nicht nur in Rußland um die Jahrhundertwende zum Vorschein trat - und die offenbar zu den Aporien der Ästhetik gehört. ${ }^{43)}$ Belyj nahm als poeta doctus von Anfang an eine zentrale, aber auch mittlere Stellung zwischen beiden Extremen ein. Obwohl er in einem noch näher zu bestimmenden Sinne den "Philosophen" zuzurechnen ist, betrachtete er weder allein die philosophische noch allein die formästhetische Seite der Kunst als erschöpfend, sondern war von Anfang an als Symbolist ein Denker der "konkreten Synthese" (Nrds 404), der an beiden Polen der modernen Ästhetik, an Sinn und Form der Kunst analytisch arbeitete. 


\section{KA P I T E L}

\section{DENKVORAUSSETZUNGEN BELYJS}

Daß er diese doppelte Fragestellung verfolgte, ist sowohl von epochentypischen wie auch von individuellen Voraussetzungen bedingt. Zu den ersteren gehört die oben skizzierte Polarisierung der philosophisch-ästhetischen Debatte in Rußland um die Rolle der Kunst zwischen den "Philosophen" und den "Künstlern" in der kulturellen Öffentlichkeit der neuen Intelligencija der Jahrhundertwende. Waren die einen primär am Sinn, so die anderen primär an den Formen der Kunst interessiert. Beiden war aber dennoch eines gemeinsam: die Emeuerung der Kultur und damit Rußlands - wie sie glaubten - aus den Kräften des schöpferischen Bewußtseins, die freilich von den einen aus den Positionen eines neuen "Sensualismus", von den anderen aus einem "Neuen religiösen Bewußtsein" erhofft und betrieben wurde.

Daß trotz dieser Polarisierung die Abkoppelung von Weltanschauung und Ästhetik nicht eintrat, sondern der gemeinsame kulturanthropologische Nenner erhalten blieb, hat wesentlich mit einem Grundzug des russischen Denkens zu tun, den man als anthropozentrisch bezeichnet hat. ${ }^{1)}$ Zum ersten Mal radikal aufgebrochen wurde die Anthropozentrik des ästhetischen Denkens durch die Abtrennung weltanschaulicher Fragen von der Ästhetik im frühen Formalismus der zwanziger Jahre. ${ }^{2)}$ Im Symbolismus dagegen wurde vorläufig zum letzten Mal - die Verbindung von Sinn und Form noch nicht aufgegeben, sondern als kulturelle Aufgabe begriffen. Und das umso mehr, als sich beide Bereiche zunehmend in ihrer Eigengesetzlichkeit abzeichneten. ${ }^{3)}$ Wenngleich die dienende oder illustrierende Funktion der dichterischen Sprache vorläufig ausgespielt zu haben schien und statt dessen ihre "Selbstwertigkeit" immer deutlicher hervortrat, so hielten die Symbolisten dennoch an der Polyfunktionalität der poetischen Sprache fest, die sowohl eine monologisch-expressive wie auch eine erkennende und dialogisch-mitteilende Aufgabe erfüllen kann. Für den nicht aufgegebenen Dialog mit den Zeitgenossen zeugen sowohl die geschichtsphilosophischen Dichtungen Bloks und Belyjs ${ }^{4}$ wie auch der neue Typus einer subjektiv engagierten, lyrisch-philosophischen Literaturkritik, in der die symbolistischen Dichter selbst darangingen, in der literarischen Öffentlichkeit neue Wert-Maßstäbe für ihre Kunst der neuen Themen und Formen zu finden. ${ }^{5)}$ In diese geistig-ästhetische Suchbewegung der Epoche ist auch Belyjs Ästhetik einzugliedern; man kann sie sogar wegen ihrer Spannweite zwischen Weltanschauung und Poetik als ihren Kulminationspunkt ansehen.

Außer den epochentypischen gibt es aber für Belyjs doppelte ästhetische Fragestellung nach Sinn und Form der Kunst einige individuelle Voraussetzungen, die aus seinem besonderen Habitus als poeta doctus resultieren. Zu diesen Faktoren gehören: 1) das bei Belyj besonders ausgeprägte Bewußtsein der Kulturkrise, in dem die Frage nach dem Sinn 
der Kunst verankert war; 2) das damit eng verbundene prekäre Selbstwertgefühl als Rebell und poète maudit; 3) der unmittelbare Praxisbezug als innovatorischer Dichter, der konkret mit den Problemen eines neuen Stils zu ringen hatte, der einherging mit einem epochalen postrealistischen Formenbruch, wodurch die Frage nach der Form dringlich wurde; 4) die axiologische Grundlegung seines Denkens, in dem sich ein naturwissenschaftliches Methoden- und Theoriebewußtsein mit Axiomen der spätidealistischen Philosophie überlagern - eine Nahtstelle, aus der der Drang nach Verbindung von Kunst - und Kulturphilosophie mit den exakten Wissenschaften herrührt.

Dieses sehr komplexe Merkmalbündel von Denkvoraussetzungen ergab eine Konstellation, aus der eine Ästhetik entstand, die sich von den ästhetischen Reflexionen seiner Zeitgenossen unterschied. Den einzelnen Strängen dieser Konstellation genau nachzugehen, wäre sehr lohnend, ist aber im Rahmen dieser Arbeit nicht durchführbar. Hier kann nur einiges gewichtend angedeutet werden, was für das weitere Verständnis der ästhetischen Grundbegriffe Belyjs förderlich sein kann.

\section{Krisenbewustsein und Selbstwertproblematik}

Das Bewußtsein der Kulturkrise teilte Belyj mit seiner Zeit, insbesondere mit den beiden ihm am nächsten stehenden Symbolisten Blok und Ivanov. In seinen Erinnerungen an Blok schreibt er:

"Der ursprüngliche Kern der Symbolisten (...), wir alle drei (A. A. Blok, ich und Ivanov) stimmten darin überein: Es naht sich die Krise des Bewußtseins und es naht sich die Krise der Kultur; und - es reift heran die geistige Revolution in der Welt. Affe drei vereinte uns natürlich die Verbundenheit mit der Ideologie Solov'evs."

Im Werk aller drei Dichter des russischen Symbolismus nimmt das Thema der Kulturkrise einen zentralen Platz ein. Dessen Erforschung ist noch Desiderat, trotz vorliegender Forschungsansätze. Für Ivanov z. B. leistete wichtige Vorarbeit J. West, der sein Buch über ihn folgendermaßen begründet:

"My reason for writing such a book is the extraordinary preoccupation of the Russian symbolist poets - Brjusov, Bal'mont, Belyj, Ivanov, Blok and a great many figures of lesser stature - with the justification $-f^{f}$ their poetry in terms of a comprehensive 'philosophy of culture'." (Hv. M. D.)

Wenngleich sich West im weiteren Verlauf seines Buches auf die Darstellung von Ivanovs Ästhetik beschränkt, so ist dennoch ein Bezugsrahmen gesetzt, in dem die wesentliche Erkenntnis erhalten bleibt, daß in den theoretischen Schriften der Symbolisten "Kunst" nicht im spätbürgerlichen Sinne als isoliert-autonomer Bereich jenseits der Lebenspraxis, sondern wieder in ihrer "weitesten Bedeutung", nämlich als "Kreativität", verstanden wurde: 
"intending their theories to apply to all branches of creativity, even though, for the most part men of letters, they based their detailed arguments mainly on poetry and drama. Indeed they looked upon symbolism not simply as a philosophy of art, but as the guiding principle of an entire way of life, with art holding pridg of place as the activity in which man realizes his whole being most fully."

Ohne daß hier auf die weitreichenden Implikationen dieses Grundpostulats der Symbolisten eingegangen werden kann, ${ }^{9)}$ soll doch zweierlei festgehalten werden: 1) daß der Kunst ein wesentlicher Beitrag zur Artikulation und Uberwindung der Bewußtseins- und Lebenskrise in der modernen Kultur zugeschrieben wird, 2) daß die formalen Probleme einer neuen "Darstellung" von Wirklichkeit tief eingebettet sind in die weltanschauliche Uberzeugung:

\section{"that art haspla purpose and power that are not suggested by the word 'representation'."}

Wie weiter aus West's Untersuchungen deutlich wird, sah Ivanov die moderne Kulturkrise vor allem als eine "Kommunikationskrise" an, in der der Einzelne vom kollektiven Bewußtsein abgetrennt ist. Die Lösung erwartete er von einem neuen Verständnis des Mythos als einer nicht rational vereinseitigten und daher kollektiv zugänglichen Erfahrungs-, Denk- und Redeweise. Im "Mythenschaffen" liegt für Ivanov die Funktion der Kunst. 11) Während Ivanov die Krise der Kultur noch für überwindbar ansieht in der Rückkehr zu einem allgemeinverpflichtenden religiösen Weltbild, in dem der Mythos - vor allem der heidnisch-sinnliche der Griechen - eine neue Rolle spielen sollte, ist Bloks Krisenbewußtsein weitaus skeptischer und radikaler. Den Rückweg in ein mittelalterliches ordo-Denken, in das im Sinne des europäischen Humanismus die antike KosmosVerbundenheit integriert wäre, sieht er als endgültig abgeschnittene Illusion an; er vertritt mit catonischer Strenge die Uberzeugung vom Untergang des Humanismus. Seine Kulturkritik ist anders gerichtet: auf die Geschichtlichkeit des modernen Menschen in der Zivilisation. Seine Reflexionen zur Geschichtsphilosophie konfrontieren den Einzelnen, der sich in der Pseudoordnung der "Kalenderzeit" optimistisch abzusichern versucht, mit der Weltbewegung des Elementaren, die in Umbruchszeiten, wie dem Untergang des römischen Weltreiches oder dem modernen "Zusammenbruch des Humanismus", die Kultur einer Epoche auf die Probe stellt. Ob es darin ein Uberleben gibt, hängt davon ab, wie weit sie noch den "Geist der Musik" "2) und das heißt, ein tragisch riskierendes Lebensgefühl enthält, das sich in der Auseinandersetzung mit dem Elementaren (in Natur, Tiefenschichten der Psyche, gesellschaftlichem Umsturz der Revolution) zu einer neuen Lebensform regenerieren kann. Als solche sieht er für die Moderne den "Künstler-Menschen" (そelovek-artist) an, der, nach Analogie des in ständiger Verwandlungsbereitschaft 
lebenden Künstlers, den Mut aufbringt, Widersprüchen sich auszusetzen und sie - selbst um den Preis des Unterganges - in eine neue Lebensweise zu integrieren.

In der Utopie des Künstler-Menschen ist Blok zwei revolutionären Geistern des neunzehnten Jahrhunderts verpflichtet: Wagner und Nietzsche. Wagner hatte an der Seite Bakunins am Dresdner Aufstand vom 4. - 9. Mai 1849 teilgenommen. In seiner Flugschrift "Die Revolution" und der Programmschrift der Exilzeit "Kunst und Revolution" (beide 1849) entwirft er das Bild des starken und schönen Menschen der Zukunft, der das gemeinsame Ziel von Kunst und Revolution sei. Blok kannte seine Schriften und entwickelte seine Idee vom Künst ler-Menschen der Zukunft produktiv weiter. Gegenüber Wagner betont Blok nicht allein dessen Intensität, Wildheit und Selbstbestimmung, sondern die tragische Grundhaltung des Künstler-Menschen, die er aufbringen muß, um den Widersprüchen seiner Existenz zwischen der Außenbestimmtheit vom Gesetz des Werdens und Vergehens und der eigenen Selbstbestimmung standzuhalten. Hierin ist er Nietzsches tragischem Pathos des "gefährlichen Lebens" verpflichtet, das nach Nietzsche den "vorbereitenden Menschen" auszeichnet, der dem Menschen der Zukunft vorangeht. "13) Blok schreibt im Jahre 1919, nach den Erfahrungen von Krieg und Revolution, nachdem er als Stenograph der Provisorischen Regierung im Winterpalais an den Vernehmungen der "Staubdämonen" (Jünger) der alten Welt teilgenommen hatte (woraus dann seine Spätschrift "Die letzten Tage der Zarenmacht", 1921, entstanden ist):

"Jedoch in dieser Bewegung (d. h. im Zusammenbruch des Humanismus, M.D.) zeichnet sich bereits die neue Rolle der Persönlichkeit ab, eine neue menschliche Rasse; das Ziel der Bewegung ist nicht mehr der ethische, der politische, nicht mehr der humane Mensch, sondern der Künstler-Mensch; er, und nur er, wird fähig sein, begierig zu leben und zu wirken in der sich eröffnenden Epophe der Stürme und Orkane, in die die Menschheit unaufhaltsam hineinstrebt."

Belyjs Krisenbewußtsein ist von dem der beiden anderen Symbolisten unterschieden. Nicht primär die Kommunikations- oder Geschichtskrise, sondern die radikale Grunderfahrung der Spaltung des modernen Bewußtseins - und deshalb der ganzen Kultur - in die beiden antagonistischen Kräfte von Ratio und Trieb stehen bei Belyj im Mittelpunkt der Kulturkritik. Er sieht sie aber nicht nur als zwei polare Grundgegebenheiten an, die seit jeher vom Bewußtsein in Einklang zu bringen sind, sondern als gefährliche Extremstrukturen, die - abgetrennt voneinander - hypertrophieren und dadurch die Weiterexistenz des Menschen in Frage stellen. Diese Problematik ist bisher nicht untersucht, trotz der Ansätze, die sich bei Stepun, Cioran und Poggioli finden. Wenngleich der zeitbedingte Aspekt des "Apokalyptischen" eine wesentliche Rolle spielt, die von Cioran eingehend untersucht wurde, wenngleich die Nihilismus-These von Poggioli Gefahren aufdeckt, die den modernen Künstler in eine Krise brachten, die von vielen nur durch Rettung in die "Form" bewältigt werden konnte, wenngleich Stepun zuzustimmen ist, daß Belyj als "Seismograph der Krise" das "Nicht-Sein der Epoche" in sich verkörperte, so erfassen alle 
drei Interpretationsversuche dennoch nicht die Tiefenstruktur des Belyjschen Krisenbewußtseins.

Dazu müßten vor allem seine drei noch gänzlich unerforschten Krisenschriften aus dem Ersten Weltkrieg, die im Revolutionsjahr 1917 abgeschlossen und im Jahre 1923 endgültig publiziert wurden, ${ }^{15)}$ untersucht werden; im Zusammenhang damit wäre auch die Analyse seiner beiden großen Extrem-Romane, "Die Silberne Taube" und "Petersburg" neu in Angriff zu nehmen. Wie hier die beiden Pole der Nietzscheschen Kulturphilosophie, das "Dionysische" und das "Apollinische", zu Krisenmetaphern der russischen Wirklichkeit und bestimmter Bewußtseinslagen in der russischen Intelligenz radikalisiert, zwar je einseitig hypertrophiert, aber hypothetisch als Extreme durchgespielt werden, darin scheint mir viel eher der Schlüssel zum Krisenverständnis Belyjs zu liegen als darin, ihn an das apokalyptische Symbolsystem zu fixieren (Cioran), inn im Kontext des europäischen Nihilismus ohne genügende Rücksicht auf seine Eigenart in die Garde der pseudoreligiösen, aber formvollendeten Nihilisten einzureihen (Poggioli) oder ihn am Maßstab des christlichen Existentialismus nach seiner Abweichung von der geforderten gottebenbildlichen Personalität zu beurteilen (Stepun). ${ }^{16)}$

Wenngleich es methodische Einwände geben mag, so sollen dennoch die später verfaßten Krisenschriften zur Verdeutlichung distinktiver Züge seines Krisenbewußtseins, als eine Voraussetzung seines ästhetischen Denkens, herangezogen werden, weil sie Gedanken in der für Belyj typischsten und ausgeprägtesten Deutlichkeit artikulieren, die bereits im essayistischen oder implizit im dichterischen Werk während des ersten Jahrzehnts bestimmend waren, in dem die Grundzüge seiner Ästhetik entstanden sind. ${ }^{17)}$

1) Den gefährlichsten Befund des modernen Bewußtseins sieht Belyj in der Trennung und Pervertierung der beiden Grundkräfte von Geist und Leben. Der Hypertrophie des Gehims steht die Verkümmerung, Vermarktung und Perversion der menschlichen Natur gegenüber. Der "theoretische Mensch" - wie ihn schon Nietzsche in seiner gefährlichen Einseitigkeit entlarvte - hat zwar den "Gipfel des Bewußtseins" erreicht, aber um den Preis, sein Leben zu verlieren. 17 a) Sein Wissen blieb abstrakt ("Die Beweisbarkeit des Daseins - ist uns zum Dasein geworden"); er selber wurde ein "vereistes Futteral logischer Formen", ${ }^{18)}$ das Begriffsembleme mit der gleichen Indifferenz konstruierte wie die Ballistik, die exakte "Wissenschaft von der Ausrottung seinesgleichen". Seine Psyche ließ er entweder verkümmern oder vermarkten, so daß sie vergröberte zu einer verhärteten oder ausschweifenden Simlichkeit, die ihn tot, langweilig, primitiv und grausam machte; $^{19)}$ er ließ seine Natur zur "Freßsucht" degenerieren, begleitet von wesenlosem Geschwätz. ${ }^{20)}$ Den Menschen des zwanzigsten Jahrhunderts in seiner Welt, die er zur maschinell-materiellen Phantomwelt verkommen ließ, beschreibt er folgendermaßen:

"Der Mensch des zwanzigsten Jahrhunderts - ein fleischloses Skelett, von Fett angeschwollen; anstelle von Wissen und von Herzen kommender Beziehungen zum Leben herrschen bei ihm zwei Einverleibungen des Lebens vor: mit 
Hilfe des Gehirns und mit Hilfe der Funktionen des Magens; die erste Einverleibung - ist 'Sprenkelung auf dem Nichts' (d. h. Sprenkel von Elektronen über einem Abgrund); und mit Hilfe dieser 'Differential-Sprenkel' entwirft er auf dem Papier die Pläne zu Kanonen; die Einverleibung der zweiten Art aber - das ist die Freßsucht; nur sie allein dominiert in ihm; der blutleere Gedanke, in Sprenkel von Elektronen verwandelt, wird zur Technik des Fraßes, die ihm künstliche, vielzähnigf Kiefer von Festungen verfertigte, durch die Kanonen ihre Furchen ziehen."

Aus dieser extremen Sicht der Bewußtseinsspaltung in der Moderne sind auch die beiden Reihen seiner immer wiederkehrenden, diametralen Metaphernpaare: Engel, Hirn, Schädel, Kapsel vs. Tier, Affe, Reptil, Ungehever, sowie die Lẹitmotive des "lebendigen Leichnams" (in der Nachfolge von Puß̌kin und Tolstoj) und der "Bombe" (in der Nachfolge von Blok und Dostojevskij) zu verstehen. 2 la)

2) Aufgrund dieser gleichzeitigen Teilhabe an der Roboter-, Markt - und Konsumwelt der Moderne einerseits und den primitiven Schichten archaischen Verhaltens andererseits, sieht Belyj den Menschen der modernen Kulturkrise auf dem Schnittpunkt von Zivilisation und Archaik. Die Vergangenheit ragt in die Gegenwart hinein. Im modernen Urbanismus treffen die Verfeinerungen einer materialistischen Stadtzivilisation mit archaischen Zügen der Versteinerung und Verwilderung zusammen:

"Die Undurchdachtheit der Verfeinerung des Lebens - zerfrißt die Kultur; und bringt sie herunter zur Wildheit; die Raffinesse von Exotik, Stilisation und der künstliche Primitive - das sind Ubergangsstadien von der Kultur zur Wildheit (...). Unter uns, in den Städten, bilden sich neue Stämme heraus: die Papuas des zwanzigsten Jahrhunderts; in einer Vielfalt von Erscheinungsformen läuft der Papua unter uns herum; er ist - 'Tangoist', er ist - 'Apache'; der 'Futurist' ist die eine Erscheinungsforgß) 'der élégant in weißen Hosen' - die andere. (...) Europa - ist eine Mulattin."

3) Die Ursache des gespaltenen Bewußtseins in der modernen Zivilisation sieht Belyj in der Falschheit des Denkens, das tot und leblos geblieben sei, sich in Kontrollfunktionen über Natur und Sinnlichkeit durch Systematik und Nomenklatur erschöpft habe, ${ }^{23)}$ statt die Bewegung des Lebens in einem "klaren Denken" ${ }^{24)}$ der Selbsterkenntnis zu erfassen und zu begleiten. 25) "Jahrhunderte konkreter Bedeutung des Lebens" habe man auf diese Weise getötet. ${ }^{26)}$ Erst der lebendige Gedanke ${ }^{27)}$ wäre die Fortsetzung der geistigen Heimat des Westens, des griechischen Denkens, das Unbewußtes - in den Mysterien und Mythen - und Bewußtes - in der Philosophie Platons und der Logik des Aristoteles umfaßt habe. ${ }^{28)}$ Das "klare Denken" unterscheidet sich vom "leblosen Denken" der Abstraktion dadurch, daß es 1) seine sinnliche Grundlage einbezieht, die wache Wahrnehmung der Sinne, die sich das Dasein "einverleibt" und darin seinem Grundzug der Bewegung begegnet; ${ }^{29)}$ 2) die lebendige Dinglichkeit der materiellen Umwelt wahrnimmt; ${ }^{30)}$ 3) den Bewußtseinszustand der "Ekstase" als auslösendes Moment des schöpferischen Denkens einbezieht. ${ }^{31)}$ Denken, so aufgefaßt, steht nicht in unversöhnlichem Gegensatz zum Glauben, sondern kann gerade seine Voraussetzung sein. ${ }^{32)}$ Denn "der Sinn - ist ein 
vielverzweigter Baum, seine Abstraktion - ist ein Stock." "Vernunft", realisiert in dieser Art von Denken, ist nach Belyj "von Ewigkeit her dionysisch". ${ }^{34)}$

Aus seiner Erfahrung mit dem "klaren Denken" wußte Belyj aber auch, daß ein solches Denken, bis zum "Funkenschlagen" verlebendigt, das sich auf das ganze Leben einläßt, Gefahren birgt: Es kann denjenigen, der es sich zumutet, bis an den Rand der Krankheit bringen: ${ }^{35)}$

"Kennen Sie den Bewußtseinszustand des Gedankens, der sich anspannt bis zum Erscheinen von Funken aus den Augen? Dieser Funke blitzt auf zwischen Ihnen und dem zufälligen Gegenstand, auf den Sie zerstreut den Blick geworfen haben - irgendwie plötzlich: leuchtet auf, verlischt; hören Sie, haben Sie je durchgedacht bis zum aufblitzenden 'Augenfunken'? Wenn $9{ }^{36}$ htt, so werden Sie sicher lachen über mich; aber dann sind Sie kein Philosoph."

Wie große Denker und Künstler vor ihm, ist Belyi vom innigen und notwendigen Zusammenhang von Krise und Wiedergeburt überzeugt:

"Das Thema der Krise ist verflochten mit dem der Wiedergeburt. Das Thema vom Untergang der Welt ist verbunden mit dem Thema der Geburt. Nicht zufällig sind daher die Stimmen, die uns zur Höhe des Geistes rufen: Es ist an der Zeit, wiedergeboren zu werden."

Als solche Mahner sieht er Merežkovskij, Ibsen, Stirner, Nietzsche und Vladimir Solov'ev an; in seiner damaligen Gegenwart: Rudolf Steiner. ${ }^{37)}$

4) Belyj wendet sich in seinem Krisendenken gegen jegliche deterministische Auffassung vom Menschen. Er glaubt an den "Primat des Schöpferischen" im Bewußtsein. ${ }^{38)}$ Trotz der Deformationen, die das moderne Individuum als Stigmata einer fehlgelaufenen Entwicklung an sich trägt, spricht er ihm die Möglichkeit zur Freiheit der Wahl zu.

Um sich - jenseits der untauglich gewordenen Sprachregelungen - verständlich zu machen, knüpft er am antiken und am germanischen Mythos an. Der Mythos fungiert bei ihm - wie auch bei den anderen Symbolisten - nicht als nostalgisches oder eskapistisches Ornament, sondern als utopisches Programm. ${ }^{39)}$ Als ein Untertext "höherer Ordnung" bildet er eine Konstante seines künstlerischen Bewußtseins und den cantus firmus seines ästhetischen Denkens. ${ }^{40)}$ Den Prozeß der Uberwindung faßt er in die verschiedenen Stufen des Mythos vom "geistigen Kampf um Selbsterkenntnis". Ausgangspunkt ist der geschlagene Tantalus, Herkules im Nesselhemd, der gequälte und zerrissene Dionysos, der "lebendige Leichnam" - alles Metaphern für den Zustand geistig-seelischer Deformation und Entfremdung des modernen Menschen. ${ }^{41)}$ Seine Lage ist zwar kritisch, aber nicht aussichtslos: Er trägt die Erimerung an das "Andere", an das verlorene - aber gerade deshalb wiederzugewinnende - Paradies, die "Erinnerung an die Erinnerung" in sich, und er kann sich noch aufraffen oder erwecken lassen zum geistigen Kampf. Als moderner Faust oder "Gottesstreiter"42) muß er zur Selbsterkenntnis kommen. Das ist das Ziel seines Kampfes. Das bedeutet: Anstatt vor sich selbst zu fliehen und dabei in "Engel" und 
"Ungeheuer" zu zerbersten, muß er beide Seiten seines Wesens akzeptieren und mit ihnen umgehen lernen:

"Wir fliehen vor uns selbst, indem wir uns aufsprengen in Schlange und Engel, so wird das Leben zum zermürbenden Kampf; bei der Bewegung nach oben tritt der schlangenhafte Wurzelstock nackt hervor; der Mensch fällt; beim Versuch, den 'Pfiff der Schlange' zu begreifen - wird der Mensch erschüttert: Der grausame Engel sucht ihn heim und verwundet ihn mit dem Flammenschwert; beide Visionen - sind Schwellen; und beide Visionen - sind Wächter; die Uberwindung der 'Wächter der Schwelle' - besteht in der tatkräftigen Vertiefung des Selbstbewußtseins des Menschen. Die Unterteilung in Gut und Böse fegt uns das Böse nicht hinweg; die Flucht vor dem Bösen bietet den Anblick einer Scheidewand innerhalb des Menschen; sein oberer Teil weiß nichts vom Leben des unteren. Der Mensch, der sich selbst erkennt - ist vieläugig, trägt Flügel und Schwanz und ist tauben-schlangenhaft; die Uberwindung des Bösen ist nicht durch Wegfegen zu erreichen; sie ist zu ejyeichen durch das innere Begreifen des Rhythmus dessen, was da Böses wirkt."

Zwei Pseudo-Auswege werden von Belyj verworfen: Das Ausleben des Verdrängten im Rausch ebenso wie die Verpanzerung in einem Schädelüberbau durch "Kastration des Herzens". Sondern die bislang nur literarisch erfüllte Aufgabe des "Gottesritters" vom Prototyp Parzival steht als Aufgabe in der Gegenwart weiterhin an. "Der historische Parzival (...) - ist erst ein Lächeln in die Zukunft. Die Zukunft - das ist unsere Zeit. Wir warten auf Parzival." 44 )

Den heimtückischsten Feind dieses Wagnisses, sich geistig auf das ganze Leben einzulassen, erblickt Belyj in "Klingsor", dem Verführer zur intellektuellen "Kastration", dem Zwingherrn aus Angst, mit dem Triebhaften nicht zurandezukommen. Sein Wohnsitz ist die Bastion des Schädels, des Hirns; sein Wirken ist teuflisch, weil lebensfeindlich.

Die Extremstruktur von Belyjs kulturkritischem Denken wie auch die Eigenart seiner Sprachgebung lassen sich an einer Stelle aus seiner zweiten Krisenschrift "Die Krise des Gedankens" zeigen. In einer eigenwilligen, aus verschiedenen Mythologemen zusammengesetzten Sprache konfrontiert er wiederum die beiden Pole von Intellekt und Trieb. Seine ebenso antithetische wie assoziative Argumentation kristallisiert sich einerseits in der Herz- und Hirnmetaphorik (Herzensbrand vs. Schädelwände) andererseits in den Appellmetaphern des Selbst (Auffliegen, Sprengung, Kelch, den der Wagende erringen wird). Wengleich die Vehemenz des metaphorischen Sprechens monomane Züge annimmt in der Wiederholung des gleichen Grundgedankens der bedrohlichen Spaltung beider Sphären der Psyche, so erreicht sie andererseits einen Grad der Verdichtung, der die Nennung der beiden Gefahren einer einseitig rauschverfallenen oder intellektgesteuerten Existenz mit einer Erlebnisintensität auflädt, wie sie der begrifflichen Sprache nicht erreichbar ist. Form und Inhalt sind nicht nur in Belyjs Kunstauffassung voneinander unabtrennbar, sondern auch sein Denken erschafft sich seine eigene Sprachform, die es nahelegt, im Wortlaut zu zitieren. Dem Leser wird dabei zugemutet, sich befremden zu lassen. 
"Der Schädel blickt in den Abgrund des Lebens: der Begriff - in die Sinnlichkeit; engelgleich ausgedörrt ist unser Gehirn; mit ausgedörrtem Gehirn blicken wir den verfetteten Leib an - ohne den Willen zum Wagnis. Ja, wir fühlen unsere Knechtschaft; ja, schon, zur Freiheit Christi - wir streben ja hin; aber das Streben ohne ursprüngliches 'Frohlocken des Reiches Gottes' - in Kraft - sieht doch so aus: Kastrierung des Herzens im Verein mit Klingsor; hinter Klingsor steht Ariman, Mephisto und - die Finsternis; oder das Streben zur Freiheit verwirklicht sich im Anheizen des Herzens durch einen Geist, der weder Kraft entfaltet noch im geringsten beflügelt ist; unser Herz erweitert sich; es steht in Flammen, aber in der Flamme ersteht uns der Drache, Luzifer; und er verführt uns zum Chlystentum (d. h. zum Rückfall in religiösen Orgiasmus nach Art der russischen Bauernsekten, cf. oben S. 44, Anm. 32).

Meine beiden Romane 'Petersburg' und 'Die Silberne Taube' zeichnen die beiden Schrecken unseres nicht zu Ende gewagten Lebens: die Befreiung in das herzlose Haupt und in den Irrsinn des Herzens. Apollon Apollonovič Ableuchov flieht vor dem Leben ins 'Haupt': in ihm bewegt er sich wie ein Reisender hin und her: aber dieses 'Haupt' ist das gelbe Haus Arimans: der Schädel, der sich ausgewachsen hat. Und der Wahnsinn des Herzens treibt zur Freiheit vom Hirn Dar'jal'skij: er erglüht im rituellen Rausch; aus dem Schreiner Kudejarov blickt ihn Luzifer an: er geht zugrunde. Unsere Freiheit geht ein kühnes Wagnis ein: über den Herzensbrand aufzufliegen zu den Schädelwänden und die Wände des Schädels aufzusprengen: Nikolaj Apollonovič verspürt die Notwendigkeit zur Sprengung in sich: als Ticken einer verschluckten Bombe; in ihm ist kein Wille zum Zersprengen - im Nichtwollen der Sprengung und im Widerwillen gegen die altersschwache Form des Lebensbewußtseins; es krümmen und verbiegen sich das Bewußtsein, ja das Leben selbst in ihm: das ist es, weshalb der Senatorensohn grimassiert auf den Seiten des Romans; herbeigekommen ist die Zeit des Wagens: selbst wenn wir sie nicht fassen, so spüren wir sie gleichwohl: - wir spüren sie als eine heruntergeschluckte Bombe; über uns hinaus sollen wir fliegen: fliegen wir nicht empor - so werden wir von innen her aufreißen.

Das Leben ist rissig geworden: es schwankt. Der Schädel wird zerschlagen werden: die lichte Taube der Ankunft wird sich herniedersenken in die Offnung unserer Rißstellen: die Vereinigung der Kopf- und Herzenswissenschaften wird die Folge sein vom Niedersteigen der Taube von jenseits des Hirns durch das Hirn hindurch auf den Thron des Herzens.

Der Kelch wird bereitet werden. Parzival: er wird mit uns sein." ${ }^{45)}$

Das Ziel des geistigen Kampfes bleibt also, sich trotz der Spaltung und Deformation der Ausgangslage selbst zu begegnen: den "Gast", das "Kind", das verschüttete Ich in uns zu erkennen und zu sich selbst zu befreien. ${ }^{46)}$ Den Ausweg aus der Kulturkrise der Moderne sieht Belyj allein in der wahren Selbstbegegnung, aus der Spontaneität des Geistes, der sich auf die ganze Existenz einläßt; seinen Beitrag dazu leistet er durch Reflexion der Bedingungen und durch künstlerische Gestaltung der Schicksale des schöpferischen Bewußtseins.

Daß das Krisenbewußtsein bei Belyj aber überhaupt diese Extremstruktur erlangen konnte, ist wesentlich auf frühe lebensgeschichtliche Prägungen zurückzuführen. Vor allem auf die frühkindliche Grunderfahrung von Gefahr und Mangel: Das unversöhnliche Gegensatzverhältnis seiner Eltern erfuhr er in der Kindheit als existentiell bedrohliche Zerreißprobe, die ihm den Antagonismus von Ratio und Trieb angstbesetzt in seine Entwicklungsmatrix einschrieb. ${ }^{47)}$ Jenes frühe Ur-Erlebnis von Bedrohung und Gespaltenheit, statt Liebe und Geborgenheit, wurde akut verschärft durch eine wochenlange Fie- 
berkrankheit des noch nicht Dreijährigen, die ihn physisch mit dem Tod bedrohte. Uber die tiefe "Furche", die die Erinnerung daran in seine Psyche eingegraben hat, schreibt er:

"Das Scharlachfieber ist - meine Genealogie; und alles, was darauf in den zu beschreibenden sechzig Tagen (Herbst 1883) angewachsen ist, ist noch äußerst unglaubwürdig (prestranno) eingefärbt; noch glaube ich nicht an die Friedlichkeit und Ungefährlichkeit der dargebotenen nüchternen Tageswelt (podannaja jav'), deren Kehrseite - der gerade durchlebte Fieberwahn ist; ich staune über die Kraft der Erinnerung an die durchlebten Fieberträume in diesen sechzig Tagen; sie zog eine Furche, die das Leben nicht ausgeglättet hat; eingraviert hat sich ein besonderer Zug der Wahrnehmung, den ich nicht angetroffen habe bei den sehr vielen Kindern, die ihre Erinnerungen mit der normalen, nüchtern-wachen Wirklichkeit, und nicht mit Krankheirt, beginnen; in ihrem Bewußtsein spaltet sich die Wirklichkeit nicht auf; im Moment der Bildung der ersten Bilder des häuslichen Lebens sind sie bereits entzweit von einem $\mathrm{Ge}-$ dächtnis, das dem Fieberwahn zugekehrt war; die Besonderheit meiner Psyche besteht in den Anstrengungen, mich zwischen diesem, dem friedlichen Bild der Kinderstube, und jenem Drunterunddrüber, das ich erst kurz davor erlebt hatte, einzurichten; alles, was hinter den Wänden hervordrang (das Chaos von Stimmen, der Streit, als irgendwelches Gebrüll erlebt), versetzte mich in Furcht und Zittern, aus dem ich herausgerissen worden bin in die Kinderstube; mit einem Wort: die Entzweiung zwischen dem dionysischen Element und dem apollinischen habe ich bereits in diesen sechzig Tagen erlebt, als den Zerfall der Wohnung selbst in die Kinderstube und in unbekannte, womöglich entsetzliche Räume der Wohnung, die mir gleichbedeutend waren mit der unbekannten Welt (Nrds 169 f.)."

Mit der gleichen Intensität, mit der er sich vor der Bedrohung ängstigte, sehnte er sich aber auch nach einem eigenen, anderen ganzheitlichen Dasein. In der Spannung von Angst und Wunsch erfuhr er als den Bereich, in dem das "Andere" möglich ist, schon ebenfalls sehr früh - seit den ersten Märchen und Musikklängen (dem Klavierspiel der Mutter) - die Kunst. Später kam die Philosophie hinzu.

Seine "Methode der Symbolisierung" entwickelte er - vor aller Ästhetik - zuerst als eine Uberlebenstechnik aus Angst und Sehnsucht. ${ }^{48)}$ Daß die Kunst einen Sinn für das Leben hat - was für Künstler der Moderne keineswegs selbstverständlich ist ${ }^{49)}$ - das ist für Belyj erlebte Wirklichkeit und genausowenig theoretisches Konstrukt wie das Bewußtsein der Krise, sondern fest verankert in Leiden und Widerstand der individuellen Erfahrung. Deshalb spielt als wesentliche Denkvoraussetzung Belyjs der induktive Gesichtspunkt von Erfahrung und Erlebnis eine so wichtige Rolle und schlägt sich in der ästhetischen Begriffsbildung nieder. Das "Erleben" wird zum zentralen Terminus seiner Ästhetik ab 1907 ("Der Sinn der Kunst"). Man kann sagen, daß durch die individuell erlebte Krise der Epoche sein ästhetisches Denken einen eschatologischen Grad außerästhetischer Dringlichkeit bekommt, der 2. B. nicht dazu führte, daß Kunst allein im Rahmen einer Spieltheorie gesehen werden konnte, sondern eine Dimension des existentiellen und utopischen Ernstes enthält, die ihr eine entscheidende Rolle für das Uberleben in der modernen Kultur zuerteilt. ${ }^{50)}$ 


\section{Asthetische Praxis}

Ebensowenig wie Krisenbewußtsein und existentielle Angewiesenheit auf die Kunst als Uberlebenschance traditionell für die Ästhetik eine Rolle spielen, ebensowenig ist es selbst verständlich, daß ein Ästhetiker selbst ein Mann der künstlerischen Praxis ist, insbesondere einer experimentell-innovatorischen. Allerdings gibt es hier dennoch eine lange Tradition: Man hat diesen Zweig der Ästhetik im Gegensatz zur philosophisch-normativen als Künstlerästhetik bezeichnet, ${ }^{51)}$ da sie viel stärker pragmatisch an den Problemen des künstlerischen Schaffens orientiert ist, als die spekulative Ästhetik der Philosophen. Vertreter dieser Art von Ästhetik sind - wie Belyj - Dichter, die typologisch dem Dichtertypus des poeta doctus zuzuordnen sind, wie z. B. Lessing und F. Schlegel in Deutschland. Belyj ist als poeta doctus und formaler Innovator zugleich ein moderner Vertreter dieser Art von Ästhetik, dessen theoretische Aussagen zur Bedeutung der Form, als Dokumentation eigener künstlerischer Erfahrung, authentischen Wert beanspruchen dürfen. ${ }^{52)}$ Das vor allem deshalb, weil ihm die stilistische Formung, die ein philosophischer Inhalt im Kunstwerk erfährt, also die "Eingestaltung" der Idee in die poetische Sprache, aber auch umgekehrt, die aktive inhaltsbildende Funktion, die die Form als ausschlaggebender Wirkfaktor der poetischen Struktur entfalten kann, ${ }^{53)}$ als ein schöpferischer Vorgang von eigener, unverwechselbarer Qualität, der der Kunst ihre Autonomie verbürgt, in seinen verschiedenen Stadien aus der eigenen ästhetischen Erfahrung und Praxis bekannt war.

Das formale Experiment und die poetische Technik nehmen aufgrund dieses unmittelbaren Praxisbezuges in seinem ästhetischen Denken komplementär zu dem Zentralbegriff des Erlebens den ästhetisch ausschlaggebenden Platz ein: ${ }^{54)}$

"Der Inhalt des Erlebnisses im Gedicht ist die Beziehung der Form der Idee zur Form des Bildes, das die Idee verkörpert (Lir. 244)."

Das hatte weitreichende Auswirkungen auf die Auffassing vom "Schönen", die von einem normativen Leitbegriff zu einem Gegenstand der ästhetischen Erfahrung und der poetischen Praxis wird. Die eigene Dichtungspraxis hatte für ihn eine doppelte Funktion: einerseits war sie Motivierung für seine Theorie, andererseits auch ihr Korrektiv.

\section{m. Naturwissenschaftliches Methoden- und Theoriebewubsein}

Das Bewußtsein der Krise und die eigene künstlerische Praxis als Basis kunsttheoretischer Reflexion - wenngleich in anderer Gewichtung - finden sich als spezifische Kombination auch bei den anderen symbolistischen Dichtern, die sich theoretisch äußerten. ${ }^{55)}$ Wodurch sich Belyj von ihnen aber grundlegend unterscheidet, das ist sein wissenschaftstheoretisches Problembewußtsein und sein philosophisches Abstraktionsvermögen. Was 
hier als Denkvoraussetzung sichtbar wird, das ist die methodische Schulung durch den naturwissenschaftlichen Positivismus - derer die anderen Symbolisten entbehrten - in dem Belyj vor allem durch seinen Vater von früh an erzogen wurde. N. V. Bugaev (1837 1903) war ein bedeutender Mathematiker, der auch in seinem Sohn das Interesse an den Grundlagen und Formalisierungsleistungen der Mathematik weckte. Gleichzeitig war er aber auch Philosoph, der sich zur Grundlagenkrise der modernen Mathematik äußerte und ein moderner Anhänger von Leibniz war. ${ }^{56)}$ Mehr unter dem Einfluß dieses außergewöhnlichen Vaters als aus eigenem Antrieb, studierte Belyj in Moskau von 1899 - 1903 Naturwissenschaften und schloß mit einem erstklassigen Diplom ab. ${ }^{57)}$ Nach dieser Pflichtübung ging er über zum Studium der Philosophie, das er nie zum Abschluß brachte. ${ }^{58)}$

Aus dem Weltbild der modernen Physik - das seit der Entdeckung des Elektromagnetismus und der Energiesätze in einem Umbruch begriffen war - übernahm er theoretisch den zeitgenössischen Energetismus, den er sich produktiv aneignete und zu seinem ästhetischen Konzept der "Energie des Schöpferischen" (energija tvorčestva) umformte. ${ }^{59)}$ Aus der naturwissenschaftlichen Methodik übernahm er praktisch das Prinzip der Beobachtung und Anordnung des Materials zum Zwecke des Experiments. Hier erwarb er sich den Sinn für Technik und meßbare Daten; auch für genaue Beschreibung, die es ermöglicht, Gesetzmäßigkeiten herauszufinden. Zur naturwissenschaftlichen Methodik gehört aber auch die hypothetische Denkweise; Hypothese und Experiment stehen miteinander in notwendigem Zusammenhang als die spekulative und die empirische Seite jeder exakten Wissenschaft.

Hierdurch bildete sich ein Grundzug seiner Ästhetik heraus: nach dem Prinzip der Induktion vorzugehen. Bestätigt wurde er darin durch ästhetische Forschungen im deutschen Positivismus, vor allem durch die empirische Ästhetik Fechners und die Forschungen zur visuellen und akustischen Wahrnehmungspsychologie bei den Naturwissenschaftlern Helmholtz und Ostwald. ${ }^{60)}$ In seinem empirischen Ansatz macht er zum Ausgangspunkt die Erfahrung, statt, wie bisher üblich in der Ästhetik, philosophische oder soziologische Normen. 61) Von hier aus kommt er zu der Erkenntnis, daß eine "Ăsthetik neuen Typus" nicht mehr traditionelle Geisteswissenschaft sein könne, sondern auf empirischer und erkenntnistheoretischer Basis in wissenschaftslogischer Hinsicht als eigenständige Disziplin begründet werden müsse. Diese Ansicht vertritt er bereits in seinem ersten Essay zur Ästhetik, "Formen der Kunst" (1902). Aber zu theoretischer Klarheit kommt er erst in seinem in dieser Hinsicht bahnbrechenden Aufsatz "Lyrik und Experiment" (1909). Hier stellt er die beiden grundsätzlichen Möglichkeiten, den Gegenstand der Ästhetik, das "Schöne" zu erfassen, gegenüber: 1) die normative, nach der das Schöne a priori fest verankert ist in einer metaphysischen Grundkonzeption, von der aus es seine Bestimmung bezieht; 2) die empirische, nach der das "Schöne" erst jeweils bestimmbar wird durch seine Erscheinungsformen, die sich historisch wandeln und immer erst a posteriori definiert werden können: 
"Wenn die Ästhetik die Wissenschaft vom Schönen ist, so ist ihr Gebiet eben das Schöne. Was ist das Schöne? Das ist entweder eine Frage von metaphysischer Geltung, die sich erhebt mit der Frage nach dem Ziel und dem Wert der Schönheit, oder es ist eine Frage positiver Art (was hält die Menschheit für das Schöne?). Im ersten Falle steht vor uns die Aufgabe, eine Metaphysik des Schönen aufzubauen, im zweiten - die ästhetische Erfahrung in der Reihe der weltweiten Denkmäler des Schönen; die Aufgabe einer exakten Ästhetik ist es - die Kunstdenkmäler zu analysieren, die Gesetzmäßigkeiten abzuleiten, die sie bestimmen; die Aufgabe einer metaphysischen Ästhetik ist es, - das einheitliche Ziel der Schönheit zu erhellen und an ihm die ästhetische Erfahrung der Menschheit zu bemessen. Aber die Einheitlichkeit einer solchen Ästhetik steht in Verbindung mit der Einheitlichkeit der Metaphysik. Wie ist eine einheitliche Metaphysik möglich? Als die notwendige Bedingung einer Theorie des Wissens selbst. Und wenn eine ideale Wissenstheorie den Anspruch auf Allgemeingültigkeit erhebt, dann ist ihre Metaphysik - eine allgemeine und verbindliche; aber der Aufbau einer allgemeinen und einheitlichen Metaphysik - das ist eine Aufgabe, die in der gegenwärtigen Zeit kaum zu verwirklichen ist; und deshalb eben ist es unmöglich, Normen der ästhetischen Werte aufzustellen; die Ästhetik ist unmöglich, als Geisteswissenschaft (Lir. 234)."

Diese unterscheidende Analyse kann als eine der wichtigsten im ästhetischen Denken Belyjs gelten. Sie bringt den wesentlichen Gedanken vom "Ende der Metaphysik" zum Ausdruck, der repräsentativ ist für die philosophische Situation seit Nietzsche. Gleichzeitig setzt er aber die metaphysische Dimension nicht außer Kraft, sondern stellt sie in nüchterner Erkenntnis der Lage zurück und damit neu zur Disposition. ${ }^{62}$

Vorerst fordert er auf zur Arbeit an einer empirischen Ästhetik auf induktiver Grundlage. Mit der Phänomenologie Husserls teilt er die Uberzeugung, daß es notwendig sei, zuallererst "zurück zu den Sachen selbst" zu gehen. Konkret auf die Ästhetik bezogen heißt das: Statt sie wie bisher als Sondergebiet innerhalb philosophischer Systeme, sozialer Programme, als Spezialgebiete der Psychologie oder Sprachwissenschaft zu behandeln, soll umgekehrt, ausgehend von den ästhetischen "Tatsachen" selbst, die Ästhetik als ein "System von Wissenschaften" aufgebaut werden (Lir. 236). Hierzu weist er folgende Wege:

1) Die Analyse der Sprachstruktur als Material der Dichtung:

"In der Lyrik (...) die Worte, die in eigentümlichen phonetischen, metrischen und rhythmischen Verbindungen angeordnet sind und die die eine oder andere Kombination von Ausdrucksmitteln bilden. Also - die Empirik jenes Gebietes der Ästhetik, welches die Gesetze der Lyrik erforscht (Lir. 235)."

2) Die komplementäre Analyse der Erlebnis- sowie der Bild-und Sujetstruktur, die für ihn beide Bestandteil der "Form" des Kunstwerkes sind, deren Begriff daher erweitert werden muß:

"Man hält mir entgegen, daß es in diesem oder jenem lyrischen Gedicht auch noch Bild, Erlebnis, Sujet gibt; Bild, Erlebnis, Sujet kann man von der Form her erforschen; es kann eine Geschichte der Sujetfügung, eine Ge- 
schichte der Bildentstehung geben. Das Gebiet der formalen Ästhetik, als Wissenschaft, ist folglich breiter (Lir. 235)."

3) Die Analyse von verschiedenen Funktionen innerhalb des Kunstwerkes erfordert, daß man die anderen Kulturwissenschaften in einem neven Methodenkanon zuhilfe nimmt:

\begin{abstract}
"Aber die Gesetze der Entstehung von Bildern (die Gesetzmäßigkeit der Systematik der künstlerischen Symbole und Erlebnisse) kann man auch von einem nicht rein ästhetischen Standpunkt aus erforschen; der Bereich der Erforschung der Gesetze der Bildentstehung kann das Gebiet der angewandten Mythologie, Psychologie, Soziologie etc. sein - je abhängig von der Methode, mit der wir das Forschungsobjekt angehen (Lir. 235)."
\end{abstract}

Belyjs induktives Forschungsprogramm mit den beiden Forderungen nach einer Struktur - und einer Funktionsanalyse, weist auf wichtige Entwicklungen der modernen Literaturwissenschaft voraus: auf den Strukturalismus der poetischen Sprache bzw. die Textinterpretation der Literaturwissenschaft in der deutschen und anglo-amerikanischen formalen Schule und im russischen Formalismus; auf den slavischen Funktionalismus Mukarorovskýs und nicht zuletzt auf die phänomenologische Schichtenanalyse Roman ingardens. Zu seiner Zeit jedoch - 1906 - war das die reine Zukunftsmusik, und Belyj beklagt die Hindernisse, die allseits einer Emanzipation der Ästhetik im Wege standen. Sie kamen nicht nur von der normativen Richtung,

"Man hat zwar gesagt, was die Kunst sein soll, aber vergessen, was sie überhaupt ist (Lir. 236)."

sondern auch von Kritikern, Kunstkennern und vor allem aus den eigenen Reihen der Dichter:

"Y...) ein Komponist, der die Theorie des Kontrapunkts durchgeht - das ist eine ganz normale Erscheinung; ein Dichter, der in das Studium von Stilfragen und Techniken vertieft ist, ist in den Augen der russischen Gesellschaft - schon fast ein Fabeltier; Musikakademien, Akademien der Bildenden Künste erfreuen sich des Patronats der Öffentlichkeit; der bloße Gedanke an die Möglichkeit einer Akademie der Dichtung löst Gelächter aus: Ungebildetheit (bezgramotnost') ist ein Verdienst des Dichters in den Augen der Gesellschaft, der Dichter oder Schriftsteller soll ungelehrt sein; (Lir. 237)."

Für Belyj ergibt sich daraus ein Selbstverständnis des modernen Künstler-Ästhetikers, in dem er mit Bahnbrechern früherer Zeiten vergleichbar wird:

"Ist es nicht Zeit für jeden, der die Kunst liebt, sich in die Abgeschiedenheit seines Arbeitskabinetts zurückzuziehen, ist es nicht an der Zeit für die Künstler und Forscher auf dem Gebiet der Ästhetik, sich zur Lage von mittelalterlichen Märtyrern zu bekennen; auf daß sie nicht auf den Scheiterhaufen der öffentlichen Schande geführt werden. Die offizielle Quasi-Ästhetik wird ihnen kein Gehör schenken; die korrumpierte Kritik wird sie ans Kreuz schlagen oder durch den Schmutz ziehen (Lir. 239)." 


\section{Positivismus und Idealismuss äulere und innere Erfahrung}

Je weiter man sich in Belyjs ästhetische Schriften einliest, desto deutlicher wird sichtbar, daß der induktive Ansatz nur die eine Seite seines theoretischen Vorgehens ist. Als Denkprodukt einer Ubergangsepoche steht sein ästhetisches Denken im Schnittpunkt von Positivismus und Idealismus.

Wenn hier von Idealismus die Rede ist, so bezieht sich das vor allem auf Belyjs Konzeption des Bewußtseins. Er steht im Grunde auf dem Kantischen erkenntnistheoretischen Standpunkt, mißt aber die führende Rolle nicht den rationalen Erkenntniskräften zu, sondern den schöpferischen. Vor allem am Anfang steht er sehr stark im Bann der Kunstmetaphysik Schopenhauers. Von ihm übernimmt er den doppelten Wirklichkeitsbegriff: die Unterscheidung einer phänomenalen und einer noumenalen Welt, womit er in scharfem Widerspruch zum einplanigen Wirklichkeitsbegriff des Positivismus steht. Der doppelte Wirklichkeitsbegriff ist eine der wichtigsten Denkvoraussetzungen für Belyjs Ästhetik. Seine Hauptthese "Kunst ist Umarbeitung der Wirklichkeit durch das schöpferische Bewußtsein" ist nur von da aus zu verstehen. Von Schopenhauer übernahm er ferner das Axiom, daß alle Erkenntnis subjektiv ist und auf dem Wege der Intuition, vor allem in der Kunst, gewonnen werden kann.

Der erkenntnistheoretische Intuitivismus steht zwar - ebenso wie der doppelte Wirklichkeitsbegriff - im Gegensatz zum Positivismus und seinem objektiven Erkenntnisbegriff; er hat aber dennoch auch eine Wurzel in der positivistischen Rückwendung des Denkens auf die Erfahrung. Hier scheint es wichtig, die verschiedenen Möglichkeiten von Erfahrung zu unterscheiden: die äußere und die innere. Die rationalen Kräfte des Bewußtseins sind im wesentlichen auf die äußere Erfahrung gerichtet, die schöpferischen vor allem auf die innere Erfahrung. Spielt für Belyj, der die Welt in beiderlei Hinsicht betrachtete - als exakter Wissenschaftler und als Künstler - also auf der einen Seite die genaue Beobachtung des empirischen Materials und die induktive Forscherhaltung eine Rolle, so auf der anderen Seite ebensosehr der Gesichtspunkt der inneren Erfahrung. Hier in gründen auch die Aussagen, die er zum vieldiskutierten "religiösen Sinn" der Kunst macht. Die führende Rolle, die Belyj dem schöpferischen Bewußtsein zumißt, welches rationale und intuitive Kräfte umfaßt, brachte es mit sich, daß seine Ästhetik nicht eine Kunstphilosophie im traditionellen Sinne wurde, sondern vor allem eine Theorie des schöpferischen Bewußtseins. Die Bedingungen, "Methoden" und Ziele des kreativen Prozesses machen den wesentlichen Inhalt seiner Ästhetik aus.

Eine weitere wichtige Konsequenz seines Bewußtseinsidealismus besteht darin, daß er - im Gegensatz zur Genieästhetik - keinen generellen, sondern nur mehr einen graduellen Unterschied zwischen Künstler und Rezipienten machen kann. Da er die schöpfe- 
rischen Fähigkeiten als konstitutiv für das Bewußtsein überhaupt ansieht - ob künstlerisch, wissenschaftlich oder in der Lebenspraxis - kann er aus der Kontaminierung seines doppelten Wirklichkeitsbegriffes und des Bewußtseinsidealismus eine Ästhetik der Verwandlung begründen. Ziel des kreativen Prozesses nach Belyj ist die "Verwandlung der Persönlichkeit", damit aber im Endeffekt auch der Wirklichkeit.

Zusammenfassend läßt sich sagen: Außer den epochentypischen Voraussetzungen für Belyjs Ästhetik gibt es individuelle, die aus seinem Krisenbewußtsein, seiner dichterischen Praxis und aus seiner Teilhabe an der naturwissenschaftlichen und der philosophischen Denkweise zu verstehen sind. Ihnen entsprechen mit innerer Notwendigkeit die drei hauptsächlichen Themenkreise seiner Ästhetik: Die Frage nach dem Sinn der Kunst, nach ihren Formen und nach der Rolle, die sie für die Selbstwerdung des modernen Menschen und damit für die Uberwindung der Kulturkrise spielen kann. Telos, Technik, Selbsterfahrung sind die leitenden Problemlinien seiner "Ästhetik neuen Typus", in der Kunst als Prototyp der Kreativität betrachtet wird. 


\section{K A P I T E L}

\section{DENKFORMEN UND DISKURSEBENEN}

Aus den epochenbedingten und individuellen Denkvoraussetzungen Belyjs ergeben sich nun bestimmte Denk- und Sprachformen seiner ästhetischen Theorie. Von Anfang an sieht er sich durch die komplexen Motive seines Denkens im Zustand einer Interessenkollision von "komplementärer Antithetik". Sein Denkideal war daran orientiert, die auseinandergefallenen Bereiche eines "ratioiden" und "nicht ratioiden" Denkens wieder miteinander zu verquicken. ") Seine ästhetische Theorie verstand er deshalb nicht als ein geschlossenes System oder Lehrgebäude, sondern als die Entwicklung einer neuen schöpferischen Denk- und Schaffensmethode. Dieser Unterschied darf nicht außer Acht gelassen werden, wenn man die Eigenheit seines Denkens verstehen will. 2) Daß er hier in einer langen, wenngleich nie richtig anerkannten Denktradition steht, darauf war schon im Zusammenhang mit dem Denkideal des "klaren Denkens" hingewiesen worden (cf. oben S. $\left.76 \mathrm{ff}^{3}\right)^{3)}$ Uber die Ausgangspositionen seines Denkens sagt er rückblickend:

"So waren also in jener Periode eine Reihe von Interessen in mir, die nicht auf einer Ebene kollidierten, sondern sozusagen in Schichten übereinander lagen, die Etagen bildeten, zu denen man auf - und abzusteigen imstande sein mußte; in einem Ausschnitt sähen diese Etagen etwa so aus:

1) Die Fakten der Wissenschaften, 2) die Wechselbeziehungen der Metho-

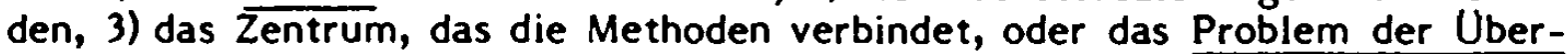
setzung der Daten der einen Methode in die Ausdrucksform der anderen Methode (z. B. Erscheinungen, die sich als Rhythmus erklären lassen etc.), 4) die Sphäre der Symbolisierung oder der kulturellen Praxis, die den Akt der Erkenntnis nicht durch Abstraktion von der Wirklichkeit schafft, sondern durch ihre Umschöpfung (Nrds 466)."

Die Fakten selbst sind für Belyj innerhalb der empirischen Betrachtungsweise der exakten Wissenschaften nie bloße Einzelerscheinungen, sondern Bestandteile eines jeweils hergestellten Methodenzusammenhanges. Wissen, so betrachtet, ist dann aber jeweils schon Interpretation. ${ }^{4)}$ Hierin gründet Belyjs Denkweise des perspektivischen Denkens. Je nachdem, in welchem Methoden- oder Modellzusammenhang ein Faktum betrachtet wird, je verschieden sind die Hinsichten, die man an ihm beleuchten kann. Durch seinen komplexen Bildungsgang war ihm klar geworden, daß diese Hinsichten jeweils in verschiedenen Konstellationen zueinander in Beziehung gesetzt werden können. Hier berührt sich Belyj mit dem "offenen Denken" der modernen Phänomenologie.

Eng zusammen mit dem perspektivischen Denken hängt die Denkform des "Transformismus"; Denkkonzepte wie "Energie" und "Rhythmus" waren für ein Denken, das an den Phänomenen den Grundzug der Bewegung erfassen will, statt sie allein in ihrer Isolierung voneinander statisch zu betrachten, wegen des hohen Grades an Dynamik, den sie enthal- 
ten, besonders geeignet. 5 )

Um ein Phänomen unter seinen verschiedenen Hinsichten und Perspektiven betrachten zu können, wendete Belyj oft die Denkweise des hypothètischen Denkens an. Er betreibt diese Denkvariante insofern, als er eine angenommene Denkrichtung bis zum Extrem austestet. Das tut er vor allem in bezug auf seine Hauptfragen: den Sinn und die Formen der Kunst. Bereits in seinem ersten Essay "Formen der Kunst" denkt er seine Grundthese "Kunst ist Umarbeitung der Wirklichkeit durch die Energie des schöpferischen Bewußtseins" unter der hypothetischen Annahme durch, daß Kunst - als ein "Produktionsvorgang" - analog zum mechanisch oder energetisch beschreibbaren Arbeitsprozeß betrachtet werden könne. Er führt diese Analogie bis an die Grenze des Haltbaren durch, bis dahin nämlich, wo er feststellen muß, daß sie im Unterschied zu einem physikalischen Prozeß nicht von einer "Energiequelle" gespeist wird, sondern von einem lebendigen und geistigen Zentrum, dem schöpferischen Bewußtsein. Sein hypothetisches Testdenken führte ihn zu Einsichten über den Prozeß der Kunst, die er sonst nicht hätte gewinnen können (cf. S. 96 ff.).

Die Resultate solcher Schneisen, die er in einen Problemzusammenhang hinein "schneidet" - er gebraucht dafür bewußt das Bild der "Schere"6) - sind oft aphoristisch zugespitzt. Stellt man zwei solche aphoristische Endprodukte einer hypothetischen Reihe einander gegenüber, stößt man leicht auf Widersprüche, z. B. in "Formen der Kunst":

1) "Die Kunst stützt sich auf die Wirklichkeit (iskusstvo opiraetsja na dejstvitel'nosti)" Formy 147.

Also: Kunst in dieser Hinsicht ist ein Prozeß der technischen Bearbeitung der Wirklichkeit, dessen Resultat sind verschiedene klassifizierbare Formen.

2) "Die Kunst ist weder logisch, noch unlogisch, sondern geistig (iskusstvo ni logično, ni nelogično, a idejno)" Formy 164.

Also: Kunst ist kein mechanischer oder energetischer Arbeitsprozeß, sondern eine Schöpfung des Geistigen im Menschen.

Auflösbar wird der Widerspruch erst, wenn man die Teilhabe der Kunst an beiden Wirklichkeiten, der empirischen und der noumenalen, hierin ausgedrückt sieht. Die Zweigleisigkeit des Denkens, die Kunst einerseits als Formprozeß, andererseits als Sinnprozeß zu betrachten, ist konstituierend für Belyjs Ästhetik. Was in "Formen der Kunst" noch in die alternierende Argumentationsstruktur eines einzigen Essays eingebunden wird, erweitert sich später zu selbständigen, nebeneinanderstehenden Essays, wie z. B. "Das Prinzip der Form in der Ästhetik" und "Der Sinn der Kunst". Wieder stehen sich zugespitzte Formulierungen diametral gegenüber:

1) "Die Kunst muß ein eigenes Erscheinungsprinzip haben. Ein solches Prinzip ist die Form der Kunst (Iskusstvo dolžno imet' princip svoego projavlenija. Takim principom javljaetsja forma iskusstva)" Formy 175. 
2) "Die Kunst hat keinen eigenen Sinn, außer dem religiösen; (Iskusst vo ne imeet nikakogo sobstvennogo smysla, krome religioznogo)" Smysl 223.

Solche Widersprüche gehören zur Oberflächenstruktur von Belyjs Denken. Man kann sie nur auflösen, wenn man die Problemstellung innerhalb der Tiefenstruktur verfolgt, die der Oberfläche zugrunde liegt. In diesem Falle wäre der gemeinsame Nenner: Die Kunst ist ein Bereich autonomer Formen. Die Kunst kann - nach dem Ende der Metaphysik zwar von keiner verbindlichen hohen Warte mehr umfaßt werden; da sie aber aus der inneren - vorwissenschaftlichen - Erfahrung heraus entsteht, kann ihr religiöser Sinn vielleicht gültiger als zuvor - zugesprochen werden.

Indem Belyj vorwissenschaf tliche Erfahrung zum Denken zuläßt, indem er die Herkunft eines Gedankens aus einem ihn begleitenden Gefühlszustand einbezieht, z. B. die ekstatische Abstammung einer Erkenntnis aus einem exorbitanten Augenblick der "clairvoyance", indem er die innere Evidenz der äußeren Beweisbarkeit neben- oder sogar überordnet, geht die begrifflich-diskursive Rede in die Intensität des lyrischen Sprechens über. Die lyrische Rede ist dann Indikator für den Grad der subjektiven Betroffenheit seines ästhetischen Denkens. Oft ist damit ein Zug zum Universalismus verbunden: Das im Augenblick Erkannte wird aufgrund der Authentizität der soeben gemachten Erfahrung - manchmal auch übereilt und später wieder zurückgenommen - in den Rang einer zeitlos gültigen Wahrheit erhoben. Zu den emotionalen Stilzügen gehört auch das polemische Eifern gegen Mißstände, der Kritik z. B., oder gegnerische Meinungen, vor allem gegen den Wissenschaftsdogmatismus oder vagen Mystizismus; Belyj polemisiert auch gegen sich selbst, ohne es ausdrücklich zu vermerken. Man kann also sagen, daß es innerhalb der theoretischen Rede Belyjs emotional engagierte Stilzüge gibt, die im inneren Zusammenhang mit seinem Denken stehen und nicht zum entbehrlichen Beiwerk degradiert werden können, sondern als Indikatoren des persönlichen Engagements den theoretischen Diskurs mitbestimmen.

Ihnen stehen auf der anderen Seite ein extremer Zug zum Schematismus oder zur philosophischen Architektonik - wie sie z. B. Schopenhauer Kant vorwirft - gegenüber. Das zeigt sich etwa in der Vorliebe für graphische Darstellung (Emblematika smysla) oder mathematische Formalisierung in Formeln oder Reihen ("Das Prinzip der Form in der Ästhetik"). Das rigide Denken, das sich hier zeigt, entspricht zwar einerseits einem ausgeprägten Bedürfnis nach Genauigkeit, aber es kann auch starr werden, z. B. sich auf Konzepte, wie das des Energetismus verbeißen, bis dahin, wo die Analogien nicht mehr fruchtbar sind, sondern verwirrend. Es gibt bei Belyj ferner das Phänomen der theoretischen Besessenheit. Dazu gehört sein immenser Belegzwang. Der Kommentar zu "Symbolismus" wurde dadurch zu einer Fundgrube der "Archäologie des Wissens" (Foucault) um die Jahrhundertwende. Er erweist Belyj als "Fachgelehrten" auf den verschiedensten Gebieten, vor allem der Philosophie, Psychologie, Sprach- und Religionswissenschaft, auch 
der Mathematik, der über die neuesten Erscheinungen international - vor allem aus dem deutschen Sprachbereich - informiert ist, die zentralen Positionen erfaßt und kritisch sichtet. In seiner Art stellt dieser Kommentar ein unersetzliches Stück interdisziplinärer Wissenschaf tsgeschichte dar und harrt noch seiner Entdeckung.

Wenn man diese verschiedenen Aspekte der Denk- und Sprachmuster Belyjs in Betracht zieht, kann manches besser verstanden werden, was auf den ersten Blick verwirrend oder konfus erscheint.

Imerhalb der Sprachformen seiner ästhetischen Theorie lassen sich vier (oder vielleicht mehr) verschiedene Diskurstypen unterscheiden:
1) der wissenschaftliche,
2) der philosophische,
3) der rhetorisch-situative,
4) der künstlerische. ${ }^{7)}$

Jede dieser Diskursebenen wäre eine eigene Untersuchung wert, vor allem aber ihre Wechselbeziehungen. Will man den Versuch machen, diese verschiedenen Ebenen wenigstens in Umrissen zu charakterisieren - wie das zum Verständnis der Grundpositionen von Belyjs Ästhetik notwendig erscheint -, so kann man sagen, daß die Aussagen des wissenschaftlichen Diskurses einmal in den Schemata und Rhythmuskurven der Verstheorie zu finden sind, aber auch in verschiedenen anderen Hinsichten: z. B. zur Sprachtheorie in "Die Magie der Worte", zur sehr schwierigen Frage der literarischen Wertung, bzw. der Normen der Kunst, in "Emblematik des Sinns". Ferner in der Auseinandersetzung mit Thesen der modernen Mathematik und Physik, mit Fragen der Wissenschaftstheorie, der Sprachwissenschaft, vor allem Humboldts und Potebnjas. Der Kommentar zu "Symbolismus" enthält einen ausgedehnten wissenschaftlichen Apparat mit Literaturlisten und Kontroversen.

Die philosophische Diskursebene ist ebenfalls noch wenig erforscht. Sie enthält wichtige Uberlegungen zum "Sinn der Kunst" nach dem "Ende der Metaphysik", die an Heidegger erimern, eine Auseinandersetzung mit der Kunstmetaphysik Schopenhauers, eine permanente Kant-Kontroverse über die Jahre von 1904 - 1910, Diskussionen erkenntnistheoretischer Probleme sowie der umstrittenen Begriffe der Kausalität und Materie, vor allem aber die Begründung eines modernen Symbolismus aus der Wertphilosophie des Neukantianismus.

Diesen beiden traditionell theoretischen Diskursebenen, der wissenschaftlichen und der philosophischen, stehen die beiden "untheoretischen": die rhetorisch-situative und die künstlerisch-lyrische gegenüber. Viele der Essays sind aus der akuten, meist polemischen Auseinandersetzung um aktuelle geistige Fragen entstanden. Leseranrede, Imperativ, Appell und Hyperbel sind stilistischer Niederschlag der emotional-situativen Motivierung. 
Teils wurden die Aufsätze auch zunächst als Vorträge gehalten, vor einem Publikum, das man rhetorisch beeindrucken wollte. Diese Tatsache der Öffentlichkeit des ästhetischen Denkens Belyjs und der anderen Symbolisten verdient größere Beachtung als das bisher geschah. In einem inneren Zusammenhang mit der rhetorisch-situativen Diskursebene ist die künstlerisch-lyrische zu sehen. Der Grad der subjektiven Betroffenheit des ästhetischen Denkens, der zur Theorie zugelassen wurde, führte - als die eine ihrer Ursachen zu einer Erscheinung, die für die literarische Entwicklung um $1900 \mathrm{im}$ gesamteuropäischen Maßstab typisch ist: zur Poetisierung nichtpoetischer Genres, ${ }^{8)}$ wie eben hier des kunstphilosophischen Essays. Verse, antithetische oder ganzheitliche Metaphorik, die Ausdruckskonvention des Mythos als Paradigma der Selbstwerdung, utopisches Wunschdenken in dithyrambischer Rhythmik - das sind einige Stilzüge der künstlerisch-lyrischen Sprechebene. Wahrscheinlich ließen sich noch weitere spezifische Denk- und Sprachformen herausfinden; hier mag es mit diesen wenigen Hinweisen sein Bewenden haben, sollte doch vor allem gezeigt werden, was gemeint ist, wenn Belyj davon spricht, daß er eine neue schöpferische Denk- und Schaffensmethode entwickeln wollte. Vielleicht ist inzwischen deutlich geworden, daß es ihm nicht darum geht, damit das rationale Denken außer Kraft zu setzen, sondern darum, seine Grenzen zu zeigen und Denkelemente eines nicht-ratioiden Denkens theoriefähig zu machen. Deshalb scheint es wichtig, die verschiedenen Diskursebenen nicht zu isolieren, sondern aufeinander zu beziehen und als modernen Versuch eines "organischen Denkens" zu verstehen. 
ZWEITER TEIL

TELOS, TECHNIK, SELBSTERFAHRUNG -

BELYJS ENTWURF EINER INDUKTIVEN ÄSTHETIK 


\section{E I N L E I T U N G}

\section{XSTHETIK DER KREATIVTTXT}

Belyjs ästhetische Theorie kann - wie sein übriges Werk - als schöpferische Reaktion auf die moderne Kulturkrise gelesen werden. Ihre wichtigsten Intentionen lassen sich den hervorgehobenen Tendenzen der Kulturkrise zuordnen. Mit der Frage nach dem Sinn der Kunst - nach dem Telos - versuchte er auf die Krise des Bewußtseins zu antworten; mit der Frage nach der "Form", als dem einheitlichen Prinzip der Kunst - verstanden in einem neuen Umfang als poetika-technika-simvolizacija - reagierte er auf die Krise der Sprache und den Formenbruch der Moderne; mit dem Rückgang auf die Unbotmäßigkeit und den Wert der ästhetischen Erfahrung und der Frage nach dem ganzheitlichen Erleben im schöpferischen Prozeß der Kunst reflektierte er die Krise der modernen Lebensformen. Belyj glaubt daran, daß es möglich sei, durch eine neue Wahrnehmungs- und Erlebnisweise, aus der eine Kunst symbolischer "Modelle von Erfahrung" geschaffen wird, verwandelnd auf die moderne Lebenspraxis einzuwirken. Telos, Technik, Selbsterfahrung erscheinen als Leitbegriffe im ästhetischen Denken Belyjs, mit denen er durch die Neudefinition von Kunst als Kreativität eine neve anthropologische Dimension der Moderne erschließen will. Es handelt sich hierbei nicht um spezifisch ästhetische Begriffe. Doch gerade als solche entsprechen sie dem erweiterten Verständnis von Kunst als Kreativität im Rahmen der Gesamtkultur, wie es am Anfang von "Simvolizm" programmatisch formuliert wird:

"Und deshalb kann die symbolistische Strömung, wenn sie den Willen zur Entwicklung und Vertiefung hat, nicht eine abgekapselte Kunstrichtung bleiben, sie muß sich mit den allemeineren Problemen der Kultur verbinden; die Umwertung der ästhetischen Werte ist nur der Sonderfall einer allgemeineren Arbeit, der Umwertung der philosophischen, ästhetischen und religiösen Werte der europäischen Kultur (Sirnv. 8)."

An dieser "allgemeineren Arbeit" der Umwertung kann die Kunst aber nur teilnehmen, wenn sie aus dem traditionellen Kanon der Harmonieästhetik heraustritt: Das Prinzip des Schöpferischen bzw. der Kreativität ist nicht mehr allein am Ideal der Schönheit und am geschlossenen Kunstwerk im Sinne der aristotelischen Ästhetik orientiert. Der Bereich der Ästhetik weitet sich aus zu einem prinzipiell nicht mehr beschränkten Feld der ästhetischen Wahrnehmung und Produktivität. In diesem Sinne ist Belyjs Ästhetik aus ihrer historischen Situation heraus zu verstehen: Sie ist eng verbunden mit dem Hervortreten der "nicht mehr schönen Künste" (Jauß). Denn in der "modernen Kunst", deren Erfahrung Belyj in seiner Ästhetik reflektierte, vollziehen sich simultan zwei komplementäre Prozesse: Es werden neue, bisher entweder tabuisierte oder verhüllte Bereiche 
der Krisen- und Grenzerfahrung zugeiassen - denen sich z. B. im modernen Roman die Thematik des "Probemenschen" verdankte; zugleich wird das Gesicht der neuen Kunst aber auch verändert durch neue Erfahrungen und Experimente mit den Medien der künstlerischen Technik - wie Sprache, Stilfiguren, Linie, Farbe und Klang.

Belyjs Ästhetik ist grenzüberschreitend: Sie beginnt als Morphologie der Kunstformen, die er - geschult an Schopenhauer - zugleich als Formen intuitiver Erkenntnis des Wesens der Welt und der Erscheinungen begreift. Doch aus dem kontemplativen Bannkreis der "Welt der Kunst" - in die eine Ästhetik nach Schopenhauer hinführte - entwickelt sie sich weiter zu einer Methode der Kreativität im Rahmen der Gesamtkultur mit dem Anspruch auf "Wertschöpfung".

Belyjs Ästhetik stellt den Theorieversuch des kreativen Subjekts dar, durch ästhetische Opposition des poetischen Bewußtseins gegen automatisierte Lebensformen die Kluft von Kunst und Leben zu überwinden, und zwar durch die Auffassung von der Kunst als schöpferischer Methode zur Neuerfassung der Wirklichkeit und zu deren poetischer Bearbeitung und Verwandlung. Kunstwerke, die aus dieser veränderten Kunstauffassung entstehen - so meint Belyj - sind vielleicht gar nicht mehr Kunst im bisherigen Sinne (Lirika 236), sondern nicht - oder noch nicht - ästhetisch kanonisierte Dokumente moderner Kreativität. Ziel solcher Kunst ist es, "Modelle der Erfahrung" (Smysl 206) zu schaffen, die zur Umgestaltung der Persönlichkeit eines prinzipiell ebenfalls kreativ gedachten Lesers oder "Kunstliebhabers" führen sollen.

Belyjs Ästhetik ist keine reine Ausdrucksästhetik, sondern Wirkungsästhetik. Zum Ausgangspunkt nimmt sie die vorhandene Wirklichkeit; ihr Ziel liegt in der Bewußtseinsveränderung. Auf Belyjs Konzept der "Verwandlung" (preobraženie) wird später näher eingegangen (cf. unten S. $174 \mathrm{ff}$ ). Was nun den Ausgangspunkt angeht, so lautet seine früheste umd immer beibehaltene These:

"Die Kunst stützt sich auf die Wirklichkeit. Die Kunst ist Umarbeitung der Wirklichkeit durch die innere Energie des schöpferischen Bewußtseins (Formy 147/158)."

Um die Bedeutung dieses Satzes, aber auch seine Tragweite zu verstehen, soll im folgenden zuerst Belyjs Wirklichkeitsbegriff näher erläutert werden. Danach soll gezeigt werden, wie sich - abhängig von der Entfaltung der Wirklichkeitsauffassung - Belyjs Methode der Symbolisierung entwickelt. 


\section{KAPITEL}

\section{DIMENSIONEN DER TIRKLICHKEIT}

\section{Existentielle Verankerung}

Die Wirklichkeit hat für Belyj nie zu den selbstverständlich gegebenen Tatsachen gehört. Lange bevor sie zu einer Frage der Kunsttheorie wurde, war sie für ihn ein unmittelbar bedrängendes existentielles Problem. Seine Wirklichkeitsauffassung ist entscheidend von seiner eigenen negativen Daseinserfahrung seit der frühesten Kindheit geprägt. Die materiale seinsmäßige Grundlage seines Denkens in bezug auf die Wirklichkeit ist nicht die Gewißheit eines tragenden Seinsgrundes, sondern im Gegenteil: Seine Grunderfahrung ist der "Mangel". ") Die ersten Eindrücke von der Wirklichkeit sind für ihn verbunden mit Fieber und Untergangsängsten. Seine Genealogie aus dem Fieber beschreibt er im ersten Band seiner Memoiren:

"Ich weiß nicht, worin die Wurzel der seltsamen Wahrnehmung fester Stützen als flüssiger liegt: im vorzeitigen Bewußtsein, oder in den Bedingungen der Temperatur (Krankheit); aber - es ist eine Tatsache: ich nehme nichts Festes wahr; ich erlebe mich, wie in einen Strudel geworfen; für einen Augenblick schwimme ich nach oben, greife nach dem Wrack des zerschellten Schiffes, das auf den Wellen fliegt; und - wieder tauche ich unter (Nrds 166)."

Der physische Mangel der Krankheit wird vom psychischen Mangel der Bedrohtheit und Verlassenheit verschärft; denn in der "gesunden" Wahrnehmung begegnet er im Zerfall der Familie Szenen von der gleichen Beängstigung wie im Fieber. Verdeckend schreibt er:

"Alles was hinter den Wänden hervordrang (das Chaos der Stimmen, Streitigkeiten, erlebt als ein Gebrüll) bringt mich dazu, Gefahr zu befürchten und zu erzittern; wenn ich dorthin (d. h. zu den Eltern, M.D.) gerate, so gerate ich ins Fieber, aus dem ich herausgerissen werde in die Kinderstube; mit einem Wort: die Entzweiung $z$ wischen dem dionysischen Element und dem apollinischen habe ich schon in jenen sechzig Tagen erlebt, als den Zerfall der Wohnung selbst in die Kinderstube und das Unbekannte, vielleicht sind mir die entsetzlichen Räume der Wohnung gleichbedeutend mit der unbekannten Welt (Nrds 170)."

Doch auf diese negative Erfahrung reagierte er nicht allein hilflos mit Angst oder Resignation, sondern mit Ausweichen, Ablehnung und Revolte. Der Mangelerfahrung steht als Gegenbewegung die Suche nach anderen und wahrhaftigeren Lebensformen gegenüber. Er hatte sehr früh in seiner äußeren Erfahrung erkennen müssen, daß sie so beschaffen war, daß man an ihr zugrunde gehen müßte, wenn sie die ganze und vor allem, wenn sie die einzige Wirklichkeit wäre. Aus existentieller Notwehr war er schon im 
vorbegrifflichen Stadium zum "Illusionisten" geworden. Ohne die Illusion einer "Gegenwelt" hätte er nicht weiterleben können (Nrds 177). In seiner inneren Erfahrung hatte er als Möglichkeit zum Uberleben entdeckt: den Leidensdruck einèr lebensfeindlichen AuBenwelt zu transzendieren in der Zuflucht zu Märchen und Musik, zur Vorstellungswelt seiner Einbildungskraft und zur Erinnerung an wenige, immer wieder zerstörte Lichtpunkte glücklichen Verstehens, die es wie Inseln im Meer des Haders und der Zwietracht in der Familie gegeben hatte, die zwar immer wieder untergegangen waren, aber offenbar den Glanz einer Verheißung zurückgelassen hatten. Der Glaube an eine andere mögliche Wirklichkeit war für ihn von der frühesten Bewußtwerdung an lebensnotwendig geworden. Die wichtigste Bedeutung dieser Gegenwirklichkeit ist vielleicht gewesen, daß er in ihr aufgrund ihres utopischen Charakters ein Hoffnungsziel, vor allem aber ein zu erstrebendes Sinnzentrum gesehen hat. Uber die Leidenszeit seiner Kindheit und über die "Gegenwirklichkeit" schreibt er:

"Nach dieser Periode von Fieber, durch die Spaltung des Bewußtseins in die Empirie der Kinderstube und die Erinnerung an das Fieber, durch das positive Faktensammeln über unser Leben, durch das unerträgliche, bittere Leiden und den Schrecken, komme ich zu einer neuen Synthese; diese Synthese ist Raisa Ivanovna (seine Bonne), die mir Lieder und Märchen vorliest.

Im Lied, im Märchen und in den Klängen der Musik ist mir ein Ausweg gegeben aus dem trostlosen Leben; die Welt ist mir nun - ein ästhetisches Phänomen; weder Fieber, noch Angst vor der Empirie unseres Lebens; das Leben ist eine Freude; und diese Freude - ist ein Märchen; aus dem Märchen heraus beginnt mein Spiel mit dem Leben; das Spiel aber - ist reinster Symbolismus.

Hier liegt das Problem der von mir und Raisa Ivanovna bewußt erbauten, dritten Welt über den Welten: der Prosa und des Fiebers; die dritte Welt - das ist Spiel, Symbol, ist 'als ob', das mir von den Klängen der fließenden musikalischen Läufe souffliert wurde: wäre nicht das Märchen gewesen, damals als mir Raisa Ivanovna geschenkt wurde, wäre ich entweder zum Idioten geworden, im Fieber versinkend; oder ich wäre vorzeitig zum Greis geworden, der prosaisch das Leben von Vater und Mutter belauert hätte; wäre ich diese Wege gegangen es wäre mein Untergang gewesen (Nrds 175)."

Hatte er in den Kindheitsjahren als "Idiot der Familie" die Gegenwirklichkeit der Kunst in Märchen und Musik für sich als zeitweise einzig mögliche Methode der Selbstbehauptung gegenüber der "schlechten Empirie" seines vom Zerfall bedrohten Elternhauses entdeckt, so wiederholte sich die Befreiung durch die Kunst in der Pubertät auf bewußter Ebene durch selbständige, aber verbotene Lektüre der Klassiker und der Modernen, allerdings um den Preis, eine "Ubertretung" zu begehen. 2)

Neben der Kunst ist es seit den Schülerjahren die Philosophie gewesen, die ihm eine Uberlebenschance und eigene Legitimierung seines gefährdeten Selbst gegenüber der Welt der "Väter" anbot. Sie gab ihm nun auch die begriffliche Möglichkeit zur Distanzierung von der deformierenden Empirie des Milieus, die er jetzt erkenntniskritisch als "trügerische Unzuverlässigkeit des Faktischen" bestimmen konnte. Mit ihrer Hilfe konnte er eine Umkehrung der gewöhnlichen Bewertung der Wirklichkeit vornehmen und sich so 
von ihrem Druck frei machen. ${ }^{3)}$ Zeitlebens hat er wohl deshalb die enge Beziehung von Kunst und Philosophie als notwendig beibehalten.

\section{Objektive und subjektive Auffassung von der Wirklichkeit}

In seinem Aufsatz "Sinn der Kunst" schreibt Belyj:

"Der Zusammenhang der jeweiligen Ästhetik mit den zugrundeliegenden Vorstellungen von der Wirklichkeit ist unvermeidlich (Smysl 196)."

Das trifft für seine eigene Ästhetik in besonderem Maße zu. Ohne Analyse seines Wirklichkeitsbegriffes ist sie nicht zu verstehen. Die Frage nach dem Verhältnis von Kunst und Wirklichkeit liegt allen seinen kunstphilosophischen Uberlegungen zugrunde. Diesem Verhältnis geht er in drei verschiedenen Hinsichten nach. Er fragt sich:

1. Wie ist die Kunst von der Wirklichkeit bestimmt, und welche Bedingungen sind ihr von hier aus vorgegeben?

2. Welchen Seinsstatus hat die Kunst in bezug auf die vorgegebene Wirklichkeit?

3. Welchen Sim hat sie in bezug auf dieselbe?

Die wichtigsten Aussagen dazu macht er in den Aufsätzen "Formen der Kunst" (1902), "Sinn der Kunst" (1907) und "Emblematik des Sinns" (1909).

Imerhalb seiner Wirklichkeitsauffassung gibt es eine Entwicklung in drei Phasen, die von diesen drei Aufsätzen bezeichnet werden. Die Summe wird erst in dem letzten groBen philosophischen Aufsatz "Emblematik des Sinns" aus dem Jahre 1909 gezogen. In dieser Entwicklung gibt es verschiedene Variable. Sie bleiben aber auf eine gleichbleibende Grundstruktur bezogen. Sie besteht in der Uberzeugung von der Existenz zweier Bereiche innerhalb der Wirklichkeit: das, was als Erscheinungswelt gegeben ist, und ihm gegenüber das, was das Wesen der Erscheinungen ist - oder was sein kann bzw. sein soll. Am Anfang kann man von Platonismus sprechen, der aber bereits mit einem Entwicklungs- oder Vollendungsdenken verbunden wird, das sehr verschiedene Einflüsse erkennen läßt. Modifizierend kommt schließlich die Vorstellung einer "Wertwelt" hinzu, die vom Neukantianismus angeregt ist.

Was die Untersuchung schwierig macht, ist, daß sich Belyj dem Problem der Wirklichkeit von zwei ganz extremen methodischen Standpunkten aus nähert, denen zwei verschiedene erkenntnistheoretische Einstellungen zugrundeliegen. Einmal betrachtet er die Rolle der Wirklichkeit für die Kunst vom objektiven Standpunkt des modernen Naturwissenschaftlers aus, der sich erkenntnistheoretisch als Realist verhält. Zum anderen betrachtet er sie vom subjektiven Standpunkt des Künstlers, der individuell wahrnimmt und erlebt, und des philosophisch Reflektierenden, der auf dem Boden einer idealistischen Erkenntnistheorie steht. Die Wirklichkeit ist also - je nach eingenom- 
menem Standpunkt - in verschiedenen Hinsichten der Betrachtung vorgegeben: Einmal als objektiv gegebener Material - und Gegenstandszusammenhang, der der Technik - sei es der des Naturwissenschaftlers oder der des Künstlers - bestimmte Bedingungen und Aufgaben stellt. Dem wahrnehmenden, erlebenden, reflektierenden oder künstlerisch schaffenden Subjekt dagegen ist die Wirklichkeit als je "meine", subjektiv bedingte Wahrnehmungs- oder Erlebniswelt gegeben, der das Ich einen Sinn und eine Bedeutung geben will oder muß. Die Bedingungen des Subjekts bestehen also in seiner individuellen Wahrnehmungs- und Erlebnisweise und im subjektiven Sinnbedarf. Der Sinnbedarf kann auf verschiedene Weise gedeckt werden. Entweder konzentriert sich das sinnsuchende Subjekt auf die anschauende Erkenntnis des Wesens der Erscheinungen in den Formen der Kunst. Oder aber es sucht den Sinn in der aktiven, schöpferischen Lebenspraxis und in der Erkenntnis des eigenen Selbst. Die Phasen der Wirklichkeitsauffassung Belyjs sind von diesen Möglichkeiten der Sinnsuche bestimmt: Zuerst geht es ihm primär - in der Nachfolge Schopenhauers - um die kontemplative Erkenntnis der Wesenheiten; in der zweiten Phase um aktiven Lebensvollzug und Selbsterkenntnis. Beim Ubergang von der vita contemplativa zur vita activa wird die Frage nach dem "Wert" für Leben und Schaffen zentral.

In der Art, wie sich Belyj von zwei ganz verschiedenen methodischen Standpunkten das Problem der Wirklichkeit perspektivisch zu erschließen sucht, zeigt sich eine Eigenart seiner Denkstruktur. Wie schon gesagt wurde (S. 86f.), ist das experimentelle Denken von verschiedenen, ja von gegensätzlichen Annahmen aus, typisch für ihn. Er bezeichnet es als die "Methodologie der Schere zwischen der Welt der Kunst und der Welt der Wissenschaft im Versuch des ideologischen Aufbaus des Symbolismus als eines Triadismus (Nrds 399)." Die Befähigung dazu erwarb er sich in der methodischen Schulung seines Denkens durch seinen Vater, der ihn das Operieren mit hypothetischen Annahmen gelehrt hatte. Rückblickend schreibt er darüber:

"Ausdrücke in der Art von 'etwas' 'das Ende', 'universaler Kampf', 'Atmosphäre'- hatten nicht die Bedeutung weltbelehrender Losungen, sondern hypothetischer Annahmen ('nehmen wir an, daß', 'setzen wir voraus', 'gesetzt den Fall'); an die Sprache rechtmäßiger Annahmen war ich herangeführt worden vom Vater, der mir die Methode ganz genauen Wurzelziehens aus willkürlichen Annahmen gezeigt hatte (Nrds 399)."

Wir hatten, um Belyjs Eigenart als Dichter-Theoretiker genauer zu erfassen, ihn als poeta doctus bezeichnet. In der Personalunion des poeta doctus sind nun in seinem Falle nicht nur der Kunstpraktiker und Kunsttheoretiker, also nicht nur Dichter und Denker vereinigt, sondern innerhalb seines Denkens koexistieren außerdem schwer zu vereinende Gegenströmungen: die Denkhaltung des exakten Naturwissenschaftlers mit positivistischer Grundausrüstung und der Fähigkeit zu mathematischer Formalisierung einerseits die des idealistischen Philosophen andererseits, dessen Denken aber zudem noch von der 
eigenen Daseinserfahrung wesentlich mitgeprägt ist, und der seine Denkpositionen im Einklang mit seiner Selbsterfahrung laufend erweitert und überprüft. Belyjs Denken kreist einerseits um Grundkonstanten, trägt andererseits das Gepräge des Experiments und der permanenten Reflexion.

Seine differenzierte Denkstruktur hat Auswirkungen auf den Aufbau seiner Kunsttheorie. In der Argumentation - besonders in "Formen der Kunst" - springt er zwischen den verschiedenen Grundannahmen laufend hin und her. Später geht er den einzelnen Annahmen gesondert nach: Es gibt Aufsätze, in denen er formalen, andere, in denen er kunstphilosophischen Fragen den Vorrang gibt. Was in "Formen der Kunst" noch im sprunghaften Argumentationsgang eines einzigen Aufsatzes verbunden ist, wird später auf je zwei antithetisch, aber komplementär zu lesende Texttypen verteilt. So stehen sich zuerst "Formen der Kunst" und "Von der Theurgie" (1903), ab 1906: "Das Prinzip der Form in der Ästhetik" und "Sinn der Kunst" sowie "Kunst der Zukunft" als Kontrastgruppen gegenüber; diese Konstellation wiederholt sich 1909: "Emblematik des Sinns" vs. "Magie der Worte" und "Lyrik und Experiment". Sinn und Form der Kunst werden von Belyj nicht systematisch, sondern perspektivisch reflektiert.

Das probeweise Operieren mit verschiedenen Grundannahmen und Perspektiven macht sein ohnehin kompliziertes Denken zwar lebendig, ist aber ziemlich sprunghaft. Doch mit solchen Extravaganzen muß man bei Belyj aufgrund seines hypothetischen und vielschichtigen Denkens rechnen. Sie sind Ausdruck seines Strebens nach einer perspektivischen Synthese des Denkens, die er der Aufsplitterung in einseitige Spezialisierung entgegensetzen will. Diesen Versuch als Unverständlichkeit abzutun, wäre nicht nur zu einfach, sondern verfälschend. Seine Vielschichtigkeit zu berücksichtigen, sie ernstzunehmen und in ihr die wichtigsten Grundzüge hervorzuheben, bietet eher die Chance, seine Originalität zu erfassen und seine ästhetischen Ansichten kritisch zu sichten. ${ }^{4)}$ Im folgenden wird sich noch deutlicher zeigen, wie sehr Belyjs Denken - und nicht nur seine künstlerische Praxis - dem Experiment verwandt ist. In dieser experimentierenden methodischen Haltung vertritt er seine Hauptthese in bezug auf die Kunst.

"Die Kunst stützt sich auf die Wirklichkeit. Die Kunst ist Umarbeitung (pererabotka) der Wirklichkeit (Formy 147)."

Diese Konstante zieht sich - trotz Modifizierungen - durch seine ganze Ästhetik. 


\section{Objektive Bedingungen der Kunst - Kunst als ProzeB technischer Bearbeitung der Wirklichkeit}

Um das Verhältnis von Kunst und Wirklichkeit neu zu bestimmen, stellt sich Belyj in seinem Debut-Essay "Formen der Kunst" bewußt gegenüber den idealistisch-spekulativen Lehrmeinungen über Ästhetik, die damals an der Moskauer Universität von L. M. Lopatin und S. N. Trubeckoj vertreten wurden, auf den Standpunkt eines materialistisch-naturwissenschaft lichen Positivismus, der in diesen Kreisen verpönt war. Das kam - nach seinem eigenen Urteil - einem Skandal gleich. ${ }^{5)}$ Denn zur Basis der Kunst erklärte er weder Ideen, noch Genie, noch die Fantasie, sondern er begann mit provokantem Understatement ganz pauschal: "Die Kunst stützt sich auf die Wirklichkeit." Als rhetorischen Clou wählte er in der gleichen Absicht ein denkbar banales Bild: vom Essen und Verdauen. Mag das gegenüber der damaligen Moskauer idealistischen Lehrmeinung auch verwegen gewesen sein, so ist dieser Ausgangspunkt für die russische Ästhetik generell so neu gar nicht. Die "materialistische" Ästhetik seit Belinskij, Cernyševskij, Dobroljubov hatte den Primat der Wirklichkeit gegeben. Das gilt auch für Turgenev, Tolstoj und - mit Modifizierungen - auch für Solov'evs "positive" Ästhetik. Teilt Belyj den Ausgangspunkt seiner Ästhetik mit den Realisten im obigen Sinne, so wird sich zeigen, worin er sich von ihnen trotzdem grundsätzlich unterscheidet.

Belyj sagt also, die Wirklichkeit sei für die Kunst wie eine Speise, ebenso lebensnotwendig wie darauf angewiesen, daß man sie zu sich nehme und verdaue. Den quasigeheiligten Bezirk der Kunst demontiert er weiter dadurch, daß er zunächst einmal heuristisch alles Subjektive und Ideelle ausklammert: Er betrachtet die Kunst als einen technischen Arbeitsprozeß mit einem bestimmten Energiehaushalt, der als energetischer Prozeß nach thermodynamischen Gesetzen geregelt ist. Zu welchen Erkenntnissen konnte eine solche heuristische Annahme führen? Belyj argumentiert folgendermaßen:

Wie jeder physikalische Prozeß ist auch der Prozeß der Kunst - gesehen als Bearbeitung der Wirklichkeit - von den objektiven Bedingungen ebendieser empirischen Wirklichkeit determiniert.

Er schreibt dazu:

"Die Kunst stützt sich auf die Wirklichkeit. Die Reproduktion der Wirklichkeit ist nun entweder das Ziel der Kunst oder ihr Ausgangspunkt. Die Wirklichkeit erscheint in bezug auf die Kunst gleichsam wie eine Speise, ohne die ihre Existenz unmöglich wäre. Jede Speise gereicht zur Erhaltung des Lebens. Deshalb ist es unumgänglich, sie zu sich zu nehmen und zu verdauen. Die Ubersetzung der Wirklichkeit in die Sprache der Kunst wird ganz genauso von einer gewissen Umarbeitung begleitet. Diese Umarbeitung, obwohl ihrem inneren Sinne nach gleichwohl Synthese, führt zur Analyse der uns umgebenden Wirklichkeit. Die Analyse der Wirklichkeit folgt notwendig aus der Unmöglichkeit, die Fülle und Vielfalt aller Elemente der uns umgebenden Wirklichkeit durch äußere Verfahren (priëm) wieder zugeben.

Die Kunst ist nicht imstande, die Fülle der Wirklichkeit, d.h. die Vorstel- 
lungen und ihren Wechsel in der Zeit, wiederzugeben. Sie zerlegt die Wirklichkeit, indem sie sie bald in Formen des Raumes, bald in Formen der Zeit darstellt. Daher verweilt die Kunst entweder bei der Vorstellung oder beim Wechsel der Vorstellungen: im ersten Falle entstehen die Raumformen der Kunst, im zweiten Falle - die Zeitformen. In der Unmöglichkeit, der Wirklichkeit in all ihrer Fülle gerecht zu werden, liegt der Grund für die Schematisierung der Wirklichkeit (im einzelnen z. B. für die Stilisierung). Die Stärke eines Kunstwerkes ist nicht selten mit der Einfachheit des Ausdrucks verbunden. Dank solcher Schematisierung hat der Schöpfer eines künstlerischen Werkes die Möglichkeit, sich, wenn auch nicht so umfassend, so doch um so genauer, bestimmter auszudrücken (Formy 147f.)."

Die Unterscheidung von Raum- und Zeitformen ist nichts Neues. Sie findet sich bereits in Lessings "Laokoon" und wieder in Schopenhavers Ästhetik. Belyj betrachtet sie jedoch in einem Zusammenhang, in dem sie eine andere Funktion erhält. Denn er geht davon aus, daß der Kunst als technischem Arbeitsprozeß von der Wirklichkeit bestimmte Bedingungen objektiv vorgegeben sind. Er hebt drei Grundzüge ihrer materialen und kategorialen Beschaffenheit hervor, aus denen sich diese Bedingungen ergeben:

1) Die apriorischen Kategorien von Raum und Zeit;

2) die verschiedenen Materialien der Gestaltung (Kunstmittel);

3) die amorphe Fülle von Gegenständlichkeiten und Vorgängen, die in Bewegung sind.

Die verschiedenen Materialien: Holz und Stein für die Architektur und Skulptur, Leinwand und Farbe für die Malerei, Wort und Sprache für die Dichtung, Ton und Klang für die Musik werfen für den Künstler je verschiedene technische Probleme auf. Den Aspekt der Kunst, daß sie "gemacht" wird und daß dieses Machen technisch gemeistert werden muß, den Künstler als homo faber, rückt er hier in den Vordergrund. Das geschieht fünfundzwanzig Jahre vor Majakovskij und im Zusammenhang mit einer "handwerklichen" Tendenz, die um die Jahrhundertwende z. B. von Stefan George oder auch von Hofmannsthal in den "Blättern für die Kunst" propagiert wird. ${ }^{6)}$ Von den verschiedenen Materialien leiten sich die Großformen der Kunst her. Sie sind aber nach Belyj nicht allein von den "Werkstoffen" bestimmt, sondern auch von den Kategorien Raum, Zeit und Kausalität. ${ }^{7)}$ Je nachdem, ob ein Gegenstand oder Vorgang in räumlicher Plastizität oder in seinem zeitlichen Verlauf oder in seinem ursächlichen Zusammenhang dargestellt werden soll, wird die Kunst sich in je anderen Formen äußern. Aus der kategorialen Beschaf fenheit der Wirklichkeit leitet Belyj fünf Grundformen der Kunst als Raum- und Zeitkünste ab, die er folgendermaßen klassifiziert:

$\begin{array}{llll}\text { 1. - 3. Raumformen: } & \text { Architektur, Skulptur, Malerei } \\ \text { 4. } & \text { Kreuzform: } & \text { Dichtung } \\ \text { 5. } & \text { Zeitform: } & \text { Musik } & \text { (Formy 149) }\end{array}$

Eine weitere objektive Bedingung ist der Kunst aus der Gegenstandsfülle der empirischen Wirklichkeit vorgegeben. Sie zwingt ihr die Notwendigkeit auf 
Verfahren der Darstellung, das heißt Auswahl- und Stilisierungsprinzipien, zu entwickeln und anzuwenden. Denn die Darstellung von Gegenständlichkeiten oder Vorgängen der Empirie in einem bestimmten Material der Kunst ist nur nach einem vorgängigen Selektionsprozeß möglich. Als Forderung an die künstlerische Technik sind aufgrund der Vielfalt der Wirklichkeitselemente zwei unvermeidliche Grundoperationen vorgegeben: die Selektion oder Auswahl bestimmter Gegenstände und deren Schematisierung oder Stilisierung. 8 )

Hier scheint mir ein wichtiges Glied in Belyjs Argumentationskette zu liegen. Denn mit dieser Aussage begründet er nicht nur die Notwendigkeit, daß die Kunst ästhetische Verfahren der Modellierung der Wirklichkeit entwickeln muß, sondern er begründet damit auch den eigenen Seinsstatus der Kunst, als einer Wirklichkeit sui generis, als einer fiktionalen Realität. Er kann nämlich zeigen, daß sich die Kunst trotz und gerade wegen ihrer Bedingtheit durch die empirische Wirklichkeit aufgrund der ästhetischen Verfahren der Selektion und Schematisierung grundsätzlich von ihr unterscheidet, daß sie ihr seinsheteronom ist. Von der Notwendigkeit, die Fülle der amorphen Wirklichkeit durch künstlerische Verfahren zu modellieren, kommt Belyj also zur seinslogischen Unterscheidung einer eigenen Seinsweise der Kunst als fiktionaler Realität, die gegenüber der empirischen Wirklichkeit der Lebenspraxis ihre eigene Autonomie hat. Damit formuliert er bereits 1902 eines der Grundgesetze einer ontologischen Grundlegung oder einer Logik der Kunst. 9) Dieser Gesichtspunkt, die Kunst aus ihren seinslogischen Voraussetzungen als eigene autonome Disziplin auch wissenschaftstheoretisch zu fundieren, ist die Hauptforderung, die Belyj an eine moderne Ästhetik stellt. Er ist sich aber klar, daß zu seiner Zeit dazu erst noch die Grundlagen erforscht werden müßten. Als solche sieht er genauere Forschungen zur Phänomenologie künstlerischer Strukturen an.

Aufgrund der Unterscheidung $z$ wischen den beiden verschiedenen Seinsweisen von Empirie und fiktionaler Realität wendet er sich aus dichtungslogischen Gründen gegen ein Verständnis von Kunst als mimetischer Reproduktion, und damit gegen eine einseitige Tendenz zur Widerspiegelung der Wirklichkeit in manchen Werken des Realismus, vor allem aber im Naturalismus. Wenn Belyj also von der unabdingbaren Notwendigkeit der empirischen Wirklichkeit für die Kunst ausgeht, so gilt das in einer ganz bestimmten Richtung: Die vorgegebene Wirklichkeit ist für ihn zwar notwendige Ausgangsbasis für die Kunst, sie ist aber nicht das Ziel der Kunst:

"Vorausgreifend sagen wir, daß jede Form der Kunst zu ihrem Ausgangspunkt die Wirklichkeit hat, zu ihrem Endpunkt aber - die Musik als reine Bewegung (Formy 153)."

Aus der eigenen Seinslogik der Kunst zieht Belyj den Schluß, daß Kunst "Umarbeitung" der Wirklichkeit sein muß, soll ihre Selbständigkeit als eigene, autonome Disziplin nicht in Frage gestellt werden. Daß auch in den Kunsttechniken des Realismus "Umarbei- 
tung" geschieht, läßt Belyj hier außer acht. Ihm kommt es vor allem darauf an, aus einer Logik der Kunst den Nachweis zu führen, daß "Umarbeitung" auch ganz anders vor sich gehen kann als in mimetischer Widerspiegelung. Gegenüber den direkt mimetischen Kunstrichtungen, die zu Belyjs Zeit noch immer den Anspruch auf Alleingliltigkeit erhoben, vertritt er kunst theoretisch das Recht auf eine nicht mimetische Kunst der Umarbeitung der Wirklichkeit. Hier, und nicht in möglichst "originalgetreuer" Kopie nach sanktionierten realistischen Kunstverfahren, liegt für ihn das Ziel der Kunst. ${ }^{11)}$ Uns heute mag Belyjs kunsttheoretischer Ansatz, der einerseits von der vorgegebenen Wirklichkeit ausgeht, andererseits von den objektiv notwendigen Verfahren der Umarbeitung: Selektion und Stilisierung, nicht sonderlich neu erscheinen. Betrachtet man ihn aber vor dem Hintergrund der Realismusherrschaft, dann kann man erkennen, daß Belyj mit der Bloßlegung der Verfahren zugleich begründen will, daß sie auch anders, als in den zur künstlerischen Norm erklärten Techniken des Realismus, angewendet werden können und daß dennoch - oder gerade deswegen - mit Recht von Kunstwerken neuer Art gesprochen werden darf. Darüber wird im folgenden noch einiges mehr zu sagen sein.

Von den Materialien der Kunst - wir würden wohl besser von Kunstmitteln sprechen - untersucht er des näheren (verständlicherweise) nur die Sprache in ihrer Zwischenstellung zwischen dem stofflichen Material der Raumkünste, mit denen sie die Bildhaftigkeit teilt, und dem reinen Klang der Musik, mit der sie vor allem durch den Rhythmus verbunden ist. ${ }^{12)}$ Als das Spezifikum der Sprache sieht er deren Zeichencharakter an, durch den die Beschreibung oder das Entwerfen von Gegenständlichkeiten der Wirklichkeit ermöglicht wird. Sprache unterscheidet sich von der unmittelbaren bildlich-visuellen Gestaltung, wie sie in den bildenden Künsten geleistet werden kann, deren Material sinnlich erfaßbar ist, dadurch, daß sie mittelbar durch die sprachlichen Zeichen arbeitet. Durch den Zeichencharakter der Sprache gewinnt die Dichtung aber einen viel größeren Umfang an Bildem der Wirklichkeit als die unmittelbaren Raumkünste. Das hat wiederum zur Folge, daß das literarische Kunstwerk wegen seines nur mittelbaren Beschreibens der Wirklichkeit in erhöhtem Maße auf die Mitwirkung des Lesers, und das heißt auf "Konkretisation", angewiesen ist als die unmittelbar darstellenden bildenden Künste. ${ }^{13)}$ Belyj schreibt über den Leser:

"In der Dichtung ist es so, daß wir auf der Grundlage des Lesbaren die Bilder und ihren Wechsel wiedererschaffen. Die Richtigkeit unserer Anschauungen wird von der Richtigkeit der Vergegenwärtigung beschreibbarer Bilder abhängen. Die Dichtung ist allumfassend, aber sie ist nicht unmittelbar (Formy 152)."

Neben Raum, Zeit und Material ist die empirische Wirklichkeit weiterhin kategorial durch die Kausalität bestimmt. In der ästhetischen Werkstruktur der Dichtung, als der Kreuzform der Raum- und Zeitkünste, sieht Belyj das Prinzip der Kausalität formal wirksam werden; aber in zweierlei Form: Die Dichtung zeichnet sich vor anderen Kunst- 
formen dadurch aus, daß ihr Inhalt in kausal zusammenhängender Form gegeben ist, was sich zeigt an der "bewußten Klarheit, die die Bilder begleitet", also etwa durch die klare Motivierung und Sukzession im Aufbau der Handlung. Ihr Inhalt ist damit in prozessualer Form gegeben, also in Bewegung. Nach Belyj ist in dieser Struktur das literarische Kunstwerk zwar von den anderen Künsten abgehoben, aber noch nicht in seiner Eigenheit gegenüber anderen Texten bezeichnet. Denn Motivierung, Sukzession und Prozessualität des dargestellten Inhalts finden sich auch in nicht künstlerischen sprachlichen Äußerungen wie Gespräch, Predigt oder Bericht. Als unterscheidendes Merkmal zu solchen Textsorten weist die Morphologie des sprachlichen Kunstwerkes - neben den logischkausalen Handlungslinien - auch alogisch-assoziative Bildstrukturen von in sich gegründetem Ganzheitscharakter auf, was sich zeigt an der "inneren Begründetheit der poetischen Bilder". Belyj hält diesen Zug des sprachlichen Kunstwerkes für das eigentlich unterscheidende Merkmal der Dichtung, für das, was für seine Wirkung als Kunstwerk entscheidend ist (Formy 150).

Indem Belyj in der metaphorischen Ebene des sprachlichen Kunstwerks das unterscheidende Merkmal der Dichtung sieht, wird ein Gedanke ausgesprochen, den schon Aristoteles in der "Poetik" entfaltet ( $\$ 21 / 22$ ).

"Weitaus das Wichtigste ist das Metaphorische. Denn dieses allein kann man nicht bei anderen lernen, sondern es ist ein Zeichen von Begabung. Denn gut zu
übertragen bedeutet das Verwandte erkennen zu können."

Belyj zitiert Aristoteles nicht, gibt aber dem Bildlichen in der Dichtung - das hier abweichend von der Tropologie einer bewußt angewendeten Rhetorik verstanden wird $^{15)}$ - eine ähnlich bevorzugte Stellung. Im Hervorheben der "inneren Begründetheit der poetischen Bilder" können wir den Keim seiner Symbolauffassung erkennen. Uber die eigene Form der Begründetheit der poetischen Bilder in der dichterischen Struktur schreibt er:

"Die Kausalität (pričinnost') kann sich auf verschiedene Weise ausdrücken: sowohl in der bewußten Klarheit (soznatel'naja jasnost'), die die Bilder begleitet, als auch in der inneren Begründetheit (vnutrennjaja obosnovannost') der poetischen Bilder (Formy 149)."

Mit der "inneren Begründetheit der poetischen Bilder" - auf deren Begründung aus der Schopenhauerschen Kausalitätslehre wir noch zurückkommen werden - erreicht Belyj nun eine Grenzlinie in seiner Argumentation über die Kunst als technischen Arbeitsprozeß von den objektiven Bedingungen her, die ihr aus der kategorialen Beschaffenheit der Empirie vorgegeben sind. Denn jetzt stößt er in der Struktur des "Produktes" auf Bedingungen der Kunst, die ihr aus dem künstlerischen Subjekt heraus gestellt werden (cf. S. $106 \mathrm{ff}$.).

Doch er verfolgt vorerst seinen induktiven Denkansatz weiter und modifiziert inn in 
bezug auf die Betrachtung des "Materials" der Gestaltung. Er trifft nämlich die Unterscheidung zwischen zweierlei Qualitäten des Materials: zwischen der stofflichen und der energetischen. Er stellt sich jetzt auf den Standpunkt des modernen naturwissenschaftlichen Energetismus, der durch die Entdeckung der Gesetze der Thermodynamik im 19. Jahrhundert im Weltbild der mechanischen Physik eine Umwälzung verursachte. Vor allem wurde der Begriff der Materie tiefgreifend verändert: dadurch daß sie nicht mehr als starre Substanz aufgefaßt wurde, sondern als Widerstand, den sie als Energie einer auf sie einwirkenden anderen Energie entgegensetzt. Das Wirken von Energie und Widerstand wurde durch die Entdeckung der Gesetze der Thermodynamik beschreibbar und meßbar. Dadurch wurde auch der Begriff der Kausalität verändert. ${ }^{16)}$ Das Denken des Energetismus, den er durch Ostwald kennengelernt hatte ${ }^{17)}$, versuchte Belyj in seinen kunst theoretischen Ansatz aufzunehmen, indem er das Material der Kunst als Widerstand bestimmt, auf den eine Energiequelle einwirkt. Als "innere Energie" (Formy 158) definiert er - zunächst noch impersonal - die schöpferische, durch künstlerische Techniken die Wirklichkeit bearbeitende Kraft des Subjekts und untersucht ihre Wirkweise im Prozeß der Kunst. Er wendet auf dieses energetische Zentrum - also auf das, was sonst Künstler oder Genie genannt wird - die beiden Grundgesetze der Thermodynamik an:

1) Energie ist in verschiedenen Formen vorhanden, die umwandelbar sind (Transformation).

2) Die Summe der Energie bleibt erhalten (Wirkung).

Für die "innere Energie" gilt dann analog dazu, daß sie in verschiedene Formen künstlerischer Bearbeitungs-Energie, je nach Material, umgewandelt werden kann. Je größer dabei der Widerstand der Materials ist, umso mehr an "innerer Energie" wird im Arbeitsprozeß verbraucht und desto weniger bleibt übrig im fertigen Kunstwerk. Je weniger an "innerer Energie" verbraucht wird, desto mehr davon bleibt erhalten, wird im Kunstwerk gespeichert und kann auf den Rezipienten weiterwirken, wenn sie von ihm freigesetzt wird. $^{18)}$ In Stein, Holz, Farbe etc. sieht Belyj zum Beispiel stärkere physikalische Widerstände als in den sprachlichen Zeichen, Ton und Klang. In den Werken der Dichtung und Musik ist deshalb mehr "innere Energie" zur Verfügung, als in den bildenden Künsten, ihre Wirkung daher intensiver. Mit der Energie-Theorie kommt Belyj von einer Morphologie der Künste daher zu einer Hierarchie mit der Musik an der Spitze.

Er postuliert also ein reziprokes Verhälthis von "innerer Energie" und äußerem Materialwiderstand. Gemäß dem an der Technik orientierten Effizienzdenken des Positivismus stellt Belyj ein Effektivitätsprinzip als Forderung an die Kunst auf:

"In den Künsten ist es uns wichtig, daß die geringste Menge an Material aufs vollständigste den Inhalt ausdrücke, den der Künstler in es hineinlegen möch te (Formy 158)." 
Kunstwerkes innerhalb des künstlerischen Prozesses. Die "innere Energie" bleibt im Kunstwerk gespeichert und kann durch einen Rezeptionsprozeß wieder freigesetzt werden.

Belyj hat also innerhalb seines positivistischen Denkansatzes einen Begriff der empirischen Wirklichkeit entwickelt, nach dem diese auf die Kunst in formaler Hinsicht konstituierend einwirkt und folgende Kriterien hat:

1) Die empirische Wirklichkeit ist ein raumzeitlich strukturierter Dingzusammenhang, der nach dem Gesetz der Kausalität abläuft und eine amorphe Fülle von Gegenständlichkeiten sowie bestimmte Materialien der Gestaltung aufweist. Diese Materialien werden darin nicht als träge Masse aufgefaßt, sondern als Widerstand, auf den die Energien einer heuristisch zunächst impersonal gedachten "Energiequelle" einwirken. Die Wirkung der energetischen Prozesse in der empirischen Wirklichkeit ist durch die thermodynamischen Gesetze geregelt. Die äußere Wirklichkeit ist aufgrund dieser Prozesse in ständiger Bewegung und Veränderung begriffen. Innerhalb dieser Veränderungen bleibt aber die Summe der Energien erhalten. Die Kunst steht vor der Notwendigkeit, die amorphe Fülle der Gegenständlichkeiten durch eigene technische Verfahren mithilfe bestimmter Materialien der Gestaltung zu bewältigen, um zu Ausdruck und Wirkung fähig zu sein. Gerade dadurch erlangt sie aber einen von der empirischen Wirklichkeit verschiedenen seinslogischen Wirklichkeitsstatus, den der fiktionalen Realität.

2) Da die Kunst aber trotz ihres seinsheteronomen Eigenstatus an der Energiestruktur der vorgegebenen Wirklichkeit teilhat, ist sie als ein eigener Wirkzusammenhang zu begreifen, der imstande ist, durch die im Kunstwerk gespeicherte "innere Energie" auf die Wirklichkeit zurückzuwirken, und zwar über das Bewußtsein ihrer Rezipienten. Die Beziehung zum Leser wird innerhalb dieses Denkansatzes von den Materialien der Kunst her auf doppelte Weise begründet: a) aufgrund des Zeichencharakters der Sprache ist die "wiederbelebende", dekodierende Tätigkeit des Lesers nötig; b) aufgrund des energetischen Charakters der Sprache entsteht ein Energiepotential im sprachlichen Kunstwerk, das vom Leser freigesetzt werden kann und eine verändernde Wirkung auf sein Bewußtsein ausüben kann. Der technische Arbeitsprozeß der Kunst erweist sich aufgrund der zeichenhaften und energetischen Qualitäten seines "Materials", der Sprache, als ein ästhetischer Kommunikationsprozeß, der nicht das abgeschlossene Werk zum Ziel hat, sondern den Rezipienten als Partner innerhalb der ästhetischen Kommunikation.

\section{Man kann zusammenfassend sagen:}

Vom Material, der Sprache, her läßt sich das sprachliche Kunstwerk sprachlogisch begründen: einmal als Zeichenstruktur mit Verweisungscharakter, zum anderen als energetische Wirkstruktur mit Appellcharakter. In der Sprache sind beide Möglichkeiten enthalten. Die technische Bearbeitung in der Kunst erweist sich als Kommunikation.

Aus der Fülle der Gegenständlichkeiten und der Notwendigkeit, sie durch Verfahren 
poetischer Technik zu modellieren (wie Selektion und Schematisierung), läßt sich das sprachliche Kunstwerk seinslogisch begründen: Hieraus leitet sich der eigene Seinsstatus der Kunst als fiktionaler Realität her.

Man kann die interessante Beobachtung machen, daß Belyj den "materialistischen" Denkansatz nicht ideologisch ausschöpft, sondern formal-logisch. Er entnimmt ihm durch seine kategoriale und materiale Analyse Bausteine zu einer Logik der Dichtung. Er konnte von seinem "materialistischen" hypothetischen Denkansatz sowohl eine sprachlogische wie auch eine seinslogische Begründung für die Autonomie der Kunst geben. Einer materialistischen Ästhetik, die sich nicht von vornherein auf ideologischen Beweiszwang festschreibt, dürfte Belyjs ästhetische Grundsatzdiskussion einiges zu sagen haben, falls man sich entschließen könnte, sie endlich genau zur Kenntnis zu nehmen.

Soweit die Aussagen, die unter der heuristischen Annahme gemacht werden konnten, die Kunst sei ein technischer Arbeitsprozeß zu den Bedingungen der empirischen Wirklichkeit.

\section{Subjektive Bedingungen der Kunst - zur Konstitution des Gegenstandes der Kunst durch das künstlerische Bewustsein}

Hatte Belyj vom hypothetisch eingenommenen Standpunkt des induktiven Naturwissenschaftlers die Kunst in formaler Hinsicht als einen impersonalen Prozeß technischer Bearbeitung der vorgegebenen Wirklichkeit angesehen, dessen Träger nur insoweit berücksichtigt wurde, als er die "Energiequelle" darstellte, so wendet er sich jetzt vom Standpunkt des individuell ästhetisch Wahrnehmenden, des Erlebenden und des philosophisch Reflektierenden der Wirklichkeit in jener Hinsicht zu, die von der Beschaffenheit und besonderen Wirkung des "subjektiven Faktors" abhängt.

Um Aussagen über diesen machen zu können, war die zuerst angewendete "materialistische" Betrachtungsweise nicht mehr imstande. Mit naturwissenschaftlichen Begriffen hatte Belyj die objektive Einwirkung der Empirie auf die Kunst als Prozeß einer besonderen Form technischer Bearbeitung in formaler Hinsicht beschreiben und bestimmte seinsund sprachlogische Züge an ihr erklären können. Die Wirkungsweise einer zunächst nur formal angesetzten und inhaltlich nicht näher bestimmten "inneren Energie" hatte er noch nach allgemeinen, für Energieprozesse gültigen Gesetzen beschreiben können, aber bei der Frage nach dem Wesen der "inneren Energie" konnte er mit naturwissenschaftlichen Begriffen keine weiteren Antworten mehr geben, weil hier der qualitative Sprung von einem technischen Arbeitsprozeß (bzw. einem physikalischen) zu einem geistigen, von einem Subjekt getragenen Schaffensprozeß gemacht werden muß. Den gleichen qualitativen Sprung von der objektiven Determiniertheit in die subjektive Seinsweise hatte er auch in der Werkstruktur aufdecken können. Hier ist er mit der objektiv-formalen Methode an Grenzen gekommen, doch nicht, ohne sie bis dahin mit Erkenntnisgewinn angewen- 
det zu haben. Es zeigt sich also, daß Belyj seine These: "Die Kunst stützt sich auf die Wirklichkeit" perspektivisch in zwei Richtungen durchdenkt: 1) Die Kunst stützt sich auf die Wirklichkeit der Objektwelt, die ihr bestimmte technische Bèdingungen stellt. 2) Die Kunst stützt sich aber ebenfalls auf die Wirklichkeit des Subjekts, aus der sich Bedingungen anderer Art ergeben. Die beiden Denkrichtungen sind gar nicht so willkürlich, wie es zuerst scheinen mag, sondern ergeben sich daraus, daß Objekt und Subjekt die beiden Grundlagen der Wirklichkeit sind. ${ }^{19)}$ Mit dem Subjekt, das zwar ebenfalls Bestandteil der Empirie ist, aber sich von ihr dadurch unterscheidet, daß es als Subjekt sowohl ein bestimmtes Verhältnis zu den Objekten der Umwelt hat, als auch ein Bewußtsein seiner selbst - "ein Verhältnis, das sich zu sich selbst verhält" ${ }^{20)}$ - mit dem Subjekt also, tritt ein Faktor der Wirklichkeit in Erscheinung, der eine andere Seinsqualität hat und in anderer Weise als die objektive Wirklichkeit auf das Werden eines Kunstwerkes einwirkt.

Gemäß seinem induktiven Denkansatz war Belyj bei der Analyse der Struktur des sprachlichen Kunstwerkes darauf gekommen, daß es als fertiges Werk sowohl die Einwirkungen der objektiven Bedingungen der empirischen Wirklichkeit aufweist, wie auch solche, die auf die Beschaffenheit des "subjektiven Faktors" verweisen. Die nicht logischen poetischen Bildstrukturen - die neben den logisch-kausalen Zügen existieren, aber die es gerade sind, die ein literarisches Gebilde zu einem ästhetischen machen - sind nach Belyj nicht "äußerlich" aus den logischen oder empirischen Bedingungen der Objektwelt begründbar, sondern "innerlich". Sie haben Ganzheitscharakter (Formy 151) und verweisen auf schöpferische Kräfte im Subjekt. Sie machen nicht nur das ästhetische Wesen des Werks aus, sondern entscheiden nach Belyj auch über seine Wirkung. Dazu zitiert er nicht einen $\ddot{A}$ sthetiker, sondern den Naturwissenschaftler H. v. Helmholtz:

"Ein Kunstwerk versetzt uns in Begeisterung und Entzücken durch eben jenen Teil an ihm, der unserem bewußten Verstehen nicht faßbar ist; gerade davon hängt die machtvolle Wirkung des Kunst-Schönen ab, und nicht von den Teilen, die wir vollständig analysieren können (Formy 151)."

Belyj postuliert nun nicht einfach die schöpferische Beschaffenheit des Subjekts, sondern sucht sie in einem induktiven Schlußverfahren evident zu machen, das er mit Hilfe der Erkenntnis- und Kunstlehre Schopenhauers durchführt. Seine metaphysischen Spekulationen über den "Willen" läßt er weitgehend weg. Er argumentiert zunächst nach Schopenhauers "Uber die vierfache Wurzel des Satzes vom zureichenden Grunde" $\left({ }^{2} 1847\right.$, 1 1813). Die logischen Züge der poetischen Werkstruktur sind der Wirkung des Satzes vom "Grund der Erkenntnis" zuzuschreiben; sie haben ihr Korrelat in der abstrakt und begrifflich denkenden Vernunft. Belyj zitiert aus "Die Welt als Wille und Vorstellung" $\left({ }^{2} 1844,{ }^{1} 1819\right), \$ 10$ :

"Wissen überhaupt heißt: solche Urteile in der Gewalt seines Geistes zu willkürlicher Reproduktion haben, welche in irgend etwas außer ihnen ihren zureichenden Erkenntnisgrund haben (Formy 150)." 
Die poetischen Bilder dagegen sind der Wirkung des Satzes vom "Grund des Seins" zuzuschreiben; sie haben daher ihr Korrelat nicht in der Vernunft, sondern in der sinnlichen Anschauung der konkreten Dinge, die Belyj - allerdings hier sehr verkürzt ${ }^{21)}$ - nach Schopenhauer als ein primäres schöpferisches Vermögen ansieht. Die zweite Begründungslinie Belyjs zielt auf eine andere Art des Schöpferischen. Sie ist der Kunstlehre Schopenhauers aus "Die Welt als Wille und Vorstellung" (3. Buch) entnommen. Belyj unterscheidet zwischen dem Bewußtsein als der "Oberfläche des Geistes" (das er hier noch vereinfachend mit logischem Denken gleichsetzt) und dem "inneren Kern des Geistes, den wir nicht kennen" (Formy 150). 22) Bei dieser Unterscheidung scheint es sich - aus allem, was dann folgt - nicht mehr um das gleiche wie vorher zu handeln. Belyj will der logischen Erkenntnis offenbar eine zweite Alternative gegenüberstellen, was auch Schopenhauer tut. Mit dem "inneren Kern des Geistes, den wir nicht kennen" ist die zweite Form schöpferischer Erkenntnis gemeint: Die geniale Anschauung der Ideen. Sie liegt ebenfalls jenseits der logischen Erkenntnis im Gebiet der "anschaulichen Erkenntnis" (5 36).

Auf diese beiden Begründungslinien, die ihn zur primären schöpferischen Anschauung der Realität und zur genialen Anschauung der Ideen in der Kontemplation geführt hatten, stützt Belyj seine zweite Hauptthese vom Primat des Schöpferischen im Bewußtsein, insbesondere im künstlerischen:

"Das Schöpferische steuert das Bewußtsein, und nicht das Bewußtsein das Schöpfer ische (Formy 150)."

Belyj wendet sich jetzt der Konstituierung des Gegenstandes der Darstellung in der Kunst zu, der weiterhin aus der empirischen Wirklichkeit stammt, und dem Wesen der "inneren Energie" des kreativen Subjekts, welches auf ihn einwirkt und seine Darstellung unternimmt. Sind die Grundoperationen der Selektion und Schematisierung der Gegenständlichkeiten dem Künstler wegen der Wirklichkeitsfülle als formale Forderung vorgegeben, so ist ihm die Art und Weise der Verfahren jedoch nicht vorgegeben. Es stellt sich die Frage, was, wie und warum etwas von ihm ausgewählt und wie es stilisiert wird. Daß Auswahl und Stilisierung notwendig sind, ist als objektive und formale Forderung vorgegeben, denn sonst könnten weder Werk noch Wirkung erreicht werden; was aber ausgewählt und wie es gestaltet wird, ist nicht von der kategorialen Beschaffenheit der Empirie vorgegeben, sondern geschieht jeweils zu den Bedingungen des künstlerischen Subjekts. Da stellen sich zwei Fragen:

Welches sind die Bedingungen des künstlerischen Subjekts?

Wie wird der Gegenstand der Kunst oder die Wirklichkeit der Kunst aufgrund dieser Bedingungen konstituiert?

Wie schon gesagt wurde (S. 97), bestehen die Bedingungen des Subjekts in seiner Wahr- 
nehmungsweise, seiner Erlebnisstruktur und, aufgrund seines subjektiven Sinnbedarfes, in der ideellen Konstruktion der Wirklichkeit.

\section{Die künstlerische Wahmehmungsweise}

Die Fähigkeit zu wacher und tiefer Wahrnehmung ist nach Belyj ein unmittelbar schöpferisches Grundvermögen. Hier spielen für ihn vor allem bestimmte Arten des kreativen Sehens eine wesentliche Rolle. Die Wahrnehmung der Wirklichkeit in der ästhetischen Einstellung ist von dem Verfahren der neutralen Beobachtung, wie es für die Wissenschaft gefordert wird, zu unterscheiden. Sie hängt ab von der Fähigkeit des Künstlers, "sehen zu können" (umenie videt'). Das "Sehen-können" hat nach Belyj zwei verschiedene Aspekte: Einmal geht es um den Tiefgang des Sehvermögens, um die "Tiefe der künstlerischen Anschauung", zum anderen geht es um seine Beweglichkeit, um die Fähigkeit zum "Neuen Sehen". Beides sind kreative Wahrnehmungshaltungen des künstlerischen Subjekts, die in engem Zusammenhang stehen mit seinem schöpferischen Konzeptionsvermögen, mit der produktiven Einbildungskraft (tvorčestvo):

"Von da aus verstehen wir den Sinn des Ausspruches, dessen sich die Künstler oft bedienen: Sie sagen, daß es wenig sei, die Dinge zu sehen, nötig sei es 'sehen zu können'. Das 'Sehen-können' ist das Vermögen, in den Bildern ihren ewigen Sinn, ihre Idee zu erfassen (Formy 171)."

Das künstlerische Sehvermögen ist eine zugleich geistige und sinnliche Wahrnehmungsweise. Wichtig für den Künstler in der Moderne erachtet Belyj die Fähigkeit zum "Neuen Sehen", das sich nicht auf die konventionalisierte Optik festlegen läßt, sondern den Gewöhnungen durch sensibilisierte und bewußt wach gehaltene Wahrnehmung entkommt. Das "Neue Sehen" ist nicht nur in der ästhetischen Einstellung wirksam, sondern es ist auch ein kreatives Vermögen, das der produktive Wissenschaftler - neben genauer Beobachtung - braucht. Es braucht auch jeder schöpferisch lebende Mensch. Es ist also nicht eine rein ästhetische Kategorie. Belyj zieht daher eine interessante Parallele zu naturwissenschaftlichen Entdeckungen auf dem Gebiete der Optik, die den neuen Wahrnehmungsweisen der modernen Kunst entsprechen und sie bestätigen, er zitiert seine damaligen Kronzeugen Helmholtz und Ostwald:

"Wie seltsam, daß wir gerade unter den Revolutionären und Innovatoren in der Kunst öfters eine Entsprechung ihrer künstlerischen Tendenzen zu den wissenschaft lichen Bestrebungen der Gegenwart entdecken; so macht der Chemiker Wilhelm Ostwald in den 'Briefen über die Malerei' viele äußerst wertvolle, erhellende Äußerungen über die Eigenschaften der Farben und über die Technik in der Malerei, wonach wir anfangen, einige Bestrebungen der Impressionisten besser zu verstehen, die zu ihrer Zeit einen ganzen Sturm von Verfolgungen auszuhalten hatten; so schreibt er unter anderem: 'Für die künstlerische Wiedergabe der Natur muß der Künstler lernen, neu zu sehen (smotret' po novomu)... (S. 153). Dieses Streben, neu zu sehen, ist bis jetzt ein endloses Thema für die 
Ubungen eines spießerhaften Scharfsinns. 'Der Künstler' - fährt Ostwald fort, 'soll sein Auge unablässig einstellen und sein Bewußtsein von der Gewöhnung entwöhnen, mit dem praktischen Ziel, die Sehempfindungen durchzuarbeiten und zu variieren; er soll sich so selbst dazu erziehen, nur Formen und Farben zu sehen, unbezogen darauf, was sie in Wirklichkeit vorstellen. In dem Maße, in dem er lernt, diese Wirklichkeit auszuschalten, wird er auch in der Lage sein, in seinen Bildern einen Eindruck von der Wirklichkeit zu übermitteln.' Wir müssen zugeben, daß sich der 'Chemieprofessor' hier in Fragen der Malerei mehr Gedanken macht als eine Menge Kunstkritiker, die manchmal bis zum Uberdruß den Künstlern ihren eigenen Humbug aufdrängen.

Wie ähnlich sind die Forderungen Ostwalds, die er dem Künstler vorhält, den Aufgaben, die zu ihrer Zeit die Impressionisten in den Vordergrund rückten. Während sie viele Jahre lang unter Druck standen, sind sie im Grunde nur auf ein gleiches Niveau mit der wissenschaftlichen Weltanschauung ihrer Zeit gegangen; ob die Académie Française wohl daran gedacht hat, während sie den 'Impressionismus' für Scharlatanerie erklärte, daß sie sich in ihrer eigenen 'Kurzsichtigkeit' beschrieb, ob die Bourgeoisie wohl bedacht hat, während sie den Impressionismus zum Gespött machte, daß sie ihrer eigenen Unwissenheit spottete? So schreibt Mauclair in seinem Buch 'Impressionismus' aus Anlaß der berüchtigten Technik Claude Monets:

"Die Vertreibung des Lokalkolorits, das Studium der Reflexe, gemalt in den Komplementärfarben, die Zerlegung von Farbtönen und der Prozeß der Malerei in nebeneinander gesetzten Fleckchen reiner Spektralfarben - das sind die wesentlichen Prinzipien des 'Chromatismus' (ein Terminus, der zutreffender wäre, als das nebelhafte Wort 'Impressionismus'). Claude Monet wendete diese Prinzipien systematisch vor allem auf die Landschaft an ...' Und vorher: 'Seine Arbeiten dienen als großartige Bestätigung der Entdeckungen, die von Helmholtz und Chevrel auf dem Gebiet der Optik gemacht worden sind' (...) (Komm. 464/65)."

Die bewußt trainierte oder die unbotmäßige Wahrnehmung eines "Neuen Sehens" sind Äußerungsformen des Schöpferischen, dem Belyj - wie schon gesagt wurde - den Primat im Bewußtsein einräumt. Im "Neuen Sehen" als Akt schöpferischer Neugier scheint mir das Besondere, daß sinnliche Anschauung der Realität und intuitiv erkennender Verstand zusammenwirken. Diese Art primärer Kreativität ist nicht allein der Kunst vorbehalten, sondern gilt allgemein.

Das deckt sich übrigens mit der primären Form des Schöpferischen, die Schopenhaver - U. a. angeregt durch Goethes Farbenlehre - der Vernunfterkenntnis gegenüberstellt. In "Uber die vierfache Wurzel des Satzes vom zureichenden Grunde" sagt er über den intuitiv erkennenden Verstand, der schöpferisch mit den sinnlichen Wahrnehmungen zusammenwirke:

"so daß er der werkbildende Künstler ist, sie nur die das Material darreichenden Handlanger (5 21)."

Neben Schärfe und Unabgegriffenheit der ästhetischen Wahrnehmung im "Neuen Sehen" unterstreicht Belyj die zweite, ihm noch wesentlichere Komponente des "SehenKönnens", die "Tiefe der künstlerischen Anschauung" (Formy 159). Sie ist nicht nur eine schöpferische Form der Wahrnehmung der Erscheinungswelt, sondern sie stellt diejenige Seite der Anschauung dar, in der sie eine intuitive Erkenntnishaltung ist, die Sinnliches 
und Geistiges umfaßt, in der Verstandes- und Gefühlserkenntnis vereint sind:

"Von hier aus wird bei uns der Gedanke geboren vom Kunstwerk, als der Synthese aus Verstand und Gefühl, zu etwas, welches die Bedingung sowohl für das eine wie auch für das andere ist (Formy 171)."

Diese Ansicht deckt sich wiederum mit der Schopenhauers. Der Vernunfterkenntnis stellt er nämlich - wie schon angedeutet wurde - eine zweite Form schöpferischer Erkenntnis gegenüber, die nicht mehr auf Erkenntnis der Erscheinungen gerichtet ist, sondern darauf, in ihnen ihr Wesen, ihre Idee zu erschauen. Sie ist dem Satz vom Grund (der Kausalität) nicht mehr unterworfen, sondern geschieht in Freiheit von den Bedingungen der Erscheinungswelt. Doch sie setzt eine qualitative Veränderung im erkennenden Subjekt voraus ("Wille und Vorst." \$33) und ist der Kunst vorbehalten. Die geniale Erkenntnis ist nach Schopenhauer Wissenschaft und Erfahrung verschlossen.

Aufgeschlossen für die "Tiefe der künstlerischen Anschauung" wird das poetische Bewußtsein nach Belyj durch einen Zustand der Gestimmtheit oder der "Stimmung" (Formy 167). Hierin haben wir eine Vorstufe zu seinem späteren umfassenderen und präziseren Erlebnisbegriff: ${ }^{23)}$

"Sklavische Kopie der Wirklichkeit kann nicht zur Identität zwischen Darstellung und Gegenstand der Darstellung führen. Die innere Wahrheit eines wiederzugebenden Gegenstandes erscheint als der wichtigste Gegenstand der Darstellung. Nicht das Bild (kartina) selbst soll in den Vordergrund gerückt werden, sondern die Wahrheitstreue der Emotionen und Stimmungen, die erlebt werden, hervorgerufen in uns durch dieses oder jenes Bild der Natur." (Formy 158).

Durch den aufschließenden Wert der Stimmung wird das Kriterium der "Wahrheitstreue" von der vorgegebenen auf die erlebte Wirklichkeit verschoben.

Die "Tiefe der künstlerischen Anschauung" hat verschiedene Implikationen: Sie bestimmt den Rang eines Kunstwerkes und verbindet Werke gleichen Ranges über die Jahrhunderte hinweg; sie unterscheidet Kunst von Herstellung und Nachbildung; sie wirkt einer normativen Bestimmung des Schönen entgegen. Da sie der Weg ist, auf dem die Kunst in der Anschauung zur Wahrheit vordringen kann, bestimmt sie den Rang eines Kunstwerkes. In der vollkommenen Erkenntnis ist sie der Philosophie ebenbürtig. Nun wird aber die "innere Wahrheit" des geschauten Gegenstandes nicht, wie in der idealistischen Philosophie, auf ihre Allgemeinheit hin beurteilt, sondern zugleich in ihrer Individualität dargestellt. Hierin ist die Kunst von der Philosophie unterschieden und ihr aufgrund ihrer Gestalthaftigkeit überlegen. Eben aufgrund der Rolle, die die Individualität in der Kunst spielt - worin Belyj von Schopenhauer abweicht, der den Dichter als "klares Weltauge" ("gänzliches Vergessen der eigenen Person", "Wille und Vorst." 36) sieht - ist aber auch eine normative Bestimmung des Schönen a priori unzulässig. Denn: 
"Die innere Wahrheit des Darzustellenden kann verschieden verstanden werden. Ein und dasselbe Bild, dargestellt von vielen Künstlern, wird nach dem Ausspruch Zolas durch das Prisma ihrer Seele gebrochen (prelomitsja skvoz' prizmu ich dưsi). Jeder Künstler erblickt in ihm verschiedene Seiten. Daher ist der Individualismus bis zu einem gewissen Grade unumgänglich in der Malerei (....) Die Schönheit ist vielgestaltig, und das Gefühl der Schönheit weitaus komplizierter, als es vielen scheinen mag (...) (Formy 159)."

Die "Tiefe der künstlerischen Anschauung" ist außerdem unterscheidendes Kriterium gegenüber dem "Handwerk", bzw. der Reproduktion oder angewandten Kunst:

"Die Malerei ist nicht Handwerk. Sie ist nicht Fotografie. Die Malerei unterscheidet sich von der kolorierten Fotografie, vom Öldruck etc. durch den Individualismus in der Auffassung von der inneren Wahrheit des Darzustellenden. Die Beziehung zur Natur von Leuten, die ihr ganzes Leben dem Studium verschiedener Licht- und Farbnuancen gewidmet haben und von Leuten, die aller Jubeljahre einmal die Natur mit ihrer Aufmerksamheit beehren, fallen nicht immer gleich aus; (Formy 159)."

Wenn nun die künstlerische Anschauungstiefe zu den Wesensmerkmalen großer Kunst gehört, dann ist sie auch verbindendes Glied zwischen der Kunst der Vergangenheit und der neuen Kunst der Gegenwart, die man damals anfeindete und der Belyj durchaus Größe zuspricht:

"Und dennoch lehnt man kategorisch die Formen der Kunst ab, die einem noch nicht verständlich geworden sind. Kann es hier nicht vielleicht eine eigene Art von Philosophie geben? Können nicht vielleicht Kunstwerke existieren, die von unserer Seite aus einiges Eindringen in ihren Sinn erfordern? Drückt nicht vielleicht die Tiefe der künstlerischen Anschauung der Darstellung des Angeschauten ein ganz bestimmtes Siegel auf? Ist etwa der Laie in der Malerei, der auf einer Ausstellung erscheint und über Vrubel' oder Hallen lacht, in die Tiefe von Kunstwerken in der Art von Botticelli, Rembrandt etc. eingedrungen? In der Seele bevorzugt er natürlich die für ihn lebhaft und deutlich gemalten ethnografischen Skizzen Vereščagins (Skizzen, nützlich für den Intellekt); Raffael, Rembrandt, Velasquez, das alles - sind halbvermoderte Kirchenfahnen, mit denen er sich naiv bewaffnet, während er der neuen Kunst den Krieg erklärt. Er kommt nicht auf den Gedanken, daß gerade sie es ist, die die wahre Erneuerung der alten Traditionen in der Malerei darstellt. Die Rebellion einiger Formen der Kunst gegen den Akademismus und Naturalismus nimmt er für eine Rebellion gegen alles Alte ... Heilige Einfalt! (Formy 159f.)."

Belyj bestimmt die Eigenart der künstlerischen Wahrnehmung als einen Zwischenzustand des Künstlers, in dem sich die Erkenntniskräfte der sinnlichen, intellektuellen und spirituellen Anschauung mischen. Er gelangt zu ihm durch die Entwöhnung der Wahrnehmung von der normalen Optik, aber auch durch eine aufschließende Stimmung. Von Aufgabe des principium individuationis, wie bei Schopenhauer, ist jedoch nicht die Rede. Im Gegenteil: Die Individualität des Künstlers kommt aus erweiterter und vertiefter Wahrnehmung, verbunden mit philosophischer Reflexion, zur schöpferischen Aneignung der Wirklichkeit, durch die ein Prisma geschliffen wird, in dem die empirische zu einer transformierten Wirklichkeit flektiert wird. Erst in diesem individuellen Brechungswinkel 
formiert sich der eigentliche Gegenstand der Kunst. Wesentlich für diesen Transformationsvorgang ist die Tiefenschärfe und der Durchdringungsgrad in der Sehfähigkeit des schöpferischen Subjekts, die durch die Oberfläche zur Anschauung der Idee in der Erscheinung vordringt. Unabhängig von den Gesetzen der Logik kann, durch die "Tiefe der künstlerischen Anschauung" und durch das "Neue Sehen", die Ideenhaftigkeit oder Geistigkeit der Dinge an ihnen erschaut - oder aber, wie man hinzufügen könnte, in sie hineingesehen - werden. Den Begriff der "idejnost"' sieht Belyj aus der Tradition des sozialen Auftrags ideologisch vorbelastet; er erhält bei ihm einen anderen, dem griechischen Verständnis wieder angenäherten, Sinn:

"Die Kunst ist weder logisch noch unlogisch, sondern geistig (idejno). Die Geistigkeit (idejnost') schließt in sich sowohl den Begriff des Logischen, wie auch den Begriff des Unlogischen. Geistigkeit ist das einzige Wesensprinzip der Kunst. Ohne mit den formalen Prinzipien in Widerspruch zu stehen, erscheint es als deren zentralste Erklärung (Formy 164)."

Zusammenfassend kann man sagen, daß die raumzeitliche Wirklichkeit in diesem ProzeB der subjektiven Aneignung eine erste Transformierung oder eine primäre Bearbeitung erfährt, die von der Wahrnehmungsschärfe und -tiefe des Künstlers abhängt, des weiteren - wie sich zeigen wird - von seiner Erlebnisintensität sowie von den philosophischen Ideen des Subjekts über Wesen und Sinn der Wirklichkeit. Diejenige Bedingung des poetischen Bewußtseins, die im zuletzt Gesagten virulent wird, hatten wir auch als den subjektiven Sinnbedarf bezeichnet, der ein ideelles Konzept der Welt verlangt. Im folgenden soll die ideelle Konstruktion der Wirklichkeit, die für die Kunsttheorie Belyjs wichtig ist, genauer untersucht werden.

\section{Die ideelle Konstruktion der Wirklichkeit}

Belyj trifft von Anfang an eine philosophische Unterscheidung zwischen zwei Ebenen innerhalb der Wirklichkeit. Terminologisch bleibt er dabei zunächst unklar - in "Formen" gebraucht er den Begriff "dejstvitel'nost"' noch in beiden Hinsichten. Erst ab 1907 unterscheidet er: die sicht- und tastbare Faktizität als "vidimost"', die ihr gegenüberstehende umfassendere Seinsebene als "dejstvitel'nost"' (Smysl 204/5). Seine Wirklichkeitsauffassung bleibt in der grundsätzlichen Doppelpoligkeit unverändert, dennoch variiert sie in der Konzeption beider Pole. Es lassen sich drei Phasen der Entwicklung unterscheiden:

1. Phase (ab 1902): Hier unterscheidet er die Erscheinungswelt, die er - noch angelehnt an Schopenhauer - als Trug ("Schleier der Maja") auffaßt, vom dahinter stehenden Wesen der Welt, das er als metaphysisches Prinzip der Bewegung denkt, die aber - im Unterschied zu Schopenhauer - nicht als blinder Wille, sondern als Bewegung auf eine Vollendung der Welt in der Zukunft gedacht wird. ${ }^{24)}$ Das Wesen der Welt kann zwar in 
der intuitiven Erkenntnis angeschaut werden, aber zwischen der trügerischen Faktizität und dem Sinnzentrum, das im Wesen der Welt (die sich auf Vollendung hin bewegt) liegt, klafft eine tiefe Diskrepanz. Dennoch ergeht an den einzelnen der Appell zur "Verwandlung"; wiederum abweichend von Schopenhauer.

2. Phase (ab 1906): Der Erscheinungswelt wird jetzt nicht mehr das Wesen der Welt, ihre Bewegung auf eine Vollendung hin, gegenübergestellt. Die Wirklichkeit begreift Belyj jetzt vom Subjekt her als das Gesamt aller inneren und äußeren Erfahrung (Smysl 205). An der Erscheinungswelt betont er nicht mehr ihren illusionären Charakter, sondern die Bedingtheit der angeblich apriorisch feststehenden Kategorien des Bewußtseins (Raum, Zeit und Kausalität) sowie die Bedingtheit der Grenzen der Wahrnehmung (Smysl 204). Die bedingte Außenwelt wird als kleinerer Teil und als Funktion der gesamten inneren Erfahrung verstanden. Die äußere wird der inneren Erfahrung untergeordnet. Das Simzentrum liegt nicht mehr in einem metaphysischen Prinzip, sondern in der inneren Erfahrung des Subjekts. Zwischen beiden Bereichen der Wirklichkeit besteht nicht mehr eine tiefe, nur kontemplativ zu überwindende Kluft, sondern an die Stelle der intuitivkontemplativen Erkenntnis des Wesens der Welt tritt jetzt die aktive Haltung des Erlebens der Welt, an dem nicht mehr nur Wahrnehmung und Imagination, sondern alle drei seelischen Grundvermögen: Verstand, Gefühl und Wille beteiligt sind. Vom "Erleben" her entwickelt er die Methode der Symbolisierung.

3. Phase (1909 - 1910): Belyj hat sich inzwischen dem Neukantianismus der südwestdeutschen Schule zugewandt. Unter Einfluß von Heinrich Rickerts Wertphilosophie sieht er als simgebende Instanz das "Seinsollende" überhaupt, den "Wert", an (dolženstvovanie, cennost"). In einem entschieden geglaubten "Ja" zum "Wert" als Norm des Lebens, der praktischen Vernunft, müsse dessen Existenz bekräftigt werden (Probl. 2, Embl. 65, 99). Die Seinsweise des "Wertes" ist weder ideal noch real, sondern symbolisch. Er hat "aufgegebenes", nicht vorgegebenes Sein. Die Erkenntnis ist nicht mehr auf das Wesen der Welt gerichtet, sondern auf das "Sein-Sollende". Werthafte Erkenntnis soll ergründen, welche neuen Werte von der praktischen Vernunft angestrebt werden müßten.

Mit der Aktivierung des Erkenntnisbegriffes hat sich auch die Auffassung von der Wirklichkeit verändert. Die Erscheinungswelt gilt nicht mehr als "Trug", sondern wird als Aktionsraum der Kultur und des schöpferischen Individuums aufgewertet. Belyj betrachtet die Wirklichkeit als hierarchisch geordneten Stufenbau bedingt wahrheitshaltiger Seinsbereiche, als "Stufenleiter von Wirklichkeiten" (Embl. 71f.). Das Sinnzentrum ist nicht mehr von der Erscheinungswelt abgetrennt, sondern in einer "Emblematik des Sinns" hierarchisch gestuft bis zu einer höchsten Wert-Instanz, dem "Antlitz" (Lik), als Symbol der absoluten Wert-Verpflichtung. Die Haltung des Subjekts wird begriffen als aktives, wertorientiertes Streben nach Selbstwerdung (Embl. 83f., 129; Budučšee 453). Als Kooperationsmodell zwischen der Welt der Erscheinungen und dem Gipfel der Werthierarchie entwickelt Belyj die Methode der Symbolisierung weiter. 
Soweit ein erster Uberblick, der noch der Erläuterung bedarf. Für die erste Phase sind maßgebend die Aufsätze "Formen der Kunst" und "Von der Theurgie". $2 5 \longdiv { \text { Faßt Belyj } }$ einerseits die Erscheinungswelt als "Trugbild" auf, so gibt es auf der anderen Seite die Wunschwelten von Nietzsches "Zarathustra" und die Hoffnung auf einen neuen Menschheitsfrühling, der nur auf dem "Dornenwege der Suche nach einer neuen Liebe und neuen Beziehungen der Menschen untereinander zu erreichen sei." ${ }^{26)}$ Vorbild dafür ist die Theurgie-Forderung Solov'evs, von der der Ansporn zur Verwandlung ausgeht. In "Formen der Kunst" schreibt Belyj:

"Die Wirklichkeit ist nicht so, wie sie uns erscheint. Ob wir uns an den wissenschaftlichen, an den philosophischen oder an den religiösen Standpunkt halten - wir kommen zu ein und demselben Resultat. Jene Wirklichkeit, die wir kennen, ist im Grunde genommen eine andere.

Ein wenig aufmerksame Betrachtung der Bilder der Wirklichkeit führt uns zu der Uberzeugung, daß sie nicht unverändert bleiben.

Bewegung ist der Grundzug der Wirklichkeit. Sie herrscht über die Bilder. Sie erschafft diese Bilder. Sie sind bedingt durch Bewegung.

Die Wirklichkeit, die uns umgibt, ist ein Trugbild, von uns geschaffen. Im eigentlichen Sinne gibt es gar keine Vorstellung, d. h. keine zwei Momente der Zeit, in denen nicht irgendein Wechsel der Vorstellung vor sich ginge, wenngleich wir das gar nicht bemerken. Was existiert, ist allein die Bewegung. Die Vorstellung ist eine Momentfotografie; der Wechsel der Vorstellungen ist eine Reihe solcher Fotografien, die von Anfang und Ende bedingt sind. In der Sprache der Inder ausgedrückt ist zwischen der Welt und uns der trügerische Schleier der Maja ausgespannt.

In allen Religionen gibt es die Gegenüberstellung zwischen unserer Welt und irgendeiner anderen, besseren." (Hv. M. D.) (Formy 165)

Der starke Einfluß Schopenhauers ist of fensichtlich. Es zeigen sich aber bereits Abweichungen. Während Schopenhauer das Wesen der Welt als blinden Willen bezeichnet, der sich allerdings in den platonischen Ideen "objektiviere", wo es einen Glauben an eine "andere, bessere Welt" jedoch nicht gibt, wird von Belyj die ständige Bewegung des Werdens zielgerichtet aufgefaßt, in Richtung auf eine bessere Zukunft. Er gibt also - im Unterschied zu Schopenhauer - dem "Weltwillen" bzw. der Bewegung eine positive Bedeutung als geistige Dynamik, und zwar durch Konjektur mit der christlichen Geschichtsteleologie oder, an anderer Stelle, mit dem säkularisierten Entwicklungsdenken. ${ }^{27)}$ So etwas liegt Schopenhauers Pessimismus fern. ${ }^{28)}$ Belyj glaubt dagegen an einen Prozeß ständiger Selbstvervollkommnung - der eschatologische Züge annehmen kann -, in dem der Mensch sich verwandeln werde. Hier ist die Gegenwirkung von Solov'ev zu erkennen, der die Vollendung der Welt als gottmenschlichen Prozeß in der Kooperation des Menschen mit dem absoluten göttlichen Prinzip dachte. ${ }^{29)}$

Mit Schopenhauers Einfluß kollidiert aber nicht nur der Solov'evs, sondern auch der Nietzsches. ${ }^{30)}$ Auf Belyj wirkte damals besonders der Zukunfts- und Verwandlungsoptimismus Nietzsches, wie er ihn in der Ubermenschen-Vorstellung des "Zarathustra" entfaltete. 31 ) 
Kennzeichnend für die Frühphase der Wirklichkeitsauffassung Belyjs scheint also, daß er nicht nur die übliche platonische Dichotomie von Phänomenal- und Noumenalwelt vertritt, sondern daß er sie mit einer teleologischen Geschichtsmetaphysik kontaminiert, deren bewegendes Zentrum als Dynamik des lebendigen Geistes gedacht wird. In dieser Verbindung zeigt sich eine Denkkonstante Belyjs: Er glaubt an die Verwandelbarkeit der Wirklichkeit. (Das gilt bis in die Revolutionszeit und ist sicher ein Motiv seiner positiven Einstellung zur Oktoberrevolution.) Diesem Glauben liegt zugrunde, daß er von einer damals eschatologisch zugespitzten - Zukunftshoffnung erfüllt ist. (So war es sicher kein Zufall, daß er sich damals - wenn er sich auf den Standpunkt des Naturwissenschaftlers stellt - gerade dem Energetismus zuwandte, einem Dynamismus auf physikalischer Ebene.)

Deshalb erfolgte die erkenntniskritische Relativierung der Erscheinungswelt auch nicht aus der resignativen Position des Pessimismus - wie bei Schopenhauer - sondern aus der dynamischen der Utopie. Wenngleich Belyj damals naiv mit einem unmittelbar "kommenden Frühling" (Solov'ev) rechnete, so wird die Verwandlung der Welt nicht als etwas Selbstläufiges gedacht, sondern abhängig von der Risikobereitschaft des Einzelnen. Hier meldet sich bereits das Krisenbewußtsein Belyjs, wovon im Vorhergehenden schon die Rede war (S. $71 \mathrm{ff}$. ), zugleich aber auch seine engagierte Gegenwehr: ${ }^{32)}$ Nur wer sich der Krise des Zeitalters stellt; wer die tragische Spannung aushält, die notwendig ist, um die hypertrophierten Extreme von Geist und Triebverfallenheit in sich zu integrieren; wer die Gefahren von Rausch oder Wahnsinn und Resignation oder Verzweiflung überwindet, die den "vorbereitenden Menschen" (Nietzsche) bedrohen, - nur der wird zur Verwandlung der Welt beitragen können. ${ }^{33)}$ Schon hier zeigt sich deutlich, daß Belyj völlig mißverstanden wird, wenn man ihn dem Nihilismus zuordnet (cf. oben S. 20ff., 27, zu Maslenikov und Poggioli).

Die Antinomie von Phänomenal- und Noumenalwelt spiegelt sich nach Belyj in den Formen der Kunst. Den realitätsgebundenen Raumkünsten stellt er - wie Schopenhauer die realitätsferneren und daher dem Wesen der Welt näheren Zeitkünste gegenüber. Höchster Ausdruck des Weltwesens ist die Musik. Auch darin weicht er von ihm ab: Während dieser in der Musik das höchste Abbild des Willens sieht ("rerum concordia discors"), ${ }^{34)}$ ist Musik für Belyj darüber hinaus symbolische Vorausdeutung auf eine "andere, bessere Welt", ein "Emblem" für die ständige Bewegung der Welt, die die Möglichkeit zur Vollendung in sich trägt, ${ }^{35)}$ allerdings muß der Einzelne bereit sein, sie zu verwirklichen. Uber das Verhältnis von Kunst und Wirklichkeit kann er deshalb sagen:

"Vorausgreifend sagen wir, daß jede Form der Kunst zum Ausgangspunkt die Wirklichkeit hat, zum Endpunkt aber - die Musik als reine Bewegung.

Ausgedrückt in der Sprache Kants - vertieft sich jede Kunst, ausgehend vom Phänomenalen ins 'Noumenale'; formulieren wir unseren Gedanken in der Sprache Schopenhauers - so führt jede Kunst zur reinen Betrachtung des Weltwillens; oder im Geiste Nietzsches gesprochen - bestimmt sich jede Form der 
Kunst durch den Grad des Hervortretens des Geistes der $34 \mathrm{fusik}$ in ihr; oder nach Spencer - jede Kunst strebt in die Zukunft (Formy 153)." 36 .

Die Bedeutung der Musik bei Belyj hat verschiedene Aspekte. ${ }^{37)}$ Im Gegensatz zur Rolle der Musik bei Blok ${ }^{38)}$ ist sie noch wenig erforscht. Auch hier kann nur einiges Wenige gesagt werden. In dieser ersten Phase wird die Musik von Belyj zwar bereits in formaler Hinsicht betrachtet, denn Belyj war mit der Entwicklung eines eigenen symphonischen Stils in seiner frühen Prosa beschäftigt, doch gleichzeitig wird die Musik von ihm in einem eschatologischen Sinne gedeutet. Wegen ihrer universalen Verständlichkeit, ihrer Geistigkeit und trotzdem ganzheitlichen Wirkung auf Geist und Körper (Konzert, Tanz und Rhythmus), sieht er in ihr den symbolisch vorausdeutenden Ausdruck "neuer Formen des seelischen Lebens (Formy 166)." Wenngleich Belyj der Musik - wie Schopenhaver, Nietzsche und Wagner in der Nachfolge der Romantiker ${ }^{39)}$ eine Sonderstellung unter den Künsten einräumt, wenngleich er an musikalischen Techniken und ihrer Ubertragbarkeit auf moderne Dichtung außerordentlich interessiert war, so beschränkt sich seine Auffassung von der Musik nicht auf ihren Charakter als Tonkunst. Wiederholt spricht er davon, daß sie mehr sei als eine Kunstform, besonders deutlich im Kommentar zu "Formen":

"In solcher Beleuchtung (gemeint ist 'Welt als Wille und Vorstellung', 5 52) ist Musik einerseits nur eine Form der Kunst, andererseits ist sie gleichsam Offenbarung des inneren Wesens des Seins selbst; in der Einstellung zur Musik sind sich eine ganze Reihe von Denkern darin einig, die Musik unter allen anderen Künsten hervorzuheben; einerseits ist die Musik nur eine Form; andererseits symbolisieren wir mit Hilfe dieser Form etwas, was seinem Wesen nach weder in Bildern, noch in der Rede, noch in Emblemen zu symbolisieren ist; die Embleme der Musik sind Embleme besonderer Art, die auf das Genaueste die innere Seite des Erlebens darstellen; in diesem Sinne analysiert Nietzsche, indem er die Musik als Emblem verwendet, die Kultur Griechenlands von dem Gesichtspunkt aus, wie in ihr dieses Emblem ('Geist der Musik') hervortritt. (....) Für Spencer ist Musik - Prophetie der Gefühle (...) Widerschein des 'Rhythmus', verstanden in einem allgemeineren Sinne. (...) Hanslick will im MusikalischSchönen etwas Höheres sehen als Gefühl (...) und für ihn ist Musik, als Form, einerseits nur Kunstform, andererseits - nur Emblem einer anderen Musik, die weder in Worten auszudrücken, noch in einzelnen Gefühlen zu erleben ist (Komm. 517 - 519)."

Belyj erinnert außerdem an die Verwandtschaft zwischen Musik und Mathematik, wie sie von den Pythagoräern, von Leibniz und Novalis erkannt worden ist (Cf. dazu unten S. 156ff.). ${ }^{40)}$

Zurückkehrend zu Belyjs Wirklichkeitsbegriff der frühen Phase, kann man sagen, daß - trotz des utopischen Pathos - eine tiefe Kluft klafft zwischen den beiden Ebenen der Wirklichkeit. Zwischen dieser und der nächsten Phase in Belyjs Wirklichkeitsverständnis liegen die Beschäftigung mit dem Kritizismus Kants und die beginnende Bekanntschaft mit dem Neukantianismus ${ }^{41}$ ), die Ernüchterung der naiven Hof fnungen auf eine Morgenröte durch die politischen Ereignisse der Revolution 1905 und die einsetzende 
Reaktion im öffentlichen Leben sowie biografische Erschütterungen. Diese Erfahrungen machten ihn skeptischer, aber auch psychologisch scharfsichtiger, vor allem ließen sie ihn die Bedeutung der nicht nur imaginierten, sondern der erlebten Wirklichkeit erkennen.

Seinen Wirklichkeitsbegriff arbeitet Belyj im Jahre 1907 im Aufsatz "Sinn der Kunst" beträchtlich um, vor allem was seinen erkenntnistheoretischen und psychologischen Standpunkt betrifft. Die religiösen Aussagen (Theurgie) werden jetzt durch neukantianische Philosopheme modifiziert. Er kommt auf seine alte Grundthese zurück, die er nun präzisiert:

"Es gibt einen anderen Zugang zum Verständnis der Kunst; dieser Zugang liegt in der Offensichtlichkeit des Faktums, daß die Kunst sich auf die Wirklichkeit stützt. Jede Form der Kunst ist bestimmt vom Gesichtspunkt jenes Grundzuges der Wirklichkeit, den sie am vollständigsten darstellt.

Hier nun erhebt sich die Frage, was denn die Wirklichkeit ist.

Das naive Bewußtsein setzt die Wirklichkeit mit der sichtbaren Tastbarkeit der Erscheinungen in eins: Die Erscheinungswelt (vidimost') wird mit der Wirklichkeit (dejstvitel'nost') verwechselt. Umfang und Inhalt der Sichtbarkeit sind unverrückbar: Wir sehen die Gegenstände im Raum in jener Zeit, wie sie die Physiologie in den beiden Dimensionen (auf der Fläche) feststellt, während wir die dritte Dimension dem Muskelgefühl zuschreiben.

Die Voraussetzung selbst der Sichtbarkeit - der Raum - wird von uns bedingt wahrgenommen; für die notwendige Bedingung des Raumes erachten wir seine Kontinuität (nepreryvnost'); aber 'es ist unzulässig, aus dem einen Faktum der Kontinuität der Bewegung auf die allgemeine Kontinuität des Raumes zu schließen' - sagt der Mathematiker Kantor. Erinnern wir uns an die Ansichten von Gauß, Lobačevskij, Beltrami, Poincaré über die Möglichkeit der Uberschneidung paralleler Linien, an die Ansichten von Silvester, C.lifford, Helmholtz über den vierdimensionalen Raum. Reed berührt sich mit Helmholtz in dem Traktat 'Geometrie des Sichtbaren (vidimogo)'. Jevons hat einleuchtend bewiesen, daß in anderen, nichtvorstellbaren Räumen wir zum Prinzip der Euklidischen Geometrie kommen könnten. Schließlich, außerhalb der Geometrie richten wir den Blick auf den Raum, als eine Erkenntnisform.

Aber vielleicht sind in den Bedingungen der Erscheinungswelt die Grenzen absolut? Auch das ist nicht der Fall: Versuchen Sie, die Grenzen des Spektrums anzugeben, und Ihre Angaben werden nicht mit denen anderer Personen übereinstimmen; bei der allmählichen Erhöhung von Tönen, die aus einer Sirene kommen, werden nicht alle gleichzeitig aufhören, diese Töne zu hören; dasselbe mit der Zeit: Erinnern wir uns an die Versuche Rochat's mit der Erweiterung des Gedächtnisses. Die Erscheinungswelt ist bedingt; ihre Grenzen sind ebenfalls bedingt. Die Erscheinungswelt deckt sich nicht mit der äußeren Wirklichkeit; die Erscheinungswelt deckt sich nicht mit der inneren Wirklichkeit (der Welt der Erlebnisse, die bei dem einen enger, bei dem anderen weiter ist).

Würde die Wirklichkeit als Sichtbarkeit definiert werden, so wäre die Wirklichkeit - Nichtwirklichkeit. Aber was ist nun die Wirklichkeit? Vom Gesichtspunkt der modernen Psychologie ist die Wirklichkeit die Gesamtheit der möglichen Erfahrung (der inneren und der äußeren); die Erkenntnistheorie definiert diese Erfahrung als den Inhalt unseres Bewußtseins: Die äußere Erfahrung ist ein Teil der inneren Erfahrung in den Formen von Raum und Zeit; die Erscheinungswelt ist ein geringerer Teil der Wirklichkeit.

Die Erscheinungswelt wird in der Kunst erlebt, d. $h$. sie wird in ein untergeordnetes Verhältnis zur inneren Erfahrung gesetzt; die Abhängigkeit der äußeren Erfahrung von der inneren Erfahrung wird von uns nicht unmittelbar erkannt, sondern mit der Methode der modernen Psychologie und der Erkenntnis- 
theorie festgestellt; die Kunst bringt diese Abhängigkeit offen zum Ausdruck (Smysl 203 - 205)." (Hv. M. D.)

Belyj revidiert seine vorherige - von Schopenhauer beeinflußte - Sicht der Erscheinungswelt als "Trugbild". Statt dessen hinterfragt er die angeblich apriorisch unveränderlichen Kategorien des Bewußtseins, Raum und Zeit, ebenfalls die anscheinend feststehenden Grenzen der sinnlichen Wahrnehmung. Nach Belyj haben sie sich als etwas erwiesen, das nicht unverrückbar ist. Mit ihren Grenzverschiebungen ändert sich aber unser Wissen von der Wirklichkeit. Je nach der Methode der Wahrnehmung erhält man einen verschiedenen Begriff von Inhalt und Umfang der Wirklichkeit.

Dieser erkenntnistheoretische Befund wird nach Belyj in der Kunst offenbar, ${ }^{42)}$ da sie erlebte Wirklichkeit darstellt. Was dem normalen Bewußtsein verdeckt bleibt, wird in der Kunst sichtbar. Vielleicht sollte man hier dazusagen: besonders in der Kunst der Moderne, die sich auf dem Wege zur Bewußtseinskunst befindet. Belyj reflektiert hierin nicht nur die ästhetische, sondern die allgemeine philosophische Situation seiner Zeit, die sich vor das Problem gestellt sah, daß die Frage nach dem Wesen der Dinge und der Welt weder wissenschaftlich noch philosophisch zu beantworten ist (Smysl 200). Deshalb werden wir auf die eigene Erfahrung verwiesen, und das heißt, insbesondere auf das eigene Erleben und damit auf das eigene Ich und seine verschiedenen Bewußtseinsschichten.

Mit dem Verzicht auf die vorher noch eingenommene metaphysische Denkrichtung hat Belyj Anteil an der Situation des Denkens um die Jahrhundertwende, die später von Heidegger als "Ende der Metaphysik" gekennzeichnet wurde. Diese Situation des "Endes" erweist sich jedoch zugleich als Situation des Aufbruchs eines neuen Denkens ${ }^{43}$, das zurückgeht auf die Erfahrung und zu den Sachen selbst. Hier berühren wir einen Wendepunkt in Belyjs ästhetischem Denken. Die ästhetische Fragestellung ändert sich grundlegend: Nicht mehr die Resultate und Formen der bisherigen Künste und der Grad ihrer Vollendung sind Hauptgegenstand seines Denkens, sondern der noch zu entdeckende Gegenstand der Kunst wird der Mensch, sein Ich, sein Bewußtsein und seine Sprache. Belyjs Interesse verlagert sich von den "Formen der Kunst" auf den Prozeß des Schaffens selbst (Buduščee 452). Die Aufgabe des Künstlers, der vor und neben aller technischen Befähigung Mensch sein soll, besteht zuallererst darin, "sich selbst zu erschaffen" und davon in der Kunst zu sprechen. Dies ist nach Belyj die dringlichste Aufgabe einer "Kunst der Zukunft":

\footnotetext{
"Mit der Kunst, mit dem Leben steht es weit schlimmer als wir denken; der Abgrund, über dem wir hängen, ist immer tiefer und finsterer geworden.

Um aus dem Bannkreis der Widersprüche hinauszukommen, müssen wir aufhören, über was nicht alles zu reden, sei es die Kunst, die Erkenntnis oder unser Leben selbst.

Wir müssen die Gegenwart vergessen: wir müssen alles noch einmal umschaffen: dazu müssen wir uns selbst erschaffen. Und der einzige Steilhang, über den wir noch klettern können, das sind wir selbst. Auf dem Gipfel erwartet uns unser Ich. Das ist die Antwort an den Künstler: Wenn er Künstler bleiben 
will, ohne aufzuhören Mensch zu sein, muß er seine eigene künstlerische Form werden.

Nur diese Form des Schaffens verheißt uns noch Rettung. Hier ist es, wo der Weg der künftigen Kunst liegt (Budušcee 453)."

Der doppelte Wirklichkeitsbegriff bleibt in seiner Zweigliedrigkeit erhalten, obwohl die Glieder jetzt anders aussehen. Es stehen sich gegenüber: die Wirklichkeit der inneren Erfahrung, des Erlebens, des Ich, und die äußere Erscheinungswelt. Das innere Erleben ist bildlos nach Belyj, während die Außenwelt uns in Bildern gegenübersteht. Beide Reihen laufen nebeneinander her. In der Kunst werden sie durch die Methode der Symbolisierung aufeinander bezogen. Die Bilder des Anscheins werden zu "Modellen" der inneren Erfahrung umgeschaffen (Smysl 205). Was Belyj jetzt - statt der Dichotomie von Wesen und Erscheinung - in den Vordergrund rückt, ist die Innen-Außen-Relation der Wirklichkeit, die vermittelt werden muß in der Sprache. Aus ihr wird die eigene Wirklichkeit der Kunst geschaffen. In diesem Zusammenhang muß es wohl auch gesehen werden, daß für Belyj der Primat der Musik - als vollendetste Kunstform - um diese Zeit (1907) fällt. Er setzt sich sowohl formal als auch ideologisch mit der Musik auf eine neue Weise auseinander. ${ }^{44)}$

Doch mit der Rückwendung auf das Ich und seine Bewußtseinsinhalte hat es bei Belyj nicht sein Bewenden. Die dritte Phase seiner Kunsttheorie ist dadurch gekennzeichnet, daß das Ich nicht willkürlich oder isoliert gesehen wird, sondern im Rahmen der Gesamtbewegung zur Erneuerung der Kultur. Dieses Denken verbindet einen ganzen Epochenzusammenhang von dem Kreis um die "Welt der Kunst" bis hin zu Mandel'štam und Achmatova. ${ }^{45)}$ Das ganzheitliche Erleben des Ich und seine schöpferische Gestaltung in einer neuen Kunst erhält seinen Rang dadurch, daß als Voraussetzung für die Erneuerung der Kultur das "Wachstum des Individualismus" angesehen wird:

"Kultur ist daher dort möglich, wo sich das Wachstum des Individualismus beobachten läßt; nicht umsonst weist Windelband darauf hin, daß die Kultur der Renaissance im Individualismus ihren Ausgang nahm; das individuelle Schaffen von Werten kann in der Folge zu einem individuell-kollektiven werden (Probl. 6)."

Und hier kommt noch die zweite wesentliche Ansicht Belyjs zum Ausdruck, daß nämlich von so beschaffener Kunst des "Ich" Werte geschaffen werden (Smys! 211f.), die für die Kultur ebenso wichtig sind, wie die sonstigen Werte, die in kulturalen Techniken entstehen. Damit die Kunst des modernen Individuums aber solche Werte schaffen kann, ist eine Grundbedingung unerläßlich: Sie muß als Norm ihres Schaffens ein grundsätzliches "Ja" zum Leben akzeptieren. Und zwar zum Leben nicht so, wie es nun einmal ist, sondern zum Leben so, wie es sein soll (Embl. 98f.). Daß es ein Sein-sollendes gibt, und daß es Wahrheit gibt, und daß beides eigenes Sein hat, unabhängig davon, ob es bereits verwirklicht ist, - daß also zu beidem grundsätzlich "Ja" gesagt wird, das ist die einzige 
Norm, die der Kunst gesetzt ist (Embl. 120). So verstanden erst wird sie werthaftes Schaffen.

Von daher leitet sich auch das Recht ab, das bisherige Leben umzuschaffen und die bisherigen Werte umzuwerten. Den Nietzscheschen Appell zur "Umwertung aller Werte" greift Belyj auf, aber er gibt eine eigene Antwort auf Nietzsche. Er entwirft eine Hierarchie der Wertgebiete der Gesamtkultur in seinem großen Aufsatz "Emblematik des Sinns". Hier haben wir auch die letzte Stufe seines Wirklichkeitsbegriffes entfaltet. Er gibt die duale Polarisierung auf zugunsten einer gestuften Hierarchie der Seins- und Wertgebiete, einer "Stufenleiter von Wirklichkeiten" (Embl. 71). Belyj vollzieht hier auf seine Weise die Wendung zur Existentialontologie, indem nämlich Ich und Wirklichkeit als aufgegebenes Sein zur Verwirklichung freigegeben werden. Dazu kann die Kunst wesentlich beitragen, weil sie in ihrem Schaffen frei ist von den Zwängen der Lebenspraxis und deshalb "Modelle von Erfahrung" schaffen kann. Das "andere", das noch unbekannte Leben, so wie es sein soll, steht vor dem Künstler als neuer Gegenstand der Kunst und des Lebens noch sprachlos.

"Hier fliegen alle Träume, die wir geträumt haben, von uns: das Sein, die Wissenschaft, Kunst, Religion, Ethik, Theosophie - alles fliegt vorbei: alles ist nur insofern wert, als es uns Andeutungen gibt; wir bleiben zurück in der absoluten Wüste, wir tauchen ein in das Nirwana des Nichtseins; und nach Maßgabe dessen, wie tief wir uns hineinbegeben, schickt uns das Wortlose seine Stimme: 'Ich - bin es.'

Die Einheit des Lebens liegt im Prozeß unseres Eintauchens; nur in dem Maße, wie wir die Zonen der Erkenntnis und des Schaffens durchschneiden, füllt sich die ungesagte Tiefe unseres Lebens an mit Klängen, Farben, Bildern.

Der Gebirgspaß (pereval), der von der Menschheit erlebt wird, besteht darin, daß jetzt die Uhr des Lebens - in der Erkenntnis, im Schaffen, im Sein ihren großen Mittag schlägt, da die Tiefe des Himmelsgewölbes von der Sonne erleuchtet ist. Die Sonne ist aufgegangen:

Sie blendet uns schon lange; die Erkenntnis, das Schaffen, das Sein bilden in unseren Augen ihre dunklen Flecken; heute wühlt die Erkenntnis vor unseren Augen ihre dunklen Flecken auf: Sie sagt uns in ihrer Sprache: 'Mich gibt es ja noch gar nicht'. Das Schaffen wühlt vor unseren Augen heute seine dunklen Flecken auf; es sagt: 'Mich gibt es ja noch gar nicht.' Unser alltägliches Leben wühlt vor unseren Augen seine dunklen Flecken auf; es sagt: 'Mich gibt es ja noch gar nicht.'

Von uns hängt die Entscheidung $a b$, ob etwas ist von dem, was existiert.

In unserem Willen steht es zu sagen: 'Nein, nichts.' Aber wir - sind ja nicht blind: Wir hören die Musik der Sonne, die heute mitten in unserer Seele steht, wir sehen ihren Abglanz im Spiegel des Himmelgewölbes; und wir sagen: 'Du bist.' (Embl. 84)."

Die ideelle Konstruktion der Wirklichkeit bleibt also in ihrer Doppelpoligkeit grundsätzlich erhalten. Was aber aufgewertet wird, ist die vorgegebene Wirklichkeit als Aktionsraum der Kultur und die Forderung an den Künstler zur "Menschwerdung" und zur prototypischen und damit wert-haften Gestaltung dieses Vorganges. 


\section{Die künst ler ische Erlebnisstruktur}

a) Das Erleben als psychischer Ganzheitsvorgang aus den drei Komponenten: Verstand, Gefühl und Wille

Der Begriff des Erlebens (pereživanie) taucht in Belyjs kunst theoretischen Schriften nicht von Anfang an auf, sondern erst in "Sinn der Kunst" (1907), und hier gleich gehäuft. In "Formen der Kunst" (1902) ist er - wie schon gesagt wurde - explizit noch nicht genannt (S. 109ff.). In der ersten Phase herrscht statt der Frage nach dem Erleben als integraler Komponente des schöpferischen Prozesses noch die nach dem "Sehen-können" und nach der "genialen Erkenntnis" vor. Die Eigenständigkeit und Tiefe der künstlerischen Wahrnehmung, die aufschließende Rolle der Stimmung und die ideelle Konstruktion der Wirklichkeit werden hier als die subjektiven Bedingungen der schöpferischen Energie verstanden. Daneben gilt Belyjs kunsttheoretisches Interesse den objektiv vorgegebenen Bedingungen der künstlerischen Technik. Seine Denkkonstante vom "Primat des Schöpferischen" ist bereits hier formuliert (Formy 150). Hier geht es Belyj vor allem um die Aufwertung der nicht rationalen Kräfte im Prozeß der Kunstschöpfung, denen aber Erkenntnisfähigkeit zugesprochen wird. Der Erlebnisbegriff ist in die Konzeption des "Schöpferischen" noch nicht integriert. Vor allem kommt die dritte Komponente der Wille, der für inn zum Erlebnisbegriff in seiner entfalteten Form dazugehört, noch nicht zum Tragen. Das erklärt sich teilweise aus der negativen Beurteilung des Willens bei Schopenhauer. Belyj teilt zwar die Meinung vom "blinden Willen" nicht, hatte aber nur ein diffuses eigenes Konzept des Willens, ehe er mit dem Neukantianismus in Berührung kam. An Stelle des Willens spricht er damals noch von der "Energie des Schöpferischen", die aber im Erlebniszusammenhang noch nicht integriert ist.

Vom intuitiven Erkenntnisbegriff Schopenhavers bis zum entfalteten Begriff des "pereživanie" fehlt also als Zwischenglied die positive Auffassung vom Willen. Diese fand Belyj philosophisch ausgeprägt erst bei H. Rickert, der vom Primat der praktischen Vernunft ausgeht und "Wert" und "Pflicht" zu Leitbegriffen eines positiv aufgefaßten, ethischen Willens macht. Hier findet er eigene Ansätze, die unter dem Einfluß der positiven Sicht des Willens bei Nietzsche und Solov'ev zwar schon entstanden, aber noch nicht zum Tragen gekommen waren, systematisiert. Wie wir gesagt hatten, war Belyj zu der Ansicht gekommen, daß in der Kunst die Erscheinungswelt nicht nur angeschaut, sondern daß sie erlebt werde. Deshalb postuliert er jetzt, daß die ästhetische Wahrnehmung innerhalb eines seelischen Gesamtzusammenhanges geschieht, der sich nicht nur in der stimmungshaften Verbindung von Wahrnehmung, Gefühl und Denken erschöpft, sondern in dem alle drei seelischen Grundvermögen des Subjekts zusammenwirken: Verstand, Gefühl und eben auch der Wille. Wurde der Künstler von Belyj zunächst positivistisch definiert als homo faber, als Macher und poetischer "Techniker" der Modellierung und Darstellung 
von Wirklichkeit; erkenntnistheoretisch als intuitiv Erkennender, der - aufgeschlossen durch eine Stimmung - vom sinnlich-geistigen Impuls zur Erkenntnis des Wesens der Welt angetrieben ist und von der Forderung, sie in Kunst zu verwandeln, - so gilt ihm jetzt der Künstler vorgängig und unmittelbar als Erlebender. Vom schöpferischen Erleben der Wirklichkeit - und nicht allein von Neuheit und Tiefe ihrer künstlerischen Anschauung her - ist sein "Machen" und Erkennen wesentlich mitbestimmt.

Zu dieser Auffassung kommt Belyj seit 1906/07. In seiner Theorie - aber bezeichnenderweise auch in seinem Werk, in seiner gleichzeitig geschriebenen "Vierten Symphonie" - werden Erleben und Thema des eigenen Selbst zentral. Und was vor allem wichtig erscheint: Der Erlebnisbegriff wird zur Basis der Symbolisierung erklärt. ${ }^{47)}$

Welches sind nun die Kriterien des voll entfalteten Erlebnis-Begriffes? Mit "pereživanie" ist nicht das einzelne punktuelle Erlebnis gemeint, sondern Erleben als aktives Weltverhalten des Künstlers, als Zusammenwirken der drei seelischen Grundvermögen in einem ganzheitlichen Lebensvorgang, als einer individuell-schöpferischen Aneignung von Wirklichkeit. Nicht mehr allein die Seh- und Erkenntnisfähigkeit des Künstlers, sondern seine Fähigkeit zum Erleben, das nun auch wesentlich vom eigenen Willen bzw. "Pflicht" oder "Sollen" mitbestimmt ist, wird als kreative Grundhaltung angesehen. Nicht die "Summe" der drei seelischen Einzelvermögen ist gemeint, sondern eine davon unabhängige Ganzheit, die auf deren Interaktion beruht. Belyj sieht darin eine psychische Größe sui generis. $^{48}$ )

"Das Erleben (pereživanie) ist unabhängig. Das Wollen (volenie) mit ihm zu verwechseln - das ist nicht möglich. Noch weiter entfernt vom Erleben sind Fühlen und Denken. Gefühl, Verstand, Wille sind der Analyse der empirischen Psychologie zugänglich, die die Seelentätigkeit zerlegt. Das Erleben ist eine Ausdrucksform der Einheit des Seelenlebens, die unabhängig ist sowohl von der Erkenntnistheorie, als auch von der Psychologie. Diese letztere ist, umgekehrt, nur in dem Falle möglich, wenn sie die unabhängige Einheit des Erlebens postuliert. Die unteilbare Ganzheit des Erlebens ist potentiell immer gegeben, sobald die eine oder andere seiner Tätigkeiten (Denken, Gefühl, Wille) gegeben ist (Komm. 513)."

Belyj sieht das Erleben als Ganzheit oder Totalität an, die zwar sowohl im Denken wie auch im Gefühl oder im Wollen erreicht, die aber auch verfehlt werden kann. Den Maßstab bildet immer die potentielle Totalität.

So kann Denken im Gesamterleben begründet sein, kann aber auch von ihm abgetrennt, rein logisch, rationalistisch vor sich gehen. Erhält sich in ihm, unbeschadet seiner logischen Klarheit, der Erlebniszusammenhang, gewinnt das Denken "Tiefe":

"Verstandesurteile, die von innen her durch das Erleben vereint sind, funkeln von den Strahlen der Weisheit. Das Vorhandensein eines allein äußeren Zusammenhanges, der diesen Urteilen den Charakter wissenschaftlicher Exaktheit verleiht, weist noch nicht auf eine Tiefe hin, die in ihnen vorhanden ist (Komm. 513)." 
Erreicht das Denken solche Tiefe, so liegt darin der Ursprung für die Idee und Symbolisierung vom Denken her.

Analoges gilt für das Gefühl:

"Dasselbe kann auch in bezug auf die Gefühlstätigkeit gesagt werden. Die einzelnen sinnlichen Eindrücke bilden, wenn man sie kombiniert, eine sinnliche Reihe, die sich bald erweitert, bald verengt. Auch hier müssen wir zweierlei Arten von Abhängigkeit unterscheiden, die ein gegebenes Gefühl bestimmen: 1) die Abhängigkeit des Gefühls von der sinnlichen Reihe, in der er es entstanden ist, 2) seine Abhängigkeit vom Erleben, das sich außerhalb der wissenschaf tlichen Psychologie befindet, aber notwendig zu postulieren ist. Von diesem Gesichtspunkt aus hört jegliche Empfindung auf Empfindung zu sein, sobald das Erleben auftaucht, welches ihm zugrunde liegt. Vom Grad des Hervortretens der erlebten Einheit, vom Grad seiner Annäherung an die Oberfläche des Bewußtseins wird die Tiefe eines Gefühls bestimmt (Komm. 514f.)".

Das Gefühl als integriertes Element des seelischen Zusammenhanges wird von bloßer Emotion scharf unterschieden. Die reine, nicht von der Erlebnisganzheit durchdrungene Empfindung kann nach Belyj nicht zum "Angelpunkt des künstlerischen Schaffens" werden.

Interessant ist nun, was er zum Willen als dem dritten Seelenvermögen sagt:

"Verbinden sich Verstand und Gefühl als Erlebnistätigkeiten, so rufen sie unweigerlich die dritte Tätigkeit - den Willen - hervor, d. h. sie werden offenkundig tätig. Ein Bild, das in uns geistige und sinnliche Prozesse in Gang setzt, löst in uns auch einen Akt des Willens aus. In der Ekstase, die gleichsam als Tor zur Realisierung des Erlebens erscheint, reißt der Schleier, der Vernunft und Gefühl zertrennt, und der Wille wird wie im Gebet von der Fülle des Erlebens durchdrungen. Die Ekstase - ist das Mittel, das mystische Erleben zu realisieren (Komm. 515)."

Hier spricht Belyj eine Auffassung vom Willen aus, die vom blinden Trieb und Begehren zu unterscheiden ist. Es zeigt sich, daß der Wille offenbar mehrere Seiten hat. Hier hebt Belyj den Willenszustand der Ekstase hervor. Wille, der aus dem Zusammenhang des Erlebens entsteht, ist als ekstatischer Ausdruck des Selbst zu begreifen, der nicht mit der passiven Ekstase des kontemplativ entrückten Mystikers zu verwechseln ist. Hier wird Ekstase als aktiver schöpferischer Akt verstanden, der den entscheidenden Impuls zur Verwandlung der Wirklichkeit auslöst. Dieser aktive Begriff der Ekstase muß von dem passiven der reinen Anschauung unterschieden werden, in der Enthebung gesucht wird. Als Modus des Willensaktes sieht Belyj den Zustand der Ekstase an, in der die Begeisterung zum künstlerischen "Handeln" entsteht, die zur Verwirklichung des zunächst nur Geschauten, Erkannten oder Gefühlten drängt. In dem Maße wie es auch "gewollt" wird, kann es zur schöpferischen Verwandlung der vorgegebenen Wirklichkeit in der Kunst kommen.

In dieser Sicht vom Willen ist das vorher schon vorhandene Konzept von der "schöpferischen Energie" wiederzuerkennen, das ebenfalls den Verwandlungsgedanken schon 
enthielt. Jetzt ist es aber fest eingebunden in die ganzheitliche Erlebnisstruktur der Persönlichkeit des Künstlers.

b) Fehlformen vereinseitigter Kunst und Ästhetik gegenüber der "wahren" Kunst aus der Totalität des Erlebens

Die Totalität des Erlebens und eng verbunden damit die kreativen Grundhaltungen der ästhetischen Wahrnehmung: Das "Sehen-können", welches zur Anschauung der Idee in den Dingen vordringt, und das "Neue Sehen", das an der Variation der Sehkonventionen arbeitet, erzeugen ein spezifisch künstlerisches Weltverhältnis, in dem die Wirklicheit schöpferisch angeeignet wird und in dem der Gegenstand oder die Wirklichkeit der Kunst als "prismatische Wirklichkeit" konstituiert werden. Bereits in dieser "primären" kreativen Bearbeitung der vorgegebenen Wirklichkeit, die mit der "Energie des Schöpferischen" geschieht, sieht Belyj eine wesentliche Vorbedingung für die "wahre" Kunst, die für ihn nie auf den reinen - von der Erlebnişbasis abgelösten - Formprozeß beschränkt bleiben kann. Im ekstatisch aktivierten Willen als Erlebniskomponente sieht Belyj den schöpferischen Impuls zur Ausdrucks-Arbeit, die in einer Innen-Außen-Relation geschieht, und zur Wirkung auf den Partner in der ästhetischen Kommunikation, dessen Bewußtsein verändert werden soll.

Von der Analyse der drei Seelenvermögen kommt Belyj zu Aussagen über drei Grundtypen vereinseitigter Kunst und Ästhetik. Einseitig gegründet auf das Denken, nach der Devise Belinskijs "Kunst ist Denken in Bildern", entsteht eine Ideenkunst oder Gehaltsästhetik, die den Sinn der Kunst im Ausdruck von Ideen und Tendenzen erblickt. Das geforderte Kunstwerk steht in der Gefahr, zur Tendenzkunst zu entarten. Einseitig gestützt auf den ethischen Willen, der zu "hohen Taten", zu moralischer Verpflichtung aufrufen soll, entsteht Kunst als "moralische Anstalt" oder eine Gesinnungsästhetik, die den Sinn der Kunst in der moralischen Aufrüstung des Lesers erblickt. Belyj grenzt die Kunst scharf gegen solche Auflagen ab:

"Wenn man aber hieraus den Schluß zieht, daß die Berggipfel der Pflicht und die Berggipfel des Schöpferischen gleichartig in der Form sind, so verfällt man in eine optische Täuschung, die diese Gipfel unserem Sehvermögen allzu nahe rückt. Verschwindet der uns verlockende Flor, der die Gipfel des Schöpferischen umgürtet: In ihm ist - die ganze Köstlichkeit, der ganze Charme der Kunst. Ohne ihn - wird die Kunst allzu zugänglich; wozu gibt es dann sie, und nicht einen Kodex von Moralvorschriften? (Smysl 207)."

Noch eine dritte Fehlform der Kunst macht Belyj aus. Der einseitige Ausdruck von Gefühlen oder die Willkür einer auf ihm beruhenden Emotionalästhetik, in dem die ästhetische Gefühlserfahrung von rein subjektiver Unverbindlichkeit bleibt, kennzeichnet er weiter in der schon vorher verwendeten Hochgebirgsmetaphorik: 
"(...) die Berggipfel des Schöpferischen verwandeln sich dann in Wolkengipfel, die von Minute zu Minute ihre Umrisse ändern, die am Leben vorbeischwimmen, wie am alltäglichen so auch am werthaften. Auf diese Weise langen wir an beim totalen Chaos.

Nein! (Smysl. 207)."

Gegenüber diesen vereinseitigten Fehlformen einer Gehalts-, Gesinnungs- oder Emotionalästhetik, die entweder Tendenzkunst oder Kunst als "moralische Anstalt" oder aber den Genuß an der autonom gesetzten Empfindung um ihrer selbst willen im l'art pour l'art einer hohlen Genuß-Dekadenz erzeugen oder rechtfertigen, fordert Belyj eine Ásthetik, die sowohl auf der Erlebnisganzheit als auch auf der durchentwickelten Form beruht.

Belyj bleibt in seiner Ästhetik der Kreativität nicht bei einer deskriptiven Ubersicht über wesentliche Faktoren des schöpferischen Prozesses stehen. Indem er sich die Frage nach der "wahren" Kunst vorlegt, geht er von der genauen Beschreibung zur Analyse über, um Kriterien zu gewinnen für eine arteigene ästhetische Norm, die einerseits genügend universal, andererseits aber auch genügend prägnant sein muß. Daraus ergibt sich dann das doppelte ästhetische Postulat einer formbewußten, auf der Erlebnistotalität beruhenden Kunst. Kunst, die dieser Simultanforderung entspricht, gestaltet nach Belyj "Modelle der Erfahrung" in symbolischen Bildern. Die symbolische Qualität der Bilder ist mehrfach bestimmt: ekstatisch konzipiert aus dem Willen zur Veränderung, geistig orientiert an Ideen, verpflichtet zur Teilnahme am Prozeß der Wertschöpfung und verwirklicht in der Anstrengung der künstlerischen Form. In dieser mehrfachen Bestimmtheit oder Uberdetermination ist die semantische Polyvalenz des "offenen" Symbols begründet, das einen Leser fordert, der sich einer Verstehensarbeit zu unterziehen bereit ist, die prinzipiell schöpferisch vor sich gehen muß.

In der kombinierten Forderung nach Sinn und Form kann Belyj dann auch einen Maßstab der Wertung begründen, an dem Kunstqualität zu messen ist: je nachdem, wie nahe sie dem Ideal einer durchgebildeten, wo nötig neuen, jedenfalls dem Sinnpotential adäquaten Form kommt; je nachdem, wieviel sie an ideeller Klarheit, ethischer Tiefe und sinnlicher Fülle in sich zu vereinen vermag. An einem solchen Maßstab läßt sich Kunst verschiedener Epochen messen. Und darauf kommt es Belyj ja wesentlich an: den Rang der modernen Kunst in Vergleich zu setzen mit der Kunst der Tradition.

Belyj fügt also die von ihm benannten Kriterien der "wahren" Kunst zu einer universalen Formel zusammen, die er auf verschiedenen Ebenen in den ästhetischen Diskurs einführt, hier auf der metaphorischen. Die Hochgebirgsmetapher, in der auch Nietzsche seine utopischen Entwürfe im "Zarathustra" angesiedelt hat, erlaubt ihm, seine Konzeption einer solchen "wahren" Kunst weiterzuentfalten, nachdem er die in der gleichen Metaphorik benannten Fehlformen der Kunst mit einem entschiedenen "Nein" abgelehnt hat. 
"Das künstlerische Bild ist einem Berge zu vergleichen, dessen Abhänge mit den Weinbergen der Ideen bedeckt sind; hier am Hang schenkt man den neuen Wein aus - den Wein eines neuen Lebens; aber nicht als Wein sind hier die Ideen gegeben: nicht direkt ergeben sie sich aus dem Bild; nötig ist die Arbeit der Umschöpfung, des Verstehens, des Enträtselns von seiten jener, die die Kunst aufnehmen, und das ist eine Arbeit 'post factum'; gegeben ist das Bild: Es ist entweder ein Weinstock oder ein unfruchtbarer Feigenbaum; nur die Zeit entscheidet darüber, ob er das eine oder das andere ist. Die Gipfel aber des Berges sind von den Wolken der Emotionen bedeckt, aus denen der Blitz aufleuchtet und der Donner dröhnt; und nur beim Zerreißen der Wolken erstrahlen uns die Eisesgipfel der Pflicht, die jedoch imstande sind, zum Krater zu werden, der die Weinstöcke der Ideen überflutet, auf daß die Hänge einer neuen Pflicht aufwüchsen zu einem Garten neuer Ideen. Zur Bewertung eines wahrhaft tiefen Kunstwerkes ist es notwendig, Arbeit zu leisten: den Weinstock zu Wein umzuschaffen (zu verstehen) und durch das Chaos der Gefühle hindurchzugehen zu den Gipfeln der Pflicht mit dem Risiko, in einen Abgrund zu stürzen. Das ist es, dem das wahre Bild der Kunst gleicht- das Bild-Symbol.

Die vulkanische Kraft des Bildes wirft vor uns allen neve Steilhänge der Werte auf, aber die Kontur des Berges - das sind die Normen der Pflicht (Simv. 207)."

\section{Zusammenfassung:}

Belyj betrachtet also die Wirklichkeit im Laufe des ersten Jahrzehnts des neven Jahrhunderts, in dem sein ästhetisches Denken entstanden ist, unter sehr verschiedenen Fragestellungen in zwei wesentlichen Aspekten: einmal vom objektiven Standpunkt des exakten $W$ issenschaftlers als vorgegebene raumzeitlich-empirische Wirklichkeit, die die Kunst in formal-ästhetischer Hinsicht bestimmt; zum anderen vom subjektiven Standpunkt des modernen Künstlers als wahrgenommene und erlebte Wirklichkeit, die schöpferisch angeeignet und umgearbeitet wird. In dieser zweiten Hinsicht ist die Wirklichkeit nicht objektiv vorgegeben, sondern sie wird als aufgegebene, erst noch zu verwirklichende Wirklichkeit verstanden. Daraus leitet sich der Sinn der Kunst her; sie hat nach Belyj wesentlichen Anteil an der Verwandlung der Wirklichkeit, weil sie ganzheitlich auf die Persönlichkeit des Rezipienten einzuwirken vermag.

Da die Wirklichkeit nicht nur vorgegeben, sondern zur Verwirklichung aufgegeben ist, besteht die Möglichkeit und Notwendigkeit zur Symbolisierung. Diese Spannung innerhalb des Wirklichkeitsbegriffs zwischen Faktizität, erlebter Wirklichkeit und einem "Sein-Sollenden", das aber nichts Irreales, sondern eine symbolische Wirklichkeit ist, wird zum entscheidenden Antrieb für die Methode der Symbolisierung nach Belyj. 


\section{KAPITEL}

\section{METHODE DER SYMBOLISIERUNG}

Belyjs ästhetisches Denken kreist vor allem um die Bedingungen der Möglichkeit symbolischen Erkennens und Darstellens von Wirklichkeit in der Moderne. Dabei geht es ihm nicht um ein modernes Symbolsystem, auch nicht primär um eine Theorie des Symbolismus, sondern um die Methode der Symbolisierung. Daß aus ihr "Prolegomena" zu einer modernen Symboltheorie gewonnen werden können, wird ihm im Laufe seiner philosophischen Entwicklung immer klarer. ") Was heißt nun "Methode der Symbolisierung"? Um das zu verdeutlichen, soll an eine Unterscheidung angeknüpf $t$ werden, die der Wiener Formalismusforscher Aage A. Hansen-Löve in seinem neuen Buch über den Begriff der "Verfremdung" macht, die er als methodisches Grundprinzip des russischen Formalismus herausarbeitet. Sehr überzeugend weist er nach, daß der ästhetische Grundbegriff der Formalisten einen über die Ästhetik hinausgreifenden Begriffsumfang hat: Verfremdung ist zugleich ein "noetisches Prinzip" wie auch ein "poetisches Verfahren". "a) Diese Unterscheidung kann m.E. fruchtbar und klärend auch auf die Konzeption des Symbols angewendet werden. Denn die Methode der Symbolisierung nach Belyj ist ebenfalls einerseits eine Denkmethode, andererseits eine Weise des künstlerischen Verfahrens. ${ }^{2}$

Belyjs Symbolkonzeption entwickelt sich in engem Zusammenhang mit seiner Auffassung von der Wirklichkeit. Es lassen sich hier analoge Entwicklungsphasen beschreiben. Dem anfänglichen Gegensatz von Erscheinungswelt und metaphysisch aufgefaßtem Wesen der Welt entsprechen als Symboltypen der ersten Phase das Erkenntnissymbol mit deiktischem Charakter und das theurgische Symbol mit appellativem Charakter. Sie haben eine zweigliedrige Struktur, analog zum doppelten Wirklichkeitsbegriff in seiner polarisierten Gestalt, und einen vertikalen Richtungsbezug: "Fenster in die Ewigkeit". Die sprachlichen Formen sind von feststehender Topik und den poetischen Verfahren der Iypisierung (Idealisierung, Stilisierung, Schematisierung) gekennzeichnet. Die Symbole dieser Gruppe sind suprahistorisch typisierten Grenzzuständen der Existenz entnommen und lassen sich den Extremhaltungen der elevatio und desperatio zuordnen. Schon diese frühen "topischen" oder auch "allegorischen" Symbole sind gesteuert von einem ethischreligiösen Impuls zur Verwandlung der Wirklichkeit. Beispiele finden sich in der frühen Lyrik und den ersten drei "Symphonien" (cf. S.131f.).

Das Symbol der zweiten Phase zeigt Veränderungen in Auffassung und Struktur, die mit dem Wandel des Wirklichkeitsbegriffes von einer starren Doppelpoligkeit zwischen Wesen und Erscheinung zur Auffassung von der Wirklichkeit als dem Gesamt aller inneren und äußeren Erfahrung des erlebenden Subjekts zusammenhängen (Smysl 204 f.). Das Symbol wird jetzt nicht mehr als Bild der Idee oder Appell zur Veränderung der schlechten Empirie begriffen, sondern als "Modell der Erfahrung" (Smysl 206) und Appell zur 
Selbstwerdung (Buduščee 453). Zugrunde liegt der oben erläuterte dreigliedrige Erlebnisbegriff aus den Komponenten: Verstand, Gefühl und Wille. Man kann jetzt von einem prozessualen Existenz-Symbol sprechen mit expressivem statt topischem Charakter. Es hat eine dreigliedrige Struktur und neben dem vertikalen einen horizontalen Richtungsbezug: seine existentielle Basis hat sich verbreitert. Die Symbolkonstruktion dieser Stufe ist wesentlich differenzierter als auf der ersten. Denn an die Stelle des Dualismus von Erscheinung und Wesen, der vom Symbol überbrückt werden sollte, tritt jetzt die InnenAußen-Relation des erlebenden Subjekts und rückt ins Zentrum der Symbolisierung. Die Idee ist nicht mehr nur der Gegensatz der Erscheinung, sondern wird als erlebte Idee in den Erlebnisprozeß des Subjekts einbezogen. Ebenfalls erlebt wird aber auch die Erscheinungswelt. Es entstehen drei Reihen, die in der Symbolisierung aufeinander bezogen werden müssen: Die innere sprachlose Erlebnissphäre muß mit Bildern der Außenwelt, die sie repräsentieren sollen, einerseits, und mit dem "unendlichen Bezug" zum Sein der Idee, andererseits, sprachlich vermittelt werden. ${ }^{3)}$ Symbole dieser Phase sind nicht mehr feststehende Bilder, "Fenster in die Ewigkeit", sondern entfalten sich in Bildsequenzen eines Themenbereiches, die die Dynamik und Differenziertheit des Erlebnisprozesses, seine "ganze Tonleiter" darstellen sollen. Beispiele dafür finden sich z.B. in den Symbolsequenzen von Belyjs "Pokal der Schneegestöber" (Vierte Symphonie) oder Bloks "Schneemaske".

Eine weitere Entwicklung in der Symbolkonzeption stellt der Ubergang vom Symbol, das aus der ästhetischen Praxis gewonnen wurde, zu einer nicht mehr ästhetischen, sondern philosophischen Kategorie dar. Belyj stellt dem künstlerischen Symbol das SYMBOL gegenüber, das er auch als "Lik" (Antlitz) bezeichnet (Embl. 79). Damit ist die symbolische Repräsentanz des "Sein-Sollenden" gemeint, die nach Belyj die oberste Instanz einer Hierarchie von Seins- und Wertgebieten darstellt. Belyj ist der Meinung, daß aus der künstlerischen Symbolisierung ein Prinzip des philosophisch-spekulativen Denkens gewonnen werden könne, das wiederum zurückwirkt auf die ästhetische Praxis. An das symbolische Sein des "Antlitzes", in dem das "Sein-Sollen" der Welt und des Menschen als aufgegebenes Sein potentiell versammelt ist, muß nach Belyj geglaubt werden (Embl. 99). Der Künstler wird von ihm unter eine absolute Wert- und Wahrheitsverpflichtung gestellt. Deshalb ist das Existenz-Symbol zugleich auch davon bestimmt, daß es seinen Wertmaßstab aus dieser obersten Instanz der Hierarchie seinsollender Seinszustände bezieht. Das individuelle Symbol wird vor diesem Hintergrund aus der Zufälligkeit und Isolierung hervorgehoben und kann individuell in einem repräsentativen Sinne genannt werden. Symbole dieser dritten Phase sind also gleichzeitig "Modelle der Erfahrung" wie auch "Repräsentanten einer Wertwelt". Diese können sie auch im Modus des Scheiterns repräsentieren. Als Symbolfiguren dieser Art kann man die "Helden" von Belyjs Trilogie betrachten: Darjal'skij, Ableuchov und Kotik Letaev - sie sind individuell und repräsentativ zugleich.

Das Symbol der Moderne, wie es Belyj in seiner entfalteten Form konzipiert, ist ein komplexes Gebilde: Es steht 1) als "Tonleiter" von Erlebnisbestandteilen in der Nähe zur 
modernen Psychoanalyse; 2) als innovatorisches Sprachprodukt einer sich ihrer Eigenqualitäten bewußt werdenden Sprache und künstlerischen Form; 3) als Repräsentant einer ontologischen Werthierarchie im Schnittpunkt von neu hervortretenden Denk-, Erfahrungs-, Sprech- und Wertungsweisen der Moderne. Es ist ein Indikator für den allgemeinen Prozeß der "Umwertung der Werte" und überdies ein konkretes Beispiel dafür, was mit diesem kulturphilosophischen Slogan in der Kunst gemeint sein kann.

\section{Symbol der ersten Phase: Deixis und Appell}

Die zugleich philosophische und sprachlich bedingte Entwicklung der Symbolkonzeption Belyjs setzt um die Jahrhundertwende ein und kann sowohl aus seinem theoretischen als auch aus dem gleichzeitig entstandenen dichterischen Werk belegt werden. Bereits in "Formen der Kunst" entwirft er einen Symbolbegriff und poetische Verfahren der Symbolkonstruktion (Formy 172 - 173). Die Symbolauffassung ist eng verbunden mit der oben beschriebenen Wahrnehmungsweise:

"Die Fähigkeit zu sehen ist die Fähigkeit, in den Bildern ihren ewigen Sinn, ihre Idee zu erkennen (Formy 171)."

Aus der Verbindung von sensibilisierter Wahrnehmung und intuitiver Erkenntnis, in der Verstand und Gefühl zusammenwirken, wozu sie "durch eine Stimmung (Formy 172)" aufgeschlossen werden, entsteht im Künstler ein symbolisches Konzeptionsvermögen, das inn zu einer ganz bestimmten Form der Symboiisierung befähigt. Deren Devise stammt von Merežkovskij: "Das Streben, etwas Artverwandtes (odnorodnoe) auszudrücken" und zwar auf dem Wege des "Verbindens von Verschiedenartigem in Eines (Formy 173)". Diese zunächst rein formale Definition erlaubt es Belyj, in seiner Frühphase zwei so verschiedene "Symbolisten" wie Ibsen und Böcklin als Vorbilder symbolischer Kombinatorik anzusehen. Denn beiden gelingt es nach Belyj, alltägliche Vorgänge auf ihren nicht alltäglichen Sinn hin transparent zu machen:

"schöpferische Versuche, das Zeitliche mit dem Nichtzeitlichen zu verbinden, in der alltäglichen Handlung ihren nicht alltäglichen Sinn zu zeigen (Formy 172)."

Ibsen gelingt es dadurch, daß er hinter einem alltäglichen zeitgenössischen Drama den "Fond" der Idee spürbar werden läßt, und zwar unaufdringlich doch mit gleicher Tiefe wie in der Musik oder im "Geist der Musik"; Böcklin (Toteninsel) dadurch, daß er ein Arrangement aus Figur, Felsen, Zypressen und Himmel (düster oder rosenfarben, je nach Fassung) in einer Einheitlichkeit der Stimmung anordnet, die nicht gestört werden dürfte. ${ }^{4)}$ Als poetisches Verfahren zu solcher Art von Symbolisierung bezeichnet er hier die künstlerische Typisierung. Er leitet sie aufgrund seiner philosophischen Hochschät- 
zung der Musik aus den musikalischen Formprinzipien ab:

"Jedes musikalische Werk besteht aus einer Reihe von Tonschwingungen; die Wahrnehmung dieser Schwingungen durch das Ohr, als Töne, ist bestimmt von der Einfachheit ihrer Verhältnisse. In der Musik ist nicht jedes Schwingungsverhältnis zulässig. Notwendig ist, $z$ wischen den unendlich verschiedenartigen Verhältnissen, die Auswahl nur der ziemlich einfachen. Die Ausdrucksfähigkeit der Melodie, die in der passenden Sortierung dieser Vehältnisse besteht, erscheint uns in den anderen Künsten bald als Idealisierung, bald als Typik, bald als Stimmung, bald als Schematisierung (Formy 173)."

Es zeigt sich hier eine interessante und für Belyj aufschlußreiche Parallelität: Was er philosophisch begründet als Symbole, die "Fenster in die Ewigkeit" (Krit. 29) seien, realisiert er formal durch eine bewußte Anleihe aus der Tontechnik der Musik, als der für überlegen gehaltenen Nachbarkunst. Macht er nun einerseits Anleihen bei der Musik, so auf der anderen Seite auch bei der Malerei. ${ }^{5)}$ Obwohl aufgrund des doppelten Wirklichkeitsbegriffes aus Wesen und Erscheinung grundsätzlich jeder Gegenstand der Symbolisierung fähig wird, so fällt doch auf, daß in seinem Frühwerk die bevorzugten Gegenstände topisch vorgeprägt sind durch Motive aus der Malerei, vor allem aus Material und Tendenzen der "Welt der Kunst", wie mythologische Gestalten der westlichen und skandinavischen Mythologie (Ritter, Riesen, Zwerge) und der russischen Folklore (Baba Jaga), worin sich die neoslavophile Richtung der russischen Künstlerkolonie Abramcevo spiegelt. ${ }^{6)}$ Symbolische Anleihen macht er ferner beim gnostischen Mythos, dem die Symbole des "Rufes", der "Heimat", der "Stube des Glanzes" u.a. entnommen sind. 7)

Neben dem deiktischen "Erkenntnis- oder Ideensymbol" kann man einen zweiten Symboltyp dieser Phase ausmachen, das "theurgisch-appellative Symbol", das ebenfalls aus der Doppelheit des Wirklichkeitsbegriffes abgeleitet werden kann. Während das Ideensymbol auf die transzendente Welt hinweist oder Andeutungen gibt, hat das theurgische Symbol bei gleicher dualer Struktur einen umgekehrten Richtungsbezug, es dient dem Appell zur "Verwandlung der Persönlichkeit". ") Hierher gehören die Symbole des Propheten, des Kindes, das zugleich Auserwählter ist oder Keim des neuen Menschen, auch die "Ruf-Symbolik", auf die schon verwiesen wurde: "zov večnosti". ") Belyj bezeichnet in dieser Hinsicht das Symbol auch als "Fenster, zu dem die Ewigkeit hereinschaut", die als "ewige Freundin" personifiziert wird und von der ein Ansporn zur Verwandlung ausgeht. ${ }^{10)}$ In die theurgisch-appellative Gruppe gehören als Symbole der Wandlung auch diejenigen, die deren Scheitern symbolisieren. Am zeittypischsten ist wohl das Symbol des "Dämon", das durch Vrubel's Lermontov-Illustrationen und seine Gemäldeserie "Dämon" zu anfangs heftig umstrittener Berühmtheit gelangte. "1) Hier zeigt sich eine psychologische Konsequenz des doppelten Wirklichkeitsverständnisses. Das Interesse der künstlerischen Darstellung gilt zwei Extremzuständen der Existenz, die suprahistorisch überhöht werden: der elevatio und der desperatio. Symbole der elevatio sind die Propheten und Führer-, Licht- und Kindergestalten, der desperatio der Dämon, der Narr, der 
Wahnsinnige. ${ }^{12)}$ Man kann als das Gemeinsame des deiktisch-appellativen Symboltypus dieser ersten Phase seine zweigliedrige Struktur bezeichnen. Die Symbole dieser Art sind in erster Linie Typen oder Ideenträger, Symbole, in denen der "allegorische Sinn" dominiert.

Für die dichterische Methode der Symbolisierung Belyjs auf dieser Stufe haben die beiden Nachbarkünste Malerei und Musik stilprägende Bedeutung. Man kann das vielleicht so sagen: auf der paradigmatischen Ebene trug die Malerei bei zur Gewinnung eines neuen Bildvorrates, der den traditionellen Kanon verbindlich gewordener Symbole erweiterte (ohne ihn deshalb außer Kraft zu setzen, wie z.B. die Beibehaltung des apokalyptischen und gnostischen Symbolreservoirs zeigt). Bei den topisch vorgeprägten Bildtypen der Malerei handelt es sich um bereits kulturell vermittelte Erfahrungs-Patterns, die deshalb auch nicht rein privaten und unverständlichen Charakter haben, sondern schon kulturell definiert sind und einem bestimmten, kulturell versierten Rezipientenkreis ein Assoziationsspektrum anbieten. Auf der syntagmatischen Ebene, d.h. bei der Frage, wie die neugewonnenen Symbole zueinander in Beziehung zu setzen seien, wirkt die Musik ein. An die Stelle einer kausal-narrativen, abbildenden und damit als "realistisch" kanonisierten Verknüpfungsweise treten jetzt neue "Syntagma", nämlich Kompositionsregeln der Musik, wie Leitmotiv, Kontrapunkt, Melodik und vor allem der Rhythmus. Mit Hilfe dieser der Musik entlehnten Verknüpfungsweisen können "nicht alltägliche Verbindungen" hergestellt werden. Die dichterische Methode der Symbolisierung hat also von der Malerei paradigmatisch, von der Musik syntagmatisch entscheidende innovatorische Anstöße bekommen. Mit der Desintegration der Erzählsequenzen im traditionellen Sinne entstand zugleich ein neues Konstruktionsprinzip für die Prosa, ein "topisch-symphonischer" ${ }^{13}$ ) Stil, mit dem Belyj die Prosa in Rußland grundlegend veränderte.

Der Dualismus von Wesen und Erscheinung hat bei Belyj also eine doppelte Funktion: einerseits ist er ein Erkenntnisprinzip, das die philosophische Grundlage ausmacht, andererseits ist er aber auch wirksam als poetisches Verfahren, das neue Verknüpfungsweisen einführt. Auf den ästhetischen Aspekt von Belyjs umstrittenem Dualismus ist seit Ellis' "Russkie Simvolisty" hingewiesen worden, zuletzt bei A. Kovač:

"This basic dualism is not an aim in itself but only the modus operandi [Hv. M.D.] allowing Belyj to attain the ultimate aim which is the recreation $99^{\prime}$ a definite myth in which the whole truth of creation will become manifest."

Ob es sich bei Belyjs Dualismus wirklich nur um einen ästhetischen modus operandi handelt, scheint mir fraglich. Dennoch zeigt sich gerade hier, daß bei Belyj ein "noetisches Prinzip" und ein ihm adäquates "poetisches Verfahren" mit innerer Logik zusammengehören. Wurde oben gesagt, daß das Erkenntnisziel der "Neuen Kunst" gewesen sei, "in der alltäglichen Handlung ihren nicht alltäglichen Sinn zu zeigen" (Formy 172), so entspricht ihm das poetische Verfahren, das Bal'mont proklamierte, "alltägliche Worte in 
nicht alltäglichen Verbindungen" zu verknüpfen. Allerdings muß man hinzufügen, daß auch "nicht alltägliche Worte" in "nicht alltäglichen Verbindungen" verknüpft werden. Der Hang zum Preziösen im Symbolismus ist auffallend.

\section{Symbol der zweiten Phase: Modell der Erfahrung}

Der Wandel im Wirklichkeitsverständnis Belyjs um 1906 ist eng verbunden mit der Aufwertung von Erfahrung und Erleben gegenüber der rein kontemplativen Erkenntnishaltung (Smysl 205). Entscheidend wird, daß in der Kunst die Wirklichkeit nicht nur angeschaut, sondern daß sie erlebt wird. Das Schöpferische (tvorčestvo) wird nicht mehr primär als eine besondere Form der Erkenntnis angesehen. Es wird nicht mehr allein der Primat des Schöpferischen innerhalb der Erkenntnis (Formy 151) betont, sondern Belyj geht nun einen Schritt weiter, indem er sagt, das Schöpferische hat den Primat vor der Erkenntnis überhaupt (Probl. 8).

Das Symbol bezeichnet er deshalb nicht mehr allein als Bild der Idee oder Appell zur Verwandlung, sondern er sagt jetzt im Unterschied zu den bisherigen Ansätzen zur Symboldefinition darüber hinaus:

"Das Symbol ist ein Bild, das aus der Natur genommen und durch das Schöpferische verwandelt worden ist. Das Symbol ist ein Bild, das in sich das Erleben des Künstlers und Züge, die der Natur entnommen sind, vereint (Probl. 8)." (Hv. M.D.)

Zwischen das "Bild der Natur" oder Erscheinungswelt und das Sein der Idee ist als neuer kombinatorischer Faktor das ganzheitliche Erleben des Künstlers eingefügt: beide außersubjektiven Reihen - Natur und Geist - werden durch den Erlebnisprozeß verändert. Das Werk, in dem Belyj zum ersten Mal mit den neuen Symbolen arbeitet, ist die "Vierte Symphonie. Pokal der Schneegestöber". Hieraus kann man seine gleichzeitig entstandene theoretische Wendung in der Symbolkonzeption belegen. Das dominierende Bild der Erscheinungswelt, das das innere Erleben im Modell darstellen soll, ist der Schneesturm. Die Idee, die im Erleben erfahren wird, ist die der "Heiligen Liebe", die Belyj bei Platon, Goethe und Solov'ev vorgedacht und gestaltet sieht. Beides, die Naturgewalt des Schneesturms wie auch das geistige Konzept der "Heiligen Liebe", werden vom Erleben gebrochen. Dem "Bild der Natur"15) werden "Züge" entnommen die aus dem Erleben bedeutsam geworden sind. Die Idee wird im Vollzug der Erfahrung gezeigt, und das heißt, in der Kollision mit der rauhen Wirklichkeit und ihren historisch, sozial und persönlich bedingten Zwängen. Ihr Scheitern, wie auch die eigentümliche Art ihres Siegens, sind je verschieden Sujet des Poems. Zugrunde liegt der Fabel die von Belyj gegebene Version seiner Liebe zu L.D. Blok, der Frau von A. Blok, seinem Freund und Dichterbruder. ${ }^{16)}$

Der Vorgang der sprachlichen Symboiisierung besteht nun darin, daß dieses Erlebnis, dem eine Idee zugrunde gelegt wird, zu dem Naturphänomen des Schneesturms in 
Analogie gesetzt wird. Es muß also eine Sprache gefunden werden, die in der Bildersequenz, die sich aus dem dynamischen Phänomen des Schneesturms bilden läßt, der ganzen "Tonleiter" der Erlebnisaspekte symbolisch Ausdruck verschafft. Sowohl das an sich bildlose innere Erleben, das nach Belyj nicht in der Oberflächenhandlung des All tags aufgeht, als auch das ebenfalls bildlose Sein der Idee kann - so scheint es ihm durch dieses dynamisierte Symbol ausgedrückt werden; vollständiger als in realistischer Abbildung.

Die Methode der Symbolisierung, die diese Zusammenhänge sprachlich realisieren will, steht also vor einer komplexen Aufgabe: die beiden Reihen der inneren und der äußeren Erfahrung, die keinen kausalen Bezug aufeinander haben, sprachlich aufgrund ihrer Analogien aufeinander zu beziehen. Es soll also sowohl die Innen-Außen-Relation sprachlich gestaltet werden, wie auch der mit ihr zu verbindende "unendliche Bezug" zwischen dem Erleben und dem Sein der Idee. Das Symbol soll als "Bild-Modell" der Erfahrung fungieren. Hierin weicht die neue Symbolkonzeption um einiges von den bisherigen Aussagen ab, führt sie aber weiter. Es liegt offenbar nicht ein Bruch vor, sondern eine Erweiterung. ${ }^{17)}$ Denn trotz der neven Bedeutung, die das Erleben erhält, bleibt die Ideenbezogenheit erhalten. Auch werden die Symboltypen der früheren Phase nicht aufgegeben, sondern sie koexistieren mit den neugewonnenen weiterhin in seinem Werk. ${ }^{18)}$

\section{Triadische Konzeption der Symbolisierung}

Zunächst also sind für das erlebte Symbol dieser Phase die drei Komponenten des künstlerischen Erlebens konstitutiv: Wille, Gefühl und Ratio. Daraus ergibt sich das triadische "Relief des Symbols" (Smysl 207), in dem es einem Berge zu vergleichen ist. Was Belyj metaphorisch mit der Gebirgsmetapher umschreibt, systematisiert er formelhaft zu einer "dreigliedrigen Symbolformel":

"Die Einheit der psychischen Aktivitäten - des Fühlens, des Wollens und des Denkens - muß im lebendigen Bild-Modell, das eben das schöpferische Symbol ist, enthalten sein. Deshalb - obwohl das künstlerische Symbol eine Idee ausdrückt - erschöpft es sich nicht in ihr; obwohl es ein Gefühl ausdrückt, ist es dennoch nicht auf die Emotion zu reduzieren, obwohl es den Willen anspornt, ist es doch nicht in die Normen eines Imperativs zu zerlegen. Das lebendige Symbol der Kunst, das von der Geschichte durch die Jahrhundertwende hindurch getragen worden ist, bringt in sich vielgestaltige Gefühle, vielgestaltige Ideen zur Brechung. Es ist - ein Potential ganzer Serien von Ideen, Gefühlen, Willensregungen. Und daher läßt sich eine dreigliedrige Formel des Symbols entwickeln, sozusagen sein dreisimiger Sinn: 1) das Symbol als Bild der Erscheinungswelt, das unsere Emotionen weckt durch die Konkretheit seiner Züge, die uns aus der Wirklichkeit unserer Umwelt bekannt sind; 2) das Symbol als Allegorie, das den geistigen Sinn des Bildes zum Ausdruck bringt: seinen philosophischen, religiösen, soziologischen; 3) das Symbol als Aufruf zum schöpferischen Leben. Aber ein symbolisches Bild ist weder das eine, noch das zweite, noch das dritte. Es ist - lebendige Ganzheit des erlebten Bewußtseinsinhaltes (SmysI 225)." 
Diese triadische Konzeption des Symbols enthält rezeptionsästhetische und produktionsästhetische Implikationen. Zunächst läßt sich in bezug auf seine "Verstehensstufen" Genaueres sagen, als im allgemeinen mit dem Hinweis auf die Polyvalenz eines Symbols geleistet wird. Denn nach Belyj hat das Symbol aufgrund seiner triadischen Struktur auch drei Verstehensebenen, die es allerdings dennoch nicht erschöpfen. Das Symbol hat einen "allegorischen" Sinn, der seinen Ideengehalt betrifft. Außerdem hat es einen "naiv-realistischen" Sinn, der von Fabel, Zeit und Milieu gebildet ist (SmysI 207). Schließlich hat es - wie schon im Anfang - einen appellativen und antizipator ischen Sinn. ${ }^{19)}$ Damit ist aber auch gesagt, daß im Symbol zwischen Autor und Leser über das Werk hinaus eine Kommunikationsverbindung geschaffen wird, die nicht auf die ästhetische begrenzt bleibt, sondern insofern als eine Symbol-Arbeit zu leisten ist, auf eine ethische Sphäre zielt. Darin liegt der Anteil des Symbols am Schaffen neuer "Werte". 20) Belyj versucht, dem Symbol in der Moderne neue Wirksamkeit zu verleihen, indem er auf seine doppelte Zugehörigkeit sowohl zur ethischen wie auch zur ästhetischen Sphäre hinweist. Sie eignet dem Symbol seit seiner Entstehung. H. Pongs hat kürzlich in seinem Alterswerk "Das Symbol als Mitte" wieder auf die zweifache Abstammung des Symbols aus dem Ritus der Gastfreundschaft und aus seiner Funktion als Zeichen, Abzeichen oder Wahrzeichen aufmerksam gemacht. ${ }^{21)}$ Wenn von Belyj der mehrfache Sinn des Symbols nicht nur in Hinblick auf seine sprachlich-semantische Multivalenz gesehen wird, ${ }^{22)}$ sondern wenn er zugleich seine beiden Hauptfunktionen hervorhebt: die zeichenhafte und auch die kommunikative, so kann man sagen, daß in seiner Symbolkonzeption wesentliche Kennzeichen des Symbols in der Kunst deutlich gemacht werden.

Die oben beschriebene Dreigliedrigkeit des Symbolbegriffes hat aber nicht nur rezeptionsästhetische Implikationen, sondern auch produktionsästhetische. ${ }^{22 a)}$ Es lassen sich nämlich je nach Schwerpunkt des Schaffens bei einem Künst ler der allegorisierende Typus unterscheiden, der vor allem Ideen darstellt, der realistische, der vor allem die Wirklichkeit schildert, und der romantisch-utopische Typus, der vor allem von der Imagination her schafft und Fantastisches oder Mögliches darstellt (Smysl 218f.). Wenngleich sich in der Praxis diese Züge im allgemeinen überschneiden, so kann man doch in vielen Fällen von der Dominanz eines dieser Hauptzüge aus zu einer typologischen Unterscheidung kommen.

\section{Die Innen-AuBen-Relation}

Sind also Intention und Umfang des Bild-Symbols von der Totalität des Erlebens her bedingt, so wird bei seinem Funktionieren als sprachliches Verfahren, also bei der Methode der Symbolisierung, die Innen-Außen-Relation relevant und problematisch. Belyj schreibt über den Prozeß der Symboiisierung in bezug auf die Innen-Außen-Relation: 
"Der Prozeß des Erbauens von Modellen zu Erlebnissen mit Hilfe von Bildern der Erscheinungswelt, das ist der Prozeß der Symbolisierung (Smysl 206)."

Dabei geht es ihm nicht um Abbildung von Elementen der einen, der psychologischen Reihe, in verwandten Bildern der anderen, der empirischen Reihe, sondern er spricht statt von Abbildern von "Modellen" der Erfahrung. Die "Treue zur Wirklichkeit" dieser Erfahrung kann nach Belyj nur "in der freien Gruppierung von Elementen der Erscheinungswelt (Smysl 212)" eingelöst werden. Die Unterscheidung von Abbild und Modell liegt gerade in dieser Operation des "freien Gruppierens der Elemente (Smysl 212)". Für den Künstler erhebt sich dabei die Frage: Nach welchen Kombinationsprinzipien sollen die Elemente zu Modellen gruppiert werden?

Hier entdeckt Belyj in der eigenen dichterischen Praxis mehr, als er in der Theorie formuliert: Es gibt zwei Steuerungszentren, die im Künstler miteinander konkurrieren, das psychische und das konstruktivistische. Das eine will die Wahrheit der inneren Wirklichkeit dokumentieren, das andere will die Schönheit der Anordnung des "Materials", d. h. der Sprache. Hier liegt eine Gelenkstelle im ästhetischen Denken Belyjs und ein künstlerisches Problem, das zu einer Umstrukturierung seiner Dichterpersönlichkeit geführt hat. Im Vorwort zur "Vierten Symphonie" beschreibt er, wie beide Impulse sich befehden, was ihn schließlich am Kunstcharakter seines Werkes zweifeln läßt:

"Während ich meine "Vierte Symphonie" zu Ende bringe, befinde ich mich in einigem Zweifel. Wer wird sie lesen? Wer braucht sie? Ich habe an ihr lange gearbeitet, ich habe mich bemüht, so genau wie möglich einige Erlebnisse zu umreißen, die sozusagen den Fond des all täglichen Lebens unterbreiten und die im Grunde genommen in Bildern nicht zu verkörpern sind. Diese Erlebnisse, die, eingebettet in die Form wiederkehrender Themen, die ganze 'Symphonie' durchzichen, sind dargestellt wie in einem Vergrößerungsspiegel. Hier nun begegnete ich zwei Arten des Zweifels. Kann man sich bei der Auswahl von Bildern zu einem Erlebnis, das im Grunde im Bilde gar nicht zu verkörpern ist, leiten lassen von der Schönheit eben des Bildes oder von seiner Genauigkeit (d. $h$. damit das Bild das mögliche Maximum an Erlebnis aufnehme)? Damit verbunden, wie soll man den inneren Zusammenhang der im Bild nicht gestaltbaren Erlebnisse (ich würde sagen, mystischen) mit dem Bildzusammenhang vereinbaren? Vor mir zeichneten sich zwei Wege ab: der Weg der Kunst und der Weg der Analyse der Erlebnisse selbst, ihre Zerlegung in ihre Bestandteile. Ich habe den zweiten Weg gewählt, und deshalb bin ich eben im Zweifel, - ist die vorliegende 'Symphonie' ein Kunstwerk oder ein Dokument des Zustandes der modernen Seele, das vielleicht für eineg, Psychologen der Zukunft interessant ist? Soviel zur Substanz der Symphonie."

Belyj beschreibt hier die Lage des modernen Symbolisten, der den Anspruch erhebt, "erlebte" Symbole zu schaffen, bzw. Bildsymbole, die in ihrer Struktur als dynamisiertes Symbol den Erlebnisprozeß selbst mit darstellen wollen. In einer Zeit, in der sowohl die Kunst der Seelenzergliederung entstand, wie auch der Kanon der sprachlichen Ausdrucksformen im Umbruch ist, wird die Versprachlichung von Erlebnissen differenzierter als traditionell. Das moderne Symbol, das mit dem Anspruch auftritt, erlebtes Symbol zu 
sein, unterscheidet sich sowohl vom "gestifteten" Symbol der Tradition - das man im Hinblick auf seinen Erlebnisgehalt als statisch bezeichnen kann - wie auch vom Goetheschen Symbol, das zwar bereits aus dem Erleben des "symbolischen Gegenstandes" hervorgegangen war, durch den Anteil, den die zergliederte Erlebnistotalität in ihm bekommt. 24)

Nun hat Belyj keineswegs die einseitig in Aussicht gestellte Schwenkung zur "Psychoanalyse" vollzogen, sondern er hat mit seiner "Vierten Symphonie" ein formal-sprachliches Unikum geschaffen, in dem er versuchte, "Psychoanalyse" zu "komponieren", d. h. sie mit musikalischen Kompositionsprinzipien zu verbinden. Erlebnissegmente werden nicht mehr narrativ-sukzessiv dargeboten, sondern in assoziativen Variationen über einige feste Themen - analog zur symphonischen Form der Musik - komponiert. Und über diese literarisch-musikalische Psychotechnik ist er sich genauso im Zweifel wie über die Substanz der Symphonie:

"Was nun die Methode des Schreibens (pis'ma) angeht, so zweifle ich auch hier. Mich hat der Konstruktionsmechanismus jener wirr erkennbaren Form interessiert, in der meine vorherigen Symphonien geschrieben sind: dort stand die Kontruktion an sich zur Debatte, und eine deutliche Vorstgylung davon, was eine 'Symphonie' in der Literatur sein sollte, hatte ich nicht."

Bisher hat Belyjs "Vierte Symphonie" ihren "Psychologen der Zukunft" noch nicht gefunden. Doch kann man vielleicht sagen, daß die Problematik einer symbolisch-modellierenden Innen-Außen-Relation kaum origineller und vor allem problembewußter als bei ihm in Angriff genommen wurde. Wenngleich Belyj den Weg der Symphonien, nachdem er hier an eine absolute Grenze gekommen war, verließ, gehört dennoch die "Vierte Symphonie" zu den sprachlich-psychologischen Unentdecktheiten des zwanzigsten Jahrhunderts. Ein Beispiel mag das verdeutlichen:

In dem Hauptmann Svetozarov (Strahlleuchter) schuf er die Figuralisierung martialisch-rhetorischer Liebesromanzen (wie sie damals in Rußland in den gebildeten Schichten beliebt waren), in der er Züge des Militärischen mit denen des Sentimentalen zu einer beklemmend präsenten Phantomfigur von sentimentaler Militanz kombinierte, die etwas von der psychischen Tiefenstruktur der säbelrasselnden Epoche Wilhelms II. und seines Vetters "Nicky" offenlegt. Gleichzeitig aber symbolisiert er in Svetozarov eine Abspaltung des "reinen" Helden Adam Petrovič. Diese Teilhabe an der pseudomartialischen Männlichkeit der Epoche bringt ihn in die Komplicenschaft zu seinem tierisch-gewalttätigen Rivalen, Svetlovas Mann; und gerade dadurch wird schließlich die Realisierung der "Heiligen Liebe" in den psychosozialen Bedingungen dieser Lebenswelt vereitelt. Svetozarov hat neben diesen Zügen aber noch eine weitere Funktion im Werkganzen: Er ist zugleich allegorischer Repräsentant für die verschlingende Gewalt, die die "Zeitlichkeit" über eine Idee und ihren "rein" bleiben wollenden Verfechter erlangen kann. ${ }^{26)}$

Es spricht vieles dagegen, daß sich Belyj in der "Vierten Symphonie" nur eine "for- 
malistische Falle" gestellt habe; ${ }^{27)}$ hier scheint anderes vorzuliegen; auf jeden Fall aber ein Forschungsfeld literaturpsychologischer Analyse, die allerdings einiges an Kunstverstand erfordern würde.

An der Analyse der Innen-Außen-Relation zeigte sich, daß es bei der ganzheitlichen Erlebniskonzeption um eine zwar totale, aber deshalb nicht etwa harmonisierende Ganzheitsvorstellung des psychischen Zusammenhanges geht. Andererseits kann man sie aber auch nicht generell als "crisis-experience" bezeichnen. ${ }^{28)}$ Vielmehr scheint es, als bestehe Belyj auf der Erlebnistotalität als Voraussetzung moderner Symbolisierung deshalb, weil grundsätzlich alle Schichten des psychischen Systems - ohne vorgängige Selektion in den Symboliserungsprozeß eingehen können. ${ }^{29)}$

\section{Der unendliche Bezug}

Ist also einerseits die Erlebnistotalität in ihrer dreigliedrigen Konstitution Basis des Symbolbegriffes, vollzieht sich die Methode der Symbolisierung im sprachlichen Realisieren der Innen-Außen-Relation, so ist die Weise des symbolischen Schaffens davon geprägt, inwiefern ihr eine Einheitsvorstellung von den getrennten Bereichen der Erscheinungs- und der Ideenwelt zugrunde liegt. Belyj bezeichnet die Weise der Symbolisierung als "obraz tvorčestva". Die Frage ist hier, welche Auffassung der Künstler von der Einheit der Welt hat, bzw. ob er überhaupt noch eine hat.

Belyj stellt die Grundthese auf, daß Symbolisierung ohne den "unendlichen Bezug" nicht möglich sei. Dieser kann in verschiedener Weise präsent sein - auch in der Form der Nicht-Realisierbarkeit oder des nur noch erhaltenen Horizontes. ${ }^{30)}$

In einem historisch-typologischen Uberblick zeigt er die verschiedenen Horizonte von Symbolisierung (Smysl 212 - 217). Die zwei Grundmöglichkeiten nach Belyj sind folgende: Entweder wird die Einheit der Welt als ens realissimum real geglaubt und bildet eine positive Grundlage des künstlerischen Schaffens, oder aber sie existiert nur als Ideal, also als eine gesuchte Größe. Ist sie real geglaubt, so offenbart sich der Sinn der Symbolisierung dem Künstler in der Metaphysik oder Mystik, als Gewißheit von Wegen zur Verwandlung der Welt. Belyj spricht in diesem Falle von Real-Symbolismus. Steht der Künstler aber innerhalb eines Weltbildes, in dem diese Einheit nicht mehr in einer Offenbarungsgewißheit geglaubt wird, sondern gesuchte Größe oder Ideal ist, was für die Moderne nach Belyj seit Shakespeare zutrifft, dann gibt es verschiedene Grade, in denen die gesuchte Größe dennoch zugrunde gelegt oder in der Kunst symbolisch erschaffen werden kann. Diese Form der Symbolisierung bezeichnet er als Ideal-Symbolismus. Das idealistische Einheitsbewußtsein kann verschiedene Grade der Deutlichkeit haben, es kann als "Idee der Vernunft" im Bewußtsein existieren, es kann als "unbewußtes Streben nach Harmonie" das künstlerische Schaffen begleiten oder aber nur noch auf die Bedingung der Möglichkeit von Symbolisierung überhaupt reduziert sein. Den ersten Fall sieht er bei 
Goethe, Shakespeare und Puskkin realisiert, den zweiten bei Tolstoj und Cechov, den dritten bei Poe und Baudelaire. Er sagt hierzu:

"Die Enthüllung der Einheit von Formen der äußeren und der inneren Erfahrung bleibt aus; das Bild der inneren Realität ist der Erscheinungswelt entnommen; die Stimme der Offenbarung tönt nicht mehr in der Seele des Künstlers, in ihm ist nur ein trübes Bewußtsein, daß es eine einheitliche Ursache der ihn quälenden Zwiespältigkeit gibt; diese Zwiespältigkeit ist in ihm und um ihn herum in voller Kraft; er sieht die Welt in all ihrem Widerspruch; und die Welt ruft Widersprüche zu seinen Erlebnissen hervor; die Gestalt (obraz) seines Schaffens bringt nur mehr eine Parallele zwischen dem gegebenen Gegenstand der Erscheinungswelt und dem gegebenen Erlebnis zum Ausdruck; möglich ist die größtmögliche Annäherung im Erleben des Künstlers an das Bild der Erscheinungswelt; dieses Maximum der Annäherung ist die Entsprechung (sootvetstvie); aber die Bedingung ihrer Möglichkeit ist die nicht offenbar gewordene Einheit, weder im Erleben noch in der Erscheinungswelt. Einer solchen Einheit ist sich der Künstler bewußt, doch nicht als Vision der Got theit, sondern als Idee der Vernunft. Der Künstler mag sich zum Pantheismus bekennen, mag sich Mystiker nennen, Realist - es ist gleich: das Bewußtsein der Einheit ist idealistisch. Von solcher Art sind z. B. Goethe, Shakespeare, Byron, derart ist auch Puškin." (Smysl 215f.).

Neben den zwei Grundmöglichkeiten des Real - und des Idealsymbolismus, in denen die Einheitsvorstellung entweder als Gottes-oder Idealvorstellung dem Schaffen a priori vorgegeben ist oder aber erst im Prozeß der Symboiisierung erschaffen wird, trifft Belyj eine weitere grundsätzliche Unterscheidung zwischen zwei verschiedenen Einstellungen des Künstlers in bezug auf die innere und die äußere Reihe der Gestaltung (Smysl 217 219). Der Romantiker erfährt die Einheit der Welt in seinem Inneren und sucht dafür nach äußerer Form; der Klassiker umgekehrt wird sie an einer äußeren Erscheinung gewahr, die ihm zugleich die Form seiner inneren Erfahrung zu sein vermag.

Die beiden Typen des Real- und des Idealsymbolismus und die beiden Einstellungsweisen des Romantikers und des Klassikers ${ }^{31}$ ) können verschiedene Kombinationen eingehen. Der Real-Symbolist vor dem Hintergrund eines metaphysisch überhöhten Weltbildes kann als klassischer oder als romantischer Künstler schaffen. Innerhalb des Real-Symbolismus der Antike und des Mittelalters klassifiziert er: Bei vorgegebener Einheits-oder Gottesvorstellung schafft der religiöse Klassiker der Antike die Bilder der olympischen Götter nach dem Vorbild der Natur, der religiöse Romantiker erschafft seinem Glauben mythologische Fabelwesen ohne Vorbild in der Natur. Bei nicht mehr kollektiv vorgegebener, sondern erst individuell im Prozeß des Schaffens hervorgebrachter Einheitsgrundlage oder Gottesvorstellung, schafft der religiöse Klassiker der Renaissance Bilder, wie Raffael oder Dürer, die ihr Maß des Göttlichen aus der Natur nehmen, der religiöse Romantiker dagegen innere Visionen wie Dante, Goya oder in der Moderne noch Vrubel', die ihr Bild des Göttlichen in der Imagination erschaffen. Entsprechend klassifiziert er innerhalb des Ideal-Symbolismus: Bei vorgegebener Idealvorstellung schafft der idealistische Klassiker der Neuzeit nach der Realität wie Shakespeare, Goethe und Puškin, der 
idealistische Romantiker nach der imeren Projektion wie Maeterlinck oder Przybyszewski. Ist die Idealvorstellung nur mehr Leitstern des Schaffens, so wäre nach Belyj der säkularisierte Klassiker, der nach der Natur schafft, in Tolstoj und Čechov, der säkularisierte Romantiker, der nach dem inneren Gesicht schafft in E. T. A. Hoffmann, E. A. Poe und $C$. Baudelaire zu finden. Belyj zeigt also, daß verschiedene Weisen der Symbolisierung $^{32)}$ je nach dem Grad der Einheitsvorstellung und nach der künstlerischen Einstellung zu Natur und Imenwelt möglich sind.

Wenn von Belyjs triadischer Symbolkonzeption gesprochen wird, so gilt das in zwei Hinsichten: einmal in bezug auf die Triade Gefühl - Verstand - Wille, die die Basis des Symbols im Erleben ausmacht; zum anderen gilt es für die Triade Subjekt - Natur Geist. Zwischen der mikrokosmischen und makrokosmischen Triade gibt es nach Belyj eine Entsprechung. Doch diese Analogie kann, wie sich gezeigt hat, sehr verschiedene Grade der Deutlichkeit annehmen. Wichtig scheint, daß das Symbol der Moderne nach Belyj nicht nur in der psychischen Triade verankert ist, sondern daß es ebenfalls mit der Dreiheit von Subjekt - Natur - Geist zu tun hat. Im gelungenen Fall repräsentiert das Symbol als "Modell" sowohl die "Innen-Außen-Relation" wie auch den "unendlichen Bezug".

Für das Symbol der zweiten Phase gelten also andere Bedingungen als bisher. Mit dem Wechsel des "noetischen Prinzips" fällt dem Erleben als kombinatorischem Faktor die zentrale Rolle zu, die früher die intuitive Erkenntnis innehatte. Dadurch wird auch das poetische Verfahren der Symbolisierung verändert; denn das Symbol kann nur dann zum "Modell" von Erfahrungen werden, wenn die Elemente des Anscheins in freier Gruppierung modellhaft umkonstelliert werden. Es geht dabei nicht um ein direktes Modellieren von Wirklichkeit, sondern um ein Modellieren von inneren und äußeren Erfahrungen, die vom Dichter mit ihr gemacht wurden, also um ein Modellieren psychisch vermittelter oder "prismatischer" Wirklichkeit. ${ }^{33)}$

\section{Symbol der dritten Phase: Vert- und Sprachschöpfung}

Die Symbolkonzeption Belyjs kommt in der dritten Phase um 1909 zu ihrem Höhepunkt. Die zweiseitige Ausprägung der Symbolisierung als Denkmethode und als poetisches Verfahren wird nicht nur beibehalten, sondern ausgeweitet. Die Hauptkonstante im ästhetischen Denken Belyjs, die Doppelfrage nach Sinn und Form der Kunst, wird wie bisher perspektivisch weiter durchdacht, vor allem in den beiden großen programmatischen Essays "Emblematik des Sinns" und "Magie der Worte". 34)

Die Voraussetzungen dafür hatte er mit dem Umbau der Symbolkonzeption um 1906 geschaffen. Er hatte erkannt, daß Kunst nicht allein als "vollkommene Erkenntnis" verstanden werden kann. Das noetische Prinzip der kontemplativen Anschauung und das poetische Verfahren, vorhandene Sprachelemente neu zu konstellieren in verbalen Uber- 
raschungseffekten à la Bal'mont - beides war noch nicht ausreichend. Symbolisierung erwies sich nicht nur als Denkmethode, sondern als Methode des "Lebensschaffens" durch Modellierung von Erfahrung. Die Basis der Symbolisierung wurde breiter: nicht mehr allein die vita contemplativa der reinen Anschauung, sondern die vita activa aus der Totalität des Erlebens - der inneren und der äußeren Erfahrung. Mit dem noetischen Prinzip änderte sich das poetische Verfahren. Nicht nur die Sprache wird verändert durch Neukombination ihrer Elemente, sondern es geht jetzt darüber hinaus um die "freie Gruppierung von Elementen der Erscheinungswelt", die in der neuen Kunst sowohl aus psychischen als auch aus formal-kompositiorischen Erfordernissen gesteuert wird. Indem Belyj das ästhetische Postulat der "freien Gruppierung" theoretisch sanktioniert und in seine Kunstlehre aufnimmt, reflektiert er eine entscheidende Wende im Kunstprozeß der Moderne: die Loslösung von den vorgegebenen Gegenständlichkeiten, die in ihrer radikalen Konsequenz zur gegenstandlosen Kunst führte. Berühmtestes frühes Beispiel in der Malerei wurde Picassos "Demoiselles d'Avignon" (1907).

Nachdem Belyj der Kunst eine zweifache theoretische Legitimation verschafft hatte 1) als besondere, unersetzbare Form der Erkenntnis, 2) als ebenfalls unersetzbare Modellierung von Erfahrung in psychisch und formal dynamisierten "offenen" Symbolen, stellt er in der dritten Phase die Frage, inwiefern die Kunst imstande ist, nicht nur neue Erkenntnisse und Erlebnisbereiche, sondern auch neue Werte zu erschaffen. ${ }^{35)}$

Schon in "Sinn der Kunst" war neben der Forderung, daß alle Schichten des psychischen Systems in der "Neuen Kunst" zur Methode der Symbolisierung zugelassen werden müssen, ebenso deutlich gefordert worden, daß die Kunst nicht nur Erlebnisse ausdrücken, sondern daß sie Werte schaffen solle (Smysl 208 - 212). Hier geht Belyj über die Grenzen der Erlebnisästhetik hinaus. Zu fragen ist, welche Art von Werten er eigentlich meint.

Er trifft hier eine wichtige Unterscheidung: Die Erschaffung von Werten in der Kunst ist vom eigenen, gegenüber der Lebenspraxis heteronomen Seinsstatus der Kunst abhängig. ${ }^{36)}$ Denn aufgrund ihrer Freiheit, oder Autonomie, die der Kunst erlaubt, fiktionale Gebilde zu schaffen, die ihre eigene "Zweckmäßigkeit ohne Zweck" haben (also eine Anordnung von Erlebnis-, Ideen und Formbestandteilen hervorzubringen, die wohl in einem der Kunst zugehörigen Sinne zweckmäßig ist, aber nicht den Zwecken der Lebenspraxis zu gehorchen hat, obgleich sie ihnen auf ihre eigene Weise zu dienen vermag) aufgrund dieser autonomen Beschaffenheit ist die Kunst imstande, Elemente von dem, was sein sollte (dolženstvovanie) und Elemente von dem, was vorhanden ist (dannost'), zu einer freien fiktionalen Konstellation zu gruppieren und in dieser Freiheit, die an einem Sollen orientiert ist, aber nicht von ihm ihr Gesetz zudiktiert bekommt, Werte zu schaffen. Und das heißt: Lebensformen zu modellieren, die so angeordnet werden, daß sie das Erreichen oder Verfehlen eines wertorientierten Lebens sichtbar machen. Belyjs "Probemenschen" der Kulturkrise: Darjal'skij (Silberne Taube), den Senatorensohn Nikolaj 
Ableuchov (Petersburg) und das Kind Kotik Letaev (im gleichnamigen Roman-Poem) kann man unter diesem Gesichtspunkt betrachten. In allen drei Werken geht es nicht nur um neve, bisher so noch nicht dargestellte Erlebnisse und Erfahrungen, sondern immer um die alte russische Frage: "Was sollen wir denn tun?". Die Frage Herzens, Černyševskijs, Tolstojs, Dostojevskijs nach dem "richtigen Leben" ist auch die Frage Belyjs.

In seiner ästhetischen Theorie will Belyj den Anspruch legitimieren, daß das sprachliche Kunstwerk auf eine unersetzbare Weise Werte (oder die Suche nach Werten) darstellen und eben dadurch "erschaffen" kann. ${ }^{37)}$ Durch diese schöpferische Leistung kann die Kunst an der Aufgabe der "Umwertung der Werte" (Probl. 8, Buduščee 453, Morgenröte 340,352$)$ teilhaben:

"Und so bringt die Vereinigung des Sein-Sollenden mit dieser oder jener Gegebenheit einen Wert hervor. Der Akt der Vereinigung jedoch, die Initiative die liegt im freien Willen der Persönlichkeit. Und deshalb sind sowohl das szientistische Wissen, wie auch die Philosophie, wie auch Ethik, Ästhetik und Religion verschiedene Arten von Schöpfertum. Erkenntnis ist vom Schaffen vorbestimmt (Smysl 211)."

Belyj geht weiter auf die Besonderheit der künstlerischen Wertschöpfung ein, die darin besteht, daß die Kunst aufgrund ihrer Unbehindertheit von den $Z$ wängen der Lebenspraxis Werte darstellen kann, die sie aber selbst nicht konkret verwirklichen kann. Das kann nur in der Lebenspraxis geschehen; nach Belyj dann, wenn sie zu einer religiös bestimmten transformiert wird. Obwohl der Kunst diese Grenzen gesetzt sind, aber auch gerade wegen dieser Grenzen, die sie von der konkreten Verwirklichung ihrer Werte entbinden, ist sie imstande, als Prototyp von Kreativität zu wirken. Am Maßstab der Lebenspraxis ist sie nicht zu messen. ${ }^{38)}$

"Das Schaffen (im außerkünstlerischen Sinn) verwirklicht Sein wie auch Erkenntnis; das eine wie das andere ist ohne den Akt des Schaffens - nur Material von toten Fakten aller Art - ein Chaos des Anfangs, aus dem Welten entstehen. Die Kunst - indem sie Bilder des Lebens umschafft in Bilder von Werten zeigt, obgleich sie diese Werte nicht verwirklicht (wie die Religion), doch Wege zu ihrer Realisierung; das was in der Kunst begonnen wird, wird vollendet in der Religion (Smys! 2IIf.)." (Hv. M. D.)

Ausgehend davon, daß die Methode der Symbolisierung in der Kunst sowohl eine Methode der "vollkommenen Erkenntnis" sein kann, was aber nicht genügt; daß sie zweitens eine Methode prototypischer Lebens- und "Seinsschöpfung" sein kann, - was auch noch nicht alles ist; daß sie schließlich auf der Grundlage der ersten beiden Stadien zu einer Methode der Wert - und Sprachschöpfung werden kann; ausgehend von diesem sich dialektisch entwickelnden Kunstverständnis, welches Erkenntnis, Erfahrung und Wertverpflichtung einschließt, ${ }^{39)}$ vertritt Belyj die Uberzeugung, daß die künstlerisch gewonnene Methode der Symbolisierung auch als umfassende philosophische Methode Geltung haben müßte, daß aus ihr der Symbolismus als moderne ganzheitliche Weltanschauung begründet 
werden könnte (Embl. 51, 140), als eine Philosophie der Kreativität:

"die Theorie des Schöpferischen, die unsere Epoche sucht, wäre im Grunde die Theorie des Symbolismus (Embl. 70)."

Prolegomena dazu hat Belyj in seiner Grundlagenstudie "Emblematik des Sinns" zusammentragen wollen, deren Bedeutung noch unerforscht ist. Im Rahmen dieser Arbeit kann nur auf ihre wichtigsten Intentionen eingegangen werden, die den Stufen in der Entwicklung der künstlerischen Methode analog sind. Belyj geht in "Emblematik" davon aus, daß wir In der Moderne zugleich auf dem Höhepunkt der alteuropäischen Kultur stehen ( $N a$ perevale) wie auch an ihrem Wendepunkt ( $N a$ rubeže). Denn die Widersprüche der Kultur sind für ihn in einem Maße ans Licht getreten wie nie zuvor (Embl. 50). Das Bewußtsein, in einer Krise der Kultur zu leben, wird von Belyj als diskursiv behandeltes Thema, vor den Krisenschriften aus dem ersten Weltkrieg, zum ersten Male in seinem Ibsen-Aufsatz aus dem Jahre 1910 reflektiert:

"Wir leben in einer Krise.

Noch nie sind die Grundwidersprüche des menschlichen Bewußtseins in der Seele mit derartiger Schärfe aufeinandergestoßen; noch nie wurde der Dualismus zwischen Bewußtsein und Gefühl, Persönlichkeit und Gesellschaft, Wissenschaft yng Religion, Moral und Schönheit derart deutlich zum Ausdruck gebracht."

Angesichts dieser Krise stellt sich Belyj die Aufgabe, Voraussetzungen zu durchdenken, die zu einer neuen ganzheitlichen Weltanschauung führen könnten, die den Dualismus der Widersprüche überwindet. Gesucht ist eine Weltanschauung, die für den Menschen der Moderne angesichts der Kulturkrise wieder ein Trost- und Sinnversprechen bereithält (Embl. 56). Dazu verhilft nicht etwa ein Ausmerzen aller Traditionen, sondern es ist notwendig, sich zur Lage des "Alexandriners" zu bekennen, und sie kreativ zu handhaben: nämlich die philosophischen Fragen und Antworten der westlichen und östlichen Denktraditionen neu zu sichten (Embl. 50). ${ }^{41)}$ Es kommt darauf an, eine großangelegte Kulturarbeit, einen Umwertungsprozeß zu leisten (Probl. 8). ${ }^{42)}$ Denn das Weltbild der modernen Wissenschaften hat nach Belyj vor der Sinnfrage versagt (Embl. 51 - 55), da es widersprüchlich ist und für Teilantworten absolute Geltung beansprucht. In Belyjs Wissenschaftskritik gibt es sowohl differenzierte Argumentation ${ }^{43)}$ als auch Sätze, wie die folgenden, die für Belyjs perspektivische Extremterminologie typisch sind:

"Wenn Wissen außerdem auch Wissen vom Sinn des Lebens ist, so ist die Wissenschaft noch kein Wissen.

Die Wissenschaft schreitet von Nichtwissen zu Nichtwissen, Wissenschaft ist die Systematik von Nichtwissen aller Art (Embl. 56)."

Belyj zieht die Möglichkeit eines rein wissenschaftlichen Weltbildes überhaupt in $Z$ weifel. Dazu wäre zuerst eine $W$ issenschaftslehre notwendig, die sich methodenkritisch 
mit den Geltungsansprüchen der Teildisziplinen auseinandersetzte. Solange eine solche Wissenstheorie noch aussteht, kann von einer wissenschaftlichen Weltanschauung mit Grund noch gar nicht gesprochen werden (Embl. 53 - 55, Lirika $231 \mathrm{ff.}$ ). Die Kunst hat dagegen als eine umfassendere Form der Erkenntnis und als eine Form des wertorientierten "Lebensschaffens" bereits Vorstöße in Richtung auf eine neue Weltsicht gewagt, die zwar erst bruchstückhaft ist, aber dennoch zur Gewinnung einer neven Weltanschauung beitragen kann.

Einen philosophischen Ausweg aus der Krise des modernen Weltbildes sieht Belyj in der neukantianischen Wertphilosophie Heinrich Rickerts. Nach Belyj geht er auf den schon von Kant bloßgelegten Widerspruch innerhalb der Vernunft zurück, daß nämlich die praktische Vernunft andere Ziele hat als die theoretische. Die praktische Vernunft will nicht möglichst viel, sondern dasjenige erkennen, was zum richtigen Leben notwendig ist. Vor allem will sie ihre Erkenntnisziele verwirklichen. Deshalb ist es unumgänglich, daß sie sich in die Erkenntnistätigkeit der reinen Vernunft kritisch einmischt. Sie ist es, die ihr eine Norm geben muß, wenn Sinnerkenntnis erlangt werden soll. Und das heißt konkret: daß sie der reinen Vernunft zur Auflage macht, ihre Erkenntnis müsse etwas "wert" sein (Embl. 63f.) bzw. einen Sinn haben. Worin kann ein solcher Wert bestehen? Nach Rickert darin, nicht nur herauszufinden, was ist, sondern wie die Welt eigentlich sein soll. Das ist die Wahrheit, die wert ist, erkannt zu werden.

\section{"Wahre Erkenntnis ist nach Rickert Erkenntnis des Sein-Sollenden und Werthaften (Embl. 65)."}

Erkenntnis, die so ausgerichtet ist, kann aber nur in Gang kommen, wenn ein Glaube existiert, der fest verwurzelt ist in einem grundsätzlichen "Ja" zum Leben und zu seiner Verwandelbarkeit (Embl. 84, 99). Dem Erkennen ist also eine Norm vorgegeben, die ihr transzendent ist. Doch das Sein-Sollen der Welt ist nicht etwas schon Existentes oder Bekanntes, sondern ist dem Menschen aufgegeben zur Verwirklichung.

Als ein Sein, das noch nicht zur Existenz im Dasein gebracht ist, kann ihm ein rationaler oder dogmatischer Begriff nicht gerecht werden, sondern es handelt sich um eine Wirklichkeit (oder ein Sein), die nur symbolisch erfaßt werden kann. ${ }^{44)}$ Um die symbolische Wirklichkeit des Sein-Sollenden begreiflich zu machen, schlägt Belyj einen großen Bogen über die Geschichte: aus der altrussischen Bildtradition entlehnt er den zentralen ikonographischen Typus des "Spas Nerukotvornyj", griech. Acheiropoietos. Den modernen neukantianischen Grundgedanken einer zu erschaffenden Wertwelt verbindet er mit der früh-christlichen byzantinischen Vorstellung vom "Lik nerukotvornyj", dem

"Antlitz, nicht von Menschenhand geschaffen." (Embl. 79/133)

In ihm sieht er das SYMBOL der Symbole. Der alte christliche Glaube an die Gottebenbildlichkeit des Menschen findet darin modernen Ausdruck. Das im menschlichen Antlitz repräsentierte "Sein-Sollende" ist nach Belyj als aufgegebene Wirklichkeit und als 
höchster "Wert" zugleich Ziel wie auch Voraussetzung echter menschlicher Kreativität. Von diesem Ziel und Grund her angetrieben - so meint Belyj - kommt wieder eine Sinnorientierung in alle Lebensprozesse, und zwar sowohl in die Erkenntnistätigkeit wie auch in die verschiedenen Aktivitäten menschlichen Schaffens.

Um dies zu verdeutlichen, stellt er eine Pyramide von Erkenntnis- und Schaffensgebieten auf, in deren Mitte sich das Sein entfaltet: vom So-Sein zum Sein-Sollenden. Belyj ist der Meinung, daß ohne einen zugrundliegenden Lebens- und Verwandlungsglauben die Gefahren von Nihilismus, Agnostizismus und Skeptizismus nicht zu bannen seien (Embl. 112). Es gibt für ihn nur zwei Möglichkeiten: weiter abzusterben oder zu leben anzufangen (Embl. 83f.). Belyjs philosophische Begründung des Symbolismus als Theorie der Kreativität, die dem Menschen seine eigene Schöpferkraft in die Hand gibt, die Wirklichkeit und sich selbst zu erfahren und, ausgerichtet an einer tragfähigen Wertorientierung, zu verwandeln, steht und fällt mit dem Glauben an das "Geheimnis" der Individualität (Embl. 73). Die Krise des modernen Bewußtseins kann nach Belyj nur überwunden werden, wenn die Bedeutung des Individuums und die Notwendigkeit, daß es weiter wachsen müsse, anerkannt werden (Embl. 74).

Das gilt in zweierlei Hinsicht: die "Tiefe" des Lebens muß erfahren werden, soll sie gültig bejaht werden können; gleichzeitig muß auch das verpflichtende Sein einer höchsten werthaften Wirklichkeit erfahren werden. Aus dieser Spannung von Erleben und Norm lebt die entfaltete Individualität, die gegenwärtig noch unerreicht ist; das eigentliche Ziel von Erkenntnis und Schaffen sollte die "Ichwerdung" des entfalteten Individuums sein $(73,129 \mathrm{f}$.$) . In einer Weltanschauung, die aus den Grundgedanken des "Wertes" und$ der Individualität zu entwickeln wäre, sieht Belyj die umfassendste philosophische Legitimation für die "Neue Kunst" des Symbolismus. Von einer so begründeten Wertorientierung her kann ihr Sinn als religiöser Sinn definiert werden. Eine solche Sinn-Auffassung der Kunst würde jedoch ihrem eigenen Prinzip, dem Prinzip einer autonomen Form, keinen Eintrag bringen, denn ihr Ausdrucksprinzip bliebe unangetastet. Mehr noch: es wäre darüber hinaus gerade die Bedingung der Möglichkeit, daß sie an einer solchen Weltanschauung mitwirken könnte.

So sehr nun Belyj einerseits die Legitimation der Kunst - ihren Sinn - immer wieder aus der Philosophie herleitet, also das hervorhebt, was beiden gemeinsam ist, ebenso eindringlich beschäftigt er sich umgekehrt weiter damit, wodurch sich die Kunst von der Philosophie unterscheidet: er fragt danach, worin ihre eigenen Verfahren bestehen, die ihre Form ausmachen und auf denen ihre Autonomie gründet. Neue Aspekte dazu bringt er in seinem sprachphilosophischen Essay "Magie der Worte", den er gleichzeitig mit "Emblematik des Sinns" geschrieben hat. Wieder geht er von der Situation der modernen Kulturkrise aus und setzt sich mit einem ihrer Aspekte auseinander, mit der Krise der Sprache. Er legt hier zum ersten Mal seine Auffassung von der Sprache dar. ${ }^{46)}$

Er geht jetzt der Erkenntnis nach, daß die spezifischen Formen des Schöpferischen 
in der Dichtung nicht nur abhängig sind von der Individualität des Künstlers und von der historischen Situation, nicht nur von der Einwirkung etwa der beiden Nachbarkünste Musik und Malerei, sondern vor allem von den schöpferischen Qualitäten, die in der Sprache selbst liegen. Gegenüber der Sprachskepsis, die sich in Rußland mit Tjutčevs Vers artikulierte:

$$
\text { "Mysi' izrečennaja est' lož"', }
$$

vertritt Belyj die Uberzeugung von der lebendigen Schöpferkraft des Wortes, die trotz der Abgestorbenheit einer abgegriffenen oder begrifflich erstarrten Sprache immer erhalten bleibe. Er nimmt eindeutig Stellung gegen die moderne Sprachskepsis: 429)."

"Die Sprache ist das machtvollste Werkzeug des Schöpferischen (Magija

Das heißt aber nicht, daß er sie ignoriert; er gibt durchaus $z u$, daß in Krisenzeiten der Sprache, wie der Jahrhundertwende, als einziger Ausweg aus der Sprachverarmung nur noch der vom Mut der Verzweiflung eingegebene "barbarische" Umgang mit dem Wort bleiben kann, der zum "Kult des Wortes" führt (Magija 435), um mit ihm das "Leichengif t" der "verwesenden Worte" zu bekämpfen (Magija 436). 47) Die Sprache ist imstande, sich zu regenerieren: aus den Schichten des Unbewußten, aus dem musikalischen Klang und aus dem zweckfreien Spiel. Die schöpferischen Kräfte der Sprache, vor allem ihre metaphorische Leistung, ermöglichen ihre Erneuerung. Sie geschieht indessen nicht nur im Spiel, sondern auch im Kampf. Im Spiel mit der Sprache wird das Rüstzeug gewonnen, um den Kampf mit dem "Unbekannten", d. h. mit dem noch nicht Benannten aufzunehmen. ${ }^{48)}$ In diesem Kampf erneuert sich die Sprache (Magija 437). Mit der sprachschöpferischen Erneuerungsleistung, die aus Spiel und Kampf erreicht wird, kann die Dichtung auf eigene und unersetzbare Weise zum "Umschaffen" alter verfestigter Lebensformen beitragen (Magija 437). Denn die "Erschaffung" neuer Werte bedarf auch neuer lebendiger Worte. Belyj spricht von einem Laut- und Bild-Feuerwerk, in dem sich eine neve lebendige Sprache zuerst artikuliert, wenn es ihr gelingt, die Grenzen des bisher Sagbaren zu überschreiten (Magija 437).

Eine neue Sprache entsteht nach Belyj an der Grenze zwischen zwei Abgründen: der "wortlosen Seele" und dem "elementaren Leben", die von der Erkenntnis nicht überbrückt werden können. Auf dieser Grenze wird "eine neue Welt im Klang" erschaffen (Magija 438).

"Jede lebendige Rede, wenn sie sich nicht offen am Wortfeverwerk der Klänge und Bilder berauscht, ist nicht eine lebendige Rede, sondern eine Rede, die vom Leichengift durchsetzt ist (Magija 439)."

Die neue Rede ist nicht in erster Linie Kommunikation, sondern sie evoziert; sie ist weder da, um zu überzeugen, noch um zu beweisen, sondern zuerst um zu "beschwören". 
Wurden früher die Leere und Finsternis, die Unbenanntheit der Welt in Bildern des Mythos erhellt, so heute durch Terminologie, - doch das Bedürfnis nach lebendiger Rede regt sich im modernen Menschen trotzdem weiter:

"Wir sind - Halbtote, Halblebendige (Magija 440)."

Nachdem Belyj seine Sprachauffassung dargelegt hat (Teil 1), ${ }^{49)}$ untersucht er Prozesse der Sprachschöpfung unter der Fragestellung, was sie im Prozeß der schöpferischen Symbolisierung zu leisten vermögen (Teil II).

"Der ganze Prozeß der schöpferischen Symbolisierung ist schon in den Ausdrucksmitteln beschlossen, die der Sprache selbst immanent sind (Magija 440)."

Entscheidend ist die metaphorische Qualität der Sprache. Uber die Stufen des Epithetons, des Vergleichs, der Synekdoche, der Metonymie hinaus ist es die Metapher, die Bekanntes ersetzen und noch Unbekanntes benennen kann; geschieht das mit genügend evokativer Kraft, so kann die Metapher als Symbol aufgefaßt werden:

"Im letzten Falle erhalten wir ein Symbol, d. h. eine unzerlegbare Einheit; Ausdrucksmittel in diesem Sinne sind Mittel der Symbolisierung, d. h. einer primären schöpf $\$ 6 j$ jschen Tätigkeit, die vom Erkennen nicht zerlegt werden kann (Magija 446)."

Doch ist jede Metapher schon ein Symbol? Belyj zeigt, daß eine Metapher, die bisher Unbekanntes benennt oder "beschwört", an der Grenze steht zwischen poetischem Schaffen und Mythenschaffen. Ist das neue Bild mit genügend innerer Energie geschaffen, kann es zu einem Symbol-Mythos werden, das heißt zu einem Wort (oder einer Wortfolge), das als Symbol eine poetisch neu erschlossene Wirklichkeit repräsentiert, an deren "Existenz" geglaubt werden kann. Was also das Symbol nach Belyj von der Metapher unterscheidet, ist die Bildkraft (sila obraza). Worte, die als Symbol wirken sollen, die auch Glauben hervorrufen sollen an das, was sie ausdrücken, müssen aus dem ganzheitlichen Erleben und zugleich aus einem wertorientierten Schaffen hervorgehen, $d . h$. sie müssen den oben geschilderten Prozeß der "Uberdeterminierung" durchlaufen haben, der die Quelle der semantischen Polyvalenz des Symbols bildet (cf. oben S. 126). Belyj ist der Ansicht, daß Mythenschaffen in der Moderne nicht ausgestorben ist, sondern weiterlebt:

"unter Menschen, die mit Bewußtsein aufgehört haben, an Wissenschaften, Kunst und Philosophie zu glauben, die aber dennoch unbewußt in sich ein lebendiges Element des Schöpferischen bergen (Magija 447)."

Von solchen Menschen werden neugeschaffene moderne Symbol-Mythen verstanden werden, die für eine Realität stehen, die anders oder direkter nicht sagbar ist.

"Die reale Kraft des Schöpferischen ist mit Bewußtsein nicht zu ermessen; 
das Bewußtsein geht dem Schaffen immer hinterdrein; das Streben nach dem Verbinden von Worten und folglich zum Schaffen von Bildern, die aus der neuen Wortbildung hervorgehen, ist ein Anzeiger dafür, daß die Wurzel der schöpferischen Bejahung des Lebens lebendig ist, unabhängig davon, ob das Bewußtsein dieses Streben rechtfertigt oder nicht. Solche Bejahung der Schöpferkraft in den Worten ist eine religiöse Bejahung; sie ist es, dem Bewußtsein zum Trotz (Magija 448)."

Für die dritte Phase der Symbolisierung sind also zwei neue leitende Positionen hinzugekommen: Symbolisierung in der Dichtung ist einerseits Wertschöpfung, andererseits Sprachschöpfung. Neve Werte in der Kunst zu erschaffen, das erfordert - über die syntagmatischen Operationen der Neukombination "alltäglicher Worte" und des "freien Gruppierens von Elementen der Erscheinungswelt" hinaus - die Schöpfung neuer, lebendiger Worte. Auf der paradigmatischen Ebene wird Erweiterung des Bild- und Wortvorrats aus dem topisch vorgeprägten Reservoir der Tradition in Philosophie (Gnosis) und Malerei jetzt noch durch Gewinnung neuer Symbole aus der wortschöpferischen Aktivität des Künstlers ergänzt.

Der gemeinsame Nenner für die Methode der Symbolisierung in ihrer entfalteten Form als Wert-und Wortschöpfung liegt in der schöpferischen Bejahung des Lebens, in der der Symbolist nach Belyj sein "einziges Dogma" zu sehen hat. Deshalb heißt es am Ende von "Magie der Worte" nicht mehr (wie auf der Hälfte): "Wir sind - Halbtote, Halblebendige", sondern antiphonisch dazu als Ausklang: "Wir sind lebendig".

\section{Zusammenfassung:}

Uberblickt man im Zusammenhang noch einmal die Denkanstrengung Belyjs, mit der er sich darum bemühte, die "Methode der Symbolisierung" ästhetisch zu reflektieren und damit der modernen Kunst eine theoretische Basis zu verschaffen, so zeigt sich, daß er einen wesentlichen Beitrag zur Theorie des postrealistischen Symbols der Moderne geleistet hat. Und es zeigt sich auch, daß gerade der Doppelcharakter seiner Kunsttheorie, die innere Verbindung poetologischer Aussagen mit philosophischen oder weltanschaulichen Postulaten, Belyj zum Verständnis des Symbols der Moderne als schöpferischem Prozeß führte, der als "Modell der Erfahrung" eines hochdifferenzierten Subjekts Ästhetik, Ethik und Erkenntnistheorie, aber auch Kulturkritik und utopischen Entwurf in sich vereint. Symbolisierung erweist sich dabei als ein literarisches Verfahren, das nicht isoliert vor sich geht, sondern als besonderer Ausdruck einer Grundfunktion des schöpferischen Bewußtseins zur Symbolisierung verstanden wird. Symbolisierung ist daher gleichzeitig als eine Methode des Denkens, der Erkenntnis und der autonomen Wert- und Sprachschöpfung zu verstehen.

An die Stelle des "gestifteten" oder kollektiv verbindlichen Symbols der Tradition tritt in der Kunst der Moderne das erlebte Symbol, das gekennzeichnet ist von psychi- 
scher und formaler Dynamik, von ideeller und werthafter Orientierung, die aber fester Rückbindung an verpflichtende Weltmodelle, Denk- oder Wertsysteme entbehrt, und von prinzipieller Offenheit ist. Das postrealistische "offene" Symbol ist nicht mehr statisch, sondern als Prozeß zu verstehen. Es ist in den meisten Fällen nicht ein Bild vollendeter Harmonie, sondern enthält ein ausgeprägtes Konfliktpotential, das die Grenzen der Harmonieästhetik sprengt. Der "unendliche Bezug" geht dem Symbol der Moderne zwar nicht verloren, kann aber oft genug nur im Modus des Scheiterns Ausdruck finden. Statt als Bild der Harmonie, erscheint das postrealistische Symbol vielfach als Paradox oder Dissonanz.

In der Dichtung tritt das moderne Symbol vorwiegend in leitmotivischer Funktion auf. Sein semantisch polyvalentes Sinnpotential entfaltet sich seriell oder prozessual (symbolistische Dichtung tendiert daher zur Zyklisierung). Das postrealistische "offene" Symbol hat in diesem Sinne auch experimentellen Charakter. Es erscheint im russischen Symbolismus vorwiegend im thematischen Bereich autobiographischer Bekenntnisdichtung oder geschichtsphilosophischer Problemdichtung (die sich mischen können), wie sich an Beispielen von Blok (z. B. Gedichtzyklus "Schneemaske", Poeme "Vergeltung" und "Die Zwölf") und Belyj ("Vierte Symphonie. Pokal der Schneestürme" und Romantrilogie "Silberne Taube", "Petersburg", "Kotik Letaev") zeigen läßt.

Prozeßcharakter, Dynamik und Offenheit des modernen Symbols können nur zureichend verstanden werden aus den spezifischen Entstehungsbedingungen der Epoche, die in einem Prozeß von der "Nachahmung" zur Entdeckung der "Wirklichkeit" (W. Hofmann) die Neue Kunst des 20. Jahrhunderts heraufführten. Entstanden im Formenbruch der Moderne, entstanden in der Epoche der beginnenden Tiefenpsychologie und entstanden aus dem Bewußtsein der Kulturkrise - steht das moderne postrealistische Verfahren der Symbolisierung als autonome Wertschöpfung vor allem im engen Zusammenhang mit dem Prozeß der "Umwertung" bzw. der Suche nach neuen Werten.

Mit diesen Entstehungsbedingungen aus einer Zeit des geistigen, sozialen und kulturellen Umbruchs ist auch ganz eng der Legitimationsdruck Belyjs und sein daraus resultierendes Rechtfertigungsstreben zu verstehen. 


\section{KAPITEL}

\section{ZUR LEGITIMIERUNG DER KUNSTLERISCHEN SYMBOLISIERUNG}

\section{Theoretische Legitimation: Symbolisches Denken in Wissenschaften und Mathematik}

Während Belyj die Methode der Symbolisierung dichterisch erprobte und poetologisch reflektierte, blieb er ständig vom Bedürfnis nach Legitimation angetrieben. Daß dieser Zug bei Belyj besonders ausgeprägt ist und ihn als poeta doctus von anderen Varianten dieses Dichtertypus in der Moderne unterscheidet, wurde schon im Ersten Teil hervorgehoben. ${ }^{1)}$ Hier soll den verschiedenen Begründungsstrategien, die er aus seinem Legitimationsbedürfnis heraus entwickelte, genauer nachgefragt werden. Vor wem und warum wollte er sich immer wieder rechtfertigen? Belyj suchte nach Legitimation in verschiedenen Richtungen: einmal vor sich selbst und vor Gleichgesinnten seiner Epoche, ${ }^{2)}$ dann aber auch vor der Generation der "Väter". 3)

Das Problem der Rechtfertigung oder Legitimation ist nicht nur bei Belyj zu beobachten, sondern es gehört in den größeren Zusammenhang der Geschichte der Subjektivität seit der Aufklärung. Zum ersten Mal artikuliert in Rousseaus "Bekenntnissen", spielt es bis hin etwa zu Kafka in der Literatur eine wichtige Rolle. Es äußert sich auf der Ebene des Werkes in auktorialen Begründungsreden einerseits und in Leseranreden oder der Orientierung an einem mitfantasierten Leser andererseits. Das Bedürfnis nach Legitimation kommt aber nicht nur innerhalb von Kunstwerken zum Ausdruck, sondern auch außerhalb: in kunsttheoretischen Reflexionen, Tagebüchern, Briefen, Manifesten oder Kommentaren zum eigenen Werk oder zu der Kunstströmung, der man sich zurechnet. In diesem Kontext von Rechtfertigung der Subjektivität vor anderen durch Literatur sollte auch die Selbstwertproblematik und Bedürftigkeit nach Legitimation bei Belyj verstanden werden. ${ }^{4)}$

Was will Belyj eigentlich legitimieren? In seinem Streben nach Rechtfertigung ging es ihm vor allem darum, daß - vereinfachend gesagt - Symbolisierung in der modernen Kunst nicht als Marotte eines provozierenden Dandy oder als Entartung einer ganzen Generation von Exzentrikern abzutun sei, sondern daß hier eine "Neue Kunst" entsteht, die repräsentativ ist für ihre Epoche. Als Kronzeugen solcher Selbstvergewisserung versteht er Ibsen und Nietzsche. Darüber hinaus will er aber noch weiteres zeigen: daß es sich nämlich bei der künstlerischen Symbolisierung nicht nur um ein Verfahren der Kunst handelt, sondern um den Sonderfall einer grundlegenden Operation des schöpferischen Bewußtseins, die allem Schaffen zugrunde liegt: der Kunst ebenso wie der Philosophie, der Religion, den Wissenschaften und allen übrigen Kulturleistungen. ${ }^{5)}$

Belyj sieht in der Fähigkeit des schöpferischen Bewußtseins zur Symbolisierung nicht 
nur eine künstlerische Technik, sondern eine geistige Grundfunktion, die einen erkenntnistheoretischen, aber auch einen kommunikativen oder wirkungsästhetischen Aspekt hat. Sie ist einerseits eine besondere und eigenständige Form der Erkenntnis; sie ist darüber hinaus aber eine ebenso eigenständige Form der Wertschöpfung, die verwandelnde Wirkung auf die Kulturgemeinschaft entfalten kann. Mit der ersten These vertritt Belyj eine erkenntnistheoretische Konzeption, die nach ihm im Neukantianismus der Marburger Schule von Ernst Cassirer in seinem dreibändigen Werk "Philosophie der symbolischen Formen" (1923) als eine, Hegel weiterführende, umfassendere "Phänomenologie des Geistes" systematisch dargelegt wurde. ${ }^{6)}$ Während Cassirer aber auf dem Gebiet der Erkenntnistheorie verbleibt, ${ }^{7)}$ geht Belyj mit seiner zweiten These von der Symbolisierung als einer eigenen Form der Wertschöpfung auf das Gebiet der komplizierten Beziehungen zwischen Ästhetik und Ethik über. Er greift über die erkenntnistheoretische Fragestellung hinaus, indem er den kommunikativen Wert symbolischer Erkenntnis in der Kunst für die Erneuerung der Kultur fruchtbar zu machen sucht. Hierin ist er der Wertphilosophie der Südwestdeutschen Schule des Neukantianismus verpflichtet, vor allem Windelband und Rickert. - Als Kronzeugen, die den universalen Anspruch der schöpferischen Symbolisierung als einer geistigen Grundfunktion mit stützen sollen, zitiert Belyj außer den beiden Kulturphilosophen führende Naturwissenschaftler, Mathematiker, Religions- und Sprachphilosophen seiner Zeit. Sie zu versammeln, mit weiterführenden Literaturangaben vorzustellen und sich anhand ausgewählter Zitate mit ihnen auseinanderzusetzen, darin besteht die Hauptfunktion des gelehrten Apparates im Kommentar zu "Simvolizm", dessen Umfang fast ein Drittel des 600 Seiten starken Buches ausmacht. Man kann daraus schließen, daß Belyj nicht nur in seiner Dichtung, sondern auch in seiner Kunst theorie an einem produktiv mitvollziehenden oder weiterdenkenden Leser orientiert ist.

Wie bei der Analyse von Belyjs Methode der Symbolisierung schon gezeigt wurde, sieht Belyj Kunst nicht mehr im Rahmen einer Theorie der Schönen Künste, sondern im Rahmen einer Theorie des Schöpferischen. Er definiert Kunst als Kreativität, als schöpferischen Umgang mit den Elementen der Erscheinungswelt ebenso wie auch mit den Materialien der Gestaltung. Er kann Kunst deshalb auf neue Weise in Beziehung setzen zu anderen Formen schöpferischer Aneignung, Darstellung und Auslegung von Welt. Hierin geht er über den spätbürgerlichen Kunstbegriff hinaus und schafft theoretische Voraussetzungen für ein neues Kunstverständnis im 20. Jahrhundert.

Belyjs Bedürfnis nach Legitimation durch Theorie entstammte, ebenso wie die künstlerische Methode der Symbolisierung selbst, biografischen Zwängen, auf die er produktiv reagierte: nämlich einem induzierten Bedürfnis nach Theorie, nach Rechtfertigung durch Definitionen und Argumente, ${ }^{8)}$ das ihn antrieb, theoretische Legitimation für seine künstlerische Praxis und für den Absprung aus der naturwissenschaftlichen Karriere zu erbringen: 
"Schon zu dieser Zeit (1900) unterschied ich streng zwei Sphären: die Sphäre des Symbolismus als Theorie, die das Recht auf die schöpferische Symbolisierung legitimiert, und die Sphäre ihres Ausbauens (Symbolismus als Symbolisierung im Ethischen, Ästhetischen etc." (Nrds 466)

Das "Recht auf die schöpferische Symbolisierung" zu legitimieren, erschien ihm deshalb umso notwendiger, als seine eigene Dichtung keine Kunst im anerkannten Sinne war. Seine "Symphonien" stellten eine Innovation des Prosastils dar, von der zur Zeit seines Entstehens nicht abzusehen war, ob hier eine Entgleisung oder eine epochemachende Erneuerung vorlag. Belyj vollzog in seiner symphonischen Prosa eine provozierende Verletzung des ästhetischen Kanons; und in eben dieser Regelverletzung war ihr Charakter als novum begründet. Damit war er aber zu einem der poètes maudits geworden (cf. oben S. 54 - 56). Das scandalon seiner neuen Existenz als Dichter, mit der er sich in den Augen der liberal-konservativen "Väter" unmöglich machte, brachte trotz seiner Ablehnung dieser für ihn fragwürdigen Autoritäten einen starken Legitimationsdruck über ihn, der schwer auf ihm lastete. Sein Pseudonym konnte ihn davon nur notdürftig entlasten. Wenn er nicht nur vor sich und vor Gleichgesinnten bestehen wollte, sondern auch vor den "Autoritäten", dann mußte er seine "skandalöse" dichterische Praxis theoretisch legitimieren können. Nach solcher Legitimation suchte er in der Philosophie, er fand sie zunächst bei Solov'ev, Schopenhauer und Nietzsche. Doch das genügte ihm nicht, er brauchte weitere stichhaltige Legitimation auf dem Beweisfelde der "Väter", in den exakten Wissenschaften und in der Erkenntnistheorie.

Als Hauptadressaten seiner theoretischen Rechtfertigung darf man wohl seinen Vater ansehen. ${ }^{9)}$ Er starb zwar schon im Jahre 1903. Doch die Verpflichtung, sich ihm gegenüber als gleichrangig auszuweisen, blieb über den Tod hinaus bestehen. Wie schon gesagt wurde (cf. oben S. 81 , bes. Anm. 56), gehörte N. V. Bugaev zu denjenigen Mathematikern seiner Zeit, die europäische Geltung erreicht hatten. Er hatte sich dazu aus kleinsten Verhältnissen unter Entbehrungen hocharbeiten müssen ${ }^{10}$ ) und nun in seinen einzigen Sohn die höchsten Erwartungen gesetzt. Aus ihm sollte etwas Bedeutendes werden, und zwar in den exakten Wissenschaften. Belyj wußte das. Mehr noch: Er achtete seinen Vater trotz vieler Vorbehalte sehr hoch und wollte ihn nicht enttäuschen. 11) Ebensowenig konnte er aber seinen Anspruch auf Eigenheit aufgeben. Als nun die hochgespannten Erwartungen des Vaters durch die Künstlerexistenz des Sohnes in Frage gestellt wurden, versuchte Belyj wenigstens seine Abtrünnigkeit zu rechtfertigen. Es kam ihm darauf an, sie als etwas zwar anderes, aber Gleichwertiges ausweisen zu können. ${ }^{12)}$ Aufgrund dieser biografisch bedingten Motivierung und seiner exponierten Position $z$ wischen Wissenschaft, Philosophie und poetischem Experiment entwickelte Belyj einen Weitblick, der ihn die Beziehung des Symbolismus in der Kunst zum "symbolischen Denken in den exakten Wissenschaften, in Mathematik und Philosophie" erkennen ließ. 12a)

Wenn Belyj von "symbolischem" Denken in den außerkünstlerischen Bereichen 
spricht, dann ist das in einem sehr weitgefaßten Sinne zu verstehen. Er meint damit die grundsätzliche Fähigkeit des menschlichen Bewußtseins, die Welt als Bedeutungszusammenhang aufzufassen und in Modellen darzustellen. Er spricht von der "teleologischen" Tendenz des Bewußtseins, Ordnungsgefüge zu erschaffen. In dem, was Belyj hier "teleologische" Tendenz nennt, ist unschwer die Einheit des transzendentalen Bewußtseins zu erkennen, die schon Kant als oberstes Prinzip der Bewußtseinstätigkeit ansah. ${ }^{13)}$ Belyj versteht aber darunter nicht nur wie Kant die intellektuelle Synthesis physikalischer und mathematischer Systeme, die vom logischen Begriffsdenken entworfen werden, sondern auch sprachliche, mythologische und vor allem eben künstlerische Modellzusammenhänge, die das menschliche Bewußtsein in seiner Geschichte bisher entworfen hat und weiter hervorbringen wird. Hierin geht er über Kant hinaus und kann als Vorläufer des erkenntnistheoretischen Symbolismus Ernst Cassirers gelten. So sieht er in der Newtonschen Mechanik, in der Euklidischen Geometrie, der Sprache überhaupt, in den mythischen Weltdeutungen, in den Religionen und in der Kunst je verschiedene Modelle des schöpferischen Bewußtseins, die Welt in Bedeutungszusammenhängen darzustellen. In diesem Spektrum produktiver Kulturleistungen ist nach Belyj die Kunst als eine eigene Modellierweise mit besonderen Formprinzipien, Wertorientierungen und mit einer ganz besonderen Wirkungsweise des "subjektiven Faktors" zu verstehen. 14

Die Begriffe oder Bilder dieser verschiedenen Modelle haben nach Belyj nicht den Charakter absoluter Wahrheiten - das wäre Dogmatismus, den er bekämpft, sondern sie haben "emblematischen Charakter". Sie enthalten eine Wahrheit, deren Geltung nicht ohne weiteres auf andere oder alle Bereiche ausgedehnt werden darf. Diese Teilwahrheiten sind aber deshalb nicht als relativ oder unverbindlich anzusehen, sondern als Bausteine zu einer "Emblematik des Sinns", einer Aufgabe, an der das schöpferische Bewußtsein weiterarbeiten muß. ${ }^{15)}$ Von dieser Position des Kritizismus aus verfolgt Belyj die Diskussion um die Probleme der wissenschaftlichen Begriffsbildung und der theoretischen Darstellung in den Naturwissenschaften. Was inn daran im Zuge seines Strebens nach theoretischer Legitimation interessiert, ist der symbolische Anteil.

Besonders umstritten war zu seiner Zeit der Begriff der "Materie". Am Kommentar zu "Formy" läßt sich ablesen, wie weit Belyj in die Probleme des "Materialismusstreites" eingedrungen ist. ${ }^{16)}$ Hier zeigt sich wieder seine besondere Eigenart als poeta doctus des russischen Symbolismus: Während er sich um Legitimierung seiner theoretischen Position bemühte, verfolgte er ebenso aufmerksam den Umbruch des physikalischen Weltbildes mit dem Wandel von der Abbild- zur Modelltheorie wie auch den vielberedeten Zusammenbruch des Deutschen Idealismus mit dem Wandel vom Intellektualismus der spekulativen Philosophie Hegels zur Lebensphilosophie; mit besonderem Interesse aber beobachtete er - trotz seiner Nietzsche-Begeisterung - das Erstarken des Neukantianismus (Komm. 511). Was nun die Materialismusdebatte angeht, so hatte mit der Entdeckung der thermodynamischen Energiesätze die Auffassung von der "Materie" eine Umwälzung erfah- 
ren. ${ }^{17)}$ Mit dem Energiekonzept war der Ubergang von einer Physik der Masse zur Feldphysik eingeleitet, der von Maxwell und Hertz mit der Entdeckung der Elektrodynamik vollzogen wurde.

Gleichzeitig mit diesen Entdeckungen begannen sich Naturwissenschaftler, vor allem Helmholtz und Hertz, die Frage zu stellen, ob die physikalischen Termini eigentlich Abbilder bestimmter Substanzen selen, oder ob es sich bei Ausdrücken wie "Ursache" oder "Kraft", die zur Definition der Materie verwendet wurden, nicht eher um Modellbegriffe handele, um selbstgeschaffene intellektuelle Symbole, die nicht in direkter Abbildung, sondern in Analogie zur Erfahrung gebildet werden. ${ }^{18)}$ Das war eine Alternative, die Belyj aufhorchen lassen mußte. Denn die Frage nach Abbildung oder Modell kam ihm umso bekannter vor, als er hier im Kern die gleiche Frage auftauchen sah, die sich auch in einer postrealistischen Ästhetik stellte: nämlich statt Abbilder vorhandener Wirklichkeit zu geben, schöpferisch konstellierte Modelle erlebter Wirklichkeit zu erschaffen. Gerade darin bestand ja die Methode der künstlerischen Symbolisierung nach Belyj. Er verfolgte deshalb die Abbild-Modell-Kontroverse ziemlich genau. Denn hier trifft er unerwartet auf Parteigänger im fremden Lager, auf "Symbolisten" unter den exakten Naturwissenschaftlern. Das war etwas, was er gesucht hatte. Das war eine Entdeckung, die ihm zu neuen Begründungslinien verhalf.

Er steht natürlich auf dem Standpunkt der Kantanhänger. Von diesem Standpunkt aus referiert er die damalige Materie-Diskussion von Schopenhauer bis zu dem ersten bedeutenden Neukantianer F. A. Lange. Langes "Geschichte des Materialismus und Kritik seiner Bedeutung für die Gegenwart" (1865) hält er für besonders wichtig; nach Belyj weist L. die "Bedingtheit der wissenschaftlichen Begriffe von Atom, Molekül, Kraft" nach und kommt zu dem Schluß, das Problem der Materie selbst sei als ein Problem der Erkenntnistheorie zu betrachten (Komm. 511)."19) Belyj zeigt, daß Lange auf Kants "Kritik der reinen Vernunft" basiert, in der von solchen Begriffen schon als von "Analogien der Erfahrung" gesprochen wird (Komm. 511). 20)

Belyj kennt sich aber eben nicht nur in der neukantianischen Literatur aus, sondern er begreift auch die motivierende Rolle, die die Uberlegungen der Naturwissenschaftler für das Aufkommen des Neukantianismus haben. ${ }^{21)}$ Er zitiert Helmholtz, Hertz und Maxwell (Komm. $470 \mathrm{f}$.). Als die beiden Hauptleistungen von Helmholtz hebt er hervor: 1) seine allgemein wissenschaftliche Formulierung des ersten Energiesatzes (Komm. 470); 2) die Bedeutung seiner Zeichentheorie (Komm. 536 f.). Auf die Zeichentheorie, deren Bedeutung er schon damals erkannte, kommt er im Rahmen seiner Uberlegungen zum Symbolismus in der modernen Mathematik zu sprechen, wovon noch die Rede sein wird. Mit der Aufstellung des Gesetzes von der Erhaltung der Energie und ihrer Transformierbarkeit (1847) hat die Diskussion um die Materie eine Wendung angenommen, die In die folgenreiche Bewegung des "Energetismus" führte. ${ }^{22)}$ Der Energie-Begriff gehört seit Helmholiz zu den naturwissenschaftlichen Theoremen, die in den Geisteswissenschaften 
Karriere machten. (Das gilt noch mehr als für den ersten Hauptsatz für den zweiten, der den Begriff der "Entropie" in Umlauf brachte.) ${ }^{23)}$ Nicht nur Belyj sah in dem Begriff der Energie eine Möglichkeit, vom Energiedenken her zu einer "Theorie des Transformismus" zu kommen, die die auseinandergefallenen Bereiche von Kultur, Geist und Natur wieder zueinander in Beziehung setzen könnte. Mit dem energetischen Prinzip schien - weit über Belyj hinaus - für die Epoche ein modernes Zauberwort gefunden zu sein, das eine ganze Flut von Deutungsversuchen nach sich zog. ${ }^{24)}$ Dennoch unterscheidet sich Belyj von den meisten von ihnen dadurch, daß er unter "Energie" keine ontologische Größe verstand, sondern ein Emblem, das nicht mehr als symbolische Bedeutung hat, das aber zur Beschreibung schöpferischer Prozesse in der Kunst angewendet werden kann (Komm. 532).

Eine zweite Begründungslinie in der theoretischen Legitimation Belyjs führt zum Symbolismus in der Mathematik. An der Entwicklung von der Euklidischen zur NichtEuklidischen Geometrie zeigt sich ebenso wie beim Ubergang vom Zahlenkontinuum zum Mengen-Rechnen, daß die Mathematik sich durch den Entwurf neuer Symbolsysteme weiterentwickelt. Belyj zitiert dazu u. a. den französischen Mathematiker Henri Poincaré (1845 - 1917), einen der führenden mathematischen Denker der Jahrhundertwende, dessen glänzend geschriebenes Hauptwerk "Wissenschaft und Hypothese" schnell weite Verbreitung fand.

"Aber auch unabhängig von den Bedingungen des theoretischen Denkens kamen Gelehrte unserer Zeit zu einem bedingten Verständnis der physikalischen und mechanischen Grundbegriffe. So schreibt Poincaré in "Wissenschaft und Hypothese": 'Man kann sagen, daß der Geist die Fähigkeit hat, Symbole zu schaffen; dank dieser Fähigkeit hat er das mathematische Kontinuum konstruiert, das nur ein besonderes System von Symbolen darstellt (...)' Und weiter: 'Wir sehen uns genötigt, immer kompliziertere Symbolsysteme zu erdenken (...)' So ist also die Konstruktion von Begriffen, die mit der Materie verbunden sind, entweder vorherbestimmt durch die Erkenntnistätigkeit - und hat daher logische Gesetzmäßigkeit (Standpunkt des Idealismus), oder die Konstruktion dieser Theorien für die Erfahrungsauslegung führt zu einer rein schöpferischen Tätigkeit - zur Imagination (voobraženie) (Gesichtspunkt des Emblematismus und des Symbolismus); die Gelehrten neigen 939 hr zum zweiten Gesichtspunkt; die Philosophen - zum ersten (Komm. 511 f.)" 257

Im Zusammenhang mit den neuen Symbolsystemen der Mathematik wird auch Helmholtz noch einmal zitiert. Belyj kannte seine Schriften - er zitiert ihn auch in anderen Zusammenhängen ( $c f$. oben S. 81 , Anm. 60) -, vor allem seine Auffassung, daß man zu Gesetzmäßigkeiten in den Wissenschaften nur kommen könne, wenn an die Stelle der konkreten Data "symbolische Vorstellungen" gesetzt werden. Er schreibt:

"Nach Helmholtz muß man zwei Reihen von Wahrheiten unterscheiden: Eine Art der Wahrheit ist die Ubereinstimmung mit der Wirklichkeit; die andere Art der Wahrheit ist die Vorstellung von ihr, als von einem logischen Prozeß, der keine Widersprüche in sich schließt; die Grundlage der Wahrheit kann in einem solchen Falle hypothetisch sein; zur ersten Art von Wahrheiten rechnet Helmholtz die Wahrheiten der Euklidischen Geometrie: der zweiten Art von 
Wahrheiten sind die Wahrheiten der sphärischen Geometrie zuzurechnen. Die Wahrheit definiert Lewes (Voprosy Žizni i ducha IǏ̌., russkij perevod) als die Gleichung ihrer Glieder; wenn den letzteren objektive Realitäten zugrunde liegen, drückt die Gleichung eine reale Wahrheit aus; wenn die Glieder der Gleichung Symbole sind, dann trägt die Wahrheit symbolischen Charakter (Komm. 537)".

Belyj hat die Weiterführung des semiotischen Ansatzes von Helmholtz, bei Hertz und Cassirer z. B., nicht gekannt. Deshalb ist es vielleicht aufschlußreich, seine Ansicht über den symbolischen Charakter und über die Abhängigkeit jeweils gefundener Wahrheiten von der angewendeten Methode anzuführen, mit der er über Helmholtz hinausgeht. Während dieser immerhin noch die Möglichkeit einer prästabilierten Harmonie zwischen Modell und Wirklichkeit zugibt, geht Belyj ganz auf den erkenntniskritischen Standpunkt der "Emblematik" über:

"Wir fügen hinzu, daß eine reale Wahrheit eine solche bleibt bis zur Kritik der Grundlegungen aller Realität; die Kritik der Grundlegungen der Wirklichkeit verleiht eben den realen Wahrheiten symbolischen Charakter; alle Aspekte der Wahrheit - sind Symbole; das was gewissen Arten von Wahrheiten realen Charakter verleiht, das ist die Methode, mit der wir eine der symbolischen Wirklichkeiten als real aufstellen und nicht als symbolisch; sobald wir die Methode wechseln und mithilfe einer neuen Methode zu neuen realen Wahrheiten kommen, stehen die ehemaligen Wahrheiten in aller ihrer Beding theit vor uns. Jede reale Wahrheit ist Dogma; am Grunde jedes Dogma aber liegt ein Symbol; und deshalb tragen die Wahrheiten jeder Geometrie unausweichlich symbolischen Charakter (Komm. 537)."

Bei den Uberlegungen zum symbolischen Charakter der Mathematik spielt für Belyj nicht nur die Einsicht eine Rolle, daß auch hier eine Form der Symbolisierung zugrunde liegt, sondern er greift außerdem einen alten Gedankengang auf, der in der Philosophie seit Platon über Leibniz bis hin in die moderne Philosophie der Mathematik immer wieder reflektiert wurde: nämlich die Analogie von Mathematik und Musik (cf. oben S. 117). Beide haben gemeinsam, daß sie Schöpfungen der ars combinatoria ${ }^{26)}$ sind; daß die Harmonien der Musik nicht nur Ausdruck innerer Gefühlsbewegung sind, sondern daß sie auf einfache Zahlenverhältnisse zurückgeführt werden können (Formy 152, Komm. 516 - 519). Schon in "Formen der Kunst" sagt Belyj:

"Die Musik ist die Mathematik der Seele, und die Mathematik - das ist die Musik des Geistes." (Formy 152)

Damit geht er zurück auf Leibniz, der Ähnliches sagte:

"Die Musik ist eine geheime und unbewußte Ubung der Seele in der Arithmetik (Komm. 516)."

Diese Betrachtung der Musik mit dem Auge des mathematischen Denkers findet er in der Moderne wieder bei Euler und bei Helmholtz, der in seinen Forschungen zur Aku- 
stik eine Wellentheorie der Musik begründete:

"Der Eindruck eines musikalischen Akkordes wird grafisch zerlegt wie die Summe einfacher und komplizierter Wellen in Elementarwellen; so ergibt sich die Möglichkeit, in Maß und Zahl eine uns bezaubernde Melodie genau auszudrücken" (Komm. 517).

Das Besondere an der Musik ist aber, daß sie gleichzeitig mit dieser mathematisch meßbaren Struktur nicht nur eine besondere Form der Kunst ist, sondern daß in ihr von jeher der innere Bezug von individuellem Erleben und Weltzusammenhang erahnt wurde, wie in keinem anderen Medium des menschlichen Schaffens sonst. Auch Belyj betrachtet die Musik - wie Nietzsche und Blok - nicht allein als Kunstform (cf. oben S. 117), sondern als Offenbarung "des inneren Wesens des Seins selbst" (Komm. 517f.). Doch ist er sich dabei bewußt, daß "Musik" in diesem Verständnis emblematischen Charakter trage, als Emblem für eine ontologische Aussage (ebenso wie die "Energie", von der vorher die Rede war). Den "Geist der Musik" versteht Belyj als Emblem für die schöpferische Spannung zwischen dem ordnenden Grundvermögen des Bewußtseins zur Symbolisierung (in dem Musik und Mathematik miteinander verwandt sind) und dem bild- und ordnungsfremden inneren Erleben bewußtseinsferner Schichten (worin Musik und Mathematik einander diametral entgegengesetzt wird; denn in dieser zweiten Hinsicht ist Musik Ausdruck des Elementaren, dessen Wesenprinzip sich im Rhythmus äußert).

Diese schöpferische Grundspannung, der im kulturphilosophischen Emblem vom "Geist der Musik" von Nietzsche Ausdruck verliehen wurde, sieht Belyj wie auch Blok in Zeiten großer Kultur, wie der griechischen, mit tragischer Risikobereitschaft ausgehalten. In der modernen Kultur beklagt er, daß sie vom Zerbrechen in die beiden abgetrennten Hälf ten von Hirn und Trieb bedroht sei (cf. oben S. 73ff.).

Im Drehpunkt der "Schere", die in die beiden Extremrichtungen auseinandergespannt ist, sieht Belyj sich und seine Generation, die "Kinder der Grenzscheide", mit ihrer "Neuen Kunst" der Symbolisierung gestellt. Ging es in der Legitimation vor den Vätern darum, vor allem die theoretische Basis dafür zu finden, so ging es ihm in der Rechtfertigung vor sich selbst und den Peers seiner Generation darum, sich mit seiner Erlebnisstruktur als repräsentativ im Sinne der Epoche zu erweisen. Ist der Tenor seiner Rechtfertigung vor den "Vätern" davon bestimmt, daß er ausruft: So etwas, was wir Symbolisten tun, das darf man. Das erlaubt Euch nicht, uns der Willkür, Entartung, der Krankhaftigkeit zu bezichtigen, denn auf dieser Form, auf Symbolisierung, beruhen alle großen Leistungen der Wissenschaft, Mathematik und Philosophie. Rechtfertigt er in diesem Strang seiner Begründungsstrategie also vor allen Dingen das Recht auf das Erbauen von Modellen der ästhetischen Erfahrung, so geht es ihm im zweiten Hauptstrang seiner Rechtfertigung um die Relevanz dieser Erfahrungen selbst.

Auch hier schreit und proklamiert er fortwährend, eigentlich bis an sein Lebensende: Wir, die Beschädigten und Zerrissenen, das "Gefecht zwischen den Jahrhunderten" (Nrds 
167), die sich nicht anpassen wollen, die sich aber auch nicht aufgeben, wir, die Kellerlochmenschen der Jahrhundertwende, die nach der Sonne greifen und ein neues anderes Leben verkünden, wir, die fatalen und dennoch entschlossenen "Probemenschen" der Kulturkrise, machen eine "Neue Kunst", zu den ehrlichsten Bedingungen, die es gibt, nämlich zu unseren eigenen. Wir stellen uns ihnen, obwohl nicht wir es sind, die sie geschaffen haben. Und darin tun wir nichts anderes als das, was die Größten vor uns, was Nietzsche und lbsen schon begonnen haben.

\section{Existentielle Legitimation: Ibsen und Nietzsche als Prototypen des Symbolisten in der Moderne}

Will man also die Fragestellung nach den Begründungslinien der Legitimation Belyjs nicht nur in ihrem theoretischen Aspekt verfolgen, unter dem er sich erkenntnistheoretisch fundierte Rechtfertigung für die Methode der Symbolisierung verschaffte, sondern will man die oben schon aufgeworfene Frage nach Rechtfertigung vor sich selbst und Gleichgesinnten seiner Generation weiterverfolgen, dann zeichnen sich hier zwei Stufen ab, die nacheinander mit der Entdeckung Ibsens und Nietzsches als Prototypen eines modernen, postrealistischen Symbolismus verbunden sind. Wenn Belyj nämlich Beispiele für seine Methode der Symboiisierung zitiert - was er im übrigen im Gang der Argumentation selten tut, worin man einen Mangel seiner theoretischen Schriften empfindet dam sind es nicht so sehr die französischen Symbolisten, sondern Henrik Ibsen in der Dichtung und Friedrich Nietzsche in der Philosophie. ${ }^{27)}$ Fragt man sich, warum gerade sie immer wieder aufgeführt werden und darüber hinaus in mehreren Aufsätzen ${ }^{28)}$ eingehend untersucht, dann kann man darin die Absicht erkennen, sie als Kronzeugen für die Relevanz der eigenen prekären Erfahrungsstruktur darzustellen, die sich im Lichte ihrer Problematik nicht mehr als individuell-zufällig, sondern als epochen-typisch verstehen läßt. Im folgenden soll kurz die Begegnung mit beiden an Wendepunkten von Belyjs Entwicklung dargestellt werden: in der Pubertät bereits mit Ibsen und zu Beginn seiner Schriftstellerexistenz mit Nietzsche. Danach soll einiges zur Bedeutung gesagt werden, die jeder von beiden für Belyjs Formierung als Dichter und Theoretiker des russischen Symbolismus gehabt hat. Dabei wird sich zeigen, daß es neben der theoretischen Legitimation vor den "Vätern" eine psychologische oder existentielle Begründungslinie der Rechtfertigung vor sich selbst und vor Gleichgesinnten seiner Epoche gibt.

Ist die Begegnung mit Nietzsche eng verbunden mit dem Problem und der Methode der "Schere", so steht die Entdeckung lbsens im Zusammenhang mit dem Komplex der Rebellion. Ibsen begegnete Belyj früher als Nietzsche. Er ist die geistige Entdeckung und Befreiung seiner Pubertät; mit Ibsen geschah seine Initiation in die moderne Kultur. Seine Bedeutung für Belyj ist nicht ohne Rückgriff auf die biografische Situation zu verstehen; was wir darüber wissen, ist Belyjs eigene Version, die er in seinen Memoiren 
unter dem Titel "Der Kampf um die Kultur" (Nrds 325 - 339) gibt:

Belyj ist an einen Punkt seiner Entwicklung gekommen, da ihn die als nutzlos empfundene Gymnasialbildung sowie die Verbote, von denen er zuhause umstellt ist, derart frustrieren, daß er einen Ausbruch nicht mehr verhindern kann, obwohl er ihn in Gewissenskonflikte stürzt, die so tiefgreifend waren, daß er sich mit ihnen offenbar bis zu seinem Lebensende auseinandersetzen mußte. Das Trauma der "Ubertretung" (prestuplenie) bildet eine Konfliktkonstante, die die Werkstruktur seiner Romane bis in die Spätzeit des "Moskau-Zyklus" ebenso bestimmt wie die Legitimationsstrategie seiner Memoiren der dreißiger Jahre. ${ }^{29)}$ Die Wurzel dieses Konfliktes reicht zurück bis ins 15. Lebensjahr, als der Zögling Bugaev versuchen will, sich eine "eigene Bildung" zu verschaffen. Frustriert von der Dürre des "humanistischen" Lehrstoffes, aber zum Lesen der Klassiker animiert durch den begeisternden Pädagogen L. J. Polivanov, Leiter des berühmten gleichnamigen Moskauer Gymnasiums der Jahrhundertwende (Nrds 292 ff.), suchte er vergebens nach Lektüre: Vom Vater zurückgescheucht an die Schulaufgaben, von der Mutter zurückgewiesen, aus Angst, er könne ihr die kostbaren Einbände ihrer belletristischen Bücher verderben, wird er zum Bücherdieb und klaut sich, wo und was er kriegen kann; zuerst bei Vater und Mutter, immer mit schlechtem Gewissen und der Angst davor, daß sein brennendes Interesse überhaupt bekannt wurde; denn er hatte die bittere Erfahrung gemacht, daß ihm Lieblingsdinge, wie Märchen und Musik anhören oder lesen lernen, sobald er sie zeigte, todsicher von einem der Eltern, die das neve Interesse sofort als Streitpunkt ausnützten, verboten wurden. Er konnte es dann nur noch entweder heimlich, mit schlechtem Gewissen, oder gar nicht mehr tun. ${ }^{30)}$ Ein offenes Gespräch war bei den seit Jahren herrschenden Spannungen ausgeschlossen. Als er zuhause alles ausgelesen hat, begibt er sich eines Tages vom Schulweg ab in den Ostrovskij-Lesesaal. Zuerst nur, um den Katalog zu mustern. Doch aus der einen Stunde werden sechs. Er gerät in einen derartigen Leserausch, daß er auch am nächsten Tag fasziniert in den Lesesaal zurückkehrt, die Schule schwänzt - dazu angestiftet im Grunde genommen vom Direktor, von Polivanov selbst:

"Die Leidenschaft, die von ihm angefacht wurde, - ist das lebendige Wort in allen seinen Erscheinungsformen: Poesie, Kunstprosa wirkten elektrisch; Probleme, die mit Ästhetik zusammenhingen, bis hin zur Philosophie der Kunst schienen mir in meiner eigenen Natur angelegt zu sein, mir von ihm in mir entdeckt." (Nrds 327)

Wahllos liest er die russischen und europäischen Klassiker, liest Hegels und Schopenhauers Ästhetik, mit der allergrößten Spannung jedoch die Modernen: Hauptmann und Sudermann, Sologub und Gippius - vor allem aber lbsen:

"Ich schlug das Buch auf: mein Untergang. Ibsen schlug ein in mich wie eine Bombe." (Nrds 330) 
Die versäumten Schultage belaufen sich schließlich auf zwei Wochen, er fälscht Entschuldigungen, wobei ihn brennende Scham quält; er bleibt insgesamt fünfzig Tage weg (Nrds 330). Er weiß, er hat die Grenze des Erlaubten überschritten und - nicht nur das: $\mathrm{Er}$ hat sich nicht nur eine einmalige Abweichung zuschulden kommen lassen, sondern eine "Ubertretung" in eine neues, verbotenes Terrain, von dem er nicht mehr wieder zurückkehren wird. Wenngleich er natürlich wieder in die Schule zurückmuß - Vater und Lehrer reagieren milde, der eine kummervoll, der andere mit insgeheimem Verständnis bleibt das Schuldgefühl. Es bleibt aber auch der Kain-Trotz der Rebellion. Eine Mischung, die ihm im Grunde schon seit früher Kindheit bekannt war. Neu ist der Kain-Komplex. Er schreibt später dazu:

"Ich wurde zum Symbolisten um den Preis des Mordes an Abel; 'Abel' - das ist die Reinheit des Gewissens in mir; fünfzig Tage, die mich nun von mir abgetrennt hatten; und zwanzig Monate danach quälte sich Kain, der Mörder des Gewissens, mit Trübsal und Furcht; aber wenn man ihm vorgeschlagen hätte, diese Erfahrung mit dem 'Verrat' noch einmal zu machen, so hätte er sie, mit doppeltem Entsetzen, wiederholt, denn im Austausch für die Reinheit der Gewänder hatte er die Kultur empfangen: denn Kain, nicht Abel - ist ihr Schöpfer." (Nrds 331)

An Ibsen wurde ihm deutlich, daß die "schöpferische Symbolisierung", die bei ihm schon als Kindheitsmuster entstanden war, ${ }^{31)}$ nicht nur die Seite des Spielerischen hat, sondern daß sie Kampf bedeutet: den Kampf des Menschen um Verwirklichung eines Ideals in den Bedingungen der Empirie des Milieus, aber auch gegen seine Widerstände und fragwürdig gewordenen Autoritäten. Dieser Kampf fordert seinen Preis: die Bereitschaft zum "Verrat" und zum Schuldigwerden in den Beurteilungsnormen der alten Werte. Ein Detail dieser Entdeckung ist vielleicht sprechender dafür als manches andere, wie elementar ihn Ibsen ergriff. Lange nämlich geht er damals mit der Fantasie um

"heimlich nach Norwegen zu entlaufen und es zu schaffen, daß er im Hause Ibsens als Kammerdiener aufgenommen würde." (Nrds 331)

Seit der Begegnung mit Ibsen ist ihm klar geworden, daß der Symbolismus für ihn eine moderne Kampfideologie werden müsse, mit Beweisen, Methoden und eigenen Ideen. Er spricht seitdem von der "gepanzerten Faust des Symbolismus" (Nrds 185, 319, 395 ). Mit Ibsen - wie auch mit Nietzsche - beschäftigt sich Belyj das ganze erste Jahrzehnt weiter, besonders ab 1905. Er sieht inn im Zeichen des Kämpfers, dessen Ernst und Präzision er bewundert, und des Künstler-Technikers, als "Ingenieur des Chaos der Seele" (Arab. 96 f.), dessen Dramenhelden Menschen der Tat seien. Er grenzt ihn gegen Dostojevskij ab (Arab. 91 - 96) und gegen eine zeitgenössische Apokalypse-Süchtigkeit in Rußland, die sich in endlosen Reden und "Kneipen-Mystik" erschöpfe (Arab. 100). Dagegen stellt er die finstere und schweigende Entschlossenheit Ibsens, den "Aufstieg ins Gebirge" (Arab. 97) und die "Wissenschaft vom Bergsteigen" (Arab. 100). Im Nekrolog auf Ibsen 
1906 wird die Identifizierung, die Belyj zwischen sich, seiner Generation und Ibsen herstellt, ganz deutlich. Ihm wird Verehrung im unübersehbaren Stil des Führerkults dargebracht, der Selbsterhöhung des Verehrenden einschließt. Denn Belyj ehrt ihn als einen Helden besonderer Art; als Freiheitskämpfer, als einen der größten Anarchisten auf den "Ruinen der Kultur" (Arab. 282), der "die Pflicht im Namen der Freiheit" auf sich genommen habe. ${ }^{32)}$. Die Bewußtseinslandschaft seiner Generation - Belyj spricht immer von "wir" -, die Ibsens Vermächtnis annimmt, faßt Belyj von jetzt an in die heroische Metaphorik des Hochgebirges, die ab 1906 zur festen Topik seines dichterischen und kunsttheoretischen Werkes wird. Wo sie auftaucht, ist Ibsen mit zu assoziieren. ${ }^{33)}$ Denn Ibsen ist ihm das anscheinend überzeugendste Beispiel eines modernen Symbolisten, dessen Kunst der "Krise des Bewußtseins" Paradoxe aufgebe. Seine Dramen verbinden Realismus und Idee, jedoch derart, daß in seinen Allegorien darüber hinaus Symbole aufscheinen von "unausgesprochenen Ahnungen und Gefahren, die uns auflauern" (Arab. 283). In Ibsen sieht er den ersten modernen Dramatiker, der nicht mehr "Menschen im Futteral" darstelle (Arab. 186), sondern Menschen der Tat, die es zerschlagen und - wenngleich erst auf der Bühne - das "Recht der Persönlichkeit" verfechten, und zwar mit allen ihren Widersprüchen:

"Diese Widersprüche (...) bilden in der Persönlichkeit ein hochkompliziertes Labyrinth von Lebensbezügen (...). Ibsen gab als erster unter den Dramatikern die tatsächliche Kompliziertheit der Bezüge wieder; seine revolutionäre Tätigkeit bestand darin, daß er uns die methodologischen Brillen herunterriß." (Arab. 186)

Dieser Kompliziertheit der Erlebnisstruktur entspreche die formale Gekonntheit der Ibsenschen Dramen und die Kompliziertheit der symbolischen Struktur (Arab. 189 - 192). Mit Ibsen legitimiert Belyj vor allem das Recht des modernen Künstlers darauf, "Probemenschen" der Kulturkrise darzustellen, die wie lbsens Helden

"nicht standhalten vor den von ihnen selbst hervorgerufenen Ereignissen des Lebens (Arab. 198)."

Das gilt für Belyjs Protagonisten auch. Solche "Helden" wie der Rebell und Altphilologe Darjal'skij und der Terrorist und Kantianer Ableuchov erscheinen in einem neuen Licht, wenn man Belyjs Berufung auf die "nicht standhaltenden" und dennoch prototypischen Dramenhelden Ibsens vor Augen hat (cf. auch oben S. $44 \mathrm{ff}$.).

Was ihn vielleicht am meisten an Ibsen beeindruckt hat, ist daß sich

"unter dem Skeptizismus und Determinismus Ibsens ein jünglingshafter Glaube an ein neues Leben verbirgt (Arab. 199)."

Er zitiert Ibsens Brief an den König in aussichtsloser Lage: 
"ich kämpfe für die Sache meines Lebens, an die ich unerschütterlich glaube (Arab. 192)."

Die Begegnung Belyjs mit Nietzsche steht in einem anderen Kontext als die mit Ibsen. Sie geschieht nicht mehr als einsamer Ausbruch eines verzweifelten von Schuld und Trotz getriebenen Knaben, sondern im Rahmen eines Generationserlebnisses, das er mit der erwachenden Jugend Rußlands teilt. Die erste intensive Begegnung mit Nietzsche fällt in den Herbst und Winter des Jahres 1899 - 1900, als er ihn im Sog der damaligen Nietzsche-Welle in Rußland ${ }^{34)}$ fasziniert gelesen hat. Vor allem "Zarathustra", aber auch die "Geburt der Tragödie" und die kulturkritischen Schriften, die dazwischen liegen. Wenn Belyj betont, daß er ihn nicht nur las, sondern "Nietzsche lebte" (Nrds 465), so ist das sicher keine zufällige Aussage, sondern Ausdruck dafür, daß Züge, die er an Nietzsche wahrnimmt, bereits in seinem eigenen Leben hervorgetreten sind. Belyj ist damals neunzehn Jahre alt und in einer stürmischen Entwicklung zu sich selbst begriffen, die er unter dem Konfliktsymbol der "Schere" deutet, wovon bereits im Zusammenhang mit der Konfliktmetaphorik die Rede war (cf. oben S. 56f.). Um nun dieses neugeschaffene Symbol der "Schere" besser zu verstehen, soll die komplexe Situation des Studenten Bugaev, aus dem sich der Künstler Andrej Belyj erst gegen Widerstände herausentwickeln wird, in ihren Widersprüchen wenigstens umrißhaft nachgezeichnet werden. Auch hier kann vorläufig nur auf Belyjs eigene Version zurückgegriffen werden, die er unter dem Titel "Das Problem der Schere" im Kapitel "Universität" seiner Memoiren (Nrds 397 488) gibt. Gegen seinen Willen Student der Naturwissenschaften, ging er nichtsdestotrotz mit Fevereifer daran, sich durch grundlegende Werke der Logik, des Positivismus und der Naturphilosophie "durchzubeißen" (Nrds 390, 402, 405). Gleichzeitig arbeitet er im Zoologischen Museum (Nrds 409 - 425) und im chemischen Labor (Nrds 425 - 450), wobei er vergebens versucht, sich einseitiger Spezialisierung zu entziehen. Außerhalb der Universität lernt er im Salon der Solov'evs die neuesten Strömungen der Kunst der Jahrhundertwende kennen (Nrds 368 - 374). Er beginnt selbst zu dichten und riskiert den "frechen Gedanken", die Prinzipien der Energetik Ostwalds auf die Ästhetik anzuwenden (Nrds 405 f.). Vor ihm tut sich eine "Schere" zwischen Naturwissenschaft und Kunst auf, und es formieren sich erste Versuche zur Synthese; der energetische Ansatz ist erst ein Anfang.

Doch es gibt nicht nur die "theoretische Schere". Ähnlich wie bei Musil gibt es für Belyj ebenfalls "Dinge, die sich nicht wissenschaftlich erledigen lassen". ${ }^{35)}$ Mit der Sensibilität und Schärfe seiner überwachen kritisch-künstlerischen Wahrnehmung fühlt er sich außerdem den $Z$ wängen einer zerfallenden spätbürgerlichen Lebenswelt ausgeliefert, denen er den Ausdruck der eigenen Empfindungen und das Recht auf Selbstwerdung entgegensetzen wollte. Den kulturkritischen Blick für das Thema des Endes der alten Kultur schärfte inm sein radikaler Freund - damals Chemiker - A. S. Petrovskij, der selbst terroristische Neigungen hat und ihn zwingt, die Widersprüche des alten "byt" scharf zu beobachten, sich ihnen zu stellen und sie nicht in vorzeitigen Synthesen zu harmonisieren 
(Nrds 473 - 475). Von hier aus leitet sich die sozialrevolutionäre Linie, die bei Belyj später zu den Themen von Revolte, Bombe, Dynamit führt. Die theoretischen und die Widersprüche der Lebenswelt boten Konfliktstoff genug, um seine Existenz prekär zu machen. Wie schon früher in seinem Leben sah er sich mit seinen Konflikten wieder ausgespannt in einer "Schere", deren Extreme ihn, bei der Intensität, mit der er jeweils beide zugleich wahrnahm, zu zersprengen drohten.

Und was hinzu kommt, die Schere hat sich verdoppelt. Uber den Konflikt zwischen Naturwissenschaften und Kunst schreibt er:

"Die Epoche der Jahre 1899 - 1900, die bis an die Grenzscheide heranführte, ist mir noch charakterisiert von dem Problem der Schere, die sich auseinanderspreizt, die zusammengeschlossen werden muß (...) und von Zweifeln wegen des Anwachsens der Schere, und der Empfindung, daß die Schere nicht zu schlieBen sei (...) die Schere wächst (...). Ich halte es kaum noch aus; (...) bis zum Jahre 1901 balanciere ich, ohne die Schere von mir zu werfen, zwischen ihren beiden Klingen, indem ich von der einen zu der anderen überlaufe; bald entlaufe ich kopfüber in die wissenschaftlichen Interessen, bald sitze ich über der Form der 'Symphonie', über Nietzsche und Merežkovskij" (Nrds 401 - 403).

Doch schon hier zeigt sich, daß es nicht allein beim "Uberlaufen" von einer "Klinge" zur anderen bleiben sollte, sondern es zeichnet sich ein Ziel ab, das von der "Schere" nicht mehr abzutrennen ist.

"Bei allem Interesse an Wissenschaft und Fakten wurde von mir das Ziel aufgestellt einer Beherrschung des Durchdenkens der Fakten im Geiste einer Weltanschauung, die auf zwei Säulen zu erbauen war; die eine - die Ästhetik, die andere - die naturwissenschaftliche Erkenntnis; das weltanschauliche Problem - die Vereinbarung beider Linien; das - lag in der Zukunft; die Gegenwart - das ist die offene Schere, die zeitweise ausglitt in die entgegengesetzten Richtungen des Trottoirs; bitte sehr, bleib mal mit dem einen Fuß auf dem einen stehen, mit dem anderen aber auf dem anderen, ohne auseinanderzufahren; und es blieb nur das eine: das Stehen im Punkte der Schere auszudrücken, als Tanz auf der Stelle." (Nrds 403)

Ist schon die Spannung der einen Schere kaum auszuhalten, so machte sie dennoch die ganze Weite der Grundspannung noch nicht aus. Neben dem Auseinanderklaffen der beiden geistigen Welten, der Welt der Kunst und der Welt der Wissenschaften, nimmt er die Kluft wahr zwischen den abgelebten Daseinsformen der alten bürgerlichen Welt und einem vorausgesehenen Umsturz. Reagiert er auf die eine als Symbolist, so auf die andere - zumindest zeitweise - als Anarchist:

"Was vor mir stand, war nicht mehr und nicht weniger, als das Programm einer Revolution des byt auszuführen; und ich, sie voraussehend, schlug hin und her, wie ein Fisch auf dem Eis, überhaupt nicht imstande, auch nur in Gedanken diesem Maximalprogramm näherzukommen, das mir vorkam, wie eine Verschwörung gegen eine tausendjährige Kultur, die sich verflüchtigt hatte in tausendjährige Sklerose." (Nrds 467) 
Für beide "Scherenerfahrungen" gab es für den Studenten Bugaev vorerst keine Lösungen. Seine Ausweglosigkeit drückt er in den beiden Zustandsbildern vom "Tanz auf der Stelle" und vom "Fisch auf dem Eise" aus. Wichtig scheint, daß die Schere zwischen den beiden Geisteswelten Naturwissenschaft und Kunst und den beiden Lebenswelten von Stagnation und Revolte bei Belyj zusammengehören. Auf seine schöpferische Methode der Symbolisierung haben beide Einfluß genommen.

Belyj sah nun seine Existenz nicht erst als Student vom Konfliktsymbol der Schere bestimmt, sondern bereits seit seiner frühen Kindheit. Die Schneiden der "Schere" erfuhr er schon in der Familie; dort nahmen sie sehr verschiedene Gestalt an. Nacheinander hatte er sich bis zur Todesangst bedroht gefühlt von Fieberwahn und dem Alptraum eines permanenten Familiendramas, die im Gegensatz erfahren wurden zum strengen Ritual der Kinderstube (Nrds 169); von der überklaren fordernden Rationalität des Vaters und der hysterisch-frustrierten Emotionalität der Mutter (Nrds 174); von der Tyrannis einer anscheinend allmächtigen Konvention und scharfer Milieukritik von seiten der "Verfremder des byt" (Nrds 185). Den Schneiden, die sich auf ihn zubewegten, begegnete er mit ebenso großer Angst wie Entschlossenheit, sich von ihnen nicht zerstören zu lassen. Er reagierte mit Flucht, Ausweichen in Idiotie, mit Rebellion und entdeckte dabei die Methode der Symbolisierung als Uberlebenstaktik:

"Das 'als ob' meiner Spiele wurde mir zum ernsten Problem des Aufbaus einer dritten im Gegensatz zu den beiden Wirklichkeiten; und dieses Spiel, als es sich zu ernsthaften Aufgaben verdichtete, nannte ich dann den Prozeß der Symbolisierung; in der Symbolisierung habe ich die Schere überwunden: 1) zwischen dem Lebensstil der Eltern und dem meinen; 2) zwischen Vater und Mutter; 3) zwischen den verschiedenartigen Behauptungen der Autoritäten, der Ljaskovskaja und den Taneevs, darüber daß man 'so leben muß', und daß man 'so nicht leben darf' (Nrds 185)."

Die Metapher der Schere wendet Belyj auf seine permanente Konfliktsituation in zweifacher Hinsicht an: einerseits symbolisiert sie die schneidende Spannung der Gegensätze und die Bedrohung, daß man von ihnen zerschnitten, d. h. zerstört werden kann. Doch neben dem "Problem der Schere" gibt es für Belyj die "Methode der Schere", nämlich die Möglichkeit, sich dem Konflikt zu stellen und aus ihm ein Instrument zu machen. Denn von einer Schere wird nicht nur zerschnitten, was zwischen ihre Schneiden gerät, sondern sie kann auch gehandhabt werden, wenn man selbst etwas anderes zerschneiden oder aufschneiden will. Die Konfliktmetapher der Schere hat zwei Aspekte: einen passiven der Bedrohung und eine aktiven der Gegenwehr. Sie symbolisiert die beiden Seiten einer Konfliktsituation: man ist ihr zwar zunächst ausgeliefert und gerät in Leiden und Gefahr, aber man kann sie auch selbst in die Hand nehmen, auf sie reagieren, indem man mit ihr umgeht. ${ }^{36)}$ Das hat Belyj immer wieder versucht und dabei eine erstaunliche Selbsterhaltungskraft bewiesen, ohne die er in seinen Belastungen längst kaputtgegangen wäre. Statt dessen zeigt sich bei ihm eine enorme Zähigkeit und ein Einfallsreichtum im 
Umgang mit Konflikten.

"Auf allen Ebenen des Lebens hat mich die Schere zerschnitten; und auf allen Ebenen des Lebens habe ich die Ausschnitte des Lebens mit der Schere zerschnitten; so habe ich das Problem der Schere überwunden; die Streitigkeiten zwischen Vater und Mutter über die Richtigkeit ihrer Ansichten entschied ich kurzerhand dahin, daß keiner von beiden recht habe, indem ich ihnen mein Recht auf meine Ansicht vom Leben und auf meine Erklärung der Erscheinungen des Lebens entgegensetzte; meine Empirie bestand im Aufdecken meiner namenlosen, mir auf keinerlei Weise erklärten Erlebnisse des Bewußtseins (...)." (Nrds 185)

Auch seine Scheren-Situation als junger Student versuchte er aktiv in die Hand zu bekommen. Zuerst dadurch, daß er die Widersprüche, die auf ihn eindringen, annimmt. Er nimmt die Exaktheitsforderung der Naturwissenschaften als Herausforderung an, läßt sich aber gleichzeitig von der Mystik Solov'evs und Maeterlincks ergreifen; er gesteht sich die ungelöste Teilhabe an der Sphäre der Formeln und Argumente wie auch an der unklaren Tiefe des Gefühls ein, die ihm in der Musik entgegentönt; er läßt die Versuchung, sich mit Gewalt und Zerstörung zu rächen, an die Schwelle des Bewußtseins dringen, um ihr mit dem Appell zur "Verwandlung" zu begegnen. Denn er nimmt die Widersprüche nicht nur an, sondern versucht, sie in einer "Neuen Kunst", seiner Zeit adäquat, zum Ausdruck zu bringen. Die beiden Extreme seiner Scheren: Kritik und Utopie werden zu den Extrempolen seiner frühen Dichtung. Zwischen der Kritik an abgelebten Daseinsformen und der Utopie eines veränderten Lebens, vollzieht er die Symboiisierung analog zur musikalischen Form der Symphonie. Satire, idealer Entwurf und musikalische Form gehen eine Verbindung ein, die Belyj zur Revolutionierung des Prosastils befähigten, der das Gesicht der russischen Literatur im zwanzigsten Jahrhundert in avantgardistischer Weise veränderte.

Diese Verbindung von scharfer Kulturkritik, utopischem Entwurf und musikalischem Rhythmus empfindet er als etwas, das er mit Nietzsche gemeinsam hat und das ihm jetzt bei der Lektüre deutlich gegenübertritt. In dieser Situation, da er Nietzsche bereits "lebte", ehe er inn kannte, mußte die Begegnung mit ihm als Denker und als lebendigem Menschen den Charakter einer Initialzündung annehmen:

"Dazu trat nun außerhalb des theoretischen Interesses die einfach besinnungslose Anziehung Nietzsches, als Künstler und als Persönlichkeit (...). Seit Herbst 1899 lebe ich Nietzsche; er ist meine Erholung, meine intimen Minuten, wenn ich, nachdem die Lehrbücher beiseite und die Philosophien weggelegt sind, mich ganz und gar seinen intimen Einblicken, seinem Satz, seinem Stil, seiner Schreibweise hingebe; in seinem Aphorismus sehe ich die Höchstgrenze der Beherrschung des Vermögens zu symbolisieren: die erstaunliche Musikalität erfüllt mich, den Musiker in der Seele, ohne Rückhalt; (...). Der Musiker-Philosoph erschien mir als der Typus des Symbolisten. Nietzsche wurde mir zu einem solchen Symbolisten bis hinein in die Gesten seiner Biografie und bis zu seinem tragischen Schicksal (Nrds 465 f.)." 
Wurde Ibsen im Zeichen der Rebellion vor allem als moralische Autorität erfahren, so Nietzsche zunächst ganz anders. Nietzsche ist für Belyj - wie für viele seiner Zeitgenossen - zuallererst ein Stilphänomen und zwar eines, in dem Musik und Sprache ein so bisher unbekanntes rhythmisches Gefüge ergeben. Belyjs eigene Versuche, symphonische Prosa zu schreiben, mußten hierin Bestätigung finden, wenn sie nicht überhaupt erst durch Nietzsche voll in Gang gekommen sind. In Nietzsche sieht Belyj die Möglichkeit einer modernen Dichtkunst aus dem "Geist der Musik" philosophisch objektiviert.

Doch nicht nur Ăsthetisches ist entscheidend, sondern die schöpferische Kraft Nietzsches, Bilder einer völlig neuen Lebensqualität zu schaffen, in der die tragische Existenz des Künstler-Menschen zur Norm einer neuen Epoche erklärt wird - wenngleich erst als Entwürfe der Sehnsucht, die nicht in der Gegenwart angesiedelt sind, sondern zurückfantasiert in die Kultur der Griechen oder voraus in die Zukunft des Ubermenschen:

"Er war mir Schöpfer hochlebendiger Bilder, deren theoretischer oder ästhetischer Sinn sich nur auf dem Wege des Mitschaffens eröffnet, und nicht bloß des Mitdenkens." (Nrds 466)

An Nietzsche gewinnt er eine Dimension der eigenen Kreativität, die über Ibsens strenges Vorbild hinausgeht, nämlich Elemente seiner eigenen Konfliktstruktur, die er zunehmend als "Schere" einer ganzen Kultur epochentypisch legitimiert sieht, in Rhythmen zu komponieren, nicht nur als abspiegelnder Chronist, sondern als Musiker der modernen Seele. Diesen Versuch treibt Belyj bis in die "Vierte Symphonie" voran, bis er an eine Grenze kommt, von der schon die Rede war (cf. oben S. 136ff.).

Neben dem ästhetischen Genuß der musikalischen Sprache, neben dem Anstoß zu eigener Kreativität, ist es aber auch der Rebell Nietzsche, der eine Seite in Belyj berührt, die schon Ibsen getroffen hatte:

"Schließlich Nietzsche, der Anarchist; Nietzsche, der Kämpfer mit der Entartung, der selbst seiner ganzen Tiefe spottet; Nietzsche, die Grenz.scheide zwischen dem Ende der alten Epoche und dem Beginn der neuen - alles das hat ihn mir lebensvoll vor Augen geführt." (Nrds 466)

Mit Nietzsche erhält die Situation der Schere, die von Belyj individuell erfahren worden war, eine überindividuelle Dimension und gesamtkulturelle Bedeutung. Ihm wird deutlich, daß die mehrfache Schere, die sich vor ihm aufgetan hatte, weder von ihm isoliert erlebt wird, noch von ihm allein geschlossen werden kann, sondern daß es dazu eines ganzen Lebens und der Anstrengung einer ganzen Kultur bedarf (Nrds 469). In Nietzsche findet er eine Interessenmischung, die der seinen sehr ähnlich ist; aus dieser Ubereinstimmung erschließt sich für Belyj eine Quelle der Rechtfertigung vor sich selbst und vor Gleichgesinnten seiner Epoche. Er kann deshalb zusammenfassend über Nietzsche sagen: 
"Ich sah in ihm: 1) den 'neuen Menschen', 2) den Praktiker der Kultur, 3) den Verneiner des alten 'byt', dessen ganzen Reiz ich an mir selbst ausgekostet hatte, 4) den genialen Künstler, mit dessen Rhythmen die ganze künstlerische Kultur durchdrungen werden muß." (Nrds 466)

Die Bedeutung Nietzsches ist - wie die Ibsens - im Lauf des ersten Jahrzehnts noch weiter über die erste Begegnung hinaus gewachsen. Sieht er 1903 in ihm noch den "gekreuzigten Dionysos", dessen Scheitern durch "Theurgie" überwunden werden könne (Arab. 237); versucht er ihn 1906 unter dem lyrischen Denkbild des "Phönix" zu deuten, der vor der goldroten Morgenröte auffliegt, in der Leiden und Selbstherrlichkeit gefährlich gemischt sind, wofür Belyj die Metapher des "Leopardenfells" entfaltet (Arab. 155 157), die von da an eine Symbolkonstante seiner Dichtung wird (bei der Nietzsche zu assozieren ist), - so rückt Nietzsche ab 1907 ins Zentrum seiner Reflexionen über die moderne Kulturkrise. Er schreibt:

"Und über unserer Kultur wächst seine Gestalt, wie die Gestalt der geflügelten Sphinx. Tod oder Auferstehung: das ist die Parole Nietzsches. Ihn zu umgehen, ist unmöglich: er - sind wir in der Zukunft, die ihrer selbst noch nicht bewußt geworden sind (Arab. 62)."

Die Bewußtwerdung seiner selbst ist das noch uneingelöste Vermächtnis Nietzsches, zu dem der Künstler der Moderne mit seiner Kunst aufgerufen ist. Das legitimiert die Darstellung von Erlebnissen, die die ganze überhaupt erst noch zu gewinnende Individualität mit ihren offenbaren und verborgenen Schichten umfassen soll. Belyj spricht von Nietzsches "taktischem Individualismus" (Arab. 67), der anzuwenden sei, um den noch unerforschten Kontinent Mensch zu entdecken, denn erst Nietzsche habe "die Seele auf ein neues Fundament versetzt" (Arab. 63). Interessant an diesen Äußerungen Belyjs über Nietzsche scheint mir vor allem, daß sie Hinweise darauf enthalten, wie sich in Rußland immer deutlicher aus dem Symbolismus heraus die Entwicklung zur modernen Bewußtseinskunst herausschält, wovon schon im Kap. 1 (57) die Rede war, die nicht Selbstzweck, sondern immer verbunden ist mit dem Appell zur Selbstwerdung (Arab. 62).

Vor diesem Hintergrund ist auch der Umbau der Symbolkonzeption, die Belyj zur selben Zeit, um 1906/07, aus dem ganzheitlichen Erleben heraus neu begründet, zu verstehen. Die "Ganzheit" eines "taktischen Individualismus" ist - wie sich gleich zeigen wird als ein ebenfalls "taktischer" Gegenbegriff zu den hervortretenden Antinomien der Kulturkrise zu begreifen. 1910, vier Jahre vor Ausbruch des ersten Weltkrieges, findet das Bewußtsein der Kulturkrise bei Belyj zum ersten Mal konzentrierten Ausdruck. Aus der individuellen Erfahrung einer Schere von Widersprüchen ist inzwischen ein Deutungsmuster für den Zustand der zeitgenössischen Kultur geworden. Nach Belyj ist sie in fünf große Antinomien zerfallen: 1) zwischen Erkenntnis und Gefühl, 2) zwischen Kontemplation und Willen, 3) zwischen Persönlichkeit und Gesellschaft, 4) zwischen Wissenschaft 
und Religion, 5) zwischen Sittlichkeit und Schönheit. ${ }^{37)}$ Das moderne Bewußtsein bringt nicht mehr die Spannkraft auf, sie durchzuhalten und zu bewältigen. Im Mittelpunkt der kulturkritischen Analyse Belyjs steht die Abtrennung von Kontemplation und Lebenswille im modernen Bewußtsein. In diesem Auseinanderfallen der vita contemplativa, die sich dem Pessimismus ergeben hat, und der vita activa, die unreflektiert der Kraft und dem Optimismus huldigt, sieht er ein gefährliches Indiz des Niederganges der Kultur. Um diese Gefahr zu überwinden, gibt es nach Belyj nur einen Weg: die Risikobereitschaft einer tragischen Weltanschauung, die sich auf das Leben und seine Widersprüche voll einläßt, selbst um den Preis des Unterganges. Allein aus einem solchen kompromißlosen Geiste könne die Kultur ernevert werden.

Als Wegbereiter dazu gelten ihm Nietzsche und Ibsen. Beide haben nach Belyj die Kultur ihrer Zeit grundsätzlich infrage gestellt, sind aber zu konträren Antworten gekommen: Nietzsche im Traum vom zukünftigen Menschen, Ibsen in der schonungslosen Analyse der zeitgenössischen Wirklichkeit, im Aufdecken des Chaos und der "Schlupfwinkel" der modernen Seele, worin Belyj die Voraussetzung sieht, einen Weg zu dem von Nietzsche entworfenen Menschentypus zu finden. Er schreibt:

"Nietzsche hat vor uns die Gestalt des zukünftigen Helden entworfen, der höher war als er selber. Ibsen hat vor uns eine ganze Galerie lebendiger Personen herausgraviert, bei denen alle Stadien der Disharmonie zwischen Kontemplation und Willen Ausdruck gefunden haben; Nietzsche gab die reale Gestalt des über ihm stehenden Menschen; Ibsen hat streng gemessen und gewogen: sich und seine Gegenwart, die tiefer steht als er; Nietzsche ohne Ibsen erinnert an die funkelnde Pracht einer Wolke zu der es keinen Zugang gibt; Ibsen ohne Nietzsche baut rauhe feste Stufen auf zu ... nun eben dieser Wolke (Arab. 171)."

Ibsen und Nietzsche werden als zwei Hälf ten gezeichnet, die unverbunden nebeneinander stehengeblieben sind. Während Nietzsche das Ziel in einem aufblitzenden Traum entwirft, aber keine Auskunft geben kann, auf welchem Wege es in der Gegenwart erreicht werden könne, viviseziert Ibsen die Gegenwart, prüft die psychische Beschaffenheit seiner Zeitgenossen, wobei er - noch vor Freud - in Bereiche vorstößt, die bis dahin verdeckt blieben. Doch je schärfer der Blick, desto skeptischer wurde sein Urteil. Er geht mit seiner Zeit hart ins Gericht, ohne ihr positive Helden zeigen zu können. Dennoch ließ er nicht davon ab, Suchende und Scheiternde auf die Bühne zu stellen, die Bruchstücke, zumindest, eines neuen Weges gehen.

"Eine positive Gestalt hat Ibsen nicht gegeben, aber er gab den irdischen Weg zu dem Traum, den real empfunden Nietzsche hat, doch zu dem er einen Weg nicht gab, denn der lebendige Weg in die Zukunft läuft durch die Gegenwart; zur Gegenwart hat sich Nietzsche polemisch verhalten; ja, und außerdem bestand das Wesen der Nietzscheschen Polemik in lyrischen Ergüssen, und nicht in einer Galerie lebendiger Personen; niemand hat besser als Ibsen die Schlupf winkel der modernen Seele gekannt, und Abgüsse von ihr in einer Reihe von Gestalten, die goß Henrik Ibsen; aber diese Gestalten zeichnen eine Treppe von Aufstiegen hinauf zu dem, was Nietzsche im Traum erschaute, zuerst im alten 
Griechenland und was ihm dann bewußt wurde als ferne Zukunft. Nietzsche gab das reale Bild einer fernen Zukunft, indem er über 'Weg und Streben' zur Zukunft hinwegsprang; das ganze Schaffen Ibsens ist Beschreibung des Mysteriums dieses Weges und Strebens in lebendigen Personen, inmitten von Lebensumständen; die Polemik mit der Gegenwart bei Ibsen besteht nicht in Lyrik, sondern in real sich entwickelnden Ereignissen, wo die Zukunft sich quält in den Krämpfen der zeitgenössischen Gegenwart; eigentliche Ziele aber des Weges gibt es bei Ibsen nicht; da, wo sich Ibsen an die Zukunft wendet, gibt es bei ihm das nicht lebendig sprechende Schema der 'drei Reiche', der 'Synthese' etc. Nietzsche schaute nur über sich: Ibsen schaute nur unter sich hinab und um sich her. Der erste setzte der Gegenwart ein reales Ziel mit Mitteln, die in der Luft hängen blieben, der zweite gab reale Mittel zu einem in der Luft hängenden Ziel; Nietzsche und Ibsen sind nicht bis zu Ende gegangene Realisten in der tiefen Bedeutung dieses Wortes (Arab. $171 \mathrm{f}$.).

Ihre Halbheit kommt nach Belyj darin zum Ausdruck, daß beide die Wirklichkeit verzerrt darstellen: Nietzsche gerät durch seine lyrisch-polemische Entstellung ins Fantastische, Ibsens Wirklichkeit wird gleichfalls grotesk durch die Fragwürdigkeit der Lebensziele, denen seine Figuren sich kämpfend zu nähern versuchen, wobei sie aber nicht standhalten.

"Für Nietzsche ist real die Zukunft - 'der Ubermensch, der Held'; aber er sieht keinen Helden in der Wirklichkeit und fällt über sie her in seiner polemischen Lyrik; da aber, wo er die Wirklichkeit zum Mittel des Aufsteigens in die Zukunft machen will, da konzipiert er die Mittel, indem er von der Zukunft ausgeht: es ergibt sich eine halbfantastische Wirklichkeit mit ihren halbfantastischen Personen, Staat, Philosophie, Kunst; die Ansicht Nietzsches vom tatsächlichen Staat, von Kirche, Philosophie ist fantastisch, wie auch in seiner Auslegung Kant und Wagner fantastisch sind; und umgekehrt werden die von der Gegenwart weit entfernten Zarathustra, Heraklit, Sokrates lebendig für uns in der Interpretation Nietzsches.

Völlig real sind die Ibsenschen Helden: uns selbst erkennen wir in den Borkman, Solness, Rubeck; aber geben Sie acht, wie Ibsen verfährt mit unseren realen Lebenszielen: er verkehrt sie in einen Alptraum, in Absurdität; er läßt Borkman mit dem Leben kämpfen im buchstäblichen Sinne; die realen Lebensbedingungen erweisen ihm jedes Ziel als Sinnlosigkeit; indem er auf dem Boden der Wirklichkeit stehen bleibt, verkehrt Ibsen das Leben in ein fantastisches Märchen, wie es auch Nietzsche verkehrt, indem er entweder entflieht ins ferne Griechenland oder es in der Zukunft erschafft (Arab. 172 f.)."

Was sind aus solcher kontrastiver Analyse für Schlüsse zu ziehen? Belyj argumentiert mit veränderten Mitteln weiter; er macht eine Plus-Minus-Rechnung auf (Arab. 173), aus der sich die Folgerung ergibt, daß beide Programme auf Paradoxe hinauslaufen: das Ziel Nietzsches schwebt in der Luft; daher ist es vorläufig nicht mehr als ein Emblem, zu dem es keinen Weg gibt; die Stufen Ibsens brechen ab, wo das Ziel sich verliert; auch er ist nur ein Anfang, ein Negativ des Weges. Doch in diesen Paradoxen liegt dennoch Wahrheit verborgen, insofern als - nach Belyj - die Möglichkeit zur Zukunft nichtsdestotrotz real gegeben ist, ebenso wie die Möglichkeit einer anderen Lebenswelt. Beide sind deshalb für Belyj Symbolisten, weil sie eine Wirklichkeit never Werte, wie Nietzsche emblematisch, oder ex negativo wie Ibsen zeigen, die eigenes und zwar 
aufgegebenes Sein hat, das geglaubt werden muß und an den Willen zur Verwirklichung appelliert. Nach Belyj müssen sowohl die alte Wirklichkeit wie auch die alten Ideale überprüft werden. Ein solcher Prozeß der Umwertung kann erst geschehen, wenn sich der moderne Mensch verwandelt in einen Menschen der tragischen Risikobereitschaft. Denn Wiedergeburt im Sinne Belyjs steht in gefährlicher Nähe zur Explosion der alten Ordnungen. Die Forderung nach Wiedergeburt enthüllt hier ihre anarchistische und revolutionäre Seite, sie wird zur "Revolution des Geistes", durch die Nietzsche und Ibsen erst vollendet werden könnten.

"Und uns bleibt nur der eine Weg: der Weg der Wiedergeburt; das Schaffen von Leben, wie auch das Leben überhaupt, hängt ab von unserer Wiedergeburt; erst dann wird die Antinomie $z$ wischen der Kontemplation der falschen Wirklichkeiten (der gegebenen wie auch der fantastischen) und dem Willen zum Leben fallen: Dynamit legen unter die Geschichte selbst, im Namen absoluter Werte, die vom Bewußtsein noch nicht entdeckt sind, das ist die furchtbare Folgerung aus Nietzsches Lyrik und Ibsens Drama. Mitsamt seinem Jahrhundert zu explodieren um des Strebens zur ursprünglichen Wirklichkeit willen - das ist das einzige Mittel nicht zugrunde zu gehen.

So antworten beinahe gleichzeitig die zwei größten Genien der zweiten Hälfte des neunzehnten Jahrhunderts; wenngleich beide noch abstrakt sind im Aufzeichnen echter Wege des Ubergangs über die uns erwartende Katastrophe, so sehen beide doch auch einen praktischen Ausweg für die heutige Zeit. Und wir haben das Recht, die Namen Nietzsches und Ibsens zu vereinigen, als die Namen der größten Revolutionäre unserer Epoche (Arab. 174)." (Hv. M. D.)

Verfolgt man die Begründungslinien der psychologisch-existentiellen Rechtfertigung Belyjs vor sich selbst und vor Gleichgesinnten seiner Epoche, so ist hier ein Punkt erreicht, an dem sich ein avantgardistisches Selbstverständnis ausspricht: Belyj versteht sich als Verfechter einer "Revolution des Geistes" und als Nachfolger der beiden "größten Revolutionäre unserer Epoche". Nimmt man hinzu, daß er zur gleichen Zeit begann, seinen Roman "Petersburg" zu schreiben, dann erweist sich die Methode der Symbolisierung als eine weit weniger esoterische Angelegenheit, als das gemeinhin angenommen wird.

Die Frage nach den Linien der Legitimationsstrategie Belyjs hat in zwei Richtungen geführt: es konnte gezeigt werden, 1) daß Belyj Symbolisierung im Rahmen einer geistigen Grundfunktion versteht, die ihm erlaubt, Kunst als eine besondere Form der Modellbildung zu verstehen, nämlich Modelle moderner individueller Erfahrung zu erschaffen, die von überindividueller Bedeutung sind; 2) daß innerhalb des Symbolismus ein avantgardistisches Potential sichtbar wird, das aus der Reaktion auf die Antinomien der Kulturkrise entstand. Indem die Frage nach der Legitimation weiter verfolgt wurde, trat ein weltanschaulicher Fond deutlicher hervor, der sich von Nietzsche und Ibsen herleitet. Mit dem Appell zur Veränderung aus einer tragischen Risikobereitschaft heraus ist zugleich das doppelte Postulat einer "Ästhetik der Widersprüche" wie auch einer "Ästhetik der Wertschöpfung" gegeben, das der "Neuen Kunst" des Symbolismus abverlangt wird. Es 
zeigt sich also eine Entwicklungslinie, die von Nietzsche und Ibsen hergeleitet, innerhalb des Symbolismus typische Bedingungen der Avantgarde in Rußland sichtbar macht, die vom Symbolismus in die Kunst der Revolutionszeit hinüberführen, u. a. zu Majakovskij. Hier erscheint Belyjs Ästhetik als ein wesentlicher Katalysator. 


\section{K A P I T E L}

\section{VER WANDLUNG DER PERSÖNLICHKEIT VON DER "THEURGIE" ZUR "REVOLUTION DES GEISTES"}

\section{Verwandlung als Ziel der Kunst in Abhängigkeit von der Form}

Zu den ästhetischen Grundbegriffen Belyjs gehört die wirkungsästhetische Konzeption des "preobraženie", der Verwandlung der Wirklichkeit über die Bewußtseinsveränderung des einzelnen Individuums durch die Kunst. Hierin erst und nicht im bereits fertiggeformten Kunstwerk sieht er das Ziel der Kunst. ") Die Kategorie des "preobraženie" ist einerseits gebunden an Belyjs mehrdimensionalen Wirklichkeitsbegriff und seine Sicht des künstlerischen Bewußtseins, andererseits an seine Auffassung von Sprache und künstlerischer Technik. Damit steht sie einerseits in einem festen weltanschaulichen Rahmen, der vom erkenntnistheoretischen Kritizismus und Bewußtseinsidealismus ${ }^{2)}$ geprägt ist, sie ist aber gleichzeitig abhängig von den neuen poetischen Verfahren eines postrealistischen Symbolismus. Auch in der Kategorie des "preobraženie", die keine rein ästhetische ist, spiegelt sich Belyjs doppeltes ethisch-ästhetisches Interesse an Sinn und Form der Kunst.

In der Unterscheidung zwischen Empirie und noumenaler Welt, wie sie ihrem Wesen nach ist oder ihrem Sollen nach sein könnte, liegt für Belyj der "Hebel", mit dem die Möglichkeit zur Verwandlung gegeben ist:

"Die Erkenntnistheorie - ist der Hebel, der die Wirklichkeit aus den Angeln hebt." (Embl. 89)

Nicht allein vom erkennenden Philosophen, sondern auch vom Künstler kann dieser Hebel in Bewegung gesetzt werden, insofern als das künstlerische Bewußtsein die Fähigkeit besitzt, in schöpferischer Freiheit die Elemente der Erscheinungswelt in der Kunst neu zu konstellieren zu "Modellen von Erfahrung" (Smysl 205f., 212), die neue Möglichkeiten und Werte in den Lebensformen antizipieren.

Die Realisierung des "preobraŽenie" in der Kunst unterscheidet sich von derjenigen in Religion und Ethik grundsätzlich dadurch, daß sie nicht im Leben, also nicht in der praktischen Einlösung, vor sich geht, sondern daß sie in sprachlichen Formen zum Ausdruck gebracht wird, die verändernd auf das Bewußtsein des Rezipienten einwirken. Trotz dieses Unterschiedes - und das ist entscheidend - sind die Intentionen zur Umgestaltung des als schlecht erfahrenen zu einem besseren Leben der Kunst und anderen Gebieten der universalen Lebenspraxis gemeinsam. Ganz verschieden von ihnen ist aber die Weise und das Medium der Realisierung. In der Kunst handelt es sich um ein fiktives und um ein verbales Geschehen, und hierin hat es seinen Ort der Wahrheit und Bewährung. Deshalb ist das "preobraženie" in der Kunst. unabdingaria Deppermann-o78395479274daß der 
Küns:ler seine Erfahrung in eine "makellose" Form bringt. Denn in der Kunst ist es nicht genug, richtige und gute Ideen zu haben oder intensiver Emotionen fähig zu sein, sondern alles hängt ab von der Eingestaltung in Form:

"Der Sinn der Kunst ist - die Natur unserer Persönlichkeit umzuschaffen; aber nur dann hat in uns der Sinn eines beliebigen Bildes einen Widerschein, wenn dieses Bild tadellos verkörpert wird in einer Reihe von technischen Verfahren." (Smysl 223f.)

Den Sinn der Kunst, nämlich an der Verwandlung von Wirklichkeit mitzuwirken, die Fülle und die Möglichkeiten des Seins und der Persönlichkeit zu realisieren, also das Leben lebenswerter zu machen - diesen sehr konkreten Sinn bezeichnet Belyj als "religiös". 3) Jeder Inhalt kann in der Kunst zum Träger solchen Sinnes werden, vorausgesetzt er ist so erlebt, daß sich seine Außenansicht und die innere Erfahrung des Künstlers so innig durchdrungen haben, daß daraus ein schöpferisch durchgeformter Gegenstand der Kunst geworden ist. ${ }^{4)}$ Belyj demonstriert das an Nekrasovs Gedicht "Tod eines Bauern", einem unscheinbaren Alltagsereignis, das künstlerisch durchgeformt weit über sich hinausweist. 5) Was Belyj unter dem "religiösen" Sinn der Kunst versteht, hat mit dem dogmatischen Verständnis von Religion nichts mehr zu tun. Sein Begriff von "religiös" ist zugleich universaler und subjektiver. Denn einerseits liegt ihm der utopische Wunsch nach Vollendung zugrunde, andererseits die eigene Erfahrung, in der die Erkenntnis unabweisbar ist, daß die Welt im Argen liegt. ${ }^{6)}$ Dennoch glaubt er daran, daß der Künstler, der sich das Ziel der eigenen Selbstwerdung setzt, aus diesem Streben heraus Kunstwerke von antizipatorischem Charakter schaffen kann, die als Modelle zur Veränderung der Lebensformen wirken können.

Diese Wirkung ist aber unlösbar gebunden an die spezifischen Bedingungen der ästhetischen Kornmunikation. Am Verfahren der Symbolisierung wurde gezeigt, daß die Sprache in der modernen ars combinatoria in einer Weise gebraucht wird - "alltägliche Worte in nicht alltäglichen Verbindungen (Bal'mont)" - die von der normalsprachlichen Verwendung weit abweicht (cf. oben S. $49 \mathrm{ff}$.).

\section{Der hohe Anspruch an den Leser}

Angesichts dessen nimmt Belyj von seinem Wirkungsanspruch und Bewußtseinsidealismus her eine unübersehbare Aufwertung des Lesers vor, wenn er ihm ein so hohes Anspruchsniveau zumutet, daß von seiner Arbeit "post factum" die Wirkung der Kunst wesentlich mit abhängt. Uber die notwendige Mitwirkung des - ebenfalls kreativ gedachten - Rezipienten von Kunst sagt er:

"(...) notwendig ist die Arbeit des Umschaffens, des Verstehens, des Enträtselns von seiten derer, die die Kunst aufnehmen (Hv. M. D.); und dies ist eine Arbeit 'post factum'; gegeben ist das Bild: es ist nun entweder ein Wein 
stock oder aber ein verdorrter Feigenbaum; nur die Zeit wird entscheiden, ob es das eine oder das andere ist. (...) Zur Bewertung eines wahrhaft tiefen künstlerischen Werkes ist es notwendig, sich einer Arbeit zu unterziehen: den Weinstock in Wein umzuschaffen (zu verstehen)." (Smysl 207)

Vorläufig kann über eine Verwandlung des Lebens nach Belyj in der Kunst nur in Symbolen gesprochen werden, weil nur sie fähig sind, die Dialektik von Sein und Sollen zu umfassen und zu gestalten. ") Die Vervollkommnung der künstlerischen Form, an die diese symbolische Rede als notwendige Bedingung ihrer Wirkung gebunden ist, steht daher im Zentrum der ästhetischen Praxis der Moderne. Für Belyj als poeta doctus steht aber zugleich auch im Mittelpunkt der ästhetischen Theorie die Erforschung poetischer Formgesetze, an der vor ihm in Rußland noch kaum etwas getan war. Den Anfang dazu macht er selbst mit stilanalytischen Untersuchungen zur Lyrik, später auch zur Prosa Gogol's. Was ihn dabei interessiert, ist die Interdependenz von Erlebnis, Idee und sprachlichen Ausdrucksformen, zum ersten Mal durchgeführt an dem ebengenannten Beispiel des Nekrasovgedichtes.

Belyjs wirkungsästhetischer Begriff des "preobraženie" reflektiert eine neue Weise von Wirkung in der Moderne. Ohne vor den Schwierigkeiten mit einem konservativen Lesepublikum zu kapitulieren, macht er in seiner Ästhetik den Versuch, einen Leser zu konzipieren, der mit neuen Stilforderungen konfrontiert werden kann. ${ }^{8)}$ Dem liegt die Uberzeugung zugrunde, daß schöpferische Kraft dem Bewußtsein überhaupt eignet. Daraufhin muß eine ästhetische Neueinschätzung des Lesers gewagt werden. Gilt für den Künstler die Regel vom "Primat des Schöpferischen" im Bewußtsein, so muß sie - nach Belyj - auch, wenngleich in vermindertem Maße, für den Rezipienten gelten (cf. oben 92f.). Hierin liegt eine alte aufklärerische Uberzeugung von der potentiellen Gleichheit aller Menschen, ${ }^{10)}$ die in der Genieästhetik reduziert wurde auf wenige "Kongeniale", was schließlich in den ästhetischen Separatismus führte.

\section{Stufen des "preobraženie"}

Betrachtet man also das Verfahren der Symbolisierung in seinem vollen Umfange, so wird verständlich, daß an den Rezipienten moderner Kunst Ansprüche gestellt werden, die einer Herausforderung seiner produktiven Kräfte gleichkamen. Die Leser-Imago des kreativen Lesers, der aufgerufen ist zur Verstehensarbeit, zur "Arbeit am Symbol" (cf. oben S. 126, 135), ist ein in sich notwendiger und ganz wesentlicher Bestandteil von Belyjs ästhetischer Theorie des schöpferischen Bewußtseins. Ohne daß hier näher auf die Theoriediskussion zur Rezeptionsästhetik eingegangen werden soll oder kann, sei darauf hingewiesen, daß in Belyjs ästhetischer Theorie lange vor der heutigen "Theoriewende" neben Aussagen zu den Bereichen der Produktions- und Wirkungsästhetik der dritte Bereich der Rezeptionsästhetik mit innerer Notwendigkeit und Logik einbezogen wird. Denn 
nach Belyj ist der Sinn der Kunst nicht bereits im Kunstwerk an sich beschlossen, sondern er kann sich erst verwirklichen in der schöpferischen Mitarbeit des Rezipienten. Ohne sie kann die wirkungsästhetische Intention der "Verwandlung der Persönlichkeit" gar nicht erreicht werden. Mit der Aktivierung eines prinzipiell für mündig erklärten Lesers, an dessen kreatives Potential er appelliert, greift Belyj über die Kantsche Formel vom "interesselosen Wohlgefallen", das das Kunstwerk im Rezipienten auslösen soll, hinaus. Denn Belyjs Ästhetik der Kreativität zielt durch das Werk hindurch auf das Engagement des aktivierten Rezipienten.

Das Konzept des "preobraŽenie" ist daher ein durchgehender Zug seines ästhetischen Diskurses, verändert sich aber in verschiedener Hinsicht. Von Anfang an spielt es eine wesentliche Rolle. In "Formen der Kunst" (1902) wird es bereits doppelt, aus Ziel und Technik - d. h. vor allem "Material" - der Kunst begründet. Zuerst ist es noch primär die Musik, von der Belyj aufgrund ihrer nichtmimetischen "Geistigkeit" - unter dem Einfluß von E. Hanslick und Nietzsche - 11) eine Antizipation "neuer Formen des seelischen Lebens" erwartet (Formy 166). Er glaubt hier noch, daß durch die Musik - die sich im modernen Musikdrama mit dem Wort verbunden hat (bei Wagner) oder mit ihrem symbolisierenden Geist die moderne Dramatik durchdringt (bei Ibsen) - das Leben in ein Mysterium verwandelt werden könne (Formy 172f.). ${ }^{12)}$ Der Musik schreibt er "apokalyptischen" Charakter zu, denn sie werde die Menschen, gleich der Posaune des Erzengels, "erwecken" (Formy 167). Doch auch in sprachlicher Hinsicht ist das "preobraženie' begründet: einmal aus dem Zeichencharakter der Sprache, die auf wiederbelebende Entzifferung durch den Leser angewiesen ist (Formy 151f.); zum anderen aus der inneren Energie des Schöpferischen, innerhalb derer die energetische Natur der Sprache ${ }^{13)}$ durch das Kunstwerk auf den Rezipienten - nach dem Gesetz von der Erhaltung der Kraft in ihren Transformationen - einwirkt und den "Geist der Musik" auf ihn überträgt (Formy 162). Das Wort wird - in Analogie zur Musik - als dynamische Energie aufgefaßt, als "erweckendes Wort" (vor allem "O teurgii", 1903). ${ }^{14)}$ Hier erhebt er die Forderung nach einer Kunst der Erweckung und Verwandlung aus Momenten existentieller Grenzerfahrung des Künstlers (von Chaos und Harmonie) durch die "wundertätige Kraft des Wortes" (O teurgii, $102 f$. .). Anklänge an die Wortgewalt der Sprache der alttestamentlichen Propheten und das Sprachenwunder der neutestamentlichen Pfingstgemeinde verbinden sich mit der modernen Handhabung des Wortes, wie sie Bal'mont empfahl: "alltägliche Worte in nicht alltäglichen Verbindungen" (Kniga simvolov). Der jugendlich-idealistische Glaube, daß dadurch die "Welt aus dem Grabesschlaf aufgeweckt werden" könnte (O teurgii, 100ff.), ist hier noch ungebrochen, wenngleich angefochten dadurch, daß die Gefahren des "Magismus" gesehen werden, eine Linie, die Belyj von Lermontov zur modernen "Dekadenz" zieht (O teurgii, 104f.).

Belyjs Sprachauffassung - und das gilt für alle drei Phasen seiner ästhetischen Theorie - ist also gekennzeichnet davon, daß er das Wort als dynamische Kraft versteht; dem 
Wort traut er die Fähigkeit zu, den lebendigen Geist ("Geist der Musik") zu übertragen. Darin ist auch sein Wirkungsverständnis begründet. Sprache, die solche Kraft besitzt, kann Veränderung bewirken. Doch sie ist nach Belyj zwei großen Gefahren ausgesetzt. Dem lebendigen Wort droht sowohl die Gefahr, zum magischen Bann zu erstarren, der Zwang statt Lebendigkeit erzeugt. Ihm droht aber andererseits die Gefahr, vom skeptischen Rationalismus des "common sense" erfaßt zu werden, der den Glauben an die erweckende Kraft des Wortes nicht aufbringen kann.

Als Führer und "Prophet der Uberwindung", der zwischen der Dürftigkeit des "common sense" und der dämonischen Hybris des "Magiers" hindurchführen könne, wird VI. Solov'ev angesehen (O teur. 119). Sein Einfluß zeigt sich schon am Titel. Denn der Begriff der Theurgie stammt von ihm und ist fester Bestandteil seines philosophischen Denkens. Auf die ganze Breite der Begriffsgeschichte dieses Terminus kann hier nicht eingegangen werden. Wichtig erscheint jedoch, daß mit Theurgie eine Auffassung des Göttlichen gemeint ist, in der dieses nicht nur als statische metaphyische Größe geglaubt, nicht nur passiv verehrt wird, sondern daß Göttliches vom Menschen gewirkt werden kann und soll. Denken, Glauben und Tun stehen bei Solov'ev in unlösbarer Verbindung. Aus den neuesten Erkenntnissen der Solov'evforschung, die von Ludwig Wenzler unter der Fragestellung nach der Freiheit und dem Bösen bei Solov'ev herausgearbeitet wurden, wird deutlich, daß für S. Denken aus der Differenzerfahrung von Gut und Böse entstand und ihm gleichbedeutend wurde mit der Verpflichtung zur Veränderung der Wirklichkeit. ${ }^{15)}$ Der Weg dazu geht für ihn - im Unterschied zu Marx, mit dem er die Handlungsorientiertheit des Denkens teilt - nicht über die äußere Veränderung des Bestehenden, über Klassenkampf und Gewalt, sondern über die innere Verwandlung der Persönlichkeit, die dann zur äußeren Veränderung führen werde. Solov'ev sagt:

"Ich verstehe die Sache anders. Ich weiß, daß jede Umwandlung von innen aus dem Geist und aus dem Herzen des Menschen - geschehen muß.

Die Menschen werden geleitet durch ihre Uberzeugung, folglich muß man auf ibfG Uberzeugungen einwirken, die Menschen von der Wahrheit überzeu-

Die notwendige Bedingung, unter der das allein geschehen kann, wird von Wenzler folgerndermaßen erläutert:

"Das ist aber nur so möglich, daß die Wahrheit in einer Gestalt erscheipt, in der sie als Appell an die Freiheit des Menschen verstanden werden kann."

Unter diesem Gesichtspunkt des absoluten Engagements betrachtete Solov'ev sowohl das Denken wie auch die Kunst; beide sind gleich notwendige Weisen verwandelnder menschlicher Kreativität. Doch das Entscheidende bei ihm ist, daß dieses Engagement sein Richtmaß nicht aus sich selbst bezieht, sondern aus dem "göttlichen Prinzip" des All-Einen. Darunter versteht er eine allem Sein zuvorlaufende Einheit der Welt, auf die 
sich Denken und Handeln vor ihrem kategorialen oder praktischen Einsetzen, in einem Seinsglauben verlassen. ${ }^{18)}$ Denn "um zu tun, was man soll, muß man wissen, was ist".

Kunst hat für Solov'ev entscheidenden Anteil an der Neu-Organisation der Wirklichkeit:

"(...) die Organisation unserer ganzen Wirklichkeit ist Aufgabe eines universalen Schöpfertums, Gegenstand einer großen Kunst - die Realisation des göttlichen Prinzips durch den Menschen in der ganzen empirisch-natürlichen Wirklichkeit, die Verwirklichung der göttlichen Kräftf durch den Menschen in der realen Existenz der Natur - die freie Theurgie." 20 )

Vor diesem umfassenden Hintergrund einer dem Menschen zugetrauten, aber ihm auch aufgegebenen "universalen Kreativität", die werthaft am "göttlichen Prinzip" der All-Einheit orientiert ist, muß man den ästhetischen Begriff des "preobraženie" bei Belyj verstehen. Daraus erklärt sich auch seine Forderung, daß der Symbolismus nicht allein eine "abgekapselte Kunstrichtung" sein wolle und dürfe. Neu hinzu kommt jedoch gegenüber Solov'ev, daß Kunst am "Umwertungsprozeß der Moderne" teilnehmen müsse (Probl. 8). Es gibt also Gemeinsames, aber auch gravierende Unterschiede zwischen Belyj und Solov'ev. Gemeinsam ist ihnen die wirkungsästhetische Ausrichtung ihrer Kunstauffassung. Gemeinsam ist ihnen aber darüber hinaus die Auffassung, daß Kunst nicht mehr als ein abgehobener Bezirk des kanonisierten Schönen gilt, als ein Reich des schönen Scheins, weitab von aller Lebenspraxis - wie noch bei Schopenhaver -, sondern daß Kunst im Rahmen einer "universalen Kreativität" verstanden wird, in der die Grenzen von Kunst und Leben durchlässig werden. Gemeinsam ist ihnen ferner, daß Kunst nicht Selbstzweck sei, sondern an Werten orientiert sein solle - der große Streitpunkt gegenüber V. Brjusov in der Symbolismusdebatte von 1910.

Sobald man aber diese Gemeinsamkeiten näher ins Auge faßt, treten aufschlußreiche Unterschiede zwischen Solov'ev und Belyj hervor. Wenngleich auch Solov'ev aufgrund seiner Uberzeugung von der "universalen Kreativität", an der jedes einzelne Individuum teilhabe, von der Verwandelbarkeit der Persönlichkeit überzeugt ist, so verläßt er bei alledem noch nicht den traditionellen Rahmen einer Wirkungsästhetik, wie er seit Aristoteles' Katharsislehre, seit Lessing und seit Schillers ästhetischer Erziehungsutopie gesetzt war. Neu bei Belyj und den Symbolisten hingegen ist die Auffassung, daß Kunst oder Literatur nicht mehr als in sich abgeschlossen-vollendetes Werk auf den Rezipienten einwirkt, sondern daß sich Verwandlung ereignet in der Interaktion zwischen einem Kunstwerk, das in einer offenen, signalgebenden oder fragmentarischen Form existiert, und einem Rezipienten, der bereit ist zum schöpferischen Mitvollzug. Das kann geschehen im Wiedererschaffen oder sogar im Zuendeerschaffen des Kunstwerkes.

In der Wertorientierung der Kunst zeigen sich wohl die gravierendsten Unterschiede. Bezieht die Kunst nach Solov'ev ihr Richtmaß nicht aus ihrem eigenen Engagement, sondern aus einem "absoluten Prinzip", so gilt das für die Symbolisten nicht mehr in 
dieser Form. Bei ihnen tritt die Verpflichtung, sich den Widersprüchen der Moderne auszusetzen und am "Umwertungsprozeß" teilzunehmen, in den Vordergrund. Die Werte, an denen die "Neue Kunst" orientiert ist, unterscheiden sich von denen Solov'evs dadurch, daß sie nicht mehr vorgegeben sind, sondern selber erst mit ihr erschaffen werden. Werte existieren nicht mehr innerhalb eines vorgegebenen Kanons, sondern nur innerhalb eines dynamischen Prozesses der Umwertung und Neuschöpfung. ${ }^{21)}$ Damit ist auch die Konzeption der All-Einheit berührt. War sie für Solov'ev noch ein göttliches Prinzip, aus dem er eine spekulative Wertmetaphysik herleiten konnte, so verliert sie im Symbolismus ihren durch Offenbarung garantierten Charakter. Sie geht aber deshalb nicht völlig verloren, sondern bleibt als religiöser Horizont erhalten, als "unendlicher Bezug" (Hegel), dem sich die modernen Künstler nur ex negativo oder allenfalls noch asymptomisch annähern können. Von daher läßt sich vielleicht die oben dargestellte Symbolkonzeption Belyjs vom Symbol als Prozeß noch besser verstehen.

Betrachtet man Belyjs Konzeption des "preobraženie" im Zusammenhang der Entwicklung seines ästhetischen Denkens, so lassen sich auch hier verschiedene Stufen unterscheiden. Am Anfang hat sein Konzept der Verwandlung noch vorwiegend prophetischen und proklamatorischen Charakter. Man kann auf dieser Stufe noch von einem Glauben an die Selbstläufigkeit der Vollendung der Welt sprechen, in dem sich noch der Fortschrittsglaube des neunzehnten Jahrhunderts auswirkt, wenngleich - wie oben schon gesagt - um die Dimension des Tragischen erweitert. Diese beiden Seiten finden Ausdruck in zwei verschiedenen Formeln, die den diametralen Metaphern von Himmel und Abgrund zugeordnet sind. Als die eine kann man Bal'monts "Budem kak solnce" (Laßt uns wie die Sonne sein) anführen, das "Künden" davon, daß der Menschheit, wenn sie sich nur verwandle, der "Weg direkt in den Himmel" gewiesen sei (O teur. 119). Die Gegenformel des "Tragismus", die auf die Gefahren von Scheitern und Untergang bei so hochgespannter Erwartung verweist, ist die vom "Leben zwischen Abgründen". 22)

Erst ab 1906 wird diese Konzeption des "preobraženie" verändert, und zwar durch die Verbindung mit dem Erlebnisprozeß pragmatisiert. Der naive Glaube an die Selbstläufigkeit ist gebrochen, die Schwerkraft persönlicher Erlebnisse und gesellschaftlicher Vorgänge (Revolution von 1905) ist stärker geworden. Eine Ernüchterung der idealistischen Position ist unübersehbar. Doch sie führt nicht zu Nihilismus und Resignation, sondern zu einer Aktivierung des individuellen, schöpferischen Einsatzes, zur Einsicht, daß Veränderung eine langwierige Arbeit erfordert. ${ }^{23)}$ Nicht durch prophetische Anklage und Verheißung, nicht durch Kontemplation des Wesens der Welt im Kontrast mit der Nichtigkeit der Phänomene ist Veränderung zu erwarten, sondern durch Vorantreiben der Erkenntnis dessen, was sein sollte; vor allem aber erst einmal durch Erschaffung des eigenen Selbst, sowie durch zähe Arbeit an einer Umwertung der alten Werte, an einer Erneuerung der Kultur mit den Mitteln einer neuen "Kunst der Zukunft". An die Stelle der Definition: Kunst ist die Höchstform der Erkenntnis, tritt jetzt die Auffassung von der Kunst als 
"Das Schöpferische setzt sowohl das Sein wie auch die Erkenntnis in Wirklichkeit um (Smysl 211)."

In der Ästhetik wird die Kategorie des "preobraŽenie" beibehalten, aber jetzt in ihrer Abhängigkeit von der Kreativität des Künstlers, von der künstlerischen Erlebnisstruktur und seiner formalen Befähigung, vor allem in "Sinn der Kunst", betrachtet. Auch der Leserbezug wird jetzt differenziert. Diese Wandlung innerhalb der wirkungsästhetischen Kategorie des "preobraženie" hängt ab vorn veränderten Verständnis der produktionsästhetischen Kategorie des "tvorčestvo", des "Schöpferischen". Wurde das Schöpferische zunächst von Belyj als intuitives Erkenntnisvermögen verstanden (Formy 170f.) worin er Schopenhauer nachfolgte - so wird jetzt darunter ein wertorientiertes Schaffensvermögen verstanden, das sich nicht allein in der Kunst verwirklicht (Smysl 211f.). In der Ästhetik wird Kunst nicht mehr vorwiegend als Erkenntnis und Form-Prozeß betrachtet - wie noch in "Formen der Kunst" - sondern als ein Schaffens-Prozeß, der neue kulturelle Werte hervorbringt, wenngleich nach wie vor in untrennbarer Abhängigkeit von ihrer formalen Gekonntheit, ihrer "Zweckmäßigkeit ohne Zweck", womit Kant ihr Gestaltprinzip definierte (Smysl 223), ${ }^{24)}$ dem Belyj voll zustimmt.

Worin liegt hier der Unterschied?

Vor allem darin, daß der Kunst ein neuer Gegenstand erschlossen wurde. Wenn nicht mehr allein die Anschauung der Welt - sowohl ihrer phänomenalen als auch ihrer noumenalen Seite -, also ihre Erkenntnis dominiert, für die eine neue angemessene Form gesucht wurde (und das tat Belyj in den Symphonien), sondern wenn als die wesentliche Aufgabe der Kultur, an der sich die Kunst beteiligt, die "Erfindung des inneren Menschen" (Musil) angesehen wird, dann ist auch "Verwandlung" nicht mehr allein ein Vorgang, in dem Erkenntnis gewonnen wird: so ist es in der Welt, so kann oder sollte es sein - sondern ein darüber hinausgreifender Prozeß der Selbstwerdung. In "Kunst der Zukunft" (1907) schreibt Belyj:

"Ein Künstler ist vor allem Mensch; sodann erst ist er Spezialist seines Handwerks (...) so übertragen wir die Frage nach dem Ziel der Kunst von der Betrachtung der Produkte des Schaffens auf die Prozesse des Schaffens selbst; die Produkte des Schaffens - das ist Asche und Magma; die Prozesse des Schaffens - flüssige Lava. (...) Mit der Kunst, mit dem Leben steht es weitaus ernster, als wir denken; der Abgrund, über dem wir hingen, ist tiefer und finsterer geworden. Um herauszukommen aus dem circulus vitiosus der Widersprüche, müssen wir aufhören, über was auch immer zu reden, sei es Kunst, Erkenntnis oder unser Leben selbst.

Wir müssen das Gegenwärtige vergessen: wir müssen alles aufs neue umschaffen: dazu müssen wir uns selbst neu erschaffen. selbst.

Und der einzige Steilhang, über den wir noch klettern können, das sind wir

Auf dem Gipfel erwartet uns unser Ich.

Das ist die Antwort an den Künstler: wenn er Künstler werden will, ohne 
aufzuhören Mensch zu sein, so muß er seine eigene künstlerische Form werden. Nur diese Form des Schöpferischen verheißt uns noch Rettung. 53).

"Hjer ist es, wo der Weg einer Kunst der Zukunft liegt (Buduščee, 450 -

Das innere Werden des modernen Menschen, seine "Menschwerdung" - von der auch Blok spricht ${ }^{26)}$ - die noch aussteht, das wird zum neuen Gegenstand der Kunst, mit dem sie ihren Beitrag zur Erneuerung der Kultur leisten kann: "peresozdanie sebja i mira (das Umschaffen des Selbst und der Welt, Smysl 223)." Was Belyj hier als "Kunst der Zukunft" bezeichnet, scheint - wie schon gesagt - die Wendung der Dichtung zur Bewußtseinskunst, vor allem zum Bewußtseinsroman, zu beschreiben. Die Entdeckung des Themas des "Ich" kann als eine seiner Quellen gesehen werden. Bei Belyj selbst ist diese Wendung mit der Arbeit an der Vierten Symphonie eingeleitet, wie man aus dem Vorwort entnehmen kann. 27)

Belyj war sich sehr klar darüber, daß diese "Kunst der Zukunf $t$ " auch einen neuen Typus von Leser erfordern würde. Die Konsequenzen für die Einschätzung des Lesers lassen sich an der Weiterentwicklung des "preobraženie" ablesen. Die Rolle des Lesers wird noch weiter aufgewertet. Hatte Belyj vorher schon die Notwendigkeit seiner Mitwirkung als Entzifferer der Sprache und geistig erweckter Rezipienten gefordert, so wird ihm jetzt noch weiteres zugemutet: nämlich die kreative und mitschöpferische Ergänzung des Kunstwerkes: "nužna rabota pretvorenija" (notwendig ist die Arbeit des Umschaffens). T.S. Eliot sieht in der modernen Kunst einen "raid on the inarticulate". Eben darum, um den noch unentdeckten Planeten "Mensch", bzw. "Ich", geht es auch bei der Kunst des neuen Gegenstandes der "Selbstwerdung" des modernen Menschen. Wenn sie wirken soll, muß der Leser eine kreative Ergänzung des Künstlers sein, er muß sich und seine kognitiven und verstehenden Kräfte aktivieren, den Gegenstand in seine eigene Sprache und Erfahrungsbreite übersetzen. Bei solchem Engagement wird und muß er sich "verwandeln".

Belyj spürt hier theoretisch im Vorhinein die eigene und die europäische Wende zum Bewußtseinsroman auf. Das scheint mir eine wichtige Einsicht in sein ästhetisches Denken zu sein, die man bei der Lektüre seiner Schriften gewinnen kann. Seine Konzeption des "tvorčestvo" und des "preobraženie" führen uns den Künstler und den Leser der modernen Bewußtseinsdichtung vor Augen. Beide haben ein Reflexions- und Formniveau erreicht bzw. zu aktivieren, das sich von der ästhetischen Einstellung im Rahmen der tradtionellen Kunst unterscheidet. Man kann es auch so sagen: Moderne Kunst, die den tradierten Kunstcharakter sowohl thematisch als auch formal sprengt, befremdet den Rezipienten. Sie kann faszinieren, hält aber zugleich auch auf Distanz. ${ }^{28)}$ So kann die Intensität neuer Formen - in der Dichtung etwa rhythmisierte Sprache, verbunden mit suggestiver Bildkraft - starke Anziehung auf die ästhetische Wahrnehmung ausüben; semantische Rätsel oder gebrochene Erzählstrukturen z. B. erzeugen dagegen oft Ver- 
ständnisstörungen. Es bleiben entweder Unbehagen oder mehr oder weniger hartnäckige Neugier zurück. Moderne Kunst kann nicht mehr in erster Linie als Genuß oder Erbauung wirken. Vielmehr heischt sie vom Rezipienten offen oder verdeckt seine Mit-Arbeit: Sie läßt ihn nicht in Ruhe, sondern beschäftigt ihn weiter - vorausgesetzt, er läßt das überhaupt zu, und winkt nicht von vornherein ab. Es spricht viel dafür, mit Belyj die kreative Rezeption moderner Kunst als eine spezifisch moderne Form nicht entfremdeter Arbeit anzusehen, deren kreatives Potential prototypischen Wert hat. 


\section{SCHLUS S :}

\section{Modell des kreativen Prozesses}

Zum Schluß soll noch einmal zurückgeschaut werden auf Belyjs eigenes Urteil aus dem Todesjahr 1934 über die "Summe" seines ästhetischen Diskurses der Jahre 1902 bis 1910, wie er sie in seinem Sammelwerk "Symbolismus" gebündelt hatte. Eine Chance konnte er seinem Buch nur geben, wenn es Leser fände, die es - trotz aller Deformationen und der Hektik, in der es entstanden war - lesen würden, als "Denkmal der Epoche" und gegen den Strich herkömmlicher Erwartungen an Werke mit Theorie-Anspruch. Das bedeutet aber, daß er auch mit einem nicht herkömmlichen Leser rechnete, von dessen produktivem Verstehen das Schicksal seines Theoriewerkes wesentlich mit abhängen werde. Im Nachhinein kann man in diesen Worten Belyjs eine Leseanweisung erkennen. Denn er legt damit doch vor allem seinem Leser nahe, die Bedingungen der Möglichkeit und die spezifische Gestalt des Denkens einer solchen Theorie, wie er sie hervorbrachte, mit zu bedenken.

Ohne daß das etwa von vornherein klar beabsichtigt gewesen wäre, zeigt sich nun im Rückblick, daß der Gang der Uberlegungen in unserem Versuch, Belyj zu verstehen, dieser Anweisung gefolgt ist. Anstatt sich sofort bedingungslos den Leitlinien seiner Ästhetik zuzuwenden, wurden zunächst die besonderen Voraussetzungen untersucht, die sowohl in Belyjs eigenem Wesen und Denken liegen, wie auch in seiner Epoche: daher die typologische Zuordnung zum Dichtertypus des poeta doctus und die Uberlegungen zum historischen Ort der Theoriebildung in Rußland; daher die Analyse von Krisenbewußtsein und Krisentendenzen, zusammengefaßt unter dem Suchbegriff der Kulturkrise; daher schließlich auch die Betrachtung der eigentümlichen Denkstruktur Belyjs.

Doch nicht nur im Vor- und Umfeld der Theorie war der Grundsatz des Kantschen Kritizismus, die Frage nach den Bedingungen der Möglichkeit, anzuwenden, sondern auch im Innenraum der Theorie: denn das Hauptstück der Kunstlehre Belyjs, die Methode der Symbolisierung, erschien nur verständlich aus einer Analyse seines multilateralen Wirklichkeitsbegriffes. Schon dabei zeigt sich der eigentliche Grundzug des Belyjschen Denkens - aus dem sich die verschiedenen Funktionsformen des hypothetischen, experimentellen, perspektivischen Denkens erklären. Belyjs Denken gilt nicht dem Aufbau eines Systems oder Lehrgebäudes, sondern es ist ein Denken in fortwährender Bewegung, das sich in produktiver Auseinandersetzung mit anderen geistigen Strömungen seiner Zeit weiterentwickelt. (Den Leitfaden dafür sollte der Kommentar liefern, von Belyj bewußt als Dokumentation des geistigen Hintergrundes seiner Entwicklung konzipiert.) Sein ästhetisches Denken ist daher nicht Systemdenken, sondern Prozeßdenken. Diese Bewegung ist aber nicht als geistige Reizüberflutung eines schwankenden Eklektikers zu verstehen, sondern es gibt - wie gezeigt wurde - bestimmte Konstanten und viele Variable. 
Zu den Konstanten gehören vor allem die beiden komplementären Axiome: 1) "schöpferische Energie" oder "Energie der Kreativität", die prinzipiell jedem Bewußtsein zugetraut und von Belyj zur unveräußerlichen anthropologischen Grundausstattung des Subjekts gerechnet wird; 2) der ebenso prinzipielle Glaube an die Verwandelbarkeit der Wirklichkeit. Je klarer diese beiden Konzepte hervortreten, umso mehr verschiebt sich Belyjs ästhetisches Interesse von den "Resultaten" der Kunst (vor allem von den Großformen der Künste) auf die Prozesse des künstlerischen Schaffens. In dem Maße wie er zunehmend unter immer neuen Perspektiven die Stadien und Dimensionen des schöpferischen Prozesses reflektiert, wandelt sich der ästhetische Diskurs Belyjs von einer Theorie der "schönen Künste" zu einer "Theorie der Kreativität", die auch die "nicht mehr schönen Künste" (Jauß) einbegreifen kann. Eng verbunden mit dem Interesse an der produktionsästhetischen Seite ist die zunehmende Aufwertung der Leserrolle, bzw. der Position und Bedeutung des Rezipienten.

Bei dem Versuch, Belyjs Ästhetik unter Gesichtspunkten zu analysieren, die sich mit seiner eigenen Leseanweisung als übereinstimmend erwiesen haben, konnte vor allem die Erfahrung gemacht werden, daß auch der hermeneutische Vorgang des Verstehens seiner ästhetischen Theorie der Kreativität nicht im mimetischen Nachvollzug bestehen konnte. Ein deskriptives Verfahren hätte nur die verwirrende Oberflächenstruktur seiner Texte erfassen können und wäre bei der Konstatierung eines "Haufens von schreiend widersprüchlichen Artikeln" stehengeblieben, oder hätte den "Koloß auf tönernen Füßen" gestürzt. Belyj war sich der hybriden Oberflächenstruktur seiner Theorie selber bewußt. Statt eines reproduzierenden Summierens ist ein produktives Verstehen nötig, das die verwirrende Oberflächenstruktur absucht auf Elemente, die einer darunterliegenden, in sich konsistenten Tiefenstruktur angehören.

Auch Belyjs ästhetische Theorie - nicht nur seine innovatorische Dichtkunst - erfordert einen kreativen Leser, der sich nicht durch seine vielfältigen Abweichungen vom gewohnten Denken in vorgespurten Bahnen abschrecken läßt. Nimmt man also die Lizenzen als produktiver Leser Belyjs in Anspruch, so darf man wohl die Chance nutzen, an seinem Denken "mitzuwirken". Und mir scheint es deshalb auch methodisch gerechtfertigt, die Grundzüge oder Leitlinien seines ästhetischen Diskurses in einem Modell anzuordnen, das er selber zwar so nicht vorgegeben hat, zu dem er aber sowohl die Bestandteile als auch die Verknüpfungsanweisungen bereitstellt. 


\section{Drei Stadien der schöpferischen Bearbeitung der Wirklichkeit}

Grafik Nr. 1: Die drei Phasen des kreativen Prozesses
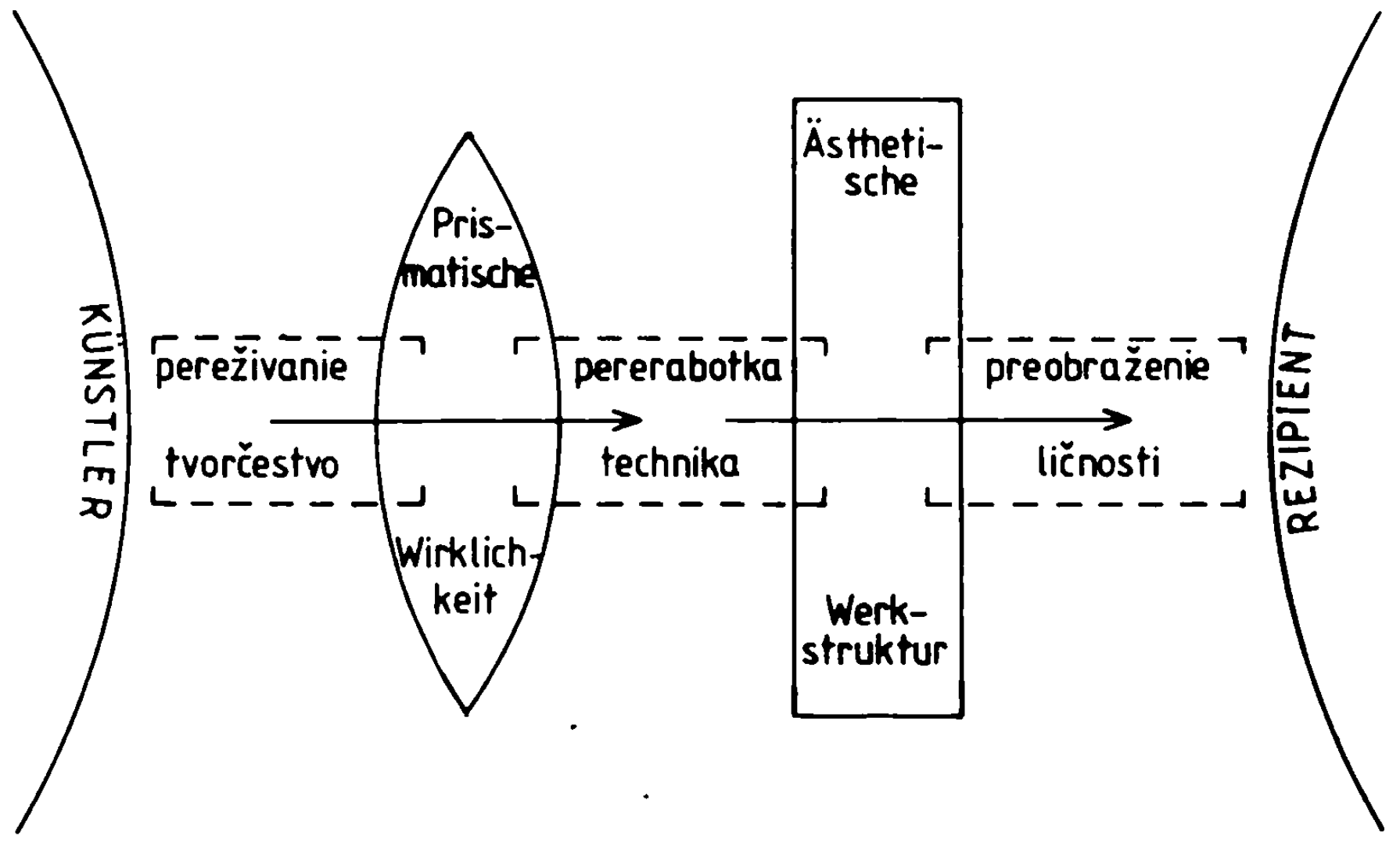

Innerhalb des kreativen Prozesses, in dem Kunst hervorgebracht wird und ihre Wirkung entfaltet, unterscheidet Belyj drei Phasen (oder Dimensionen) schöpferischer Bearbeitung der Wirklichkeit. Seine Grundthese:

"Die Kunst ist schöpferische Bearbeitung der Wirklichkeit durch die innere Energie des künstlerischen Subjekts."

läßt sich demnach in dreifacher Hinsicht entfalten.

1. "Pereživanie-tvorčestvo - schöpferische Aneignung der Wirklichkeit und Konstitution des Gegenstandes der Kunst als "prismatische Wirklichkeit".

Für Belyj beginnt der schöpferische Prozeß nicht erst mit dem Formprozeß des Werkes im engeren Sinne, sondern er bezieht bereits das vorauslaufende Stadium der ästhetischen Wahrnehmung und Erfahrung der Wirklichkeit ein. Auf der anderen Seite endet der kreative Prozeß auch nicht im vollendeten Werk, sondern er wird aufgefaßt als 
Kommunikationsprozeß, der den Rezipienten und seine ebenfalls schöpferisch gedachte Mitwirkung einschließt und eigentlich ihn zum Ziel hat in der Wirkabsicht des "preobraženie ličnosti". 1)

In der ersten Phase geschieht also eine schöpferische Aneignung der Wirklichkeit, die zu den Bedingungen des künstlerischen Subjekts vor sich geht. ${ }^{2}{ }^{2} \mathrm{Zu}$ ihnen gehören wahrnehmungsästhetische, ideelle und psychologische Komponenten:

a) die künstlerische Wahrnehmung des "Sehen-Könnens", des "Neuen Sehens" und der "Tiefe der künstlerischen Anschauung"; b) die ideelle Konstruktion der Wirklichkeit aus dem Verhäl tnis ihrer empirischen und ideellen Komponenten; c) die ganzheitliche Erlebnisstruktur aus den Konstituenten des Verstandes, des Gefühls und des Willens, deren Grenzwerte größtmögliche Differenziertheit, Intensität und Totalität sind.

Bereits in dieser ersten Phase, also bereits in der je eigenen Art und Weise des Künstlers, sich der Wirklichkeit zu nähern - in seinem Weltverhalten - setzt die Methode der Symbolisierung ein. Schon in der künstlerischen Wahrnehmung wird damit begonnen, eine Innen-Außen-Relation herzustellen; an sich "bildlose" innere Erfahrungen werden in Beziehung gesetzt zu Dingen oder Vorgängen in der Außenwelt. ${ }^{3)}$ In der ideellen Auffassung der Wirklichkeit wird der "unendliche Bezug" der Innen-Außen-Relation zur Welt der Ideen hergestellt. Beide wirken aufeinander ein: der vertikale Bezug zur Idee und der horizontale Vorgang der Innen-Außen-Relation werden in der Erlebnistotalität kombinatorisch miteinander verflochten.

Man kann sagen, daß hier eine "primäre" Bearbeitung der Wirklichkeit stattfindet, in der das poetisch wahrnehmende und reflektierende, das erlebende und in der produktiven Einbildungskraft imaginierende Bewußtsein des Künstlers ein Weltverhältnis erschafft, in dem der Gegenstand der Kunst als "prismatische Wirklichkeit" konstituiert wird. Auf diese Weise wird die Notwendigkeit, aus der Fülle der Gegenstandswelt eine Selektion zu treffen, nach den Bedingungen der schöpferischen Aneignung des künstlerischen Subjekts er füllt.

2. "Pererabotka-technika" - die formale Bearbeitung der "prismatischen Wirklichkeit" zu einem künstlerischen Gebilde

Das zweite Stadium des kreativen Prozesses ist bestimmt von der Einwirkung formal-objektiver Faktoren der Realität, die die äußere Form des Kunstwerks konstituieren: von den Kategorien des Raumes und der Zeit, von der Notwendigkeit zur Stilisierung oder Typisierung, von der Beschaffenheit der Sprache als einer zugleich zeichenhaften und energetischen Struktur, von den Konstruktionsgesetzen der Bildfügung und Bildverknüpfung und schließlich vom Rhythmus, der aus Erlebnisinhalten, Bildzusammenhang und Wortklängen entsteht und formende Kraft ausübt.

Die Methode der Symbolisierung tritt hier in der Phase der Versprachlichung der 
"prismatischen Wirklichkeit" hervor. Sie hat aber wie gesagt an beiden Stadien des kreativen Prozesses Anteil: schon im ersten Stadium wirkt sie innerhalb des Konzeptionsvermögens der produktiven Einbildungskraft, im zweiten dann innerhalb des poetischen Vermögens, sprachkünstlerische Verfahren zu entwickeln. Man kann dieses Stadium als "sekundäre" Bearbeitung der Wirklichkeit bezeichnen. Hier wird die "prismatische Wirklichkeit" der Kunst in einem "technischen Arbeitsprozeß" zum fertigen Kunstwerk gestaltet. Jetzt muß allerdings angemerkt werden, daß es sich bei der Unterscheidung der ersten beiden Phasen nur um eine idealtypische Trennung und Nacheinanderschaltung handelt. Im einzelnen Falle müssen sie nicht nacheinander ablaufen. Vielleicht tun sie das überhaupt niemals, sondern es können sowohl aus dem ersten Stadium als auch aus dem zweiten Anstöße zur künstlerischen Bearbeitung der Wirklichkeit kommen: sowohl aus dem Erleben oder von Ideen, Wahrnehmungen als auch von Materialbeschaffenheit, Sprachstruktur, Klang, Rhythmus, von bestimmten poetischen Verfahren. Literarische Traditionen können einwirken oder werden bewußt gebrochen.

In der formalistischen Kunsttheorie wurde zeitweise der "technische Arbeitsprozeß", das Stilistisch-Handwerkliche an der Kunst, verabsolutiert; aus den Faktoren der primären Aneignung der Wirklichkeit wurde einseitig die wahrnehmungsästhetische Komponente des verfremdenden "Neuen Sehens" herausgelöst. ") In der Erlebnisästhetik dagegen wurden - ebenfalls einseitig - die ideellen, philosophischen und biographisch motivierten Faktoren überbewertet. In Belyjs Ästhetik kann man den Versuch erkennen, beide Bereiche in ihrer Wirksamkeit im kreativen Prozeß zu berücksichtigen. Die Methode der Symbolisierung kann als ein kreatives Modell der Methode der Verfremdung gegenübergestellt werden.

Die beiden ersten Stadien der schöpferischen Aneignung und Bearbeitung der Wirklichkeit sollten hier heuristisch getrennt betrachtet werden, um ihre Bedingungen und partiellen Abläufe leichter erkennen zu können. ${ }^{5)}$

3. "Preobraženie ličnosti" - die energetisçhe Auffassung von der Kunst als Kommunikationsprozeß

Doch mit den beiden ersten Stadien wird der kreative Prozeß nach Belyj nicht beendet, sondern er findet erst im Leser seinen Abschluß. Ziel der Kunst ist für Belyj nicht das vollendete Kunstwerk als Selbstzweck, sondern das "preobraženie ličnosti", die "Verwandlung der Persönlichkeit". Belyj versteht den kreativen Prozeß, in dem Kunst hervorgebracht wird und wirkt, als eine besondere Form von Kommunikation: man kann sagen, daß er in der ästhetischen Kommunikation den idealen Fall gelungener Mitteilung sieht (in einer eigens mit ihr erschaffenen Form), die zur Veränderung in den "Formen des seelischen Lebens" führen kann. Noch das dritte Stadium des kreativen Prozesses ist von der Wirkung der "schöpferischen Energie" im Künstler bestimmt. Durch das "Material" der Kunst, das in der schöpferischen Aneignung der Wirklichkeit zur "prismatischen 
Wirklichkeit" umgeschaffen, das mit poetischen Verfahren formal zur Gestalt gebracht wurde, durch dieses "Material" und durch das fertige Kunstwerk hindurch wirkt die "schöpferische Energie" auf den Leser ein, der selber schöpferisch "entgegenkommend" gedacht wird. Im Vorgang des "preobraŽenie" (während einer kreativ gedachten Rezeption von Kunst) findet die Auswirkung der "primären" und "sekundären" Bearbeitung der Wirklichkeit durch das künstlerische Subjekt auf das Bewußtsein je verschiedener, aber ebenfalls kreativ vorgestellter Rezipienten statt. Belyj rechnet damit, daß die Kunst zur Verwandlung der Persönlichkeit fähig sei. Damit setzt er sich einerseits über die Verstehensschwierigkeiten bei einem konservativen Lesepublikum hinweg, andererseits hält er sie aber auch für überwindbar, indem er ein Anspruchsniveau schafft und aus seinem Bewußtseinsidealismus heraus auch begründet, das die Rolle des Lesers beträchtlich aufwertet.

Grafik Nr. 2: Die drei Phasen des kreativen Prozesses und der doppelte Wirklichkeitsbegriff

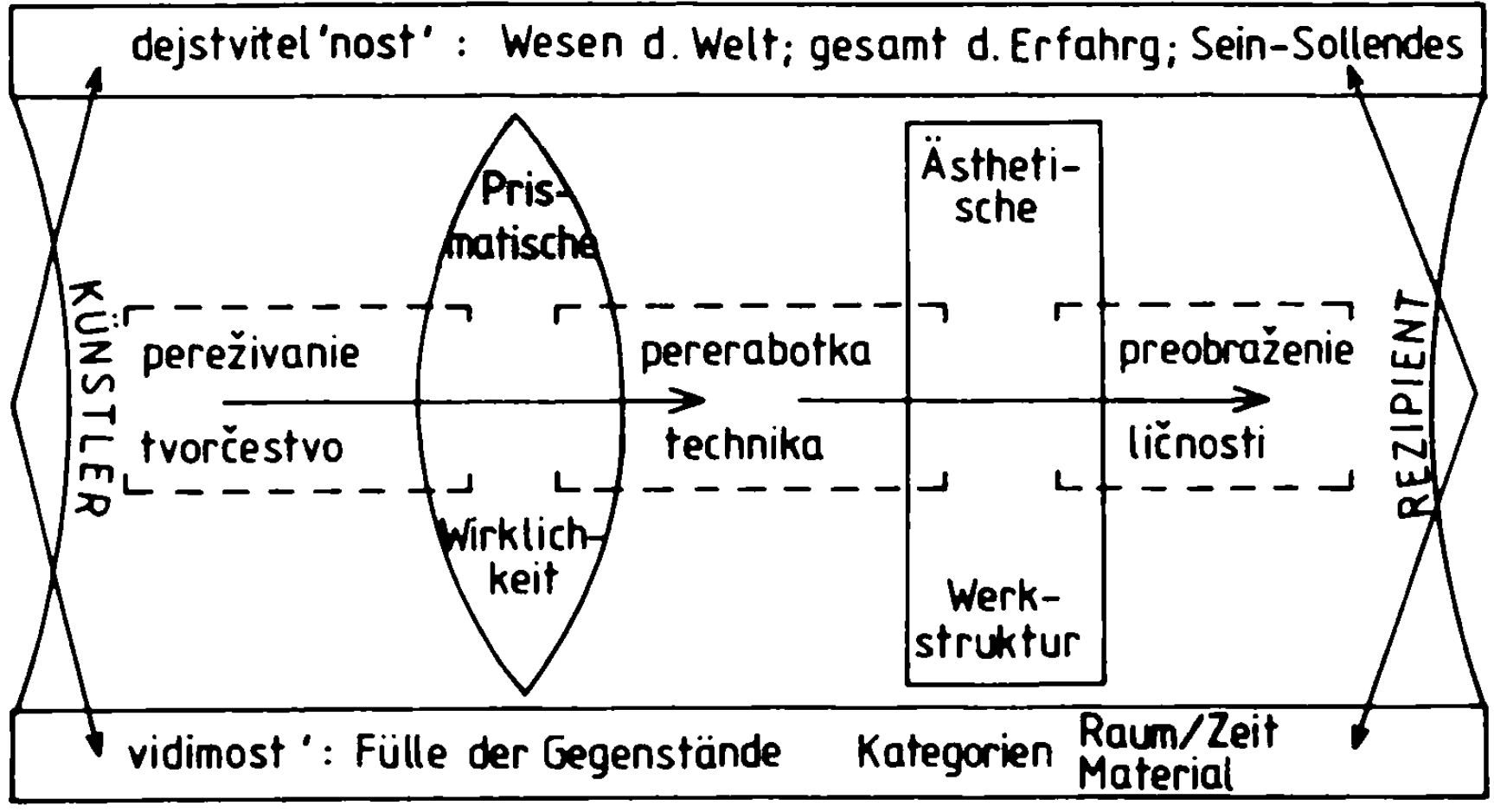

Auf alle drei Phasen des kreativen Prozesses wirken nach Belyj die beiden Ebenen, die er innerhalb seines mehrdimensionalen Wirklichkeitsbegriffes unterscheidet, ein: die empirische und die ideell-metaphysische, die Erscheinungswelt (vidimost') und die umfassendere Wirklichkeit (dejstvitel'nost').

Die Einwirkung der beiden Wirklichkeitsbereiche auf den kreativen Proze $B$ ist von Belyj in der Entwicklung seiner Theorie verschieden beurteilt worden, wie oben im Kapitel über den Wirklichkeitsbegriff dargelegt wurde. In dieser Modellskizze kann das nur sehr vereinfacht angedeutet werden. 
Grafik Nr. 3: Die drei Phasen des kreativen Prozesses, der doppelte Wirklichkeitsbegriff und das entfaltete Konzept des "pereživanie"

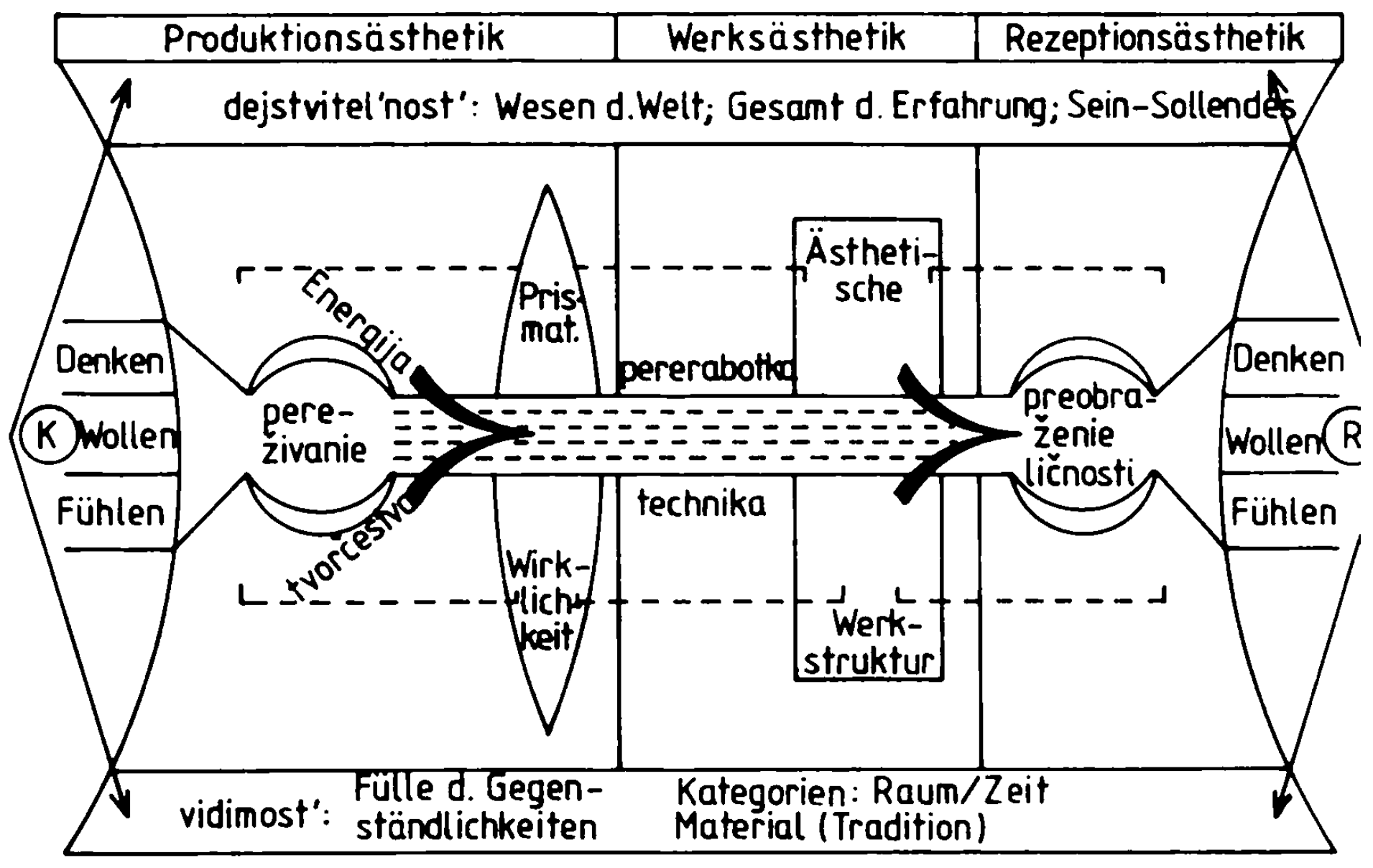

Den drei Phasen des kreativen Prozesses nach Belyj lassen sich drei Hauptgebiete der allgemeinen Ästhetik zuordnen: die Produktionsästhetik, die Werkästhetik und die Rezeptionsästhetik. Die treibende Kraft des kreativen Prozesses sieht Belyj in der "schöpferischen Energie". Und dieses energetische Moment hat er immer beibehalten. In der entfalteten Form seiner Theorie verbindet er den energetischen Ansatz mit dem Erlebniskonzept, das er in "Sinn der Kunst" 1907 unter dem prägenden Einfluß der Psychologie Wundts entwickelt. ${ }^{6)}$ Wieweit ihn auch Diltheys Erlebnisbegriff dabei beeinflußt hat, ist noch zu erforschen. Auf jeden Fall zitiert er ihn im Kommentar zu "Simvolizm" ausführlich. ") Wichtig ist, daß Belyj die Energie der Kreativität nur dann voll wirksam sieht, wenn im "Zusammenhang des Seelenlebens" (Dilthey) alle drei psychischen Grundkräfte: Denken, Wollen und Fühlen zusammenwirken. Gleiches gilt analog für die schöpferische Rezeption. 


\section{Zur Autonomie der Kunst. Einige Folgerungen aus Belyjs Modell des kreativen Pro- zesses}

Zur Auseinandersetzung um die Autonomie der Kunst, wie sie von den Symbolisten im "Symbolistenstreit" von 1909 geführt wurde, in dem sich zwei Gruppen gegenüberstanden: auf der einen Seite Brjusov und hinter ihm die "Künstler" der "Welt-der-Kunst"Gruppe und des kommenden Akmeisraus; auf der anderen Seite die "Philosophen", zu denen in verschiedenem Grade V. Ivanov, Belyj und Blok gehörten, die auf dem Boden der "positiven" Ästhetik in der Nachfolge Solov'evs standen und seinem Theurgie-Konzept nahestanden, - läßt sich aus der zusammenfassenden Modellskizze des kreativen Prozesses nach Belyj einiges verdeutlichend dazu sagen, inwiefern Belyj zwischen beiden Extrempositionen eine mittlere Stellung einnimmt. Er vertritt nämlich die These: wenngleich die Kunst sich als Bestandteil der Gesamtkultur versteht und der Künstler eine weltanschauliche Basis hat, von der er Ziele der Kunst ableitet und damit seinem Schaffen Werte setzt, so kann und muß dennoch von der Kunst als einem autonomen Bereich gesprochen werden.

Belyj kann die Kunst vor allem deshalb nicht als einen Bereich von absoluter Autonomie ansehen, weil er sie nicht mehr im Rahmen der spätbürgerlichen Auffassung von Kunst begreifen kann, in der sie als ein Reich des schönen Scheins gilt, das von aller banalen Lebenswirklichkeit abgetrennt ist, sondern im Rahmen einer Auffassung von Kreativität, die nicht auf das künstlerische Bewußtsein allein beschränkt ist. Belyj versteht Kunst im Rahmen einer schöpferischen Grundhaltung, die in allen Bereichen der Kultur notwendig ist. Sie ist unvereinbar mit jeglichem Dogmatismus und besteht darin, daß Schöpferisches immer zugleich die ganze Psyche an den jeweils dominierenden Einzelfähigkeiten teilhaben läßt. So ist bei einem großen Wissenschaftler, dessen Ratio dominiert, Kreativität erst dann möglich, wenn er nicht einseitig ratioid ist; bei einem großen Staatsmann, wenn er nicht allein politisch-strategisches Genie besitzt; bei einem Dichter, wenn er nicht auf Inspiration oder Technik allein beschränkt bleibt. Was das "Schöpferische" angeht, so hebt Belyj einen ebenso wichtigen wie gefährlichen Tatbestand hervor: Obwohl das Schöpferische anscheinend allgemein anerkannt und verehrt wird - sieht es aber im konkreten Fall oft anders aus: es löst bei seinem Auftauchen Angst und Anfeindung aus; das hat oft genug dazu geführt, daß schöpferische Menschen nicht verstanden oder schlimmer noch, unter Pathologieverdacht gestellt wurden (Formy 151).

Das künstlerische Bewußtsein wird vor dem Hintergrund einer allgemeineren Auffassung von Kreativität als gesteigerter Sonderfall betrachtet. Daher unterscheidet es sich nach Belyj von dem des engagierten Rezipienten - abgesehen vom formalen Talent nicht grundsätzlich, sondern nur graduell. Belyjs Ästhetik ist deshalb von der Genieästhetik abzugrenzen, und zwar in doppelter Hinsicht: in bezug auf den Künstler und in bezug 
auf den Rezipienten. Dem Künstler wird nicht absoluter Ausnahmecharakter als Genie zugesprochen, der Rezipient nicht von vornherein als beschränkt oder als Banause angesehen (oder ausgespielt gegen die wenigen Kongenialen, die meistens selber Künstler sind), sondern Belyj glaubt an seine schlummernden schöpferischen Möglichkeiten. Die spezifischen Äußerungsformen des Schöpferischen im Künstler sieht Belyj in der besonderen Kombination von Fähigkeiten, wie sie innerhalb der ersten und zweiten Phase des künstlerischen Prozesses nötig sind: also die besondere Weise der künstlerischen Wahrnehmung, die Herstellung eines "Weltverhältnisses" als Prisma der Wirklichkeit, der ekstatische Wille zu Ausdruck und Verwandlung, sowie das Talent im Umgang mit poetischen Verfahren. Formales Talent allein kann deshalb nach Belyj große Kunst nicht hervorbringen.

Was nun die Autonomie der Kunst angeht, so sieht Belyj sie in folgendem: Wesentlich für jeden Faktor der "kreativen Kombination" beim Künstler ist, daß er für sich genommen ein autonomer Vorgang sein darf und keinerlei normativen Forderungen unterstellt werden darf. Die einzige Norm, die Gültigkeit hat für den kreativen Prozeß der Kunst, ist der Höchstgrad von Intensität und Totalität, sowie das freie und größtmögliche Zusammenwirken aller Faktoren. Die Autonomie der Kunst ist also bereits in der "primären" Bearbeitung der Wirklichkeit durch das nicht beschränkte poetische Bewußtsein begründet. Wird es bereits in der ästhetischen Erfahrung, die per se unbotmäßig ist, behindert, so nützt ihm formale Uneingeschränktheit wenig oder nichts. Wird Autonomie bereits hier verfehlt, kommt es zu den schon beschriebenen einseitigen Fehlformen der Tendenzkunst (mit eingeschränkter ästhetischer Wahrnehmung und einseitigem Ideenbezug oder Moralappell) oder zur L'art-pour-l'art-Kunst, im Sinne eines preziösen Genusses an der Wahrnehmung bzw. Empfindlichkeit oder der Form als Selbstzweck, mit mangelndem Ideenbezug und ethischer Defizienz. Wie in der "primären" ist die Autonomie der Kunst aber auch in der "sekundären" Bearbeitung der Kunst begründet oder kann hier verfehlt werden. Die Entwicklung neuer poetischer Verfahren einzuschränken - was von einem formfeindlichen Typ von Zensur versucht wird -. ist eine andere Weise, die Autonomie der Kunst zu verletzen. Belyj vertritt die Ansicht: nicht von einer weltanschaulichen oder werthaften Einstellung des Künstlers aus, sondern von Versuchen, die einzelnen Faktoren des kreativen Prozesses zu reglementieren, droht der Kunst Schaden an ihrer Autonomie.

Wenn von Autonomie der Kunst gesprochen wird - so zeigt Belyj außerdem - dann ist allerdings zu berücksichtigen, daß der Künstler nie isoliert schafft, sondern daß er innerhalb eines Epochen- und Traditionszusammenhanges steht. Auf diese unvermeidlichen Einwirkungen auf die "Autonomie" des einzelnen Künstlers kommt er bereits in "Formen der Kunst" zu sprechen. Der Rang eines Künstlers bemißt sich nicht zuletzt danach, in welchem Verhältnis er zu diesen Bedingungen steht. Bereits in der Phase der "schöpferischen Aneignung" der Wirklichkeit, in der sie zu einer "prismatischen Wirklichkeit" umgeschaf- 
fen wird, kommt es innerhalb einer Generation oder Epoche zu Erlebnis- oder Wahrnehmungsmustern, zu vorbildhaft wirkenden Kombinationen von Gegenstandserfahrung, Emotions- oder Stimmungspatterns, die "Typen prismatischer Wirklichkeit" schaffen, die dann als bevorzugte Sujets in der Kunst erscheinen. Schrittmacher solcher typisierender Prismatisierung waren z. B. Botticelli: Frühling; Goethe: Werther; Böcklin: Toteninsel; Klinger: Blaue Stunde. Daraus erklärt sich u. a. die "Schulbildung", vor allem in der Malerei, in der Individuelles kanonisiert wird, in der dann schließlich epigonal kopiert wird.

Die typisierende Prismatisierung von Gegenständen für die Kunst hat - nach Belyj noch weitere Implikationen. Sie wirkten sich nicht nur auf die Kanonisierung bestimmter Sujets aus, sondern - darüber hinaus - auf die Kanonisierung ästhetischer Ideale von Schönheit. An diese Prismentypen, die mit bestimmten kunsttechnischen Verfahren gestaltet werden, heften sich Auffassungen von ästhetischer Schönheit, die als Darstellungskonventionen allgemeine ästhetische Verbindlichkeit beanspruchen oder erlangen. Sie begründen den ästhetischen Kanon einer Epoche, der vom Publikum akzeptiert und nicht selten aus Gewohnheit verabsolutiert oder für "überzeitlich" erklärt wird. Treten nun Künstler auf, die z. B. aufgrund der Abweichung eines der Faktoren der "primären" Bearbeitung diese Prismentypen verändern, oder aber Künstler, die zwar die Prismentypen nicht verändern, aber neue ästhetische Verfahren einführen, dann wird - auf je verschiedene Weise - der bestehende Kanon vom Künstler verletzt. Der Rezipient ist zunächst verprellt. Für ihn kommt es jetzt darauf an, ob er oder wie lange er dem alten Kanon verhaftet bleibt, oder ob er genügend kreative Mitarbeit aufbringt, um die Änderung des Kanons als neue Möglichkeit der Kunst zu begreifen. Als ein Beispiel dafür, wie ein bestimmter Faktor der "primären" Bearbeitung der Wirklichkeit zur Abweichung vom bestehenden Kanon führen kann, führt Belyj die "Tiefe der künstlerischen Anschauung" an. Gerade sie kann - da an der "inneren Wahrheit" eines Gegenstandes verschiedene Seiten "erschaut" werden können - zu einer neuen Weise der Prismatisierung führen, die eine Abweichung vom akzeptierten Kanon zur Folge hat. Belyj führt als Beispiel Monets Seerosen-Bilder an. Mit diesen Uberlegungen gibt er eine einleuchtende Erklärungsmöglichkeit für die Historizität bestimmter ästhetischer Schönheitsideale.

Bei dieser Gelegenheit weist er noch auf eine weitere interessante Tatsache hin: die Abweichung vom bestehenden Kanon wird im allgemeinen vom Publikum oder von der etablierten Kunstkritik nicht neutral festgestellt, sondern in die Form eines negativen Werturteils gekleidet. Belyj besteht aber darauf, daß es sich genau umgekehrt verhalten kann: die Erzeugung einer neuen prismatischen Wirklichkeit in der Kunst, die durch die "Tiefe der künstlerischen Anschauung" hervorgerufen wurde, ist eigentlich gerade die Quelle für ein positives Werturteil, insofern nämlich als sie ermöglicht, über die Tradition hinweg, Kunstwerke ganz verschiedener Kanonisierung einander als gleichrangig zuzuordnen. Gerade aufgrund der Originalität, mit der jeweils Wirklichkeit angeschaut wur- 
de, läßt sich gleicher Rang von Werken z. B. der Renaissance mit denen der Moderne begründen, Werke also mit ähnlich hohem Rang bei ganz verschiedenem ästhetischem Ideal.

Mit dieser Situation eines umbrechenden Werte- und Formenkanons war Belyj als Künstler der Jahrhundertwende konfrontiert und reflektiert sie deshalb besonders in seiner Kunst theorie. 


\section{ANMERKUNGEN}

\section{EINLEITUNG:}

\section{POSITIONEN DER FORSCHUNG}

1. Zur Entstehung von "Symbolismus": Mdr $376 \mathrm{ff}$.

2. Eine Ubersicht der wichtigsten Artikel findet sich bei K.V. Močul'skij: Andrej Belyj, 141-150.

3. Das hypothetisch-aphoristische Denken und den lyrisch-rhythmisierten Stil, sowie die Systemferne im theoretischen Werk teilt Belyj mit seinem philosophischen Vorbild F. Nietzsche. Cf. Nrds $465 \mathrm{f}$.

4. Cf. Mdr 376.

5. Cf. Mdr 376 f.; Močul'skij: Belyj, 140. Der Kommentar zu "Symbolismus" und seine explikatorische und komplementäre Funktion blieben in der Forschung bisher unberücksichtigt.

6. D.E. Maksimov: Poézija i Proza Al. Bloka, 217 f., 230-232.

7. V. Brjusov: Ob odnom voprose ritma. Po povodu knigi Andreja Belogo "Simvolizm". In: Apollon 11 (1910), 52-60.

8. B. Grifcov: Andrej Belyj. Simvolizm (...) Lug zelenyj (...) Arabeski (...). -In: Russkaja mysl' S(1911) $190 \mathrm{ff}$.

9. F. Stepun: Andrej Belyj. Simvolizm. - In: Logos 1 (1910) 280-282.

10. D.E. Maksimov: Poezija i Proza Al. Bloka, weist auf die "Tendenz zur Poetisierung nichtpoetischer Genres" als Grundzug der symbolistischen Literaturkritik hin: auf ihre Ausprägung bei Belyj, Brjusov, Ivanov (192); auf ihre Tradition seit Herzen (193); auf Parallelen in der kritischen und philosophischen Prosa des Westens (195 f.), u.a. bei Nietzsche und B. Christiansen ("Philosophie der Kunst", 1909).

11. a.a.O., $230 \mathrm{f}$.

12. S.D. Cioran: The Apocalyptic Symbolism of Andrej Belyj, 43.

13. Zur Rezeption Belyjs im russischen Formalismus cf.: Oleg A. Maslenikov: The Frenzied Poets, 81, Anm. 39; K.V. Močul'skij: A. Belyj, 150; V. Erlich: Russischer Formalismus, 40-44; E.M. Thompson: Russian Formalism and Anglo-American New Criticism, 13-15, 27-30, 75 f.; Aage A. Hansen-Löve: Der russische Formalismus. Methodologische Rekonstruktion seiner Entwicklung aus dem Prinzip der Verfremdung, 43-61, 128-131, 55/192, $304 \mathrm{f}$.

14. Cf. V. Erlich: Russischer Formalismus, 307 (Teamarbeit R. Wellek/A. Warren), 308 ff. (Formalismus und "New Criticism"); E.M. Thompson: Russian Formalism and Anglo-American New Criticism (hier erstmals auch zum philosophischen Hintergrund beider Richtungen), cf. oben S. 9 ff.

15. Cf. D. TschiŽewskij: Einleitung zu Belyjs "Kotik Letaev", VI.

16. Hier entstanden die stilkritischen Arbeiten von A. Hönig, D. Burkhart und H. Smilga zu Belyjs Romanprosa.

17. Hierin übernimmt er die Position Sklovskijs, z.B. in "O teorii prozy", 1929, 205 ff., der die Weltanschauung eines Künstlers im Gegensatz zu seiner Poetik sieht: als "Arbeitshypothese", die vom "Handwerk" vertilgt werden müsse zu einem "Dunghaufen", auf dem seine Kunst unabhängig gedeiht; oder als Arsenal, dem er formale Verfahren entnehmen kann. Cf. dazu J. Holthusen "Andrej Belyj und Rudolf Steiner" (1956). Belyjs Beziehung zur Anthroposophie wird hier reduziert auf eine Quelle formaler "priëmy", z.B. für Stilfiguren der Spiegelbildlichkeit: "Konstruktion eines Sujets aus dem Anagramm" (189), Umkehrung in der Reihenfolge der Bewußtseinsvorgänge Dudkins (191).

18. Tschižewskij, übernimmt nicht die formalistische Opposition von Ideengehalt und Stil, wie sie Šklovskij lehrte.

19. L. Trockij: Literatur und Revolution, Berlin 1968, 48 "Belyj - ist ein dahingeschiedener und wird in keinem geist wiederauferstehen."

20. D. TschiŽewskij: Einleitung zu Belyjs "Kotik Letaev", S. VI.

21. Zum Symbolistenstreit cf. J. Holthusen: Studien zur Ästhetik und Poetik, 36-42; R.D. Kluge: Westeuropa und Rußland im Weltbild Aleksandr Bloks, Kap. III "Franzosen 
oder Deutsche"; A. Knigge: Die Lyrik V1. Solov'evs und ihre Nachwirkung bei A. Belyj und A. Blok, 252-255; 266-80; auch A. Blok: Sobr. soč. v vos'mi tomach, t. S, 756-58.

22. Cf. Poetik und Hermeneutik II. Immanente Ästhetik-Ästhetische Reflexion. Lyrik als Paradigma der Moderne. Hg. von W. Iser, 264-296, 512 ff.

23. Hier trifft sich Belyj in seinen ästhetischen Forderungen mit T.S. Eliot (nach E. Thompson, 37, 78):

1. daß in der Kunst Geist und Sensibilität vereint sein sollten ("the thought felt");

2. daß der künstlerische Wert in allgemeingültigen Werten der. Kulturgemeinschaft begründet sein sollte.

24. Cf. W. Schmid: Der ästhetische Inhalt, 18.

25. Cf. Mo'́cul'skij: Andrej Belyj, 139.

26. J. Pflanzl: Weltbild und Kunstschau des Russischen Symbolismus in der theoretischen Gestaltung durch $A$. Belyj, beschränkt sich ausdrücklich methodisch auf eine Interpretation der "theoretischen Sicht" Belyjs, ohne Gegenüberstellung mit der "dichterischen" (Einleitung).

27. Cf. Ellis: Russkie Simvolisty, 1.

28. Cf. Ivanov-Razumnik: Russkaja literatura ot 70-godov do našich dnej, 380.

29. Allerdings stellt sich diese Frage deshalb nicht für J. Pflanzl, weil sie Belyj auch als Dichter-Mystiker (81) auf dem Wege zum geschlossenen Weltbild sieht ("Aufhebung aller Gegensätze", 95), was so nicht haltbar ist.

30. Belyjs Auseinandersetzung mit Schopenhauer (Simv. 62, 466, 507 u.a.) wird nicht berücksichtigt.

31. J. Pflanzls philosophische Untersuchung (1946) steht zeitlich zwischen den beiden Aufsätzen Stepuns zu Belyj. Beide zitieren einander nicht. Sie kommt in ihrer Arbeit zu einem anderen Resultat als Stepun (1934): durch die Analyse der Wertphilosophie und ihrer Bedeutung für Belyj (absolutes "Ja" zum "Wert") kann sie von einer "Religion des Lebens" (žiznetvorčestvo) sprechen. Diese Ansicht - die ähnlich auch von Močul'skij (1955) vertreten wird - könnte für Stepuns Umbewertung von Belyjs ästhetischer Theorie von Bedeutung gewesen sein. Trotz ihrer Einseitigkeit und Vereinfachungen wäre wünschenswert, daß sie gedruckt innerhalb der Sekundärliteratur zugänglich wäre.

32. Z.B. K. Pomorska: Russian Formalist Theory and its Poetic Ambiance, 66.

33. Moxul'skij: Andrej Belyj, stützt sich fast ausschließlich auf die Memoiren Belyjs, deren subjektive Perspektive und Tendenz zur Entstellung oder Stilisierung, vor allem auch zur Rechtfertigung, ihren Dokumentationswert relativieren. Cf. dazu: F. Stepun: Pamjati Andreja Belogo, 171 f. "protokollarische Genauigkeit der Erinnerungen", "Und dennoch kann man den Erinnerungen Belyjs nicht glauben", "aufgebaut auf der genialen Schiefheit des Belyjschen Blicks". V. Chodaseviz: Andrej-Belyj. -In: Nekropol', 71: Erinnerungen an Blok "in zwei Versionen, die sich ausschließen und gleichermaßen unhaltbar sind". C. Vol'pe: Einleitung zu Mdr, IX, "Memoiren, die an die sowjetische Gegenwart gerichtet sind, Versuch, sich vor ihr zu rechtfertigen." A.K. Tarasenko: Poézija Andreja Belogo, 116 "selbstkritisch ... schonungslos". Mocul'skij weist Zitate nicht aus und paraphrasiert seitenweise.

34. Moćul'skij: Andrej Belyj, 54 ff., zeigt aber gleichzeitig auch, welch verhängnisvollen und beinah tödlichen Ausgang der Versuch, das Leben in ein Mysterium oder in Kunst zu verwandeln, für Belyj persönlich (und für die betroffene Nina Petrovskaja) genommen hat; gestützt auf V. Chodasevič: Konec Renaty. - In: Nekropol', 7-25.

35. Poggiolis These einer Konvergenz von Symbolismus und Dekadenz wird auch von J. West: Russian Symbolism. A Study of Vyačeslav Ivanov and the Russian Symbolist Aesthetic. London 1970, vertreten (Ähnlichkeit der ästhetischen Postulate). A. Kovač: Andrej Belyj: The 'Symphonies', konstatiert dagegen den Ubergang von Dekadenz zu Symbolismus als zwei verschiedenen Stadien und Kunsthaltungen, "Prozeß des Ubergangs vom Stil der russischen Dekadenten zum Stil der religiösphilosophisch orientierten Symbolisten (275)" im Zyklus der Symphonien, diesen Ubergang weist er an der Entwicklung der Bildelemente von Belyjs Erzählstil nach. Der Begriff der westeuropäischen "Dekadenz", wie ihn Poggiolo vertritt, als einer amoralisch-nihilistischen Kunstströmung mit hochgesteigertem Formniveau, ist in- 
zwischen durch die Forschung modifiziert. Cf. K.H. Bohrer: Die Ästhetik des Schreckens, 89 (über die Bedeutung einer "Ästhetik der Wahrnehmung" für die Kunsthaltung der Dekadenz), 528 (über die Entwicklung des Dekadenz-Begriffs zu einem polemischen Urteil), 530 (zum Stand der Dekadenz-Forschung verweist Bohrer auf E. Koppen: Dekadenter Wagnerianismus. Studien zur europäischen Literatur des fin de siecle. Berlin/N.Y. 1973). Ein modifizierter Dekadenz-Begriff wäre auf seine Eignung für die Konvergenztheorie neu zu befragen.

36. Die Starrheit seines binären Denkens zeigt sich zum Beispiel an der Beurteilung des "ästhetischen Mystizismus" S. Kierkegaards; dessen "suggestive definition of the poet as a 'spy of god' (135) "deutet er als romantische Vorform des pseudoreligiösen Selbstverständnisses des russischen symbolistischen Dichters. So fruchtbar der Hinweis auf Kierkegaard ist, so oberflächlich ist seine Beurteilung. Poggioli kann der adogmatischen Form des Religionsverständnisses bei Kierkegaard, die sicher als Quelle einer modernen Religiosität angesehen werden kann, gar nicht gerecht werden, weil in seinem Urteil keine Kategorien dafür enthalten sind (cf. 135).

37. Zum veränderten Selbstverständnis der russischen Intelligenz um 1900 als Folge des (ambivalent aufgenommenen) sozialen Wandels cf. George Fischer: The Intelligentsija and Russia. - In: C.E. Black (Ed.): The Transformation of Russian Society. Aspects of Social Change since 1861, 262-267 (Ambivalenz statt der früher vorherrschenden Radikalität).

38. Cf. 2.B. S.D. Cioran: The Apocalyptic Symbolism of Andrej Belyj, "In the crisisexperience and not in dogmas lies the basis of religion and its universality (53)".

39. Cf. J. Scherrer: Die Petersburger Religiös-Philosophischen Vereinigungen, 11-18, 4043 (zur Entwicklung des Symbolismus als religiöser Weltanschauung).

40. Die Genealogie der psychologischen These vom Symbolismus als "Mentalität" geht über Maslenikov auf Chodasevit: Nekropol', 10 ff. zurück.

41. Deshalb kann Cioran die biographische Basis Belyjs als "Familienapokalypse", den Gegensatz von Dorf und Stadt als "pastorale" bzw. "urbane" Apokalypse verstehen, sein autobiographisch-philosophisches Roman-Poem "Kotik Letaev" in der Spannung von "kosmischer Erinnerung" und "Passionsspiel des Christuskindes", sein nachrevolutionäres Tagebuch "Zapiski Čudaka" als "Kreuzigung" in der "imitatio Christi".

42. Was Cioran im Laufe der Untersuchung unter Apokalypse versteht, wird immer umfangreicher: er unterscheidet zwischen "positiver" und "negativer" Apokalypse, je nach Uberwiegen von dualistischen oder synthetischen Strukturen (68). Wachstum und Individuation (im Sinne Jungs) nennt er eine "Serie von Apokalypsen" (164 f.). Im indischen Denken entdeckt er eine "zyklische" oder "serielle" Apokalypse, im hebräischen die "einmalige" (154). Es gibt auch eine "low-key"-Apokalypse ("Silberne Taube") mit dennoch kosmischen Ausmaßen (136) und ähnliches mehr. Kurz, einem derart leistungsfähigen Gummibegriff begegnet man - selbst in der Literaturwissenschaft - selten.

Gleich zu Anfang atrophiert er schon zu zeitgeschichtlichen Ausmaßen von höchst fragwürdiger Generalisierung: "Die Geschichte hatte in Rußland einen Punkt erreicht, da das zukünftige Utopia nicht mehr geleugnet werden konnte, sei es nun, daß dieses neue Utopia ein sozialpolitisches oder theokratisches werden sollte. Vergangenheit und Gegenwart wurden einmütig verdammt. Der Antichrist - oder die bürgerlich kapitalistische Periode -waren im Aufstieg, wonach die Ankunft des Neuen Jerusalem - oder des sozialen Utopia - verkündet werden mußte. Das konnte nicht erreicht werden ohne Blutvergießen, Pest und Jüngstes Gericht - oder eine blutige Revolution. So sind also die Bezugsbegriffe, ob religiös oder sozialistisch, frei austauschbar. Beide passen bewunderswert zum Geist der Zeit. Die dramatischen Requisiten und Bühneneffekte der 'Apokalypse' eigneten dem Inhalt der katastrophalen Ereignisse, die in Rußland folgen sollten (14)."

Bei einem solchen methodischen Ansatz werden in der Tat die Kategorien -die erst gar nicht definiert werden - austauschbar. Es gibt aber eine Stelle in seinem Buch, an der C. selbst andeutet, wie man seinem Thema präziser hätte beikommen können: "Der Inhalt des neuen Symbolismus der Jahrhundertwende in Rußland war religiös und die Form war eschatologisch; denn er bildet sich vorrangig als eine Interpretation der historischen und kulturellen Zeichen der Zeit heraus in Ubereinstimmung mit einem apokalyptischen Syndrom (26)." Downloaded from PubFactory at 01/10/2019 05:16:17AM 
Eine begriffliche Klärung der drei Begriffe: religiös, eschatologisch und apokalyptisch wäre hier notwendig gewesen. Statt dessen werden sie - bei ganz verschiedenem Umfang - mehr oder weniger synonym verwendet, woraus die Begriffsverwirrung entsteht, die durch das ganze Buch andauert. Denn die Mentalität des "Neuen religiösen Bewußtseins" in Rußland ist nicht deshalb eschatologisch, weil sie sich der apokalyptischen Darstellungskonvention bedient, sondern umgekehrt: diese ist nur eines von verschiedenen Mythologemen der Tradition, und zwar sowohl der außerapokalyptisch-christlichen, der gnostischen, als auch der heidnisch-antiken (Nietzsche, Ivanov).

Vor allem wäre es wichtig, zu zeigen, daß eine "eschatologische Mentalität" nicht notwendig mit dem apokalyptischen Symbolsystem verkoppelt sein muß, sondern neben dem "apokalyptischen Dogma von Schöpfung durch Zerstörung" auch die Vorstellungen der Selbstwerdung, des Weges und der Verwandlung zuläßt. Cf. dazu z.B. D.E. Maksimov: Poézija i Proza Al. Bloka, 70 (Menschwerdung), 64 ff. ("Pflicht des Weges"), $58 \mathrm{f}$. (Evolution und Transformation).

42a. Cf. A. Belyj: Vospominanija o Bloke. Letchworth 1964, 15.

43. Cf. O. Maslenikov: The Frenzied Poets, 220. Während M. die apokalyptische Tendenz in Belyjs Symbolismus noch als einen Aspekt herausstellt, generalisiert Cioran sie zum "Schlüssel" für sein Werk (47).

44. Wenngleich dieser Versuch scheiterte, ist seine Bedeutung für die in der Emigration weiterwirkenden Kulturphilosophen nicht erloschen.

45. Cf. A. Kovač: Andrej Belyj: The "Symphonies". K. verfolgt den Gesichtspunkt der "Umwertung" im Zyklus der vier Symphonien. Nach $K$. besteht sie darin, die scheinbar harmonisierten Widersprüche der alten Kultur bloßzulegen (Vorbild Nietzsche). Um sie auf neue Weise wieder zu versöhnen, baue Belyj einen weitgespannten "synkretistischen Rahmen" (19) auf, in dem Sinn-Angebote des griechischen Polytheismus, des jüdisch-christlichen Monotheismus und der indischen Religion zueinander in Beziehung gesetzt werden.

Das Stilverfahren der "symphonischen Form" solle die Darbietung der "rerum concordia discors" (Schopenhauer/Horaz) leisten (25).

46. Mit Ausnahme der Symphonien. Nach Poggioli: "deservedly forgotten (153)".

47. Cf. V.F. Chodasevič: Nekropol', 8-12. So aufschlußreich seine Analyse des psychologischen Erlebnismodus der Intensitätsmanie im russischen Symbolismus ist, so kritikbedürftig ist seine reduktionistische Gleichsetzung des komplexen geistesgeschichtlichen Phänomens "Symbolismus" mit seiner psychologischen Erscheinungsweise, die man nach C. als Gruppenpsychose verstehen soll.

48. Was darüber hinausgeht, ist unerforscht, vor allem die kulturphilosophischen Schriften der Weltkriegszeit, die Beziehung Belyjs zur Gruppe "Skify" um IvanovRazumnik und seine geistige Entwicklung nach 1917. 


\section{ERSTER TEIL:}

\section{ANDREJ BELYJ ALS DICHTER-THEORETIKER - KRISENBEWUSSTSEIN UND DENK VORAUSSETZUNGEN}

\section{Kapitel: Der poeta doctus als Dichtertypus der modernen Kulturkrise}

1. Cf. G. v. Wilpert: Sachwörterbuch der Literatur Stuttgart ${ }^{5} 1969$ (=Kröner TA 231), 290. Was die theoretische Klarheit über Probleme des künstlerischen Schaffens angeht, so gibt es da sehr verschiedene Grade. Man kann das z.B. am Dialog zwischen Schiller und Goethe beobachten. Während Schiller zu einem Neuansatz der Asthetik durch seine Kritik an Kants kategorischer Bestimmung des Schönen kam ("Anmut und Würde", 1793; cf. dazu: K.H. Bohrer: Die Ästhetik des Schreckens, 5961) finden sich in Goethes Prosa ebenfalls auf Kant zurückgehende Einsichten in das Wesen des Symbolischen ("Anschauliche Urteilskraft", 1827), die bis heute gültig geblieben sind; cf. dazu H. Pongs: Das Symbol als Mitte, 16, 104-133.

2. Cf. V. Orlov: Istorija odnoj družby-vraždy. Auch zwischen Blok und Belyj fand, wenngleich über hundert Jahre später und in sehr anderen Formen, ein spannungsreicher Dialog statt.

3. Zitiert nach R. Williams: Gesellschaftstheorie als Begriffsgeschichte, 66.

4. Cf. H.A. Korff: Geist der Goethezeit. Bd. II, Leipzig 61962, 273-290; III, 265-280. Zum Wandel der Kunstphilosophie seit der Romantik cf. K.H. Bohrer: Die Ästhetik des Schreckens, 59-63. Zur "Zersetzung des Ganzen": cf. Claudio Magris: Archivar des Negativen. Robert Musils Tagebücher. - In: Die Zeit, 12.2.78. Zur "Dissoziation der Interessen" cf. Raymond Williams: Gesellschaftstheorie als Begriffsgeschichte, 55.

5. Seit R. Poggioli (Teorija dell'arte d'avanguardia. Bologna 1962) und H.M. Enzensberger (Die Aporien der Avantgarde. - In: ders.: Einzelheiten. Ffm. 1962) begannen, den zum Schlagwort verkommenen, aber unentbehrlichen Begriff der "Avantgarde" in die literaturtheoretische und ideologiekritische Diskussion einzubeziehen, seit $P$. Bürger (Theorie der Avantgarde. Ffm. 1974), A. Flaker (Je li nam pojam "Avangarda" potreban ? - In: Umjetnost riječi. Zagreb XV, 2, 1971, 155-160; ders.: Poredbena književnost i Povijest književnosti. Granice pojma Avangarda. Zagreb 1976) und Robert C. Williams (Artist in Revolution. Portraits of the Russian Avant-garde 1905-1927. Bloomington/London 1977) an einer Begriffsklärung weitergearbeitet haben, kann der Begriff der "Avantgarde" nicht mehr einfach synonym mit dem Terminus "Moderne" verwendet werden.

Uber den Begriff des "Modernismus" als Orientierungsbegriff, um den vielgestaltigen literarischen Prozeß zwischen 1880 und 1925 als Epoche zu erfassen, cf. R.-D. Kluge: Vom kritischen zum sozialistischen Realismus, 17, 226.

Solange jedoch nicht geklärt ist, ob der Begriff der Avantgarde als "Stilformation" (Flaker) zureichend bestimmt wäre, solange auch der Zeitraum noch nicht geklärt ist, für den er gelten soll, scheint es legitim, ihn auf Wegbereiter avantgardistischen Denkens, Kunstschaffens und Selbstverständnisses anzuwenden, die m.E. auch von ihrer Reaktion auf die Herausforderung durch die moderne Kulturkrise her verstanden werden könnten, anstatt nur von Stilprozessen innerhalb der "literarischen Reihe" oder vom Protest gegen die "Institution Kunst" (Bürger).

Im Sinne eines "Krisenreflexes" wird der Terminus "Avantgarde" z.B. von K.H. Bohrer (Die Ästhetik des Schreckens, München 1979, 17, 519) auf "Dichter des Argwohns" aus der nach-nietzscheschen Generation von 1880 angewandt, u.a. auch auf A. Blok, cf. auch J. Holthusen, der Belyj und Krleža in die AvantgardeDiskussion einbezieht: "Im Vergleich zur Ästhetik und den künstlerischen Verfahrensweisen der Avantgarde sind ihre historisch und kulturtypologisch bedingten Vorstellungswelten sicherlich noch unzureichend beschrieben (...) es ist an der Zeit, den Funktionszusammenhang zwischen bestimmten Bildkomplexen, ideologischen Tendenzen und künstlerischen Verfahrensweisen wo irgend möglich aufzudecken." (Hv.M.D.). - ders.: Tiergestalten und metamorphe Erscheinungen in der Literatur der russischen Avantgarde (1902-1923), S. 4. 
Zu der Auffassung von der Avantgardekunst als Dichtung der Krise wird im folgenden noch einiges zu sagen sein.

6. Cf. Walter Jens: Statt einer Literaturgeschichte, $14 \mathrm{f}$.

7. Wenngleich Belyj als die für die Moderne typischste Ausprägung des poeta doctus angesehen werden kann, so tragen die anderen bedeutenden Symbolisten ebenfalls Züge des reflektierenden Dichters cf. V. Erlich: Russischer Formalismus, 56; K. Pomorska: Russian Formalist Theory and its Poetic Ambiance, 55; D.E. Maksimov: Poézija i Proza Al.Bloka, 176-183; bes. 181 (zu Blok); 203 ff. (zu Brjusov), 209 f. (zu Ivanov), 210-221 (zu Belyj); ferner D.E. Maksimov: V. Brjusov. Poézija i pozicija, 47, 57, 64, 66 f.; 3. West: Russian Symbolism, 48, 107 f. West gibt vom Erwartungshorizont des Systemdenkens den Vorzug V. Ivanov als Theoretiker des russischen Symbolismus; im Urteil über Belyjs "unsystematisches" Denken beruft er sich auf F. Stepun: Mystische Weltschau. Will man nicht allein den formalen Gesichtspunkt anwenden, sondern nach den inhaltlichen Positionen beider Dichter-Theoretiker fragen, so stellt Belyj gegenüber Ivanov eine spezifisch moderne Variante des poeta doctus insofern dar, als er die "beiden Kulturen" der Moderne repräsentiert: die naturwissenschaftliche und die traditionell-geisteswissenschaftliche.

8. F. Stepun: Andrej Belyj. Simvolizm (...). - In: Logos 1 (1910), 280. Zitiert nach D.E. Maksimov: Poézija i Proza Al.Bloka, 217.

9. Daß Belyj hiermit eine kulturelle Differenz der Moderne repräsentiert, läßt sich an der anglo-amerikanischen Kontroverse über die "Two cultures" zeigen, wie sie in den fünfziger Jahren zwischen Literaten und Naturwissenschaftlern geführt wurde. Eine Ubersicht gibt Paul Konrag Kurz: Literatur und Naturwissenschaft. - In: ders.: Uber moderne Literatur I, Ffm. 1967, 72-100.

10. F. Stepun: Op. cit. 280.

11. Cf. Nrds, 397-408 (Universität. 1. Das Problem der Schere); zum Bedürfnis nach Rechtfertigung cf. S. 150 ff. dieser Arbeit.

12. Cf. F. Stepun: Pamjati Andreja Belogo, $170 \mathrm{ff}$.

13. Cf. Karl Jaspers: Vernunft und Existenz, 26. Zum Legitimationsproblem des genialen Unzeitgemäßen zitiert er Kierkegaard: "Es ist etwas an mir, als wäre ich etwas Großes, aber auf Grund der verrückten Konjunkturen gelte ich nur wenig."

14. Zum Problem der Modernisierung und des sozialen Wandels cf. Hans-Ulrich Wehler: Das deutsche Kaiserreich, Göttingen 1973, bes. 71: "Zugrunde aber lag allen wichtigen Problemen der Reichspolitik das prinzipielle Dilemma, daß die Spannung $z w i s c h e n$ der voraneilenden ökonomischen und sozialen Entwicklung zur Industriegesellschaft auf der einen Seite und der überkommenen starren politischen Strukturen auf der anderen Seite nicht überwunden werden konnte und sollte."

Dieses "prinzipielle Dilemma" gilt über das deutsche Kaiserreich hinaus auch für die andren beiden traditionalen Gesellschaften der Mittelmächte, Rußland und Ósterreich. Cf. dazu C.E. Black (Hg.): The Transformation of Russian Society, 8 ("the acceptance of change" vs. unverändert starre "nature of authority"); George Fischer: The Intelligentsia and Russia, a.a. O, 262; G. Stökl: Russische Geschichte, 559 ff., ("Politische Stagnation und industrielle Revolution").

15. Zum Wertkonflikt zwischen Sozialdarwinismus und christlicher Ethik cf. Hannsjoachim Koch: Der Sozialdarwinismus, München 1973, 64,67, $69 \mathrm{f}$.

16. Uber das Nebeneinander von Wissenschaftsglaube und Rationalitätsprotest in der Vorkriegsgesellschaft, ein Antagonismus, der ebenfalls nicht nur für Deutschland zutrifft, cf. G. Kotowski u.a. (Hg.): Das wilhelminische Deutschland. Stimmen der Zeitgenossen. Ffm. 1965, 129, 117; Allan Bullock: The Double Image, 70 (ambivalente Haltung zur Urbanisierung).

17. Zum Doppelgesicht der Kunst im späten neunzehnten Jahrhundert als Renommieroder Protestkunst cf. A. Hauser: Sozialgeschichte der Kunst und Literatur, 859 (Paris als Kulturzentrum und die "große Oper"); W. Benjamin: Charles Baudelaire. Darin: "Die Bohème", S. 9-32 (Zur Verwandtschaft des Künstlers mit dem Verschwörer und dem Lumpenproletariat); cf. auch die originelle Gegenüberstellung von Wilhelm II. und dem Anarchisten Erich Mühsam bei Ulrich Linse: Der Rebell und die 'Mutter Erde': Asconas 'Heiliger Berg' in der Dichtung des anarchistischen Bohemien Erich Mühsam. - In: Monte Veritá. Berg der Wahrheit. Lokale Anthropologie als 
Beitrag zur Wiederentdeckung einer neuzeitlichen sakralen Topographie. Zürich 1979 (Ausstellungskatalog).

18. F. Nietzsche: Ecce homo. II, 1152 (weitere Belege cf. K. Schlechta: Nietzsche-Index zu den Werken in drei Bänden, 371).

19. Gedanke und Terminus der "Weitauslegung" oder "Interpretation" stammen ebenfalls von Nietzsche. Cf. K. Jaspers: Vernunft und Existenz, 13. Die Möglichkeit zu neuen Wertschätzungen des Daseins ist die Konsequenz der Forderung Nietzsches nach Umwertung. Cf. auch Karl Löwith: Nietzsches Vollendung des Atheismus, 7-18, bes. S. 9; Löwith zeigt, daß Nietzsche mit diesem Versuch, den L. vor allem in den "Gleichnisreden Zarathustras, der ein 'fünftes', antichristliches Evangelium sein will", sieht, zur Uberwindung des europäischen Nihilismus ansetzt, indem er zur Erziehung des Willens, "zur Lust und Kraft der Selbstbestimmung" aufrufe ("Die Fröhliche Wissenschaft", \$ 347; "Zur Genealogie der Moral", II, \$ 22). Demnach wären zwei gängige Weisen der Nietzsche-Rezeption revisionsbedürftig, die beide Reduktionen Nietzsches sind: im Westen auf den amoralischen Philosophen des Ásthetizismus (z.B. bei P. Garnier: Gottfried Benn. Un demi siècle vécu par un poète allemand. Paris 1959, 7, der Nietzsche in Gegensatz zu Marx stellt: "Beim einen öffneten sich die tausend leuchtenden Blüten einer Ästhetik ohne Gott, beim anderen buk man das Brot der Ethik - die 'nourritures terrestres'."); im Osten auf den Ideologen der bürgerlichen Reaktion, des Amoralismus und des faschistischen Ubermenschen (cf. G. Lukács: Die Zerstörung der Vernunft) Werke, Bd. 9, Neuwied 1962. Differenziertere Urteile finden sich in den neueren sowjetischen SymbolismusForschungen zu Nietzsche, z.B. bei B.V. Michajlovskij: Simvolizm. - In: Russkaja literatura konca XIX-XX v., 239 f.; D.E. Maksimov: Poézija i Proza Al.Bloka, 77, 81.; Nietzsche wird aber immer noch einseitig als Philosoph der "Ewigen Wiederkehr des Gleichen" beurteilt, was gleichgesetzt wird mit einer Philosophie des Pessimismus und Nihilismus. Cf. Oberarbeitg. 2. Aufl. Zur Nietzsche-Rezeption um die Jahrhundertwende und zu neueren Forschungsergebnissen cf. Bruno Hillebrand: Nietzsche und die deutsche Literatur. Bd. I und II. Tübingen 1978 TTexte und Bibliographie).

20. Zur Kulturkritik vor Nietzsche in Deutschland, die in einer produktiven Auseinandersetzung mit dem Rousseauismus in zwei Stufen vor sich ging: 1) in der Protestbewegung des Sturm und Drang gegen die intellektualistische und gesellschaftlich uniformierte Kultur der Aufklärung; 2) in der idealistischen Kulturkritik Schillers und der Frühromantik, vor allem in Schillers Briefen "Uber die ästhetische Erziehung des Menschen" (1795) und Hölderlins "Hyperion" (1797/99), cf. H.A. Korff: Der Geist der Goethezeit, Bd. 1, 69-76 ("Die Fragwürdigkgit der Kultur"), Bd. III, 107-117 ("Das Leiden an der Menschheit"), Leipzig 1958 und 1966.

Die deutsche Kulturkritik um 1800 ist vor allem um die Klage über den Zerfall der Ganzheit zentriert, der durch Arbeitsteilung und Spezialisierung verursacht wurde, dessen Heilung aber noch in der Wiederversöhnung von Geist und Natur gesucht wird. Dieser Glaube hält jedoch nicht mehr lange an.

Im neunzehnten Jahrhundert radikalisiert sich die Kulturkritik zunehmend, im Werk von J. Paul und Heine z.B., bis sie bei Wagner - verbunden mit dem revolutionären Protest von 1848 - verschärften Ausdruck findet, vor allem in seinen ästhetischen Schriften. Hier ist der Punkt erreicht, an dem Nietzsche einsetzte. Die Positionen der deutschen Kulturkritik um 1800 blieben nicht auf Deutschland beschränkt, sondern wurden in der Nachfolge von S.T. Coleridge in der englischen Kulturphilosophie, vor allem von Carlyle, M. Arnold und Ruskin aufgegriffen und weitergeführt, die im 19. Jahrhundert auf Deutschland zurückwirkten (Carlyle z.B. auf Nietzsche, Ruskin auf die Künstler des fin de siècle). Cf. dazu Raymond Williams: Gesellschaftstheorie als Begriffsgeschichte. Studien zur historischen Semantik von "Kultur".

21. F. Nietzsche: Die Geburt der Tragödie, l, $102 \mathrm{f}$.

22. Cf. K. Löwith: Nietzsches Vollendung des Atheismus, 9 (zum Gesichtspunkt der "Anthropologie" bei Nietzsche).

23. Cf. K. Jaspers: Vernunft und Existenz, 25, der Kierkegaards Ausdruck des "Probemenschen" zitiert: "im hurnanen Sinne kann sich niemand nach mir bilden ... Ich bin ein Mensch, wie er in einer Krisis notwendig werden könntegizeimpversuctiskranifnchen

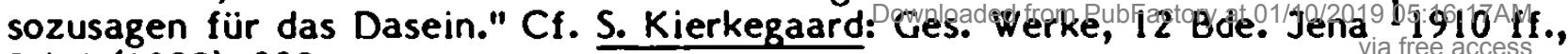
Bd. 4 (1922). 332. 
24. R.M. Rilke: Die Aufzeichnungen des Malte Laurids Brigge. Frankfurt 1976, 24-26 (Kulturkritik), 52 (Zeit der anderen Auslegung). Die Entstehungszeit des Buches erstreckt sich über fünf Jahre: 1904-1909.

25. Cf. F. Nietzsche: Die Geburt der Tragödie, I, 82,87.

26. Cf. T.S. Eliot: The Metaphysical Poets. - In: Selected Prose of T.S. Eliot, 64: "In the seventeenth century a dissociation of sensibility set in, from which we have never recovered."

27. Cf. R.-D. Kluge: Westeuropa und Rußland im Weltbild Aleksandr Bloks. Teil I, Kap. V., 84-128, "Der Geist der Musik".

28. Robert Musil: Der Mann ohne Eigenschaften, 592.

29. Op. cit., 596.

30. Beide Genres haben in Rußland eine Tradition im neunzehnten Jahrhundert: der Typus der "Aufzeichnungen" seit Gogol' (Aufzeichnungen eines Wahnsinnigen); Turgenev (Aufzeichnungen eines Jägers) über Dostojevskij (Aufzeichnungen aus dem Kellerloch)bis zu Belyj (Aufzeichnungen eines Sonderlings); der Typus des kritischen Staatsromans seit Tolstojs "Krieg und Frieden", Dostojevskijs "Dämonen" über Belyjs "Petersburg" bis zu Bulgakovs "Meister und Margarita" oder SolŽenicyns "Der erste Kreis der Hölle". Zu den beiden Genres cf. J.-U. Peters: Turgenevs "Zapiski ochotnika" innerhalb der očerk-Tradition der 40er Jahre, 5-11; Der russische Roman. $\mathrm{Hg}$. von Bodo Zelinsky. Düsseldorf 1979, $42 \mathrm{ff}$.

31. Cf. A. Blok: Aus den erläuternden Aufzeichnungen für das Künstlertheater zu "Rose und Kreuz". - In: Ders.: Sobr. soč. v. 6 t., t. 4, 443-445 (zu "kvadratnost"' als Prinzip von Trägheit und Erstarrung).

32. Cf. dazu die ausführliche Darstellung von Lehre, Ritual und Verbreitung der Chlysten bei Karl Konrad Grass: Die russischen Sekten. 1. Bd. Die Gottesleute oder Chlüsten nebst Skakunen, Maljawanzü, Panijaschkowzü u.a. Leipzig 1966. Unveränderter fotomech. Nachdruck der Originalausgabe Leipzig 1907. Zu Moskau, Tula als Zentren der "Chlystovక̌̌ina". S. I, X, 3, 30 f., 245, 249; zu Ekstase und Askese im "radenie" (von radet' - Gott arbeiten) S. 11, 19, 29, 244 ff., 366 ff.; zu Geheimhaltung und Arkandisziplin $336 \mathrm{ff.,} \mathrm{356.} \mathrm{Eine} \mathrm{innere} \mathrm{Affinität} \mathrm{Belyjs} \mathrm{zum} \mathrm{Chlystovstvo}$ beobachtete Marina Cvetaeva, die darin einen Schlüssel zum Verständnis Belyjs sieht, cf. Marina Cvetaeva: Plennyj duch. - In: Dies.: Proza. Letchworth 1969, 160225, bes. 193, 221. Auf diese Zusammenhänge, die bisher in der Forschung nicht bearbeitet wurden, kann hier nur hingewiesen werden.

33. Cf. A. Blok/A. Belyj: Perepiska, 261 (Brief an Belyj vom 6. Juni 1911); außerdem A. Blok: Predislovie k "Sobraniju stichotvorenij". - In: Ders.: Sobr. soč. v 8 t., t. 1, s59 (v. 9. Jan. 1911).

34. A. Belyj: Serebrjannyj golub'. München 1967, 176; dt.: Die Silberne Taube. München/Zürich 1964, 98 f.

35. Belyjs Nietzschekritik wäre ein Kapitel für sich; hier zeigt sich nur ein Aspekt, der weiter untersucht werden müßte. Cf. dazu Alfred Guth: Nietzsches "Neue Barbaren", 9, 24 f. Guth kritisiert Nietzsches Anspruch, ästhetische Kategorien der "Gestaltung" aus dem Bereich der Wortkunst auf den des Menschen oder des Volkes zu übertragen: "(...) kann man aus dem Menschen ein klassisches Kunstwerk machen, wie Nietzsche es versteht? (...) Die Ubertragung ästhetischer Kategorien auf Gebiete, die mit Kunst nichts zu tun haben, beweist, wie sehr Nietzsche als Künstler denkt, auch wenn er sich die mögliche Zukunft des Menschen vorzustellen versucht."

36. Cf. F. Nietzsche: Werke III, 329.

37. Cf. A. Flaker: Roman o Revolucionarnom Gradu, 467-484 (zur Opposition von "Staatsmacht und Revolutionspotential").

38. A. Belyj: Peterburg, Moskva 1978, 24, 326; dt. Petersburg, Wiesbaden 1959, 9, 441.

39. Man kann sagen, daß Belyjs Nietzschekritik sich u.a. an den Denktraditionen der russischen Religionsphilosophie Tolstojs und Solov'evs orientiert.

40. Cf. Michael Worbs: Wissenschaft und Literatur im Fin de siècle, 302-316, bes. 306.

41. Vor und neben der dichterischen gibt es auch eine Sprachkrise der Philosophie. Der Veränderung der Denkrichtung in der nachhegelschen Anti-Systemphilosophie rom geschlossenen zum offenen Denken zeitigte ein Sprachproblem, von dem die veränderten Formen im philosophischen Redestil bei den beiden Philosophen der Kulturkrise im neunzehnten Jahrhundert, Kierkegaardariangp N1ietzischiestzeutgen. Zu 
Kierkegaards Kommunikationsstrategie der "indirekten Mitteilung" und des verrätselnden Pseudonyms, zu Nietzsches Selbstkritik der ratio im Aphorismus cf. Heinz-Horst Schrey: Die Uberwindung des Nihilismus bei Kierkegaard und Nietzsche. - In: Zeitschrift für systematische Theologie. 21 (1950) 90-109, bes. 96-98; Heinz Krüger: Der Aphorismus Nietzsches als philosophische Form. - In: ders.: Studien über den Aphorismus als philosophische Form. Ffm. 1956, 81-133, bes. 81-107.

Mit der Öffnung des philosophischen Denkens auf eine Philosophie des ganzen Menschen und auf die Phänomenologie hin, ging eine Öff́nung der philosophischen Rede einher, die sich in der künstlerischen Diktion Schopenhauers ankündigte, die bei Nietzsche und Solov'ev dazu führte, daß sie neben diskursiver Philosophie Lyrik über die gleichen Themen schrieben, so daß ihre Wirkung von ihrer Sprachkunst nicht zu trennen ist. Auch die grundlegende Wandlung der philosophischen Sprache bei Lev Sestov, Martin Buber und Heidegger ist eine Folge der veränderten Denkformen. Vor dem Hintergrund dieser neuen "Sprachregelung" muß auch die Lyrisierung der Terminologie in A. Bloks geschichtsphilosophischer Essayistik beurteilt werden, vor allem wenn polemisch der Vorwurf des Irrationalismus erhoben wird. Cf. dazu D.E. Maksimov: Poézija i Proza Al. Bloka, 192, 195, (zur "Poetisierung nichtpoetischer Genres" als Phänomen der Ubergangsepoche bei Blok und im europäischen Kontext).

42. Die Sprachkrise der Moderne ist keine neue Erscheinung, sondern hat eine Tradition seit Hume, Hölderlin und Wordsworth, cf. Richard Sheppard: The Crisis of Language, 323-336, bes. 323.

43. Cf. Hugo von Hofmannsthal: Ein Brief. - In: ders.: Gesammelte Werke in Einzelausgaben, Bd. 8, Prosa II, 7-20 bes. 11 f. "Mein Fall ist, in Kürze, dieser: Es ist mir vollkommen die Fähigkeit abhanden gekommen, über irgend etwas zusammenhängend zu denken oder zu sprechen.(...), sondern die abstrakten Worte, deren sich doch die Zunge naturgemäß bedienen muß, um irgendein Urteil an den Tag zu geben, zerfielen mir im Munde wie modrige Pilze."

Der "Fall" Hofmannsthal ist in der Forschung wiederholt Gegenstand hermeneutischer und kritischer Untersuchungen gewesen. Eine Ubersicht über die teils konträren Positionen seit P. Requadt (1955) und W. Jens (1957) über R. Brinkmann (1961), G. Wunberg (1965), W. Mauser (1969) bis zu Claudio Magris (1975) gibt Wolfram Mauser: Hugo von Hofmannsthal. Konfliktbewältigung und Werkstruktur. Eine psychosoziologische Interpretation. München 1977 (= Kritische Information 59), $191 \mathrm{f}$.

Während man sich weitgehend darin einig ist, im "Chandos-Brief" ein Dokument moderner Sprachproblematik von hohem Symptomwert für den Dichter selbst und die Denk- und Wertkrise seiner Zeit zu sehen (W. Mauser: a.a.O., 118, spricht von "Proverb-Charakter"), differieren die Meinungen über seine "epochale" Bedeutung. Wenngleich es schwerfallen mag, den zum Konservativismus neigenden Aristokraten Hofmannsthal mit einer "Revolution" in Verbindung zu bringen, und sei es auch "nur" einer poetologischen, so spricht doch vieles dafür, daß hier mit "seismographischer Empfindsamkeit für (...) die Spannungen und Störungen der Atmosphäre" (cf. R. Brinkmann: Hofmannsthal und die Sprache. DVjs 35, 1961, 71) unter der Metapher der Zeitenwende ein Umbruch der Sprache im voraus aufgespürt wurde, der den biographischen Anlaß kritischer Uberprüfung des eigenen Frühwerks überschreitet. Hofmannsthals "Literaturbrief" eignet ein Grad der Radikalität in der Analyse, der bis dato nicht erreicht war. Die Radikalität im Ziehen der Konsequenzen jedoch war seine Sache nicht; ihm gelang dagegen ein moderner Balanceakt; der "allomatischen Lösung" des "erreichten Sozialen" entspricht der noble Kompromiß, den er zwischen dem Unsagbaren und dem "Notwendigen" schließt; denn für ihn ist trotz aller Skepsis "Reden Menschheit", denn "Mit Reden kommen die Leut zusammen". (Cf. H.v. Hofmannsthal: Gesammelte Werke in Einzelausgaben, Dramen IV, 83, 24).

44. TjutZevs Vers entspricht eine Stelle in Hofmannsthals Drama "Der Kaiser und die Hexe" (1897), das er noch vor dem "Chandos-Brief" schrieb. Beinahe wortgleich beklagt er den Zustand der Sprachverwirrung:

"Ja, im Mund wird mir zur Lüge,

Was noch wahr schien in Gedanken."

Cf. Hugo v. Hofmannsthal: Gesammelte Werke in Einzelausgaben. Gedichte und lyrische Dramen. Stockholm 1952, 267. 
45. F.I. Tjutčev: Silentium (1830), Tjutčevs "Fall" liegt anders als der Hofmannthals, vor allem früher: er ist Ausdruck der romantischen Sprachskepsis. Sie bezieht sich nicht auf die Sprache überhaupt, sondern auf die unüberbrückbare Kluft, die er zwischen der inneren, poetischen Sprache des Dichters, der "Musik der Seele", und der gängigen Sprache der "Menge" klaffen sieht. Die Opposition von "Dichter" und "Menge" ist konstituierend für das Selbstverständnis des romantischen Dichters (cf. z.B. Puškin "Poèt $i$ tolpa"). Neben dem Zweifel an der poetischen Kommunikation ist die romantische Sprachskepsis aber auch auf die Unzulänglichkeit der Sprache als Medium des dichterischen Ausdrucks gerichtet. Sie reicht nicht aus, die inneren Erlebnisse und Visionen des Dichters angemessen auszudrücken. Während V. Gofman: Jazyk simvolistov, nur den zweiten Aspekt betont, sieht J. West: Russian Symbolism, auch den ersten, der für Tjutčev der wichtigere zu sein scheint. Denn Tjutčev besteht wie Hölderlin darauf, die "lebendige Sprache der Götter" (Solov'ev) - und das heißt, das vollmächtige dichterische Wort - in einer Zeit der Sprachinflation, u.a. durch Journalismus und Presse, "rein" zu erhalten, selbst um den Preis des NichtVerstandenwerdens. Dichter wie Tjutčev und Hölderlin erfahren sich als "Dichter in dürftiger Zeit" und sehen sich vor dem Paradox, durch die Enthaltsamkeit des poetischen Schweigens die Wahrheit der Dichtung zu bewahren. Cf. dazu M. Heidegger: Erläuterungen zu Hölderlins Dichtung, $46 \mathrm{f}$. Als Dichter solchen Ranges wurde Tjutčev durch V. Solov'ev 1895 wiederentdeckt, cf. V. Solov'ev: Poézija F.I. TjutČeva. Werke (Brüsseler Ausgabe) VI, 117-134, und für die Symbolisten bedeutsam. Zu TjutZevs Bedeutung für die russischen Symbolisten cf. V. Gofman: Jazyk simvolistov, 60; J. Holthusen: Ästhetik und Poetik des russischen Symbolismus, 34; R.-D. Kluge: Westeuropa und Rußland im Weltbild Aleksandr Bloks, 27, 286; J. West: Russian Symbolism, 73 f. (zu Tjutčevs "poetic silence"), 137 f. (zur Reaktion Brjusovs, Ivanovs und Belyjs auf Tjutčevs Sprachskepsis).

46. Cf. R. Sheppard: The Crisis of Language, 325. Sheppard deutet die Sprachkrise literatursoziologisch als Folge des soziokulturellen Wandels. Der Zerfall des sozialen Diskurses führte zu Chaos- und Krisenerfahrung im Bürgertum um 1900. S. beruft sich auf R. Barthes: Writing Degree Zero. London 1967, 48, 63: "Writing therefore is a blind alley and it is because society itself is a blind alley." (327).

S. bietet eine monokausale Erklärung an, die im Widerspruch zu der ebenfalls von inm festgestellten Tradition der Sprachkrise steht, bei der es sich of fenbar um eine zwar geschichtliche, aber nicht allein soziologisch erklärbare Erscheinung handelt. Denn neben sozıologischen Ursachen gibt es solche, die im Wesen der Sprache selbst angelegt sind. Der Streit zwischen den Nominalisten - nach denen die Sprache den Dingen nur Namen gibt - und den Realisten - nach denen die Sprache als Logos eigenes Sein hat - ist so alt wie die Philosophie. Die nominalistische Sprachkritik, die den grundsätzlich metaphorischen Charakter der Sprache feststellt, der ihre Wahrheitsgültigkeit in Frage stellt, sowie die Tendenz der Sprache, ihre Metaphern zur begrifflichen Konvention erstarren zu lassen, die dann mit eigenem Sein ausgestattet werden, wurde im neunzehnten Jahrhundert von Nietzsche und Mauthner eingeleitet und von Wittgenstein weitergeführt. Cf. F. Nietzsche: Uber Wahrheit und Lüge im außermoralischen Sinn. III, 309-322. F. Mauthner: Beiträge zu einer Kritik der Sprache. 3 Bde. Stuttgart 1901-1903. L. Wittgenstein: Tractatus logico-philosophicus (erstmals veröffentlicht im letzten Band von Ostwalds "Annalen zur Naturphilosophie", 1921) und ders.: Philosophische Untersuchungen. - In: ders.: Schriften 1, 7-84, 279-544. Wittgenstein brachte in den beiden Werken zwei sehr verschiedene Systeme der Sprache hervor; im "Tractatus" eine Modelltheorie der Sprache, in den "Philosophischen Untersuchungen" eine Handlungstheorie der Sprache als "Sprachspiele". Die zweite Theorie enthält eine scharfe Kritik der ersten, gerade deshalb aber auch ihre notwendige Ergänzung. Cf. Norman Malcolm: Ludwig Wittgenstein. - In: Encyclopedia of Philosophy. New York/London 1967, Bd. 8. Die Sprachkrise der Moderne kann nicht nur literatursoziologisch verstanden werden, sondern muß im Zusammenhang mit der philosophischen Sorachkritik gesehen werden. Cf. Allan Janik und Stephan Toulmin: Wittgenstein's Vienna, Kap. 5 "Language, Ethics and Representation". Janik/Toulmin gehen zwar auch von den soziologischen Bedingungen der philosophischen Sprachkritik aus, bezieten aber in 
ihre Analyse andererseits die Entwicklungslogik der philosophischen Denkbewegung mit ein: "(...) between 1800 and 1920, the problem of defining the essential scope and limits of the reason was twice transformed: first, into the problem of defining the essential scope and limits of representation and, subsequently, into that of doing the same for language." (121).

47. Cf. W. Eschenbacher: Fritz Mauthner und die deutsche Literatur um 1900, 83 ff. (Die Kommunikationskrise in der Literatur um 1900), 87 (deren literarische Konsequenzen).

48. Ibid., $94 \mathrm{f}$. (zu Thema, Motiv und positiver Wertschätzung des Schweigens), $96 \mathrm{f}$. (Schweigen in Spannung zur Sprache bei Kierkegaard, Hofmannsthal und Rilke, 20. Sonett an Orpheus).

Auch in der Sprachkritik der nachnietzscheschen Philosophie spielt die Erkenntnis, daß Schweigen angesichts einer nicht mehr tauglichen Sprache zur ethischen Notwendigkeit werden kann, eine große Rolle, cf. L. Wittgenstein: "Wovon man nicht reden kann, darüber muß man schweigen", Vorwort. Schriften I, 7.

Schweigen wird sowohl philosophisch als auch poetologisch aufgewertet: cf. $M$. Heidegger: "Wer (...) im Miteinander schweigt, kann eigentlicher 'zu verstehen geben', das heißt Verständnis ausbilden, als der, dem das Wort nicht ausgeht." Sein und Zeit, Tübingen 1957 , 164; Jacques Lacan: Ecrits, 249, "daß sie (d.h. die leere Sprache, M.D.) weit frustrierender sein kann als Schweigen."

49. Das gilt nicht nur für die Moderne, sondern die Paradoxie von Sprachohnmacht und Sprachvollmacht hat Geltung für zwei Typen außergewöhnlichen Sprechens: für den Dichter und für den Propheten. Nicht erst die Symbolisten setzten beide zueinander in Beziehung, sondern bereits Púskin ("Prorok", "Poèt"). Auch Hölderlin und Wordsworth bezeugen beide Zustände, $c f$. R. Sheppard: The Crisis of Language, 323 ("the poet's experience of spiritual death and rebirth, linguistic aridity and plenitude.")

50. Daß das "schlechte Verhältnis zu den Wörtern" über die Laufbahn eines Schriftstellers entscheiden kann, untersucht Jean-Paul Sartre: Der Idiot der Familie. Gustave Flaubert. Band 1-3, Hamburg 1977 If./Paris 1971, Bd. 1, S. 11.

51. Cf. W. Pailer: Die frühen Dramen M. Gor'kijs in ihrem Verhältnis zum dramatischen Schaffen A. P. Cechovs. München 1978 (= Slavistische Beiträge 122), Kap. 3 und 4, S. $30-112$.

52. Cf. R.-D. Kluge: Westeuropa und Rußland im Weltbild Al. Bloks, 24-27 (zur formalen Bedeutung von Fet für Blok).

53. Die stilistische Bedeutung, die Belyj als Innovator der russischen Prosasprache zukommt, ist vor allem aus dem völlig neuen Sprachstil, dem "symphonischen" Stil, zu erklären. Von den Anfängen in den vier Symphonien (1899-1908) über sein RomanPoem "Kotik Letaev" (1917) bis hin zu seinem formalen Meisterstück, dem Poem "Pervoe Svidanie", verläuft diese Stillinie. Cf. S. Karlinsky: Symphonic Structure in Andrej Belyjs "Pervoe Svidanie". -In: California Slavic Studies, Vol VI, Berkeley and Los Angeles 1971, $63 \mathrm{ff}$. Eine gründliche erste Analyse des "symphonischen" Stils der frühen Prosa gibt A. Kovač: Andrej Belyj: The "Symphonies. K. untersucht sowohl die philosophische Motivation, die sich aus der Auffassung der Musik bei Wagner (5456), bei Nietzsche und Schopenhauer (59-65) speist, als auch die Strukturzüge des symphonischen Stils. (Zu literarischen Analogien zur musikalischen Form, 83-98, 153-158, 170-189; zur "Wortsymphonie" 218-226).

54. Was für weitreichende Konsequenzen diese Entwicklung hatte, untersuchten z.B. an der russischen Literatur der Symbolisten V. Gofman: Jazyk simvolistov; an der deutschen Literatur von Musil, Rilke und Kafka bis zu den Expressionisten W. Jens: Der Mensch und die Dinge. Die Revolution der deutschen Prosa. - In: ders.: Statt einer Literaturgeschichte, 113-138.

Beide zeigen, daß es bereits vor dem ersten Weltkrieg zu einem radikalen Formenbruch kam, der die Tradition des neunzehnten Jahrhunderts beendete. Jens sagt: "Der Einschnitt ist unübersehbar; die neue Sprache formt einen neuen Menschen, schafft neue Situationen und erobert neue Bereiche. 'Extremtypen' (...) verdrängen Individuen (...) mit Heyms '5. Oktober' ertönt zum ersten Mal die Fanfare der Revolution (131)." Analoges stellt Gofman fest: "Wir wohnen einer halsbrecherischen Metamorphose bei (golovolomnyi metamorfoz): die semantischeßemittel der 7 Rade 
werden zu Motoren des poetischen Gedankens. Die semantischen Verbindungen, die eine Trope bilden, erweisen sich als Enthüllung und Verkörperung einer zu schaffenden Welt, als Quelle und Auswahl eingebildeter Beziehungen und Gesetzmäßigkeiten dieser Welt (68)."

Als die folgenreichste Konsequenz der "semantischen Belebung des Wortes" stellen beide fest:

1.) Der sprachliche Prozeß kehrt sich um, denn die Sprache bildet nicht mehr vorhandene Welt $a b$, ist nicht mehr Instrument mimetischer Darstellung von Wirklichkeit, sondern sie erschafft eine eigene, nicht mehr mimetisch gewonnene "Gegenwirklichkeit", sie offenbart ihre eigene Schöpferkraft, anstatt weiter nur Medium zu sein.

2.) In diesem Prozeß der Umkehrung "zerbröckelt die Vergleichsebene", indem nämlich der metaphorische Vergleich zugunsten einer metaphorischen Identifikation aufgegeben wird. Schlagendstes Beispiel ist Kafkas "Verwandlung"; Gregor Samsa wird nicht mehr mit einem Käfer verglichen, sondern er "ist" einer. Dasselbe hat kürzlich J. Holthusen: Weltmodelle moderner slavischer Dichter, 10, auch an der Tiermetaphorik bei Krleža und Belyj nachgewiesen. Einig sind sich die beiden Kritiker, Jens und Gofman, im Aufweis des sprachlichen Befundes. Verschieden ist aber ihre Erklärung für die Ursachen dieses Prozesses der metaphorischen Identifikation. Gofman erklärt ihn aus der Dichtungstheorie der Symbolisten, aus der schöpferischen Imagination des Dichters, die eigenmächtig den sprachlich geschaffenen "Dingen" eigenes Sein verleiht. Dazu zitiert er Belyj "Magie der Worte": "Die Unabhängigkeit des neuen Bildes (...) drückt sich darin aus, daß das Schaffen es mit ontologischem Sein ausstattet, das von unserem Bewußtsein unabhängig ist." Das heißt, daß damit der Dichter in die Nähe des Mythenschöpfers gerückt wird. Jens gibt da eine andere Erklärung. Er leitet den "Stil der redenden Dinge" (bzw. Tiere) aus der Verselbständigung der Dinge ab, über die der Mensch die Verfügung verloren hat, die er sich selbstherrlich zugerechnet hatte. Jens spricht vom "Aufstand der Dinge", die den Menschen in der "Zerteilung der Welt" zu überwältigen drohe.

Hier liegt offenbar ein poetologisches Problem. Festhalten kann man, daß ein und dasselbe nicht-mimetische Stilphänomen der metaphorischen Identifikation verschieden motiviert sein kann.

55. Cf. V. Gofman: Jazyk simvolistov, über die "zweiseitige Beziehung zum Wort" bei den Symbolisten. Der von der Romantik überkommenen Sprachskepsis ("bessilie slov") steht eine "Fetischisierung des Wortes" gegenüber, in der dem Wort eine gnoseologische und darüber hinaus eine ontologische Schlüsselstellung eingeräumt werde, und zwar unter dem sprachphilosophischen Einfluß der Humboldtschüler Steinthal und Potebnja.

56. Cf. K. Pomorska: Russian Formalist Theory and its Poetic Ambiance, 55; A. HansenLöve: Der russische Formalismus, 44,54.

57. In V. Sklovskijs Theorem der "Verfremdung" kann man den literaturtheoretischen Niederschlag dieses ersten Stadiums der Reaktion auf die Sprachkrise sehen. Dieser verursachende Zusammenhang, der insofern komplex ist, als er Bestandteil der umfassenderen Reaktion auf die Kulturkrişe der Moderne ist, kann als Erklärung für die "unangenehme Heterogenität" des Sklovskijschen Begriffs der Verfremdung herangezogen werden, die Wolf Schmid feststellt, cf. ders.: Poetische Sprache in formalistischer Sicht, 262 f. Bei seinem detaillierten Versuch, Kriterien von Verfremdung zu ordnen, wird deutlich, daß es sich hier um mehr als einen formalen "priëm" handelt, nämlich um einen ästhetischen Begriff, der alle drei Bereiche der Asthetik, die Wahrnehmungs- und Erlebnisstruktur des Autors, das Stilverfahren eines Werkes und die Rezeptionsweise des Lesers betreffen kann. "Verfremdung" ist als ästhetischer Begriff offenbar von weiterem Umfang, als ihn ein reines Stilverfahren haben kann. Es scheint, als sei er von W. Schmid in die falsche Kategorie eingeordnet worden, weshalb dann auch seine ästhetische Komplexität als "Heterogenität" mißverstanden wird. Cf. dazu die neue Analyse zum russischen Formalismus von A.A. Hansen-Löve: Der russische Formalismus. H.-L. macht das Prinzip der Verfremdung zur Grundlage einer methodologischen Neuerfassung dieser Schule. Gleich zu Anfang bestimmt er seinen Umfang: als "noetisches Prinzig" 4 4nd "poetisches Verfahren", wodurch begriffliche Klacheitogeschaffentanirid.1/10/2019 05:16:17AM 
58. Diese Ansicht wird bestätigt durch die Bedeutung des "konstruktiven Prinzips", das Hansen-Löve: Der russische Formalismus, 232, als konstitutiv für die zweite Phase des risssischen Formalismus nachweist, die die erste der "paradigmatischen" Dekontextuierung abgelöst habe.

59. Cf. J. Striedter: Transparenz und Verfremdung, 275.

60. Zitiert nach Claudio Magris: Archivar des Negativen. Robert Musils Tagebücher. In: Die Zeit, 17.2.78. Bei der Uberprüfung des Zitats stellte sich heraus, daß es von Nietzsche stammt. "Der Fall Wagner." 7. Abschnitt. Für Hilfe beim Aufsuchen des Zitats danke ichG. Bielfeldt.

61. Cf. V. Gofman: Jazyk simvolistov, 81-84, "Proizchodit sdvig predmeta reči" (82). Der in der Stilfigur der Katachrese ausgelöste Bewegungsvorgang der semantischen Beziehungen setzt sich weiter fort, indem sich die Trennung von Abstrakta und Konkreta auflöst, beide stecken sich gegenseitig an ("cretok-mečta" / Bal'mont; "I v duše pod tichim vetrom / Nakrenilis' parusa" / Brjusov). Wortverbindungen werden durch Klangverbindungen ausgelöst ("I gadost' delaet Gades"; "Fantomnyj bes atomnyj ves (...)"; "O, osijannaja Osanna (...)" / Belyj: Pervoe svidanie.)

Cf. W. Jens: Der Mensch und die Dinge. "In den Oxymora Musils und Kafkas ("sengende Kälte"; "ich rief ohne Klang"), der dinglichen Vivifizierung ("klagende Fenster"; "verwestes Licht") und der Zusammenfügung heterogener Elemente ("sie hatte plötzlich von sich ein (...) abgebrochenes, wie ein Armstumpf fuchtelndes Gefühl") beginnt sich ein Prozeß abzuzeichnen, in dessen Folge die Vergleichsebene zerbröckelt und das "wie" zugunsten des "ist", der Vergleich zugunsten der Identifikation, aufgegeben wird (130), cf. oben Anm. 54.

62. Cf. K. Bal'mont: Budem kak solnce. 1912, 205.

63. Cf. V. Brjusov: Trorčestvo. Zitiert nach V. Gofman: Jazyk simvolistov, 77.

64. Cf. J. Striedter: Transparenz und Verfremdung, 278-282. Zum "symbolischen" Konstruktivismus, wie er in Belyjs ästhetischer Theorie poetologisch erarbeitet wird, cf. unten S. $133 \mathrm{ff}$.

65. Cf. René Wellek / Austin Warren: Theorie der Literatur. Frankfurt 1972 (= FAT 2005), $207 \mathrm{f}$. Die Polarität zwischen Metaphorik und Metonymie. - In: Jens Ihwe (Hg.): Literaturwissenschaft und Linguistik. Bd. II/1. Frankfurt $1971=$ Ars poetica 8), 323-333.

66. Cf. Boris Pasternak: V lesu. - In: Stichi i poemy 1912-1931. Sočinenija Bd. I Ann Arbor 1961, 89. Zur Metapher des Brandes bei Brjusov:

Kostra rastorgnutaja sila

Dvuch tel sožgla odnu mećtu

(V. Brjusov: Puti i pereputja, t. II, 187);

bei Annenskij:

Na serdce temno, kak $v$ mogile (...)

Ja znal, cto pożar ja ujmu (...)

Nu vot (...) i ogon' potušili,

A ja umiraju v dymu

(zitiert nach A. Flaker: Die slavischen Literaturen, 412);

bei Majakovskij: Oblako v $\xi$ tanach, "bewirkte die Metapher 'Feuersbrunst des Herzens' die Sequenz: Brand eines Bordells - Feuerwehr in Aktion - der Dichter, der aus dem Herzen herausspringen will" - damit illustriert A. Flaker die "realisierte" Metapher Majakovskijs. Cf. ders.: Die slavischen Literaturen zur Zeit des Modernismus. Das Auftreten der Avantgarde und des Expressionismus. - In: Neues Handbuch der Literaturwissenschaft. Bd. 19, 423.

67. Cf. J. Striedter: Transparenz und Verfremdung, $282 \mathrm{ff}$.

68. Cf. A. Belyj: Peterburg. Moskva 1978, 109; dt. Wiesbaden 1959, 135.

69. In der Konzentration auf das Medium der Sprache selbst sind zwei Stadien zu unterscheiden: das Extrem der metalogischen Sprache ("zaum"'), radikal exploriert von V. Chlebnikov und A. Kručenych, und die gemäßigtere Form der "sperrigen Sprache" (tugoj jazyk), die den Wiederanschluß der "selbstwertigen Sprache" an den sozialen Diskurs vollzieht. Cf. A. Flaker: Die slavischen Literaturen, $422 \mathrm{f}$.

70. Auf Belyjs stilprägende Bedeutung für die moderne russische Literatur wurde schon früh und wiederholt hingewiesen: 
Nikolaj Berdjaev: Krizis iskusstva. Moskau 1918. B. bringt Belyj in Zusammenhang mit Picasso aus Anlaß des Erscheinens seines "Astral-Romans 'Petersburg"' (36-47); V. Šklovskij: O teorii prozy. Moskau 1929, 205-225 ("Ornamental'naja Proza. Andrej Belyj.") S. beurteilt Belyj als Erneuerer der Romanform aus der ornamentalen Formtradition Gogol's und Leskovs; als Demonstrationsobjekt für seine beiden Theoreme der "Verfremdung" und der "Konstruktion des Sujets aus dem priëm" (vor allem "Kotik Letaev"); E. Zamjatin vergleicht B. mit Joyce, da er wie dieser eine Prosa geschaffen habe, die ebensowenig übliches Russisch sei wie Joyce's Sprache übliches Englisch, - eher ein persönliches Idiom, das er zum Vehikel einer glanzvoll exzentrischen Vision gemacht habe; cf. E. Zamjatin: Lica. New York 1967, 73 ff. (zuerst 1936); B. Pasternak: Uber mich selber. Versuch einer Autobiographie. Ffm. $1959,46$.

Von den Literaturwissenschaftlern Tschižewskij, Mirskij, Holthusen, Struve und Flaker wurden diese Urteile im wesentlichen übernommen und weitergeführt. Man sieht daran, daß die Rolle der zeitgenössischen Literaturkritik für die nachfolgende Literaturwissenschaft recht hoch zu veranschlagen ist.

71. Cf. z.B. G.V. Plechanov: Iskusstvo i obščestvennaja そ̌izn'. - In: ders.: Kunst und gesellschaftliches Leben. Berlin 1955 ( $1912 / 13$ in "Sovremennik"), 229-310. P. rechtfertigt vom soziologischen Standpunkt aus die Verweigerung des Künstlers in der kompromißlosen Haltung des l'art pour l'art schon am Beispiel Puškins gegenüber einer utilitaristischen Kunstauffassung, die prinzipiell anfällig sei für ideologische Dienstbarkeit: "daß jede Macht immer die utilitaristische Kunstauffassung bevorzugt" (245).

72. Die Radikalisierung der ästhetischen Wahrnehmung, die mit einer Verhäßlichung der Welt konfrontiert ist, weist K.H. Bohrer: Die Ästhetik des Schreckens, vor allem an der Kunst der englischen Präraffaeliten nach, die den "Stil" der Jahrhundertwende vorbereiteten; cf. S. 25-27.

73. Zitiert nach Bohrer: Die Ästhetik des Schreckens, 543. Uber die Kategorie des "Choks" als zentraler ästhetischer Erfahrung der Moderne, die er in der Auseinandersetzung mit Freud ("Jenseits des Lustprinzips") und Bergson ("Matière et mémoire) gewann; cf. Walter Benjamin: Uber einige Motive bei Baudelaire. - In: ders.: Charles Baudelaire. Ein Lyriker im Zeitalter des Hochkapitalismus. Ffm. 1974 (= sk tb wissenschaft 47) ("1939 "Zeitschrift für Sozialforschung ") S. 110-113: "Die Frage meldet sich an, wie lyrische Dichtung in einer Erfahrung fundiert sein könnte, der das Chockerlebnis zur Norm geworden ist. (...) Baudelaire hat es zu seiner Sache gemacht, die Chocks mit seiner geistigen und physischen Person zu parieren (...) Das Gefecht stellt das Bild dieser Chockabwehr."

74. Zum "Dandy" als sozialer Stilfigur des modernen Dichters cf. K.H. Bohrer: Die Ästhetik des Schreckens, 31-4l. Ausgehend vom "Aggressionscharakter" des Ásthetizismus schaltet sich Bohrer in die Debatte der kritischen Umwertung eines bislang polemisch belasteten Dekadenzverständnisses ein; cf. S. 89 bes. 528-530 (neuere Literatur). Wie an der Dekadenz so auch an ihrem dichterischen Repräsentanten, dem "Dandy", zeigt er die intensivierte, "subversive" Wahrnehmungsstruktur, die zum indirekten, anarchistischen Protest gegen die of fiziellen Normen führte, in dem Kunst "zum letzten Mal die auratische Qualität von Gefahr besaß" (23). Bohrer ergänzt die wegweisende Arbeit zum Dandy-Problem von Rainer Gruenter: Formen des Dandyismus. Eine problemgeschichtliche Studie über Ernst Jünger. - In: Euphorion, Bd. 46, Heft 3 (1952), S. 170-201, durch sozial-psychologische und zeitgeschichtliche Bezüge.

75. Cf. Gotthard Wunberg (Hg.): Das junge Wien. Ósterreichische Literatur und Kunstkritik. 1887-1902. 2. Bde. Tübingen 1976; Wolfram Mauser: Hugo von Hofmannsthal. Konfliktbewältigung und Werkstruktur. Eine psychosoziologische Interpretation. München 1977 (= Kritische Information 59), 16 f. (Motive der Gruppenbildung), 86-89 (Das 'junge Wien'); Ursula Renner: Leopold Andrians "Garten der Erkenntnis". Literarisches Paradigma einer Identitätskrise in Wien um 1900. Ffm./Bern $1981(=$ Literatur und Psychologie 3), S. 278 ff. zum Aspekt der informellen Gruppe als "facilitating environment".

76. Cf. Georg Peter Landmann (Hg.): Der George-Kreis. Eine Auswahl aus seinen 
Schriften. Köln/Berlin 1965 (= Neue Wissenschaftliche Bibliothek 8); Michael Winkler: George-Kreis. Stuttgart 1972 (= Sammlung Metzler 110).

77. Cf. The Bloomsbury Group. A Study of E.M. Forster, Lytton Strachey, Virginia Woolf, and their Circle. By J.K. Johnstone. London 1954; Quentin Bell: Virginia Woolf. A Biography. Triad Paladin 1976, 68, 94, 170; ders.: Bloomsbury (Triad Paladin-Books) London 1974.

78. A. Belyj: Načalo veka, 107-116. Die "Argonauten" waren ein Moskauer Freundeskreis von Dichtern und Intellektuellen, der sich nicht primär als literarische Gruppe verstand, sondern als ein "Kreis von Andersartigen" (kružok Zudakov), die sich das utopische Ziel einer "universalen Kulturrevolution" gesetzt hatten. Den festen Kern bildeten die Dichter Belyj und Ellis-Kobylinskij. Ohne festes weltanschauliches Programm, ohne Organisation existierte die Gruppe, die sich in den Wohnungen von Mitgliedern und Freunden traf, von 1903-1910. Belyj bezeichnet sie als die eigentlichen "Symbolisten", die sich von den "Dekadenten" dadurch unterscheiden, daß sie "Egozentrismus, Solipsismus - das Schicksal der Dekadenz" überwinden wollten. "Uns interessierte das Problem einer neuen Kultur und einer neuen Lebensweise, in der die Kunst - der machtvollste Hebel ist, deren Formeln aber erst in der Zukunft deutlich ausgesprochen werden; vorläufig - war es noch zu früh, von ihnen zu sprechen; unsere Aufgabe war - ein angemessenes Scherflein auf dem Altar dieser Zukunft darzubringen, die of fenbar ungeordnet und widersprüchlich sein würde."

79. Das Kunstleben der Jahrhundertwende in Moskau und Petersburg ist seit 1890 in kunstsoziologischer Hinsicht dadurch gekennzeichnet, daß sich Künstler und Literaten zu Gruppen zusammenschlossen, die teils offiziellen teils privaten Charakter hatten. Uber die Gruppenbildung unter bildenden Künstlern, die in Petersburg aus Benois' Schulfreundeskreis der "Nevskij Pickwickiers" zur Vereinigung und Zeitschrift "Welt der Kunst" führte, in Moskau zur "Moskauer Künstlergenossenschaft" und "Moskauer Gesellschaft der Kunstliebhaber" cf. die kunstsoziologische Studie von G.J. Sternin: Das Kunstleben Rußlands an der Jahrhundertwende. 16-18, $158 \mathrm{ff}$., 214.

Kristallisationszentren der Gruppenbildung waren die immer zahlreicher werdenden Zeitschriften; cf. E. Stenbock-Fermor: Das Silberne Zeitalter der russischen Literatur. In: Rußlands Aufbruch ins 20. Jahrhundert, 278; G. Donchin: French Influences on Russian Symbolist Versification; C. Gray: Das große Experiment. Die russische Kunst 1863-1922, 36 ff. Eine Neuerscheinung in der Geschichte der russischen Intelligenz waren die Religiös-Philosophischen Gesellschaften in Moskau und Petersburg, cf. J. Scherrer: Die Petersburger Religiös-Philosophischen Vereinigungen. Die Entwicklung des religiösen Selbstverständnisses ihrer Intelligencija-Mitglieder (19011917). Zur literarischen Gruppenbildung gibt es nichts Vergleichbares; man bleibt auf die Memoirenliteratur angewiesen. Hier liegt ein kunstsoziologisches Forschungsgebiet. Einiges zu den Kreisen der Solov'evs, Merežkovskijs und um V. Brjusov findet sich bei O.A. Maslenikov: The Frenzied Poets. Andrey Biely and the Russian Symbolists; R. Poggioli: Poets of Russia, 55-62 (zu den Zeitschriften). Ebenfalls um die Verlage bildeten sich literarische Gruppierungen, z.B. die Musagetes-Gruppe um 1910 in Moskau. Zur "Turmgesellschaft" (bašnja) V. Ivanovs in Petersburg cf. A. Belyj: NaČalo veka, 313 3-327 ("Vjąeslav Ivanov", "Bałennyj Ki tel").

80. R.M. Rilke: Worpswede. Bielefeld und Leipzig 1903. Uber die Künstlerkolonie des Moskauer Mäzens Savva Mamontov, "Abramcevo" (auf dem ehemaligen Familiensitz des Schriftstellers Aksakov) cf. G.J. Sternin: Das Kunstleben Rußlands, 157 f.; C. Gray: Das große Experiment, 14-29.

81. Cि. den Ausstellungskatalog "Monte Verità. Berg der Wahrheit. Lokale Anthropologie als Beitrag zur Wiederentdeckung einer neuzeitlichen sakralen Topographie." Milano 1978.

82. Dieses Gebiet der Literatursoziologie wird erst seit wenigen Jahren erforscht. Zur Gruppenbildung als Ausdruck der Suche nach sozialen Formen des künstlerischen Schaffens cf. H. Kreuzer: Die Bohème. Analyse und Dokumentation der intellektuellen Subkultur vom 19. Jahrhundert bis zur Gegenwart. Stuttgart 1971. Neben literarhistorischer Dokumentation gibt es neuerdings auch den Versuch, die Motive zum Gruppenanschluß bei Schriftstellern zu untersuchen. Cf. Friedhelm Kröll: Die 
Eigengruppe als Ort sozialer Identitätsbildung. Motive des Gruppenanschlusses bei Schrif tstellern. -In: DVjs 52, 1978, 652-671.

83. F. Nietzsche: Werke, I, 20 (Vorwort zur "Geburt der Tragödie").

84. Cf. Robert Musil: Notizheft, 15, 36; cf. G. Müller: Dichtung und Wissenschaft, 12.

85. Ist die Existenzmetapher des "Kellerlochmenschen" auf Dostojevskij zurückzuführen, aber darüber hinaus auf die Strömungen des politischen "Untergrundes" - so ist die andere Protestmetapher des "Reinen" verbunden mit der Rezeption Nietzsches, wie sie sich z.B. in Bal'monts Titel "Laßt uns wie die Sonne sein" (Budem kak solnce) niederschlug.

86. Das erste Psychogramm Belyjs gab V.F. Chodasevič: Andrej Belyj. - In: ders.: Nekropol', 61-100; bes. $67 \mathrm{f}$.

87. Auf die Metaphern der "Schere" und "Bombe", des "Kelches" und der "Spirale" wird später näher eingegangen, cf. unten S. $162 \mathrm{ff}$. Hier sei auf einige ihrer Quellen hingewiesen: Die Metapher der "Bombe" wird bereits, ehe Belyj mit der Arbeit an "Petersburg" begann, in Bloks kulturkritischem Essay "Stichija i kul'tura" (1908) als Ausdruck für ein "unabweisbares Gefühl der Katastrophe" verwendet. Cf. dazu L.K. Dolgopolov: Istorija sozdanija romana (Peterburga). - In: A. Belyj: Peterburg. Moskva 1978, 350 (Anm.) Das Bild des "Kelches", "Pokals" oder "Grals" ist wohl von Wagner angeregt. Belyj verwendet es als Titel seiner "Vierten Symphonie": Pokal der Schneegestöber. Das Denkbild der "Spirale" ist Gemeingut des russischen Symbolismus. Es findet sich, außer bei Belyj, auch bei A. Blok; cf. D.E. Maksimov: Poèzija i Proza Al.Bloka, 8, 41, sowie bei Ivanov.

Wenn hier von Konfliktkonstanten oder Metaphern dafür die Rede war, so geschieht das angeregt durch neuere Forschungen innerhalb der Literaturpsychologie. Nachdem in dieser Richtung bisher weitgehend ahistorische Textbetrachtung betrieben wurde, wird nun der Versuch gemacht, soziologische und zeitgeschichtliche Bezüge zu integrieren. Dazu hat sich das Problem des "Konflikts", in dem sich psychologische und soziologische Komponenten verschränken - und zwar in doppelter Hinsicht: auf der Ebene des Autors und auf der des Werkes - als geeignet erwiesen. Cf. dazu die methodische "Vorüberlegung" bei Wolfram Mauser: Hugo von Hofmannsthal, 2-29 (zum "Konflikt". bes. 9-11, 17 f.) Es wäre zu überlegen, ob innerhalb eines "Konflikt-Modells" Diskrepanz- und Entwurfsmetaphern als spezifische Formen von Konflikt-Metaphorik betrachtet werden können. Das Beispiel Belyjs legt dies nahe, $\mathrm{cf}$. auch unten S. $163 \mathrm{ff}$.

88. Für diese Phase der Identitätsbildung in der Adoleszenz wurde der sozialpsychologische Terminus der "Sozialisation in eigener Regie" gegenüber der primären Sozialisation in der Familie und der sekundären in den Erziehungsinstitutionen geprägt, cf. Handbuch der empirischen Sozialforschung. Hg. von René König. Bd. 6 Jugend. Stuttgart 1976 (= dtv 4241), 115. Sie ist abhängig von "Peers", Gleichaltrigen, die Vergleich und Stützung bieten. Ebenfalls wichtig für diesen Prozeß sind aber auch "relevante Andere", die jenseits der Kompetenzfelder der Eltern und "Peers" stehen. Deren Bedeutung untersuchte bereits George H. Mead: Mind, Self and Society. Chicago 1934; dt. "Geist, Identität und Gesellschaft aus der Sicht des Sozialbehaviorismus." Ffm. 1973 (stw 28), 17.

Belyjs Selbstinterpretation zufolge (Nrds $354 \mathrm{ff.,} \mathrm{469-476)} \mathrm{ist} \mathrm{inm} \mathrm{sein} \mathrm{Protest} \mathrm{gegen}$ die Schwerkraft des "Milieus" (byt) durch zwei verschiedene Arten von Stützung möglich geworden: "legale" Bestätigung fand er im Kreis der Solov'evs, "illegale" durch die kritisch-radikale Haltung seines Freundes A.S. Petrovskij, der ihn zur Selbstprüfung zwingt: "Die Wohnung der Solov'evs war in jenen Jahren unabdingbar, als Ausweg in die Kultur; Aleksej Sergeevič (Petrovskij) war mir genauso unabdingbar, als Kontrolleur meiner Rechte auf diesen Ausweg, denn er kannte in mir, was andere in mir nicht sahen, er kannte in mir meinen Untergrund; meine Konspiration und den ganzen Grad meiner Illegalität; mein Ausweg in die Kultur ohne 'Bombe', die im Untergrund zubereitet war, wäre sowohl leichtwiegender als auch verantwortungsloser gewesen, hätte es nicht A.S. gegeben, der mich mehr als einmal in meine Katakomben zurückgetrieben und mich in der Chemie der explosiven Stoffe unterwiesen hat (Nrds 475).

89. Cf. V. Erlich: Russischer Formalismus, 56. Erlich, geleitet vom Denkmodell der 
Opposition, stellt Belyj als Prototyp des poeta doctus aufgrund seiner Erudition den "plebejischen" Futuristen gegenüber, die außerdem durch das Moment der "Rebellion" gekennzeichnet seien. Wenngleich die erste Opposition zutrifft, so gilt das nicht für die zweite. Denn Belyj ist weder in die Rolle des formbewußten, esoterischen Alexandriners, des "Kabinettdichters", des "Veteranen der Versforschung" noch in die eines "Wächters über das Mysterium" hineinzupressen. Kann man Belyj theoretisch als Vorläufer der Formalisten bezeichnen, so von seinem Selbstverständnis her als Vorläufer der Futuristen. Auch der Zug zur Plattform und Polemik ist bei ihm vorgeprägt.

90. Die Polarität von "elevatio" und "desperatio" im Selbstverständnis moderner Dichter kann erschlossen werden aus einer motivgesetzlichen Dialektik, die sich in den konträren Motiven des "Aufschwungs" oder "Aufstiegs" ("elevatio") und des "Abgrundes" oder "Absturzes" ausdrückt. Diesen Zusammenhängen gehen die folgenden drei großen motivgeschichtlichen Untersuchungen nach: Karl Pestalozzi: Die Entstehung des lyrischen Ich. Studien zum Motiv der Erhebung in der Lyrik. Berlin 1970, IX ("grundlegende Veränderung im Verhältnis des Menschen zu sich selbst", die im lyrischen Ich um 1900 hervortritt), X (zum Leitmotiv der "elevatio" in der Kunst um 1900), 183, 186 f. (zum Problem des "Umschlags" von "elevatio" und "ennui" bei Baudelaire), 310 (zu "Entrückung" und "Absturz" im Ikarus-Motiv bei Stefan George); zum entgegengesetzten Motiv cf. Alfred Doppler: Der Abgrund. Studien zur Bedeutungsgeschichte eines Motivs. Graz/Wien/Köln 1968. Karl Heinz Bohrer: Die Ästhetik des Schreckens. Die pessimistische Romantik und Ernst Jüngers Frühwerk. München 1978, 168-185 (Die Metapher des Blech-"Sturzes" und Edgar Allan Poes "Maelstrom"), 325-358 (zur Kategorie des "Augenblicks" als Strukturelement des Avantgardismus).

91. Cf. J.P. Sartre: Der Idiot der Familie. Gustave Flaubert. 1821-1857. I. Die Konstitution. Reinbek bei Hamburg, 1977 (= dnb 78), 7. 

gencija

1. Zum Begriff der "Intelligencija" cf. J. Scherrer: Die Petersburger Religiös-Philosophischen Vereinigungen, 16,25-38.

2. Cf. R.-D. Kluge: Der Dichter als Prophet und Richter. In ders. (Hg.): Gegenwartsliteratur in Osteuropa. München 1982.

3. Cf. A. Flaker: Stilistic Formation. - In: Neohelicon. Acta Comparationis Litterarum Universarum 1-2 (1975), 183-207, bes. 200 ff. "Stilistic Formation and the social function of literature". Flaker leitet den Begriff der "sozialen Funktion" von Jan Mukarovsky ab und zeigt einen fruchtbaren methodischen Weg zur Beurteilung von Literatur, die unter den Bedingungen eines außerästhetischen Engagements entsteht. "Art, therefore, has function other than merely the aesthetic, and the contrasts 'between the subordination and predominance of the aesthetic function in the hierarchy of functions' is characteristic of art." Das Binnenzitat stammt aus J. Mukarovský: Studie z estetiky, Prag 1966.

4. Zur These von der "geistigen Renaissance", cf. F. Stepun: Pamjati Andreja Belogo, 163 f.; K. Moxul'skij: Andrej Belyj, 109; G. Sternin: Das Kunstleben Rußlands; 17 f.; J. Scherrer: Die Petersburger religiös-philosophischen Vereinigungen, 11 f.; G. Stökl: Russische Geschichte, 620.

5. Cf. G. Sternin: Das Kunstleben Rußlands, 255, 270.

6. Den Hinweis, auf diese Zusammenhänge verdanke ich Rolf-Dieter Kluge, der zum ersten Mai die ideologische Bedeutung des narodniðestvo für den kritischen Realismus in der russischen Literatur um 1900 untersucht hat. Cf. R.D. Kluge: Vom kritischen zum sozialistischen Realismus, Teil 1, 25-78.

7. Cf. A. Blok: Sobr. soč. v 6 t., t. 5, 259-68.

8. A.a.O., 262, 266, 268. Blok beschwört zwei große Vorstellungen Gogol's vom Weg Rußlands: 1) Rußland als "fliegende Trojka" mit unbekanntem Ziel ("Tote Seelen"); 2) Rußland als "Kloster", seine kranke Seele ist nur durch brüderliche Liebe zu heilen, zu der die Intelligenz, die "besten Söhne Rußlands" aufgerufen sind ("Ausgewählte Stellen aus Briefen an Freunde"). Cf. N. Gogol: Sein Vermächtnis in Briefen. München 1965 (= Kleine russische Bibliothek), $128 \mathrm{f} ., 142$.

9. Cf. Maximilian Braun: Dostojevskij. Das Gesamtwerk als Vielfalt und Einheit. Göttingen 1976, 189, $231 \mathrm{f}$.

10. Cf. R.-D. Kluge: Vom kritischen zum sozialistischen Realismus, $37 \mathrm{f}$.

11. G. Sternin: Das Kunstleben Rußlands, 19.

12. Die folgende Darstellung einiger Aspekte des narodničestvo stützt sich auf G. Stökl: Russische Geschichte. Von den Anfängen bis zur Gegenwart. Stuttgart 1965T= Kröners Taschenausgabe 244), "Die revolutionäre Bewegung", bes. S. 547-581, 814 f.; R.-D. Kluge: Vom kritischen zum sozialistischen Realismus, Teil I, S. 25-56.

13. Cf. R.-D. Kluge: op. cit., 31 .

14. Cf. G. Stökl: op. cit., 582 f., 584.

15. Cf. G. Stökl: op. cit., $575 \mathrm{f}$.

16. Cf. G. Stökl: op. cit., 576 f.; R.-D. Kluge: op. cit., 33; Helmut Dahm: Die Chance der Philosophie und das Verhängnis der slawophilen Utopie. - In: Rußlands Aufbruch ins 20. Jahrhundert. Hg. v. G. Katkov, E. Oberländer u.a. Olten und Freiburg, 1970, 234-262, bes. 251; George L. Kline: Changing attitudes toward the Individual. In: C.E. Black: Transformation of Russian Society. Cambr./Mass. 1960, 606-624, bes. 608-6 17 (zur Tradition des anthropozentrischen Denkens, in die Lavrov und Michajlovskij eingeordnet werden).

17. Cf. R.-D. Kluge: op. cit., 35 f., $229 \mathrm{f}$.

18. Cf. J. Scherrer: Die Petersburger Religiös-Philosophischen Vereinigungen, 13.

19. Cf. Ernst Benz: Geist und Leben der Ostkirche. Hamburg 1957 (= Rowohlts deutsche Enzyklopaedie 40) zu den Gefahren der Orthodoxie: S. 173 f. (z. Staatskirchentum) $175 \mathrm{f}$. (z. Verselbständigung der Liturgie), S. 176 zur "Preisgabe der 'Welt": "So hat sich die Orthodoxie of $t$ nur zu bereitwillig von der Aufgabe dispensiert, die Welt 
christlich zu gestalten, und hat sich gern damit getröstet, daß diese Welt sowieso bis zum Jüngsten Tag 'im Argen liegt'. Die meisten sozialpolitischen Impulse auf russischem Boden sind nicht von orthodoxen Gläubigen, sondern von Gegnern der Kirche und der Religion ausgegangen - ganz im Gegensatz zu den angelsächsischen Ländern, wo die soziale Erneuerung im wesentlichen von bewußten Christen vor allem der freikirchlichen Kreise getragen wurde."

20. Cf. L. Wenzler: Die Freiheit und das Böse nach Vladimir Solov'ev. Freiburg/München $1978,24$.

21. Zur Entwicklung des Positivismus und Idealismus in Rußland cf. H. Dahm: Die Chance der Philosophie und das Verhängnis der slawophilen Utopie. - In: Rußland im Aufbruch, 234-262, bes. 250 ff. Zur Bedeutung des sozial-revolutionären Anthropozentrismus in der russischen Philosophie cf. George L. Kline: Changing attitudes toward the Individual. - In: C.E. Black ( $\mathrm{Hg}_{\mathrm{.} .}$ : Transformation of Russian Society. Cambr./Mass. 1960, 606-624. Interessant scheint mir Kline's Hinweis auf die Idealismus-Kritik Herzens und Belinskijs, vor allem am "Impersonalismus" Hegels, in der wesentliche Positionen der Kritik Nietzsches und Kierkegaards vorweggenommen worden seien (608).

22. Diesen Hinweis auf Beziehungen der "geistigen Renaissance" der Jahrhundertwende zur Ideenwelt der narodniČestvo-Intelligenz verdanke ich Rolf-Dieter Kluge.

23. Cf. George Fischer: The Intelligentsia and Russia. - In: C.E. Black (Hg.): Transformation of Russian Society, 253-274.

24. Das Krisenbewußtsein war relativ schwach innerhalb des Liberalismus, stark ausgeprägt jedoch im radikalen Flügel der Intelligenz. Von den Marxisten wurde die Krise vorwiegend sozio-ökonomisch interpretiert, nach der Krisenlehre von Marx. Der Weg zur Lösung wurde im Klassenkampf gesehen. Von den SR (und teilweise den demokratischen Liberalen) wurde sie im Sinne eines eschatologischen Kulturpessimismus als drohender Untergang der Kultur gedeutet, dem man jedoch mit einem kosmopolitischen Erneuerungsdenken zu begegnen suchte, in dem die Uberwindung des Nihilismus aus den schöpferischen Kräften des Individuums erwartet wurde.

25. Cf. J. Scherrer: Die Petersburger Religiös-Philosophischen Vereinigungen, 417.

26. Zur Bedeutung des apokalyptischen Symbolsystems als Bezugsrahmen für das Krisenbewußtsein in Rußland vor der Revolution, bes. bei A. Belyj, cf. S.D. Cioran: The Apocalyptic Symbolism of Andrej Belyj, 9-25 ("The Context").

27. Die of $t$ isoliert gesehene apokalyptische Geschichtsauffassung Solov'evs wird zum ersten $\mathrm{Mal}$ in den Zusammenhang seines Denkens eingeordnet von $\mathrm{L}$. Wenzler: Die Freiheit und das Böse nach VI. Solov'ev, Kap. 11 ("Eschatologie: die endgültige Uberwindung des Bösen und die Vollendung der Geschichte").

28. Das "Gotterbauertum" ist noch wenig erforscht. Hier ist auf die Dissertation von R. Sesterhenn hinzuweisen, die sich mit den Beziehungen Gor'kijs zum "Gotterbauertum" beschäftigt und inzwischen in Freiburg, bei R.-D. Kluge, abgeschlossen wurde. Cf. Raimund Sesterhenn: Das Bogostroitel'stvo bei Gor'kij und Luna'̌arskij bis 1909. Zur ideologischen und literarischen Vorgeschichte der Parteischule von Capri. München 1982 (im Druck).

29. Cf. J. Scherrer: Die Petersburger Religiös-Philosophischen Vereinigungen, 40-51 (z. Entwicklung des Symbolismus als religiöse Weltanschauung).

30. Cf. L. Wenzler: Die Freiheit und das Böse nach VI. Solov'ev, 24 (zur Bedeutung und Wirkung Solov'evs um 1900), der auch das folgende Urteil von J. Scherrer: (op. cit. 55) zitiert: "Es muß ... festgehalten werden, daß es nahezu keinen religiösen Denker oder Schriftsteller der behandelten Epoche gab, der nicht in irgendeiner Hinsicht selbst wenn er das, wie Rozanov direkt leugnete - von Solov'ev beeinflußt war."

31. Cf. H. Friedrich: Die Struktur der modernen Lyrik, 46.

32. Cf. F. Nietzsche: Werke II, 205.

33. Cf. G. Fischer: The Intelligentsia and Russia, a.a.O. 262: "Russia for the first time was modernizing actively and extensively ....".

34. Zur Einstellung des frühen Gor'kij zum Leser cf. G. Sternin: Das Kunstleben Rußlands, 27-29.

35. Zu Benois' "Programm" cf. G. Sternin: op. cit. 252, 254, 260.

36. Cf. D.E. Maksimov: Poézija i Proza Al. Bloka, 187 ff. (Kriterien symbolistischer 


\section{Literaturkritik).}

37. Cf. F. Nietzsche: Werke II, 241.

38. Cf. G. Sternin: Das Kunstleben Rußlands, Kap. V (ausführliches Material zur "Welt der Kunst").

39. Cf. G. Sternin: op. cit., 255, 266.

40. Cf. Sternin: $219,235$.

41. "Philosophen" unter den Malern gab es wenige. Jedoch der bedeutendste Maler der Jahrhundertwende, M.A. Vrubel', war ein Vertreter des "Geistigen in der Kunst". Als sein Nachfolger kann in dieser Hinsicht $\mathrm{V}$. Kandinskij angesehen werden, der von der Kunstlehre des russischen Symbolismus entscheidend beeinflußt wurde, cf. C. Gray: Das große Experiment, $107 \mathrm{f}$.

41a. Cf. G. Sternin: Das Kunstleben Rußlands, 261.

42. Zum "Symbolistenstreit" cf. J. Holthusen: Ästhetik und Poetik des russischen Symbolismus, 36-42; R.-D. Kluge: Westeuropa und Rußland im Weltbild A. Bloks, Kap. 3 "Franzosen und Deutsche; A. Knigge: Die Lyrik VI. Solov'evs und ihre Nachwirkung bei A. Belyj und A. Blok, 252-255, 266-280; A. Blok: Sobr. soč. v 8 t., t. $5,756-758$.

43. Cf. K.H. Bohrer: Die Ästhetik des Schreckens, 19; zur Kritik an Bohrers generalisierender These vom Ásthetischen als Widerspruch des Moralischen cf. M. Deppermann: Dichter des Argwohns. Ernst Jünger und die "Ästhetik des Schreckens". Bemerkungen zu: Karl Heinz Bohrer: Die Ästhetik des Schreckens. Die pessimistische Romantik und Ernst Jüngers Frühwerk. München (Hanser 1978). - In: Sprachkunst X (1979), Jahressonderband: Komparatistik in Österreich, 234-241. 


\section{Kapitel: Denkvoraussetzungen}

1. Zum anthropozentrischen Denken: in der russischen philosophischen Kritik am Rationalismus und Impersonalismus bei Hegel und Marx cf. George L. Kline: Changing attitudes toward the Individual, 608-617; 618-622 (zur Marxismus-Kritik die beiden verschiedenen anthropologischen Konzepte der Kant- und Nietzschenachfolger) cf. auch oben S. 62, Anm. 21; in der russischen Religionsphilosophie cf. L. Wenzler: Die Freiheit und das Böse nach VI. Solov'ev, bes. Kap. 12 "Solov'ev als Denker und Anwalt der Freiheit", in dem W. zeigt, daß Freiheit und Personalität zu den Grundlagen des philosophischen Denkens bei Solov'ev gehören; im russischen Realismus cf. R.-D. Kluge: Wandlungen im russischen Realismus an der Jahrhundertwende (1880-1910). -In: Die slawischen Kulturen in der Geschichte der europäischen Kulturen (18.-20. Jahrhundert). Berlin 1978 (im Druck); ferner Wenzel Götte: Nachwort zu "Andrej Belyj, Im Zeichen der Morgenröte. Erinnerungen an Aleksandr Blok", 601 f., zum russischen Denken: "Es geht immer vom Menschen aus und kehrt zum Menschen zurück. Im Zentrum steht immer die Frage nach der Fruchtbarkeit des Denkens für das Leben. Deshalb konnte auch eine Philosophie als eine 'abstrakte' Wissenschaft auf russischem Boden keine besondere Geltung erlangen; deshalb konnte auch die Kunst im Sinne des L'art pour l'art sich dort nicht halten."

2. Stellvertretend für die reduktionistische Denkrichtung des Formalismus cf. $V$. Sklovskij: O teorii prozy, 205. "Die philosophische Weltanschauung eines Schriftstellers -das ist seine Arbeitshypothese. Genauer gesagt, vom Sein der literarischen Form ist das Bewußtsein des Schriftstellers bestimmt. Schriftstellerische Krisen kongruieren mit Krisen der Genres. Der Schriftsteller geht gänzlich auf in seinem Handwerk." Zur Verabsolutierung der reduktionistischen Position aus polemischem Abgrenzungsbedürfnis ("literaturnost"' vs. "naučnoe mifotvorčestvo") im frühen Formalismus cf. Aage A. Hansen-Löve: Der russische Formalismus, 176 f.; zur kommunikationstheoretischen "Offnung" im späten Formalismus durch Vygotskij und Bachtin S. 426-464.

3. Cf. J. Holthusen: Studien zur Ästhetik und Poetik des russischen Symbolismus, Kap. II "Asthetik und Poetik als konkurrierende Gesetze". So sehr Holthusen sich verdient gemacht hat um die Erforschung konkurrierender Gegensätze innerhalb des Symbolismus (33 f.), so kann doch den Schlüssen, die er daraus zieht, nicht überall zugestimmt werden, nämlich die Inkonsistenz der Ästhetik Belyjs ("hybrides Lehrgebäude"), die Unvereinbarkeit der Blokschen Antithesen (Ideal und Realität des Elementaren) sowie Ivanovs Scheitern an der Diskrepanz von Mythos und Logos zu konstatieren und darin die Essenz des russischen Symbolismus zu sehen. Die sowohl ästhetische wie auch problemgeschichtliche Rolle, die die drei jüngeren Symbolisten gespielt haben, scheint mir eher im Rahmen einer kulturwissenschaftlichen Betrachtung, die beide Bereiche, Weltanschauung und Formauffassung, umgreift, zureichend erforscht werden zu können.

Daß aus der methodischen Verknüpfung ideengeschichtlicher und struktural-typologischer Gesichtspunkte neue Erkenntnisse über die Eigenart symbolistischer Dichtung gewonnen werden können, zeigt D.E. Maksimov: Poézija i Proza Al. Bloka, nicht nur in bezug auf Blok (z.B. an der formkonstituierenden Funktion der "Idee des Weges" für die Zyklisierung), sondern auch an der Bedeutung der symbolistischen Literaturkritik als eines integralen Bestandteiles des russischen Symbolismus (186192) sowie durch typologische Gegenüberstellung mit der weltanschaulich indifferenten Gegenströmung des Akmeismus (98).

4. Cf. R.-D. Kluge: Die Rolle Polens in Aleksandr Bloks Versepos "Vozmezdie"; D. TschiŽewskij: Einleitung zu "Kotik Letaev", VI f., "Ideologisch ist die dichterische Prosa vom größten Interesse (...). Diese Romane stellen Versuche dar, die russische Wirklichkeit - Stadt und Land - zu interpretieren (...)." Uber die enge Verbindung von Idee und Struktur cf. neuerdings A. Flaker: Roman o Revoluciarnom Gradu (zur sowohl thematisch wie auch stilistisch realisierten ideologischen Opposition: Staatsmacht vs. Revolutionspotential in Belyjs "Peterburg").

5. Cf. D.E. Maksimov: Poèzija i Proza Al. Bloka, 186-192; cf. oben. 
6. A. Belyi: Vospominanija o Bloke, $254 \mathrm{f}$.

7. J. West: Russian Symbolism. A study of Vyacheslav Ivanov and the Russian symbolist aesthetic, 1.

8. J. West: op. cit., 1 f.

9. Cf. unten S. 92, $142 \mathrm{f.,} 150,153$.

10. Cf. 3. West: op. cit., 2.

11. Die Grundzüge von Kunst als Mythenschöpfung legt Ivanov in seinem Buch "Po zvezdam" (Zu den Sternen) dar. Zum Zusammenhang zwischen Kommunikationskrise und Mythenschöpfung cf. J. West: op. cit., 66, 126 (zur Krise des Individualismus in der Moderne und dem Bedürfnis nach echter Kommunikation), 70 (zum "kollektiven Bewußtsein"), $82 \mathrm{f.,} 85 \mathrm{ff}$, $136 \mathrm{f}$. (zu Ivanovs Auffassung vom Mythos als moderner Möglichkeit von religiöser Kunst). Die Wiederentdeckung des Mythos in der Moderne ist eine gesamteuropäische Erscheinung - und in diesem Kontext müßte Ivanov weiter erforscht werden -, die als Symptom der Krise des modernen Bewußtseins angesehen werden kann. Sie ist vor allem in Hinblick auf die Wandlung des philosophischen Weltbildes vom einseitig geist-zentrierten Idealismus zu einem biozentrischen Lebensgefühl zu sehen, die seit Schelling und Schopenhauer immer deutlicher hervortrat. Das Interesse für die nicht rationale Repräsentation von Wirklichkeit im Mythos wuchs mit der zunehmenden Erforschung des "anderen Schauplatzes" (Freud), des Unbewußten, cf. Z.B. H. Lang: Die Sprache und das Unbewußte, $19 \mathrm{ff}$. Auf die Dialektik von fortschreitender Modernität und Rückwendung zum Archaischen, die u.a. an der Hinwendung zum Mythos in der Moderne ablesbar ist, weist eingehend hin K.H. Bohrer: Die Asthetik des Schreckens, 76 ff. Bohrer führt als Beispiele der "irrationalistischen" Moderne mit starker Beziehung zum Mythos z.B. Benn, Kafka, H.H. Jahnn, wie auch die französischen Surrealisten an, wehrt sich aber gleichzeitig gegen eine einseitig ideologiekritische Diskreditierung dieser Paradoxie, indem er auf den subversiven Charakter vorideologischer Wahrnehmung hinweist, aus dem eine "neve Bewußtheit über die Tendenzen des gegenwärtigen Zeitalters" gewonnen werden könne, die an die romantischen Vorbilder Novalis und Schlegel anknüpfen könnte (77).

12. Cf. A. Blok: Krušenie gumanizma (1919). Sobranie soč. v. 6 t., V, 452-472. Blok sieht die Krise der Kultur in der gleichen fatalen Trennung von Geistigem und Elementarem im zivilisatorischen Bewußtsein, die zum Erstarren und Absterben führt, wie die führenden europäischen Kulturkritiker Carlyle, Matthew Arnold, Nietzsche, Kierkegaard, Solov'ev und T.S. Eliot. Was Carlyle im "Helden", Nietzsche im "Ubermenschen", Solov'ev in der Doppelheit von "Gottmenschentum" und "Sophia", T.S. Eliot in der Forderung nach dem "thought felt" als Möglichkeit der Heilung ansehen, das faßt Blok unter der Metapher des "Geistes der Musik" (461). Cf. dazu R.-D. Kluge: Westeuropa und Rußland im Weltbild A. Bloks, Kap. V "Der Geist der Musik", S. 84-128, D. Wörn: Aleksandr Bloks Drama Pesnja Sud'by (Das Lied des Schicksals), 157 f., 170, 216, 499. Unabhängig vom Gesichtspunkt der Kulturkrise untersuchen die Opposition Kultur- Nicht-Kultur im Rahmen einer strukturalistischen Kulturtypologie B.A. Uspenskij et al.: The Semiotic Study of Cultures. - In: Structure of Texts and Semiotics of Cultures. The Hague/Paris 1973, 1-28, bes. S. 2 (zu Blok).

13. Cf. F. Nietzsche: Werke II, 166. Zu Blok und Wagner cf. R.-D. Kluge: Westeuropa und Rußland im Weltbild Bloks, 110 ff., Rolf Laschet: Aleksandr Bloks Deutung der Oktoberrevolution. Freiburg 1979 (= Maschinenschriftliches Manuskript/Staatsarbeit. Slavisches Seminar der Universität Freiburg), S. 63-74, 103-106.

14. A. Blok: Krułenie gumanizma. - In: ders.: Sobr. soč. v 6t. Moskva 1971, t. 5, 472.

15. Cf. A. Belyj: Krizis Žizni (Die Krise des Lebens), geschrieben Dornach 1916; Krizis mysli (Die Krise des Gedankens), geschrieben Dornach-Moskau 1916/17; Krizis kul'tury (Die Krise der Kultur), geschrieben Basel-Dornach-Moskau 1912/1916/1918. Alle drei Schriften wurden unter dem Titel A. Belyj: Na perevale. Berlin, Peterburg, Moskva (Izd.Z.I. Grzebina) 1923 veröffentlicht. (S. 7-66: Krizis žizni; 69-144; Krizis mysli; 147-199; Krizis kul'tury).

16. Zum Aspekt der Krise bei Belyj cf. F. Stepun: Pamjati Andreja Belogo, 165, 182: R. Poggioli: Poets of Russia, 161; S.D. Cioran: The Apocalyptic Symbolism of Andrej 
Belyj, 40-42, $51-55$ ("crisis-experience").

17. Methodische Anmerkung: Die Grundzüge von Belyjs Krisenbewußtsein bilden sich bereits in den ersten zehn Jahren seines literarischen Schaffens, zwischen 1902 und 1912, heraus. Im folgenden soll das durch Zitate oder Hinweise auf aufschlußreiche Stellen aus dem Frühwerk belegt werden.

17a. Darauf weist bereits der Titel "Auf der Paßhöhe" (Na perevale) hin. Cf. außerdem Krizis žizni, 8; Krizis mysli, 114: "Wir sind gewaltige Pyramiden, qualvoll hervorgetrieben aus kosmischen Fiebern; wir sperren unsere Seele in uns ein, mitten in die quadratische Finsternis, nachdem wir sie in den bleischweren Sarkophag aus Verstand gelegt haben; durch die Arterien unseres Körpers kommen Lemuren in das quadratische Zimmer - in unsere Brust - hereingestampft - eine Stimme ruft: Wer hat das Haus so schlecht gebaut (...) ?' Das Kommando über sie führt als Aufseher Mephisto (Faust II, 5. Akt). Uber der Pyramide irgendwo hoch oben, dröhnt die Stimme des Tartarus."

Das Problem der "Verhirnung" (Benn) als Symptom der Kulturkrise beschäftigte Belyj seit den ersten Auseinandersetzungen mit der "Dörrfischrationalität" (Musil) des positivistischen Wissenschaftsdogmatismus und dem platten Fortschrittsoptimismus. In der dritten Symphonie "Die Rückkehr" (1902-1905) geht der Protagonist, der Chemiker Chandrikov, wegen seiner "unwissenschaftlichen Ansichten" daran zugrunde. Seine "kulturelle" Abweichung von der allgemein akzeptierten Wissenschaftlichkeit spricht er bei dem Festessen aus, das er nach Abschluß seiner Dissertation über den "Bau des Hexahydrobenzols" den Professoren seiner Fakultät gibt; sie kommen ihm wie "Kentauren aus der Vorzeit" vor, die sich an "wuchtigen Ziegelsteinen" (ihren Büchern) festhalten, die sie untereinander austauschen. Auf die Ansprache seines Chefs kontert Chandrikov mit einem Gegen-Toast:

"Der betrunkene und vor Wut kochende Chandrikov bat um das Wort und man begriff, daß einem bevorstand, Frechheiten und wüstes Zeug anzuhören. Er sagte: Da Sie sich an mich, als einen Vertreter des exakten Wissens wenden, trinken Sie auf die Entwicklung der exakten Wissenschaften, der Künste, der Philosophie und der gesellschaftlichen Interessen. Tief gerührt von Ihrem Toast, weise ich dennoch diese Ansprache an mich zurück. Uber vieles mache ich mir Gedanken, und in manchem habe ich vielleicht recht. Doch die Entwicklung meines Gedankens läuft dem, was Sie gewöhnt sind, Kultur zu nennen, völlig zuwider. Ich sehe keine ruhige Zukunft für die Menschheit, vorangetrieben von der Entwicklung der Wissenschaften, der Künste, der Philosophie und der sozialen Interessen, wenn sie ihre Formeln nicht ändern werden'."

Cf. A. Belyj: Die Vier Symphonien. Vozvrat, 79 f. Ist es hier der "theoretische Mensch", dessen Gefahr Belyj bannen möchte, so prangerte er auch dessen Kehrseite, die Vergröberung und Perversion seiner Psyche, bereits scharf in seinem Frühwerk an, vor allem in seinem kulturkritischen "Offenen Brief: Einige Worte eines Dekadenten an die Adresse der Liberalen und Konservativen." - In: Mir iskusstva 11-12 (1903), 65-67:

"Sie haben uns genötigt, ihre unsinnigen Begierden bis zum Absurden zu treiben, um sie dann angeekelt von uns zu werfen. (...)

Aber wer hat uns denn bis an den Abgrund geführt?

Uns wirft man Prinzipienlosigkeit vor. Aber das ist eine lllusion. Die anscheinende Prinzipienlosigkeit ist unvergleichlich wohltuender als ein beschränktes Prinzip. ...

Unter der Jugend gibt es sowohl Kranke, als auch um den Verstand Gekommene, als auch Lasterhafte. Und ihrer sind viele. Und ihre Zahl wächst. Häufig sind Anlaß dazu Vererbung und der Einfluß einer oberflächlichen Kultur - die vorangegangenen Generationen haben sich mit besonderer Sorgfalt bemüht, sowohl ihre Mängel in ihren Kindern festzumachen, als auch deren Leben mit geisttötender Mittelmäßigkeit auszufüllen. (...)

Wir wollen ihre erbärmlichen Fahnen nicht in die Hand nehmen, die so hochtrabend nach Richtungen heißen - sie schauen zu uns her, wie zu seltenen Tieren (...) Und sie alle beschimpfen sich freundschaftlich.

Aber sie haben Unrecht, denn sie sind schlimmer als wir."

18. Krizis Žizni, 26.

19. Krizis Žizni, 9, cf. auch S. 8-11 (über die "Fehlentwicklung"̈ des Denkens5eit 4 der 
Renaissance).

20. Cf. Krizis Kizni, 32 (zu den verschiedenen Formen des "Geschwätzes").

21. Cf. Krizis žizni, $10 \mathrm{f}$.

2la. Mit dem Scharfblick des großen Stilisten hat Kkiovskij das stilistische Grundäquivalent dieser extremen Spaltung in der archisemantischen Opposition von "roj/stroj" (Schwarm/System) erkannt. Cf. V. Šklovskij: O teorii prozy, 166 (als Beispiel für Sujetfügung aus dem priëm zweier metaphorischer Reihen in "Kotik Letaev").

22. Cf. Krizis žizni, $18 \mathrm{f.g} 48 \mathrm{f}$. (über Archaik in der Moderne. Die entsprechende Metapher des Frühwerks ist der "Kentaur").

23. Cf. Krizis mysli, 73, 88 (Denken als Kontrolle).

24. Cf. Krizis mysli, 97-99 (Abschnitt 24), enthält eine detaillierte, sprachlich kühne Beschreibung der Prozesse des "klaren Denkens".

25. Cf. Krizis mysli, $112 \mathrm{f}$. (über Selbsterkenntnis als Aufgabe der Gegenwart, jenseits von Mystik und dem transzendentalen Subjektivismus Husserls); 136 (über den Prozeß der Verdrängung durch philosophische Abstraktion).

26. Cf. Krizis Žizni, 8.

27. Cf. Krizis kul'tury, 153.

28. Cf. Krizis Zizni, 59; Krizis mysli, 137 ("Schweif" und "Kelch" der Griechen).

29. Cf. Krizis mysli, 81 (Bedeutung der sinnlichen Grundlage des Denkens, 2.B. des "Bitteren" bei Meister Eckart); 84 (zum Denken bei Aristoteles, das "Bewegung" erfaßt).

30. Cf. Krizis Žizni, 28 "Was ist eine Hand? Das weiß nur der, der selbst eine Hand hat; er weiß, daß seine Hand - ein Organ des seelischen Ausdrucks ist; und keineswegs eine "Extremität", wie das die Anatomien verkünden; das Studium von Muskelverkürzungen mit sehr tönenden lateinischen Bezeichnungen trägt zum Wissen von der Hand nicht bei; solches Studium vollzieht sich hauptsächlich am Leichnam; der Leichnam der Hand - ist keine Hand; die Hand - ist in den Gesten, und am Leichnam gibt es keine Gesten; in ihm gibt es die Zuckung, die mit Hilfe von elektrischem Strom hervorgerufen wird; (...) Wissen von der Hand - das ist die Geste von Isadora Duncan; und diese Geste wird mir ein Leichenstudium nie geben; ich sehe sie in der Fingerbewegung des Täufers bei Leonardo da Vinci; Leonardo da Vinci und die Duncan - sie haben die Hand gekannt; die Naturwissenschaftler kennen keine Hände; sie kennen (...) - "Extremitäten", die nicht einem Menschen gehören, sondern dem Affen bei Krylov; nach seinem Vorbild haben wir unser Leben aufgebaut."

(Was für den Chirurgen notwendig ist, wurde auf das ganze Leben übertragen.)

31. Krizis mysli, 89 (Geburt des Gedankens); das "klare Denken" findet Belyj zum ersten Male seit den Griechen wieder bei Abaelard als Ausweg aus den beiden Denkextremen der Mystik und des Rationalismus, in der Moderne bei Rudolf Steiner. Cf. Krizis mysli, 97.

32. Cf. Krizis Kizni, 26.

33. Krizis žizni, 27.

34. Krizis mysli, 97.

35. Belyj bezieht sich hier vor allem auf eigene Erfahrung, in der er sich mit Nietzsche vergleicht: "Ich kenne mein Los. Es wird sich einmal an meinen Namen die Erinnerung an etwas Ungeheures anknüpfen - an eine Krise, wie es keine auf Erden gab, an die tiefste Gewissens-Kollision, an eine Entscheidung, heraufbeschworen gegen alles, was bis dahin geglaubt, gefordert, geheiligt worden war. Ich bin kein Mensch, ich bin Dynamit (Hv. M.D.)." Krizis kul'tury, 148-151; Belyj zitiert Nietzsche, cf. Ecce homo, Werke II, 1152.

36. Cf. Krizis kul'tury, 153.

37. Cf. Krizis Žizni, 11.

38. Cf. unten S. 92 f.

39. Auf die Möglichkeit, daß der Mythos als Programm fungieren kann, weist der amerikanische Theologe R. Niebuhr hin. Zu den Aspekten der Realität, die nıcht allein rational, sondern mythologisch begriffen werden können, zählt er: Wert, ontologische Tiefe der Existenz, Problem des Bösen, Transzendenz. Er fordert statt Entmythologisierung, die den primitiven mit dem bleibenden Mythos verwechsele, die Rückkehr zu einer reflektierten Auffassung des Mythos - ohne Dogmat:k - 
sondern im Rückgriff auf eigene Erfahrung und Wissen des Menschen. Cf. R. Niebuhr: The Truth in Myth. - In: The Nature of Religious Experience, 133; "Great myths have actually been born out of profound experience and are constantly subject to verification by experience."

40. Eine Wende in der literaturwissenschaftlichen Forschung zum Mythos zeichnet sich im sowjetischen Strukturalismus ab. Cf. Z. Minc: Rezension zu D.E. Maksimov, Poézija i Proza Al. Bloka. - In: Voprosy literatury, 10 (1976) 228 f. zum Mythos bei Blok ("Erzählung vom Sinn der irdischen Existenz"). "Indessen fällt der "Mythos des Weges', eine höchst interessante Komponente des Blokschen künstlerischen Bewußtseins, weder mit der realen Evolution des Dichters, noch mit den Aussagen Bloks über die eigene Entwicklung, noch mit der Lösung des Themas des Weges in den einzelnen Werken zusammen. Der poetische 'Mythos vom Weg' - das ist am ehesten eine Art 'Text höherer Ordnung', eine Invariante, in bezug auf die Einzeltexte als ihre Varianten hervortreten."

41. Zu "Tantalus", nach einem Drama von Ivanov, cf. Krizis kul'tury, 114 ff.; zur Metapher vom "Nesselhemd" oder dem "roten Domino" cf. Mdr. 92, Nrds 75; zum "geschundenen Dionysos" ebenfalls Ivanov; zum "lebendigen Leichnam" (živoj trup), nach dem gleichnamigen Drama Tolstojs, cf. Krizis žizni, 37, 50 f.

42. Cf. Krizis mysli, 113.

43. Cf. Krizis žizni, 136.

44. Cf. Krizis žizni, 139.

45. A.a.O.

46. Cf. Krizis kul'tury, 165, 170.

47. Cf. Nrds 71 f.; mehr darüber unten S. ff.

48. Cf. Nrds 170; S.D. Cioran: The Apocalyptic Symbolism, $47 \mathrm{f}$.

49. Cf. z.B. G. Benn vs. Reinhold Schneider: Soll die Dichtung das Leben bessern? Rundfunkkontroverse v. 15.11.1955 WDR.

50. Diesen eschatologischen Grundzug teilt Belyj mit der Kunstauffassung Solov'evs, die dieser in den folgenden drei programmatischen Aufsätzen in der letzten Phase seines Denkens niederlegte: "Die Schönheit in der Natur" (Krasota v prirode) 1889; "Der allgemeine Sinn der Kunst" (Obščij smysl iskusstva) 1890; "Der erste Schritt zur positiven Ästhetik" (Pervyj šag k položitel'noj èstetike) 1894. Er vertritt folgende Hauptthesen: 1. "Das ästhetisch Schöne muß zur realen Besserung der Wirklichkeit führen." Bisher existieren "bloß fragmentarische Anfänge der wahren Kunst". Eine ästhetische Theorie muß der Kunst "weite Horizonte der Zukunft eröffnen. (1889) 2. Schön ist jeder dargestellte Gegenstand, wenn er sowohl in seinem So-Sein wie auch "im Licht der zukünftigen Welt", des "Sein-sollenden Seins", gestaltet wird. Den modernen Weg zu solcher Kunst sieht er vor allem in der Darstellungsweise der Diskrepanz zum Ideal, die sowohl in der Tragödie wie auch in der Komödie - auf je verschiedene Weise - möglich ist. Die "Kunst der Zukunft wird in neuen Formen" auftreten. (1890)

3. Aus diesen Voraussetzungen sieht er die Uberwindung des "ästhetischen Separatismus" und die Verwirklichung der "Fülle des Lebens" (Hv.M.D.) als gefordert und erreichbar an. (1894)

Aus diesen Aussagen von eschatologischer Dringlichkeit kann eine Konzeption avantgardistischer Kunst herausgelesen werden, die neue Gesichtspunkte in die augenblickliche Debatte um die "Avantgarde" (cf. Anm. 5, zu S. 35 dieser Arbeit), vor allem für die russische "Avantgarde" in ihrer Eigengestalt, einbringen kann. Das gilt vor allem für ihre - gegenüber Westeuropa -besonderen Voraussetzungen. In der Ásthetik Solov'evs könnten Grundlagen für eine positive Bestimmung von "Avantgarde" gefunden werden, die über die zumeist negative Abgrenzung zur Tradition hinausführen.

51. Cf. E. Meumann: Einführung in die Ästhetik der Gegenwart. Leipzig 1908, $100 \mathrm{f}$.

52. Cf. Simv. 241: "ein großer Dichter macht Schule nicht nur dank seiner unmittelbaren Einwirkung, sondern auch daher, daß sein Arbeitszimmer ungewollt eine Lehrkanzel für Stilistik ist: nur er kann Antwort geben auf verwickelte, quälende Fragen nach der Form, die unausweichlich vor jedem auftauchen, der die Schönheit schätzt. Wenn alles das niedergeschrieben würde, was die Dichter zu Fragen der Form sagen, dann 
hätten wir gewaltiges Material zur rein wissenschaftlichen Bearbeitung jenes Teiles der Ästhetik, der die Lyrik betrifft; und wie würden sich die Literaturprofessoren verwundern, daß ihre vieljährigen, von Generation zu Generation weitergegebenen Wortergüsse über die Dichtung nicht den hundertsten Teil an Wissenschaftlichkeit von dem an sich trügen, der in die Augen stechen würde, wenn wir die Kommentare von Dichtern zu Dichtern vor uns hätten."

53. Zur "Eingestaltung" der Idee cf. R. Musil: TAER, 717. Zur inhaltsbildenden Kraft der Form cf. J. Tynjanov: Das Problem der Verssprache (1924), über künstlerische Verfahren als indirekt inhaltsbildender Faktor. Neuerdings auch W. Schmid: Der ästhetische Inhalt, 24. Uber Probleme, die aus dieser inhaltsbildendèn Funktion der Form entstehen, schreibt Belyj bereits im Vorwort zur "Vierten Symphonie", die er einerseits als "Dokument der modernen Seele", andererseits als "strukturelle Aufgabe" betrachtete: "Ich erkannte, daß die Genauigkeit der Struktur erstens die Fabel der Technik unterordnet (es kam öfter dazu, daß die 'Symphonie' ausschließlich um des strukturellen Interesses willen verlängert wurde), und daß die Schönheit eines Bildes nicht immer zusammenfällt mit der Gesetzmäßigkeit seiner strukturellen Form." (S. 2).

54. Cf. Princip Formy (1906), 194; "Lirika i Eksperiment" (1909), 235, 237 f., 244-54 (Beispiel: Nekrasov, Smert' krestjanina; Auszug).

55. Für die Koexistenz von lyrischer Weltempfindung und poetischer Reflexion im "Autor-Ich" eines Dichters prägte D.E. Maksimov in Bezug auf Blok den literaturtheoretischen Terminus des "poetischen Bewußtseins". Cf. D.E. Maksimov: Poézija i Proza Al. Bloka, 37 f. "Die 'substanziale' Gestalt des Autors, von der seine ganze Dichtung (...) vereinigt und beleuchtet wird, (...) die einheitliche Quelle aller Gesichter des Dichters - das ist seine lebendige Person, die "außerhalb der Kunst" steht, aber die Kunst hervorbringt und klarer macht. (...) Eben in dieser 'in der Vielfalt einheitlichen' Gestalt des Autors sind sein Pathos, seine lyrische Glut, sein Gefühl für Gewissen, Schönheit und Elan konzentriert - alles das, was uns an Blok bezaubert und was wir für das Wichtigste an ihm halten (...) aber auch die Ideen und Potenzen, die sich in seinem schöpferischen Bewußtsein entwickeln."

Was mit den "Ideen und Potenzen" des poetischen Bewußtseins gemeint ist, erläutert Maksimov in Kap. 9 seiner Analyse der "Kritischen Prosa" Bloks. Er spricht - in Analogie zu den "musikalischen Ideen" des österreichischen Musikkritikers Eduard Hanslick - von "poetischen Ideen" (327), die sich von diskursiv-begrifflichen Ideenkonzepten unterscheiden: "Der poetische Gedanke unterscheidet sich vom logisch gefaßten Gedanken dadurch, daß er in seiner Grundlage oder auch blo $\beta$ in seiner bedeutungsmäßigen assoziativen Aura - wie auch das poetische Wort und das dichterische Bild - vieldeutig, polysemantisch und hindurchgelassen ist durch die ganze potentielle Fülle des menschlichen Bewußtseins, wobei er die Welt der menschlichen Ideale einschließt, d.h. werthaften Inhalt in sich trägt (328)." Die Funktion der "poetischen Gedanken" sieht $M$. darin, daß sie "Integratoren" der poetischen Struktur darstellen (38, 329): in der Lyrik als "Symbol-Mythen" vom Typus der "Schönen Dame", "Nachtviole", "Schreckenswelt", "Nachtigallengarten" etc.; in der Prosa als "Symbol-Kategorien", wie "Musik" oder "Geist der Musik", "Künstlermensch", "Kultur", "Zivilisation", "Element", "Vergeltung". Maksimov sieht in ihnen das Destillat von Erfahrungen, die kulturell vermittelt sind: "Sie alle spiegeln in dem einen oder anderen Maße die tatsächliche Erfahrung der Menschheit und des Dichters wider und die hinter dieser Erfahrung stehenden realen Sphären des Lebens, der Kultur und des Bewußtseins (331)."

Untereinander stehen sie im Zusammenhang: "Die Symbole der Blokschen Prosa befinden sich in komplizierten Beziehungen zueinander und bilden in ihrer Gesamtheit einen Strom von Ideen, von geistiger Erfahrung, das Ebenbild gewissermaßen eines dynamischen, in Schwingung versetzten Systems - dessen, was wir die poetische Weltanschauung Bloks, des Dichter-Denkers, nennen können (334)."

56. In bezug auf Geburts- und Todesjahr von N.V. Bugaev bestehen Unklarheiten. Belyj schreibt: "Ich wurde im Oktober 1880 geboren; mein Vater war schon fünfundvierzig Jahre alt; sein Geburtsjahr fällt in das Todesjahr Puškins (Nrds 26)." Demnach wäre er 1835 geboren, Puskin starb jedoch 1837. NV 249, spricht er von sechsundsechzig 
Lebensjahren. A. Kovač: Andrej Belyj: The 'Symphonies', gibt als Todesjahr 1902 an, Belyj den 29. Mai 1903 (NV 247 ff, Nrds 33). N.V. Bugaev war ein Mathematiker von europäischem Rang. "Zeitlebens stand er im Briefwechsel mit führenden Mathematikern seiner Zeit wie Liuewel, Klein, Poincaré und anderen; an zwei französischen mathematischen Zeitschriften war er jahrelang Mitarbeiter. Er wurde einer der Begründer der Moskauer Mathematischen Gesellschaft und der Zeitschrift "Matematičeskij Vestnik", als Vorsitzender der ersten und als Herausgeber des zweiten wirkte er etliche Jahre (Nrds 29); ebenso als Dekan der naturwissenschaftlichen Fakultät der Moskauer Universität. Unter seinen Moskauer Kollegen gaḅ es nur wenige, die ihm in seinem Denken folgen konnten (Nrds 22). Im Jahre 1897 trat er auf dem Internationalen Mathematikerkongre $B$ in Zürich mit einem Referat über die Unterbrochenheit (Diskontinuität) des mathematischen Zahlenkontinuums hervor; diese Erkenntnis wurde zu seiner Zeit von Poincaré und dem Physiker Lodge bestätigt, später durch die Einführung von "Mengen" in die Mathematik von B. Russel, Couture und Kantor.

N.V. Bugaev gehörte zu den ersten, die einen Einblick hatten in die Grundlagenkrise der modernen Mathematik, die erst im zwanzigsten Jahrhundert offenkundig wurde. Mit der Entdeckung der Diskontinuität der Zahlenreihe war dem mechanischen Determinismus der Boden entzogen. (Cf. A. Belyj: Krizis mysli, 77-82, 87.)

N.V. Bugaev war nicht nur Mathematiker sondern auch Philosoph. Erzogen in der positivistischen Tradition des englischen Empirismus vertrat er das Ideal der rationalen Klarheit und einer strengen logisch-wissenschaftlichen Methodik. Von sich und seinen Schülern, vor allem aber von seinem Sohn forderte er absolute Klarheit der Definition und Beweisführung (Nrds 22-24, 66 f.). Darin ging er - ebenso wie in seiner Methodenbesessenheit - bis zum Extrem, so daß seine "Uberklarheit" inn oft "dunkel" und unverständlich erscheinen ließ (Nrds 24). Er befand sich in ständigen Auseinandersetzungen und war ein fanatischer Streiter, wo es um die Propagierung seiner Ansichten ging.

Im Laufe der beiden letzten Jahrzehnte des neunzehnten Jahrhunderts galt seine geistige Anstrengung der Uberwindung des Positivismus. In ständiger Auseinandersetzung mit den Positivisten und Metaphysikern der Moskauer Intelligenz entwickelte er seine Thesen einer "evolutionären Monadologie" in der Nachfolge von Leibniz (Nrds 29 f., 34). Dabei ging er sowohl von seinen eigenen mathematischen Entdeckungen einer neuen "Arithmologie" aus wie auch von einer originellen Erkenntnistheorie (Nrds 36).

Seine wissenschaftlichen und philosophischen Erkenntnisse publizierte er in folgenden Werken:

- Matematika kak orudie naučnoe i pedagogiŽeskoe. Moskau 1875.

- Obక̌čija osnovanija isčislenija E (x). Posvjaščaetsija pamjati Lejbnica. Moskau 1885.

Osnovy evolucionnoj monadologii. Iz Kurnala "Voprosy filosofii i psichologii". Moskau 1893.

(Auch zitiert bei N.O. Losskij: History of Russian Philosophy. NY 1972, $161 \mathrm{f.;}$ cf. A. Kovač: A. Belyj: The 'Symphonies', 252 f.)

- Lehrbuch der Arithmetik (cf. Nrds 73).

57. Cf. NV 247.

Matematika i naućno-filosofskoe mirovozrenie (cf. Krizis mysli, 80).

58. Zu Belyjs Studiengang: "In mir entstand der Plan, zwei Fakultäten zu absolvieren; die Kenntnis der Naturwissenschaften ging ein in den Kreis meiner philosophischen Anliegen (Nrds 391). Mein Achtjahresplan (vier Jahre naturwissenschaftliche Fakultät, vier Jahre philologische); bei allem Interesse an den Wissenschaften und Fakten setzte ich mir das Ziel, die Methode des Durchdenkens der Fakten im Geiste einer Weltanschauung zu beherrschen, die auf zwei Säulen erbaut wäre; die eine -die Ásthetik, die andere -die Naturwissenschaft; das weltanschauliche Problem - die Verknüpfung beider Linien (Nrds 403). In meinem Kopf reifte der Plan einer eigenen Universität: ich entwarf einen Plan für einen Durchgang durch die Fächer; ich hatte fließende Interessen an den Fakten in einem Prozeß der Erklärung 
der Stellung der Wissenschaften im System der Wissenschaften (Nrds 405)." Sein Hauptinteresse gilt von Anfang an interdisziplinären Fragen, dem Umbruch des naturwissenschaf tlichen Weltbildes, vor allem der Uberwindung der mechanistischen Weltauffassung (Nrds 405-407) durch einen noch zu entwickelnden Symbolismus (Nrds 408).

59. Mit der Energetik wurde Belyj zu Beginn seines naturwissenschaftlichen Studiums bekannt: "Nachdem ich mir Gedanken über die notwendigen Fakten gemacht hatte, nachdem ich mich mit der Energetik vertraut gemacht hatte, beginne ich nun das energetische Prinzip in einer Transform der Formen der Kunst aufzusuchen; ein verwegener Gedanke wirft seinen Schatten voraus: auch die Formen der Kunst unterliegen der Metamorphose; Räumlichkeit, Zeitlichkeit - das sind Modifikationen eines nicht gegebenen Ganzen; der Gedanke arbeitet am Begriff des RaumZeitlichen, am Studium eines Faches, das Studenten noch nicht gelehrt wird; irgendwo regt sich das Vorgefühl des Relativitätsprinzips; ich bin, wobei das Laboratorium, das Zoologische Museum in Vergessenheit geraten, hinter den Gedanken von Hanslick und Helmholtz her, im Versuch, das Gesetz der Äquivalente in der Ästhetik aufzuspüren (Nrds 406). Cf. Formy iskusstva, Simv 156-62, 167; Princip Formy, Simv 182-193 (zur Ubertragung energetischer Prinzipien auf die Ästhetik).

Uber die Bedeutung des Energetismus als eines kognitiven Modells für Ästhetik und Literaturtheorie um die Jahrhundertwende, cf. Joachim Metzner: Die Bedeutung physikalischer Sätze für die Literatur. DVjs (1) 1979, 1-34. Metzner weist darauf hin, "daß aus naturwissenschaftlichen Sätzen auch Werkstrukturen, Stilprinzipien und ganze ästhetische Systeme abgeleitet werden können (3)." Wenngleich sich seine Studie mit dem zweiten Hauptsatz der Thermodynamik, dem sog. Entropiegesetz, beschäftigt, so gibt er doch auch Hinweise auf ästhetische Implikationen des Energieerhaltungssatzes, "auf dessen 'poetische Seiten' schon sein Entdecker Helmholtz hingewiesen hat ('Uber die Wechselwirkungen der Naturkräfte und die daraus bezüglichen neuesten Ermittlungen der Physik' in: Populäre wissenschaftliche Vorträge, 1. Heft 1867 , 56)." S. 6; cf. ferner Heinz Setzer: Wilhelm Ostwald und die Rolle der Energetik für Gor'kij. - In: Welt der Slaven XXV, 2. Jg. NF. IV, 2 (1980), S. 394-427.

60. Zu Fechner: Simv 508 f., 473.

Zu Helmholtz: Simv 151, 196 f., 470 f., 519.

Zu Ostwald: Simv 23, 467, 470, 471, 519; Nrds 407.

61. Zur russischen Ästhetik vor dem Symbolismus cf. J. West: Russian Symbolism, Kap. 1, The Nineteenth - Century Heritage, 5-47; René Wellek: Geschichte der Literaturkritik, Bd. 3, Das späte 19. Jahrhundert, Berlin/New York 1977 (= Komparatistische Studien Bd. 6), 248 ff.

62. Mit dem Wort vom "Ende der Metaphysik" wurde die Situation des nachidealistischen Denkens in der Moderne von Heidegger gekennzeichnet. Damit ist zwar einerseits der Endpunkt einer Entwicklung gemeint, aber nicht der Schlußpunkt überhaupt, sondern im Ende dieser Art zu denken ist zugleich der Anfang einer neuen Denkungsart beschlossen. In seiner Schrift "Das Ende der, Philospphie und die Aufgabe des Denkens". - In: Zur Sache des Denkens, Tübingen ${ }_{1976}$ ( 1969) schreibt er: "Die alte Bedeutung unseres Wortes "Ende" bedeutet dasselbe wie Ort; 'von einem Ende zum anderen' heißt: von einem Ort zum anderen. Das Ende der Philosophie als Metaphysik ist der Ort, dasjenige, worin sich das Ganze ihrer Geschichte in seine äußerste Möglichkeit versammelt. Ende als Vollendung meint diese Versammlung (63)."

Doch Heidegger hält das Denken deshalb nicht für erschöpft, sondern erneut zu seinem Ursprung zurückgeführt. Durch das "Ende der Metaphysik" wird ein neues Denken der "Offenheit" freigesetzt, das sich auf das bisher unbenannt mitgedachte Sein, "auf die Sache selbst" richtet (68). Denselben Gedanken vom Ende des bisherigen Philosophierens spricht Karl Jaspers in seinen Vorlesungen über "Vernunft und Existenz", München 1973 (gehalten 1935) aus. Das Ende der Philosophie - im Unterschied zu Heidegger - sieht er in zweierlei Gestalt: im Ende des allzu selbstgewissen Vernunf tidealismus Hegels und in der allzu radikalen - wenngleich als "Ausnahme" unbedingt notwendigen und revolutionierenden - Infragestellung der

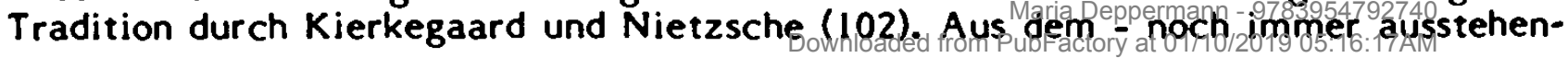


den -Begreifen des Endes wird das philosophische Denken - ebenso wie bei Heidegger - zu seinem Ursprung verwiesen, nämlich außer der Vernunft nun auch seine Existenz zu be-denken.

Der Prozeß, den die beiden deutschen Philosophen bereits überblicken, wird von Belyj erst durchgemacht. Ebenso wie sie fragt er den Bedingungen eines neuen Denkens nach - vor allem in bezug auf die Ásthetik - das er in der symbolischen Denkform kommen sieht. 


\section{Kapitel: Denkformen und Diskursebenen}

1. Zu dieser Unterscheidung cf. R. Musil: Der mathematische Mensch. - In: TAER, 596. Wie Belyj hat auch Musil Anteil an der methodischen Umorientierung des Denkens seit Nietzsche. V. Erlich: Der russische Formalismus, $310 \mathrm{ff.}$, sieht diesen Prozeß, der zu "einer Umwälzung der Denkformen" führte, vor allem gegen zwei "Trugschlüsse" aus dem 19. Jahrhundert gerichtet:

1. gegen den extremen Empirismus, der nur das unmittelbar Gegebene als wahr annimmt;

2. gegen einen groben Monismus, der "heterogene Ebenen auf homogene Gesetze zurückführt" (zitiert nach A. Köstler, Yogi und Kommisar, NY 1945, 238).

Die Urteile über die "Inkonsistenz" von Belyjs Denken, wie sie verschieden akzentuiert von Stepun, Holthusen, J. West abgegeben werden, berücksichtigen die Wandlung der Denkformen nicht, sondern gehen vom Erwartungshorizont des Systemdenkens aus.

2. Im oben angedeuteten Zusammenhang der Krise des nach-idealistischen Denkens sollte man Belyjs Suche nach der Entwicklung seiner neuen schöpferischen Denk-und Ausdrucksmethode sehen. Für Belyj - wie auch für Musil -ist Kunst eine besondere Form der Erkenntnis; sie kann "Beiträge zur geistigen Bewältigung der Welt" geben, cf. R. Musil: TAER, 788, und zwar durch ihre besondere schöpferische Art des poetischen Denkens, welches die Wirklichkeit in der produktiven Einbildungskraft symbolisch auf ihre Möglichkeiten hin transzendiert.

3. Karl Jaspers: Vernunft und Existenz, 108, sieht als wesentliche Chance der nachidealistischen Krise des Denkens an, daß nicht zum Zuge gekommene Denktraditionen der philosophia perennis neue Aufmerksamkeit auslösen: "Einsichten, deren Gehalt wir rückläufig im Philosophieren der Vergangenheit wiedererkennen. Was schon getan wurde, aber durchweg ohne letztes methodisches Selbstbewußtsein blieb, meinen wir noch einmal eigentlich zu verstehen."

4. Zum Methodenzusammenhang: cf. Nrds 405, 463, Simv. 231. Daß die Wirklichkeit und die "Tatsachen" uns als jeweils "ausgelegte" begegnen, führte schon Nietzsche zu der Frage nach dem "perspektivischen Charakter des Daseins" überhaupt, cf. F. Nietzsche: II, 249.

5. "Rhythmus" ist ebenso wie "schöpferische Energie" ein für Belyj zentraler Begriff, der sowohl ästhetische wie auch außerästhetische Bedeutung hat.

6. Bei Belyj gibt es nebeneinander das "Problem der Schere" und die "Methode der Schere". Das erste besteht in der Erfahrung von Diskrepanzerlebnissen, deren Konflikte dadurch bedrohlich werden, daß jeder "Ausschnitt" den Anspruch auf Alleingeltung erhebt. "Auf allen Ebenen des Lebens haben mich Scheren zerschnitten; und auf allen Ebenen des Lebens habe ich mit der Schere die Lebensausschnitte zerschnitten; so habe ich das Problem der Schere überwunden (Nrds 185)." Cf. ferner: Nrds 167, 174, 181 f., 397, 401-403, 464-469.

7. Den Hinweis hierauf verdanke ich einem Gespräch mit dem Wiener Formalismusforscher Aage A. Hansen-Löve.

8. Cf. D.E. Maksimov: Poezija i Proza Al. Bloka, 192-195.

9. Vor allem scheint mir aufgrund dieser Verflechtungen die formalistische Denkkonvention der "Opposition" nicht fruchtbar für die Beurteilung des ästhetischen Denkens von der Art Belyjs. Hier geht es um eine starre Zweigliedrigkeit des Unterscheidens aus dem Sprachdenken der strukturalen Linguistik, die für Systeme wie das Phonemsystem oder ein abgegrenztes synchrones Sprachcorpus anwendbar sind, auch für eine strukturierende Katalogisierung, die aber auf komplizierte Wechselbeziehungen methodisch nur auf Unkosten des Gegenstandes, der erfaßt werden soll, angewendet werden können. 
ZWEITER TEIL:

TELOS, TECHNIK, SELBSTERFAHRUNG

BELYJS ENTWURF EINER INDUKTIVEN ASTHETIK

\section{Kapitel: Dimensionen der Wirklichkeit}

1. Auf das Problem des Seinsmangels hat kritisch hingewiesen F. Stepun: Pamjati Andreja Belogo, 170. Grundsätzliches zur Kategorie des "Mangels" für die Konstitution des Subjekts bei J. Lacan bei H. Lang: Die Sprache und das Unbewußte. Jacques Lacans Grundlegung der Psychoanalyse. Ffm. 1973, Kap. IV/1, V/2. Es wäre vielleicht lohnend, Lacans Kategorien auf Belyj anzuwenden. Cf. auch oben S. 78.

2. Cf. die dramatische Beschreibung dieses Vorgangs in Nrds 325-339 ("Der Kampf um die Kultur"). Dieses zweite Initiationserlebnis in die "Welt der Kunst" hinterließ aufgrund des "verbrecherischen" Charakters, den es in der fehlgelaufenen Erziehung des Jungen annehmen mußte, einen tiefsitzenden Rechtfertigungsdrang. Mehr darüber unten S. 150-171. Darin ist eine wesentliche Motivationswurzel für seine theoretische Grundlegung eines modernen Symbolismus zu sehen. Cf. A. Belyj: Warum ich Symbolist geworden bin und nicht aufgehört habe es zu bleiben ... (Rukopis' 1928). (Zitiert von Nivat, Maksimov und Cioran).

3. Zum doppelten Wirklichkeitsbegriff bei Solov'ev und zu seiner Bedeutung für die symbolistische Dichtung cf. A. Knigge: Die Lyrik Solov'evs, 25.

4. Der Versuch, Belyjs "Widersprüche" zu analysieren, wurde mit mehr Uberzeugungskraft - weil mit philosophischem und nicht nur formalistischem Verständnis - als bisher in der Forschung zu Belyj von E. Thompson: Russian Formalism, gemacht, cf. S. 57.

5. Cf. Nrds 406: "Mein Referat 'Uber die Formen der Kunst' - das war ein Skandal in der metaphysischen studentischen Familiengemeinschaft, die sich um Lopatin und Trubeckoj geschart hatte - ein doppelter Skandal:

1. das Erscheinen eines 'Dekadents' auf dem Katheder;

2. die Verkündung von Empirie und Induktion da, wo der metaphysische 'Normativismus' herrscht."

Lev Michajlović Lopatin (1855-1920) war - wie übrigens auch N.V. Bugaev (Belyjs Vater) - Vertreter der russischen Leibniz-Schule. Cf. Nrds 229-231; H. Dahm: Die Chance der Philosophie, 251. Sergej Nikolaevic Trubeckoj (1862-1905), Freund V. Solov'evs, der zusammen mit seinem Bruder (E.N. Trubeckoj) das "geistige Erbe der slawophil-theosophischen und kirchlich-nationalen Alleinheitskonzeption (...) des Solov'evschen Denkens der 70er und 80er Jahre" fortführte, war Professor für Geschichte der Philosophie des Altertums an der Universität Moskau. Cf. H. Dahm: op. cit. $247 \mathrm{f}$.

6. Zum "Machen" in der Kunstanschauung um $1900 \mathrm{cf}$. Bruno Markwardt: Geschichte der deutschen Poetik, Bd. V, Das zwanzigste Jahrhundert, Berlin 1967, 768 f. "Neue Technik" war ein Begriff Hofmannsthals in seinem Briefwechsel mit St. George (1892), "geistige Kunst auf Grund einer neuen Fühlweise und Mache". "Mache" vs. organisch Gewachsenes - Leitterminus der kunsttechnischen Essays der "Blätter für die Kunst". Cf. V. Majakovskij: Kak delat' stichi 1926 . - In: ders.: Polnoe sobr. soz. v 13 t. Moskva 955 ff. t. 12, 81-117.

7. Cf. dazu I. Kant: Kritik der reinen Vernunft, I. Transzendentale Elementarlehre. Erster Teil. Die Transzendentale Ästhetik. I. Abschnitt. Von dem Raume. 2. Abschnitt: Von der Zeit.

8. Für diese literaturtheoretische Aussage war Belyj dadurch sensibilisiert, daß Selektion und Schematisierung gleichzeitig von ihm bevorzugte Stilverfahren sind. Darauf weist für die Frühwerke hin A. Kovač: Andrej Belyj, 28-34 (Anleihe bei Stilverfahren aus den Nachbarkünsten, Malerei: Stilisierung und Perspektive); 84 ff. (Musik: Leitmotive und Kontrapunkt).

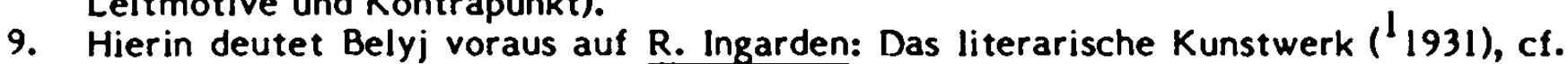
"Das Problem der Spinsweise des literarischen Werkes", 6 ff.; K. Hamburger: Die Logik der Dichtung (1957), cf. "Die Begriffsbildung 'Dichtung und Wirklichkeit"', S. $15 \mathrm{ff}$. 
10. Cf. R. Ingarden: Das literarische Kunstwerk, 3. Kap. "Die Grundstruktur des literarischen Werkes". Der Zusammenhang von Erforschung der Werkstruktur und Feststellung des eigenen Seinsstatus auf diese Weise, ist die Einlösung dessen, was Belyj hier einleitet.

11. Hier reflektiert Belyj theoretisch die kunsthistorische Abwendung vom Realismus in der Malerei ("stil' modern" vs. "peredvižniki"; Entwicklung postrealistischer Stilverfahren der Dichtung, vor allem in der eigenen "symphonischen" Prosa). Für diesen Vorgang sucht er nach kunsttheoretischer Legitimation.

12. Rhythmus- und Bildtheorie blieben Belyjs bevorzugte Forschungsgebiete. Cf. "Lirika i eksperiment" (wo er das Gesetz der Abweichung von Metrum und Rhythmus entdeckt). Cf. dazu: V.F. Chodasevič: Nekropol', 78. "Smysl iskusstva" und "Magija slov" (zur Bildtheorie eines postrealistischen Symbolismus).

13. Mit der Analyse des Zeichencharakters und der Frage nach der "Konkretisation" weist Belyj auf Literaturtheorien des tschechischen Strukturalismus voraus. Cf. die knappe Zusammenfassung bei W. Schmid: Der Textaufbau in den Erzählungen Dostojevskijs, 17-22.

14. Aristoteles, Poetik. Reclam 2337, 58. Die Untersuchung der dichtungsspezifischen "konjunktiven Kräfte" findet sich in der deutschen formalen Schule bei Walzel, Ermatinger, Lämmert und Burger. In Gegensatz zu Aristoteles stellt sich $\underline{H}$. Pongs: Symbol als Mitte, 58-60.

15. Alogische Sprachstrukturen in der Dichtung sind ein "Befund", der auch anders als bei Belyj gedeutet werden kann. Sowohl in der Rhetorik wie auch in der bewußten Kombinatorik werden alogische Sprachformen erzeugt. Während die Rhetorik auf praktische Zwecke (Uberredung etc.) abzielt, intendiert die Kombinatorik moderner Dichtung, z.B. bei den französischen Symbolisten oder auch bei V. Brjusov, bewußt eine Verrätselung der Konventionen von Wahrnehmung und Sprache, um den Leser zu sensibilisieren.

16. Zum Begriff der Kausalität bei Belyj cf. Formy 149 f.; Komm. 507, 509. Belyj versteht ihn nach Schopenhauers erkenntnistheoretischer Grundlegung der Kaysalität "Uber die vierfache Wurzel des Satzes vom zureichenden Grunde" (21847, 1813). Wie Schopenhaver setzt er Kausalität gleich Materie.

17. Ostwald wird von Belyj sowohl zustimmend als auch mit kritischer Reserve zitiert (Simv. 23 f., 464, 467 f., 471, 484, 513, 519; Nrds s. Register). Das Verhältnis zu ihm wäre genauer zu untersuchen. Uber die Bedeutung $O$. 5 um die Jahrhundertwende in Rußland cf. Heinz Setzer: Wilhelm Ostwald und die Rolle der Energetik für Gor'kij, a.a.O.

18. Belyj versteht die Sprache nicht nur als Zeichensystem, den Leser als Dekodierenden; sondern er begreift die Sprache als energeia, die im Hörer oder Leser Impulse auslöst, weil sie Kraft überträgt. Hierin folgt er der Sprachauffassung von Herder und Humboldt. Diese Lehre wurde in Rußland vor allem durch Aleksandr Potebnja (1836-1891) vertreten, der bei $\boldsymbol{H}$. Steinthal (1823-99), dem Herausgeber der sprachwissenschaftlichen Werke Humboldts, in Berlin studiert hatte. Cf. R. Wellek: Geschichte der Literaturkritik. Bd. 3, 261 f. Zum Einfluß Potebnjas auf Belyj Cf. V. Gofman, Pomorska, Thompson, Hansen-Löve (mit ausführlicher Potebnja-Bibl.), C. Anschuetz: Word Creation in Kotik Letaev and Kreščennyj Kitaec, Ann Arbor 1973, Univ.-Microf. Nr. 73-9595.

19. Der alternierende Aufbau in Belyjs "Formen der Kunst" erinnert an den sehr ähnlichen in Schopenhavers "Welt als Wille und Vorstellung".

20. Cf. S. Kierkegaard: Die Krankheit zum Tode. Bremen 1949, S. 18, "Der Mensch ist Geist. Aber was ist Geist? Geist ist das Selbst. Aber was ist das Selbst? Das Selbst ist ein Verhältnis, das sich zu sich selbst verhält, oder ist das im Verhältnis, daß das Verhältnis sich zu sich selbst verhält."

21. Was Belyj hier im Auge hat, ist m.E. nicht so sehr der Satz vom "Grunde des Seins", als der vom "Grunde des Werdens", $c f$. A. Schopenhauer: Uber die vierfache Wurzel des Satzes vom zureichenden Grunde, \$17 "Die erste Klasse der möglichen Gegenstände unseres Vorstellungsvermögens ist die der anschaulichen, vollständigen, empirischen Vorstellungen (...) empirische, theils sofern sie nicht aus bloßer Gedankenverknüpfung hervorgehn, sondern in einer Anregung der Empfindung unse- 
res sensitiven Leibes ihren Ursprung haben, auf welchen sie, zur Beglaubigung ihrer Realität stets zurückverweisen." Hat es der Satz vom "Grunde des Werdens" mit der ersten Klasse zu tun, so der vom "Grunde des Seins" mit der dritten, cf. $\$$ 35: "Die dritte Klasse der Gegenstände für das Vorstellungsvermögen bildet der formale Theil der vollständigen Vorstellungen, nämlich die a priori gegebenen Anschauungen der Formen des äußeren und inneren Sinnes, des Raumes und der Zeit." (Sie betreffen Arithmetik und Geometrie).

22. Dieses Schopenhauerzitat kann ich nicht nachweisen.

23. Komm. 513-516, Anm. 5 (und zwar die erste, es gibt deren zwei) ist erst 1910 hinzugefügt worden. 1902 war der Erlebnisbegriff Belyjs noch gar nicht ausgebildet, sondern erst ab 1906/7.

24. An dieser, wie auch an anderen Stellen, wäre zu überlegen, welche Rolle der Einfluß Hegels auf Belyj gespielt haben könnte. Darauf kann hier nicht eingegangen werden. Er wird gelegentlich von Belyj zitiert, aber eher beiläufig z.B. Nrds (s. Register), Probl. 8, Komm. 458.

25. "Von der Theurgie" ist nicht in den Sammelband "Symbolismus" aufgenommen worden, cf. Novyj put' 9 (1903), 100-123.

26. A.a.O., 110.

27. Cf. Anm. 25. Hegel hat ja in bestimmter Weise auch auf das Entwicklungsdenken Solov'evs eingewirkt, das erst in der Spätzeit von der eschatologischen Geschichtsauffassung abgelöst wurde. Er schreibt: "Dieses Gesetz (d.h. der Entwicklung, M.D.), logisch formuliert von Hegel, wurde, von einem anderen Gesichtspunkt aus, auf die Biologie angewandt von Herbert Spencer. Seine folgerichtige und volle Anwendung auf die Geschichte der Menschheit aber ist, soviel mir bekannt ist, nicht vollzogen worden." Cf. Bd. I (Brüsseler Ausg.), 255. Genau diesen Anspruch stellte S. an sich. Cf. dazu: L. Wenzler: Die Freiheit und das Böse nach VI. Solov'ev, 157 ff. ("Die Auslegung des Modells der Entwicklung durch den Begriff der Freiheit").

28. An Abweichungen von und Belyjs Auseinandersetzung mit Schopenhauer ist die bisherige Forschung vorbeigegangen. Cf. dazu Embl. 62 (Kritik an Sch.s metaphysischem Einheitsprinzip und seiner Subjekt-Definition); Komm. 466 (Neben weiterer Hochschätzung Sch.s, als "größtem Künstler unter den Philosophen", Kritik an seiner logischen Beweisführung und "verfehlten Terminologie"); 507 (über den emblematischen Charakter seiner Terminologie und der Metaphysik des Willens).

29. "Von der Theurgie", 119. Cf. V. Solov'ev: "Vorlesungen über das Gottmenschentum". Deutsche Gesamtausgabe, Bd. 1, dazu L. Wenzler: Die Freiheit und das Böse (...), $291 \mathrm{f} ., 316 \mathrm{f}$. ("Geschichtliches Handeln als freie Theurgie").

30. Der Einfluß Nietzsches auf Belyj ist noch unerforscht. J. Pflanzl: Weltbild und Kunstschau, sieht nur den Einfluß Schopenhauers - ohne Belyjs Abweichungen und Kritik an ihm - und kommt deshalb zu einseitigen Aussagen. Die Bedeutung Solov'evs, die sich vor allem in "Von der Theurgie" (1903) zeigt -aber auch später fehlt ganz, ferner die Einwirkung des "Neuen religiösen Bewußtseins" (die allerdings damals noch nicht erforscht war), sowie die Nietzsches. Die Theorie des Schöpferischen ist bereits hier vorgeprägt, vor allem der ideelle Appell zur Veränderung des Bewußtseins (cf. "Von der Theurgie"). Von Rickert wurde sie nicht erst übernommen, wenngleich durch seine Wertphilosophie systematisiert. Umgekehrt nimmt F. Stepun: Pamjati Andreja Belogo, nur die Opposition Solov'ev - Neukantianismus zur Kenntnis. Nietzsches Einfluß zu dieser Zeit wäre zu untersuchen z.B. an "Zoloto v lazuri", "Otkrytoe pis'mo", "O teurgii", "Simvolizm kak miroponimanie". Cf. ferner Nrds 465 ff. und S. $158 \mathrm{ff}$. dieser Arbeit.

31. Cf. "Von der Theurgie" 117, 119. Belyj spricht von "Gratwanderung" und "Todesbereitschaft" im Geiste von Nietzsches "Zarathustra"; von Solov'ev als dem "Propheten der Möglichkeit zur Uberwindung".

32. Cf. "Von der Theurgie", 103; "Die Krise des westlichen Denkens hat das Steuer der Hoffnungen der heutigen Menschheit auf die Kunst gerichtet, unter dem Druck ihrer Verzweiflung zerriß diese Kunst, wobei sie die Grenzen des seelischen Lebens erweitert hat. $\mathrm{Zu}$ jener Zeit erstand die wundertätige Kraft des gewöhnlichen Wortes 'in nicht alltäglichen Verbindungen', die sich aber nicht einmal in der Asthetik fortgepflanzt hat, denn Schönheit - ist ein Surrogat der Theurgie, d.h. 
dessen, was in der Kunst durchschimmert." Belyj glaubt, daß gerade angesichts der Krise - die er hier allerdings noch auf das "westliche Denken" beschränkt sieht - die Dichtung wieder neue Sprachkraft erlangen könne, die der Macht des Wortes in der Rede der Propheten gleichkäme.

33. Cf. "Von der Theurgie", 104. Belyj kritisiert Nietzsches Polarisierung des "Dionysischen" und "Apollinischen", in der er die Hypertrophie von "Wille" und "Vorstellung" bei Schopenhauer fortgeführt sieht. Er meint dagegen, daß beide Prinzipien als Ausdruck ein und desselben, nämlich der Ganzheit des Menschen, anzusehen seien.

34. Cf. A. Schopenhauer: Die Welt als Wille und Vorstellung, 3. Buch, Kap. 39.

35. Cf. Formy 152 f., 156, 162 u.a. In dieser Auffassung, die das Ideelle oder Geistige an der Musik betont, konnte sich Belyj auf den bedeutenden Wiener Musikkritiker Eduard Hanslick (1825-1904) berufen, cf. Formy 165, 168, Komm. 518 f., dessen Hauptwerk "Vom Musikalisch - Schönen" (1854) in zahlreichen Ubersetzungen, auch in russischer, vorlag. Cf. A. Kovač: Andrej Belyj "The Symphonies", 21, 278, 281. Zur Bedeutung Hanslicks als "founder of modern music criticism" cf. Janik/Toulmin: Wittgenstein's Vienna, 103-108.

36. Cf. Belyjs Kritik seiner "universalen Formel", Smysl, 196 f.

37. Zum Spektrum der Musik bei Belyj cf. Formy 152 f., 156, 162, 166 f., 169 f., 173; 165, 168 (Hanslick); Komm. Formy 516-521; Komm. Smysl 544-546; "Von der Theurgie", 100, 112-116 (Nikolaj Medtner). Im Jahre 1907 kommt es zu einem Wandel in Belyjs Einschätzung der Musik cf. "Protiv muzyki", Vesy 3 (1907), in der Polemik mit E.K. Medtner (cf. Zolotoe runo, 5 (1907) 56-62). Cf. James L. Rice: Rezension zu A. Kovač, Andrej Belyj "The Symphonies". -In: The Russian Review, Jan. 1978, vol. 37, No. 1; G. Nivat: Histoire d'une "tératogénèse" biélyienne (Les rapports entre Emilij Medtner et Andrej Belyj), 93-132.

38. Zum "Geist der Musik" bei A. Blok cf. das grundlegende Werk über Bloks Weltanschauung von R.-D. Kluge: Westeuropa und Rußland im Weltbild A. Bloks, Kap. V, 84-128; D. Wörn: A. Bloks Drama Pesnja Sud'by, 499, 157 f., 170, 216; D.E. Maksimov: Poézija i Proza Al. Bloka, 61 f., 56-58.

39. Cf. Komm. 544.

40. Cf. unten S. $156 \mathrm{f}$.

41. Zur Bedeutung des Neukantianismus für Belyj cf. J. Pflanzl: Weltbild und Kunstschau, $58 \mathrm{ff}$. Cf. auch den Nekrolog Stepuns, sowie ders.: A. Belyj. - In: Mystische Weltschau, 293, außerdem unten S. $153 \mathrm{ff}$.

42. Cf. H. Henel: Erlebnisdichtung und Symbolismus. - In: DVjs 32, 1958, 71-98, bes. S. $80 \mathrm{ff}$.

43. Cf. oben S. 81, Anm. 57, ferner: L. Wenzler: Die Freiheit und das Böse nach VI. Solov'ev, 17 ("Epoche des Ubergangs in der europäischen Denkgeschichte").

44. Cf. Anm. 57 zu S. 81 .

45. Ff. A. Achmatova: Mandel'štam. - In: Diess.: Sočinenija. T. 1-2. 0.O. West-Germany 1967. T.2, $166 \mathrm{ff}$.

46. Cf. A. Blok, A. Belyj: Perepiska, 261.

47. Cf. A. Belyj: Kubok metelej (1908), "statt eines Vorwortes". Hier hebt er die zentrale Bedeutung des "pereživanie" hervor, sowie die zwei Reihen von Bild und Erlebnis: die äußere sprachliche Reihe der Bilder, die innere bild- und sprachlose Reihe des Erlebens.

48. Cf. A. Belyj: Von den Grenzen der Psychologie. - In: ders.: Symbolismus, 31-48; bes. 34. Zur "Ganzheit" als einem der Schlüsselbegriffe der Lebensphilosophie cf. K.H. Bohrer: Die Âsthetik des Schreckens, 476; D. Wörn: A. Bloks Drama Pesnja Sud'by, 215, Anm. 5 (zu Verlust und Ideal der "Ganzheit"; mit weiteren Literaturverweisen). 


\section{Kapitel: Methode der Symbolisierung}

1. Cf. Embl. 51: "Der Symbolismus als Weltanschauung ist möglich.

Was aber sind die Prolegomena einer solchen Weltanschauung? Worin liegt ihr schöpferischer Sinn? (...) Unsere Aufgabe ist es, nur auf Wegmarken für ein künftiges System des Symbolismus hinzuweisen; es muß mit diesen Wegmarken rechnen; andernfalls droht ihm Dogmatismus in dieser oder jener Form (Embl. 140)."

1a. Cf. Aage A. Hansen-Löve: Der russische Formalismus, $19 \mathrm{f}$.

2. Wenn immer wieder in der Belyjforschung die "Ambivalenz" Belyjs (Konglomerat aus Weltanschauung und Formalismus) kritisch-negativ als Manko vermerkt wurde, so kann diese Unterscheidung vielleicht zu einer Klärung des ästhetischen Denkens bei Belyj beitragen; cf. dazu E. Thompson: Russian Formalism and Anglo-American New Criticism, 11: "Worum es Belyj geht, ist nun nicht nur eine Dichtungsrichtung und ein kritisches System, sondern es sind die Grundlagen des menschlichen Denkens." E. Thompson weist darüber hinaus nach, daß jeder Asthetik - auch dem Formalismus eine Weltanschauung zugrunde liegt, ob das nun zugegeben wird oder geleugnet. An einer aufschlußreichen Ăußerung von Ėjchenbaum kann sie zeigen, daß diese Einsicht auch im russischen Formalismus nicht völlig gefehlt hat, cf. B. Ejchenbaum: Skvoz' literaturu. Würzburg 1972, 5 f.: "Jeder Literaturforscher, gleichgültig welches Arbeitsgebiet er wählt, muß das, was er sagt, nicht nur auf einer Reihe von ästhetischen, sondern auch erkenntnistheoretischen Prämissen basieren, die er ohne Beweis annimmt und die heterogener Natur sind. Wie auch immer er versucht, sich in seiner engen Provinz abzuschließen, wie weit entfernt von Ästhetik und Erkenntnistheorie er auch zu sein scheint, die verborgenen Prämissen werden sich in seiner Methode zeigen; denn in den Geisteswissenschaften, mehr als in anderen Disziplinen, gibt es keine Methode, die nicht mit irgendeiner Art von philosophischer Basis verbunden wäre."

3. Cf. H.G. Gadamer: Wahrheit und Methode, XXII, "Die Aufgabe, der 'unendliche Bezug', ist geblieben." Gadamer sagt das in der oben skizzierten Situation der Philosophie am "Ende der Metaphysik" in Hinblick auf die letzte große Gestalt in der Tradition der europäischen Metaphysik, "die spekulative Dialektik Hegels". Belyj steht auf dem Standpunkt, daß Ideen eigenes Sein haben; allerdings geht es ihm zunehmend nicht mehr allein um eine Philosophie der Ideen, sondern in den Vordergrund rückt die Bedeutung von "Werten". Zum Sein der Idee cf. auch W. Benjamin: Ursprung des deutschen Trauerspiels, Ffm. 1963, der ebenfalls zwischen "Phänomenen" und "Ideen" unterscheidet, von denen er glaubt, daß sie eigenes Sein in der Ordnung oder dem Reich der Ideen haben (8). Uber den Zusammenhang zwischen beiden sagt er: "Vielmehr sind die Ideen deren (d.h. der Phänomene, M.D.) objektive Anordnung, sind deren objektive Interpretation"; und das heißt für B., sie sind gleichzeitig deren "Repräsentation" (15).

4. Daraus, daß zwei so unterschiedliche Künstler wie Böcklin und Ibsen hier als "Symbolisten" fungieren, wird deutlich, daß es sich in der ersten Phase von Belyjs Symbolverständnis noch um eine vorwiegend formale Bestimmung des Symbolischen handelt. Sie kann sowohl ein handlungsloses "Arrangement" von stilistischer Einheit, wie auch die ideelle Tiefe der Symbolisierung (z.B. in Ibsens "Wildente") umfassen, die nicht in Stimmung oder Typisierung aufgeht, sondern aus dem tragisch erlebten Zusammenstoß zwischen Ideal und Wirklichkeit hervorgeht.

5. Daß Belyj, trotz seiner einseitigen Bevorzugung der Musik, in seiner ästhetischen Theorie bis 1906, wesentliche Impulse stilprägender Art aus der Topik und Technik der Malerei der Jahrhundertwende bezog, vor allem aus der Kunst des Jugendstils und der Präraffaeliten, zeigt A. Kovač: Andrej Belyj: The "Symphonies", 28-46.

6. Cf. A. Kovač: op. cit., 37-46; D. Wörn: A. Bloks Drama, 457-460 (Neopopulismus und Folklore um 1900).

7. A. Kovač: op. cit. 76-79, 264-267.

8. Die appellative Orientierung ist ein Grundzug Belyjs, der zum ersten Mal explizit hervortritt in seinem symbolistischen Manifest "Von der Theurgie", cf. unten S. 175 ff. 
9. Die Ruf-Symbolik gehört zu den frühesten Symbolkonstanten Belyjs, schon in "Pevica", Mir iskusstva, 7-12 (1902) 302 f. heißt es: "Mit Zittern bekennen wir uns zu den Signalen 'von drüben' (ottuda). Das ist die Ewigkeit, die ihre Posaune ertönen läßt: 'Erwachet, erwachet': die Welt ist reif geworden'...".

10. Cf. "Von der Theurgie", $108 \mathrm{f}$.

11. Cf. G.J. Sternin: Das Kunstleben Rußlands, 193 f., 300 (zu Vrubel's LermontovIllustrationen 1891); L.D. Blok: Byli i nebylicy, 70, 99 f.

12. Daneben gibt es Symboltypen, die zwischen beiden Grenzzuständen liegen, bzw. an beiden Anteil haben wie zu z.B. die "Kentauren" oder das Symbol der "Maske"; das erste ist bes. für Belyj, das zweite für Blok typisch. Cf. dazu 1. Masing-Delic: The Mask Motiv in A. Bloks Poetry. - In: Russian Literature 5 (1973), 79-101.

13. In der Belyjforschung ist es üblich geworden, von seinem "symphonischen" Stil zu sprechen, vor allem induziert von Belyjs eigenen präferierenden Aussagen zur Musik (in der Frühzeit). Man sollte aber die andere stilbildende Hälfte, die Topik Belyjs, nicht übersehen. Beide gehören zusammen als die paradigmatische und die syntagmatische Komponente seines Stils, deshalb scheint es mir angebrachter, von einem "topisch-symphonischen" Stil zu sprechen.

14. Cf. A. Kovac: Andrej Belyjs: The "Symphonies", 74.

15. Wenn Belyj hier von "Bild der Natur" spricht, so muß kritisch angemerkt werden, daß es sich nicht nur um "Natur" im ursprünglichen Sinne handelt, sondern um bereits kulturell und sprachlich vermittelte Erfahrungen mit Natur. Gerade der Topos des "Schneesturms" ist ein typisch russisches literarisiertes Erfahrungsmuster lange vor Belyj und Blok; cf. z.B. Pułkin "Der Schneesturm" (Povesti Belkina).

16. Außer Belyjs Versionen: "Pokal der Schneegestöber", "Petersburger Drama" (Mdr 57100) und "Erinnerungen an Blok", Kap. 6, gibt es die davon abweichende Darstellung von L.D. Blok: Byli i nebylicy, $50 \mathrm{ff.;}$ auch $A$. Blok: Pesnja sud'by, enthält eine Gestaltung dieses Themas; cf. D. Wörn: A. Bloks Drama Pesnja sud'by, $148 \mathrm{f} ., 178 \mathrm{f}$.

17. Die Frage nach Brüchen oder Entwicklung bei Belyj müßte weiter untersucht werden. Hier sei darauf hingewiesen, daß B. zur Polemik mit sich selbst neigt -ohne das immer deutlich zu sagen-, deren hyperbolische Argumentation dazu angetan ist, Entwicklungslinien zu überwuchern.

18. Obwohl Belyj an anderer Stelle auf der Trennung von Symbol und Allegorie bestanden hat, kann man sagen, daß die frühen deiktisch-appellativen Symbole der Allegorie nahestehen, d.h. daß bei ihnen der "allegorische Sinn" dominiert. Die expressiven Existenzsymbole, die sich in Bildsequenzen entfalten, sind dagegen Symbole im eigentlichen Sinne, vor allem, da sie die Bedingungen der Mehrdeutigkeit erfüllen (Smysl 208).

19. Die Unterscheidung verschiedener Verstehensstufen des Symbols steht der Auffassung vom mehrfachen Schriftsinn des biblischen Wortes im Mittelalter immer noch nahe; cf. dazu Friedrich Ohly: Vom geistigen Sinn des Wortes im Mittelalter. Darmstadt 1966, I, der von der für Kunst und Exegese gestellten Aufgabe spricht, "das Wort auf seine Bedeutung hin transparent zu machen".

20. Belyj spricht vom Sinn-Einsatz (Smysl 207 f.), den der Leser in einer "Arbeit post factum" leisten müsse, um ein Symbol aufzuschließen; eine Sinnarbeit also, die über semantische Dekodierung hinausgeht; cf. dazu Paul Ricoeur/E. Jüngel: Metapher, 47. R. spricht von der ganz persönlich zu leistenden "Arbeit am Sinn", um die Wirkkräfte des Symbols zu entbinden.

21. Cf. H. Pongs: Symbol als Mitte, 111 passim. (Zum Ursprung des Symbols aus Brauch und Ritual, aus dem das Bild-Zeichen hervorging, das solches Tun repräsentierte).

22. Zu Symbol und Allegorie, einer seit Goethe geläufigen Unterscheidung, cf. u.a. (in bezug auf A. Blok) Z. Minc: Simvol u Bloka. - In: Russian Literature VIl-VIIl May 1979, S. 193-248 (zur "Mehrwertigkeit" des Symbols).

22a. Unter "Produktionsästhetik" wird hier der Bereich des Schaffensprozesses verstanden.

23. Andrej Belyj: Die Vier Symphonien, Vorwort zur "Vierten Symphonie".

24. Dieser Aspekt, daß das postrealistische Symbol der Moderne nicht mehr "gestiftet" (cf. H.G. Gadamer: Wahrheit und Methode, 148), sondern in oben beschriebener Weise "erlebtes Symbol" ist, fehlt in der Studie von Z. Minc. Cf. dagegen J. 
Striedter: Transparenz und Verfremdung, 275; M. Chraptschenko: Literatur und Modellierung der Wirklichkeit. - In: Sinn und Form 25 (1973) 129; J. Aler: Als Zögling zwischen Maeterlinck und Mach, 243-245; H. Pongs: Symbol als Mitte, 23 f., 59 f. (S. $104 \mathrm{ff}$. "Symbol-Einsichten Goethes").

25. Andrej Belyj: Die Vier Symphonien. Vorwort zur "Vierten S."

26. op. cit. 133-157 (3. Teil "Volnenija strasti").

27. Cf. A. Kovat: Andrej Belyj: The "Symphonies", 242 ff. ("A Formalist Trap").

28. S.D. Cioran: The Apocalyptic Symbolism, gibt Belyjs Begriff des "pereživanie" pauschal mit "crisis-experience" wieder. Obwohl er auf eine der wichtigsten Quellen des "pereživanie", W. Wundts "Grundzüge der Psychologie", verweist (53-55), kommt er zu dem reduktionistischen Schluß, daß für Belyj aufgrund seines hysterischen Emotionalismus ( $41 \mathrm{f}$., 52) und seines übersteigerten apokalyptischen Krisenbewußtseins ein anderer, als der Erlebnisbegriff der "Krisenerfahrung", gar nicht in Frage kommen kann. Eine Analyse des "perežıvanie" fehlt, die dieses Urteil stützen könnte.

29. Cf. Embl. $76 \mathrm{f}$. (verschiedene Zonen des Bewußtseins werden in Erkenntnis und Schaffen durchlaufen).

30. Z.G. Minc: Simvol u Bloka, untersucht die Frage, was das Symbol der Tradition, vor allem der Romantik von dem der "Neuen Kunst" unterscheide. Sie stellt die These auf, daß die Unterscheidung auf einer veränderten weltanschaulichen Grundlage beruhe. Gegenüber dem "Theismus der Romantik" sei es in der russischen Moderne zu einer "pantheistischen" Weltanschauung gekommen, die nicht mehr mit dem klassischen Pantheismus Spinozas übereinstimme, sondern sich aus verschiedenen Komponenten zusammensetze.

"Es zeigt sich, daß mit eben diesen Gedanken vom Pantheismus der Versuch zusammenhängt, die Auffassung und Struktur des Bildes in der "Neuen Kunst" von den ihr sehr nahestehenden Traditionen der Romantik abzuheben.

Wir werden hier nicht die (im Prinzip äußerst wesentliche) Frage nach dem Zusammenhang der "pantheistischen" Bestrebungen des russischen Symbolismus mit dem klassischen Pantheismus der Spinozarichtung untersuchen. Wir merken nur an, daß einerseits der Zusammenhang mit der Spinoza-Tradition von der Mehrzahl der "älteren Symbolisten" als sehr wichtig aufgefaßt wurde. Gleichzeitig ist der "Pantheismus" der russischen Symbolisten (unter ihnen auch I. Konjevskoj-Oreus) - ein System von Ansichten, die sich mit der Spinoza-Richtung durchaus nicht decken. Es umfaßt die Stützung auf die deutsche Philosophie zu Anfang des neunzehnten Jahrhunderts (vor allem auf Schelling / ... / ) und die bedeutende Einwirkung der "Synthese"-Idee Solov'evs und die Beziehung zur postromantischen Kunst (in erster Linie - zum Erbe Tjutčevs, zum französischen Symbolismus). Schließlich ist eine überaus wichtige Komponente der "pantheistischen" Vorstellungen der russischen Symbolisten die Nietzscherichtung mit ihrem Streben, die mythologischen Grundlagen des Weltverhältnisses wiedererstehen zu lassen.

In der Bilanz bildete sich die Vorstellung vom zugleich einen und vielgestaltigen Sein heraus, in der die universale Einheit dem Subjekt erschien als im Prinzip unendliche Reihen von "Entsprechungen" (correspondences) der einen Erscheinungen zu den anderen, als das "Durchschimmern", das "Durchscheinen" der einen durch die anderen. Eine adäquate (oder zumindest relativ adäquate) Darstellung einer solchen Weltkonstruktion kann nur symbolisch sein - "das Durchscheinen" der einen Bedeutungen des Wort-Bildes durch die anderen (194 f.)" Man fragt sich, ob eine solche Definition eines modernen russischen "Pantheismus" herausragenden Zügen des russischen Symbolismus wie z.B. der Rolle des Individuums, des Erlebens, der Wertschöpfung oder des "preobraZenie" gerecht werden kann. Sie erscheint dafür zu unscharf.

31. Unter "Klassiker" und "Romantiker" versteht Belyj nicht die üblichen Epochenbezeichnungen, sondern zwei verschiedene Schaffenstypen des Künstlers. Beim ersten ist Ausgangspunkt die äußere Erfahrung, beim anderen die innere. Eine solche typologische Unterscheidung zwischen dem "extrovertierten" und dem "introvertierten" Künstler trifft auch W. Dilthey: Uber die Einbildungskraft der Dichter. - In: Zs. für Völkerpsychologie und Sprachwissenschaft. 10 (1878) $87 \mathrm{f}$. In abgeänderter 
Fassung wieder abgedruckt unter dem Titel: Goethe $\mu$ nd die dichterische Phantasie. - In: Wilhelm Dilthey: Das Erlebnis und die Dichtung. Berlin 1906, S. 177, 198.

32. Daß unter "obraz tvorčestva" sowohl die "Weise" wie auch das "Bild" des Schaffens verstanden werden kann, darauf weist hin J. Striedter: Transparenz und Verfremdung, 272.

33. Auf das spezifische Defizit, das aus der Ubertragung von Modellierungsprinzipien aus den Naturwissenschaften auf die Kunst entsteht, weil nämlich in solchem Modelldenken der "subjektive Faktor" und seine Erlebnisbasis ausgeschaltet werden, verweist kritisch $\mathrm{M}$. Chraptschenko: Literatur und Modellierung der Wirklichkeit, $118,128 \mathrm{f}$.

34. In den vier wichtigsten Aufsätzen der dritten Phase wird die Sinnfrage in "Emblematik des Sinns" und "Das Problem der Kultur", die Formfrage in "Magie der Worte" und "Lyrik und Experiment" diskutiert.

35. Das Ziel der Kunst, die Verwandlung der Persönlichkeit (bzw. der Menschheit), bleibt als wirkungsästhetische Ausrichtung bestehen, trotz der produktions-ästhetischen Veränderungen in der Symbolkonzeption.

36. Zur Begründung des besonderen Seinsstatus der Kunst bei Belyj cf. oben S. 101 .

37. Zwischen wertorientiertem Schaffen und unverbindlichem ästhetischem Experiment in der Kunst unterscheidet Belyj bereits sehr deutlich in "Sinn der Kunst" (1907):

"Die Prozesse des Schaffens selbst sind gegeben; sie lassen sich beschreiben; hier ist das eine oder andere Experiment möglich; die Normen aber dieser Prozesse sind die Ideen der praktischen Vernunft, die die Bedingungen der Möglichkeit vorab bestimmen (...) (Smysl 217 f.).

Interesssant an dieser Unterscheidung scheint mir, daß Belyj einen Horizont für das ästhetische Experiment absteckt, in dem die Verbindung des Ästhetischen mit dem Ethischen nicht nur möglich erscheint, sondern als Forderung an die Kunst ausdrücklich erhoben wird. Cf. dazu: Komm. 465:

"Wir haben begriffen, daß der sogenannte Ästhetizismus, da wo er in all seiner schonungslosen Konsequenz durchgeführt worden ist, übergeht in sein entgegengesetztes Prinzip - in das Prinzip des Ethischen; der Inhalt der Schönheit erweist sich, kaum daß wir versuchen ihn zu formulieren, als verbunden mit dem ethischen Moment; richtiger: der Inhalt der Moral und der Inhalt der Schönheit sind ein und derselben Norm unterstellt. Deshalb führte der konsequente Asthetizismus Wilde's ihn zum Verständnis Christi als des Ideals der Schönheit; zum Ideal der Schönheit wurde für ihn die Persönlichkeit, die in sich das "maximum" an Gutem verkörperte. Genauso ist Nietzsche, indem er die Formen der existierenden Moral umstürzte - hauptsächlich Moralist; die Ideologie Ibsens unterstreicht ebenso das ethische Moment; nur geht das ethische Prinzip, das von der Schönheit her bestimmt ist, nicht in den Formen der Moral auf, wohl aber in einer Norm, als einem transzendenten Sollen; daher mußten die großen Symbolisten des XIX. Jahrhunderts, gerade dadurch, daß sie tief in das Wesen der ethischen Normen eindrangen, als Zerstörer von existıerenden Formen der Moral erscheinen."

Cf. ferner Probl. 10.

38. Wenn der Unterschied im Seinsstatus zwischen Kunst und Lebenspraxis nicht in Betracht gezogen wird, muß es zu Fehlurteilen über die Wirkungsweise der Kunst kommen. Ein Beispiel dafür scheint mir die Argumentation von S.D. Cioran: The Apocalyptic Symbolism, zu bieten, der das Scheitern des russischen Symbolismus darin begründet sieht, daß ihren Worten keine Taten folgten: "New being cannot be created by words without deeds (24)." Nach diesem Maßstab kann man eine religiöse Erweckungsbewegung beurteilen, muß aber eine sich religiös verstehende Kunstrichtung mißverstehen. Kunst ist immer Wort, das durch die Tat von ihr selbst nicht eingelöst zu werden braucht.

39. Einer Anregung von R.D. Kluge folgend sei hier darauf hingewiesen, daß man Belyjs Weg als Kunst theoretiker von der Kunst als "genialer Erkenntnis" über die Kunst als "Modell der Erfahrung" bis hin zur Kunst als "Wert- und Sprachschöpfung" mit dem Hegelschen Denkbild des dialektischen Dreischrittes von These, Antithese und Synthese interpretieren kann. Man müßte diesen Gedanken vielleicht noch dadurch modifizieren, daß die ersten beiden "Gegensätze" nicht Antithesen in einem sich 
ausschließenden Sinne sind, sondern zwei Seiten eines Ganzen, das von vorherein wenn auch noch unklar - intendiert war.

40. Cf. A. Belyj: Krizis soznanija i Genrich Ibsen. - In: Arabeski, 161.

41. Cf. oben S. 86, Anm. 3.

42. Zum Zentrum einer solchen Kulturarbeit sollte der Moskauer Verlag Musagetes werden. Cf. F. Stepun: Mystische Weltschau, 285 ff.; A. Belyj: Mdr. 376 ff.

43. Cf. Lirika, $231 \mathrm{ff}$.

44. Cf. Emblematika, 66: "Die Klasse der Begriffe vom Werthaften gehört, da sie weder gnoseologisch noch psychologisch ist, zur Klasse der symbolischen Begriffe." Cf. dazu R. Niebuhr: The Truth Value of Myth, $119 \mathrm{f}$. (Wert als nicht allein rational faßbare Größe).

45. Cf. Emblematika, 67: " (...) die Bildlichkeit des Ausdrucks aber - das ist das Los der symbolischen Begriffe; der Symbolismus des Ausdrucks charakterisiert die Niederungen der Erkenntnis; aber auch auf den Gipfeln der Erkenntnis kommen wir zum Begriff in bildhafter Form". Deshalb ist es auch die Kunst, die zu solcher Art von symbolischen Begriffen Beiträge leistet, sogar Vorbilder anbietet.

"und wir wenden uns den Bildern $z u$, die in den Künsten entstehen, vom Gesichtspunkt des Hervortretens der Einheit in ihnen; und die Gipfel des künstlerischen Schaffens bringen uns vollendete Bilder der Menschheit vor Augen, sie ziehen uns hin zu den Gipfeln der Pflicht.

(...) Von solcher Art ist Dantes Beatrice, von solcher Art sind die Bilder Christi und Buddhas; die Kunst geht hier über in Mythologie und Religion; im Zentrum der Kunst soll das lebendige Bild des Logos stehen, d.h. das Antlitz (lik)"(Embl. 79)

Zum "Spas Nerukotvornyj" cf. Konrad Onasch: Ikonen. Berlin-Ost 1961, S. 347 f.

46. Belyjs Sprachauffassung steht sehr stark unter dem Einfluß von $A$. Potebnja und $A$. Veselovskij, cf. Komm. 618 ff. Cf. zum Einfluß Potebnjas die Arbeiten von C. Pomorska, Gofman, Hansen-Löve, Anschütz.

47. Uber die "Barbarismen" der poetischen Sprache äußerte sich bereits kritisch Aristoteles in seiner "Poetik" (Kap. XXII). Zur Aristoteles-Renaissance in Rußland in den Zehner und Zwanziger Jahren cf. Hansen-Löve: Der russische Formalismus, $24 \mathrm{f}$.

48. Zum Ringen um eine neue Sprache cf. T.S. Eliot: Four Quartets, East Coker V:

"(...)

Trying to learn to use words, and every attempt

Is a wholly new start, and a different kind of failure

Because one has only learnt to get the better of words

For the thing one no longer has to say, or the way in which

One is no longer disposed to say it. And so each venture

Is a new beginning, a raid on the inarticulate."

(Hv. M.D.)

49. In Belyjs Sprachauffassung sind noch weitere Gedanken wichtig, als die hier genannten. Vor allem seine Sprachkritik der naturwissenschaftlichen Terminologie (Magija 439) und seine Einsicht, daß Erkenntnis sprachlich vermittelt ist (Magija 438).

In beiderlei Hinsicht geht Belyj in seiner Kritik der Sprache als Erkenntnisinstrument davon aus, daß sowohl die wissenschaftliche als auch die philosophische Sprache Erkenntnis nur im Modell oder in Analogie darstellen kann.

50. Belyj wählt das Beispiel der Mondsichel, um zu zeigen, wie Metaphorisierung vor sich gehen und zur Symbolisierung führen kann (Magija 442-448). 


\section{Kapitel: Zur Legitimierung der künstlerischen Symbolisierung.}

1. Cf. oben S. 37 f., S. 53-57.

2. Der Zug zur Selbstbegründung zieht sich durch sein ganzes Werk. Belyj versteht sich als Teilhaber einer gesamteuropäischen Protestbewegung, die eine Revolution in der Kunst auslöste, der "Kinder der Grenzscheide". Cf. z.B. am Anfang seines Denkens das Plädoyer für die "Neue Kunst" Vrubel's und die "Rebellion" der Modernen in der französischen Malerei (Formy 160) aus dem Jahre 1902; am Ende seines Lebens dominiert das Thema der Rechtfertigung noch immer: cf. seine Verteidigung der Grenzgänger zwischen Altem und Neuem als "Gefecht zwischen den Jahrhunderten" (Nrds 167), auch Nrds 3-18, 191-201.

3. Belyjs Verhältnis zu den "Vätern" ist kompliziert. Innerhalb der "Väter-Generation" unterscheidet er zwischem dem liberal-konservativen Establishment der positivistisch gesinnten Moskauer Professoren-Intelligenz und den nicht angepaßten Individualitäten unter ihnen. Zur ersten Gruppe gehören vor allem die tonangebenden Größen der Moskauer Universität, die er in seinem Elternhaus kennengelernt hatte: die Mathematiker, die Positivisten und die "Leuchten der Humanität und des Fortschritts" (Nrds 10). Seine Verachtung für ihre Gesinnung und ihren Lebensstil erklärte er öffentlich in seinem "Offenen Brief an die Liberalen und Konservativen" im Jahre 1903. Er warf ihnen beschränkten Idealismus, Prinzipienstarrheit und Desinteresse an der Jugend vor. Er verurteilte die Mittelmäßigkeit und Oberflächlichkeit ihrer Lebensführung: "Sie haben uns genötigt, ihre sinnlosen Begierden bis zum Absurden zu treiben, um sie dann mit Ekel von uns zu werfen" (Mir iskusstva 1903, v. 11-12, Chronika zu N ${ }^{\circ}$ 7, S. 65 f.). Dennoch war der Kult der Wissenschaften, den sie verbreiteten, (Nrds 178, über die "Priester der Wissenschaften") so stark, daß er sich auch vor ihnen rechtfertigen wollte. Doch echte Autoritäten waren sie für ihn nicht. Seine Achtung galt den von ihnen in Gesinnung und Lebensführung abweichenden Individualitäten: neben dem begabten Pädagogen L.I. Polivanov (Nrds $260 \mathrm{ff}$.), vor allem M.S. Solov'ev, dem Bruder des Philosophen, den er als moralische Autorität verehrte und der seinerseits der einzige unter den "Vätern" war, der Belyjs Bedeutung als Künstler sofort erkannte (Nrds. 360-387).

Achtung hatte er auch vor den Milieukritikern und "Sonderlingen"; zu ihnen gehörten die Brüder Taneev (Nrds 136-153) und die beiden Onkel Belyjs aus der Bugaev-Linie (Nrds 127-136).

Eine Sonderstellung unter den "Vätern" räumt er seinem eigenen Vater ein, der dem Alter nach sein Großvater hätte sein können (Nrds 24-26). Obwohl er ihn gefürchtet, gehaßt und unter ihm gelitten hat, blieb die Hochachtung vor seiner wissenschaftlichen Redlichkeit und Bedeutung davon unangetastet. Obwohl ihn seine Methodenbesessenheit (Nrds $22 \mathrm{f.}$ ) und sein fanatisches Streben nach absoluter rationaler Klarheit (Nrds 23) eher unverständlich erscheinen ließen, zählt er ihn doch unter die drei großen "Lebensbegleiter" seiner Jugend. Neben Polivanov und M.S. Solov'ev habe er bleibenden Einfluß auf ihn gehabt:

"Sein Einfluß ist gewaltig: im Einverständnis, in Unstimmigkeiten, in scharfen weltanschaulichen Gefechten und in der Geste verstohlener, brennender Liebe hat er mich aktiv durchdrungen; die Ubereinstimmung in den Ansichten und sogar die Polemik mit ihm haben den Kreis meiner Interessen bestimmt; mit ihm habe ich gerechnet - in der Kindheit, in der Knabenzeit, in der Jugend, als reifer Mann" (Nrds 19).

Von der Polemik gegen die liberal-konservativen "Väter" blieb er deshalb nach Belyj ausgenommen, weil er ohnehin als "Verfremder des Milieus" (Nrds 37-43) zu ihnen im Gegensatz stand. Dazu ist anzumerken, daß man weder allein von den Selbstaussagen Belyjs noch allein von den fiktionalen Vaterfiguren der Romane, von der "ödipalen Serie" der "Letaevy-Korobkiny-Ableuchovy" ohne weiteres auf Belyjs Verhältnis zu Vater und Vätern schließen kann. Chodasevičs These vom "Freudschen Verbrechen gegen den Vater" (cf. V.F. Chodasevit: Nekropol', 81 ff. als durchgängiges Motiv bei Belyj) schließt sicher eine Komponente auf, scheint mir aber korrekturbedürftig: eine Direktübertragung ödipaler Konflikte und Todeswünsche von der Werkebene zurück auf die Ebene des Autors ist sicher als Generalisierung nicht zulässjg. Dieses 
Thema harrt noch seiner Erforschung. Zum methodischen Problem der Trennung und Vermittlung von Werk- und Autorebene cf. W. Mauser: Hugo v. Hofmannsthal, 9 ff.

4. Neuere Forschungen zur Legitimationsproblematik werden in der literaturwissenschaftlichen Diskursanalyse und Diskurskritik in Anlehnung an die poststrukturalistischen Untersuchungen $M$. Foucaults und J. Lacans betrieben. Cf. Kittler/Turk: Urszenen, bes. S. 10-20, $381 \mathrm{ff}$.

Kittler/Turk sehen die rationalen Begründungsstrategien des künstlerischen Subjekts von zwei Seiten her grundsätzlich durchkreuzt: 1) von der Triebstruktur, die von Begehren und Macht gesteuert ist (Foucault); 2) von der Selbsttätigkeit der Sprache ("Grenzwert eines weißen Rauschens"), deren das Subjekt nicht eigentlich mächtig sei (Lacan); gegenüber solcher "Subversion des Subjekts" soll hier die bewußt unternommene Strategie der Rechtfertigung im Falle Belyjs zunächst einmal ernst genommen werden. Das scheint die Chance zu bieten, verschiedene Formen der Rechtfertigung zu erkennen, aus denen sich Schlüsse ziehen lassen, die Neues an der Gestalt Belyjs und an der Strömung des russischen Symbolismus hervorheben können.

5. Cf. Komm. 457-465 zu den verschiedenen Formen schöpferischer Grundeinstellung in den verschiedenen Kulturgebieten.

6. Cf. Ernst Cassirer: Philosophie der symbolischen Formen, I, V.C. geht - wie Belyj von der Feststellung aus, daß die herkömmliche Erkenntnistheorie eines allein logisch-begrifflichen Denkens "für eine methodische Grundlegung der Geisteswissenschaften nicht ausreicht." $C$. versteht seine Philosophie als Weiterführung Hegels und Kants. Er will zeigen, daß die "Selbsttätigkeit des Geistes" noch andere legitime und philosophiefähige Formen annehmen kann:

"Statt lediglich die allgemeinen Voraussetzungen des wissenschaftlichen Erkennens der Welt zu untersuchen, mußte dazu übergegangen werden, die verschiedenen Grundformen des 'Verstehens' der Welt bestimmt gegeneinander abzugrenzen und jede von ihnen so scharf als möglich in ihrer eigentümlichen Tendenz und ihrer eigentümlichen geistigen Form zu erfassen. Erst wenn eine solche 'Formenlehre' des Geistes wenigstens im allgemeinen Umriß feststand, ließ sich hoffen, daß auch für die einzelnen geisteswissenschaftlichen Disziplinen ein klarer methodischer Uberblick und ein sicheres Prinzip der Begründung gefunden werden könne."

7. Zur Beurteilung von E. Cassirer in der neuesten sowjetischen Forschung zur Struktur des mythologischen Denkens cf. E.M. Meletinskij: Poètika mifa. M. 1976, 44-55. Im ersten Teil seines Buches gibt M. einen umfassenden kritischen Uberblick über die neuere Literatur zur Theorie des Mythos (12-162).

8. Belyj hatte in der positivistischen Erziehung durch seinen Vater die Erfahrung gemacht, daß nur das zählte, was mit Argumenten bewiesen werden konnte. $\mathrm{Er}$ selbst hatte sich erst dann "Achtung erwerben" können, als er eine bestimmte Terminologie beherrschte, die als gültige Rede im Diskurs mit dem Vater anerkannt wurde (Nrds 388-395). Daher sein Hang zum Dozieren.

Die strenge Forderung nach Genauigkeit der Formulierung (Nrds 212 f.), nach stringenter Beweisführung (Nrds 185), nach genauer Kenntnis der grundlegenden Primärtexte der Philosophen und Wissenschaftstheoretiker hat seine Formierung zum Ideologen des russischen Symbolismus von Grund auf geprägt.

Für den definitorischen Purismus des Vaters gibt er folgendes Beispiel:

"Er forderte Formulierung; er formulierte dauernd.

Einmal, im Disput:

'Und was ist Bewußtsein?'

'Na und, so sagen Sie es doch selber!'

'Bewußtsein', und ein Lächeln des Triumphes drang scharf durch den Fragenden hindurch,

'das ist das Wissen von etwas im Zusammenhang mit etwas.'

Manche seiner Formeln waren originell, elegant; sein Disput mit dem Gegner lief auf die Forderungen hinaus, ganz genau zu formulieren; und auf sokratische Weise brachte er zum Bewußtsein, daß der Streitende Worte gebrauchte, die er selbst gar nicht genau formulieren konnte; wie grimmig der Vater in seiner Forderung nach der Formel war:

'Also, Boren'ka, ich gebe dir fünf Minuten für den Beweis, daß dein Hamsun ein Künstler ist.' 
Und die Uhr wurde hervorgezogen; und fünf Minuten lang schwieg er; aber wenn ich es nicht schaffte, bis zum Ende der sechzigsten Sekunde der fünften Minute die Verteidigung Hamsuns, durchgeführt in den Formeln eines klaren Denkens, zu Ende zu bringen, dann halfen keinerlei Argumente mehr etwas; und, klarer Fall -von Hamsun blieben nur noch Staub und Asche" (Nrds 67).

9. Interessant ist die folgende Beobachtung Belyjs: Zwischen der absoluten theoretischen Gründlichkeit seines Vaters und dem bohrenden Wissenwollen in seiner eigenen Generation sah er eine gemeinsame Grundhaltung: beide verachteten die liberalen "Schwätzer", die ihr Wissen aus zweiter Hand bezogen; beide verband die Anstrengung, sich durch grundlegende Werke "durchzubeißen":

"Der Vater-'Großvater' und der Sohn-'Enkel' reichten einander die Hand gegen den Leichtsinn der 'Väter'; als ich den Vater sah, als ich die Onkel sah, als ich dann Valerij Brjusov, als ich Ellis sah, da habe ich mich immer gefragt: was verbindet bei aller offenbaren Uneinigkeit diesen alten Sonderling, der über Turgenev nicht hinausgekommen ist, insgeheim mit ... Brjusov, mit ... Ellis.

Und später begriff ich: es verbindet sie die Gründlichkeit, die Tatsache, daß sie sich trotz allem durch ideologische Bücher 'durchbeißen'; der Vater biß sich durch Spencer, Hume, Leibniz durch; Ellis hat sich seinerzeit durch Marx durchgebissen; Brjusov hat sich durch Spinoza durchgebissen; ich biß mich in jener Zeit durch Schopenhauer und fing an, mir an Kant die Zähne auszubeißen; Storoženko und Aleksej Veselovskij aber haben sich durch nichts durchgebissen, sie machten sich gar nicht daran, wirklich an etwas zu nagen; und gerade das war es, was den Vater zum Stöhnen brachte" (Nrds 31 ).

10. Cf. Nrds 26-36.

11. Cf. Nrds 391 f.

12. Das gelang ihm auch. Cf. Nrds $24 \mathrm{f}$. Obwohl der Vater seine Ideen ablehnte, so billigte er doch die selbständige Art des Denkens und des methodischen Vorgehens im ersten kunst theoretischen Essay seines Sohnes "Formen der Kunst" (1902).

12a. Der Zusammenhang von künstlerischem und außerkünstlerischem Symbolismus, wie er für Belyj relevant ist, wird in der Forschung zum literarischen, insbesondere zum russischen Symbolismus bisher kaum berücksichtigt. Je mehr man sich aber auf dieses Thema einläßt, desto deutlicher zeigt sich, daß hier bei Belyj, aber auch über ihn hinaus, ein Zusammenhang berührt wird, der sehr weitreichende Beziehungen sichtbar macht: Um die Jahrhundertwende sind sie ebenso vielfältig wie bisher noch wenig erforscht.

Die lange tradierte Berührungsscheu zwischen Natur- und Geisteswissenschaft mag dazu beigetragen haben. Trotzdem bemühten sich schon in den fünfziger Jahren, verstärkt aber erst im letzten Jahrzehnt, einzelne Forscher darum, diesen nicht so leicht greifbaren Zusammenhängen auf die Spur zu kommen. Cf. Heinrich Henel: Erlebnisdichtung und Symbolismus (1958), der weitere Literatur aus den fünfiziger Jahren anführt (M.B. Hesse, Peacock, Emrich). Jan Aler: Als Zögling zwischen Maeterlinck und Mach (1971); Gerd Müller: Dichtung und Wissenschaft (1971); Janik/Toulmin: Wittgenstein's Vienna (1973); John Neubauer: Symbolismus und symbolische Logik (1978); Michael Worbs: Wissenschaft und Literatur im Fin de siècle (1978); Joachim Metzner: Die Bedeutung physikalischer Sätze für die Literatur (1979). Ihre Ergebnisse, - vor allem die von Janik/Toulmin über "Wittgenstein's Vienna" - haben auf den Untersuchungsgang dieser Arbeit auf zweierlei Weise eingewirkt: Zum einen haben sie die Relevanz der Beobachtungen, die man an Belyjs Legitimationsstrategie machen kann, bekräftigt; sie haben aber auch dazu beigetragen, daß sich so etwas wie ein analytischer Blick allmählich schärfen konnte.

13. Zur "teleologischen" Tendenz des Bewußtseins cf. I. Kant: Kritik der reinen Vernunft, Erstes Buch, Zweiter Abschnitt $\$ 17$. Belyj zitiert hierzu den russischen Kantianer Celpanov ("Das Problem der Wahrnehmung des Raumes").

"Zu den wichtigsten Schlüssen gehört Celpanovs Ansicht über das teleologische Prinzip, als unabdingbare Voraussetzung des Kritizismus. Hier verbindet sich, nach unserer festen Uberzeugung der Kritizismus durch die Teleologie mit dem Symbolismus, denn der Symbolismus, der die notwendige Voraussetzung der Teleologie ist, krönt das Gebäude, dessen Fundament der Kritizismus ist." (Komm. 480)

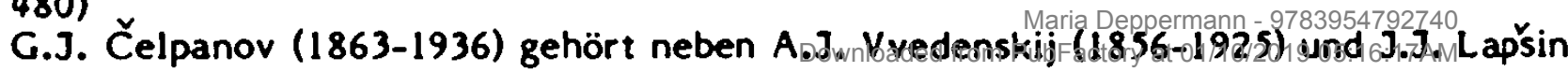


(1870-?) zu den bekanntesten Vertretern des russischen Neukantianismus. Cf. $\mathrm{H}$. Dahm: Die Chance der Philosophie, 250. In der Fähigkeit des Bewußtseins zur Integration sieht auch E. Cassirer: Philosophie der symbolischen Formen, die Voraussetzung seiner symbolisierenden Tätigkeit:

"Es gibt demnach kein "Etwas" im Bewußtsein, ohne daß damit eo ipso und ohne weitere Vermittlung ein 'Anderes' und eine Reihe von anderen gesetzt würde" (I, 32 f.).

Cassirer spricht vom "Integral" des Bewußtseins (I, 41): Die Leistung seiner Symbole bleibe ein Rätsel, "wenn sie nicht in einem ursprünglichen, im Wesen des Bewußtseins selbst gegründeten geistigen Verfahren ihre letzte Wurzel hätten" (I, 41). In Bd. III, $10 \mathrm{ff}$. bezieht er sich direkt auf Kants Prinzip der "synthetischen Einheit der Apperzeption" als "Urfunktion" und "Focus" seiner Erkenntnistheorie.

14. Auch hierin berührt sich Belyj mit Cassirer: In der Erkenntnis, der Kunst, in Mythos und Religion sieht $C$. je "eigene symbolische Gestaltungen, die den intellektuellen Symbolen, wenn nicht gleichartig, so doch ihrem geistigen Ursprung nach ebenbürtig sind. Keine dieser Gestaltungen geht schlechthin in der anderen auf oder läßt sich aus der anderen ableiten, sondern jede von ihnen bezeichnet eine bestimmte geistige Auffassungsweise und konstituiert in ihr und durch sie zugleich eine eigene Seite des 'Wirklichen"' (I, 9). Die methodische Grundannahme verschiedener "Weltmodelle" wurde in der Kulturtypologie des russischen Strukturalismus von Lotman und seiner Tartuer Schule aufgegriffen und weiterentwickelt. Der wunde Punkt bleibt jedoch die Verdrängung des "subjektiven Faktors", der in der Kunst sicher nicht auf einen transzendentalen, ahistorischen Ordnungsfaktor begrenzt bleiben kann. Cf. die Kritik von $M$. Chrapčenko: Literatur und Modellierung der Wirklichkeit. - In: Sinn und Form 25(1973), 115-119.

15. Auch Cassirer spricht von "Bausteinen" des Wirklichen (I, 24) und von einem je verschiedenen Wirklichkeits- und Wahrheitsbegriff in Wissenschaft, Religion oder Kunst (I, 24 f.). Bei ihm fehlt jedoch das hierarchische Prinzip, das Belyjs "Emblematik des Sinns" von Cassirers logischem Symbolismus unterscheidet.

16. Zum "Materialismusstreit" cf. Hans-Ludwig Ollig: Der Neukantianismus. Stuttgart 1979 (= Sammlung Metzler, Band 187). Hier liegt die erste knappe Ubersicht über den Neukantianismus vor, der "um die Jahrhundertwende zur tonangebenden Philosophie in Deutschland avancierte". Ollig erläutert, daß der "Rekurs auf die erkenntniskritische Fragestellung" sich vor allem gegen eine "materialistische Fundamentalphilosophie" richtete, die einen ungerechtfertigten Objektivismus vertrat, "der die Subjektkomponente im Erkenntnisvorgang mehr oder weniger gänzlich unter den Tisch fallen lassen wollte" (S. I f.).

17. Zur Bedeutung von Helmholtz und der allgemein wissenschaftlichen Formulierung des ersten Energiesatzes "Uber die Erhaltung der Kraft" (1847), der bereits von dem Heilbronner Arzt Robert Mayer gefunden worden war ("Bemerkungen über die Kräfte der unbelebten Natur", 1842), cf. E. Cassirer: Philosophie der symbolischen Formen, 1, 114 f.; III, 478 f.; III, 540 f.; J. Metzner: Die Bedeutung physikalischer Sätze für die Literatur. In: DVjs I (1979), $6 \mathrm{f}$.

18. Für die Tragweite der Abbild-Modell-Kontroverse sind aufschlußreich die Untersuchungen von Allan Janik und Stephen Toulmin: Wittgenstein's Vienna (1973). Vor dem Hintergrund der Kulturkrise in der österreichischen Gesellschaft vor dem ersten Weltkrieg analysieren die Autoren den Problemzusammenhang von Sprache, Kommunikation und symbolischem Ausdruck als miteinander verbundene Symptome der allgemeinen Krisensituation (117), um Wittgensteins radikale Sprachkritik, wie er sie in seinem "Traktatus Logico-Philosophicus" vornahm, verständlicher zu machen (132). Dabei beziehen sie Probleme des naturwissenschaftlichen Denkens mit ein, die für Wittgensteins Modelltheorie der Sprache und seine symbolische Logik von zentraler Bedeutung waren. Eine Schlüsselstellung nehmen Heinrich Hertz (139143) und Ludwig Boltzmann (143-145) ein. Heinrich Hertz war Schüler von Helmhol tz, der auch das Vorwort zu seinem Hauptwerk "Die Prinzipien der Mechanik, in nevem Zusammenhange" (1894) schrieb. Durch experimentelle Prüfung der Maxwellschen Theorie elektromagnetischer Felder, die damals selbst Physikern kaum verständlich war, kam er zur Entdeckung elektromagnetischer Wellen, die von entscheidender technischer Bedeutung für die Funk- und Radiotechnik wurden. 
Max Planck sagte in seiner Gedenkrede auf ihn: "Für die Physik lag die Bedeutung der Hertzschen Versuche in erster Linie in der Tatsache, daß Licht und elektrische Wellen dieselbe Erscheinung darstellen." (Cf. Max Planck: Physikalische Abhandlungen und Vorträge, Bd 3, Braunschweig 1958; auch A. Belyj: Kom. 471).

Mit dem Ubergang von der klassischen Mechanik zum elektrodynamischen Weltbild stellte sich auch die Frage nach dem Charakter und der Gültigkeit der wissenschaftlichen Begriffe auf neue Weise, je nachdem, welches Erkenntnisideal leitend war. In dieser Frage standen sich zwei Fronten gegenüber: die Positivisten unter Führung von Mach und Avenarius (133-138) vertraten die erkenntnistheoretische Position des Sensualismus in der Tradition des englischen Empirismus Hume's und Locke's. Alle Erkenntnis wird von ihnen direkt auf die Sinneswahrnehmung, also auf Erfahrungen - und zwar sowohl auf äußere als auch auf innere - zurückgeführt. Aufgabe der Wissenschaft ist für Mach, die Sinnesdaten in ihrer einfachsten und ökonomischsten Form zu beschreiben. Das geschieht, indem die kleinsten Elemente aller Erfahrung, die Empfindungen, ermittelt und in Ordnungsbegriffen nach dem Prinzip der "Denkökonomie" zusammengefaßt werden zu größeren Komplexen. Diese Begriffe oder "Gedankensymbole" haben die Funktion abstrakter Nachbildungen oder Herstellungsregeln, die den grundsätzlichen Lebensprozessen der Selbsterhaltung und Anpassung dienen. Vorstellungen wie "Ich", "Körper" oder "Materie" sind in Machs pragmatischer Variante des Sensualismus nur "denkökonomische" Einheiten, in der physisch und psychisch zu definierende Grundelemente zusammengefaßt gedacht werden. Die pragmatisch-antimetaphysische Perspektive Machs verbindet sich bei ihm mit einer darwinistischen Einstellung, die - orientiert am Nutzwert - auch sein Erkenntnisideal bestimmt. Nicht die Wahrheit wissenschaftlicher Theorien ist sein Ziel, sondern ihre Exaktheit und Zweckmäßigkeit für eine angemessene Beschreibung physikalischer Vorgänge. Mach war einer der einflußreichsten Köpfe des intellektuellen Wien der Jahrhundertwende. Hofmannsthal hörte seine Vorlesungen, Musil schrieb seine Dissertation über ihn, William James verblüffte er als "rein intellektuelles Genie", Einstein war sein bedeutendster Schüler, selbst bis in die Reihen der russischen Marxisten drang, vermittelt durch Bogdanov, der "Machismus" ein. (Zu Mach und Musil cf. auch Gerd Müller: Dichtung und Wissenschaft (1971), 67-74; Jan Aler: Als Zögling zwischen Maeterlinck und Mach (1971), 238-241, 266-280).

Gegenüber dem Empiriokritizismus stehen Vertreter der Helmholtz-Schule wie Heinrich Hertz und Max Planck, aber auch Ludwig Boltzmann, auf dem Standpunkt des Kantischen Kritizismus. Die apriorischen Komponenten der wissenschaftlichen Begriffsbildung wurden von ihnen in Rechnung gestellt. Wesentliche Voraussetzungen für dieses Denken hatte Hermann von Helmholtz mit seiner Zeichentheorie geschaffen. Hertz sieht die Funktion der wissenschaftlichen Begriffe nicht in einer bloßen Reproduktion der Sinneseindrücke, sondern in der "Darstellung" der experimentell gefundenen Daten. Sie sind nach seiner Auffassung als "Modelle" der Erfahrung zu konzipieren statt als deren "Abbilder".

Janik/Toulmin verdeutlichen den Unterschied:

"In dieser Art von Darstellung, sind die Menschen nicht bloß passive Zuschauer, denen 'Vorstellungen', wie die Hume'schen 'Eindrücke' oder die Machschen 'Empfindungen' einfach zustoßen; im Gegenteil, Darstellungen sind bewußt konstruierte Schemata für das Erkennen" (140).

Hertz hat gegenüber Machs denkökonomischem ein konstruktives Erkenntnisideal. Ihm geht es nicht allein um Beschreibung der vorhandenen Erfahrung, sondern er fordert von einem Modellbegriff, daß er ein Instrument sei, um künftige Erfahrung voraussehen zu können. Dazu muß er drei Kriterien haben: 1) logische Konsistenz; 2) Beziehung oder Analogie zu den empirischen Daten; 3) Einfachheit und Klarheit in der Darstellungsweise (Cf. Hertz: Prinzipien der Mechanik, 2). An die Stelle der abbildenden "Gedankensymbole" Machs stellt Hertz mathematisch formalisierte Modelle. Dafür ein Beispiel: Es ist möglich, daß einem Phänomen - wie dem Licht sowohl ein optisches wie auch ein elektromagnetisches Modell zugeordnet werden kann. Beide führen zu neuen experimentellen Ergebnissen und schließen sich nicht aus. 
Hertz vergleicht ein System solcher Modelle mit einer "systematischen Grammatik" (Hertz: Prinzipien, 47), der gegenüber sich die Abbild-Begriffe nur wie notdürftige Sprachführer ausnähmen, die den Anfänger in die Umgangssprache einführen. Eine der Hauptleistungen der Hertzschen "Modelle" sehen Janik/Toulmin darin, daß in ihrer Struktur bereits die Grenzen für ihre Gültigkeit mit definiert sind. Diese Grenzen werden nicht, wie bei Mach, in der äußeren Äbgrenzung zur Metaphysik bestimmt, sondern sie können von innen her definiert werden, indem nämlich ihr Geltungsbereich auf mechanische Prozesse eingeschränkt ist. Hertz stellt kritisch fest, daß die Modellbegriffe der Mechanik nicht auf selbst die niedrigsten Prozesse des Lebens angewendet werden können (Hertz: Prinzipien, 45). Hertz trug mit seiner Theorie mathematischer Modelle dazu bei, daß hypothetische Modelle, wie vor allem das Atommodell, das nach dem Vorbild des Sonnensystems konzipiert wurde, entwickelt werden konnten. Dennoch wurde Hertz stark angefeindet in seiner Zeit; ebenso wie auch Ludwig Boltzmann (1844-1906), der Erfinder der "statistischen Mechanik", dessen Auffassung von der theoretischen Physik ebenfalls kantianische Elemente enthält.

Er verfolgte Hertz' Konzept theoretischer Modelle weiter. Hertz' "Mögliche Sequenz beobachtbarer Vorgänge" arbeitete er aus zu einem "multidimensionalen Raum" mit verschiedenen Bezugsachsen, denen die mechanischen Teilchen zugeordnet werden können. Die Totalität dieses theoretischen Raumes bringt das "Ensemble aller möglichen Zustände" zur Darstellung, in dem jeder aktualisierte Zustand distribuiert werden kann, Boltzmanns Konzept eines "Raumes theoretischer Möglichkeiten", in bezug auf den der aktuelle Zustand eines physikalischen Systems spezifiziert werden kann, hatte für die Entwicklung der Physik im zwanzigsten Jahrhundert zentrale Bedeutung. Max Planck erkannte das sofort und hielt Boltzmanns Modell für einen "Geniestreich". Durch die Notwendigkeit statistischer Erklärung in der Quantenphysik wuchs die Bedeutung der Boltzmannschen Bezugsgrößen noch weiter.

Für Wittgenstein wurden sowohl der Begriff der "Darstellung" wie auch der des "Raumes theoretischer Möglichkeiten" zu Grundlagen seiner symbolischen Logik.

Dieser Exkurs hat zwar zunächst keinen direkten Bezug zu Belyj. Doch mir scheint, daß die Richtung, in der er nach Legitimation suchte, hier weiter ausgeleuchtet wird. Das symbolisierende Modelldenken, das Belyj in der Kunst auf die Erlebnisweise des künstlerischen Subjekts anwenden wollte, ist ein zeittypischer Zug auch des wissenschaftlichen Denkens, der sich in mehr oder weniger bewußtem Rekurs auf die erkenntniskritische Fragestellung Kants herausbildete.

Uber die grundsätzliche Bedeutung der Kantschen "Revolution der Denkart" für die Herausbildung des Symbolismus cf. auch Heinrich Henel: Erlebnisdichtung und Symbolismus. - In: DVjs 32 (1958), 81 f.: "Wie die Kantische Philosophie ist also die symbolistische Dichtung sowohl phänomenologisch wie kritisch."

19. Zu F.A. Lange cf. H.-L. Ollig: Neukantianismus, 15-21; Ollig zitiert u.a. eine sehr positive Charakteristik Langes von Berdjaev, aus der man auf eine beträchtliche Wirkung Langes in Rußland schließen kann (15). Cf. auch A. Belyj: Nrds, 470. Sein Hauptwerk erschien 1921 bereits in der 10. Aufl.

20. Cf. 1. Kant: Kritik der reinen Vernunft, Zweites Buch, Zweites Hauptstück, 3, 3, AC.

21. H.-L. Ollig: Neukantianismus, bezeichnet Helmholtz als "Anreger" dieser Strömung; E. Cassirer hebt besonders die Bedeutung der Zeichentheorie von Helmholtz für den modernen Rekurs auf die erkenntniskritische Fragestellung hervor, cf. III, 335 f., 153, 377. Eine wichtige Rolle mißt er auch $\mathrm{H}$. Hertz und seinen "Prinzipien der Mechanik" (1894) zu, cf. I, 5; III, 25.

22. Zum Energetismus cf. Heinz Setzer: Wilhelm Ostwald und die Rolle der Energetik für Gor'kij. a.a.O.

23. Cf. J. Metzner: Die Bedeutung physikalischer Sätze für die Literatur. - In: DVjs 1 (1979) $5 \mathrm{ff}$.

24. a.a.O., bes. 4-16, zu den Auswirkungen des Energiedenkens auf den Kulturpessimismus Spenglers, Benns, auf Freuds psychoanalytische Energetik, auf Zamjatin und M. Proust. 
25. Henri Poincaré, ein Vetter des französischen Präsidenten Raymond Poincaré (18641934), Professor an der Sorbonne, leistete bahnbrechende Arbeiten auf dem Gebiet der Mathematik (einer der Mitbegründer der modernen Topologie) und theoretischen Physik. Er gilt als einer der Vorläufer Einsteins. In seinen beiden Hauptwerken "Wissenschaft und Hypothese" (1902; dt. 1904) und "Wissenschaft und Methode" (1908; dt. 1914) setzte er sich mit Grundlagenfragen der Mathematik auseinander. Belyj kannte inn durch seinen Vater, der zeitlebens im Briefwechsel mit ihm stand (Nrds 29).

26. Cf. John Neubauer: Symbolismus und symbolische Logik, 66-68, 72, (zur Kombinatorik in Dichtung, Mathematik u. Musik bei Novalis).

27. Zu Nietzsche und Ibsen cf. Formy (171-173): Smysl 226; Probl. 7-9; Arab. 171-174. Zur Ergänzung des theoretischen Sammelbandes "Simvolizm" wird deshalb der Essayband "Arabeski" herangezogen, in dem Belyj Proträts und Analysen einzelner Dichter gibt und zu Themen der Auseinandersetzung um den Symbolismus Stellung nimmt.

28. Aufsätze zu Ibsen und Nietzsche: Ibsen und Dostojevskij (1905). - In: Arab. 91-100; Henrik Ibsen (1909). - In: Arab. 281-284; Die Krise des Bewußtseins (1910). - In: Arab. 161-210; ferner: Nrds 330 ff. Symbolismus als Weltverständnis (1903). - In: Arab. 220-238; Phönix (1906). - In: Arab. 147-157; Friedrich Nietzsche (1907). - In: Arab. 60-91; Linie, Kreis, Spirale des Symbolismus (1912). - In: Trudy i dni 4-5 (1912) 13-22; Kreisbewegung. -Trudy i dni 4-5 (1912) 51; ferner Nrds 465 ff.

29. Zum Zusammenhang von Konfliktpotential und Werkstruktur cf. das neue literaturpsychologische Modell von Wolfram Mauser, das er im methodischen Vorspann seines Hofmannsthal-Buches konzipiert. Cf. W. Mauser: Hugo von Hofmannsthal, 229, bes. 17 f. (cf. auch Anm. 87 zu S. 56 dieser Arbeit).

30. Zur Behinderung der Entwicklung Belyjs durch sinnlose Verbote:

"Aber es gab das Gefühl brennender Scham, bei dem bloßen Gedanken daran, daß jemand zufällig von meiner Neigung erführe; und es gab die Angst: dann wird man mich sofort der Musik berauben; denn bittere Erfahrung hatte mir gezeigt: jedes Hervortreten eines Interesses an irgendetwas endete mit einem Verbot; das Interesse am Vater mit seinen Erklärungen der Geschichte mit dem 'Kettenschwanz'-Affen endete: mit dem Verbot jedes konkreten Umgangs mit dem Vater; so hatte man mich einst der Njanja beraubt und Raisa Ivanovnas; es war Doktor Rodionov gekommen und hatte die Märchen weggenommen:

'Sie - sind schädlich für inn!'

Ich hätte bloß zugeben sollen, daß die Musik mir - Trost ist; und ich hätte zu hören bekommen:

'Musik ist schädlich für dich; wage ja

nicht zuzuhören;'

Mutter wird den Flügel abschließen und alles ist zu Ende (Nrds 183).

Cf. Nrds 202-204, 212 f., 312, 74 f.

31. Zur Vorform kindlicher Symbolisierung cf. Nrds 170.

32. Aus Belyjs Nekrolog auf Ibsen (1906):

"Ewiges Gedenken.

Laßt uns die Pechfackeln entzünden. Auf unseren Händen laßt uns tragen den Leib des erloschenen Helden. Laßt uns ihm Schwert und Schild umwinden mit Fichtenzweigen. Dort, auf hohem Berge, wollen wir ihn, den Einen, verlassen. (...) Gefallen ist der Held (...)

Die Menschheit hat einen Dornenweg beschritten. Sie muß sich von der Niederung losreißen zur Sonne. Es gibt keine Rückkehr von diesem Wege, es gibt hier keine Kompromisse: es gibt nur den Kampf der Pflicht vor sich selbst und vor den Menschen. (...)

Unter unseren Füßen ist eine Schlucht. Uber unserem Kopfe eine eisige Höhe, vielkämmig. Für uns gibt es nicht Ruhe, für uns gibt es nicht Vollendung. Wir müssen gehen, immer gehen, wenn wir uns und der Menschheit ein Ziel setzen. Wir müssen den Kampf mit den Chimären des Geistes durchhalten. Aber seien wir getrost darauf vorbereitet, daß dann, wenn der Kampf zu Ende sein wird, vor uns nur die Ruinen der vor uns stehenden Kultur mit ihren verfallenen Institutionen sein

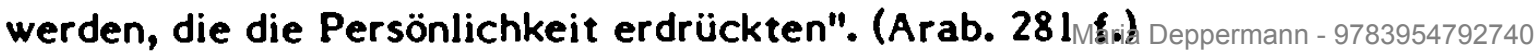


33. Zur Hochgebirgsmetaphorik bei Belyj cf. bereits "Erste Symphonie". Eroica. (1904), O teurgii (1903), Smysl (1907), Prolog zu "Kotik Letaev" (1916). In ihr ist nicht nur der Einfluß Ibsens zu erkennen, sondern auch der Nietzsches.

34. Zur Nietzsche-Rezeption in Rußland cf. U.a. L.D. Blok: Byli i nebylicy, 29; R. Labry: Alexandre Blok et Nietzsche. - In: La Revue des études slaves, vol. XXVII, Paris 1951, 201-208; R.-D. Kluge: Westeuropa und Rußland im Weltbild A. Bloks.

35. Aus Musils Notizheft 15, S. 36 ff., zitiert nach Gerd Müller: Dichtung und Wissenschaft, 12.

36. Man kann im Falle Belyjs die interessante Beobachtung machen, daß Symbolisierung in seinem Sinne in engem Zusammenhang mit Konfliktsituationen und Konfliktbewältigungsversuchen steht. Die Konfliktmetapher der "Schere" erweist sich als ein modernes Symbol, das insofern mehrsinnig ist, als es verschiedene Seiten desselben Problems auszudrücken vermag. Sie ist ein Zustandsbild und Instrument der Konfliktlösung in einem.

In dem schon oben (S. 56, Anm. 87) erwähnten, neven literaturpsychologischen Konfliktmodell, das W. Mauser in der "Vorüberlegung" zu seiner psychosoziologischen Untersuchung methodisch erläutert, wird darauf hingewiesen, daß Konfliktbewältigung sowohl die Ebene des Autors wie auch die des Werkes umfaßt, "wobei Konflikterfahrung und Konfliktdarstellung einander in sehr unterschiedlichem Ausmaß entsprechen." Cf. Wolfram Mauser: Hugo von Hofmannsthal, 9.

Man kann das Symbol der "Schere" auch von dem traditionellen christlichen Konfliktsymbol des Kreuzes her verstehen, das in zweierlei Hinsicht abgewandelt erscheint: 1) wird es säkularisiert; der religiöse Bezug ist verblaßt; doch immer noch symbolisiert es die "Passion" eines Menschen, sein Leiden; 2) die starr verbundenen Achsen des Kreuzes weichen den beweglichen Schneiden der Schere, die als Bedrohung erfahren, aber auch als Instrument gehandhabt werden kann.

37. Zu den Antinomien der Kulturkrise cf. A. Belyj: "Die Krise des Bewußtseins und Henrik Ibsen." - In: Arab. 161-210. 


\section{Kapitel: Verwandlung der Persönlichkeit}

1. Wie schon oben, S. 102,105 f. gesagt wurde, faßt Belyj Kunst nicht allein als Ausdrucksprozeß auf, sondern als einen Kommunikationsprozeß, der den Leser notwendig mit einschließt. Dafür bringt er semiotische, energetische und schließlich existentielle Argumente. Er überschreitet die Grenzen der Gestaltästhetik und eröffnet mit seiner Leser-Imago des produktiven Lesers neue Möglichkeiten einer Wirkungsästhetik im zwanzigsten Jahrhundert.

2. Die Bedeutung des Kantischen Kritizismus als Befreiung vom "Dogmatismus" und Basis des modernen Symbolismus analysiert Belyj in seinem Jubiläumsartikel zu Kants 100. Todestag, "Kritizismus und Symbolismus" (1904) cf. Simv. 20-30, Komm., $466 \mathrm{f}$.

Ähnliches stellt Heinrich Henel: Erlebnisdichtung und Symbolismus. - In: DVjs 32. Jg., 1958, XXXII, 71-98, fest: "So wie nun Kant erst 150 Jahre nach der Revolution in der Naturwissenschaft die Revolution in der Methaphysik bewirkte, so, scheint mir, hat die Dichtung nochmals zwei bis drei Generationen gebraucht, um sich des neuen Denkprinzips zu bemächtigen (81)."

3. Was Belyj als Bedingung der verwandelnden Wirkung der Kunst ansieht, nämlich die innige Verbindung von Idee und Form, vermittelt im künstlerischen Erleben und Schaffensprozeß, kritisiert J. Holthusen: Studien zur Ästhetik und Poetik, 27, als den "wunden Punkt" von Belyjs Ásthetik, in dem er nur die ungelöste Opposition von "priëm" und "religiösem Sinn", der "auf der Stelle tritt", erblicken kann. Ähnlich argumentiert er in bezug auf das Problem des Engagements bei Belyj, das keine "moralische Begründung der Kunst" (28) enthalte, sondern esoterisch bleibe; "preobraženie" versteht er als "Verklärung", die durch die "musikalische Kraft des Lautes" bewirkt werde. In beiden Fällen scheint mir der formalistische Reduktionismus der Sklovskij-Schule Einsichten in die Eigenheit Belyjs zu verstellen, die durch eine intentionale Interpretation, die sich erst einmal auf die eigenen Voraussetzungen Belyjs einläßt, hervorgehoben werden können.

4. Belyj schreibt dazu:

"Der Umwälzung (pereval), die sich im Bewußtsein vollzieht, entspricht eine Veränderung in der Ausdrucksmethode der Symbole der Kunst." (Cf. Simvolizm kak miroponimanie, 225).

Darin drückt sich ein Umbruch des Kunstverständnisses aus, der für die Kunst der Moderne grundlegend wurde. Belyj spricht vom Ubergang der klassisch-"aristokratischen" zu einer nicht mehr auf Harmonie festgelegten "demokratischen" Kunstauffassung; unter Preisgabe der schönen Form reißt sie Abgründe auf, "leuchtet die Untiefen des Geistes aus", stellt sich aber immer noch die Aufgabe, statt im Erlesenen, jetzt im "Alltäglichen auf Ewiges" hinzuweisen (Simv. kak mirop. 226).

5. Cf. Lirika, 242-244.

6. In dieser Spannung von religiösem Ideal und Erfahrung des Mangels und des Scheiterns ist der religiöse Sinn der Kunst beschlossen.

Es geht bei Belyj keineswegs um religiöse Vorbildliteratur, sondern die Weise der Realisierung des religiösen Sinnes der Kunst ist vorwiegend in der Diskrepanzerfahrung, d.h. ex negativo, zu finden. Diese Möglichkeit moderner "religiöser" Kunst hatte schon Solov'ev in seinen ästhetischen Schriften erkannt; cf. V. Solovev: Deutsche Gesamtausgabe, Bd. VII, 183:

"jede wahrnehmbare Darstellung irgendeines Gegenstandes und einer Erscheinung im Hinblick auf ihren endgültigen Zustand oder im Lichte der zukünftigen Welt ist ein Kunstwerk." (Hv. M.D.)

Als moderne Weise der Darstellung in einer sich religiös verstehenden Kunst sieht er ehrlicherweise nur noch die indirekte Darstellung vollkommener Schönheit in der Diskrepanz zum Ideal an (18\%). Neue Formen werde erst die "Kunst der Zukunft" finden (189).

7. Cf. Embl. 67 "die Vereinigung der Ziele der Erkenntnis mit etwas, das sich jenseits 
der Grenzen der Erkenntnis befindet."

8. Die Diskussion darüber, was dem Leser in der Moderne zugemutet werden kann, vor allem dann, wenn ein wirkungsästhetischer Anspruch vom Künstler erhoben wird, wurde um die Jahrhundertwende in Rußland mit sehr verschiedenen Argumenten geführt (cf. oben S. 66 ff.).

10. F. Stepun: Pamjati Andreja Belogo, weist auf diese aufklärerische Tendenz Belyjs hin: "Der an den Fortschritt und die 'Evolution des menschlichen Bewußtseins' glaubende 'Weltbürger' ist nie endgültig in Belyj abgestorben (181)." Allerdings zieht Stepun aus seiner konservativen Kritik an Belyj den einseitigen Schluß, daß seine aufklärerische "Gleichmacherei" aller historisch gewordenen Lebensformen geistiger "Bolschewismus" sei. Während Stepun hier einseitig überzieht, läßt S.D. Cioran: The Apocalyptic Symbolism, Belyjs Entwicklungsdenken ganz außer Acht, sondern verabsolutiert - trotz der salvierenden Klausel im Vorwort -seine zeitweiligen apokalyptischen Tendenzen.

11. Cf. Formy, 165, 168 (zu Hanslicks "musikalischen Ideen"); 171 (zu Nietzsches "Geist der Musik").

12. Belyjs Einstellung zur Musik wandelt sich um 1907, cf. "Protiv muzyki" (1907), "Buduščee iskusstvo" (1907). Während er anfangs unter dem Einfluß von Schopenhauers Kunstmetaphysik und Nietzsches "Geburt der Tragödie" die Musik als Höchstform der Kunst bewunderte, erhebt er jetzt starke Vorbehalte gegen ihre formauflösenden, "exotischen" und "buddhistischen" Tendenzen (Simv. 449 f.). Cf. auch James L. Rice: Rezension zu A. Kovač: Andrej Belyj: The 'Symphonies'. - In: The Russian Review, Jan. 1978, Vol. 37, Nr. 1, 116 f.

13. Belyj steht hier der Sprachauffassung Humboldts nahe. Er betrachtet die Sprache in zweierlei Hinsicht: erstens ihren Zeichencharakter, aber zweitens eben auch ihren Charakter als schöpferische Energie, bes. in "O teurgii" (1903), "Magija slov" (1909).

14. Cf. K. Mołul'skij: A. Belyj, 54, der diesen Artikel für Belyjs "symbolistisches Manifest" hält. Dem ist zuzustimmen, was die frühe Phase angeht, ab 1906 nicht mehr; denn von da ab ändert sich die Basis von Belyjs Symbolismus.

15. Cf. Ludwig Wenzler: Die Freiheit und das Böse nach Vladimir Solov'ev, 59.

16. op. cit. 61.

17. op. cit. 61 .

18. op. cit. 104.

19. op. cit. 120.

20. op. cit. 120.

21. Dieser Gesichtspunkt, den Symbolismus im Zusammenhang mit der Umwertungsproblematik zu sehen, ist bisher in der Forschung nicht diskutiert worden. Erst A. Kovaz: Andrej Belyj: The 'Symphonies', hat ihn seiner Analyse von Belyjs Frühwerk zugrundegelegt, ohne jedoch die weitreichenden Konsequenzen daraus zu berücksichtigen. Nimmt man den Gesichtspunkt der Umwertung ernster, dann kann man daraus auf neue Beziehungen des Symbolismus zur Kunst der Avantgarde schließen. Vor allem ließe sich von hier aus der philosophische und ästhetische Hintergrund aufklären, der zu den spezifisch russischen Bedingungen der Avantgarde-Kunst hingeführt hat.

22. Cf. A. Belyj: Pevica. - In: Mir iskusstva 7-12 (1902) $302 \mathrm{ff.;} \mathrm{ders.:} \mathrm{O} \mathrm{teurgii} 116 \mathrm{ff.;}$ ders.: Neskol'ko slov dekadenta (...) In: Mir iskusstva 11-12 (1903) 65-67 ("Wer hat uns denn bis an den Abgrund geführt? /..."). Die moderne, nachhegelsche Möglichkeit, einen Entwicklungsbegriff zu denken, der nicht mehr teleologisch oder zielgerichtet abläuft, und der die tragischen Komponenten von Risiko und Scheitern mit einschließt, legt D.E. Maksimov: Poézija i Proza Al. Bloka, seiner Interpretation Bloks zugrunde.

23. Diese Wendung Belyjs vom naiv-idealistischen Verwandlungsglauben zur Konzeption des Symbolismus als Beitrag zum Umwertungsprozeß der modernen Kultur wurde, außer in der unveröffentlichten Dissertation von J. Pflanzl: Weltbild und Kunstschau, entweder nicht berücksichtigt, wie z.B. bei Holthusen, Cioran, oder mißverstanden, wie bei Maslenikov oder Poggioli.

24. Gegen Kunst als reine Anschauung bzw. Erkenntnis wendet sich Belyj ausdrücklich in "Kunst der Zukunft": 
"Anschauung in der Kunst ist ein Mittel: sie ist Mittel, um den Appell zum Leben-Schaffen herauszuhören (Buduščee 449 f.)."

25. Mit diesen Worten schließt Beljy seine Programmschrift "Simvolizm" im Jahre 1910.

26. Cf. Andrej Belyj/A. Blok: Perepiska, 261.

27. Er zweifelt daran, "ob die vorliegende Symphonie überhaupt ein Kunstwerk ist oder ein Dokument des Bewußtseinszustandes der modernen Seele", das höchstens einen künftigen Analytiker interessieren könnte. Symptomatisch scheint mir die dazugehörige Äußerung Belyjs: "Mich interessierte der Konstruktionsmechanismus jener unklar erkannten Form, in der meine vorangegangenen 'Symphonien' geschrieben sind (.......) Deshalb sah ich meine 'Vierte Symphonie' während der Arbeit bloß als strukturelle Aufgabe an." Sowohl der Gegenstand wie auch die Formproblematik flößen ihm Zweifel am "Kunstcharakter" seines Werks, im traditionellen Verständnis, ein. Hier zeigt sich nun, daß das Thema des Ich zu einem Zeitpunkt auf taucht, da gleichzeitig auch die Form der Darstellung problematisch geworden ist. Mit Recht fragte sich Belyj daher: "Wer soll das lesen? Wem nützt das etwas?"

28. Cf. dazu Gabriele Schwab: Das augenlose Schweigen, Zur Subjektivität in Virginia Woolfs "The Waves". - In: Freiburger Literaturpsychologische Gespräche 1. Hg. v.J. Cremerius, W. Mauser, C. Pietzcker, F. Wyatt. - Ffm./Bern 1981 (= Europäische Hochschulschriften. Reihe I. Deutsche Sprache und Literatur. Bd. 391, S. 150) (über spezifische Wirkungsbedingungen moderner Kunst). 
Schluß: Modell des kreativen Prozesses

1. Damit unterscheidet sich das Modell des kreativen Prozesses nach Belyj grundsätzlich vom semiotischen Kommunikationsmodell von Sender-Kanal/Botschaft-Empfänger, das der Informatik entlehnt ist, wo der "subjektive Faktor" weder im Sender noch im Empfänger systemrelevante Bedeutung hat. Dieser Unterschied ist hier nur als Problemanzeige gedacht; auf eine weitere Diskussion an dieser Stelle muß verzichtet werden.

2. Ähnliches hat z.B. auch M. Haubrich im Auge, wenn er von der je eigenen "Ausgangswirklichkeit" eines Autors spricht, die er dann typisierend oder charakterisierend gestalte, cf. Michael Haubrich: Typisierung und Charakterisierung in der Literatur. Dargestellt am Beispiel der Kurzgeschichten A.P. Čechovs. - Mainz 1978/Diss./

3. Unter "Außenwelt" sind sowohl Natur und Alltagswelt zu verstehen als auch kulturell tradierte Vorstellungsweisen, in denen beide Bereiche erlebt oder vorgestellt worden sind. Z.B. Belyjs Symbol des "Schneesturms" beruht nicht nur auf Parallelisierung innerer Erlebnisse mit einem Naturvorgang, sondern auch mit einem literarisch tradierten Natur-Topos (von Puškin, Gogol', Tolstoj z.B.).

4. Sklovskij, Ejchenbaum u.a. negierten sowohl den psychologischen wie auch den weltanschaulichen Anteil an der Konstitution des Gegenstandes der Kunst als "prismatische Wirklichkeit", bei Dilthey fehlt das deutliche Bewußtsein der InnenAußen-Relation und die Einsicht in die Eigenständigkeit poetischer Verfahren. In der modernen Literaturpsychologie, die lange Zeit zur Reduktion des Schaffensvorganges auf den Reflex psychoanalytischer Antriebe neigte, ist erst in neuester Zeit der Versuch gemacht worden, psychische Struktur und formale Bedingungen der Kunstproduktion methodisch zueinander in Beziehung zu setzen. So z.B. bei Peter von Matt: Die Opus-Phantasie, wo die Möglichkeiten einer literaturpsychologischen Produktionsästhetik über die rein psychologischen Bedingungen erweitert werden.

5. Es wäre interessant, den Prozeß weiterzuführen und die getrennten Stadien aufeinander zurückzubeziehen, dazu müßte aber weiteres Material herangezogen werden.

6. Cf. Mdr 376.

7. Cf. Komm. 513-516. 


\section{LITERATURVERZEICHNIS}

\section{Andrej Belyj: ausgewählte Texte und Siglen (chronologisch)}

1902

2. Symphonie. Dramatique.

Simfonija (2-ja, dramatǐ̌eskaja), v 4-ch častjach. Moskva: Skorpion 1902; auch in: Sobranie sočinenij. Moskva/Pašukanis 1917. Bd. IV, und in: Cetyre simfonii. Andrej Belyj. Die vier Symphonien. Nachdruck der Ausgaben Moskau 1917, 1905 und 1908 mit einer Einleitung von Dmitrij Tschižewskij. München 1971 (= Slavische Propyläen 39).

Die Sängerin.

Pevica. - In: Mir iskusstva 7-12 (1902) 302-304.

Formen der Kunst.

Formy Formy iskusstva. - In: Mir iskusstva 7-12 (1902) 343-361; auch in: Simvolizm. Moskva 1910, 149-174; 507-523 (überarbeitet)

1903

Von der Theurgie.

O teur. O teurgii. - Novyj put' 9 (1903) 100-123.

Brief eines Studenten der Naturwissenschaften. (Student-estestvennik.) Po povodu knigi D.S. Merežkovskogo "L. Tolstoj i Dostojevskij". Otryvok iz pis'ma. - Novyj put' 1 (1903) 155-159.

Offener Brief eines Dekadenten.

Neskol'ko slov dekadenta, obraš̌ennych $k$ liberalam i konservatoram. Otkrytoe pis'mo. - In: Mir iskusstva 11-12 (1903) 65-67 (Chronika zu Nr. 7).

1904

Nordische Symphonie. Die Erste. Eroica.

Severnaja simfonija (1-ja, geroičeskaja), v 4-ch častjach. Moskva:Skorpion 1903/4; auch in: Sobranie soćinenij. Moskva/Pašukanis 1917. Bd. IV.

Gold in Azur.

Zoloto v lazuri. Moskva:Skorpion 1904.

Kritizismus und Symbolismus.

Krit. Kriticizm i simvolizm. Po povodu stoletija so dnja smerti Kanta. - In: Vesy 2 (1904) 1-13; auch in: Simvolizm, 20-30; $466 \mathrm{f}$.

Symbolismus als Weltverständnis.

Simvolizm kak miroponimanie. - In: Mir iskusstva 5 (1904) 173-186; auch in: Arabeski. Moskva 1911, 220-240, und in: N.L. Brodskij U.a.: Literaturnye manifesty. Ot simvolizma k oktjabrju. Sbornik materialov. Moskva 1929. Nachdruck: The Hague/Paris 1969 (= Slavistic Printings and Reprintings 135), 30-36.

Fenster in die Zukunft.

Okno $v$ budušee. - In: Vesy 12 (1904) 1-11; auch in: Arabeski, 138-146 (überarbeitet).

Von der Zweckmäßigkeit.

O celesoobraznosti. - In: Novyj put' 9 (1904) 139-153; auch in: Arabeski, 101114.

Vom Wissenschaftsdogmatismus.

O naučnom dogmatizme. - In: Sb. Svobodnaja sovest'. Kn. I (1906), 164-172. (Von Belyj datiert auf 1904).

Von den Grenzen der Psychologie.

O granicach psichologii. - In: Simvolizm, 31-48; 467-483 (Von Belyj datiert auf 1904)

Rückkehr. 3. Symphonie. 
Vozvrat (Tret'ja simfonija). Moskva/Grif 1905; auch Berlin:Epocha 1922 und in: Cetyre simfonii. Andrej Belyj. Die vier Symphonien. Nachdruck der Ausgaben Moskau 1917, 1905 und 1908 mit einer Einleitung von Dmitrij Tschižewskij. München 1971 (= Slavische Propyläen 39).

Die Apokalypse in der russischen Dichtung.

Apokalipsis $v$ russkoj poézii. - In: Vesy 4 (1905) 11-28; auch in: Lug zelenyj. Moskva:Al'cion 1910, 222-247.

Ibsen und Dostojevskij.

Ibsen i Dostojevskij. - In: Vesy 12 (1905) 47-54; auch in: Arabeski, 91-100.

1906

Henrik Ibsen.

Genrik Ibsen. - In: Vesy 7 (1906) 55 f.

Henrik Ibsen.

Genrik Ibsen. - In: Zolotoe runo 6 (1906) 73-75; auch in: Arabeski, 281-284.

Der Strauch.

Kust. Rasskaz. - In: Zolotoe runo 7-9 (1906) 129-135; auch in: Rasskazy. Andrej Belyj. Erzählungen. Gesammelt und eingeleitet von Ronald E. Peterson. München 1979 (= Slavische Propyläen 141).

Der Rachen der Nacht: Auszug aus einem Mysterium.

Past' noči:otryvok misterii. - In: Zolotoe runo 3 (1906) 62-71.

Das Prinzip der Form in der Âsthetik.

Princ. Princip formy $v$ estetike. - In: Zolotoe runo 11-12 (1906) 88-96; auch in: Simvolizm, 175-194; 524-535.

Die religiöse Grundlage des Individualismus.

Religioznoe osnovanie individualizma. - In: Sb. Svobodnaja sovest'. Kn. II (1906), 275-279.

Über einen Sammelband zur Philosophie der Naturwissenschaften.

O sbornike po filosofii estestvoznanija. Moskva:Tvorčeskaja mysl' 1906. - In: Zolotoe runo 3 (1906) 150-153.

Phönix.

Feniks. - In: Vesy 7 (1906) 17-29.

1907

Kunst der Zukunft.

Bud. Buduščee iskusstvo. - In: Simvolizm, $449-453$ (Von Belyj datiert auf 1907)

Friedrich Nietzsche.

Friedrich Nietzsche. - In: Vesy 7 (1908) 45-50, 8 (1908) 55-65, 9 (1908) 30-39;

auch in: Arabeski, 60-91 (Von Belyj datiert auf 1907)

Auf der Paßhöhe. Vl. Wider die Musik.

Na perevale. VI. Protiv muzyki. - In: Vesy 3 (1907) 57-60.

Auf der Paßhöhe. VIII.

Na perevale. VIll. Sinematograf. - In: Vesy 7 (1907) 50-53.

Der Sinn der Kunst.

Smysl Smysl iskusstva. - In: Simvolizm, 195-230; 535-567 (Von Belyj datiert auf 1907) Vladimir Solov'ev.

Vladimir Solov'ev. - In: Arabeski, 387-394 (Von Belyj datiert auf 1907)

Karl Vorländer.

Karl Vorländer. Neokantianskoe dviženie v socializme. - In: Pereval 5 (1907) 56 f.

Pokal der Schneegestöber (4. Symphonie).

Kubok metelej (4-ja simfonija). Moskva:Skorpion 1908; auch in: Četyre simfonii. Andrej Belyj. Die vier Symphonien. Nachdruck der Ausgaben Moskau 1917,1905 und 1908 mit einer Einleitung von Dmitrij Tschižewskij. München 1971 (= Slavische Propyläen 39).

Der Symbolismus und die russische Kunst. 
Simvolizm i russkoe iskusstvo. - In: Vesy 10 (1908) 38-48.

Der Symbolismus (Vortrag).

Simvolizm (Publičnaja lekcija). - In: Vesy 12 (1908) 36-41; auch in: Arabeski, 241-248.

Asche. Verse.

Pepel. Stichi. Peterburg:Šipovnik 1909. 2. Aufl. Moskva:Nikitinskie subbotniki 1929. 3. Aufl. Moskva/Leningrad: GIZ 1935.

Urne.

Urna. Moskva:Grif 1909.

Die silberne Taube.

Serebrjannyj golub'. - In: Vesy 3,4,6,7,10,11,12 (1909); einzeln: Moskva:Skorpion 1910. 2. Aufl. in: Sobranie sočinenij. Bd. VIl. Moskva/Pašukanis 1917. 3. Aufl. Berlin:Epocha 1922. Bd. 1 u. 2. Nachdruck: Mit einer Einleitung von Anton Hönig. München 1967 (= Slavische Propyläen 38).

Deutsche Ubersetzungen: L. Wiebeck. Frankfurt 1912; Stettin 1927. Gisela Drohla. München/Zürich 1964 (= Knaur Tb 71).

Emblematik des Sinns.

Embl. $\quad$ Emblematika smysla. - In: Simvolizm, 49-143; 457-506.

Lyrik und Experiment.

Lir. $\quad$ Lirika i eksperiment. - In: Simvolizm, 231-285; 567-618.

Magie der Worte.

Magija Magija slov. - In: Simvolizm, 429-448; 618-626.

Das Problem der Kultur.

Probl. Problema kul'tury. - In: Simvolizm, 1-10; 457-465 (Die letzgenannten vier Aufsätze werden von Belyj datiert auf 1909)

1910

Simv. Simvolizm. Moskva:Musagetes 1910. Nachdruck: München 1969 (= Slavische Propyläen 62).

Komm. Der Kommentar zu "Simvolizm", S. 457-633, wird getrennt zitiert.

Grüne Wiese.

Lug zelenyj. Moskva:Al'cion 1910.

Krone oder Kranz.

Venec ili venok. - In: Apollon 11 (1910) 1-4 (Chronika).

$\underline{1911}$

Arabesken.

Arab. Arabeski. Moskva:Musagetes 1911. Nachdruck: München 1969 (= Slavische Propyläen 63).

1912

Uber den Symbolismus.

O simvolizme. - In: Trudy i dni 1 (1912) 10-24; 2 (1912) 1-7.

Linie, Kreis, Spirale - des Symbolismus.

Linija, krug, spiral' - simvolizma. - In: Trudy i dni 4-5 (1912) 13-22.

Kreisbewegung.

Krugovoe dviženie. - In: Trudy i dni 4-5 (1912) 51-73.

1913

Petersburg.

Peterburg. 1. unvollständige Fassung (nur Druckfahnen) Jaroslavl:Nekrasov 1912; 1. Ausgabe in: Sirin. Sb. I-III (1913-14), einzeln: Petrograd:Sirin 1916; 2. Ausgabe (um ein Drittel gekürzt) Berlin:Epocha 1922; 3. Ausgabe (ebenfalls gekürzt, doch mit Korrekturen) Moskva:Nikitinskie subbotniki 1928.

Nachdruck der ungekürzten Erstausgabe 1913/1916: Mit einer Einleitung von 
Georgette Donchin. Letchworth 1967 (= Bradda Plain Literary Texts).

Nachdruck der gekürzten Moskauer Ausgabe von 1928: Mit einem Vorwort von K. Zelinskij. Moskva: GIZ 1935. Mit einer Einleitung von Dmitrij Tschižewskij. München 1967 (= Slavische Propyläen 29). Mit Einleitung von A.S. Mjasnikov, Nachwort von P.G. Antokol'skij und Kommentaren von L.K. Dolgopolov. Moskva:Chud. lit. 1978.

Deutsche Ubersetzungen: Nadja Strasser. München 1919. Gisela Drohla. Wiesbaden 1959. München (dtv 25). Frankfurt 1976 (= Bibliothek Suhrkamp 501).

Die Krise des Lebens.

Krizis Žizni. - In: Birževye vedemosti. 15. März 1916, einzeln: Peterburg:Alkonost 1918; auch in: Na perevale. Berlin/Peterburg/Moskva:Grzebin 1923.

Gesammelte Werke (unvollständig)

Sobranie sočinenij. t. 4: 1. i 2. simfonija; t. 7: Serebrjannyj golub'. Moskva/Pasukanis 1917.

Kotik Letaev.

Kotiv Letaev. - In: Skify Sb. I-II (1917-18); einzeln: Peterburg/Berlin: $\dot{E}_{p o c h a}$ 1922.

(Geplante Ausgabe für Izd. Nikitinskie subbotniki, 1928, kam nicht zustande. Vorwort Belyjs dazu in: Novyi zurnal, kn. 101 (New York 1970) 69-71 und in: Andrei Biely. Kotik Letaev. Traduit du russe par Georges Nivat. Lausanne 1973, 209-212)

Nachdruck der Berliner Ausgabe von 1922: Mit einer Einleitung von Dmitrij Tschižewskij und Anton Hönig. München 1964 (= Slavische Propyläen 3).

Rudolf Steiner und Goethe in der Weltanschauung der Gegenwart.

Rudol'f Stejner i Gete $v$ mirovozzrenii sovremennosti. Moskva:Duchovnoe znanie 1917.

Die Revolution und die Kultur.

Revoljucija i kul'tura. Moskva:Leman i Sacharov 1917. Nachdruck: Letchworth 1971 (= Russian Titles for the Specialist 13).

Die Krise des Gedankens.

Krizis mysli. Peterburg:Alkonost 1918 (Von Belyj datiert auf 1916/1917)

Die Krise der Kultur.

Krizis kul'tury. Peterburg/Alkonost 1920 (Von Belyj datiert auf 1912-16-18)

Erste Begegnung.

Pervoe svidanie. Petrograd:Alkonost 1921. 2. Aufl. Berlin:Slovo 1922.

Erinnerungen an A.A. Blok (Erste, kürzere Version).

Vospominanija ob A.A. Bloke. - In: Zapiski mectatelej 6-7 (1922) 7-122.

Nachdruck: Mit einer Einleitung von Georgette Donchin. Letchworth 1964.

Erinnerungen an A.A. Blok (Zweite Version).

Vospominanija ob A.A. Bloke. - In: Epopeja I-IV (1922-1923). Nachdruck: München 1969 (= Slavische Propyläen 47).

Deutsche Ubersetzung: Im Zeichen der Morgenröte. Erinnerungen an Aleksandr Blok. (Aus dem Russischen von Swetlana Geier. Mit einem Nachwort von Wenzel Götte). Basel 1974.

Auf der Paßhöhe. (Enthält alle drei Krisenschriften).

$\mathrm{Na}$ perevaie. I. Krizis žizni. II. Krizis mysli. III. Krizis kul'tury. Berlin/Peterburg/Moskva:Grzebin 1923.

Warum ich Symbolist geworden bin (...)

Poxemu ja stal simvolistom i počemu ne perestal im byt' vo vsech fazach moego idejnogo i chudožestvennogo razvitija (MS CGALI, rukopis' 1928; auch Puškinskij Dom, Archiv Ivanova-Razumnika, F 79/op. 3/Nr. 62, p. 13).

Auf der Grenzscheide zweier Jahrhunderte. 
Nrds. Na rubeže dvuch stoletij. Moskva/Leningrad: ZiF 1930. 2. Aufl. (mit Index) 1931. Nachdruck: Mit einer Einleitung von Georgette Donchin. Letchworth 1966 (= Rarity Reprints 4).

Jahrhundertanfang.

NV Načalo veka. Mit einem Vorwort von L. Kamenev und Index. Moskva/Leningrad: GiCHL 1933. Nachdruck: Chicago 1966 (= Russian Study Series 61). Zwischen zwei Revolutionen. (Erinnerungen 1905-11).

Mdr Meždu dvuch revoljucij. Mit einem Vorwort von C. Vol'pe. Leningrad: Izd. pisatelej v Leningrade 1934. 2. Aufl. 1937. Nachdruck: Chicago 1966 (= Russian Study Series 60).

Gogol's Meisterschaft.

Masterstvo Gogol'ja. Moskva/Leningrad: GICHL 1934. Nachdruck: Mit einer Einführung von Dmitrij Tschižewskij. München 1969 (= Slavische Propyläen 59). A. Blok/A. Belyj: Briefwechsel.

Aleksandr Blok i Andrej Belyj: Perepiska. Redakcija, vstupitel'naja stat'ja i kommentarii V.N. Orlova. Moskva 1940 (= Letopisi gosudarstvennogo literaturnogo muzeja, kniga sed'maja). Nachdruck: München 1969 (= Slavische Propyläen 65).

Gedichte und Poeme.

Stichotvorenija i poèmy. Hg. T.Ju. Chmel'nickaja. Moskva/Leningrad: Sovetskij pisatel' 1966 (= Biblioteka poeta).

Verwandeln des Lebens. Erinnerungen an Rudolf Steiner. (Aus dem Russischen von Swetlana Geier. Mit einem Nachwort von Wenzel Götte). Basel 1975. 2. Aufl. 1977.

(Originalmanuskript bisher unveröffentlicht)

Erzählungen.

Rasskazy. Gesammelt und eingeleitet von Ronald E. Peterson. München 1979 (= Slavische Propyläen 141). 


\section{Quellen und Darstellungen zur Krise der Kultur}

BERDJAEV, Nikolaj: Kriziz iskusstva. Moskva 1918.

BLOK, Aleksandr: Sobranie sočinenij v vos'mi tomach. Moskva/Leningrad 1960-1963.

----- : Sobranie sočinenij v šesti tomach. Moskva 1971.

--.--- / Andrej Belyj: Perepiska. s.o.

BLACK, C.E. (Ed.): The Transformation of Russian Society. Aspects of Social Change since 1861. Cambr./Mass. 1960.

BURGER, Peter: Theorie der Avantgarde. Frankfurt 1974 (= es 727).

BULLOCK, Allan: The Double Image. - In: M. Bradbury and James McFarlane: Modernism. 1890-1930. Penguin Books ${ }^{2} 1978$.

BURCKHARDT, Jacob: Weltgeschichtliche Betrachtungen. Hg. und eingeleitet von Rudolf Stadelmann. Tübingen 1949 (Erstausgabe 1872).

DAHM, Helmut: Die Chance der Philosophie und das Verhängnis der slawophilen Utopie. In: Rußlands Aufbruch ins 20. Jahrhundert. Politik - Gesellschaft - Kultur. 1894-1917. $\mathrm{Hg}$. von Erwin Oberländer u.a. Olten und Freiburg 1970, 234-263.

ENZENSBERGER, Hans Magnus: Die Aporien der Avantgarde. - In: Ders.: Einzelheiten. Frankfurt 1962, 290-315.

ESCHENBACHER, Walter: Fritz Mauthner und die deutsche Literatur um 1900. Eine Untersuchung zur Sprachkrise der Jahrhundertwende. Frankfurt/Bern 1977 (= Europäische Hochschulschriften. Reihe I. Deutsche Literatur und Germanistik 163).

FISCHER, George: The Intelligentsia and Russia. - In: Black, C.E. (Ed.): The Transformation of Russian Society. Aspects of Social Change since 1861. Cambr./Mass. 1960, 253274.

FLAKER, Aleksandar: Je li nam pojam "Avangarda" potreban? - In: Umjetnost riječi XV, 2 (1971) 155-160.

----- : Granice Pojma Avangarda. - In: Umjetnost riječi XX, 3 (1976) 347-352.

------ : Avant-Garde: Literature and Painting. - In: International Comparative Literature Association. Ninth Congress. Innsbruck 1979, 1-10.

-.-.-- : Roman o Revolucionarnom Gradu. - In: Umjetnost riječi XX, 4 (1976) 467-484.

FRANK, Joseph: The Widening Gyre: Crisis and Mastery in Modern Literature. Bloomington 1968.

GUTH, Alfred: Nietzsches "Neue Barbaren". - In: Nietzsche. Werk und Wirkungen. Hg. von Hans Steffen. Göttingen 1974 (= KI. Vandenhoeck-Reihe 1394).

HABERMAS, Jürgen: Legitimationsprobleme im Spätkapitalismus. Frankfurt $1973(=$ es 623).

HAZARD, Paul: Die Krise des europäischen Geistes. Hamburg 1939 (Originalausgabe: La crise de la conscience européenne. Paris 1935).

HEIDEGGER, Martin: Sein und Zeit (1927). Tübingen ${ }^{8} 1957$.

-.--- : Hölderlin und das Wesen der Dichtung (Rede von 1936). - In: Ders.: Erläuterungen zu Hölderlins Dichtung. Frankfurt 1971.

----- : Das Ende der Philgsophie und die Aufgabe des Denkens. - In: Ders.: Zur Sache des Denkens (1969). Tübingen 1976.

HOFMANNSTHAL, Hugo v.: Ein Brief. - In: Ders.: Gesammelte Werke. Hg. von Herbert Steiner. Stockholm/Frankfurt 1945 ff., Bd. 8, 7-20.

HOLTHUSEN, Johannes: Tiergestalten und metamorphe Erscheinungen in der Literatur der russischen Avantgarde (1902-1923). - In: Bayerische Akademie der Wissenschaften. Philosophisch-historische Klasse. Sitzungsberichte. 12 (1974) 3-58.

JANIK, Allan \& Stephen Toulmin: Wittgenstein's Vienna. New York 1973.2

JASPERS, Karl: Vernunft und Existenz. Fünf Vorlesungen (1935). Bremen 21947.

JENS, Walter: Statt einer Literaturgeschichte (1957). Pfullingen 1978.

KIERKEGAARD, Sören Aaby: Gesammelte Werke. Hg. von Hermann Gottsched und Christoph Schrempf. Jena $1910 \mathrm{ff}$.

Bd. 1/2 Entweder - Oder, ein Lebensfragment, herausgegeben von Victor Eremita (1843).

Bd. 4 Stadien auf dem Lebensweg (1845).

----- : Die Krankheit zum Tode (1849). Bremen 1949.

------ : Tagebücher. Ubersetzt von Th. Haecker. 2 Bde. Innsbruck 1923. Bd. 1. 
KLINE, George L.: Changing attitudes toward the Individual. - In: C.E. Black: Transformation of Russian Society. Aspects of Social Change since 1861. Cambr./Mass. 1960, 606-624.

KLUGE, Rolf-Dieter: Die Rolle Polens in Aleksandr Bloks Versepos "Vozmezdie". - In: Welt der Slaven IX (1964) 426-435.

----- : Vom kritischen zum sozialistischen Realismus. Studien zur literarischen Tradition in Rußland. 1880-1925. München 1973 (= List Tb Wiss. 1447).

--.-- : Wandlungen im russischen Realismus an der Jahrhundertwende. 1880-1910. In: Die slawischen Kulturen in der Geschichte der europäischen Kulturen (18.-20. Jahrhundert). $\mathrm{Hg}$. Gerhard Ziegengeist u.a. Berlin. Akademie der Wissenschaften der DDR. 1978 (im Druck)

--.-- : Zur Deutung der Musik in der Dichtungstheorie einiger russischer Romantiker und Symbolisten .- In: Die Musikforschung. Hg. von der Gesellschaft für Musikforschung. Kassel und Basel 0.J. Jg. 22, H. 1, 13-22.

-.-- : Der Dichter als Prophet und Richter. - In: Ders. (Hg.): Gegenwartsliteratur in Osteuropa. München 1982.

KOSELLECK, Reinhart: Kritik und Krise. Ein Beitrag zur Pathogenese der bürgerlichen Welt. München 1959.

KRUGER, Heinz: Der Aphorismus Nietzsches als philosophische Form. - In: Ders.: Studien über den Aphorismus als philosophische Form. Frankfurt 1956, S. 81-133.

LACAN, Jaques: Ecrits. Paris 1966. Deutsch: Schriften. Ausgewählt und hg. von Norbert Haas. Die Ubersetzung besorgte Rodolphe Gasché u.a. Bd. 1-2. Freiburg 1973-1975.

LASCHET, Rolf: Aleksandr Bloks Deutung der Oktoberrevolution. Freiburg 1979 (= Maschinenschriftliches Manuskript. Staatsarbeit. Slavisches Seminar der Universität Freiburg).

LOWITH, Karl: Nietzsches Vollendung des Atheismus. - In: Nietzsche. Werk und Wirkungen. $\mathrm{Hg}$. von Hans Steffen. Göttingen 1974 (= KI. Vandenhoeck-Reihe 1394) 7-18.

MAUSER, Wolfram: Hugo von Hofmannsthal. Konfliktbewältigung und Werkstruktur. Eine psychosoziologische Interpretation. München 1977 (= Kritische Information 59).

MAUTHNER, Fritz: Beiträge zu einer Kritik der Sprache. 3 Bde. Stuttgart 1901-1903.

MEREŽKOVSKIJ, Dmitrij: Grjaduščij Cham. - In: Poljarnaja zvezda 1 (1905).

MUSIL, Robert: Gesammelte Werke in Einzelausgaben. Hg. von A. Frisé. Bd. I. Der Mann ohne Eigenschaf ten. Hamburg 1952.

NIEBUHR, Reinhold: The Truth Value of Myths. - In: The Nature of Religious Experience. Essays in Honor of Douglas Clyde Macintosh (1937). New York 1971, 117-135.

VIETZSCHE, Friedrich: Werke in drei Bänden. Hg. von Karl Schlechta (1966). Darmstadt 1973, darin: Bd. I. Die Geburt der Tragödie. S. 7-134. Unzeitgemäße Betrachtungen. S. 135-434. Bd. II. Die Fröhliche Wissenschaft. S. 7-274. Also sprach Zarathustra. S. 275562. Ecce homo. S. 1063-1160. Bd. Ill. Uber Wahrheit und Lüge im außermoralischen Sinn. S. 309-322.

NIETZSCHE. Werk und Wirkungen. Hg. von Hans Steffen. Göttingen $1974 \quad(=\mathrm{KI}$. Vandenhoeck-Reihe 1394).

PAILER, Wolfgang: Die frühen Dramen M. Gor'kijs in ihrem Verhältnis zum dramatischen Schaffen A.P. Cechovs. München 1978 (= Slavistische Beiträge 122).

PETERS, Jochen-Ulrich: Turgenevs "Zapiski ochotnika" innerhalb der očerk-Tradition der 40er Jahre. Zur Entwicklung des realistischen Erzählens in Rußland. Berlin/Wiesbaden 1972.

POGGIOLI, Renato: The Theory of the Avant - Garde. Translated from the Italian by Gerald Fitzgerald. Cambr./Mass. 1968 (Originaltitel: Teoria dell'arte d'avanguardia. Bologna 1962).

RILKE, Rainer Maria: Die Aufzeichnungen des Malte Laurids Brigge. Frankfurt 1976 (= Bibliothek Suhrkamp 343).

RUSSLANDS Aufbruch ins 20. Jahrhundert. Politik-Gesellschaft-Kultur. 1894-1917. Hg. von E. Oberländer u.a. Olten und Freiburg 1970.

SARTRE, Jean-Paul: Der Idiot der Familie. Gustave Flaubert. Bd. 1-3. Hamburg 1977 ff. (Orig. Paris 1971).

SCHREY, Heinz-Horst: Die Uberwindung des Nihilismus bei Kierkegaard und Nietzsche. In: Zeitschrift für systematische Theologie 21 (1950) 90-109. 
SETZER, Heinz: Wilhelm Ostwald und die Rolle der Energetik für Gor'kij. - In: Welt der Slaven XXV, 2. Jg. NF. IV, 2 (1980), S. 394-427.

SHEPPARD, Richard: The Crisis of Language, - In: Modernism. 1890-1930. Ed. by M. Bradbury and James McFarlane. Penguin Books 21978.

\{TÖKL, Günther: Russische Geschichte. Von den Anfängen bis zur Gegenwart. Stuttgart 21965 ( = Kröners Taschenausgabe 244).

TJUTČEV, Fedor: Stichotvorenija, Pis'ma. Moskva 1957.

WAGNER, Richard: Sämtliche Schriften und Dichtungen. 12 Bde. Leipzig 1871. Bes. Bd. 3, darin: Die Kunst und die Revolution. Das Kunstwerk der Zukunft.

WILLIAMS, Raymond: Gesellschaftstheorie als Begriffsgeschichte. Studien zur historischen Semantik von "Kultur". München 1972 (Originaltitel: Culture and Society 17801950, London 1958).

WILLIAMS, Robert C.: Artists in Revolution. Portraits of the Russian Avant-garde. 19051925. Bloomington/London 1977.

WITTGENSTEIN, Ludwig: Schriften I. Frankfurt 1969, darin: Tractatus logico-philosophicus. S. 7-84. Philosophische Untersuchungen. S. 279-544.

WORBS, Michael: Wissenschaft und Literatur im Fin de siècle. - In: Sprache im technischen Zeitalter 68 (1978) 302-316.

WÖRN, Dietrich: Aleksandr Bloks Drama Pesnja Sud'by (Das Lied des Schicksals). München 1974 (= Slavistische Beiträge 81). 


\section{Ausgewählte Literatur zur ästhetischen Theorie.}

1. Quellen und Darstellungen.

ALER, Jan: Als Zögling zwischen Maeterlinck und Mach. Robert Musils literarischphilosophische Anfänge. In: Probleme des Erzählens in der Weltliteratur. Hg. von Fritz Martini. Festschrift für Käte Hamburger zum 75. Geburtstag. Stuttgart 1971, 234-290.

ARISTOTELES: Poetik. Reclam 2337.

BENJAMIN, Walter: Uber einige Motive bei Baudelaire. - In: Ders.: Charles Baudelaire. Ein Lyriker im Zeitalter des Hochkapitalismus. Frankfurt 1974 (= Suhrkamp Tb Wissenschaft 47) (urspr. 1939, Zs. für Sozialforschung).

-..- : Ursprung des deutschen Trauerspiels. Revidierte Ausgabe besorgt von Rolf Tiedemann. Frankfurt 1963.

BLOK, Ljubov' Dmitrievna: Byli i Nebylicy. Podgotovka teksta: I. Paulmann. Predislovie i kommentarii L.S. Flejsmana. Bremen 0.J. (= Studien und Texte 10).

BOHRER, Karl Heinz: Die Ästhetik des Schreckens. Die pessimistische Romantik und Ernst Jüngers Frühwerk. München 1978.

Pis'ma BRJUSOVA k P.P. Percovu 1894-96. Moskva 1927.

CASSIRER Ernst: Philosophie der symbolischen Formen. Teil 1-3 (Berlin 1 1923-29) Darmstadt 2 1954-58.

CHRAPTSCHENKO, Michail B.: Literatur und Modellierung der Wirklichkeit. - In: Sinn und Form 25 (1973) 115-134.

DONCHIN, Georgette: French Influences on Russian Symbolist Versification. - In: The Slavonic and East European Review. XXXIII Nr. 80, 1954.

ÉJCHENBAUM, Boris M.: "Skvoz' Literaturu". Sbornik statej. Leningrad: Academia 1924. Nachdruck: Würzburg 1972; auch The Hague 1962.

ELIOT, T.S.: Four Quartets. - In: Ders.: Collected Poems. 1909-1962. London 1977, 187224.

Selected Prose of T.S. ELIOT. Ed. with an Introduction by Frank Kermode. London 1975. FLAKER, Aleksandar: Stilistic Formation. - In: Neohelicon. Acta Comparationis Litterarum Universarum 1-2 (1975) 183-207.

------ : Die slavischen Literaturen zur Zeit des Modernismus. Das Auftreten der Avantgarde und des Expressionismus. - In: Neues Handbuch der Literaturwissenschaft. $\mathrm{Hg}$. von Klaus von See. Bd. 19 Jahrhundertwende - Jahrhundertwende II. Bandherausgeber: Hans Hinterhäuser. Wiesbaden 1976, 391-428.

-..-- : Symbolism or Modernism in Slavic Literatures? - In: Russian Literature VII (1979) 329-348.

FRIEDRICH, Hugo: Die Struktur der modernen Lyrik. Von Baudelaire bis zur Gegenwart. Hamburg 1956 (= Rde 25).

GADAMER, Hans-Georg: Wahrheit und Methode. Tübingen ${ }^{2} 1965$.

GOETHE, Johann W.v.: Werke. Hamburger Ausgabe in 14 Bdn. (1955) Hamburg ${ }^{1966 . ~ B d . ~}$ 13, darin: Anschauende Urteilskraft. S. 30 f. Bedeutsame Fördernis durch ein einziges geistreiches Wort. S. 37-41.

-..-- : Maximen und Reflexionen. Nach den Handschriften des Goethe- und SchillerArchivs hg. von Max Hecker. Weimar 1997 (= Schriften der Goethe-Gesellschaft. Bd. 21).

GOETHES Briefe. Hamburger Ausgabe in 4 Bänden. Bd. II. Briefe der Jahre 1786-1805. Hamburg 1964.

GRAY, Camilla: The Russian Experiment in Art: 1863-1922. New York 1971.

HAMBURGER, Käte: Die Logik der Dichtung. Zweite, stark veränderte Auflage. Stuttgart 1968 ('1957).

HAUSER, Arnold: Sozialgeschichte der Kunst und Literatur. München 1972 ( 1953$).$

HEISS, R.: Wesen und Formen der Dialektik. Köln/Berlin 1959.

HENEL, H.: Erlebnisdichtung und Symbolismus. - In: DVjs 32 (1958) 71 -98.

HOFMANN, Werner: Von der Nachahmung zur Wirklichkeit. Die schöpferische Befreiung der Kunst. 1890-1917. Köln 1970.

INGARDEN, Roman: Das literarische Kunstwerk. Tübingen 1965 (urspr. Halle/S. 1931).

KANT, Immanuel: Werke in zehn Bänden. Herausgegeben von Wilhelm Weischedel. Darmstadt 1975, darin: Bd. 3/4 Kritik der reinen Vernunft. Bd. 8 Kritik der Urteilskraft.

S. 237-620. 
KITTLER, Friedrich A./Horst Turk: Urszenen. Literaturwissenschaft als Diskursanalyse. Frankfurt 1977.

KLUGE, Rolf-Dieter: Westeuropa und Rußland im Weltbild Aleksandr Bloks. München 1967 (= Slavistische Beiträge 27).

MAERKER, Peter: Die Ästhetik der südwestdeutschen Schule. Bonn 1973.

MATT, Peter v.: Die Opus-Phantasie. Das phantasierte Werk als Metaphantasie im kreativen Prozeß. - In: Psyche 33 (1979) 193-212.

MELETINSKIJ, E.M.: Poétika mifa. Moskva 1976.

METZNER, Joachim: Die Bedeutung physikalischer Sätze für die Literatur. - In: DVjs 1 (1979) $1-34$.

MEUMANN, E.: Einführung in die Ästhetik der Gegenwart (1908). Leipzig ${ }^{2} 1912$.

MINC, Z.G.: Simvol u Bloka. - In: Russian Literature VII (1979) 193-248.

MULLER, Gerd: Dichtung und Wissenschaft. Studien zu Robert Musils Romanen "Die Verwirrungen des Zöglings Törless" und "Der Mann ohne Eigenschaften". Uppsala 1971 (= Acta Universitatis Upsaliensis. Studia Germanistica Upsaliensia 7).

MUSIL, Robert: Gesammelte Werke in Einzelausgaben. Hg. von A. Frisé. Bd. II. Tagebücher, Aphorismen, Essays. Hamburg 1957 (zitiert als TAER).

NEUBAUER, John: Symbolismus und symbolische Logik. München 1979.

OLLIG, Hans-Ludwig: Der Neukantianismus. Stuttgart 1979 (= Sammlung Metzler 187).

PONGS, Hermann: Symbol als Mitte. Marburg 1978.

RENNER, Ursula: Leopold Andrians "Garten der Erkenntnis". Literarisches Paradigma einer Identitätskrise in Wien um 1900. Ffm./Bern 1981 (= Literatur ung Psychologie 3).

RICKERT, Heinrich: Der Gegenstand der Erkenntnis. (1892) Tübingen ${ }^{6} 1928$.

RICOEUR, Paul/Eberhard Jüngel: Metapher. Zur Hermeneutik religiöser Sprache. Mit einer Einleitung von Pierre Gisel. München 1974 (= Evangelische Theologie. Sonderheft). ROTHACKER, E./Johannes Thyssen: Intuition und Begriff. Bonn 1963.

SCHERRER, Jutta: Die Petersburger Religiös-Philosophischen Vereinigungen. Die Entwicklung des religiösen Selbstverständnisses ihrer Intelligencija-Mitglieder (1901-1917). Berlin 1973 (= Forschungen zur osteuropäischen Geschichte 19).

SCHMID, Wolf: Der Textaufbau in den Erzählungen Dostoevskijs. München 1973 (= Beihefte zu Poetica 10).

-.-- : Der ästhetische Inhalt. Zur semantischen Funktion poetischer Verfahren. Im Anhang Diskussionsthesen von B.J. Amsenga, J. van der Eng-Liedmeier, J.M. Meijer, A.L. Sötemann und eine Replik des Autors. Lisse 1977 (= Utrecht Slavic Studies in Literary Theory 1).

---- : Poetische Sprache in formalistischer Sicht. Zu einer neven Anthologie russischer Formalisten. - In: Zs f. franz. Sprache und Literatur 83 (1973) 260-270.

SCHMIDT, R.: Kants Lehre von der Einbildungskraft mit besonderer Rücksicht auf die Kritik der Urteilskraft. Leipzig 1926.

SCHOPENHAUER, Arthur: Die Welt als Wille und Vorstellung. Zürich $1977(=$ detebe 140 I-IV).

----- : Uber die vierfache Wurzel des Satzes vom zureichenden Grunde. Zürich 1977 (= detebe $140 / \mathrm{V})$.

SOLOV'EV, Vladimir: Sobranie sočinenij. Bd. 1-12. Brjussel' 1966-1970.

T. 1-10 Nachdruck von: Sobranie sox̌inenij Vladimira Sergeeviča Solov'eva (...)

Pod redakciej i s primexanijami M.S. Solov'eva i E.L. Radlova. Vtoroe izdanie.

T. 1-10. S.-Peterburg, ohne Jahr (1911-1914), darin:

T. 3. Čtenija o Bogočelovečestve. S. 1-181

T. 6. Krasota $v$ prirode. S. 33-74

T. 6. Obščij smysl iskusstva. S. 75-92

T. 7. Poézija F.I. TjutČeva. S. 117-134

T. 7. Pervyj ł̌ag k položitel'noj èstetike. S. 69-77

SOLOWJEW, Wladimir: Deutsche Gesamtausgabe. Hg. von Wladimir Szylkarski, Wilhelm Lettenbauer und Ludolf Müller. Freiburg/München $1953 \mathrm{ff.,} \mathrm{darin:}$

Bd. 1. Vorlesungen über das Gottmenschentum. S. 537-750

Bd. VIl Die Schönheit in der Natur. S. 117-167

Der allgemeine Sinn der Kunst. S. 169-189

Die Dichtung F.I. Tjutčevs. S. 354-368 
Der erste Schritt zu einer positiven Ästhetik. S. 346-352.

STERNIN, Grigori: Das Kunstleben Rußlands an der Jahrhundertwende. Dresden 1976 (= Fundus Bücher 42/43).

STRICH, Fritz: Das Symbol in der Dichtung (Vortrag von 1939). In: Ders.: Der Dichter und die Zeit. Bern 1947, 13-39.

TSCHIŽEWSKIJ, Dmitrij: Skovoroda. Dichter, Denker, Mystiker. München 1974 (= Harvard Series in Ukrainian Studies 18).

TYNJANOV, Jurij: Problema stichotvornogo jazyka. Leningrad 1924. Nachdruck: The Hague 1963.

WELLEK, René: Geschichte der Literaturkritik. 1750-1950. Berlin/New York 1977 l= Komparatistische Studien. Bd. 5.6), darin: Bd. 3. Das späte 19. Jahrhundert.

WENZLER, Ludwig: Die Freiheit und das Böse nach Vladimir Solov'ev. Freiburg/München 1978 (= Symposion 59). 
2. Spezielle Sekundärliteratur zu Andrej Belyj.

BJALIK, B.A. (Hg.): Russkaja literatura konca XIX. - načala XX v. 1901-1907. Moskva 1971.

BRJUSOV, Valerij: Ob odnom voprose ritma. Po povodu knigi Andreja Belogo "Simvolizm". - In: Apollon 11 (1910) 52-60.

CHODASEVIC, V.F.: Nekropol'. Vospominanija. Paris 1976 (urspr. Paris 1934-38).

CIORAN, Samuel D.: The Apocalyptic Symbolism of Andrej Belyj. The Hague/Paris 1973.

ELLIS (Pseudonym für Leo Kobilinski): Russkie simvolisty. (K. Bal'mont, V. Brjusov, A. Belyj.) Moskva 1910. Nachdruck: Great Britain 1972.

ERLIFH, Victor: Russischer Formalismus. Frankfurt 1973. (Originaltitel: Russian Formalism 1955).

GOFMAN, Viktor: Jazyk simvolistov. - In: Literaturnoe nasledstvo 27-28 (1937) 54-105.

GRIFCOV, Boris: Andrej Belyj. Simvolizm (...) Lug zelenyj (...) Arabeski (..) In: Russkaja mysl' 5 (1911) 190.

HANSEN-LOUVE, Aage A.: Der russische Formalismus. Methodologische Rekonstruktion seiner Entwicklung aus dem Prinzip der Verfremdung. Wien 1978 (= Veröffentlichungen der Kommission für Literaturwissenschaft 5 ).

HOLTHUSEN, Johannes: Andrej Belyj und Rudolf Steiner. - In: Festschrift für Max Vasmer. Wiesbaden 1956, 187-192.

---- : Studien zur Ästhetik und Poetik des russischen Symbolismus. Göttingen 1957.

-..-- : Die Bedeutung des Stils bei Andrej Belyj. - In: Russian Literature 5 (1973) 65-78.

--.-- : Weltmodelle moderner slavischer Dichter. Andrej Belyj und Miroslav Krleža. - In: Innsbrucker Beiträge zur Kulturwissenschaft. Hg. von der Innsbrucker Gesellschaft zur Pflege der Geisteswissenschaften. Slavica Aenipontana 2 (1978) 3-18.

IVANOV-RAZUMNIK, R.I.: Russkaja literatura ot 70 ych godov do našich dnej. Berlin 61923.

---- : Aleksandr Blok - Andrej Belyj. Peterburg:Alkonost 1919. Nachdruck USA 1967 (= Russian Study Series 64) und Letchworth 1971 (= Bradda Books, Rarity Reprints 15).

-..-- : Peterburg Belogo. Teilnachdruck des Buches "Veršiny". Petrograd 1923. Mit einer Vorbemerkung von Dmitrij Tschižewskij. München 1972 (= Slavische Propyläen 118).

KNIGGE, Armin: Die Lyrik VI. Solov'evs und ihre Nachwirkung bei A. Belyj und A. Blok. Amsterdam 1973 (= Bibliotheca Slavonica 12).

KOVAC, Anton: Andrej Belyj: The 'Symphonies' (1899-1908). A Re-Evaluation of the Aesthetic-Philosophical Heritage. Bern/München 1976 (= Europäische Hochschulschriften. Reihe XVI, Bd. 8. Slawische Sprache und Literatur).

LITERATURNOE Nasledstvo 27-28. Moskva 1937.

MAKSIMOV, Dmitrij E.: Poézija i Proza Al. Bloka. Leningrad '1975, ${ }^{2} 1981$.

MASLENIKOV, Oleg A.: The Frenzied Poets. Andrey Biely and the Russian Symbolists. Berkeley and Los Angeles 1952.

MICHAJLOVSKIJ, B.V.: Simvolizm. In: Russkaja literatura konca XIX - načala XX v. 1901-1907. Hg. von B.A. Bjalik. Moskva 1971.

MOČUL'SKIJ, K.V.: Andrej Belyj. Paris 1955.

NIVAT, George: 'Ultima Thule', ou l'itinéraire du symbolisme russe. - In: Cahiers du Monde Russe et Soviétique. Vol. XV, 1-2 (1974) 7-17.

-..-: Eléments pour une biographie d'Andrej Belyj. - In: Cahiers du Monde Russe et Soviétique. Vol. XV, 1-2 (1974) 17-22.

--.- : L'oeuvre polémique, critique et journalistique d'Andrej Belyj. - In: Cahiers du Monde Russe et Soviétique. Vol. XV, 1-2 (1974) 22-41.

ORLOV, VI.: Istorija odnoj "družby-vraždy". Einleitung zu: A. Blok - A. Belyj. Perepiska. S.o.

PFLANZL, Jutta: Weltbild und Kunstschau des Russischen Symbolismus in der theoretischen Gestaltung durch A. Belyj. Wien 1946 (= Maschinenschriftliche Diss.).

POGGIOLI, Renato: The Poets of Russia. 1890-1930. Cambridge/Mass. 1960.

POMORSKA, K.: Russian Formalist Theory and its Poetic Ambiance. The Hague 1968 (= Slavistische Printings and Reprintings 82).

SKLOVSKIJ, Viktor: O teorii prozy. Moskva 1929. 
----- : Technika pisatel'skogo. Moskva/Leningrad 1928. Nachdruck Leipzig 1977, darin: Ornamental'naja Proza. Andrej Belyj. S. 205-225.

-.--- : Andrej Belyj. In: Russian Sovremennik II (1924) $232 \mathrm{ff.}$

-... : Pjat' Zelovek znakomych. (A. Belyj, E. Zamjatin, B. Pil'njak, K. Fedin, L. Leonov.) Tiflis 1927.

(STEPUN) F.S.: Andrej Belyj. Simvolizm. In: Logos (Moskva) I (1910) 280-282.

STEPUN, Fedor A.: Pamjati Andreja Belogo 1934 . - In: Ders.: VstreXi. New York 1968, 160-186.

--.-- : Andrej Belyj. - In: Ders.: Mystische Weltschau. Fünf Gestalten des russischen Symbolismus. München 1964, 279-356.

STOJNIČ-CARIČIČ, Milosava: Simbolistička doktrina Andreja Belog. Beograd 1971.

STRIEDTER, Jurij: Transparenz und Verfremdung. Zur Theorie des poetischen Bildes in der russischen Moderne. - In: Immanente Ästhetik - Ästhetische Reflexion. Lyrik als Paradigma der Moderne. Hg. von W. Iser. München 1966 (= Poetik und Hermeneutik II), 263-296.

TARASENKO, A.K.: Poézija Andreja Belogo. - In: Ders.: Stat'i o literature. T. I. Moskva $1958,76-117$.

THOMPSON, Ewa M.: Russian Formalism and Anglo-American New Criticism. A Comparative Study. The Hague/Paris 1971.

TOMAŠEVSKIJ, Boris: O stiche. Stat'i. Moskva 1929.

TROCKIJ, L.: Literatur und Revolution. Berlin 1968.

TSCHIZEWSKIJ, Dmitrij: Einleitung zU: Andrej Belyj. Kotik Letaev. München 1964. s.o. WEST, James: Russian Symbolism: A Study of Vyacheslav Ivanov and the Russian Symbolist Aesthetic. London 1970.

ZAMJATIN, Evgenij: Andrej Belyj 1936 . - In: Ders.: Lica. New York 1967, 73-81.

ŽIRMUNSKIJ, V.: Voprosy teorii literatury. Leningrad 1928.

Nachtrag zum Literaturverzeichnis:

KLUGE, R.-D.: Wie funktioniert ein symbolistisches Gedicht ? Zu A. Bloks "Schnerinaske". - In: Zeitschrift für Slavische Philologie 1/1982.

------ : Nochmals: der russische Symbolismus. A. Blok und F. Nietzsche. Zum Stand der Diskussion. - In: Beiträge der Bundesrepublik Deutschland zum 2. Weltkongreß der Sowjet - und Osteuropastudien. Garmisch '80. Berlin 1982. 